EDGARD BORGES MALTA

\title{
INVESTIGAÇÃO EXPERIMENTAL DAS VIBRAÇÕES INDUZIDAS PELA EMISSÃO DE VÓRTICES EM CATENÁRIAS SUJEITAS A PERFIS DE CORRENTEZA VARIÁVEL, ORTOGONAIS AO PLANO DE LANÇAMENTO
}

Tese apresentada à Escola Politécnica da Universidade de São Paulo para obtenção do Título de Doutor em Engenharia Naval. 

EDGARD BORGES MALTA

\section{INVESTIGAÇÃO EXPERIMENTAL DAS VIBRAÇÕES INDUZIDAS PELA EMISSÃO DE VÓRTICES EM CATENÁRIAS SUJEITAS A PERFIS DE CORRENTEZA VARIÁVEL, ORTOGONAIS AO PLANO DE LANÇAMENTO}

Tese apresentada à Escola Politécnica da Universidade de São Paulo para obtenção do Título de Doutor em Engenharia Naval.

Área de concentração:

Engenharia Naval

Orientador:

Prof. Dr. André L. C. Fujarra 


\section{Catalogação-na-publicação}

\section{MALTA, EDGARD BORGES}

INVESTIGAÇÃO EXPERIMENTAL DAS VIBRAÇÕES INDUZIDAS PELA EMISSÃO DE VÓRTICES EM CATENÁRIAS SUJEITAS A PERFIS DE CORRENTEZA VARIÁVEL, ORTOGONAIS AO PLANO DE LANÇAMENTO. São Paulo, 2015. 341 p.

Tese (Doutorado) — Escola Politécnica da Universidade de São Paulo. Departamento de Engenharia Naval e Oceânica.

1.Vibrações 2.Curvas planas 3.Lançamento de embarcações I.Universidade de São Paulo. Escola Politécnica. Departamento de Engenharia Naval e Oceânica Departamento de Engenharia Naval e Oceânica. II. t. 


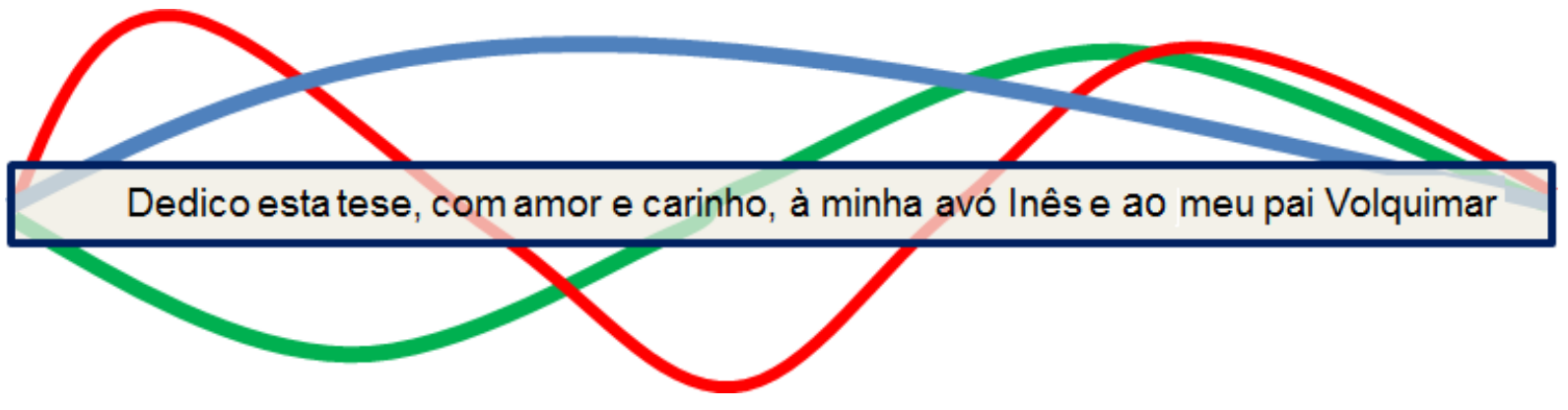





\section{Agradecimentos}

Gostaria de citar algumas das pessoas nessa longa caminhada que culminou com esta tese de doutorado e pelo menos mencionar algumas das pessoas importantes nestes últimos quatro anos.

Primeiramente, os professores com quem tenho trabalhado no TPN: Professores Kazuo Nishimoto, André Fujarra, Alexandre Simos, Cláudio Muller e Eduardo Tannuri.

Os meus sócios da Technomar Carlos Fucatu, Fabiano Rampazzo, Felipe Rateiro e Marcelo Cyrillo que seguram as pontas durante todo esse processo de fechamento do texto, como também os parceiros da Adoca (Humberto Makiyama e Denis Taniguchi), Argonáutica (Felipe Ruggeri, Guilherme Feitosa, Rafael Watai e Rodrigo Lavieri).

Os demais colegas de trabalho, por todo o suporte que tive no tanque de provas para a realização dos ensaios: os "mergulhadores" Rodrigo Cunha, Thomas Degermann, Vinicius Vaguetti, Dênnis Maluf, Felipe Pierrobom e Fábio Amorim, ao técnico Oygres Siqueira, e aos engenheiros Pedro Cardozo, Rodolfo Gonçalves, Daniel Prata, Thiago Peternella, Rodrigo Schiller, Rafael Máximo, Raul Dotta e o parceiro André Gallina. Aos demais amigos do Rugby Poli que me possibilitaram participar de um grupo incrível que tem sido importantíssimo para a minha vida pessoal e profissional.

Dos que participaram mais diretamente na tese, quero citar também os Professores Celso Pesce e Guilherme Franzini, com todo auxílio teórico e analítico que possibilitaram as conclusões deste texto. Mais que isso quero agradecer aos que trabalharam diretamente na execução, análise e revisão do texto Rodrigo Paizão Amarante, e ainda neste contexto, Prof. Dr. André Luís Condino Fujarra pela orientação com zelo e empenho.

E finalmente, à minha família: avós (Aparecido e Rosa), mãe (Maria), irmãos (Victor e Letícia) e todos os demais. Mas principalmente, ao meu amor Alice. 



\section{Sumário}

Resumo

Abstract

Lista de Figuras

V

Lista de Tabelas

xvii

Lista de Símbolos

xix

1 Organização da Tese

xxi

2 Introdução e Motivação

3 Objetivos

4 Fundamentos Teóricos e Considerações sobre o VIV 9

4.1 O fenômeno de VIV: Aspectos Gerais . . . . . . . . . . . . . . . . . . . . . 9

4.2 Efeito do VIV nas estruturas flexíveis longas . . . . . . . . . . . . . . . 14

4.3 Frequências e modos naturais nas estruturas flexíveis longas . . . . . . . . 22

4.3.1 Solução para as estruturas flexíveis verticais . . . . . . . . . . . . 24

4.3.2 Solução para as estruturas flexíveis lançadas em catenária . . . . 26

4.3.3 Comparações entre métodos para obtenção das frequências e modos naturais . . . . . . . . . . . . . . . . 27

5 Complemento Bibliográfico Pertinente ao Escopo da Tese

5.1 Com relação à fenomenologia geral do VIV . . . . . . . . . . . . . . . . . . 31 
5.2 Com relação ao VIV nas estruturas flexíveis . . . . . . . . . . . . . . 33

5.3 Com relação ao VIV nas linhas . . . . . . . . . . . . . . . . . 35

5.4 Com relação à avaliação das linhas em condições reais . . . . . . . . . . . . 43

$\begin{array}{lll}6 & \text { Metodologia } & 47\end{array}$

6.1 Materiais e equipamentos . . . . . . . . . . . . . . . . 47

6.1.1 Modelo de linha flexível . . . . . . . . . . . . . . . . . . . 47

6.1.2 Tanques de Prova . . . . . . . . . . . . . . . . . . . . . . . . . . 49

6.1.3 Sistema de monitoramento óptico . . . . . . . . . . . . . . . . 57

6.1.4 Demais equipamentos relevantes . . . . . . . . . . . . 62

6.2 Métodos . . . . . . . . . . . . . . . . . . . . . . 64

6.2.1 Configurações de lançamento do modelo . . . . . . . . . . . . . . 66

6.2.2 Ensaios preliminares para caracterização do modelo . . . . . . . . . 75

6.3 Matrizes de Ensaios . . . . . . . . . . . . . . . . . . . . 78

6.4 Metodologia de análise dos dados . . . . . . . . . . . . . . 86

6.4 .1 Método da decomposição modal . . . . . . . . . . . . . . . . 100

7 Resultados Experimentais

7.1 Resultados na linha flexível vertical . . . . . . . . . . . . . . . . . 110

7.1.1 Detalhes extras dos ensaios com a linha flexível vertical . . . . . . . 110

7.1.2 Resultados síntese obtidos com a decomposição modal: Linha Vertical115

7.2 Resultados nas linhas flexíveis lançadas em catenária . . . . . . . . . . . 121

7.2.1 Detalhes extras dos ensaios com as linhas flexíveis lançadas em catenária . . . . . . . . . . . . . . . . . . . . . 121

7.2.2 Resultados síntese obtidos com a decomposição modal: Linhas em Catenária . . . . . . . . . . . . . . . . . . . . 132

7.3 Análises comparativas e discussões sobre os resultados experimentais . . . . 148 
A.1 Vertical - Velocidade de $0,779 \mathrm{~m} / \mathrm{s}$ e $V_{r 1}=6,01 \ldots \ldots \ldots 171$

A.2 Vertical - Velocidade de $0,981 \mathrm{~m} / \mathrm{s}$ e $V_{r 1}=7,57 \ldots \ldots . \ldots 177$

A.3 Vertical - Velocidade de $1,380 \mathrm{~m} / \mathrm{s}$ e $V_{r 1}=10,69 \ldots \ldots$. . . . . . . 183

A.4 Vertical - Velocidade de $1,740 \mathrm{~m} / \mathrm{s}$ e $V_{r 1}=13,44 \ldots \ldots$. . . . . 189

A.5 Vertical - velocidade de $2,200 \mathrm{~m} / \mathrm{s}$ e $V_{r 1}=16,96 \ldots \ldots$. . . . . . 195

Anexo B - Resultados de VIV nas linhas em Catenária-1 201

B.1 Catenária-1 - Velocidade de $0,819 \mathrm{~m} / \mathrm{s}$ e $V_{r 1}=8,19 \ldots \ldots 202$

B.2 Catenária-1 - Velocidade de $1,1 \mathrm{~m} / \mathrm{s}$ e $V_{r 1}=11,01 \ldots \ldots$. . . . . . 208

B.3 Catenária-1 - Velocidade de $1,37 \mathrm{~m} / \mathrm{s}$ e $V_{r 1}=13,74 \ldots \ldots$. . . . . . . 214

B.4 Catenária-1 - Velocidade de $1,94 \mathrm{~m} / \mathrm{s}$ e $V_{r 1}=19,36 \ldots \ldots$. . . . . . 221

Anexo C - Resultados de VIV nas linhas em Catenária-2 227

C.1 Catenária-2 - Velocidade de $0,774 \mathrm{~m} / \mathrm{s}$ e $V_{r 1}=7,74 \ldots \ldots$. . . . 228

C.2 Catenária-2 - Velocidade de $1,05 \mathrm{~m} / \mathrm{s}$ e $V_{r 1}=10,47 \ldots \ldots$. . . . . 234

C.3 Catenária-2 - Velocidade de $1,28 \mathrm{~m} / \mathrm{s}$ e $V_{r 1}=12,79 \ldots \ldots$. . . . . . 240

C.4 Catenária-2 - Velocidade de $1,39 \mathrm{~m} / \mathrm{s}$ e $V_{r 1}=13,95 \ldots$. . . . . . . . 246

Anexo D - Resultados de VIV nas linhas em Catenária-3 253

D.1 Catenária-3 - Velocidade de $0,632 \mathrm{~m} / \mathrm{s}$ e $V_{r 1}=6,85 \ldots$. . . . . . . 254

D.2 Catenária-3 - Velocidade de $0,915 \mathrm{~m} / \mathrm{s}$ e $V_{r 1}=9,92 \ldots \ldots$. . . . . 260

D.3 Catenária-3 - Velocidade de $1,13 \mathrm{~m} / \mathrm{s}$ e $V_{r 1}=12,29 \ldots \ldots$. . . . . 266

D.4 Catenária-3 - Velocidade de $1,43 \mathrm{~m} / \mathrm{s}$ e $V_{r 1}=15,47 \ldots \ldots . \ldots . . \ldots 272$

Anexo E - Resultados de VIV nas linhas em Catenária-4 279

E.1 Catenária-4 - Velocidade de $0,537 \mathrm{~m} / \mathrm{s}$ e $V_{r 1}=6,87 \ldots$. . . . . . . 280 
E.2 Catenária-4 - Velocidade de $0,818 \mathrm{~m} / \mathrm{s}$ e $V_{r 1}=10,47 \ldots \ldots$. . . . . 286

E.3 Catenária-4 - Velocidade de $1,34 \mathrm{~m} / \mathrm{s}$ e $V_{r 1}=17,17 \ldots$. . . . . . . . 292

E.4 Catenária-4 - Velocidade de $1,42 \mathrm{~m} / \mathrm{s}$ e $V_{r 1}=18,22 \ldots . \quad \ldots .298$

F.1 Catenária-5 - Velocidade de $1,12 \mathrm{~m} / \mathrm{s}$ e $V_{r 1}=6,95 \ldots \ldots 6$

F.2 Catenária-5 - Velocidade de $1,3 \mathrm{~m} / \mathrm{s}$ e $V_{r 1}=8,10 \ldots 312$

F.3 Catenária-5 - Velocidade de $1,4 \mathrm{~m} / \mathrm{s}$ e $V_{r 1}=8,67 \ldots \ldots$. . . . . 318

F.4 Catenária-5 - Velocidade de $1,67 \mathrm{~m} / \mathrm{s}$ e $V_{r 1}=10,39 \ldots . . \ldots 324$

F.5 Catenária-5 - Velocidade de $1,95 \mathrm{~m} / \mathrm{s}$ e $V_{r 1}=12,12 \ldots 330$

F.6 Catenária-5 - Velocidade de $2,27 \mathrm{~m} / \mathrm{s}$ e $V_{r 1}=14,12 \ldots 336$ 


\section{Resumo}

A investigação experimental do fenômeno de vibrações induzidas pela emissão de vórtices (VIV) em modelos flexíveis longos lançados em catenária e sujeitos a perfis de correnteza variável e ortogonais ao plano de lançamento é o tema principal desta tese de doutorado. O objetivo, neste trabalho, é identificar, descrever e discutir os comportamentos dinâmicos do VIV nas catenárias sob correnteza variável, comparando-os com aqueles exibidos por este fenômeno agindo em um cilindro flexível vertical. Desta forma, tenciona-se contribuir para a compreensão mais geral do VIV nas linhas oceânicas utilizadas na exploração de petróleo e gás no mar. Neste contexto, muito se sabe sobre o comportamento do VIV em cilindros rígidos montados em suportes elásticos, bem como em cilindros flexíveis não curvados, ambos os arranjos com um vasta literatura descrevendo não só os comportamentos dinâmicos, como também suas relações com os aspectos fluidos que lhe dão origem. Contudo, no caso dos cilindros flexíveis longos, ainda existem pontos que precisam de compreensão mais profunda, particularmente aqueles que representam condições mais próximas da operação oceânica real - o lançamento em catenária e a ação de um perfil variável e ortogonal de correnteza. Para tanto, um dispositivo denominado braço giratório foi projetado e construído para que experimentos com modelos de catenária em correnteza variável com a profundidade fossem conduzidos no tanque de provas físico do laboratório Tanque de Provas Numérico (TPN), caracterizando uma pesquisa inédita no tema. Como condições de ensaio foram consideradas diferentes configurações geométricas da catenária, todas comparadas com um cilindro flexível vertical ensaiado tanto no braço giratório, como também em tanque de reboque. Tratados segundo uma técnica de decomposição modal, os resultados de deslocamento ao longo dos modelos nessas condições de ensaio permitiram a identificação e a descrição de comportamentos dinâmicos bastante parecidos nas catenárias, sempre comparados àqueles do modelo vertical, o que trouxe grande abrangência à compreensão do VIV nas linhas flexíveis em geral. Como contribuição adicional, este trabalho dotou o tanque de provas do TPN de um equipamento bastante interessante para ampla gama de investigações sobre as interações fluido-estruturais - o braço giratório. 
Palavras-chave: VIV, experimentos em tanque de provas, modelos flexíveis na vertical e em catenária, decomposição modal, correnteza variável. 


\section{Abstract}

The experimental investigation of Vortex-Induced Vibrations (VIV) on long catenary models and subjected to non-uniform velocity profiles, orthogonal to the catenary's plane, it is the main subject of this doctoral thesis. As a main goal, this work search to identify, describe and discuss the dynamic behaviors of VIV on catenary lines under non-uniform velocity profiles, comparing the results with those coming from the same phenomenon acting on flexible cylinders in a vertical configuration. Thus, it is intended to help for a more general understanding of VIV in offshore lines used in the oil and gas exploration at sea. In this context, much is known about the behavior of VIV on rigid cylinders elastically supported, as well as on flexible cylinders with no curvature, both configurations counting with a large literature describing not only the dynamic behaviors, but also their relationships with hydrodynamics aspects. However, in the case of long flexible cylinders, there are still more points to be understand, particularly at those conditions closer to the offshore operations - with catenary lines under variable current profile. Under those considerations, a rotating-arm was designed and assembled in the model basin at Numerical Offshore Tank (TPN), Brazil, for model tests under non-uniform current profile, featuring itself as an unpublished research on this topic. Different catenary geometries were tested in the rotating-arm at USP and also in the towing tank at Institute for Technological Research of the State of São Paulo (IPT), Brazil, all of them being compared with a vertical flexible cylinder. From those conditions of test, data was analyzed according to a technique of modal decomposition, so the motion results from all the models allowed the identification and the description of a dynamic behavior quite similar in the catenary when compared to that from a vertical cylinder, which has brought great understanding about the VIV on flexible lines. As an additional contribution, this work has provided to the TPN's model basin an interesting device for a wide variety of researchs on fluid- structural interaction - the rotating-arm.

Keywords: VIV, small-scale experiments, vertical and catenary flexible models, modal decomposition, non uniform current profile. 


\section{Lista de Figuras}

2.1 Arranjo dos experimentos realizados em [Rateiro, 2010] e [Malta, 2010]. . 1

2.2 Arranjo do suspensório de risers (RSAA), extraído de [Masetti \& Costa, 2009] . . . . . . . . . . . . . . . . . 2

2.3 Esquema das condições experimentais previstas para esta tese. . . . . . . 4

4.1 Número de Strouhal em função do número de Reynolds, adaptado de [Blevins, 1990]. . . . . . . . . . . . . . . . 10

4.2 Variação dos coeficientes de força no cilindro fixo, mediante variação dos regimes de escoamento. Fonte: $[$ Assi, 2009]. . . . . . . . . . . . . . 11

4.3 Amplitudes e frequências de resposta transversal devido ao VIV, apresentadas como função da velocidade reduzida. Resultados marcados com dizem respeito a um cilindro com baixa massa reduzida, $m^{*}<6$, e aqueles marcados com $\diamond$ dizem respeito a um cilindro com alta massa reduzida, $m^{*}>6$. Fonte: [Williamson \& Govardhan, 2008]. . . . . . . . . . . . . . . 13

4.4 Mapa com os tipos de emissão de vórtices durante a oscilação forçada de um cilindro circular rígido. Os padrões são compostos por vórtices simples $(\mathrm{S})$ e também por pares de vórtices $(\mathrm{P})$, compondo arranjos alternados conhecidos como padrões $(2 \mathrm{~S}),(2 \mathrm{P})$ e o padrão $(\mathrm{P}+\mathrm{S})$, os principais na região de sincronização. Fonte: [Williamson \& Govardhan, 2008]. . . . . . . . . . . . . . . . . . 14

4.5 Diagrama com principais códigos numéricos para análise de VIV, extraído de [Larsen et al., 2001a]. . . . . . . . . . . . . . . . . 15

4.6 Coeficientes de massa adicional, à esquerda, e de força de sustentação, à direta, apresentados em [Gopalkrishnan, 1993]. . . . . . . . . . . . . 16

4.7 Variação da faixa de amplitude por velocidade reduzida para diversas razões de massa, extraída de [Gopalkrishnan, 1993] . . . . . . . . . . . . 17 
4.8 Amplitudes adimensionais de [Gopalkrishnan, 1993], com base em cilindros forçados, comparadas com aquelas obtidas por [Vikestad, 1998], a partir de experimentos com cilindros rígidos montados em suporte elástico de um grau de liberdade. . . . . . . . . . . 18

4.9 Exemplo de análise das faixas de excitação modal para uma estrutura flexível vertical sujeita a um perfil de velocidades linearmente variável com a profundidade. Análise conduzida pelo código numérico VIVANA, conforme descrição encontrada em [Larsen et al., 2010] . . . . . . . . . . . 19

4.10 Curvas de interpolação do coeficiente de sustentação para estimativa da amplitude de resposta, resultados extraídos de [Larsen et al., 2001b] . . . 20

4.11 Comparação entre o modelo de [Srinil et al., 2009] e [Vandiver \& Li, 2005] para um modelo de catenária. . . . . . . . . . . . 21

4.12 Parâmetros utilizados para descrever os movimentos na estrutura flexível lançada em catenária, adaptado de [Pesce \& Martins, 2005]. . . . . . . . 23

4.13 Comparação entre frequências naturais obtidas via método WKB e pelo código PoliFLEX [Pesce \& Martins, 2005] . . . . . . . . . . . . . . 28

4.14 Comparação entre modos naturais obtidos via método WKB e aquele obtido via PolifLEX (a parâmetros diferentes de rigidez axial) [Pesce \& Martins, 2005]. . . . . . . . . . . . . . . . . . . 28

4.15 Variação das frequências naturais da catenária segundo análises conduzidas em $[$ Srinil, 2010] . . . . . . . . . . . . . . . . . . . . . . . 29

5.1 Padrões de emissão de vórtices identificados em [Jauvtis \& Williamson, 2004] pela técnica de PIV. Difenrença entre as formações $2 \mathrm{P}$ e $2 \mathrm{~T} \ldots \ldots$. . . . . . . . . . . . . . . . . . . 32

5.2 Arranjo Esquemático do Modelo Flexível utilizado em [Fujarra, 2002]. . . 33

5.3 Exemplo de variação da amplitude de resposta ao longo da linha no caso da deflagração de ondas progressivas, extraída de [Vandiver \& Marcollo, 2003]. . . . . . . . . . . . . . . . 36

5.4 Arranjo do experimento em Castine 1981, realizado por [Vandiver, 1993]. 37

5.5 Identificação de regiões com relação ao modos de vibrar, extraído de [Vandiver et al., 1996] . . . . . . . . . . . . . . . . . 37 
5.6 Arranjo do braço giratório do Marintek [Lie et al., 1997] . . . . . . . . . 38

5.7 Resposta espectral da linha flexível em perfis variáveis de velocidade, resultado obtido de [Lie et al., 1998] . . . . . . . . . . . . . . . . . . . 39

5.8 Arranjo Esquemático do experimento com perfil de correnteza não uniforme realizado por $[$ Lie \& Kaasen, 2006] . . . . . . . . . . . . . . . . 39

5.9 Exemplo de análise dos movimentos longitudinais em velocidade $V=$ $0.54 \mathrm{~m} / \mathrm{s}$ (foco nos modos de vibrar de número 10 a 29), extraída de [Lie \& Kaasen, 2006] . . . . . . . . . . . . . . . . . . . . . . . . . . 40

5.10 Avaliação analítico-numérica do efeito da tração imposta dinamicamente ao topo de uma linha vertical, realizada por [Da Silveira et al., 2007]. . . 42

6.1 Trecho do modelo flexível utilizado nos ensaios. No detalhe, os alvos refletivos utilizados pelo sistema de rastreamento. . . . . . . . . . . . . . 48

6.2 Calibrador Hidrodinâmico do Tanque de Provas Numérico. . . . . . . . . 50

6.3 Detalhes de projeto do braço giratório do Calibrador Hidrodinâmico do

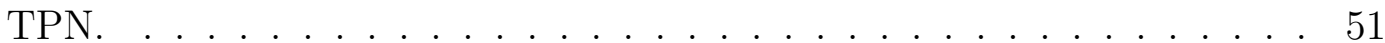

6.4 Instalação do trilho e do eixo central do braço giratório no CHTPN. . . . 52

6.5 Verificação do nivelamento do trilho do braço giratório. Medida para redução das vibrações estruturais do aparato experimental. . . . . . . . . . 52

6.6 Procedimento de montagem do braço giratório com a necessidade de utilização de uma talha e mergulhador para apoio e realização das fixações imersas.

6.7 Arranjos preliminares com modelos construídos em PVC para a comparação entre os perfis de velocidade constante e linearmente variável na radial.

6.8 Arranjo geral de uma catenária rebocada pelo braço giratório, na condição onde a âncora é posicionada junto ao eixo central de rotação.

6.9 Montagem de uma linha lançada em catenária no tanque de reboque do IPT.

6.10 Câmera submersa utilizada para avaliação dos movimentos da porção submersa das linhas flexíveis. 
6.11 Diferentes tipos de fitas refletivas. Algumas não permitem muito tempo de imersão por conta da absorção de água, que as tornam invisíveis ao sistema de monitoração. . . . . . . . . . . . . . . . . . . . . . . . . . . . 58

6.12 Estruturas utilizadas na calibração das câmeras. . . . . . . . . . . . . . . 59

6.13 Método de calibração das câmeras através de haste com cálibre na ponta. 60

6.14 Saída da rotina desenvolvida para ajuste do posicionamento prévio das câmeras submersas. . . . . . . . . . . . . . . . . . . . . . . . . 61

6.15 Uso do sistema de monitoramento óptico para determinar os campos visuais de cada câmera. . . . . . . . . . . . . . . . . . . . . . . . . 62

6.16 Detalhe do bloco de força (seis componentes) montado em conjunto com o atuador unidirecional no topo dos modelos ensaiados. . . . . . . . . . . 63

6.17 Bancada eletrônica embarcada no braço giratório, responsável pelo controle e monitoramento complementar do conjunto de ensaio. . . . . . 63

6.18 Operação e monitoração do ensaio feita remotamente via rede sem-fio. . 64

6.19 Fluxograma de procedimentos, com os materiais e métodos utilizados. . 65

6.20 Arranjo geral do experimento com a configuração de modelo flexível na vertical. . . . . . . . . . . . . . . . . . . . . . 67

6.21 Arranjo geral da instalação do modelo vertical no braço giratório. . . . . 68

6.22 Em destaque, duas das cinco câmeras submersas utilizadas na primeira configuração para o monitoramento do movimento do modelo ensaiado no braço giratório.

6.23 Segunda configuração das câmeras submersas, fixas ao eixo central do braço giratório. . . . . . . . . . . . . . . . . . . . . 6 69

6.24 Características dimensionais da primeira catenária, ou Catenária-1. . . . 70

6.25 Detalhe do posicionamento da âncora próxima ao eixo central do braço giratório. . . . . . . . . . . . . . . . . . . 70

6.26 Arranjo geral do experimento com as câmeras posicionadas depois do eixo central e fundo falso em toda estrutura inferior do braço- giratório. . 71

6.27 Arranjo geral do experimento na condição de lançamento da Catenária-4. 71 
6.28 Comparação dos arranjos de catenária ensaiadas no braço giratório do CHTPN. Em azul, a representação dos alvos reconhecidos pelo sistema de monitoramento óptico. Nomenclatura dos arranjos: acima, à esquerda, Catenária-1; acima, à direita, Catenária-2; abaixo, à esquerda, Catenária-3; abaixo, à direita, Catenária-4. Configurações de lançamento em ordem crescente do ângulo de saída no topo. . . . . . . 72

6.29 Sistema de câmeras submersas utilizado para a monitoração da Catenária-5, ensaiada no IPT. . . . . . . . . . . . . . . . . . . . . 73

6.30 Arranjo da Catenária-5 ensaiada em correnteza transversal no tanque de reboque do IPT, extraído de [PETROBRAS \& LMO, 2013] . . . . . . . . 74

6.31 Exemplo de ensaio de decaimento para a determinação das frequências naturais de um dos arranjos de lançamento do modelo, no caso, o vertical. 75

6.32 Identificação das frequências naturais a partir do deslocamento dos alvos do ensaio de decaimento para a condição Vertical. . . . . . . . . . . . . 76

6.33 Identificação das frequências naturais a partir das amplitudes modais obtidas de decaimento para a condição Vertical. . . . . . . . . . . . . . 77

6.34 Apresentação da Catenária-1 no plano $Y Z$, em conjunto com a variação de velocidade reduzida a longo de seu comprimento. . . . . . . . . . . 87

6.35 Identificação das frequências naturais em exemplo de ensaio de decaimento da Catenária-1. . . . . . . . . . . . . . . . . . . 88

6.36 Análise das séries modais de decaimento, obtidas com base no procedimento de decomposição modal aplicado às séries de deslocamento dos alvos monitorados para a Catenária-1. . . . . . . . . . 89

6.37 Estimativa do coeficiente linear de amortecimento em primeiro modo de vibrar para a Catenária-1. . . . . . . . . . . . . . . . . . . . . . 90

6.38 Modos de vibrar da linha flexível no arranjo Catenária-1: fora do plano de lançamento marcados com "o" e no plano por " $\times$ " . . . . . . . . . . . 91

6.39 Exemplo de séries temporais para a Catenária-1 de deslocamento dos alvos na direção $Y$, avaliados com relação às respectivas PSD, à direita. $\mathrm{O}$ eixo das ordenadas à esquerda em $m$ e à direita $\mathrm{em} m^{2} . s$ com a média ajustada para o número do alvo. . . . . . . . . . . . . . . . . . . 92 
6.40 Trajetórias dos alvos ao longo da linha Catenária-1, apresentados segundo os planos $X Y, Z Y$ e $Z X$. . . . . . . . . . . . . . . . . . . 93

6.41 Trajetórias dos alvos ao longo da linha Catenária-1, apresentados segundo os planos dados pelas direções $t$ e $b, n$ e $b$, bem como $n$ e $t$. . 94

6.42 Exemplo evolução temporal dos deslocamentos para a Catenária-1 de cada alvo ao longo da linha, apresentados nas direções $X Y$ e $Z$. . . . 95

6.43 Exemplo de visualização de evolução temporal para a Catenária-1 nas direções tnb. . . . . . . . . . . . . . . . . . . . . 96

6.44 Amplitudes modais como função da velocidade reduzida calculada com a frequência natural do primeiro modo no plano de lançamento, $V r_{1}$ para Catenária-1. Ordenadas obtidas via: valores máximos, no alto; valores mínimo, ao centro; e desvios- padrão de resposta modal, abaixo. . . . . . 98

6.45 Amplitudes modais como função da velocidade reduzida calculada com a frequência natural do primeiro modo no plano de lançamento, $V r_{n}$ para Catenária-1. Ordenadas obtidas via: valores máximos, no alto; valores mínimo, ao centro; e desvios- padrão de resposta modal, abaixo. . . . . . 99

6.46 Análise conjunta das amplitudes e frequência modais, neste caso, observadas com a execução da matriz de ensaios referentes à Catenária-1. 100

6.47 Exemplo de resultado da decomposição modal aplicada ao conjunto de séries temporais monitoradas em ensaio de VIV com a Catenária-1. Componentes direcionais definidas com base nas equações (6.2) . . . . . . 102

6.48 Exemplo de resultado da decomposição modal obtida com base nas equações (6.3), posteriormente ponderadas pelos modos naturais da Catenária-1. . . . . . . . . . . . . . . . . . . 103

6.49 Exemplo de resultado da estimativa para as amplitudes modais segundo a equação (6.4): às esquerda, com base em sinais temporais originais de um ensaio com a Catenária-1, e à direita, com sinais filtrados. . . . . . . 104

6.50 Séries temporais das amplitudes modais na direção $Y$ : à esquerda, calculadas com base na equação (6.2), e à direita, com base na equação (6.3) para a Catenária-1. . . . . . . . . . . . . . . . . 105

6.51 Séries temporais das amplitudes modais na direção $Y$, calculadas com base na equação (6.4) para a Catenária-1. . . . . . . . . . . . . . . . 106 
6.52 Comparação da amplitude modal obtidas de (6.3) e (6.4) com relação a velocidade reduzida variável ao longo da linha para Catenária-1 sob velocidade máxima $U_{\max }=0.914 \mathrm{~m} / \mathrm{s} \ldots \ldots$. . . . . . . . . 106

6.53 Avaliação da amplitude modal com relação a velocidade reduzida variável ao longo da Catenária-1, calculada com base na velocidade nominal máxima de $U_{\max }=0.914 \mathrm{~m} / \mathrm{s}$ e nas respectivas frequências naturais de cada modo. . . . . . . . . . . . . . . . 107

7.1 Séries temporais de deslocamento ao longo do modelo, obtidas com base no referencial global, na condição de $U_{\max }=0,13 \mathrm{~m} / \mathrm{s}$ e $T_{0}=37 \mathrm{~N}$ (escala do modelo). . . . . . . . . . . . . . . . . . . . . . . . . 111

7.2 Séries temporais de deslocamento ao longo do modelo, nas direções $X, Y$ e $Z$, obtidas com base no referencial local (não-inercial). Caso referente a $U_{\max }=0,13 \mathrm{~m} / \mathrm{s}$ e $T_{0}=37 \mathrm{~N}$ (escala do modelo). . . . . . . . . . . 112

7.3 Trajetórias ao longo do comprimento do modelo flexível vertical, referentes ao ensaio em $U_{\max }=0,13 \mathrm{~m} / \mathrm{s}$ e $T_{\text {topo }}=37 \mathrm{~N}$ (escala do modelo). Apresentação feita no plano XY . . . . . . . . . . . . . . . 113

7.4 Evolução temporal dos deslocamentos ao longo do modelo, nos planos $X Y$, referentes ao ensaio com a linha vertical em $U_{\max }=0,13 \mathrm{~m} / \mathrm{s}$ e $T_{\text {topo }}=37 \mathrm{~N}$ (escala do modelo. . . . . . . . . . . . . 114

7.5 À esquerda, PSD na direção $X$ ao longo do modelo vertical em $U_{\text {max }}=$ $0,13 \mathrm{~m} / \mathrm{s}$ e $T_{\text {topo }}=37 \mathrm{kN}$. À direita, respectivos resultados de PSD para a direção $Y \ldots \ldots$. . . . . . . . . . . . . . . . . . . . . . . . . . 114

7.6 Modos naturais de vibrar do modelo de linha vertical, obtidos conforme a equação (4.17) . . . . . . . . . . . . . . . . . . 116

7.7 Variação das amplitudes modais por velocidade reduzida calculada com a frequência natural do primeiro modo de vibrar transversal da linha vertical. Valores calculados com base na média de máximos, média de mínimos e média dos desvios padrões. . . . . . . . . . . . . . . . . . 117

7.8 Variação das amplitudes modais por velocidade reduzida calculada com a frequência natural de cada modo de vibrar da linha vertical. Valores calculados com base na média de máximos, média de mínimos e média dos desvios padrões. . . . . . . . . . . . . . . . . . . 118 
7.9 Desvio padrão das amplitudes modais e respectivas frequências de resposta dominante na direção transversal ao escoamento incidente (cross flow, CF) da linha vertical. Velocidades reduzidas calculadas com base na frequência natural do primeiro modo de vibrar transversal. . 119

7.10 Desvio padrão das amplitudes modais e respectivas frequências de resposta dominante na direção longitudinal ao escoamento incidente (inline, IL) da linha vertical. Velocidades reduzidas calculadas com base na frequência natural do primeiro modo de vibrar transversal. .. 120

7.11 Identificação das frequências naturais a partir do deslocamento dos alvos do ensaio de decaimento para a condição Catenária-1. . . . . . . . . . 122

7.12 Identificação das frequências naturais a partir das amplitudes modais, obtidas de decaimento para a condição Catenária-1. . . . . . . . . . . . . 123

7.13 Identificação das frequências naturais a partir do deslocamento dos alvos do ensaio de decaimento para a condição Catenária-2. . . . . . . . . . . 124

7.14 Identificação das frequências naturais a partir das amplitudes modais, obtidas de decaimento para a condição Catenária-2 . . . . . . . . . . 125

7.15 Identificação das frequências naturais a partir do deslocamento dos alvos do ensaio de decaimento para a condição Catenária-3. . . . . . . . . . 126

7.16 Identificação das frequências naturais a partir das amplitudes modais, obtidas de decaimento para a condição Catenária-3. . . . . . . . . . . . 127

7.17 Identificação das frequências naturais a partir do deslocamento dos alvos do ensaio de decaimento para a condição Catenária-4. . . . . . . . . . 128

7.18 Identificação das frequências naturais a partir das amplitudes modais, obtidas de decaimento para a condição Catenária-4. . . . . . . . . . . . . 129

7.19 Identificação das frequências naturais a partir do deslocamento dos alvos do ensaio de decaimento para a condição Catenária-5. . . . . . . . . . 130

7.20 Identificação das frequências naturais a partir das amplitudes modais, obtidas de decaimento para a condição Catenária-5. . . . . . . . . . . . . 131

7.21 Modos de vibrar do arranjo Catenária-1 . . . . . . . . . . . . . . 133 
7.22 Variação das Amplitudes Modais através da interpolação do sinal do ensaio pela velocidade reduzida baseada na frequência natural do primeiro modo de vibrar para o arranjo Catenária-1 . . . . . . . . . . . . 134

7.23 Variação das Amplitudes Modais através da interpolação do sinal do ensaio pela velocidade reduzida baseada na frequência natural de cada modo de vibrar para o arranjo Catenária-1 . . . . . . . . . . . . . . . . . 134

7.24 Desvio padrão das amplitudes modais através da interpolação do sinal do ensaio e frequência de resposta máxima do movimento cruzado (cross) por $\mathrm{Vr}$ baseado na frequência natural do primeiro modo de vibrar para o arranjo Catenária-1 . . . . . . . . . . . . . . . . 135

7.25 Desvio padrão das amplitudes modais através da interpolação do sinal do ensaio e frequência de resposta máxima do movimento na direção do fluxo (in-line) por Vr baseado na frequência natural do primeiro modo de vibrar para o arranjo Catenária-1 . . . . . . . . . . . . . . 135

7.26 Modos de vibrar do arranjo Catenária-2 . . . . . . . . . . . 136

7.27 Variação das Amplitudes Modais através da interpolação do sinal do ensaio pela velocidade reduzida baseada na frequência natural do primeiro modo de vibrar para o arranjo Catenária-2 . . . . . . . . . . . . 137

7.28 Variação das Amplitudes Modais através da interpolação do sinal do ensaio pela velocidade reduzida baseada na frequência natural de cada modo de vibrar para o arranjo Catenária-2 . . . . . . . . . . . . . . 137

7.29 Desvio padrão das amplitudes modais através da interpolação do sinal do ensaio e frequência de resposta máxima do movimento cruzado (cross) por Vr baseado na frequência natural do primeiro modo de vibrar para o arranjo Catenária-2 . . . . . . . . . . . . . . . . . . 138

7.30 Desvio padrão das amplitudes modais através da interpolação do sinal do ensaio e frequência de resposta máxima do movimento na direção do fluxo (in-line) por Vr baseado na frequência natural do primeiro modo de vibrar para o arranjo Catenária-2 . . . . . . . . . . . . . . . . 138

7.31 Modos de vibrar do arranjo Catenária-3 . . . . . . . . . . . . . . . 139 
7.32 Variação das Amplitudes Modais através da interpolação do sinal do ensaio pela velocidade reduzida baseada na frequência natural do primeiro modo de vibrar para o arranjo Catenária-3 . . . . . . . . . . . . 140

7.33 Variação das Amplitudes Modais através da interpolação do sinal do ensaio pela velocidade reduzida baseada na frequência natural de cada modo de vibrar para o arranjo Catenária-3 . . . . . . . . . . . . . . . . . 140

7.34 Desvio padrão das amplitudes modais através da interpolação do sinal do ensaio e frequência de resposta máxima do movimento cruzado (cross) por Vr baseado na frequência natural do primeiro modo de vibrar para o arranjo Catenária-3 . . . . . . . . . . . . . . . . . . . . . 141

7.35 Desvio padrão das amplitudes modais através da interpolação do sinal do ensaio e frequência de resposta máxima do movimento na direção do fluxo (in-line) por Vr baseado na frequência natural do primeiro modo de vibrar para o arranjo Catenária-3 . . . . . . . . . . . . . . . . . 141

7.36 Modos de vibrar do arranjo Catenária-4 . . . . . . . . . . . . . . . 142

7.37 Variação das Amplitudes Modais através da interpolação do sinal do ensaio pela velocidade reduzida baseada na frequência natural do primeiro modo de vibrar para o arranjo Catenária-4 . . . . . . . . . . . . 143

7.38 Variação das Amplitudes Modais através da interpolação do sinal do ensaio pela velocidade reduzida baseada na frequência natural de cada modo de vibrar para o arranjo Catenária-4 . . . . . . . . . . . . . . . . . 143

7.39 Desvio padrão das amplitudes modais através da interpolação do sinal do ensaio e frequência de resposta máxima do movimento cruzado (cross) por Vr baseado na frequência natural do primeiro modo de vibrar para o arranjo Catenária-4 . . . . . . . . . . . . . . . . . . 144

7.40 Desvio padrão das amplitudes modais através da interpolação do sinal do ensaio e frequência de resposta máxima do movimento na direção do fluxo (in-line) por Vr baseado na frequência natural do primeiro modo de vibrar para o arranjo Catenária-4 . . . . . . . . . . . . . . . . . 144

7.41 Modos de vibrar do arranjo Catenária-5 . . . . . . . . . . . . . . 145 
7.42 Variação das Amplitudes Modais através da interpolação do sinal do ensaio pela velocidade reduzida baseada na frequência natural do primeiro modo de vibrar para o arranjo Catenária-5 . . . . . . . . . . . . 146

7.43 Variação das Amplitudes Modais através da interpolação do sinal do ensaio pela velocidade reduzida baseada na frequência natural de cada modo de vibrar para o arranjo Catenária-5 . . . . . . . . . . . . . . . 146

7.44 Desvio padrão das amplitudes modais através da interpolação do sinal do ensaio e frequência de resposta máxima do movimento cruzado (cross) por $\mathrm{Vr}$ baseado na frequência natural do primeiro modo de vibrar para o arranjo Catenária-5 . . . . . . . . . . . . . . . . . 147

7.45 Desvio padrão das amplitudes modais através da interpolação do sinal do ensaio e frequência de resposta máxima do movimento na direção do fluxo (in-line) por Vr baseado na frequência natural do primeiro modo de vibrar para o arranjo Catenária-5 . . . . . . . . . . . . . . . . . 147

7.46 Variação nas amplitudes modais CF para todos os modelos considerados nos ensaios com o braço giratório, no CH-TPN. . . . . . . . . . . . . . . 149

7.47 Reconstrução da deformada da Catenária-1 no sistema de coordenadas $(\mathrm{t}, \mathrm{n}, \mathrm{b})$, sob velocidade $U_{\max }=1,94 \mathrm{~m} / \mathrm{s} \ldots \ldots \ldots$

7.48 Amplitudes modais acopladas obtidas para o ensaio da Catenária-1 ( $U_{\max }$

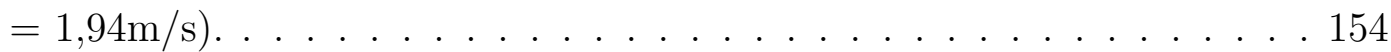

7.49 Comparação do modo de vibrar obtido numericamente para Catenária-1 e modelo analítico. . . . . . . . . . . . . . . . . . . 156 


\section{Lista de Tabelas}

5.1 Conversões de propriedades entre a escala do modelo e da escala real adaptado de [Rateiro et al., 2012].

6.1 Propriedades do modelo de linha flexível, em escala de 1:100, comparado com as respectivas propriedades do riser em escala real. Fonte: [Rateiro et al., 2012]. . . . . . . . . . . . . . . . . . . . . . . 49

6.2 Características geométricas e operacionais do Calibrador Hidrodinâmico e seu braço giratório. . . . . . . . . . . . . . . . . . . . . . 53

6.3 Características geométricas e operacionais do tanque de reboque do IPT. . 56

6.4 Características das câmeras submersas utilizadas nos experimentos desta pesquisa. . . . . . . . . . . . . . . . . . . . . 5 57

6.5 Propriedades dos arranjos de catenárias realizados no CH-TPN . . . . . . . 73

6.6 Características dimensionais da Catenária-5, ensaiada no IPT. . . . . . . . 74

6.7 Matriz de ensaios para o arranjo Vertical, realizada no braço giratório do CHTPN. . . . . . . . . . . . . . . . . 80

6.8 Matriz de ensaios para o arranjo Catenaria-1, realizada no braço giratório do CHTPN. . . . . . . . . . . . . . . . . . . . 81

6.9 Matriz de ensaios para o arranjo Catenaria-2, realizada no braço giratório do CHTPN.

6.10 Matriz de ensaios para o arranjo Catenaria-3, realizada no braço giratório do CHTPN.

6.11 Matriz de ensaios para o arranjo Catenaria-4, realizada no braço giratório do CHTPN.

6.12 Matriz de ensaios para o arranjo Catenaria-5, realizada no tanque de reboque do IPT.

7.1 Comparação das frequências analíticas e numéricas em Hz na escala real. 155 


\section{Lista de Símbolos}

$A_{n} \quad$ Amplitude modal para o n-ésimo modo de vibrar.

$b(s) \quad$ Coordenada bi-normal na coordenada curvilínea s.

$C_{a} \quad$ Coeficiente de massa adicional

$C_{D} \quad$ Coeficiente de arrasto ou drag.

$C_{L} \quad$ Coeficiente de sustentação ou lift.

d Distância horizontal de lançamento da catenária.

D $\quad$ Diâmetro do cilindro.

EI Rigidez flexional.

EA Rigidez axial.

$f \quad$ Frequência de vibração do cilindro.

$f_{n} \quad$ Frequência natural de vibração.

$f_{s} \quad$ Frequência de Strouhal ou frequência de emissão dos vórtices.

$f^{*} \quad$ Frequência reduzida de emissão.

$F_{r} \quad$ Número de Froude.

H Profundidade de lançamento da linha em catenária.

L Comprimento total da linha de riser.

$m \quad$ Massa do cilindro.

$m^{*} \quad$ Massa reduzida.

$m_{d} \quad$ Massa do volume fluido deslocado.

$m_{a} \quad$ Massa adicional do cilindro.

$n \quad$ Número do modo de vibrar.

$n(s) \quad$ Coordenada normal na posição curvilínea s.

Re Número de Reynolds.

$S_{t} \quad$ Número de Strouhal.

$t \quad$ Coordenada tangente na posição curvilínea s.

$T(s) \quad$ Tração na posição curvilínea s.

$T_{0} \quad$ Tração no TPD.

$U_{\max } \quad$ Velocidade do escoamento incidente.

$u \quad$ Deslocamento horizontal com relação a linha estática. 
$v \quad$ Deslocamento fora do plano da catenária.

w Deslocamento na direção vertical com relação a linha estática.

w Peso imerso da linha em configuração de catenária.

$V_{r} \quad$ Velocidade reduzida adimensionalizada pelo primeiro modo de vibrar.

$V_{r} n \quad$ Velocidade reduzida adimensionalizada pelo n-ésimo modo de vibrar.

Grego:

$\zeta \quad$ Coeficiente de amortecimento estrutural linear.

$\theta \quad$ Ângulo de inclinação do cilindro.

$\theta \quad$ Ângulo de inclinação com a horizontal na posição curvilínea s da linha lançada em catenária.

$\theta_{\text {Topo }} \quad$ Ângulo no topo da linha, com respeito à horizontal.

$\lambda \quad$ Fator de escala.

$\mu \quad$ Viscosidade dinâmica do fluído.

$v \quad$ Viscosidade cinemática do fluído.

$\rho \quad$ Densidade do fluído.

$\varphi_{n}(s) \quad$ n-ésimo modo de vibrar em função da sua posição s ao longo da linha.

$\Omega_{n} \quad$ Frequência natural do n-ésimo modo de vibrar. 


\section{Organização da Tese}

O Capítulo 2 introduz o tema abordado nesta tese, contextualizando os trabalhos propostos de investigação experimental com vistas aos objetivos definidos no Capítulo 3.

Em seguida, nos capítulos 4 e 5, é realizado um estudo sobre o tema das vibrações induzidas pela emissão de vórtices em linhas flexíveis, estabelecendo foco nos aspectos mais importantes deste fenômeno, com vistas a sua utilização na análise e interpretação dos resultados experimentais obtidos durante o desenvolvimento da tese.

Este estudo foi fundamental para a etapa seguinte, descrita no Capítulo 6, onde materiais e métodos selecionados para a execução dos trabalhos de pesquisa experimental foram apresentados e discutidos à luz das demandas exigidas para uma melhor compreensão dos comportamentos dinâmicos esperados. Nesse mesmo capítulo, destaca-se também a definição das condições de ensaio selecionadas para o consecução dos objetivos traçados na tese, as quais, até onde se tem conhecimento, compõem um conjunto original de dados sobre o VIV nas linhas flexíveis longas. Além disso, o Capítulo 6 também descreve em detalhes os métodos de análise utilizados para a redução e discussão dos resultados apresentados no Capítulo 7.3.

Na etapa final deste texto, esses resultados serviram para comparações realizadas entre os comportamentos de VIV na linha vertical e nas catenárias, quatro delas ensaiadas em perfil variável de velocidades (no CHTPN) e uma em perfil uniforme de velocidade (no IPT), permitindo conclusões e perspectivas apresentadas no Capítulo 8.

Finalmente, nos anexos são apresentados resultados das análises sobre as séries temporais para outras condições de corrente relevantes, representando as respostas mais significativas do extenso conjunto investigado. 


\section{Introdução e Motivação}

A presente tese de doutorado foi escrita pelo M.E. Edgard Borges Malta, sob orientação do Prof. Dr. André Luis Condino Fujarra, como resultado do programa de Pós-graduação em Engenharia Naval desenvolvido junto à Escola Politécnica da Universidade de São Paulo.

A pesquisa mais adiante descrita foi realizada na sequência de um programa de mestrado, [Malta, 2010], quando foram realizados experimentos com uma unidade flutuante do tipo semissubmersível no tanque de reboque do Instituto de Pesquisas Tecnológicas do Estado de São Paulo (IPT), ver Figura 2.1.

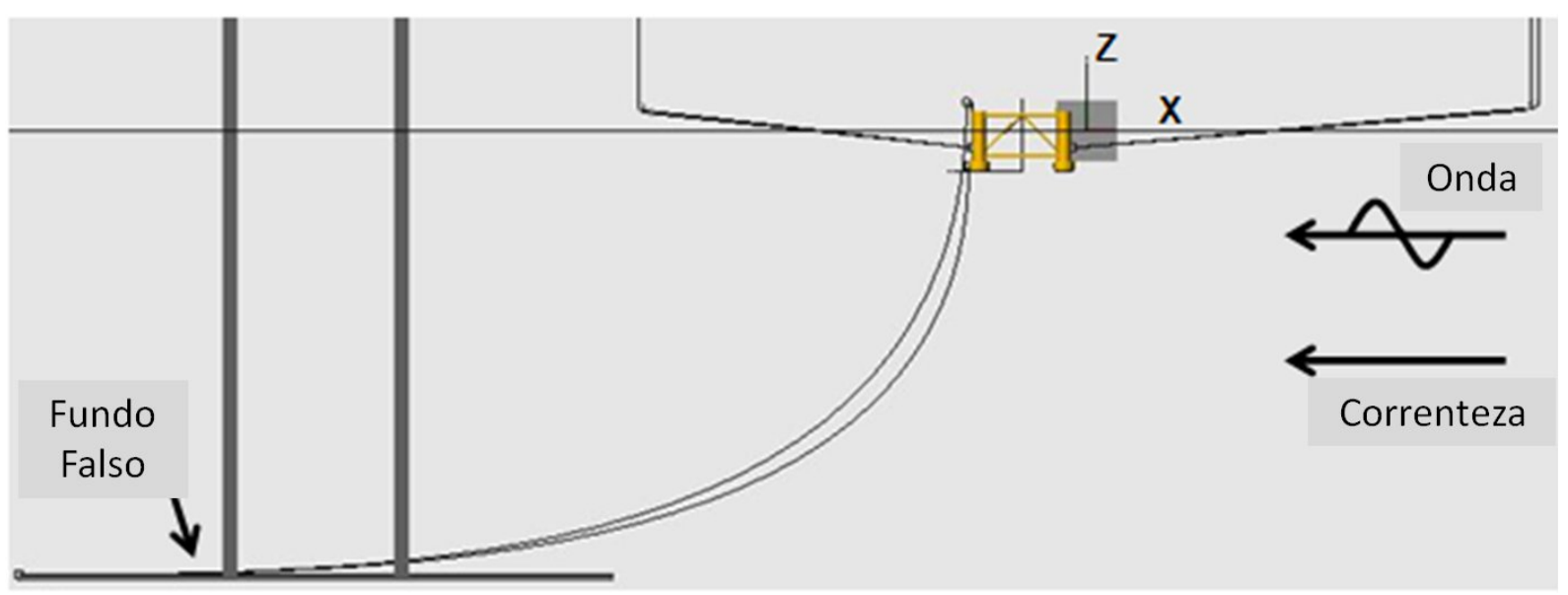

Figura 2.1: Arranjo dos experimentos realizados em [Rateiro, 2010] e [Malta, 2010].

Em conjunto com os resultados apresentados em [Rateiro, 2010], os procedimentos experimentais e o estudo dos efeitos das linhas na unidade flutuante foram investigados, suscitando a importância de se considerar o fenômeno de Vibrações Induzidas pela Emissão de Vórtices (VIV, de Vortex-Induced Vibrations) nas catenárias, o que definiu o foco do presente doutorado.

Assim sendo, as recentes descobertas de reservas de petróleo e gás natural em águas cada vez mais profundas, incluindo aquelas do chamado Pré-sal, são exemplos que levaram 
a exploração desses recursos naturais a profundidades superiores aos 2000m. Nos últimos anos, para acompanhar o aumento das lâminas d'água, foram desenvolvidas significativas inovações tecnológicas em sistemas flutuantes, em sistemas de ancoragem, bem como nos risers ${ }^{1}$ e umbilicais.

Agentes ambientais como as ondas do mar, os vento e a própria correnteza marinha atuam direta ou indiretamente sobre as estruturas oceânicas (particularmente amarras, risers, umbilicais, entre outras), provocando falhas por solicitação extrema ou fadiga de longo termo.

Como soluções, inovações tecnológicas têm sido apresentadas na tentativa de desacoplar os movimentos da unidade, ver [Tellier \& Thethi, 2009], dentre as quais se destaca aquela onde o riser é suspenso e ancorado por amarras conforme apresentado, por exemplo, em [Masetti \& Costa, 2009], solução posteriormente avaliada por [Dantas et al., 2010] e [Pereira, 2011]. Contudo, mesmo com movimentos consideravelmente desacoplados resultantes desses novos sistemas, um dos problemas que permanece e preocupa os projetistas é aquele devido ao fenômeno de VIV em qualquer um dos segmentos ilustrados na Figura 2.2.

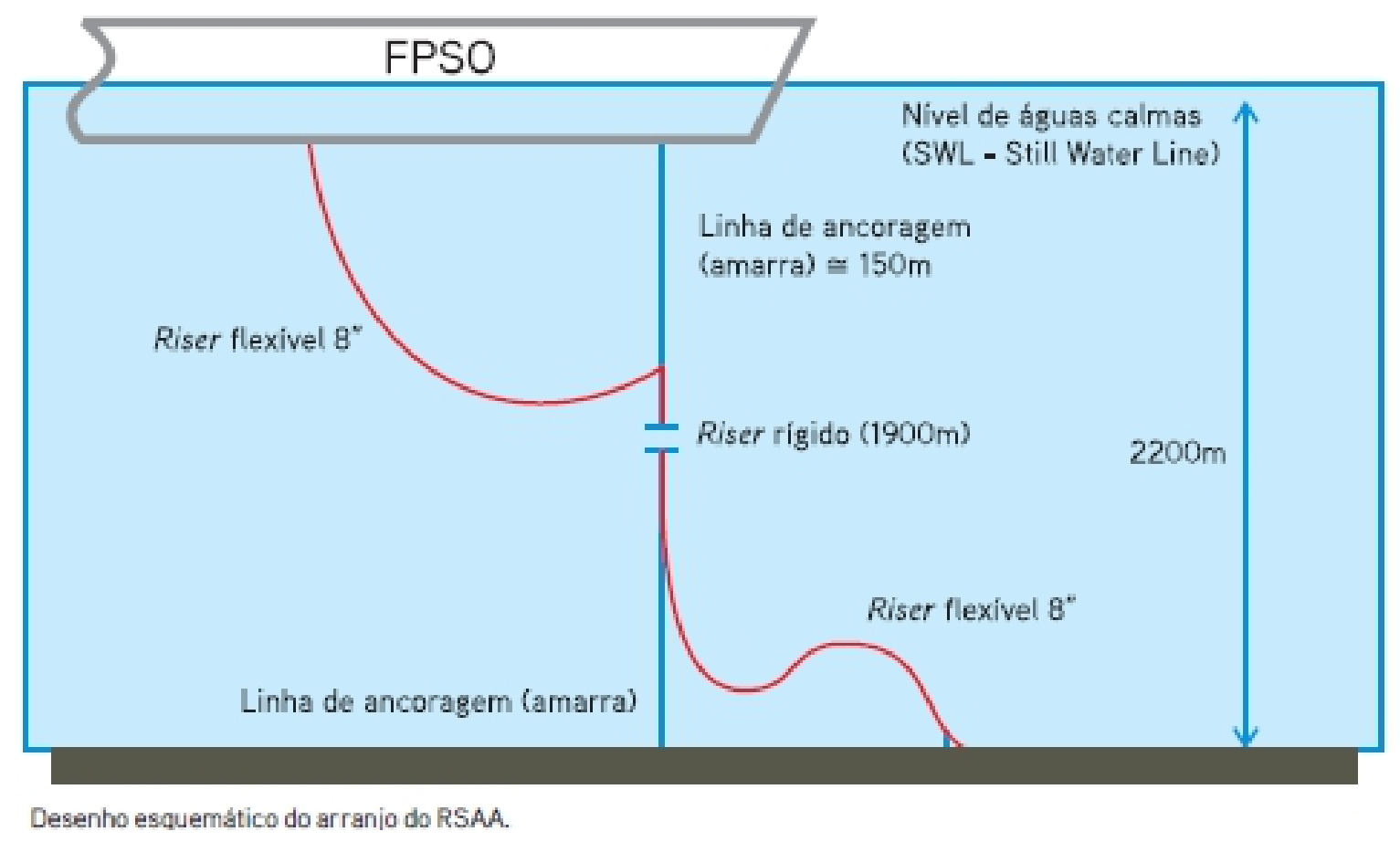

Figura 2.2: Arranjo do suspensório de risers (RSAA), extraído de [Masetti \& Costa, 2009].

\footnotetext{
${ }^{1}$ Estruturas tubulares para a exploração/transporte dos hidrocarbonetos (óleo e gás), do fundo do mar para a unidade flutuante.
} 
Em linhas gerais, o fenômeno de VIV ocorre quando a frequência de liberação dos vórtices, motivada pela separação da camada limite próxima a um corpo rombudo, assume valor próximo a uma das frequências naturais envolvidas, deflagrando um quadro ressonante de vibrações predominantemente transversais à direção da correnteza incidente, causando carregamentos indesejáveis que podem levar à fadiga precoce da estrutura.

As VIV, de fato, podem ocorrer em vários tipos de estruturas oceânicas, tanto nos risers de exploração, linhas de amarração e umbilicais (todas estruturas de grande razão de aspecto e muitos modos naturais excitáveis), quanto também nas próprias plataformas flutuantes - do tipo: Spar ${ }^{2}$, Tension Leg Platform (TLP) ${ }^{3}$ ou semissubmersível (SS) ${ }^{4}$. No caso das plataformas flutuantes, estruturas de pequena razão de aspecto, sabe-se que as VIV podem suscitar quadros ressonantes com maior período, nos graus de liberdade contidos no plano da superfície livre, o que lhes confere nomenclatura ligeiramente diferente - Movimentos Induzidos pela Emissão de Vórtices (VIM, de Vortex-Induced Motions).

Embora resultados em escala real ofereçam uma abordagem completa do problema de VIV (ou VIM) nas estruturas oceânicas, os resultados assim obtidos são de complicadíssima obtenção, além de, em geral, serem extremamente afetados por outros aspectos como a turbulência intrínseca ao cenário real, a coexistência de ondas, entre outros.

Portanto, de uma maneira geral as investigações do fenômeno de VIV têm sido realizadas com base em modelos reduzidos e experimentos simplificados conduzidos em tanques de prova, aumentando o controle e reduzindo o número de variáveis envolvidas. Inicialmente, pesquisadores sobre o assunto se concentraram apenas nas oscilações transversais à correnteza incidente sobre cilindros circulares rígidos montados em suportes elásticos, determinando forças e deslocamentos devido ao VIV. Com a evolução das pesquisas, perceberam, então, que as oscilações na direção longitudinal à correnteza desempenham papel importante, na medida em que promovem uma amplificação das respostas na direção transversal. Nas últimas duas décadas, no entanto, teve início uma massiva concentração de pesquisas no investigação do VIV em cilindros flexíveis, incorporando questões de difícil tratamento como a coexistência de excitação modal e os efeitos da inclinação do cilindro em relação ao perfil de correnteza.

\footnotetext{
${ }^{2}$ Unidade flutuante dotada de uma única coluna de pequena razão de aspecto.

${ }^{3}$ Unidade flutuante ancorada por tendões fortemente tracionados.

${ }^{4}$ Unidade flutuante dotada de três ou mais colunas, ancorada por amarras lançadas em catenária.
} 
Pois é neste "exato" ponto em que se insere esta pesquisa, buscando descrever os comportamentos dinâmicos do VIV em cilindros flexíveis longos, agora lançados em catenária e submetidos à um perfil de correnteza variável com a profundidade e perpendicular ao plano de lançamento, ver Figura 2.3.

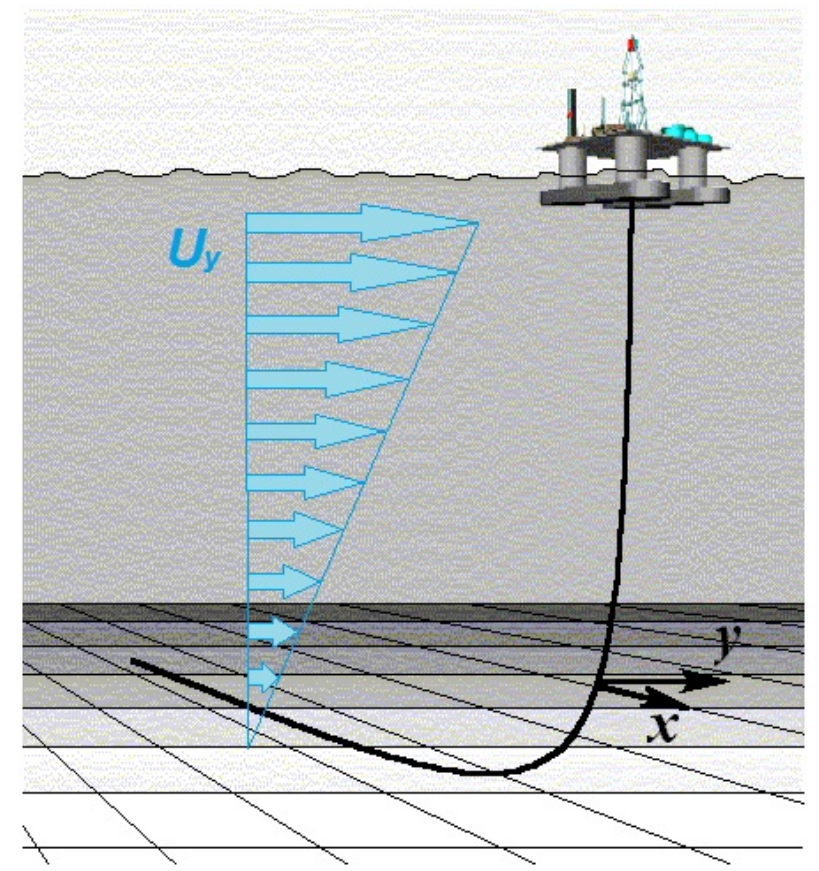

Figura 2.3: Esquema das condições experimentais previstas para esta tese.

Embora aparentemente simples na concepção, experimentos de VIV com modelos flexíveis lançados em catenária e sob a ação de correnteza variável são extremamente complicados, principalmente por conta das características tridimensionais desse problema, capaz de promover interações fluidos-estruturais ao longo de todo o comprimento. Existe também a dificuldade de se obter resultados coerentes em escala reduzida, face às razões de aspecto e números de Reynolds envolvidos. Não por outro motivo, os efeitos do VIV nas catenárias têm sido comparados com aqueles advindos de sua ação nos cilindros flexíveis retos, buscando padrões usuais, descritos por comportamentos e parâmetros importantes como: a razão de massa do sistema ${ }^{5}$; o coeficiente de amortecimento; a restauração do sistema e a própria velocidade do escoamento incidente. Com relação à velocidade, sabese de sua relação direta com frequência de emissão dos vórtices, $f_{s}$, definida com base no parâmetro adimensional $S t=f_{s} \cdot D / U$, conhecido como número de Strouhal ${ }^{6}$.

\footnotetext{
${ }^{5}$ Quociente entre a massa estrutural em oscilação e a massa de fluido deslocado.

${ }^{6}$ Em meados do século XIX, o físico tcheco Vincenc Strouhal realizou experimentos onde demonstrou a relação direta entre a frequência de emissão dos vórtices, $f_{s}=0,185 U / D$, a dimensão característica do corpo imerso, $D$, e a velocidade do escoamento incidente, $U$.
} 
Algumas referências sugerem que parte substancial da complexidade nos experimentos com modelos flexíveis longos advenha das mudanças entre frequências e modos de vibrar excitados simultaneamente, o que dificulta a caracterização de eventuais comportamentos dinâmicos conhecidos. Lembrar que, para a definição das frequências e modos naturais de estruturas flexíveis, características relacionadas à rigidez (flexional, axial e/ou geométrica) e à distribuição de massa são fundamentais na configuração na vertical, inclinada e também na catenária.

Apesar de complexa, no entanto, a realização de experimentos de VIV com modelos em tanques de prova é bastante promissora e, se apoiada por uma boa caracterização das frequências e modos naturais, pode levar a avanços contundentes na compreensão desse fenômeno, com ganhos para proposições teóricas cada vez mais eficientes que evitem o superdimensionamento das estruturas oceânicas.

Sendo assim, considerando-se apropriadamente os pontos mencionados aqui, ainda existe demanda por experimentos como os mais adiante descritos, com os quais acreditase ter contribuído para certo avanço nessa fronteira do conhecimento. 


\section{Objetivos}

O principal objetivo deste doutorado é a investigação experimental de modelos flexíveis lançados em catenária, sujeitos ao fenômeno de VIV devido à incidência de correnteza linearmente variável com a profundidade e perpendicular ao plano de lançamento. Tal investigação visa compreender os comportamentos dinâmicos assim identificados, buscando compará-los com aqueles usualmente descritos na literatura, assim, ampliando a compreensão desse fenômeno nas soluções tecnológicas mais recentes no cenário da produção de petróleo e gás no mar.

Para tanto, este doutorado tem como objetivos complementares:

- A construção de um aparato experimental específico para esta classe de experimentos, a serem conduzidos no tanque de provas físico do TPN;

- A viabilização de uma monitoração eficiente de deslocamentos imersos ao longo dos modelos flexíveis longos;

- A proposição de uma metodologia eficiente de análise, capaz de revelar comportamentos dinâmicos conhecidos em meio à resposta bastante complexa da excitação multimodal.

Os próximos capítulos descrevem todas as atividades envolvidas na busca pelo atendimento destes objetivos, detalhando e discutindo os resultados assim obtidos. 


\section{Fundamentos Teóricos e Considerações sobre o VIV}

Neste capítulo são apresentados os principais conceitos sobre as vibrações induzidas pela emissão de vórtices, particularmente no tocante à fenomenologia geral e aos efeitos sobre as estruturas flexíveis longas (verticais ou lançadas em catenária). Alguns desses conceitos são a base dos códigos comerciais para a estimativa do fenômeno de VIV, amplamente utilizados nos projetos atuais de linhas oceânicas.

\subsection{O fenômeno de VIV: Aspectos Gerais}

Vibrações induzidas pela emissão de vórtices (VIV) são movimentos induzidos em corpos rombudos sujeitos ao escoamento fluido que, mediante perturbação inicial, deflagra um processo perene de flutuações no campo de pressões próximo, promovidas pela liberação coordenada de vórtices, ou conjuntos de vórtices.

De seu lado, quando também acontecem de maneira alternada, essas flutuações impõem forças de sustentação e de arrasto, respectivamente transversais e longitudinais à direção do escoamento incidente, que acabam possibilitando os movimentos evidenciados.

Intrinsecamente, os próprios movimentos acabam por mudar a natureza da formação e emissão dos vórtices, de tal modo que conduzem a um comportamento ressonante de amplitudes dependentes da frequência de liberação dessas estruturas fluidas. Este efeito, no entanto, é diferente daquele esperado para um processo de ressonância usual, pois no VIV a frequência de emissão dos vórtices, agente excitador neste fenômeno, deixa de aumentar com o aumento da velocidade do escoamento, mantendo-se próxima da frequência natural corpo.

De fato, sabe-se que: a frequência de emissão dos vórtices, $f_{s}$, está relacionada à velocidade do escoamento, $U$, e a dimensão característica do corpo, $D$, através do 
adimensional conhecido como número de Strouhal, equação 4.1; e que ao seu comportamento típico de aderir à frequência natural do corpo dá-se o nome de sincronização, ou lock-in na nomenclatura inglesa.

$$
S t=\frac{f_{s} \cdot D}{U}
$$

De acordo com a Figura 4.1, pode ser vista a relação entre o número de Strouhal e o número de Reynolds para cilindros fixos, $R e=\rho U D / \mu$; este último caracterizado pela relação entre forças de origem inercial, proporcionais a $\rho x U x D$, e forças de origem viscosa, proporcionais a $\mu$, sendo $\rho$ a massa específica do fluído e $\mu$ sua viscosidade dinâmica. Note que, para uma larga faixa de números de Reynolds, o Strouhal dos cilindros circulares se mantem em aproximadamente $S t=0,20$, o que, portanto, define uma relação linear entre a frequência de emissão dos vórtices e a velocidade do escoamento.

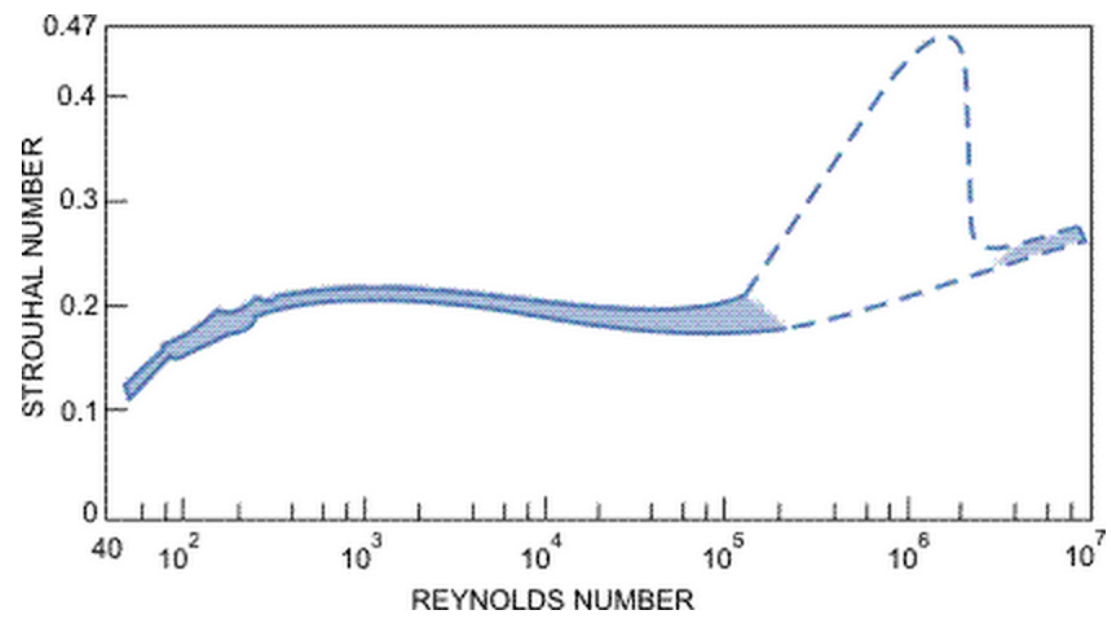

Figura 4.1: Número de Strouhal em função do número de Reynolds, adaptado de [Blevins, 1990].

Embora não apreciáveis sob a óptica da sincronização, as pequenas variações no número de Strouhal se devem ao fato da esteira de vórtices responder de maneira diferente com relação ao regime de escoamento, resultando na mudança nos coeficientes de força atuante no cilindro. Uma boa descrição da relação entre os regimes de escoamento e os coeficientes de força transversais e longitudinais nos cilindros fixos pode ser encontrada em [Assi, 2009], aqui sintetizada na forma da Figura 4.2.

Note como a esteira se modifica com o aumento do número de Reynolds, evoluindo de um arranjo simétrico em regime laminar para um regime de emissão alternada de vórtices, que se mantém até o regime turbulento, obviamente com alterações estruturais 
que impactam nos valores dos coeficientes de força.

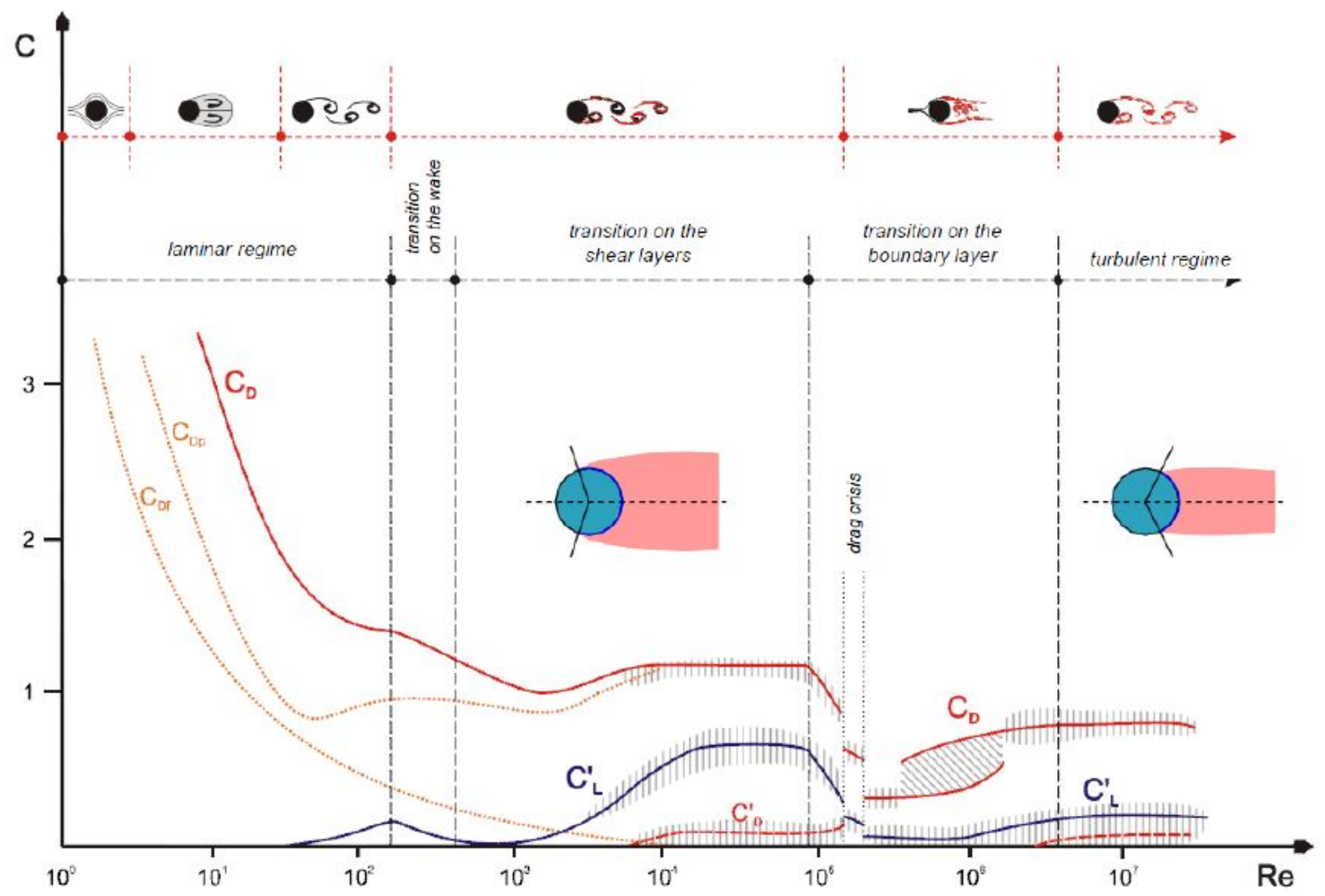

Figura 4.2: Variação dos coeficientes de força no cilindro fixo, mediante variação dos regimes de escoamento. Fonte: [Assi, 2009].

Outro parâmetro adimensional utilizado na caracterização e discussão do fenômeno de VIV é a chamada velocidade reduzida, definida usualmente com base na frequência natural do corpo, $f_{n}$, sua dimensão característica, no caso $D$, e, naturalmente, a velocidade do escoamento, ver equação 4.2 .

$$
V_{r}=\frac{U}{f_{n} \cdot D}
$$

De acordo com a literatura sobre o VIV, sabe-se haver relação entre sua amplitude de resposta e os valores de velocidade reduzida na faixa de sincronização, tipicamente caracterizada por $4 \leq V_{r} \leq V_{r}^{\max }$, onde a velocidade reduzida máxima $V_{r}^{\max }$ depende do tipo de estrutura excitada por este fenômeno.

Segundo [Williamson \& Govardhan, 2008], por exemplo, em velocidades reduzidas menores que quatro as amplitudes de resposta transversal são muito baixas. Contudo, na medida em que as velocidades reduzidas aumentam dentro da faixa de sincronização, diferentes ramos de reposta são identificados, cada qual com seu níveis de amplitude 
associados a padrões distintos de emissão dos vórtices. Na Figura 4.3, retirada daquela referência, podem ser identificados dois conjuntos de resultados: o primeiro, de maiores amplitudes, relacionado a cilindros com baixos valores de inércia própria comparada à inércia do volume de fluido deslocado, $m^{*}<6$; e o segundo, de menores amplitudes, relacionado aos cilindros com maiores valores dessa inércia relativa, $m^{*}>6$.

Desta forma, sabe-se que o parâmetro $m^{*}$, também conhecido como massa reduzida ou razão de massa, impõe sensíveis modificações no comportamento dinâmico geral dentro da faixa de sincronização; ver equação 4.3.

$$
m^{*}=\frac{m}{\rho \frac{\pi}{4} D^{2}}
$$

Para cilindros com valores baixos desse parâmetro, $m^{*}<6$, mediante o aumento progressivo da velocidade reduzida, o comportamento dinâmico se modifica segundo três ramos distintos, conhecidos como: initial excitation, para $3,5<V_{r}<4,0$; upper branch, para $4,0<V_{r}<7$, 0; e lower branch, para 7,0< $V_{r}<12,0$. Por outro lado, para cilindros com valores mais altos do parâmetro de massa reduzida, $m^{*}>6$, se verificam menores amplitudes apenas na forma da initial excitation, para 5,0< $V_{r}<6$, 0; e do lower branch, para $6,0<V_{r}<8,0$. 

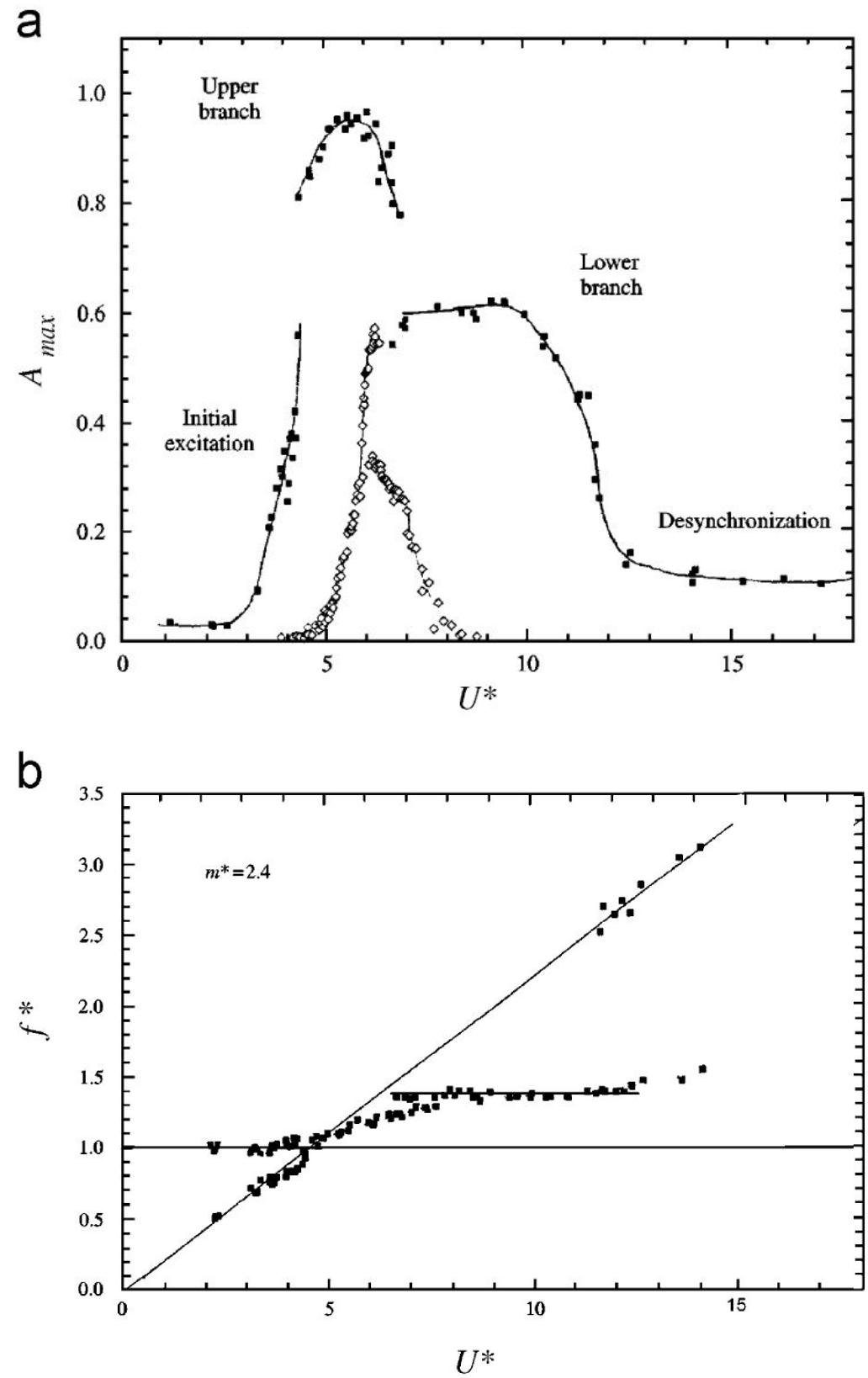

Figura 4.3: Amplitudes e frequências de resposta transversal devido ao VIV, apresentadas como função da velocidade reduzida. Resultados marcados com $\mathbf{\square}$ dizem respeito a um cilindro com baixa massa reduzida, $m^{*}<6$, e aqueles marcados com $\diamond$ dizem respeito a um cilindro com alta massa reduzida, $m^{*}>6$. Fonte:

[Williamson \& Govardhan, 2008].

Ainda de acordo com [Williamson \& Govardhan, 2008], as diferenças entre ramos de resposta na faixa de sincronização estão associadas a padrões típicos de emissão, dentre os quais se destacam: o padrão alternado de emissão de vórtices simples (2S), na região de initial excitation; o padrão alternado de emissão $(\mathrm{P}+\mathrm{S})$ em oscilação forçada, típico da região de upper branch; e o padrão alternado de emissão aos pares $(2 \mathrm{P})$, na região de lower branch. Ver Figura 4.4 em associação com a Figura 4.3. 


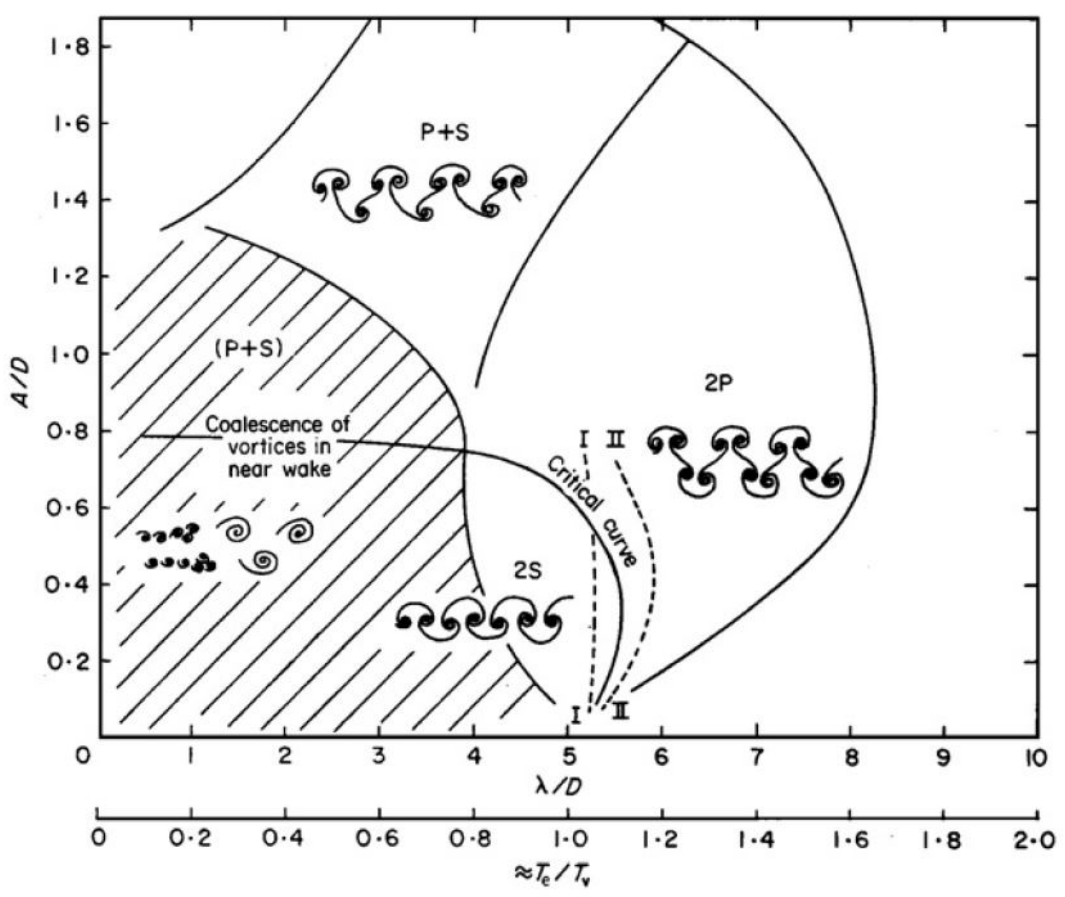

Figura 4.4: Mapa com os tipos de emissão de vórtices durante a oscilação forçada de um cilindro circular rígido. Os padrões são compostos por vórtices simples (S) e também por pares de vórtices $(\mathrm{P})$, compondo arranjos alternados conhecidos como padrões $(2 \mathrm{~S})$, $(2 \mathrm{P})$ e o padrão $(\mathrm{P}+\mathrm{S})$, os principais na região de sincronização. Fonte:

[Williamson \& Govardhan, 2008].

\subsection{Efeito do VIV nas estruturas flexíveis longas}

Apesar da semelhança em relação a muitos dos aspectos fenomenológicos aqui apresentados, a comparação entre os comportamentos dinâmicos nos cilindros rígidos, forçados ou montados em suporte elástico, e os comportamentos identificados nos cilindros flexíveis impulsionaram as investigações teórico- experimentais para abordagens mais complexas, na tentativa de representar condições reais de operação. Exemplos de abordagens deste tipo podem ser encontrados, por exemplo, em [Gopalkrishnan, 1993] e [Vikestad, 1998].

De fato, muito se sabe quanto ao fenômeno de VIV no cilindro rígido em escoamento uniforme, com padrões de emissão bem compreendidos e uma boa estimativa das amplitudes de resposta ressonante para um modo natural bem definido. Entretanto, o mesmo não se pode dizer com relação ao VIV nos cilindros flexíveis longos, particularmente por conta de aspectos como a excitação simultânea de mais de um modo natural de vibrar e a variação do escoamento ao longo do comprimento, quer seja por conta do próprio perfil variável de velocidades, quer pela própria condição 
geométrica do lançamento desses cilindros - inclinados ou curvados. Dois bons trabalhos a respeitos destes dois aspectos geométricos podem ser respectivamente encontrados em [Franzini et al., 2009] e [Assi et al., 2014].

Importante destacar que, sujeitos a condições de correnteza variável com a profundidade e lançamento inclinado ou curvado, os cilindros flexíveis longos se assemelham muito às condições reais de operação de risers para exploração de petróleo no mar, cuja resposta ao VIV é sabidamente caracterizada pela simultaneidade de modos naturais de vibrar, o que exige uma série de metodologias para a obtenção de parâmetros e comportamentos que caracterizem cada regime de resposta.

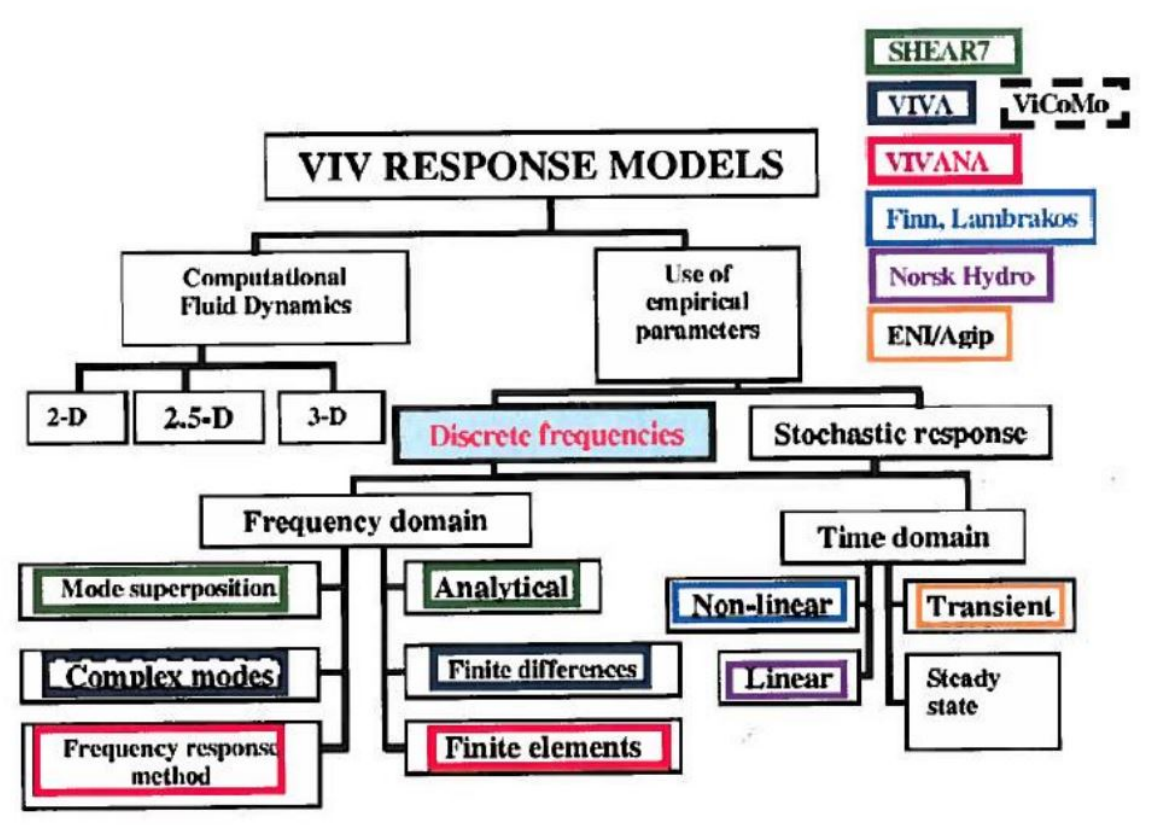

Figura 4.5: Diagrama com principais códigos numéricos para análise de VIV, extraído de [Larsen et al., 2001a].

Neste cenário, baseados em estimativas teóricas e experimentais, existem códigos comercias que buscam predizer a resposta do VIV nas estruturas flexíveis longas. De acordo com a Figura 4.5, retirada de [Larsen et al., 2001a], ainda que as abordagens numéricas via Fluido Dinâmica Computacional (CFD) ofereçam entendimento para a proposição desses códigos, é das abordagens experimentais que vêm os parâmetros e considerações quanto à predição do VIV nas estruturas flexíveis longas, quer seja segundo métodos discretos no domínio da frequência, quer por métodos estocásticos no domínio do tempo.

Percebe-se, portanto, a premente demanda por experimentos que ampliem a compreensão do fenômeno de VIV nas estruturas flexíveis longas - conduta que norteia 
a presente pesquisa de doutorado.

Conforme mencionado, muito da fenomenologia do VIV nas estruturas flexíveis se assemelha àquela bastante discutida com base nos cilindros rígidos montados em suportes elásticos. Neste sentido, coeficientes de massa adicional e de sustentação, em alguns códigos, são utilizando coerentemente com base nos resultados experimentais encontrados, por exemplo, no trabalho de [Gopalkrishnan, 1993]. De acordo com a Figura 4.6, percebe-se um amplo mapeamento dos coeficientes de massa adicional e de sustentação, apresentados como função da amplitude adimensional (ou amplitude ratio, $A / D)$ e da frequência adimensional, obtida segundo a equação (4.4), que é praticamente o inverso da razão entre a velocidade reduzida $V_{r}$ e o número de Strouhal $S t$.

$$
\hat{f}=\frac{D \cdot f_{o s c}}{U}
$$
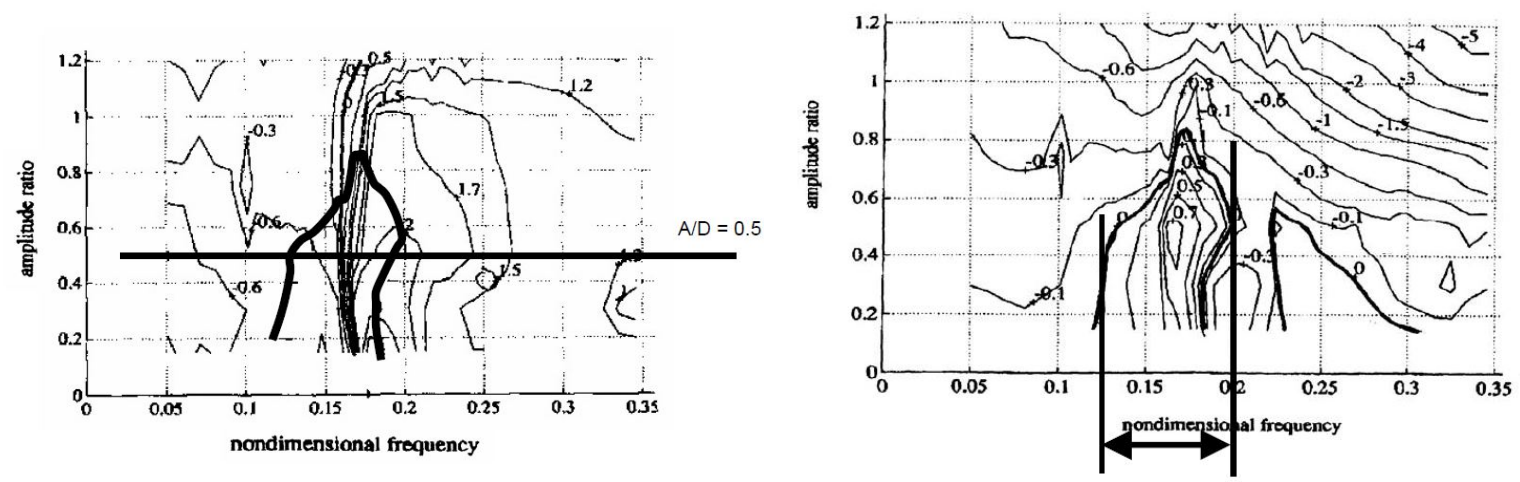

Figura 4.6: Coeficientes de massa adicional, à esquerda, e de força de sustentação, à direta, apresentados em [Gopalkrishnan, 1993].

Note que nos gráficos se faz destaque para a amplitude adimensional $A / D=0,5 \mathrm{e}$ para a faixa de sincronização típica. Importante citar que, neste caso, $f_{\text {osc }}$ diz respeito à frequência de oscilação forçada do cilindro utilizado para a obtenção dos resultados experimentais de [Gopalkrishnan, 1993] e que os coeficiente de sustentação negativos, de fato, dizem respeito a efeitos de amortecimento do sistema considerado.

Os trabalhos experimentais descritos em [Gopalkrishnan, 1993] oferecem, ainda, resultados que mostram a importância da razão de massa, $m^{*}$, e sua influência na faixa de sincronização. De acordo com a Figura 4.7, a sincronização, caracterizada por respostas com amplitude acima de $0.4 D$, acontece na faixa de $4<V_{r}<20$, para o cilindro com $m^{*}=1$, e na faixa de $4<V_{r}<10$, para cilindro com $m^{*}=3$. 


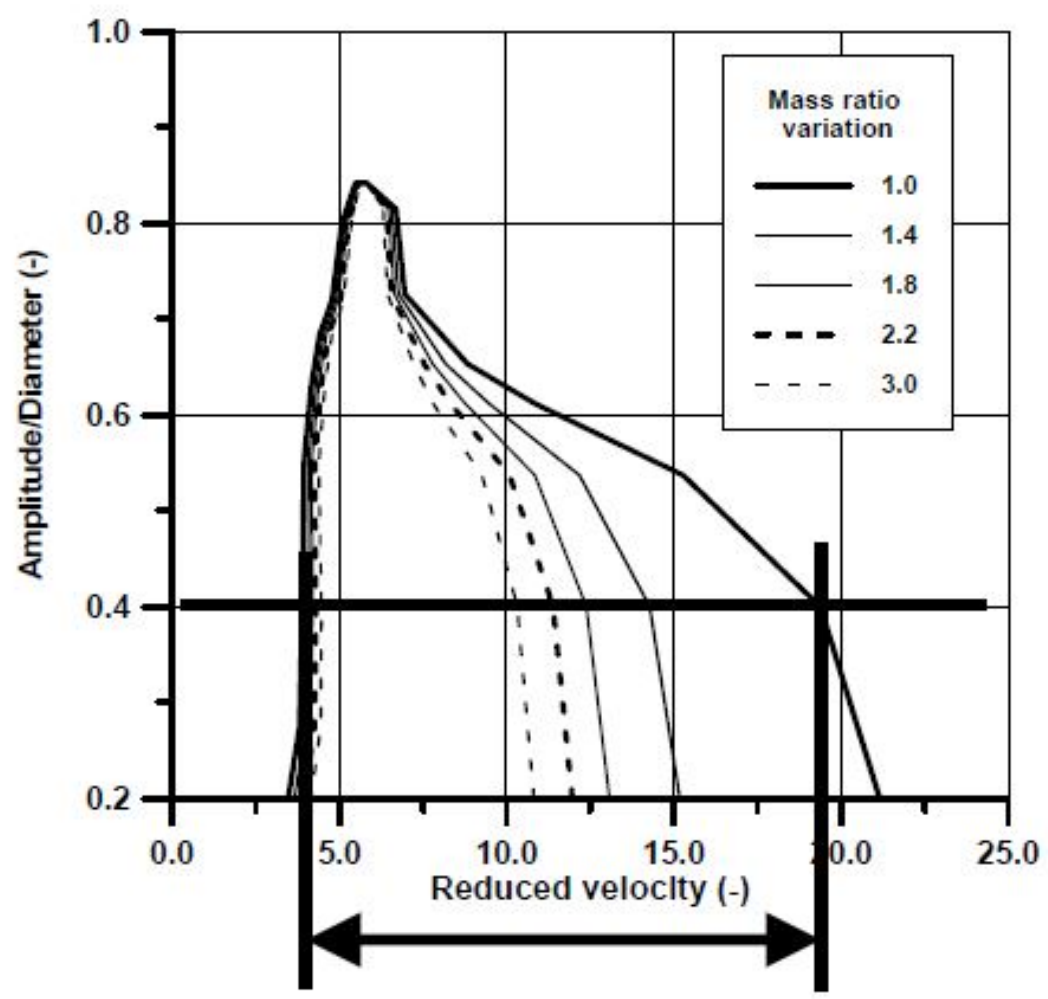

Figura 4.7: Variação da faixa de amplitude por velocidade reduzida para diversas razões de massa, extraída de [Gopalkrishnan, 1993].

Importante destacar que se pode relacionar a frequência adimensional, $\hat{f}$, com a razão de massa, $m^{*}$, neste caso, valendo-se também do respectivo coeficiente de massa adicional fluido estacionário, $m_{a}$.

$$
\hat{f}=\frac{1}{V_{r}} \sqrt{\frac{m^{*}+1}{m^{*}+m_{a}}}
$$

A Figura 4.8 compara as amplitudes adimensionais obtidas por [Gopalkrishnan, 1993], com base em movimentos forçados, e aquelas obtidas por [Vikestad, 1998], a partir de experimentos com cilindros rígidos montados em suporte elástico livres para oscilar na direção transversal ao escoamento incidente. De acordo com essa figura, nota-se que em termos de sincronização, as duas abordagem são absolutamente equivalentes. Quanto às amplitudes de resposta, no entanto, percebe-se que a importância do grau de liberdade na predição do VIV. De fato, de acordo com a literatura recente, sabe-se que a liberdade de oscilação simultânea na direção longitudinal permite aos cilindros amplitudes de respota ainda maiores que aquelas identificadas por [Vikestad, 1998]. 


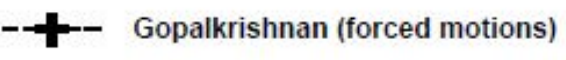

$\checkmark$ Vikestad (freely oscillating cylinder)

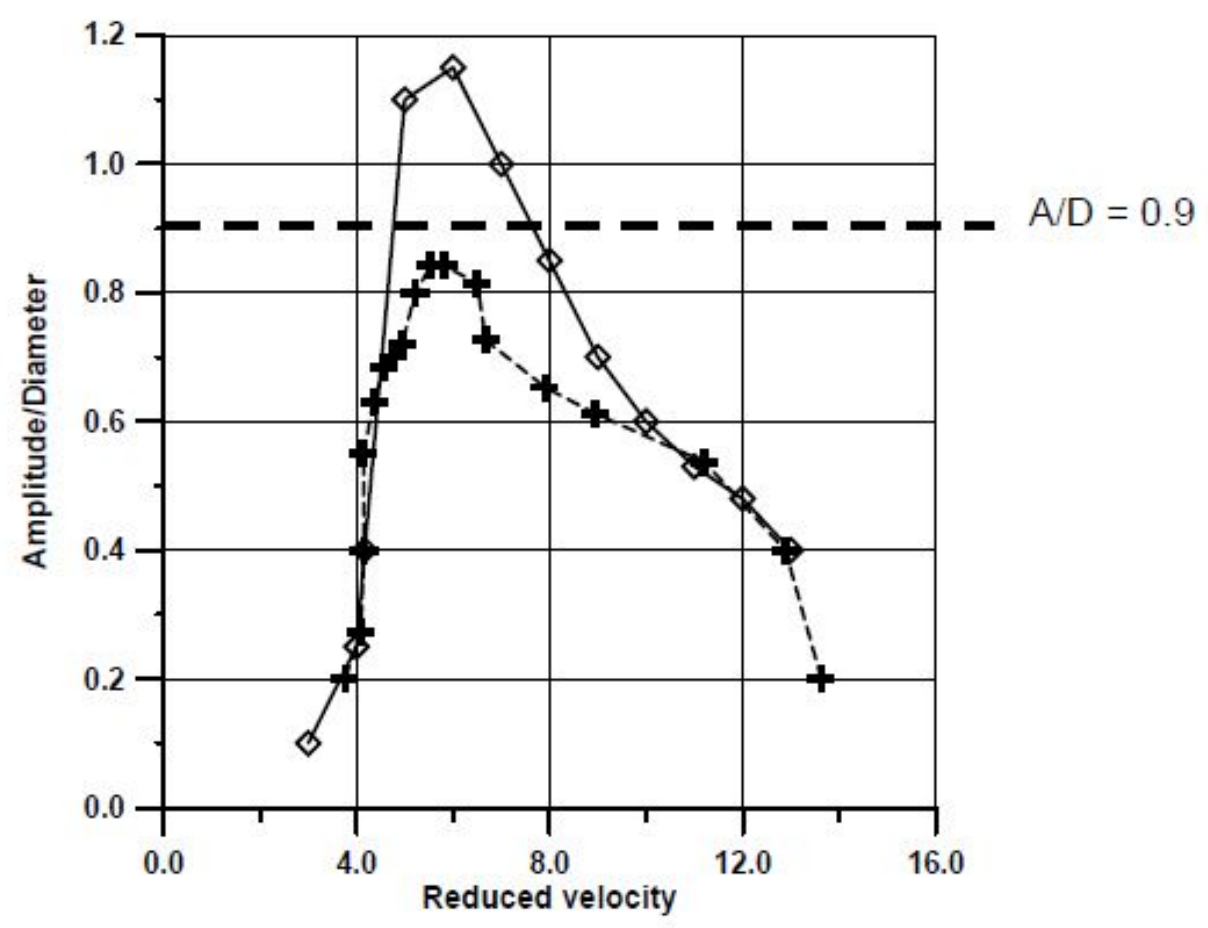

Figura 4.8: Amplitudes adimensionais de [Gopalkrishnan, 1993], com base em cilindros forçados, comparadas com aquelas obtidas por [Vikestad, 1998], a partir de experimentos com cilindros rígidos montados em suporte elástico de um grau de liberdade.

Percebe-se, portanto, que a determinação da(s) frequência(s) naturais é procedimento importantíssimo na previsão do VIV, dependente da própria característica geométrica da estrutura, particularmente com relação às condições de contorno. Por exemplo, nas estruturas flexíveis verticais dominadas pelo efeito da tração, $T$, ou seja, aquelas onde os efeitos de rigidez flexional é desprezível, a determinação das frequências naturais se faz de maneira expedita, através da equação 4.6.

$$
f_{n}=\frac{n}{2 L} \sqrt{\frac{T_{0}}{m+m_{a}}},
$$

onde: $n$ diz respeito ao n-ésimo modo natural de vibrar; $L$ é o comprimento total da estrutura vertical; $T_{0}$ a tração no topo; $m$ é a massa estrutural por unidade de comprimentos e $m_{a}$ a respectiva massa adicional seccional, medida em fluido estacionário.

Pragmaticamente falando, determinadas as frequências naturais da estrutura sujeita 
ao VIV, são definidas as regiões de sincronização para cada velocidade de escoamento. De acordo com a Figura 4.9, pode-se verificar um exemplo dessa metodologia de análise aplicada no código VIVANA [Larsen et al., 2001b], segundo a qual se identificam as diferentes regiões de excitação para os quatro primeiros modos de vibrar de uma linha flexível vertical.

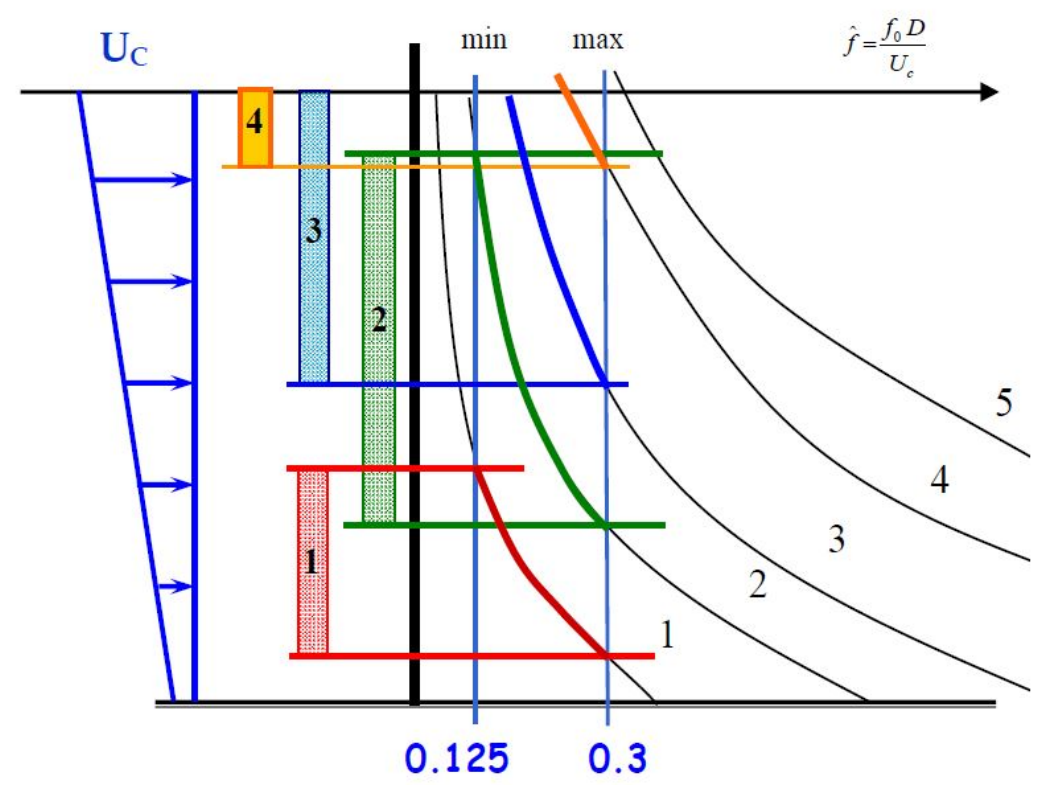

Figura 4.9: Exemplo de análise das faixas de excitação modal para uma estrutura flexível vertical sujeita a um perfil de velocidades linearmente variável com a profundidade. Análise conduzida pelo código numérico VIVANA, conforme descrição encontrada em [Larsen et al., 2010].

Nesse exemplo, note que, para um dado perfil de velocidades linearmente variáveis com a profundidade e frequências naturais bem determinadas para a estrutura flexível vertical, são definidas as regiões propensas à sincronização dos respectivos modos naturais; sendo estas, definidas de acordo com a faixa de frequências adimensionais que vai de $\hat{f}_{\text {min }}=0,125$ a $\hat{f}_{\text {max }}=0,300$. Note que, dos cinco primeiros modos naturais considerados, apenas o quinto deles não se mostra passível de excitação em nenhuma região da estrutura.

No que tange à determinação das respectivas amplitudes de resposta em cada um dos modos naturais exitados pelo perfil de velocidades considerado, a solução implementada nos códigos mais conhecidos é caracterizada por uma busca através de interpolações das curvas de sustentação para cada região dentro da faixa de excitação, como mostrado na Figura 4.10. Sendo assim, códigos como os apresentados em [Vandiver \& Li, 2005] e [Larsen et al., 2001b] buscam o equilíbrio entre a energia de excitação e dissipação do sistema através da iteração das amplitudes de resposta. 


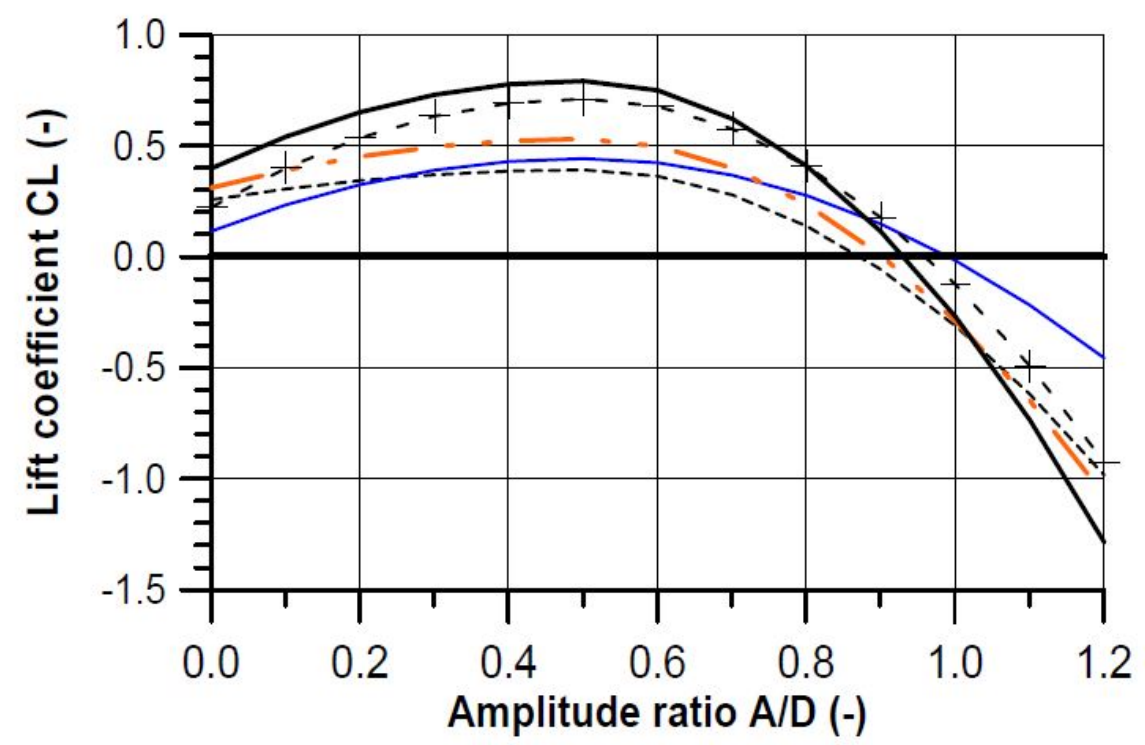

Figura 4.10: Curvas de interpolação do coeficiente de sustentação para estimativa da amplitude de resposta, resultados extraídos de [Larsen et al., 2001b].

Outra consideração sobre as amplitudes de resposta para cada modo de vibrar é feita com relação à coexistência ou alternância modal. De acordo com [Schiller et al., 2014], sabe-se que esses mecanismos de interação intermodal afetam diretamente as análises de fadiga das linhas oceânicas; daí o crescente interesse pela compreensão mais aprofundada dos mesmos.

Há, ainda, uma segundo grupo de códigos (ou abordagens numéricas) que adotam modelos analíticos de cunho fenomenológico, normalmente baseados no oscilador de van der Pol, para a determinação das amplitudes modais de resposta. Em [Srinil et al., 2009], tem-se uma comparação entre esta abordagem fenomenológica e aquela empírica adotada no código proposto em [Vandiver \& Li, 2005], aqui sintetizada no gráfico da Figura 4.11.

Importante destacar que, mediante a adoção dos modelos fenomenológicos, normalmente emergem aproximações para a obtenção da amplitude modal como função de parâmetros de massa-amortecimento. É o caso do equacionamento presente na Figura 4.11, onde a amplitude adimensional de resposta, $A / D$ é apresentada como função do parâmetro Skop-Griffin. 


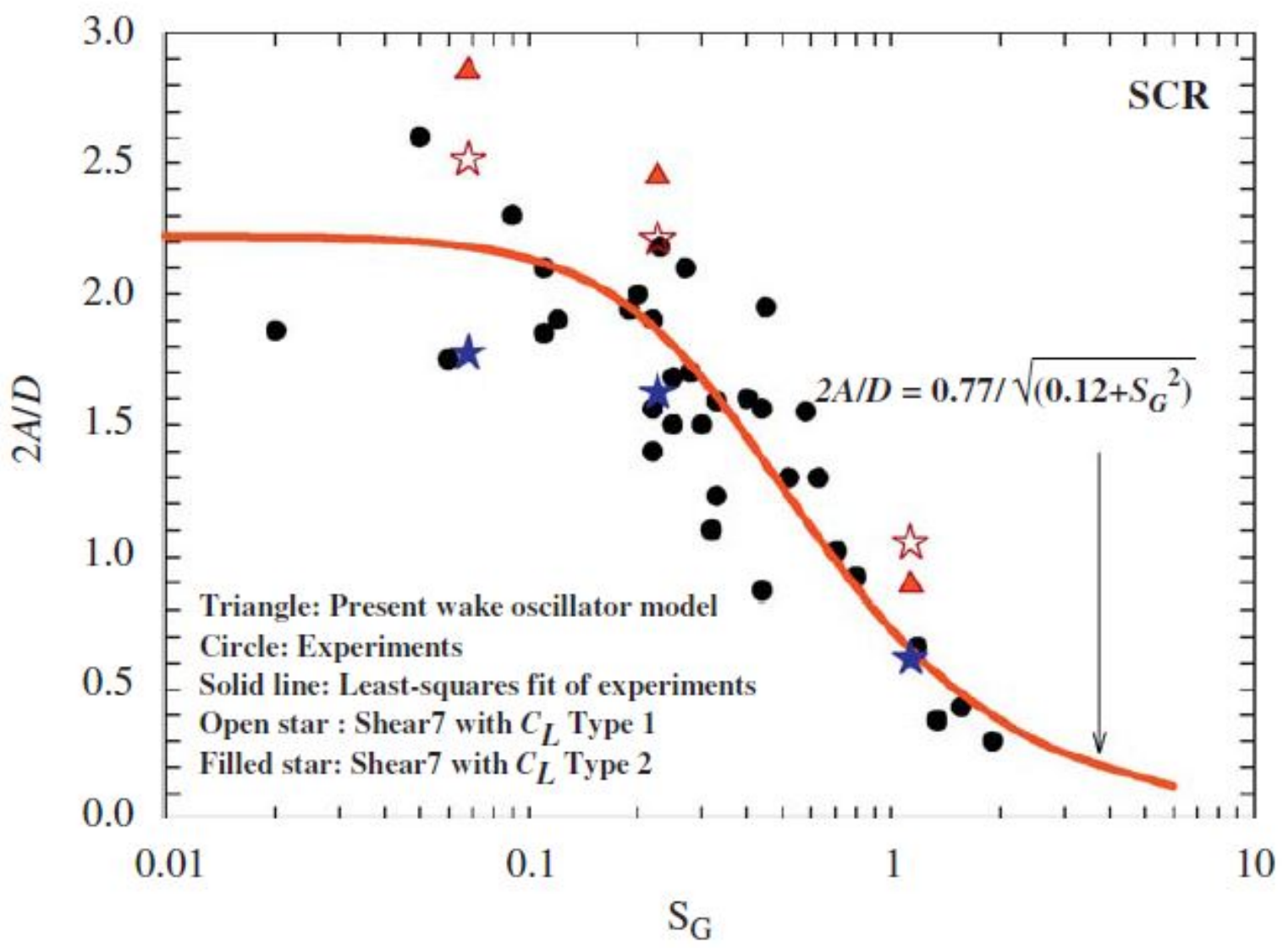

Figura 4.11: Comparação entre o modelo de [Srinil et al., 2009] e [Vandiver \& Li, 2005] para um modelo de catenária.

Historicamente, ver [Williamson \& Govardhan, 2004] e [Vandiver, 1993], o parâmetro de massa-amortecimento foi inicialmente proposto por Scruton, em 1955, para a caracterização das vibrações induzidas pelo escoamento de ar incidindo sobre estruturas flexíveis em balanço. Essa proposição foi rapidamente adotada pelo meio científico, tornando-se conhecida como o número de Scruton, $S_{c}$, definido de acordo com a equação 4.7. Para fazer uso da nomenclatura atual, note que nessa equação $\delta=2 \pi \zeta$, onde $\zeta$ diz respeito à razão entre o amortecimento estrutural e o amortecimento crítico do sistema.

$$
S_{c}=\frac{2 m \delta}{\rho D^{2}}=\pi^{2} m^{*} \zeta
$$

No início da década de 1970, o grupo de pesquisadores liderado por Griffin procurou ampliar a aplicação do parâmetro proposto por Scruton, abrangendo uma variedade maior de estruturas, inclusive aquelas em água, para as quais o parâmetro de massa reduzida, $m^{*}$, são bem menores que aqueles característicos das vibrações em ar. Então, em meados daquela década, foi definido o que é largamente conhecido como parâmetro 
massa-amortecimento de Skop-Griffin, $S_{G}$, apresentado na equação 4.8.

$$
S_{G}=2 \pi S t^{2} \frac{2 m \delta}{\rho D^{2}}=2 \pi^{3} S t^{2} m^{*} \zeta
$$

Note que nesta equação, além do parâmetro de massa reduzida e do coeficiente de amortecimento crítico, comparece também o número de Strouhal característico da estrutura, St.

Desta forma, considerando que em sua maioria os códigos numéricos para previsão do VIV são baseados em estimativas para a determinação das amplitudes modais, empíricas ou semi-empíricas, e, principalmente, baseados na determinação precisa dos modos naturais de vibrar da estrutura em estudo, a seguir são apresentados os fundamentos teóricos para a obtenção desses modos.

Importante antecipar que frequências e modos naturais de vibrar podem ser determinados via modelos analíticos ou numéricos, dependendo da estrutura analisada e do grau de precisão que se deseje. Em [Chatjigeorgiou, 2008b] e [Chatjigeorgiou, 2008a], da mesma forma que em [Pesce et al., 1999], são apresentadas formas analíticas para estimativa das frequências e modos naturais de vibrar das estruturas flexíveis longas. Estas referências servem de base para a determinação das frequências e modos naturais de vibrar de cilindros verticais e lançados em catenária, ambos abordados nesta tese.

\subsection{Frequências e modos naturais nas estruturas flexíveis longas}

Nesta seção são apresentadas as principais equações utilizadas para determinar e descrever as frequências e modos naturais das estruturas flexíveis longas e esbeltas. Basicamente são apresentadas duas condições que representam os casos de interesse desta tese, quais sejam as estruturas flexíveis verticais e aquelas lançadas em catenária. Na Figura 4.12 são apresentados os parâmetros envolvidos na descrição dos movimentos mais gerais de uma estrutura lançada em catenária. 


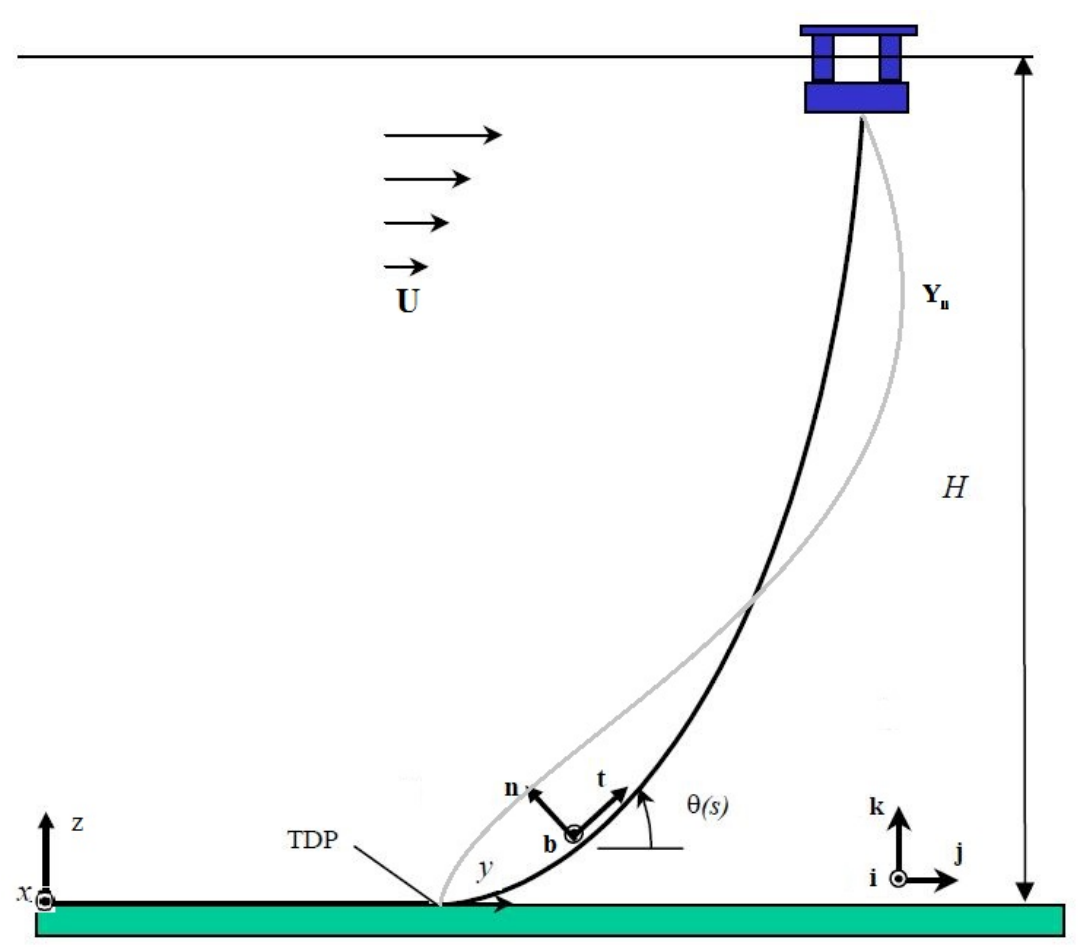

Figura 4.12: Parâmetros utilizados para descrever os movimentos na estrutura flexível lançada em catenária, adaptado de [Pesce \& Martins, 2005].

Para este problema, mais geral, as equações 4.9, 4.10 e 4.11 representam o comportamento completo da estrutura flexível ilustrada.

$$
\begin{aligned}
\left(m+m_{a}\right) \frac{\partial^{2} u}{\partial t^{2}}+c \frac{\partial u}{\partial t}= & \frac{\partial}{\partial s}\left\{T \frac{\partial u}{\partial s}+\right. \\
& E A\left(\frac{\partial y}{\partial s} \frac{\partial v}{\partial s}+\frac{\partial z}{\partial s} \frac{\partial w}{\partial s}+\right. \\
& \left.\frac{1}{2}\left(\left(\frac{\partial u}{\partial s}\right)^{2}+\left(\frac{\partial v}{\partial s}\right)^{2}+\left(\frac{\partial w}{\partial s}\right)^{2}\right)\right)\left(\frac{\partial x}{\partial s}+\frac{\partial u}{\partial s}\right)- \\
& \left.E I \frac{\partial}{\partial s}\left(\frac{\partial^{2} u}{\partial s^{2}}\right)\right\}+F_{x} \\
\left(m+m_{a}\right) \frac{\partial^{2} v}{\partial t^{2}}+c \frac{\partial v}{\partial t}= & \frac{\partial}{\partial s}\left\{T \frac{\partial v}{\partial s}+\right. \\
& E A\left(\frac{\partial y}{\partial s} \frac{\partial v}{\partial s}+\frac{\partial z}{\partial s} \frac{\partial w}{\partial s}+\right. \\
& \left.\frac{1}{2}\left(\left(\frac{\partial u}{\partial s}\right)^{2}+\left(\frac{\partial v}{\partial s}\right)^{2}+\left(\frac{\partial w}{\partial s}\right)^{2}\right)\right)\left(\frac{\partial y}{\partial s}+\frac{\partial v}{\partial s}\right)- \\
& \left.E I \frac{\partial}{\partial s}\left(\frac{\partial^{2} y}{\partial s^{2}}+\frac{\partial^{2} v}{\partial s^{2}}\right)\right\}+F_{y}
\end{aligned}
$$




$$
\begin{aligned}
\left(m+m_{a}\right) \frac{\partial^{2} w}{\partial t^{2}}+c \frac{\partial w}{\partial t}= & \frac{\partial}{\partial s}\left\{T \frac{\partial w}{\partial s}+\right. \\
& E A\left(\frac{\partial y}{\partial s} \frac{\partial v}{\partial s}+\frac{\partial z}{\partial s} \frac{\partial w}{\partial s}+\right. \\
& \left.\frac{1}{2}\left(\left(\frac{\partial u}{\partial s}\right)^{2}+\left(\frac{\partial v}{\partial s}\right)^{2}+\left(\frac{\partial w}{\partial s}\right)^{2}\right)\right)\left(\frac{\partial z}{\partial s}+\frac{\partial w}{\partial s}\right)- \\
& \left.E I \frac{\partial}{\partial s}\left(\frac{\partial^{2} z}{\partial s^{2}}+\frac{\partial^{2} w}{\partial s^{2}}\right)\right\}+F_{z}
\end{aligned}
$$

Nestas equações, note que $m+m_{a}$ é a massa por unidade de comprimento da estrutura, considerando a parcela de massa adicional e $c$ diz respeito à constante de amortecimento. O termo entre chaves, por sua vez, representa a rigidez da estrutura, considerando os efeitos de rigidez axial, proporcionais a $(E A)$, e os efeitos de rigidez flexional, proporcionais a $(E I)$. Note também que a posição de equilíbrio da estrutura é dada pelas coordenadas $(x, y, z)$, enquanto que a dinâmica em torno da mesma é descrita como função do sistema de coordenadas $(u, v, w)$. Neste caso, forças externas devido ao VIV são representadas por $F_{x}, F_{y}$ e $F_{z}$.

Mediante simplificações, soluções para casos particulares de interesse podem ser obtidas. Nas próximas subseções soluções particulares para as estruturas flexíveis verticais e lançadas em catenária são apresentadas.

\subsubsection{Solução para as estruturas flexíveis verticais}

No caso particular da estrutura flexível vertical, a equação geral que governa sua dinâmica é dada pela equação 4.12, definida com base: na coordenada $s$ ao longo da linha; na massa linear total $m_{t}$ (incluindo massa adicional) e na rigidez flexional $E I$.

$$
m_{t} \frac{\partial^{2} q}{\partial t^{2}}+E I(s) \frac{\partial^{4} q}{\partial s^{4}}-\frac{\partial}{\partial s}\left(T(s) \frac{\partial q}{\partial s}\right)=0
$$

Note que, neste caso, $q(s, t)$ é o movimento normal ao eixo da estrutura e que a variação da tração na linha $T(s)$, na condição de equilibro, pode ser escrita de acordo com a equação 4.13 , onde $T_{0}$ é a tração no topo e $w$ diz respeito ao peso por unidade de comprimento da estrutura na água.

$$
T(s)=T_{0}+w(s-L)
$$


Conforme apresentado em [Chatjigeorgiou, 2008b], frequências e modos naturais de vibrar para este caso podem ser analiticamente obtidos mediante algumas aproximações para a solução da equação 4.15, reanalisada de acordo com o seguinte conjunto de adimensionais 4.14 .

$$
\begin{gathered}
\hat{q}=q / L ; \Omega=\omega^{2} m L / w ; K=E I / w L^{3} ; \hat{T}=T_{0} / w L-1 \\
-K \hat{q}^{\prime \prime \prime \prime}+(\hat{T}+x) \hat{q}^{\prime \prime}+\hat{q}^{\prime}+\Omega^{2} \hat{q}=0
\end{gathered}
$$

Sob a ótica dos adimensionais, considera-se que a contribuição da rigidez flexional no problema da estrutura vertical seja desprezível, $K<<1$, o que permite identificar funções de Bessel de ordem zero, $J_{0}$ e $Y_{0}$, como soluções para o problema, ver equações 4.16 e 4.17 .

$$
J_{0}(2 \Omega \sqrt{\hat{T}+1}) Y_{0}(2 \Omega \sqrt{\hat{T}})-J_{0}(2 \Omega \sqrt{\hat{T}}) Y_{0}(2 \Omega \sqrt{\hat{T}+1})=0
$$

As soluções da equação $4.16 \mathrm{em} \Omega$ define as frequências naturais $\Omega_{n}$. Sendo assim, os modos de vibrar da linha vertical flexível podem ser escritos como apresentado na equação 4.17.

$$
\hat{q}=A\left[J_{0}(2 \Omega \sqrt{\hat{T}+1})-\frac{J_{0}(2 \Omega \sqrt{\hat{T}})}{Y_{0}(2 \Omega \sqrt{\hat{T}+1}) Y_{0}(2 \Omega \sqrt{\hat{T}})}\right]
$$

Por outro lado, em [Vandiver \& Li, 2005] é apresentada solução para a determinação das frequências e modos naturais de vibrar da estrutura flexível vertical, articulada nos dois extremos e considerando os efeitos da tração variável e também da rigidez flexional, ver equações 4.18 e 4.19 .

$$
\begin{aligned}
& \int_{0}^{L} \sqrt{-0.5 \frac{T(s)}{E I(s)}+0.5 \sqrt{\left[\frac{T(s)}{E I(s)}\right]^{2}+4 \frac{m(s) \omega_{n}^{2}}{E I(s)}} d s}=n \pi, n=1,2,3, \ldots
\end{aligned}
$$

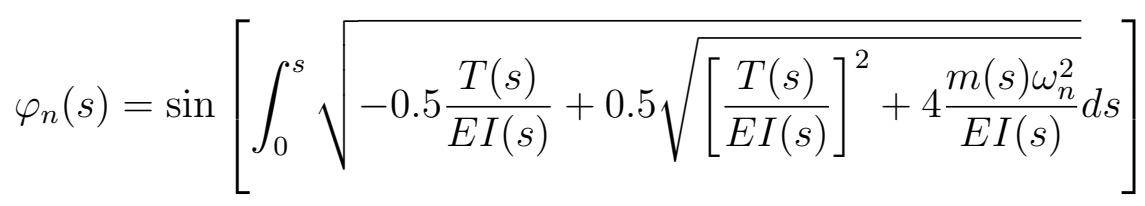




\subsubsection{Solução para as estruturas flexíveis lançadas em catenária}

Métodos analíticos também podem ser aplicados na determinação das frequências e modos naturais da estrutura flexível lançada em catenária, ou linha, como por vez também é denominada neste texto.

Neste contexto, desconsiderando os efeitos de arrasto devido a correnteza e também da rigidez flexional, a equação da linha estática em coordenadas cartesianas pode ser escrita com base nas equações 4.20 .

$$
\begin{aligned}
& y(s)=\alpha \sinh ^{-1}\left(\frac{s}{\alpha}\right) \\
& z(s)=\alpha\left[\cosh \left(\frac{y}{\alpha}\right)-1\right] \\
& \theta(s)=\operatorname{atan} \frac{z^{\prime}}{y^{\prime}}
\end{aligned}
$$

onde $\sinh$ e cosh são as funções seno e cosseno hiperbólico, calculadas com base no parâmetro $\alpha=T_{T D P} / w$, que diz respeito à razão entre a tração no TDP e o peso efetivo da linha.

Seguindo metodologia parecida com aquela utilizada para as estruturas flexíveis verticais, segundo [Pesce et al., 1999], com a mesma consideração de rigidez flexional desprezível, mas agora com a variação da tração como apresentada em (4.21), pode-se avaliar analiticamente as frequências naturais e modos de vibrar da linha em catenária.

$$
T(\theta(s))=T_{T D P}(1+\beta \tan (\theta(s)))
$$

Complementarmente, adicionando a hipótese de variação da tração linear ao longo da linha, a determinação das frequências naturais pode novamente ser feita com base em funções de Bessel de ordem zero; equação 4.22.

$$
\begin{aligned}
& J_{0}\left(2 \frac{\omega}{\beta \mu} \sqrt{1+\beta \mu}\right) Y_{0}\left(2 \frac{\omega}{\beta \mu}\right)-J_{0}\left(2 \frac{\omega}{\beta \mu}\right) Y_{0}\left(2 \frac{\omega}{\beta \mu} \sqrt{1+\beta \mu}\right)=0 \\
& \varphi_{n}(\xi)=A\left[J_{0}\left(2 \frac{\omega}{\beta \mu} \sqrt{1+\beta \mu \xi}\right)-\frac{J_{0}\left(2 \frac{\omega}{\beta \mu}\right)}{Y_{0}\left(2 \frac{\omega}{\beta \mu}\right)} Y_{0}\left(2 \frac{\omega}{\beta \mu} \sqrt{1+\beta \mu \xi}\right)\right]
\end{aligned}
$$

onde $\xi=\tan (\theta) / \tan \left(\theta_{\text {Topo }}\right), \mu=\tan \left(\theta_{\text {Topo }}\right)$ e $\beta$ advêm da linearização da tração ao longo da linha, equação 4.21 . 
Outra forma de se obter as frequências e modos naturais de vibrar é baseada no método $\mathrm{WKB}^{1}$, também apresentado em [Pesce et al., 1999], segundo a qual o equacionamento do problema pode ser reescrito conforme apresentado na equação 4.24.

$$
\begin{aligned}
& A_{n}=n \pi\left(\int_{0}^{\tan \left(\theta_{\text {Topo }}\right)} \frac{d \zeta}{\sqrt{F(\zeta)}}\right)^{-1} \\
& \Omega_{n}=A_{n} \tan \left(\theta_{\text {Topo }}\right) / L \sqrt{\frac{T_{T D P}}{\left(m+m_{a}\right)}} \\
& \varphi_{n}=A_{n} F(\zeta)^{-1 / 4} \sin \left(A_{n} \int_{0}^{\zeta} F(x)^{-1 / 2} d x\right),
\end{aligned}
$$

onde $\zeta=\tan (\theta)$ e $F(\zeta)=T(\zeta) / T_{T D P}$.

Para esta segunda aproximação, as frequências naturais são calculadas de maneira direta, ou seja, sem a necessidade de se buscar as soluções para uma função característica.

Conforme apresentado mais adiante neste texto, essa formulação se mostra de grande valia na comparação entre resultados numéricos e experimentais da caracterização modal das estruturas flexíveis longas, podendo, assim, de maneira expedita, avaliar se a resposta em condições específicas são coerentes.

\subsubsection{Comparações entre métodos para obtenção das frequências e modos naturais}

Apresentadas as formas analíticas para a obtenção das frequências e modos naturais neste texto, mostra-se pertinente uma comparação com os resultados semelhantes obtidos a partir de código específico para a análise das estruturas flexíveis. Neste caso, toma-se como referência o código PoliFLEX, sucintamente descrito em [Pesce \& Martins, 2005].

Cumpre destacar que, no caso do PoliFLEX, podem ser obtidas as frequências naturais tanto no plano de lançamento da catenária (YZ), quanto fora do mesmo; assim como os rectivos modos de vibrar, descritos de acordo com o sistema coordenado $(x, y, z)$.

Com relação às frequências naturais, as comparações analítico-numéricas mostram que os valores para os primeiros modos de vibrar da catenária são bem similares, ver Figura 4.13. Para os modos mais altos, no entanto, os resultados obtidos pelo método WKB se assemelham as condições com altos valores de rigidez, demonstrando efeitos ligados a aplicação da hipótese de inextensibilidade

\footnotetext{
${ }^{1}$ Acrônimo para Wentzel-Kramers-Brillouin, sobrenome dos físicos que desenvolveram este método para solução aproximada de equações diferenciais parciais a coeficientes que variam no espaço
} 


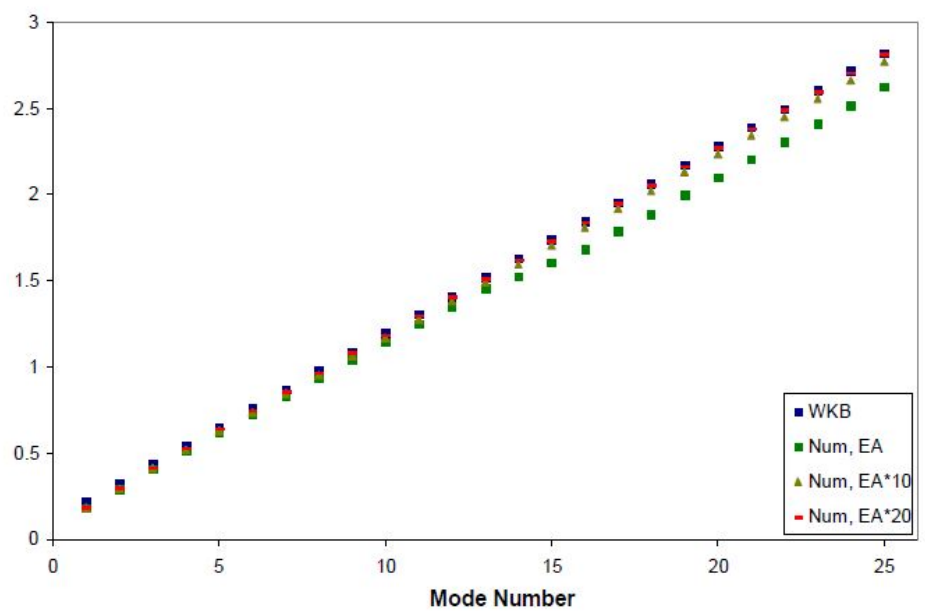

Figura 4.13: Comparação entre frequências naturais obtidas via método WKB e pelo código PoliFLEX [Pesce \& Martins, 2005].
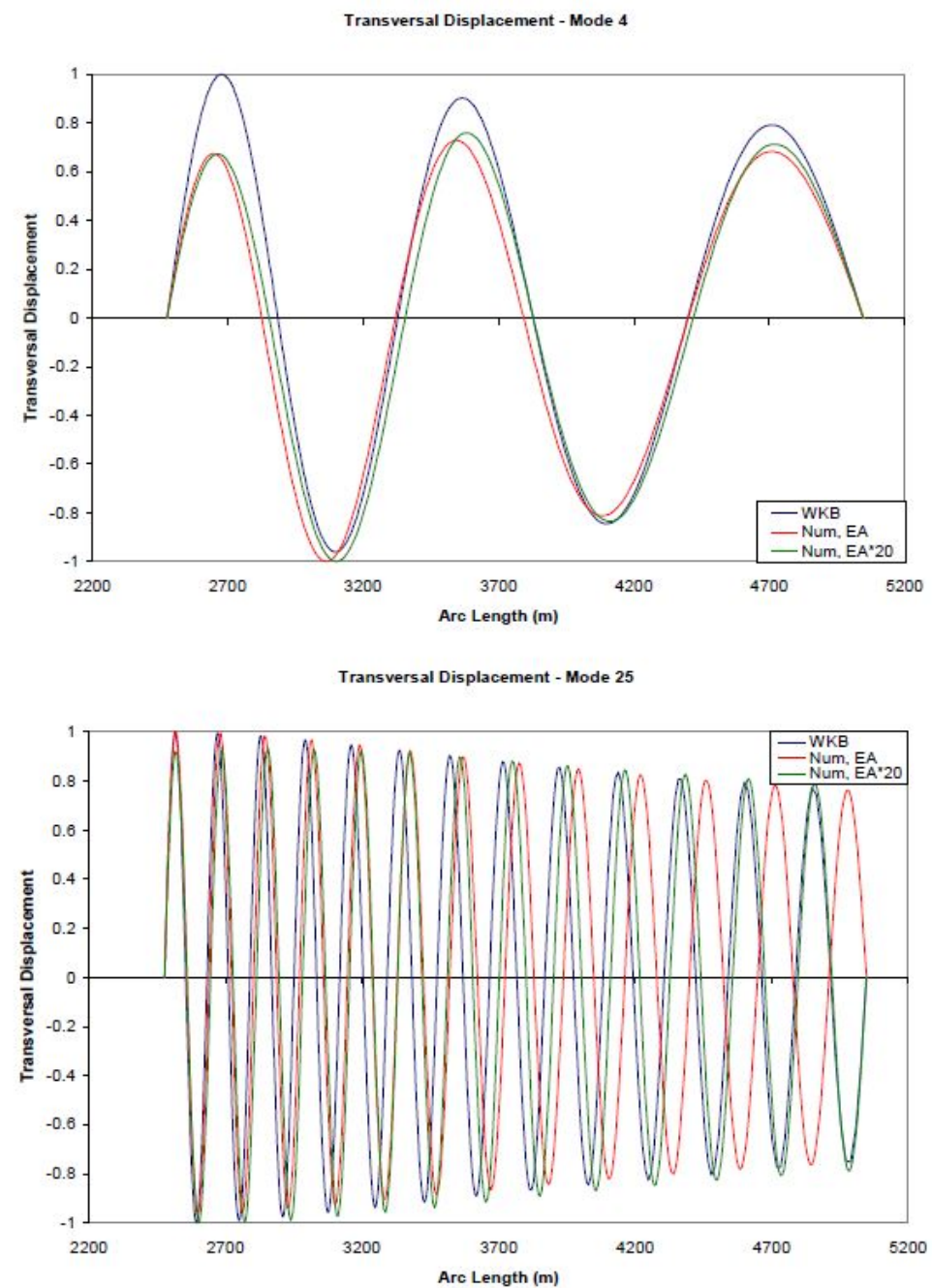

Figura 4.14: Comparação entre modos naturais obtidos via método WKB e aquele obtido via PolifLEX (a parâmetros diferentes de rigidez axial) [Pesce \& Martins, 2005]. 
A Figura 4.14, gráfico acima, apresenta o quarto modo natural de uma catenária típica, obtido com base no método WKB, portanto, sob hipótese de inextensibilidade. Ao mesmo tempo, compara esse mesmo quarto modo com aquele obtido com código PoliFLEX, que considera dois valores diferentes de rigidez axial, $E A$. Pode-se notar que a semelhança entre métodos é muito alta, com uma pequena diferença na região conhecida como Touch Down Zone (TDZ).

Por outro lado, no gráfico abaixo na mesma Figura 4.14, são comparados os resultados para um modo natural mais alto, o de número 29. Neste caso, nota-se uma diferença significativa entre os deslocamentos transversais, o que demonstra os efeitos das aproximações assumidas para a solução do problema via método WKB.

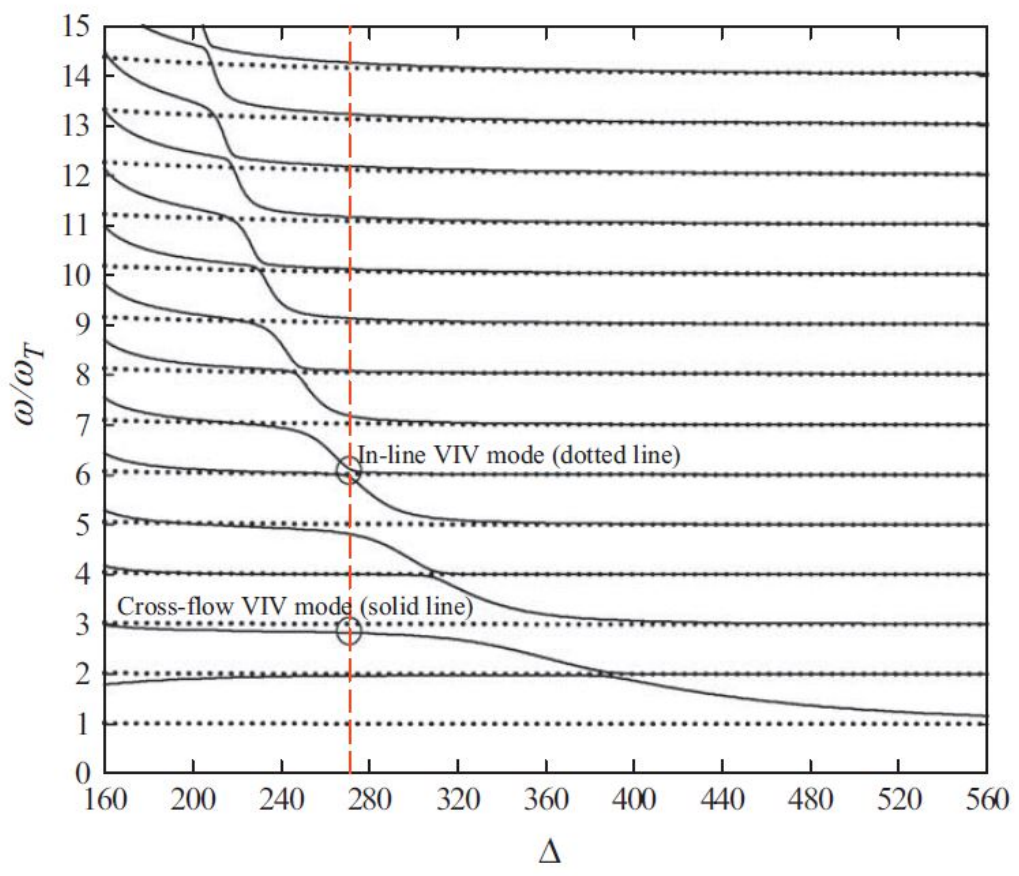

Figura 4.15: Variação das frequências naturais da catenária segundo análises conduzidas em [Srinil, 2010].

Outra comparação interessante é apresentada em [Srinil, 2010], agora sobre os efeitos da razão entre a tração do topo e a rigidez flexional. Nessa comparação, frequências naturais são adimensionalizadas por $\omega_{T}=2 \pi f_{1}$, que é a primeira frequência natural de um cabo tracionado, conforme equação 4.6. Mediante o parâmetro $\Delta=L \sqrt{T_{0} / E I}$, podem ser comparadas diversas condições de carregamento na catenária, onde: altos valores $(\Delta>560)$ representam linhas dominadas pela tração; e baixos valores $(\Delta<560)$ representam casos similares a risers rígidos lançados em catenária, ou seja, aqueles onde as frequências dependem da rigidez flexional. Ver Figura 4.15. 
Além da variação das frequências naturais, é importante notar a existência de condições onde as frequências naturais possuem valores muito próximos, $(\Delta=272)$. Estas condições são propícias à coexistência modal excitada pelo fenômeno de VIV.

Conforme se pode depreender dos fundamentos apresentados neste capítulo, muito da metodologia empregada para a consideração do VIV no projeto de estruturas flexíveis longas, verticais ou lançadas em catenária, depende de investigações baseadas em experimentos extremamente controlados, tônica da abordagem desenvolvida mais adiante neste texto.

Antes disso, porém, no capítulo 5, é feito um complemento bibliográfico acerca dos principais trabalhos que abordam experimentalmente o problema do fenômeno de VIV atuando em estruturas flexíveis longas, destacando-se as considerações práticas importantes para os trabalhos aqui desenvolvidos. 


\section{Complemento Bibliográfico Pertinente ao Escopo da Tese}

As referências bibliográficas que complementam o conjunto de informações que auxiliam a interpretação dos resultados de VIV desta pesquisa dizem respeito, principalmente, a informações sobre: arranjos experimentais típicos; técnicas de monitoração; procedimentos de análise e avaliações analítico-numéricas para a compreensão dos efeitos da variação das condições de excitação.

\subsection{Com relação à fenomenologia geral do VIV}

Existe uma vasta literatura dedicada à discussão geral do fenômeno de VIV, particularmente focada na excitação de poucos graus de liberdade, dentre as quais se destacam [Sarpkaya, 2004], [Gabbai \& Benaroya, 2005] e [Williamson \& Govardhan, 2004].

Em [Sarpkaya, 2004] é feita uma revisão crítica dos métodos experimentais e numéricos de investigação do VIV, elencando os pontos importantes para a compreensão da iteração fluido-estrutural decorrente.

Por outro lado, em [Gabbai \& Benaroya, 2005] são apresentados modelos fenomenológicos baseados em: osciladores de esteira, osciladores elásticos de grau de liberdade, decomposição de forças, e todos os aspectos pertinentes à abordagem analítica do problema. Adicionalmente, também são apresentados resultados numéricos que consideram o acoplamento completo da iteração do campo de velocidades e a resposta estrutural do sistema excitado pelo VIV.

Em [Williamson \& Govardhan, 2004], por sua vez, é discutida a relação dos resultados de VIV com valores cada vez mais baixos do parâmetro de massa- amortecimento, $m^{*} \zeta$, obtendo descrições mais coerentes com os comportamentos de estruturas em escala real. Também são apresentadas técnicas experimentais e numéricas com vistas à identificação 
dos padrões de emissão de vórtices via técnica de PIV - Particle Image Velocimetry, método óptico para a medição de velocidade; às teorias de transferência de energia que dão origem aos modos de vibrar e às relações entre força/vorticidade e o conceito de elasticidade eficaz proposta por Leonarg, Roshko e Shiels.

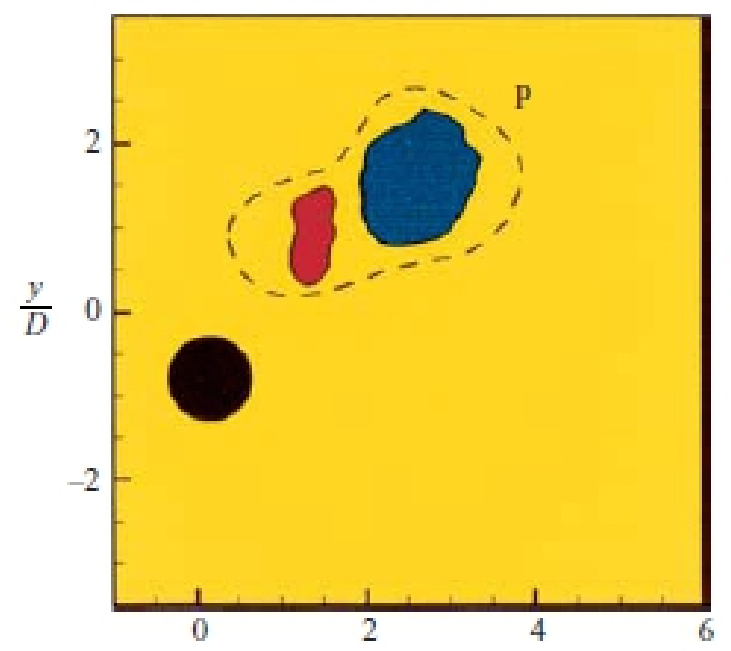

(a) $2 \mathrm{P}$ mode

Vortex pair $\mathrm{P}$

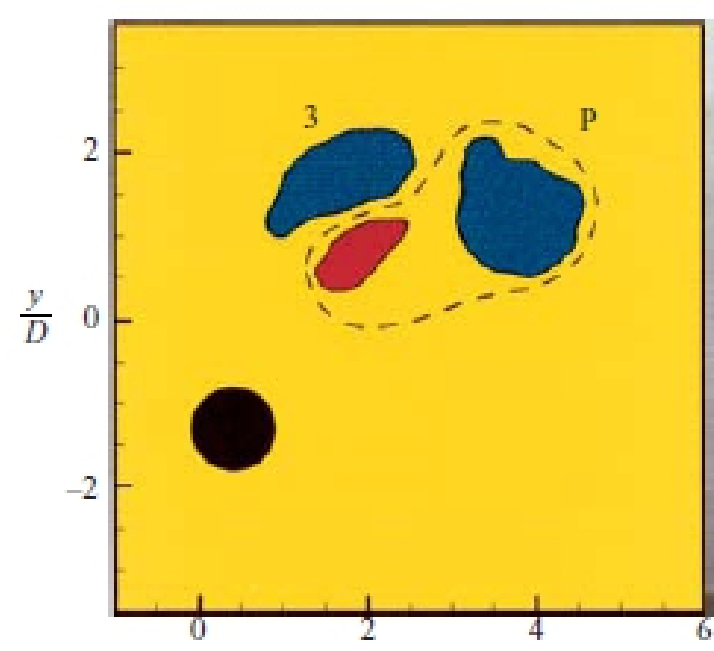

(b) $2 \mathrm{~T}$ mode

Vortex pair $\mathrm{P}$

Figura 5.1: Padrões de emissão de vórtices identificados em

[Jauvtis \& Williamson, 2004] pela técnica de PIV. Difenrença entre as formações 2P e $2 \mathrm{~T}$.

Outra referência importante no cenário das pesquisas em VIV é [Jauvtis \& Williamson, 2004]. Nela compreende-se com mais detalhes a importância dos graus de liberdade transversal e longitudinal no comportamento dinâmico da estrutura. Os testes realizados para baixos valores do parâmetro de massa-amortecimento $\left(0.001<m^{*} \zeta<0.1\right)$ e moderados números e Reynolds $(1000<R e<15000)$ mostram que para cilindros com $m^{*}>6$ existe pouca influência nos movimentos longitudinais na resposta de VIV transversal ao escoamento incidente. Por outro lado, para cilindros com $m^{*}<<6$, surge um ramo peculiar de resposta dentro da faixa de sincronização, chamado 
de Super-Uppper-branch, caracterizado por amplitudes transversais de aproximadamente uma vez e meia o diâmetro, associadas a uma emissão $2 \mathrm{~T}$, ou seja, três vórtices a cada meio ciclo de oscilação; ver Figura 5.1. Esta constatação sugeriu mudanças nos procedimentos de análise do VIV nos projetos de linhas oceânicas.

\subsection{Com relação ao VIV nas estruturas flexíveis}

Em [Vandiver, 1993] já havia sido apontado que, até então, "nova geração de experimentos" seria baseada em cilindros flexíveis longos, responsáveis por relacionar os conceitos desenvolvidos a partir de cilindros de até dois graus de liberdade e as observações do VIV em escala real.

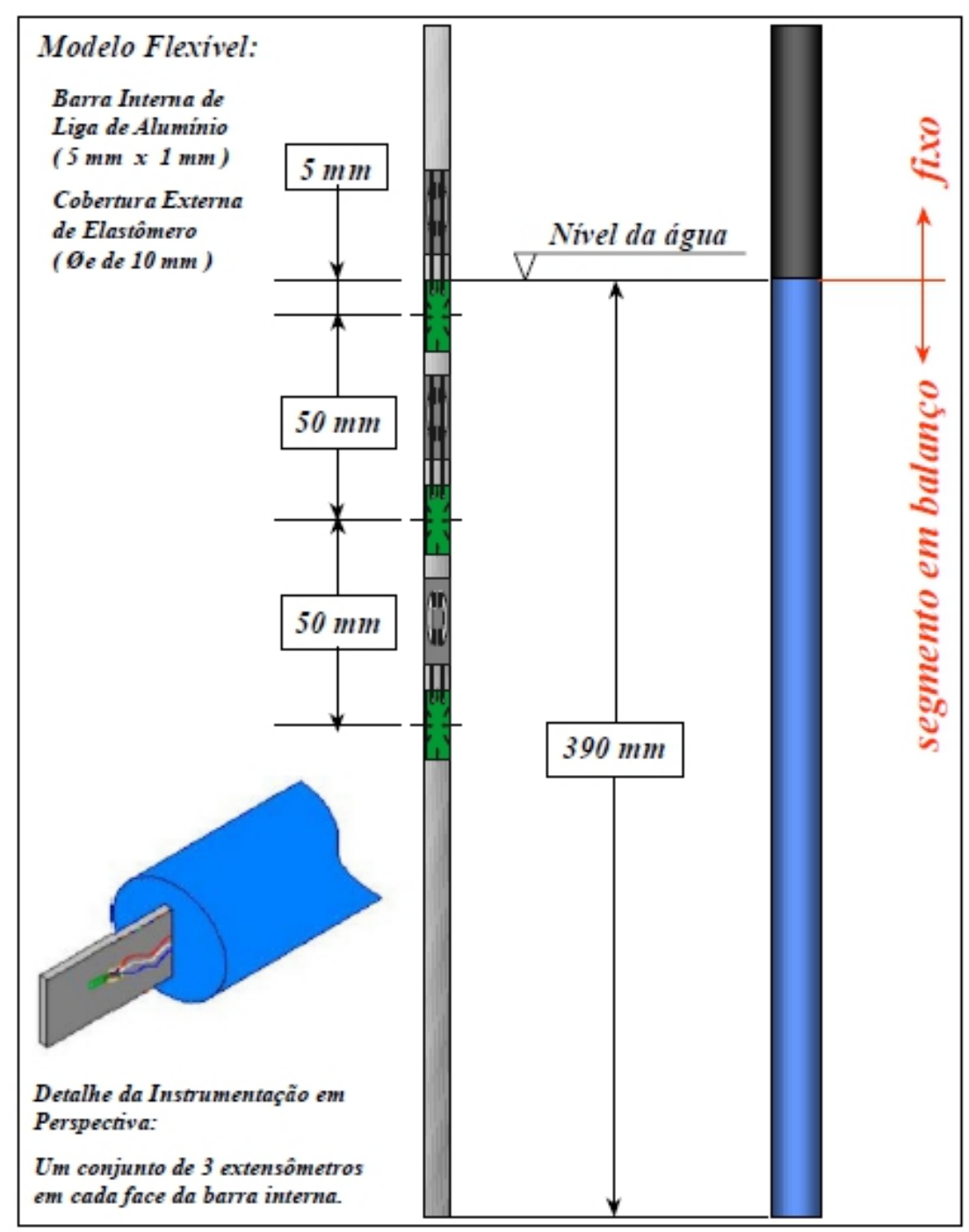

Figura 5.2: Arranjo Esquemático do Modelo Flexível utilizado em [Fujarra, 2002].

Exemplos de experimentos desta geração são aqueles realizados pelo grupo de 
pesquisa da USP - Universidade de São Paulo, particularmente aquele apresentado em [Fujarra, 2002]. Uma descrição do modelo utilizado naquela pesquisa é apresentada na Figura 5.2, utilizado para a investigação do fenômeno de VIV na condição de balanço vertical. Os resultados obtidos realmente confirmaram o apontamento feito em [Vandiver, 1993].

Os dados apresentados em [Chaplin et al., 2005a] e [Chaplin et al., 2005b] referem-se os experimentos com uma linha vertical tracionada, sujeita a escoamento de velocidade $1 \mathrm{~m} / \mathrm{s}$ apenas em sua porção inferior. O modelo foi construído com $28 \mathrm{~mm}$ de diâmetro, $13,12 \mathrm{~m}$ de comprimento e razão de massa igual a 3. Os movimentos transversais e longitudinais foram medidos por 32 extensômetros igualmente espaçados, com os quais puderam ser evidenciados movimentos transversais com desvios padrão maiores do que $0,50 D$, referentes à excitação de até oito modos naturais de vibrar.

Outras referências importantes são [Huera-Huarte \& Bearman, 2009a] e [Huera-Huarte \& Bearman, 2009b], nas quais a resposta dinâmica de linhas flexíveis verticais em baixos modos de vibrar é apresentada para razão de massa de 1.8 e coeficiente de massa-amortecimento de aproximadamente 0.05. Nos experimentos, o VIV agindo sob um modelo de $16 \mathrm{~mm}$ de diâmetro é investigado para regimes de escoamento com $1200<R e<12000, V_{r}<16$, agindo em $40 \%$ da parte inferior do comprimento de 1,5m. A tração no topo foi adotada entre 15 e $110 \mathrm{~N}$, o que representou frequências naturais entre 3 e $7 \mathrm{~Hz}$. Assim, a amplitude de resposta transversal foi de até $0,70 \mathrm{D}$ e longitudinal de até $0,20 D$.

Em [Pesce \& Martins, 2005] a dinâmica de linhas em catenária é caracterizada pela coexistência de oscilações em diversas escalas de tempo, as quais dependem de diversos parâmetros de rigidez. Neste caso, os principais parâmetros de rigidez envolvidos pela rigidez geométrica, ou da própria catenária; a rigidez axial EA(s); a rigidez flexional EI(s); entre outras devido rigidez imposta pela eventual presença de conexões ou iteração com o solo.

A similaridade dos movimentos de uma linha flexível nas escalas real e reduzida, envolve a identidade do número de Froude, mesma representação das ondas de gravidade. A partir disto decorrem as escalas das diversas grandezas geométricas, cinemáticas, inerciais e dinâmicas, conforme mostra a Tabela 5.1. Note que as dimensões do laboratório praticamente impõem que a escala reduzida de comprimento, caracterizada pelo fator de escala $\lambda$. Por outro lado, risers são estruturas de grande esbeltez, tal fato traz consequências diretas à representação em escala reduzida como 
apresentado em [Rateiro et al., 2012].

Tabela 5.1: Conversões de propriedades entre a escala do modelo e da escala real adaptado de [Rateiro et al., 2012].

\begin{tabular}{lcc}
\hline Grandeza & Dimensão Física & Escala \\
\hline Comprimento & $L$ & $\lambda$ \\
Massa & $M$ & $\lambda^{3}$ \\
Tempo & $T$ & $\sqrt{\lambda}$ \\
Área & $L^{2}$ & $\lambda^{2}$ \\
Volume & $L^{3}$ & $\lambda^{3}$ \\
Diâmetro & $L$ & $\lambda$ \\
Rigidez axial $(E A)$ & $\frac{M L}{T^{2}}$ & $\lambda^{3}$ \\
Rigidez flexional $(E I)$ & $\frac{M L^{3}}{T^{2}}$ & $\lambda^{5}$ \\
Rigidez à torção $(G J)$ & $\frac{M L^{3}}{T^{2}}$ & $\lambda^{5}$ \\
Peso por unidade de comprimento & $\frac{M}{T^{2}}$ & $\lambda^{2}$ \\
Tração & $\frac{M L}{T^{2}}$ & $\lambda^{3}$ \\
Ângulo & $r a d$ & - \\
Curvatura & $\frac{1}{L}$ & $\frac{1}{\lambda}$ \\
Período & $T$ & $\sqrt{\lambda}$ \\
Frequência & $\frac{1}{T}$ & $\frac{1}{\sqrt{\lambda}}$ \\
\hline
\end{tabular}

\subsection{Com relação ao VIV nas linhas}

Para o caso das vibrações nas linhas, estruturas flexíveis longas, sabe-se que dependendo do escoamento incidente e da disposição geométrica da linha pode ocorrer excitação multimodal. Conforme já apresentado, as faixas de sincronização têm ocorrência passível de previsão, mediante o conhecimento do perfil de velocidades e do conhecimento de alguns parâmetros adimensionais da estrutura, como a massa reduzida e o coeficiente de amortecimento. Também é importante a relação entre a frequência de emissão de vórtices e as frequências naturais do sistema.

De fato, segundo [Vandiver, 1993], os parâmetros de maior importância para a verificação da existência de sincronização são a fração de variação da velocidade $\delta V / V_{\max }$ e o número de frequências naturais, $N$, passíveis de excitação no intervalo de velocidades considerado. Além disso, em casos com altos valores de amortecimento, esperam-se amplitudes de resposta de pouca magnitude, portanto, desprezíveis.

Sendo assim, existem três aspectos importantes para a previsão da sincronização nas linhas, quais sejam: 
- o parâmetro Skop-Griffin, $S_{G}$, não ser alto, o que dá margem a amplitudes significativas de resposta de VIV;

- a proximidade entre a frequência de emissão dos vórtices, $f_{s}$, e alguma frequência natural;

- a possibilidade da faixa de frequência de excitação incluir várias frequências naturais simultaneamente, resultando em um excitação multimodal, com características randômicas.

Quando o terceiro aspecto se faz presente, existe também a possibilidade de propagação de ondas no cilindro e o parâmetro utilizado empiricamente para caracterizar este efeito é aquele dado pelo produto do número do modo, $n$, pelo coeficiente de amortecimento modal, $\zeta_{n}$. Segundo [Vandiver, 1993], com base nesse parâmetro, é possível avaliar se a natureza do comportamento dinâmico da linha será marcada por ondas progressivas em comprimento infinito, ou por ondas estacionárias como em cilindros flexíveis de comprimento finito. Para valores de $n \zeta_{n} \approx 1$ as ondas progressivas predominam e a resposta da amplitude modal deixa de ser constante ao longo do comprimento. Neste caso, as respostas devem ser maiores na região de excitação, segundo previsão apresentada na Figura 4.9, e menores na região de dissipação. Uma representação desta variação de amplitude pode ser vista na Figura 5.3.

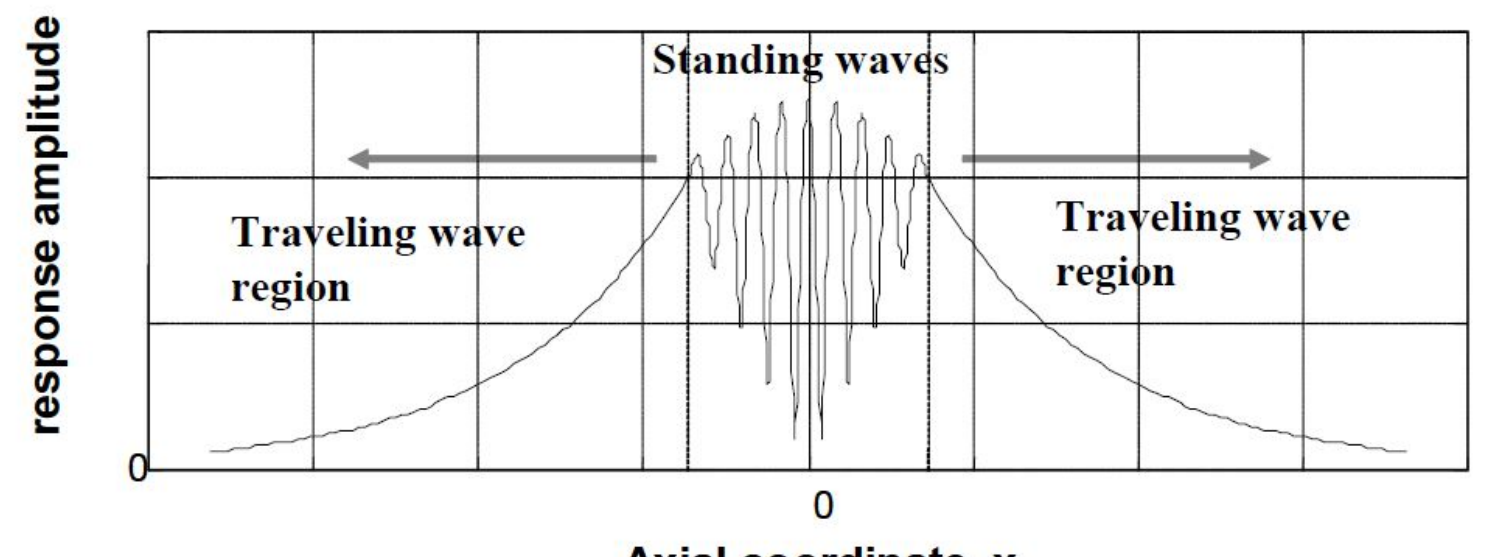

Axial coordinate, $\mathbf{x}$

Figura 5.3: Exemplo de variação da amplitude de resposta ao longo da linha no caso da deflagração de ondas progressivas, extraída de [Vandiver \& Marcollo, 2003].

Ainda com relação à excitação multimodal, estudos apresentados em [Vandiver et al., 1996], baseados em experimentos realizados em 1994 como o arranjo da 
Figura 5.4, concluem sobre as regiões de existência de um ou vários modos de vibrar, tomando como base a estratificação da correnteza. A Figura 5.5 ilustra essa regiões no espaço dado pelas combinações da fração de variação da velocidade $\delta V / V_{\max }$ e o número de frequências naturais, $N$.

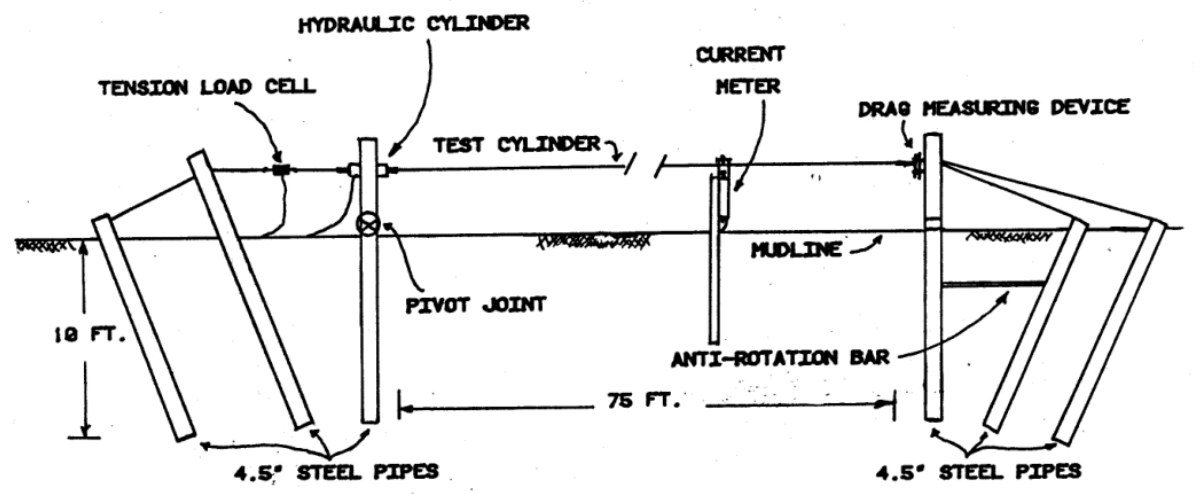

Figura 5.4: Arranjo do experimento em Castine 1981, realizado por [Vandiver, 1993].

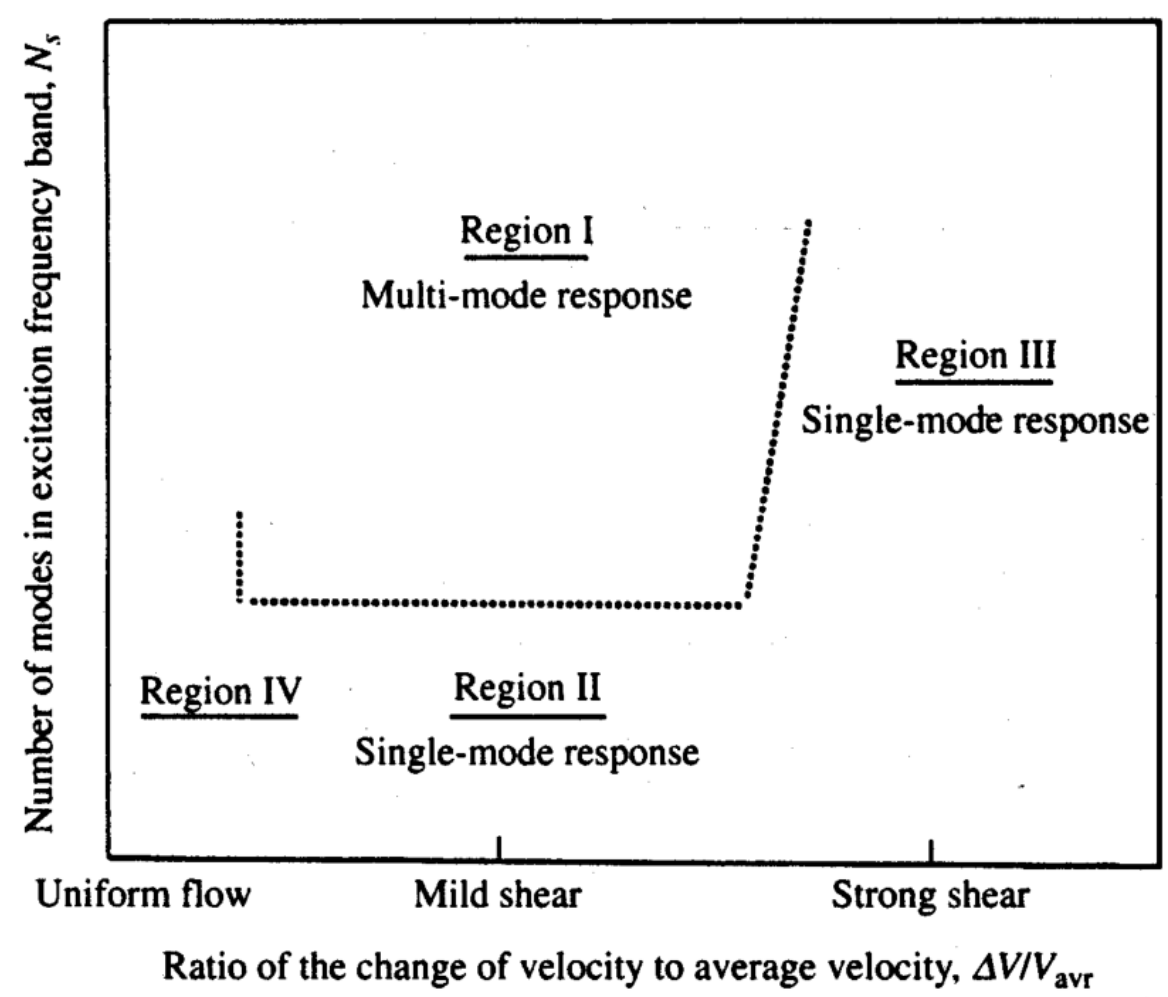

Figura 5.5: Identificação de regiões com relação ao modos de vibrar, extraído de [Vandiver et al., 1996].

Outro tipo de experimento com linhas refere-se a avaliação do VIV em perfil não uniforme de velocidades, induzido por uma plataforma giratória. O experimento com um 
tubo de $20 \mathrm{~mm}$ de diâmetro e 12,6m de comprimento, instrumentado com 9 acelerômetros internos e inclinado naquela plataforma giratória, [Lie et al., 1997], foi pioneiro no estudo do VIV nestas condições, tendo como objetivo a melhorar compreensão do fenômeno em perfil não uniforme de velocidades. A interação entre as frequências e modos de vibrar ainda precisa ser totalmente compreendida, de maneira a estabelecer um modelo confiável para a previsão do VIV. Algumas tendências observadas a partir de diferentes condições de escoamento, no entanto, mostraram que a principal conclusão diz que, apesar da resposta muitas vezes ser composta por vários modos, esta continua sendo dominada por uma frequência padrão, mesmo para casos com uma elevada diferença entre as velocidades no topo e na base do modelo.
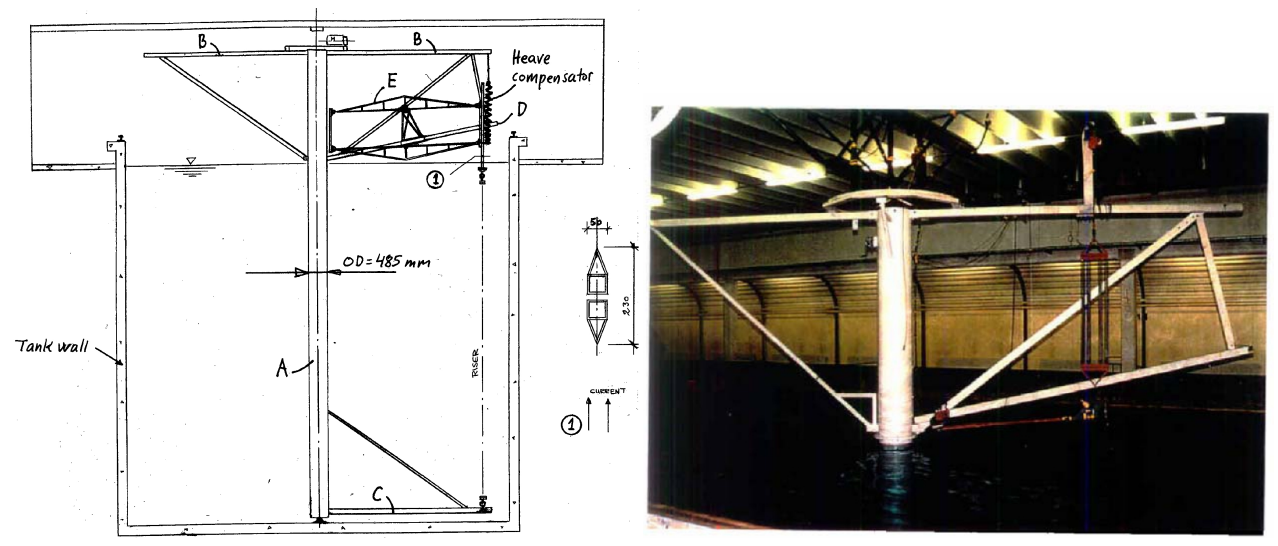

Figura 5.6: Arranjo do braço giratório do Marintek [Lie et al., 1997]

Em [Lie et al., 1998], dois novos modelos de riser foram ensaiados na mesma plataforma giratória, um liso e outro com flutuadores testados em diferentes posições verticais, portanto, impondo inclinações em relação à direção vertical. Como resultados, o modelo vertical liso apresentou excitação unimodal, enquanto o inclinado apresentou duas frequências excitadas simultaneamente. Para os casos em perfil não uniforme de velocidades, com a linha inclinada, mais de uma frequência se mostrou presente, como ilustrado na Figura 5.7. 


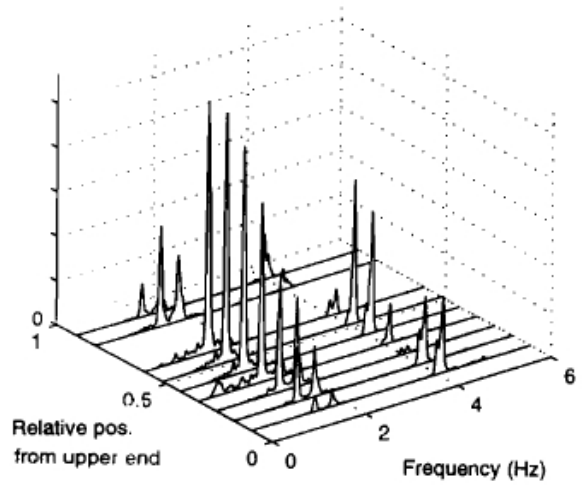

Figura 5.7: Resposta espectral da linha flexível em perfis variáveis de velocidade, resultado obtido de [Lie et al., 1998].

Outro ensaio em perfil de velocidade não uniforme é apresentado em [Lie \& Kaasen, 2006]. Conforme ilustrado na Figura 5.8, o modelo de riser teve a tração mantida constante, via conjunto formado por roldana e bóia, e com a imposição do reboque no topo, em velocidades constantes entre 0,16 e $2 \mathrm{~m} / \mathrm{s}$, foi submetido a diferentes perfis linearmente variáveis com a profundidade. Ao todo, 29 extensômetros foram posicionados a cada $3 \mathrm{~m}$ para avaliação dos movimentos transversais e longitudinais. Além disso, células de carga foram utilizadas para avaliar a tração nas duas extremidades do modelo.

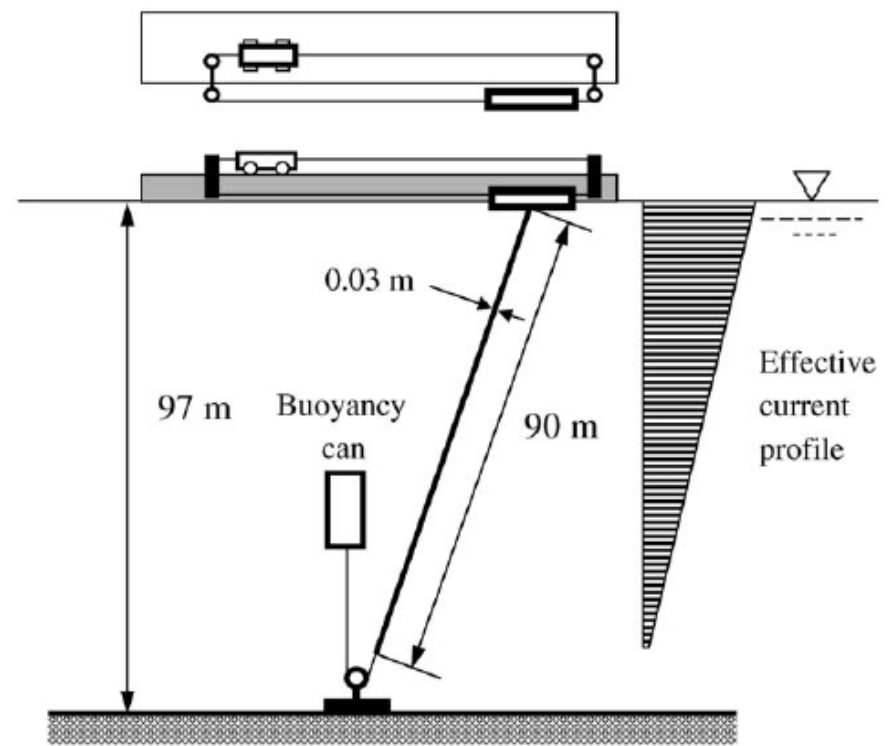

Figura 5.8: Arranjo Esquemático do experimento com perfil de correnteza não uniforme realizado por [Lie \& Kaasen, 2006].

De uma maneira geral, os experimentos em [Lie \& Kaasen, 2006] mostraram que a 
resposta apresenta uma ampla faixa de frequências excitadas, como pode ser visto na Figura 5.9. Em alguns testes, frequências espectrais distintas puderam ser vistas, correspondendo a um modo de vibrar específico, com faixas de respostas mais amplas para os movimentos da direção longitudinal do que transversal. No ponto médio do riser, a frequência no pico ressonante para os movimentos transversais foi aproximadamente igual a frequência de Strouhal, $f_{y} \approx f_{s}$, e a frequência no pico ressonante para os movimentos longitudinais duas vezes maior do que a frequência Strouhal, $f_{x} \approx 2 f_{s}$.
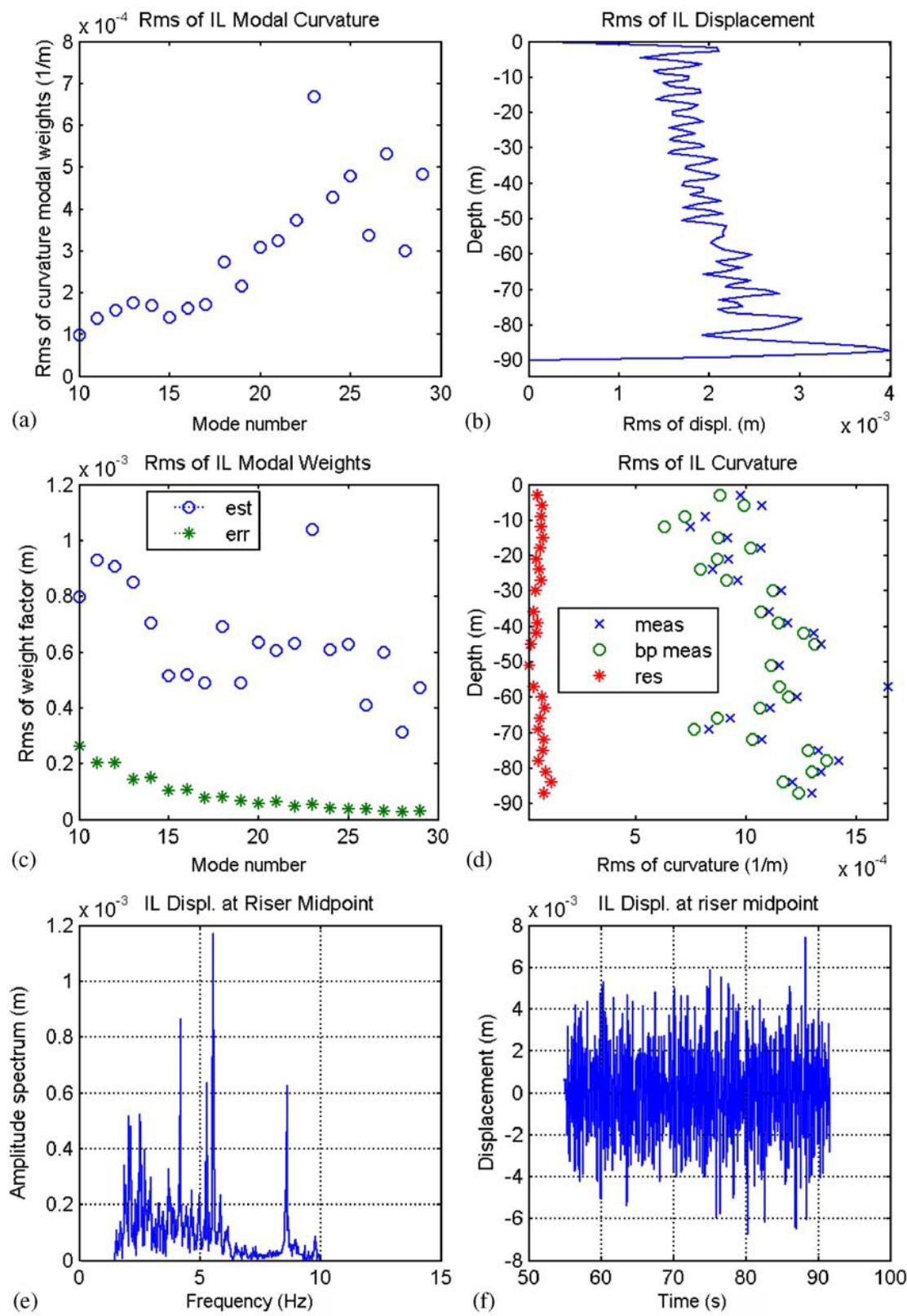

Figura 5.9: Exemplo de análise dos movimentos longitudinais em velocidade $V=0.54 \mathrm{~m} / \mathrm{s}$ (foco nos modos de vibrar de número 10 a 29), extraída de

[Lie \& Kaasen, 2006] 
Além disso, o desvio padrão do movimento ao longo do comprimento do riser foi calculado para indicar a magnitude do VIV durante cada teste. Na direção transversal, esse desvio padrão foi tipicamente de $0,25 D$ do diâmetro, quase independente da velocidade de escoamento, enquanto para a direção longitudinal, os valores ficaram na faixa de $0,05 D$ a $0,08 D$.

Um ponto importante durante a avaliação dos modos de vibrar nos experimentos de [Lie \& Kaasen, 2006] teve relação com o fato da instrumentação estar igualmente espaçada, o que limitou o número máximo de modos avaliados. Pode ser demonstrado que, em casos como aquele, o número de modos observáveis é igual ao número de pontos instrumentados ao longo do comprimento, resultado que limita as análises das vibrações longitudinais, visto que, nesta direção, devem haver frequências e modos mais altos de vibrar.

Com relação ao sistema de aquisição, até onde se pôde apurar, um sistema óptico para a avaliação dos movimentos da linha flexível foi originalmente utilizado em [Hong et al., 2002]. Nesse trabalho, dois modelos de riser, feitos de polietileno e teflon em dimensões diferentes, foram usados para experimentos de oscilação forçada na extremidade superior. Para medição tridimensional dos movimentos, doze câmeras foram utilizadas. Como resultado geral, pode se dizer que a maior amplitude de resposta induzida por vórtices foi obtida na parte inferior do modelo, para todas as frequências e amplitudes de excitação forçada.

No que tange aos métodos de análise do VIV, em [Pesce et al., 2006] são apresentados resultados obtidos com a aplicação original da Hilbert-Huang Transform (HHT), técnica de análise indicada para fenômenos não-lineares, estacionários ou não, modulados em amplitude e/ou frequência. Sendo assim, a técnica HHT apresentada com detalhes em [Huang, 1998] permite o tratamento de sinais mediante decomposição em "modos" intrínsecos, ou Intrinsic Mode Functions (IMF), obtidos por um procedimento de decomposição chamado de Empirical Mode Decomposition (EMD) e individualmente analisados com a transformada de Hilbert clássica. Pesce, Fujarra e Kubota aplicam esta técnica aos fenômenos VIV, tendo como objetivo o aprofundamento das análises, na busca por resultados instantâneos de frequência e amplitude, portanto, aumentando o entendimento dos fenômenos de excitação multimodal, modulação e mudança em frequência, inclusive com vistas às energias relacionadas.

Uma interessante avaliação analítico-numérica do VIV pode ser vista em [Da Silveira et al., 2007]. Nesse trabalho, o efeito do movimento vertical devido a uma 
unidade flutuante atuando no topo de risers verticais é analisado de maneira equivalente. Para tanto, um procedimento numérico é aplicado na simulação dinâmica do riser, via elementos finitos, e acoplado a um modelo analítico de natureza fenomenológica para a representação da excitação de VIV (via equação de van der Pol). Assim, as amplitudes de movimento em cada posição ao longo do comprimento são entradas para o modelo fenomenológico, que responde com uma força transversal aplicada ao riser, procedimento que também prevê a atualização da matriz de rigidez a cada passo de integração no tempo. Paralelamente, no mesmo trabalho, análises semelhantes do problema são realizadas com um código comercial de simulação. Para a avaliação de frequências e modos de vibrar, a técnica HHT também é aplicada, o que ajudou a distinguir as mudanças entre modos excitados. Dois casos solicitados por um perfil uniforme de velocidades foram tomados como exemplo: um tubo vertical sob tração de baixa magnitude, comparada com seu peso próprio, e uma linha vertical sob alta pré-tração. Como resultados gerais, foram obtidos comportamentos interessantes devido ao VIV: no primeiro caso, dominados pela tração adicional devido a correnteza; enquanto no segundo, a pré-tração, com efeito maior que o causado pelo perfil de correnteza, foi quem dominou o processo de sincronização dos modos naturais. Na Figura 5.10 é apresentado um exemplo da variação da resposta devido à tração no topo.
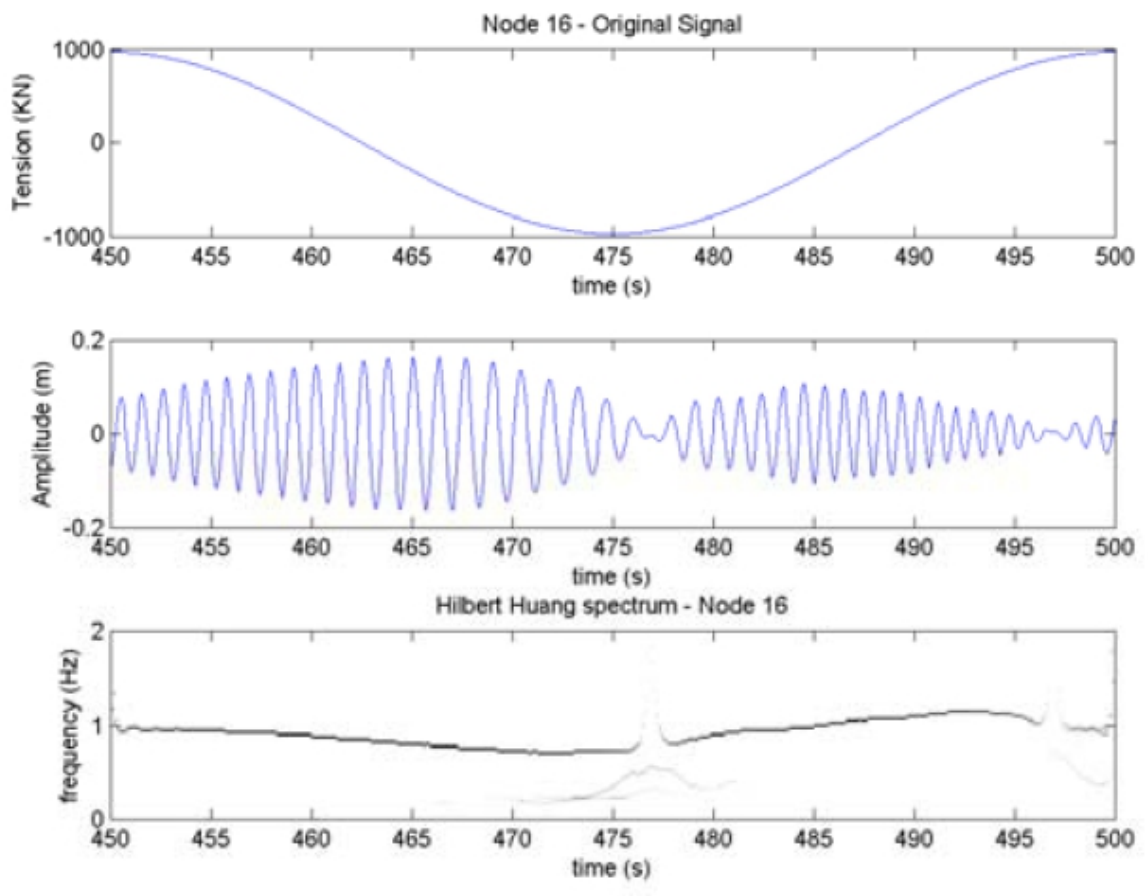

Figura 5.10: Avaliação analítico-numérica do efeito da tração imposta dinamicamente ao topo de uma linha vertical, realizada por [Da Silveira et al., 2007]. 
Recentemente, em [Josefsson \& Dalton, 2010], problema de natureza semelhante foi tratado exclusivamente segundo a abordagem numérica. Nesse caso, o fluido foi representado pela equação de Navier-Stokes, com solução baseada em Large Eddy Simulation (LES) e método das faixas, obtendo-se o campo de velocidades para a determinação do comportamento dos vórtices em números de Reynolds variando de 8000 a 10000. Assim sendo, o resultado do campo de velocidades é a entrada para a equação de uma barra modelada segundo Euler-Bernoulli, de onde são calculados os deslocamentos do riser via método WKB e decomposição modal. As condições de contorno para as equações do campo de velocidades e os movimentos da estrutura são atualizados a cada passo no tempo. Com base neste procedimento, o estudo indicou que a resposta dinâmica é maior no riser solicitado por tração variável, quando comparado com o riser sob tração constante, demonstrando a importância deste assunto na avaliação de tensões e fadiga em estruturas deste tipo.

\subsection{Com relação à avaliação das linhas em condições reais}

Como informações nas condições reais também são de grande importância para a compreensão do fenômeno de VIV, alguns programas foram criados com este objetivo, contando com uma série de experimentos realizados no âmbito do Norwegian Deepwater Program (NDP), conforme apresentado em [Halse, 2000]. Importante destacar que, apesar de sua importância incontestável, aqueles experimentos foram conduzidos sob condições de variação da correnteza devido à turbulência inerente e excitação combinada de ondas e ventos, o que, portanto, tem exigido comparação com resultados experimentais advindos de tanques de prova, onde as condições de excitação são muito mais controladas. Em [Lehn, 2003] estão disponíveis resultados com todas as séries temporais auferidas pelo NDP.

Estudos como os comentados acima têm servido de entrada para os códigos analíticonuméricos já comentados no capítulo anterior, em alguns casos, calibrados com base em experimentos forçados, posteriormente extrapolados para os modos de vibrar de estruturas flexíveis longas, conforme discutido em [Venugopal, 1996]. Tal estratégia gera algumas incertezas, exigindo altos fatores de segurança nos projetos.

Assim sendo, o desenvolvimento dos códigos de análise do VIV nas linhas continua sendo constantemente atualizado com coeficientes obtidos a partir de experimentos conduzido em condições específicas, porém, gradativamente mais próximas das condições 
reais. Um bom exemplo deste tipo de trabalho é conduzidos pelo grupo de pesquisa liderado pelo Prof. J. Kim Vandiver, cujos principais resultados são apresentados nos próximos parágrafos.

Buscando solução para o problema de interação fluido estrutural típico, a equação 5.1 é resolvida para cada modo dentro da faixa de excitação do VIV, permitindo a obtenção de contribuições modais na resposta final da estrutura.

$$
M_{n} \ddot{q}+C_{n} \dot{q}+K_{n} q=F_{n}
$$

onde:

$$
\begin{array}{ll}
M_{n} \text { é a massa modal } & M_{n}=\int_{0}^{L} \varphi_{n}^{2}(s) m_{t}(s) d s \\
C_{n} \text { é o amortecimento modal } & C_{n}=\int_{0}^{L} \varphi_{n}^{2}(s) c(s) d s \\
K_{n} \text { é a rigidez modal } & K_{n}=-\int_{0}^{L} \varphi_{n}(s) \varphi_{n}^{\prime \prime}(s) T(s) d s \\
F_{n} \text { é a força de excitação modal } & F_{n}=\int_{0}^{L}\left|\varphi_{n}(s)\right| P_{n}(s, t) d s
\end{array}
$$

Com relação a força de excitação modal, esta é calculada com base nos coeficientes de sustentação, $C_{L}$.

$$
P_{n}(s, t)=\frac{1}{2} \rho D U^{2}(s) C_{L n}(s) \sin \left(2 \pi f_{n} t\right)
$$

Em [Vandiver \& Li, 2005] e [Larsen et al., 2001b] são apresentadas discussões quanto à maneira de se considerar a força de excitação e o amortecimento. Segundo aqueles trabalhos, na região do lock-in devem ser utilizados os mesmos coeficientes de sustentação, $C_{L}$, tanto para os cálculos da força de excitação, $P_{n}(s, t)$, quanto para os cálculos do amortecimento, $c(s)$.

Em [Venugopal, 1996], no entanto, sugere-se que os efeitos do amortecimento tenham natureza distinta dentro e fora da região de lock-in. Assim, para o cálculo do amortecimento modal são considerados coeficientes $c$ para cada região, conforme equação 5.3.

$$
\begin{aligned}
& c(s)=\frac{\omega \pi \rho D^{2}}{2}\left[\frac{2 \sqrt{2}}{\left.\sqrt{(} \omega D^{2} / \nu\right)}+C_{s w}\left(\frac{A}{D}\right)^{2}\right]+C_{\text {low }} \frac{1}{2} \rho D U \text { região abaixo do lock-in } \\
& C_{h i g h} \frac{\rho U^{2}}{2 \omega} \quad \text { região acima do lock-in } \\
& C_{L} \frac{\rho D U^{2}}{2 \omega A} \quad \text { região dentro do lock-in }
\end{aligned}
$$


onde: $C_{l o w}, C_{h i g h}$ e $C_{s w}$ são coeficientes definidos empiricamente, sendo que $c(s)$ tem unidade de força por velocidade por comprimento.

Esta metodologia considera que a energia absorvida pela geração de vórtices se mantém em equilíbrio com a energia de amortecimento, o que permite a determinação das amplitudes adimensionais modais, $A_{n} / D$, conforme equação 5.4 .

$$
\frac{A_{n}}{D}=\frac{0.5 \int_{L} \rho U(s)^{2} C_{L}(s)\left|\varphi_{n}(s)\right| d s}{\omega_{n} \int_{L} \varphi_{n}^{2}(s) c(s) d s}
$$

Além disso, Vandiver apresenta a equação 5.5 em seus trabalhos, segundo a qual, define o modo máximo excitado pelo fenômeno de VIV agindo em estruturas flexíveis dominados pela tração, $n_{\max }$.

$$
n_{\max }=2 S_{t} \frac{U_{\max }}{D} L \sqrt{\frac{m+m_{a}}{T}},
$$

Alternativa para a definição deste modo máximo também é feita com base: no coeficiente de arrasto, $C_{D}$; no coeficiente de massa adicional, $C_{a}$; e na razão entre a densidade estrutural e a densidade do fluído, $\rho_{s} / \rho_{f}$. Ver equação 5.6.

$$
n_{\text {max }}^{2}=\frac{2 \pi S t^{2}}{C_{D}} \sin \theta \frac{U_{\max }^{2}}{U^{2}}\left(\frac{\rho_{s}}{\rho_{f}}+C_{a}\right) \frac{L}{D}
$$

Tais estimativas são apenas um indicativo do número de modos de vibrar passíveis de excitação pelo VIV e, assim mesmo, só devem ser aplicadas no caso de cilindros flexíveis que respondam a um baixo número de modos de vibrar.

Finalmente, há que se destacar que este é apenas um dos procedimentos de avaliação do VIV nas linhas, aqui apresentado como exemplo da abordagem usualmente adotada. Ainda existem poucos experimentos com estruturas flexíveis lançadas em catenária para avaliação multimodal do VIV em perfis uniformes e não uniformes de correnteza, cujos resultados podem contribuir para a compreensão mais profunda do VIV nestas condições, portanto, contribuir com os procedimentos de projeto de risers. As referências apresentadas acima em conjunto com aquelas apresentadas no capítulo 4 foram utilizadas na interpretação dos resultados dos experimentos conduzidos nesta tese, definindo métodos mais atuais de análise, inclusive mediante comparações 
analítico-numéricas.

Finalizada a apresentação dos subsídios teórico-experimentais pertinentes ao escopo da presente pesquisa, nos próximos capítulos são apresentados os procedimentos experimentais, respectivos resultados e discussões desenvolvidos com vistas aos objetivos traçados para a tese. 


\section{Metodologia}

O presente capítulo tem como principal finalidade apresentar a metodologia utilizada para o alcance dos objetivos da tese.

Nesse contexto, na seção 6.1 incluem-se os materiais e equipamentos empregados na condução dos ensaios físicos, enquanto na seção 6.2 são apresentados os métodos aplicados para a condução da pesquisa. Cada um desses tópicos foi devidamente distribuído em seções e subseções, de modo a dar fluidez de leitura e organização ao corpo do texto.

Ainda no que tange ao conteúdo deste capítulo, outras duas seções foram incorporadas, dado que foram avaliadas como parte da metodologia adotada: a seção 6.3, que apresenta e discute aspectos inerentes aos casos ensaiados, e a seção 6.4, que trata da metodologia adotada para análise dos resultados advindos das abordagens utilizadas.

\subsection{Materiais e equipamentos}

Com relação aos materiais e equipamentos utilizados, optou-se, por concisão, pela apresentação exclusiva daqueles que são mais relevantes, de maneira a não sobrecarregar o leitor com detalhes desnecessários.

Dessa maneira, serão apresentados, nessa ordem, o modelo de linha flexível empregado (que representa um riser em escala reduzida), os locais em que os ensaios foram realizados e o sistema de monitoramento de movimentos utilizado. Por fim, mantendo o foco nos equipamentos mais importantes para a obtenção dos resultados, são apresentados os demais dispositivos relevantes.

\subsubsection{Modelo de linha flexível}

O modelo de riser ensaiado foi exatamente o mesmo utilizado em [Rateiro et al., 2012], que consiste em um tubo flexível de silicone preenchido com microesferas de aço, 
utilizadas para conferir maior peso próprio à linha e, portanto, garantir a similaridade dinâmica do modelo. Além do peso próprio, outras propriedades físico-mecânicas foram cuidadosamente consideradas para garantir a maior similaridade possível.

A disponibilidade de utilizar a mesma linha que [Rateiro et al., 2012], encerra vantagens demasiado importantes. Dentre elas, é possível citar:

- A metodologia empregada por [Rateiro et al., 2012] no projeto da linha levou em consideração sua similaridade geométrica e dinâmica, com relação a risers reais, o que permite extrapolação dos resultados obtidos em escala reduzida para o cenário real de operações de perfuração e/ ou prospecção de petróleo e gás no mar;

- O projeto da linha foi predominantemente baseado na Similaridade de Froude, contudo, sem descartar os comportamentos dinâmicos mais importantes do fenômeno de VIV;

- Consistentemente com a metodologia utilizada no projeto do modelo, sua confecção foi cuidadosamente monitorada e verificada, de maneira que as propriedades do modelo construído, "as built", retrataram com boa aproximação os valores esperados;

- A utilização do referido modelo flexível dispensou a realização/repetição de ensaios de caracterização no âmbito desta tese, permitindo seu encaminhamento direto aos experimentos principais do trabalho de pesquisa.

A Figura 6.1 ilustra um trecho do modelo flexível, objeto de estudo da presente seção. No detalhe, em vermelho, são mostrados dois dos alvos refletivos utilizados pelo sistema de monitoramento óptico que é apresentado na seção 6.1.3.

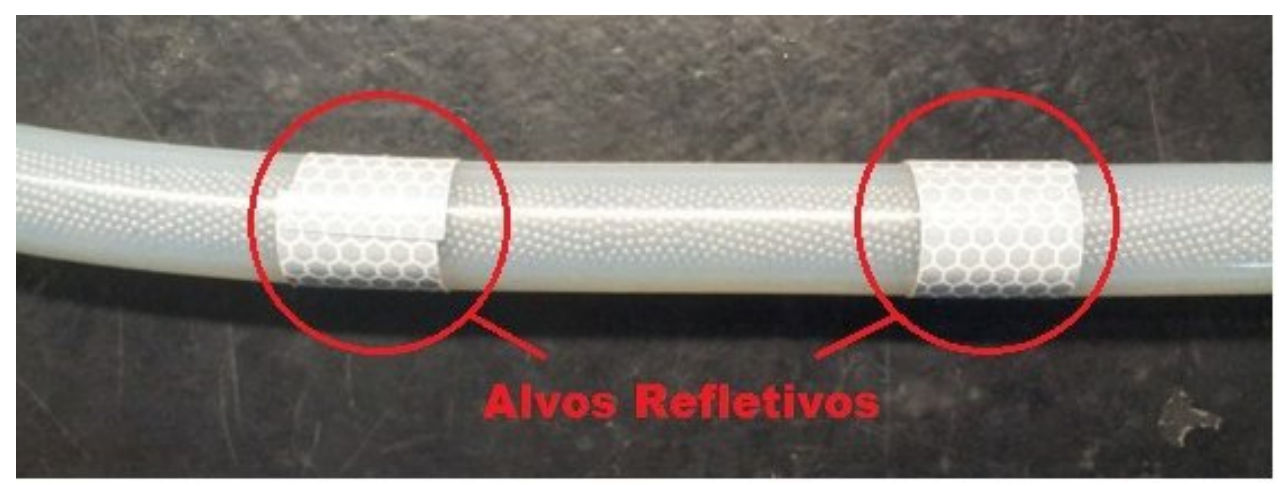

Figura 6.1: Trecho do modelo flexível utilizado nos ensaios. No detalhe, os alvos refletivos utilizados pelo sistema de rastreamento. 
Na seção 6.2.2 são apresentados os principais ensaios de caracterização realizados em [Rateiro et al., 2012], além de outros realizados especificamente para os fins deste trabalho.

Como síntese importante para a presente subseção, a Tabela 6.1 apresenta as propriedades físico-mecânicas fundamentais para os trabalhos de investigação mais adiante apresentados e discutidos.

Tabela 6.1: Propriedades do modelo de linha flexível, em escala de 1:100, comparado com as respectivas propriedades do riser em escala real. Fonte: [Rateiro et al., 2012].

\begin{tabular}{lrrr}
\hline \multicolumn{1}{c}{ Dados } & Escala $(\mathbf{1}: \mathbf{1 0 0})$ & Modelo projetado & Modelo construído \\
\hline Diâmetro interno $(\mathrm{mm})$ & 1.826 & 15.8 & 15.8 \\
Diâmetro externo $(\mathrm{mm})$ & 2.191 & 22.2 & 22.2 \\
Peso na água $(\mathrm{N} / \mathrm{m})$ & 0.726 & 7.308 & 7.308 \\
Rigidez axial EA $(\mathrm{kN})$ & 2.362 & 1.91 & $1.0-1.6$ \\
Rigidez flexional EI $\left(\mathrm{Nm}^{2}\right)$ & $1.20 \mathrm{E}-03$ & $8.86 \mathrm{E}-02$ & $5.60 \mathrm{E}-02$ \\
Comprimento de flexão $(\mathrm{mm})$ & 71 & 61 & 49 \\
Coef. massa adicional, $a=m a / m$ & 0.522 & 0.52 & 0.52 \\
\hline
\end{tabular}

\subsubsection{Tanques de Prova}

Os ensaios referentes aos objetivos desta tese foram realizados em dois locais distintos, a saber: o Calibrador Hidrodinâmico do Tanque de Provas Numérico $(\mathrm{CHTPN})^{1}$ e o Tanque de Reboque do Instituto de Pesquisas Tecnológicas do Estado de São Paulo (IPT).

Para melhor compreensão dos motivos que levaram à escolha desses dois locais, a seguir, ambos serão descritos com vistas às diferenças e os ganhos potenciais oferecidos a esta pesquisa, de forma que os resultados obtidos se complementem e permitam maior compreensão do VIV nas linhas flexíveis longas.

\subsubsection{Calibrador Hidrodinâmico - CHTPN}

O Calibrador Hidrodinâmico do TPN (CHTPN) possui $14 \mathrm{~m}$ de comprimento por $14 \mathrm{~m}$ de largura e profundidade de 4m. É dotado de 148 batedores (flaps), distribuídos em 4 conjuntos de 37 elementos posicionados em cada uma de suas laterais e que podem ser

\footnotetext{
${ }^{1} \mathrm{O}$ Tanque de Provas Numérico é um dos laboratório vinculados ao Departamento de Engenharia Naval e Oceânica (PNV) da Universidade de São Paulo.
} 
acionados independentemente para a geração e/ou absorção de ondas, ver Figura 6.2. Esta última funcionalidade do CH-TPN, no entanto, não foi necessária para os experimentos mais adiante descritos.

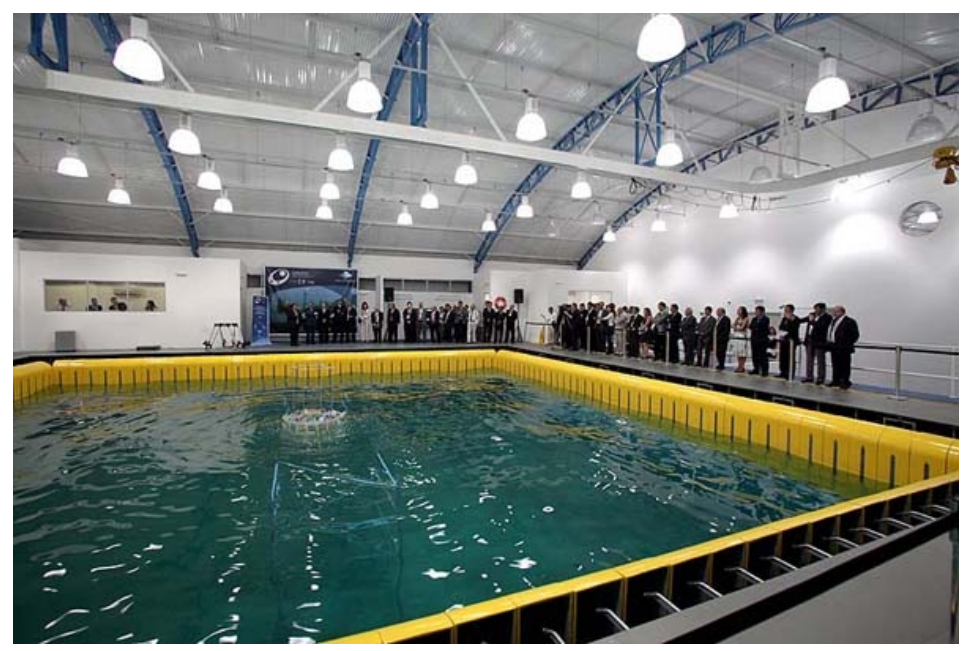

Figura 6.2: Calibrador Hidrodinâmico do Tanque de Provas Numérico.

$\mathrm{Na}$ realidade, pelas suas características, o CHTPN é considerado um tanque oceânico, construído com a finalidade principal de obtenção experimental dos coeficientes hidrodinâmicos advindos da ação das ondas sobre os sistemas navais e oceânicos de interesse. Ensaios de reboque, em princípio, não seriam possíveis nesta infraestrutura.

Particularmente no que tange às vibrações induzidas pela emissão de vórtices no segmento offshore, sabe-se tratar de fenômeno dependente da correnteza incidente sobre dutos submersos. Sendo assim, a fim de aumentar a gama de fenômenos passíveis de serem ensaiados no CHTPN, inclusive os desta tese, foi projetado e construído um mecanismo, denominado braço giratório (ou "rotating arm"), que permite emular a ação da correnteza em modelos, a despeito da pequena extensão do tanque ${ }^{2}$, ver Figura 6.3.

\footnotetext{
${ }^{2}$ Embora o uso do termo tanque seja corriqueiro para se referir ao CHTPN, cabe ressaltar que, a rigor, a expressão é inadequada, pela referência aos tanques de reboque. Apesar disso, o presente texto utilizará, eventualmente, essa terminologia, por conveniência.
} 


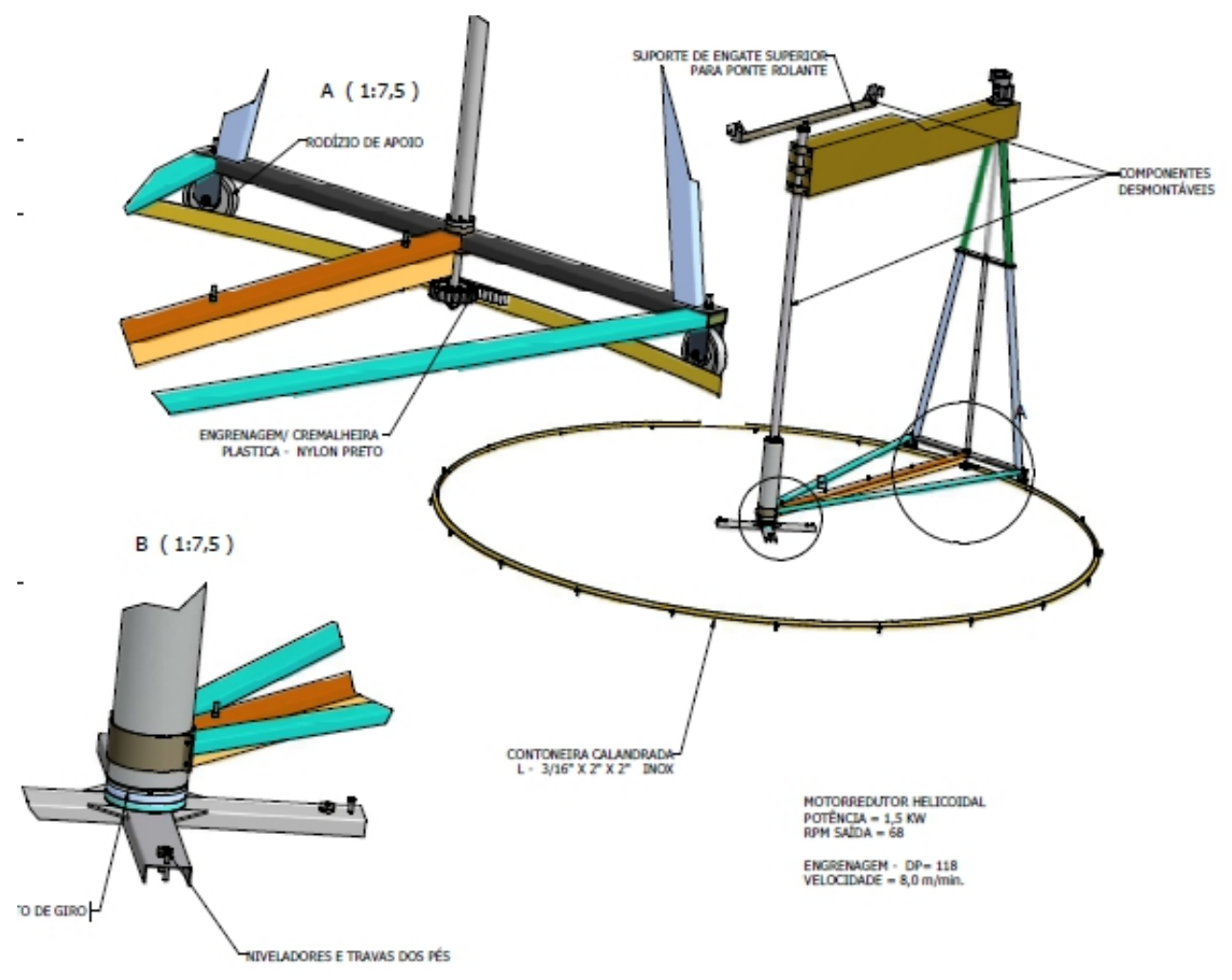

$T$

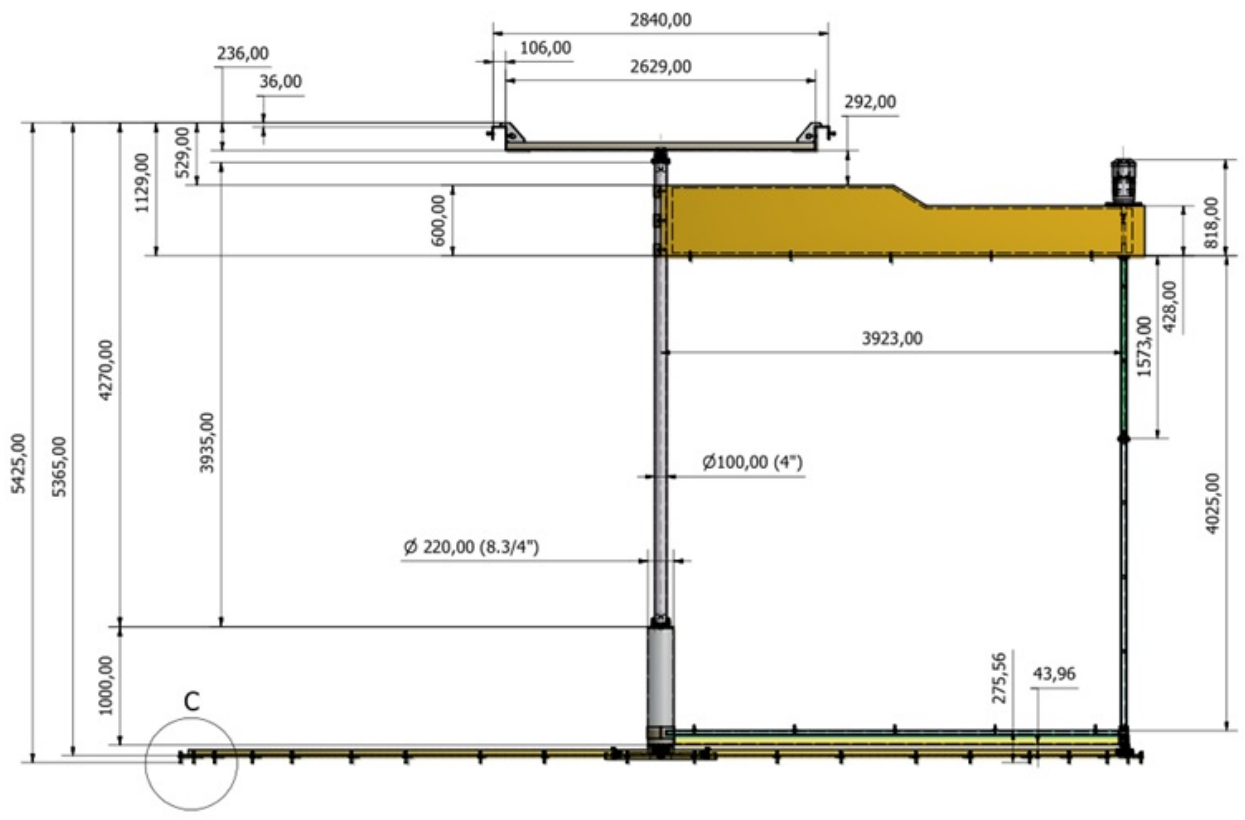

Figura 6.3: Detalhes de projeto do braço giratório do Calibrador Hidrodinâmico do TPN.

Em linhas gerais, o braço giratório é um equipamento composto por um eixo central, preso ao fundo do tanque e à ponte rolante, de onde partem duas estruturas radiais: uma superior, caracterizada como uma "viga-caixão" onde o topo do modelo é montado; e uma inferior, responsável por sustentar um piso móvel onde a extremidade oposta do modelo 
repousa ou é fixada. As extremidades radiais dessas duas estruturas são interligadas por uma terceira, em forma de trapézio, responsável pelo movimento de rotação de todo o conjunto. Para tanto, um trilho/cremalheira fixado ao fundo do tanque garante a trajetória circular.

A Figura 6.4 ilustra a instalação do eixo vertical e do trilho que fazem parte da estrutura do braço giratório. Durante a montagem, foram tomadas várias medidas preventivas a fim de evitar, por exemplo, vibrações indesejadas do conjunto advindas do eventual desnivelamento dos trilhos, ver Figura 6.5.

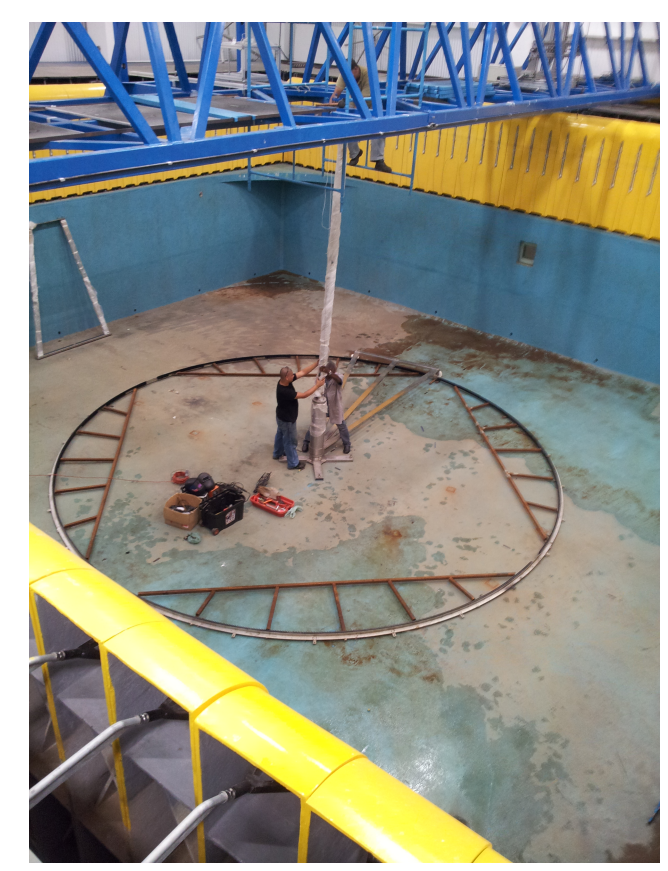

Figura 6.4: Instalação do trilho e do eixo central do braço giratório no CHTPN.

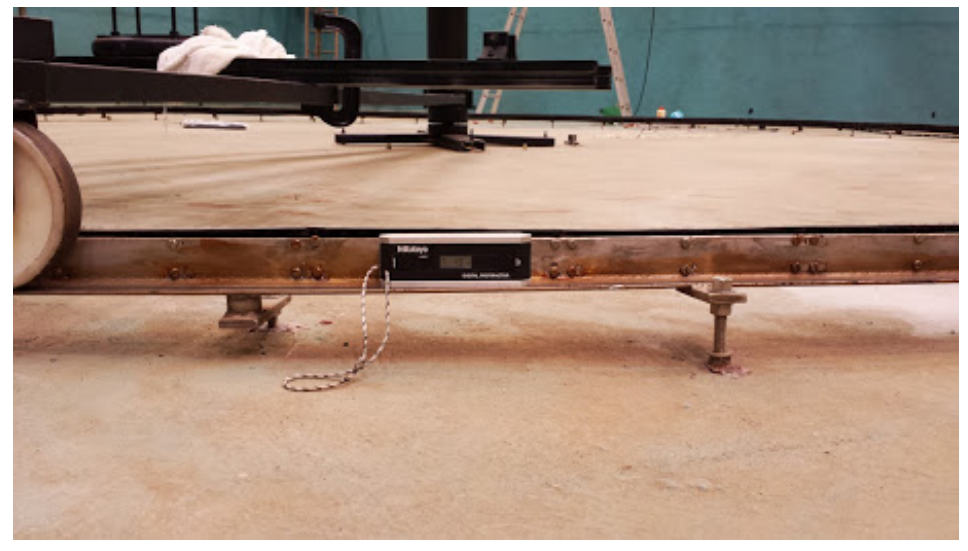

Figura 6.5: Verificação do nivelamento do trilho do braço giratório. Medida para redução das vibrações estruturais do aparato experimental.

Instalados o trilho e o eixo central, foi possível a colocação do braço- giratório em si, 
estrutura amarela da Figura 6.6. Cumpre mencionar que o projeto do braço giratório foi pensado para montagem e desmontagem rápidas (em torno de duas horas cada), necessitando três pessoas, dentre elas um mergulhador.

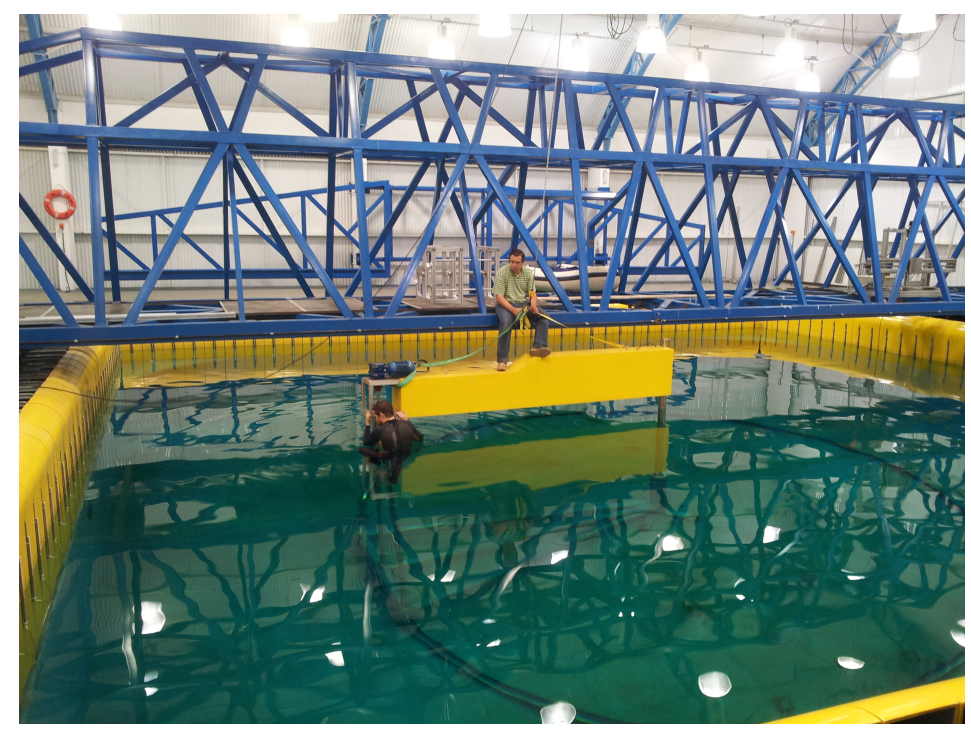

Figura 6.6: Procedimento de montagem do braço giratório com a necessidade de utilização de uma talha e mergulhador para apoio e realização das fixações imersas.

A Tabela 6.2 compila as principais características do CHTPN e do braço giratório.

Tabela 6.2: Características geométricas e operacionais do Calibrador Hidrodinâmico e seu braço giratório.

\begin{tabular}{lc}
\hline Comprimento total & $20 \mathrm{~m}$ \\
Largura total & $20 \mathrm{~m}$ \\
Profundidade & $4 \mathrm{~m}$ \\
Comprimento útil (entre flaps) & $14 \mathrm{~m}$ \\
Número de geradores/absorvedores & 148 \\
Raio máximo para posiconamento do modelo & $3,5 \mathrm{~m}$ \\
Velocidade tangencial máxima & $0,3 \mathrm{~m} / \mathrm{s}$ \\
\hline
\end{tabular}

Assim sendo, a do braço giratório no CHTPN confere ao tanque a possibilidade de executar ensaios sob duas condições que, anteriormente, sequer aventadas:

- Perfis de correnteza constante, para os casos das linhas dispostas verticalmente; 
- Perfis variáveis, nos casos das linhas lançadas em um plano radial passando pelo centro de rotação do braço.

Nesse sentido, a título de exemplo, a Figura 6.7 ilustra a instalação concomitante de dois modelos tubulares em PVC (um horizontal e outro vertical), ensaiados para a comparação entre os possíveis perfis de velocidade de correnteza gerados com o uso do braço giratório.

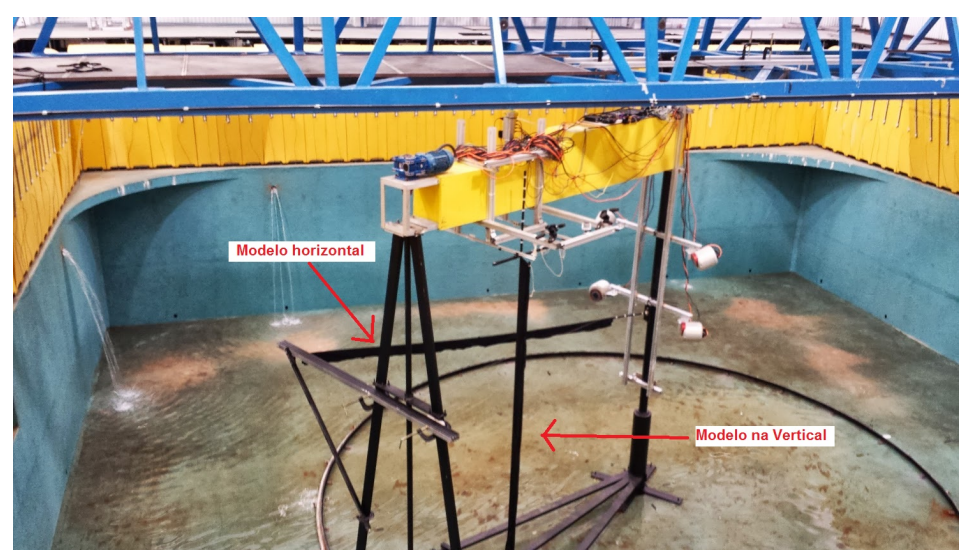

Figura 6.7: Arranjos preliminares com modelos construídos em PVC para a comparação entre os perfis de velocidade constante e linearmente variável na radial.

Dadas as características do braço giratório, é possível perceber que, em princípio, ensaios realizados com o uso dessa estrutura podem gerar uma esteira difusa, de maneira que o modelo fique sujeito às vorticidades geradas e não dissipadas no transcorrer de uma volta completa.

Cabe salientar, todavia, que a utilização de modelos flexíveis suficientemente esbeltos, caracterizados por baixas frequências relativas associadas aos primeiros modos naturais de vibrar, permitem que o braço seja movimentado a baixas velocidades de rotação, o que garante que uma volta completa seja suficiente para a caracterização desejável do fenômeno em estudo. 


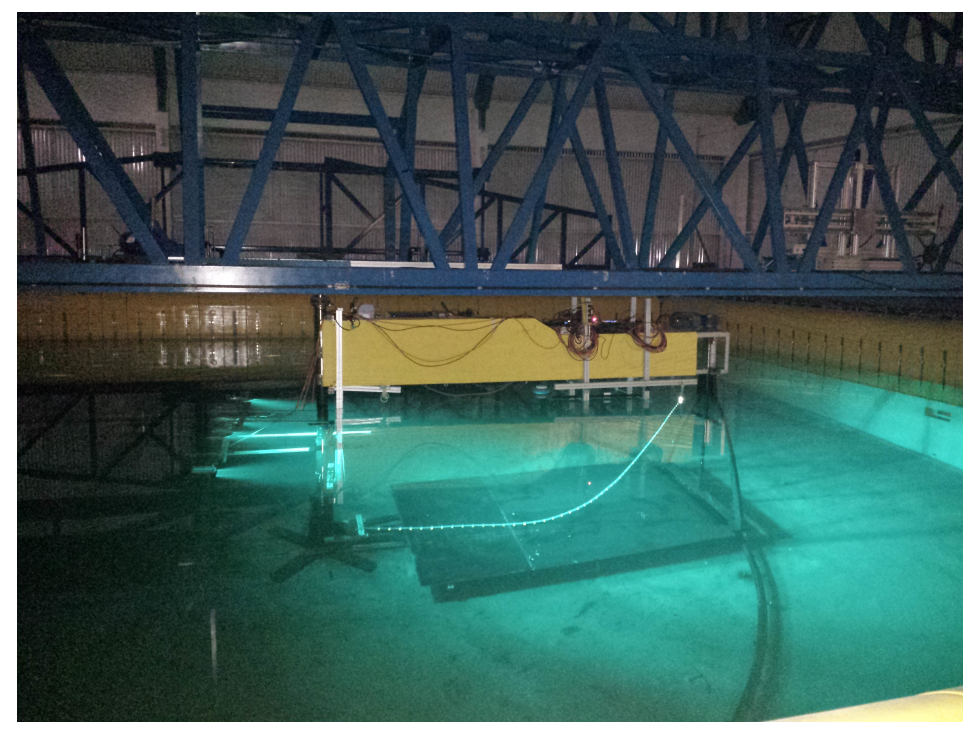

Figura 6.8: Arranjo geral de uma catenária rebocada pelo braço giratório, na condição onde a âncora é posicionada junto ao eixo central de rotação.

Por fim, apenas com a finalidade de ilustrar outra possível montagem no braçogiratório, ilustra-se a Figura 6.8, na qual também é possível verificar a estrutura plana de fundo, sobre a qual é possível o posicionamento e ancoramento adequados da extremidade inferior de uma catenária.

\subsubsection{Tanque de reboque do IPT}

O tanque de provas do IPT possui 280m de comprimento, 6,6m de largura e 4,0m de profundidade. Nesse tanque é possível a simulação de correntezas pela movimentação controlada de um carro de reboque, Figura 6.9, capaz de atingir velocidades de até $3 \mathrm{~m} / \mathrm{s}$. Neste caso, para experimentos onde seja necessária, a geração de ondas também pode ser realizada a partir de equipamentos instalados em suas extremidades. 


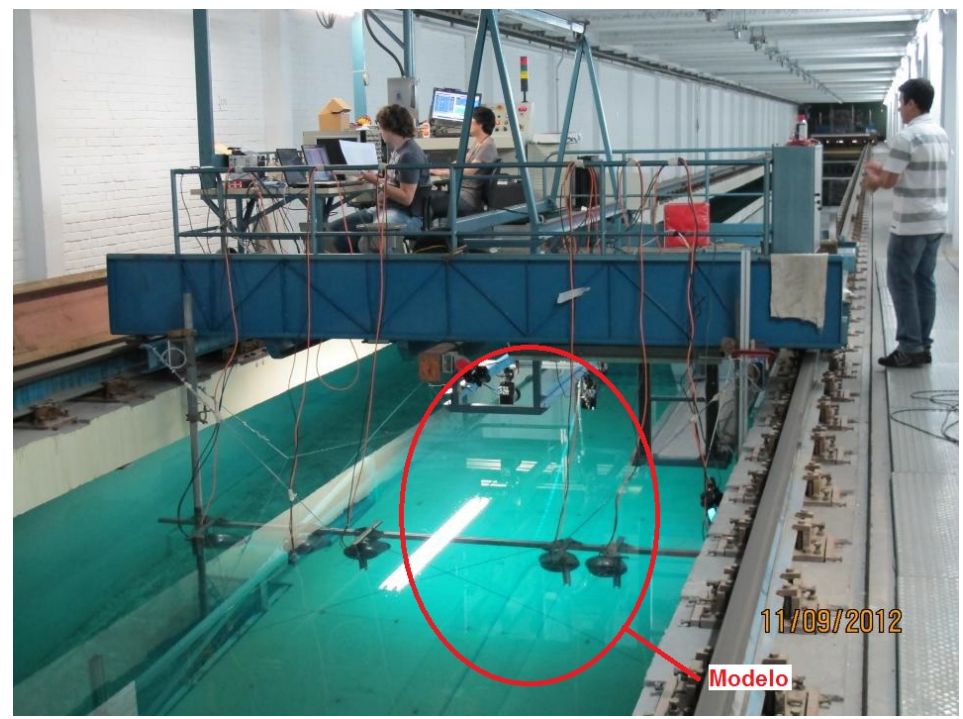

Figura 6.9: Montagem de uma linha lançada em catenária no tanque de reboque do IPT.

Nesta figura, além do carro de reboque, também é possível perceber o arranjo para experimentos com linhas flexíveis lançadas em catenária, neste caso, sob ação de perfis constantes de velocidade de correnteza. Note que, também no IPT, faz-se necessária a utilização de um fundo móvel para posicionamento e ancoramento da porção inferior da catenária.

A Tabela 6.3, de forma resumida, apresenta as principais características geométricas e de operação do tanque de reboque do IPT.

Tabela 6.3: Características geométricas e operacionais do tanque de reboque do IPT.

\begin{tabular}{lc}
\hline Propriedades & \\
\hline Comprimento total & $280 \mathrm{~m}$ \\
Largura total & $6,6 \mathrm{~m}$ \\
Profundidade & $4 \mathrm{~m}$ \\
Velocidade de reboque máxima & $3 \mathrm{~m} / \mathrm{s}$ \\
Número de geradores de onda & 2 \\
\hline
\end{tabular}

A disponibilidade de utilização desses dois tanques para os ensaios relativos aos objetivos desta tese amplia sobremaneira a gama de experimentos possíveis, propiciando a medição e registro diversificado de comportamentos dinâmicos em termos das configurações utilizadas, abrangendo um maior contingente de cenários e, portanto, suscitando discussões e conclusões mais amplas. 


\subsubsection{Sistema de monitoramento óptico}

Durante a concepção de um experimento físico é necessário determinar quais grandezas devem ser determinadas, dependendo dos objetivos almejados. No entanto, independentemente do tipo e da finalidade dos testes experimentais a serem executados, é fundamental a determinação do conjunto de equipamentos mais adequados para realizar o monitoramento dos ensaios e avaliar as as grandezas desejadas.
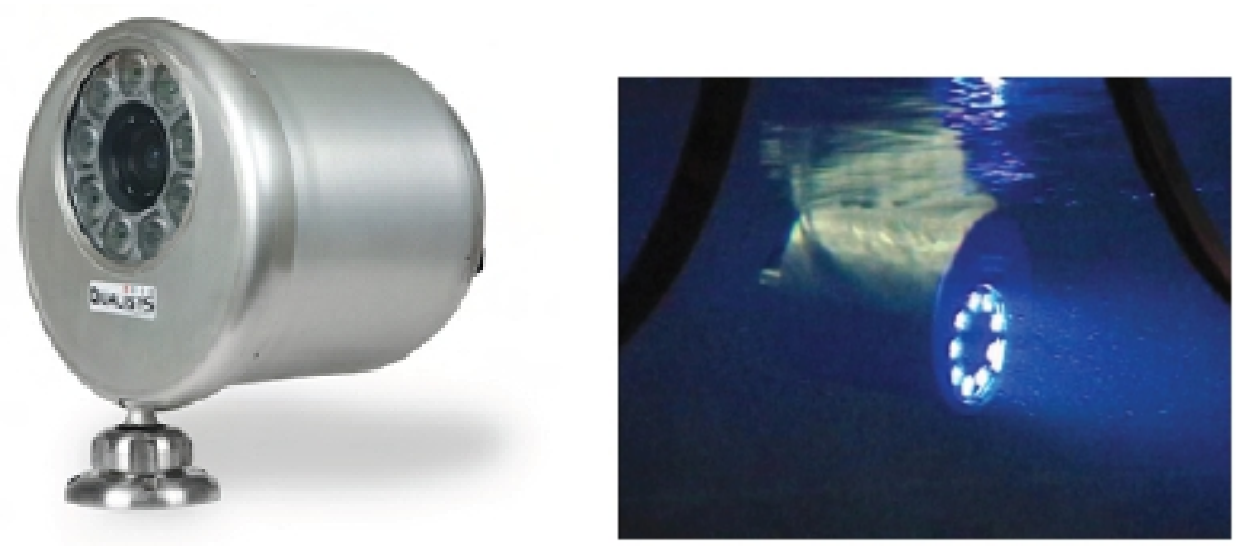

Figura 6.10: Câmera submersa utilizada para avaliação dos movimentos da porção submersa das linhas flexíveis.

De maneira alternativa às instrumentações convencionais, e com as vantagens de ser minimamente invasiva, permitindo o monitoramento direto da dinâmica global e local do modelo, propõe-se a utilização de um sistema comercial de rastreamento de movimentos por imagens, composto de câmeras que possuem emissores e receptores de luz em comprimentos adequados, assim como a ilustrada na Figura 6.10.

A título de documentação, a Tabela 6.4 traz as característica das câmeras submersas adotadas para os experimentos submersos conduzidos no âmbito desta pesquisa.

Tabela 6.4: Características das câmeras submersas utilizadas nos experimentos desta pesquisa.

\begin{tabular}{lc}
\hline Dimensões & 300x300x240 mm \\
Peso & $12 \mathrm{~kg}$ \\
Ângulo de visão & 30 graus \\
Profundidade máxima & $10 \mathrm{~m}$ \\
Precisão a 10m de distância & $\pm 2 \mathrm{~mm}$ \\
\hline
\end{tabular}

Esse sistema de câmeras possui características importantes como a alta precisão (da 
ordem de décimos de milímetros), a facilidade de calibração e uso e a flexibilidade de montagem, além do fato de possuir um código dedicado que permite a geração automática de arquivos digitais com os históricos temporais dos deslocamentos, velocidades, acelerações, rotações e/ ou ângulos, conforme a necessidade do usuário e de acordo com um sistema global de referências definido por ele.

O rastreamento do objeto/modelo é feito a partir de alvos refletivos fixados sobre a superfície do mesmo, como já mencionado e ilustrado na Figura 6.1. A Figura 6.11, por sua vez, apresenta dois dos diversos tipos de fitas refletivas passíveis de serem utilizadas em conjunto com o sistema de câmeras (submersas e/ou aéreas).

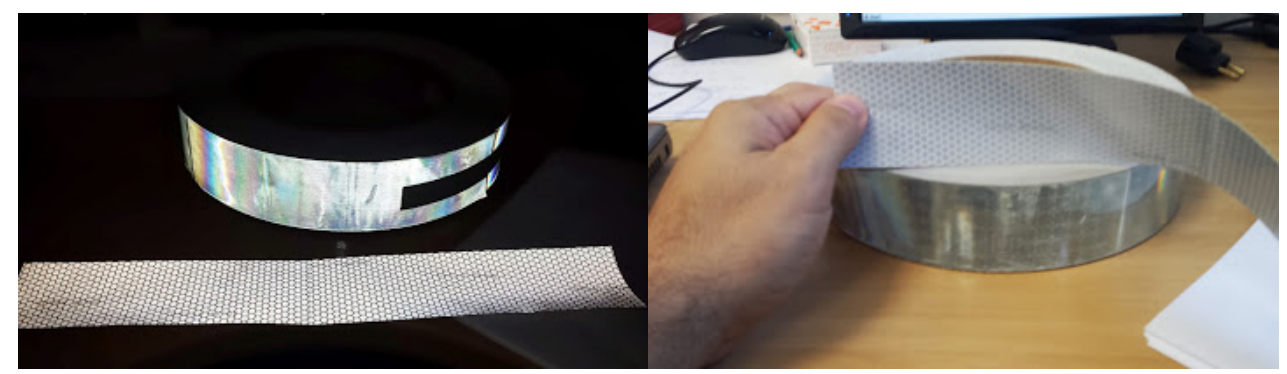

Figura 6.11: Diferentes tipos de fitas refletivas. Algumas não permitem muito tempo de imersão por conta da absorção de água, que as tornam invisíveis ao sistema de monitoração.

É importante notar que um sistema de monitoramento como esse permite, grosso modo, o rastreamento de movimentos a partir da geração de um arquivo de vídeo, ou seja, um conjunto de quadros (ou fotos, ou frames) que são, intrinsecamente, bidimensionais. A natureza dos ensaios realizados demanda, entretanto, a determinação das séries temporais de deslocamentos (tridimensionais) dos alvos reconhecidos pelo código integrado.

Em termos práticos, é necessária a obtenção de conjuntos de ordenadas no espaço tridimensional, a partir de informações bidimensionais. Matematicamente, o procedimento é equivalente à resolução de um sistema de duas equações a três incógnitas, dito indeterminado. Como cada imagem gerada por uma câmera traz um conjunto de duas coordenadas, são necessárias ao menos duas câmeras para que essa transformação seja passível de ser realizada.

O uso de duas câmeras, portanto, encerra quatro equações nas mesmas três incógnitas, gerando uma redundância. Dessa forma, o sistema pode ser resolvido numericamente, por exemplo, com o uso do Método dos Mínimos Quadrados (MMQ). Consequentemente, o aumento no número de equações (e, em correspondência, de câmeras), aumenta a redundância e permite reduzir os resíduos associados à aplicação 
de métodos numéricos.

A determinação dessa transformada, que associa coordenadas bidimensionais de um par de imagens a um ponto no espaço tridimensional, é usualmente conhecida como calibração do sistema de câmeras, caracterizando-se como um procedimento essencial para a utilização do sistema de monitoramento óptico para fins de rastreamento.

Saliente-se que, matematicamente, a aproximação numérica efetuada por essa transformação é válida, a rigor, para um determinado domínio. Pontos fora desse domínio podem ser avaliados, mas as incertezas envolvidas podem ser significativas.

$\mathrm{Na}$ prática, a calibração do sistema de câmeras consiste, inicialmente, no estabelecimento de um plano de referência, a partir de uma estrutura dotada de alvos refletivos em posições fixas e pré-determinadas, conhecida pelo sistema de monitoramento. Essa estrutura de referência é, por vezes, denominada de cálibre. Ver, como exemplo, o detalhe A da Figura 6.12). O cálibre ilustrado naquela figura possui formato em "L" com quatro alvos refletivos distribuídos da seguinte forma: um no vértice do ângulo idealmente reto; outros dois colineares ao primeiro ao longo da haste de maior comprimento do "L"; e um último, fixado na extremidade da haste menor.

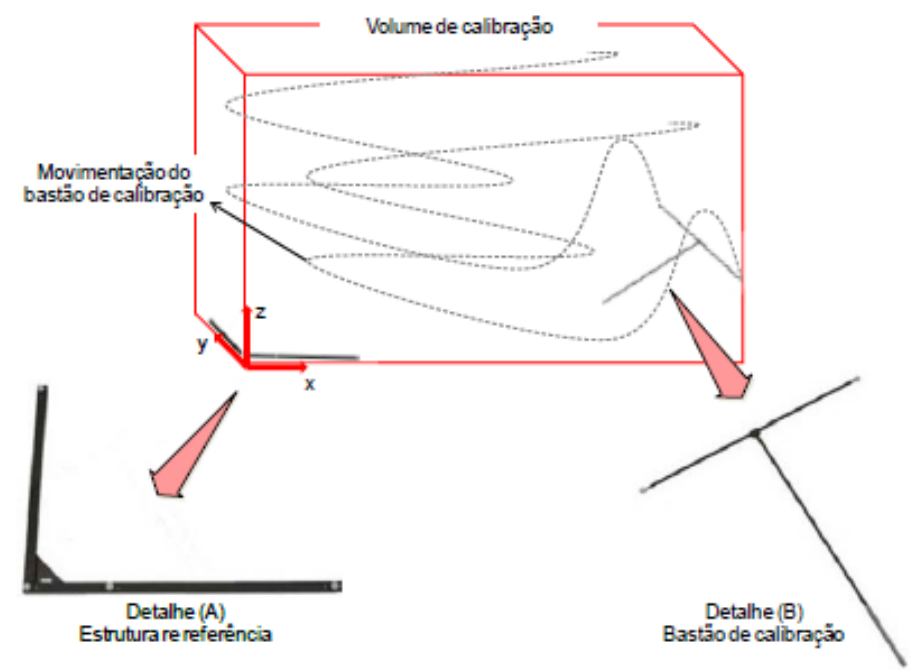

Figura 6.12: Estruturas utilizadas na calibração das câmeras.

Ao posicionar essa estrutura na região que se pretende monitorar o objeto/ modelo, o sistema reconhece automaticamente os alvos e determina um sistema de referências a partir dele, centrado no vértice (encontro das hastes), com direção $x$ determinado pelos três alvos colineares sobre a maior das hastes e com a direção y perpendicular ao primeiro e coplanar aos quatro alvos fixos. 
A terceira direção, direção $z$, é determinada pela regra da mão direita, sendo perpendicular ao plano $x y$. Os versores correspondentes aos eixos do sistema $0 x y z$ formam, portanto, uma base ortogonal positiva (Figura 6.12, em vermelho).

O passo seguinte, consiste na movimentação de outra estrutura (bastão de calibração, detalhe B da Figura 6.12), durante um tempo pré-determinado pelo usuário. O conjunto de todas as posições assumidas pelos dois alvos nas extremidades do bastão e reconhecidos pelo sistema de câmeras forma um volume de controle, correspondente ao domínio sob o qual a citada transformação matemática é válida.

Para as câmeras aéreas, via de regra, a calibração é rápida e sem problemas decorrentes.

Por outro lado, diversos fatores concorrem para uma maior dificuldade na calibração das câmeras submersas: a dificuldade de posicionamento do cálibre, a pequena extensão do bastão de calibração (frente à lâmina d água), exigindo o uso de um prolongamento adaptado, a turbidez da água, a luminosidade difusa, etc. A Figura 6.13 apresenta uma situação em que a calibração das câmeras aquáticas apresentou algum desses problemas.

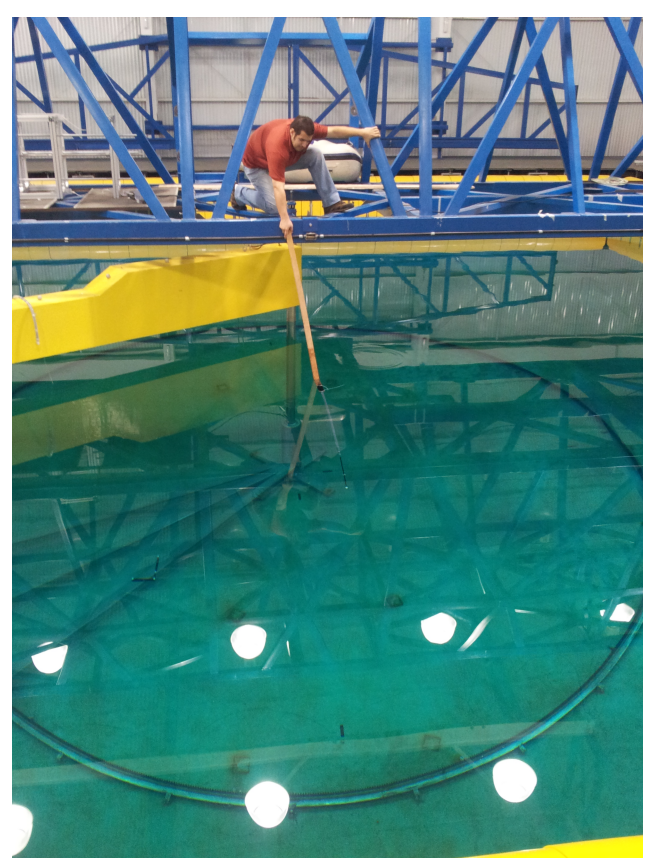

Figura 6.13: Método de calibração das câmeras através de haste com cálibre na ponta.

Independentemente dos eventuais problemas que podem surgir durante a calibração das câmeras, a necessidade de um mergulhador para posicioná-las dentro do tanque é quase imprescindível. A fim de minimizar o tempo de exposição desse profissional ao ambiente imerso do tanque, assim favorecendo um posicionamento mais adequado nas câmeras 
de maneira racional, e buscando a percepção do maior número possível de alvos, foi confeccionada uma rotina numérica capaz de efetuar rotações e translações das câmeras, a partir de suas posições previamente determinadas.

A Figura 6.14 permite a visualização das posições ideais concebidas a partir de uma rotina desenvolvida na presente pesquisa, bem como os campos de visão (regiões coloridas) de cada câmera, evidenciando as regiões em que a linha poderá ser alocada, de maneira que um número maior de alvos possa ser reconhecido e o mergulhador seja menos demandado.

Saliente-se que as posições e ângulos assim determinados são aproximados. Mesmo assim, a quantidade de retrabalho evitada com o uso dessa rotina, bem como o tempo economizado com a montagem do aparato na água, por um mergulhador, se configuram como ganhos consideráveis.

Os dados de entrada da rotina numérica confeccionada para a previsão da posição das câmeras foram obtidos por meio de testes preliminares, conforme ilustra a Figura 6.15. Esses testes tiveram como objetivo a determinação do campo visual de cada câmera e, assim, a definição preliminar do volume de controle a ser utilizado pelo sistema de monitoramento.

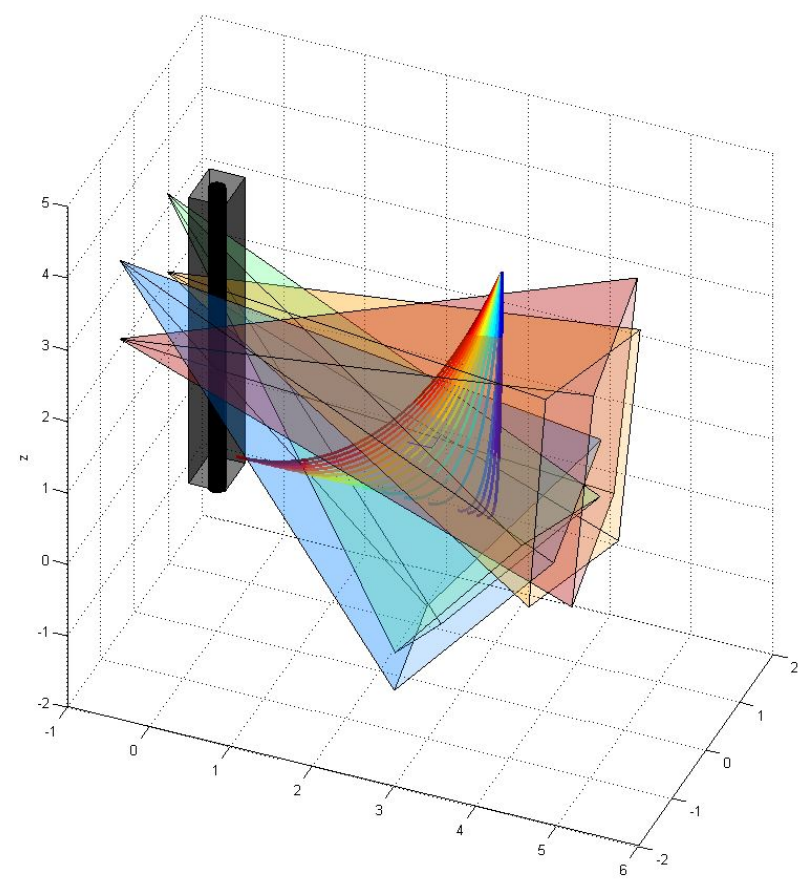

Figura 6.14: Saída da rotina desenvolvida para ajuste do posicionamento prévio das câmeras submersas.

Além disso, a delimitação da região do espaço permite o posicionamento adequado do cálibre e, portanto, torna o processo de calibração das câmeras mais eficaz. 


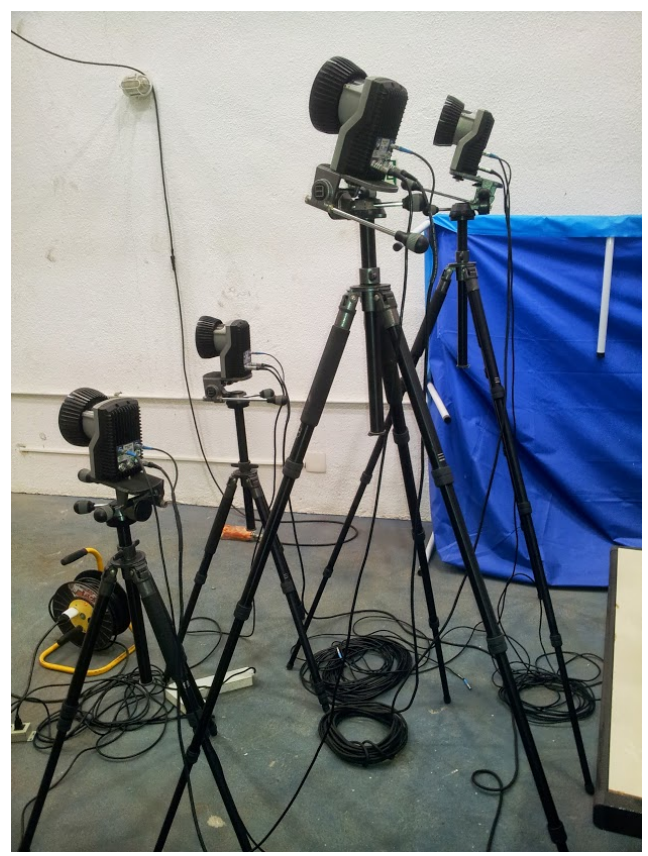

Figura 6.15: Uso do sistema de monitoramento óptico para determinar os campos visuais de cada câmera.

Finalmente, há que se destacar que a rotina numérica gerada possui um potencial uso, dado que diversos grupos de trabalho da Universidade, em particular da Escola Politécnica, e também do IPT, se utilizam desse mesmo sistema de monitoramento e enfrentam, corriqueiramente, dificuldades relativas ao processo de calibração. Assim, essa ferramenta pode ser entendida como um dos ganho secundário da presente pesquisa.

\subsubsection{Demais equipamentos relevantes}

Além da utilização do sistema de rastreamento óptico para monitoramento dos movimentos dos alvos refletivos dispostos ao longo do modelo flexível, outros equipamentos foram instalados para o controle sobre certos parâmetros e acompanhamento das grandezas de interesse dos ensaios.

Dentre os demais equipamentos relevantes empregados detacam-se:

- O sistema de controle da rotação imprimida ao braço giratório;

- O dispositivo para controle da posição vertical do topo do modelo (atuador unidirecional); e

- O bloco de força instalado entre o ponto de fixação do modelo e o atuador (Figura 6.16), com a finalidade de ajustar e monitorar a tração efetiva no topo do modelo flexível. 


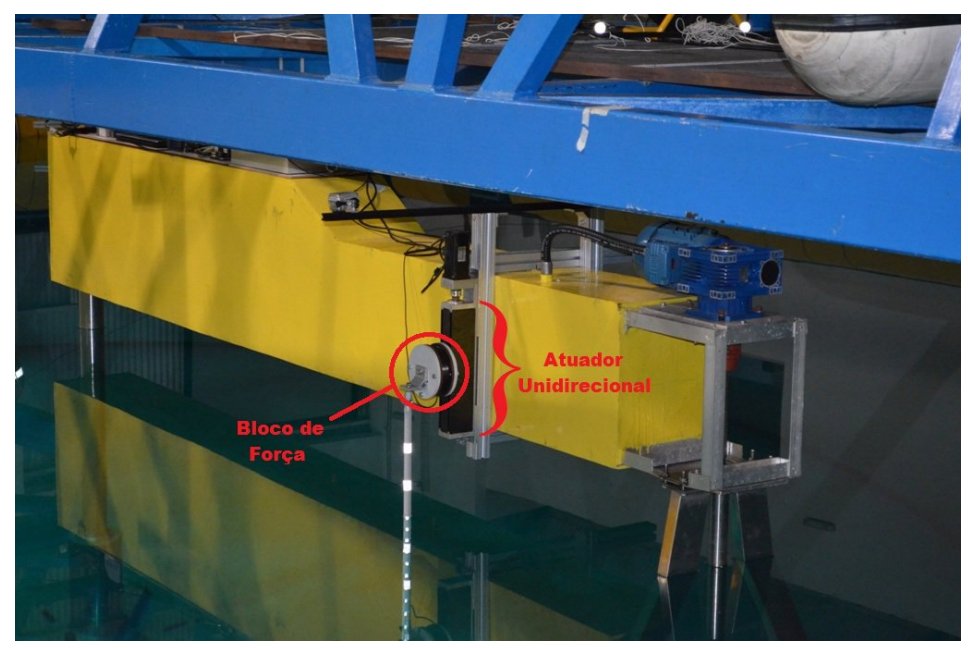

Figura 6.16: Detalhe do bloco de força (seis componentes) montado em conjunto com o atuador unidirecional no topo dos modelos ensaiados.

As medidas de tração foram registradas remotamente, via rede sem fio, por um código específico capaz de gerar arquivos digitais com as séries temporais advindas do bloco de força. Os componentes eletrônicos que permitem o controle e monitoramento desejados foram instalados em uma bancada disposta sobre o braço, portanto, rotacionando solidariamente ao conjunto de dispositivos utilizados em cada ensaio. Detalhes sobre essa montagem pode ser visualizados na Figura 6.17.
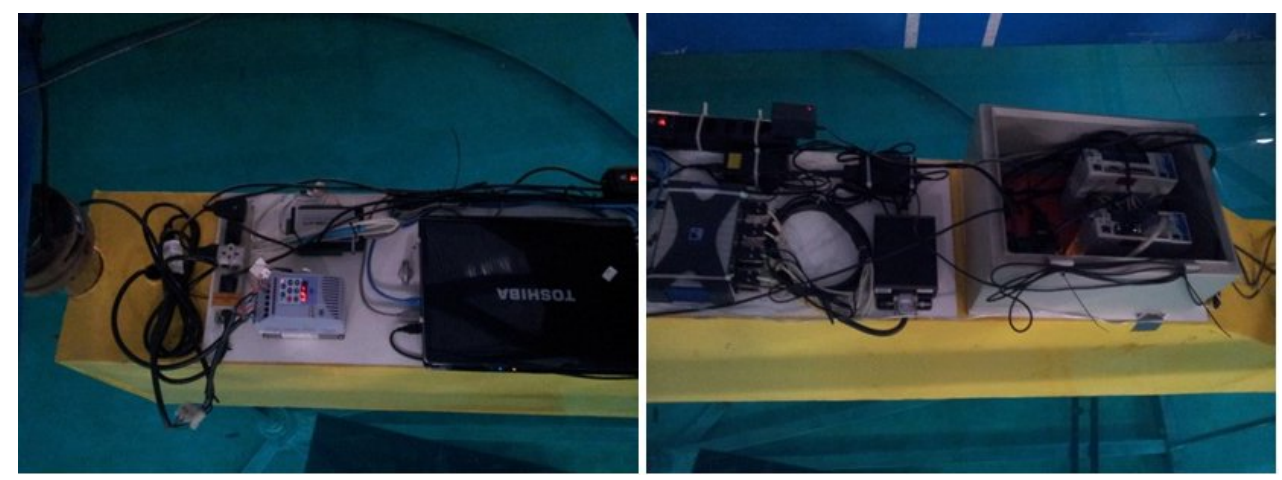

Figura 6.17: Bancada eletrônica embarcada no braço giratório, responsável pelo controle e monitoramento complementar do conjunto de ensaio.

O monitoramento remoto foi possível graças a um computador também instalado na bancada eletrônica montada sobre o braço giratório. Esse computador foi responsável pelo gerenciamento dos vários componentes eletrônicos e pelo monitoramento das informações fornecidas pelo bloco de força.

A escolha pelo embarque dos componentes no braço giratório agilizou os procedimentos dos ensaios, sem perturbar o sistema com modificações manuais, comuns 
quando existe a necessidade de alterações entre os casos avaliados definidos na matriz de ensaios apresentada na seção 6.3. Desta forma, tal estratégia diminuiu eventuais distorções decorrentes das práticas usuais e permitindo que um único operador conduzisse os ensaios, ver Figura 6.18.

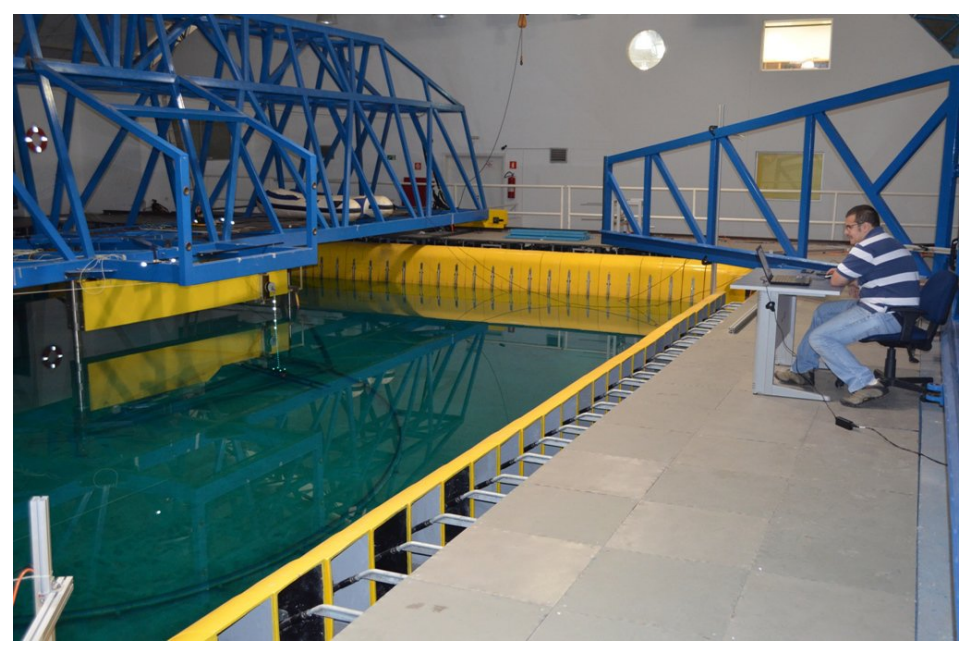

Figura 6.18: Operação e monitoração do ensaio feita remotamente via rede sem-fio.

Conforme mencionado, para a medição e registro das trações foi utilizado um bloco de força de seis componentes (três forças e três momentos). A Figura 6.16 apresenta, em detalhe, a montagem desse bloco solidário ao atuador unidirecional responsável pelo posicionamento vertical da extremidade emersa dos modelos.

Para entender melhor os detalhes da necessidade de utilização dos demais dispositivos, bem como suas respectivas funções, em termos de complementar os recursos anteriormente apresentados, faz-se necessária a apresentação do aparato experimental como um todo, de modo a permitir ao leitor um entendimento mais amplo do conjunto de materiais e equipamentos utilizado, bem como sua relação com o alcance dos objetivos definidos no capítulo 3.

Essa apresentação foi estrategicamente colocada na seção 6.2 a seguir, de sorte que as explicações adicionais estejam intimamente ligadas aos métodos utilizados ao longo desta tese.

\subsection{Métodos}

Mediante os materiais apresentação na seção anterior, é possível depreender que a principal vertente do presente trabalho é a experimental. Entretanto, é necessário entender que formulações analíticas (determinísticas, empíricas e fenomenológicas) e códigos/programas 
foram utilizados para complementar e dar suporte aos ensaios realizados, desde a sua concepção, passando pela sua realização e culminando nas análises e conclusões advindas dos resultados auferidos.

Buscando ilustrar as abordagens utilizadas e a forma como elas se inter- relacionam no encaminhamento dado à presente pesquisa, utilize-se a Figura 6.19, que permite a compreensão das etapas realizadas e do encadeamento lógico existente entre elas. A coluna central, formada por retângulos preenchidos em azul ou verde, configuram-se como o sequenciamento cronológico das tarefas realizadas.

Assim, como primeiro passo, foi realizado o levantamento bibliográfico, imprescindível para a compreensão e análise dos resultados mais adiante apresentados.

A diversidade, a relevância e a profundidade da base de dados levantada são os fatores que permitem entender a pertinência do tema, as formas de abordagem com que ele é tratado, o nível de percepção que se tem do problema em termos físicos e matemáticos e, por fim, depreender o limite do conhecimento com relação ao objeto de pesquisa, também conhecido como "estado da arte". Nesse sentido, comentários adicionais aos que já foram expostos não apresenta, neste momento, efeito prático.

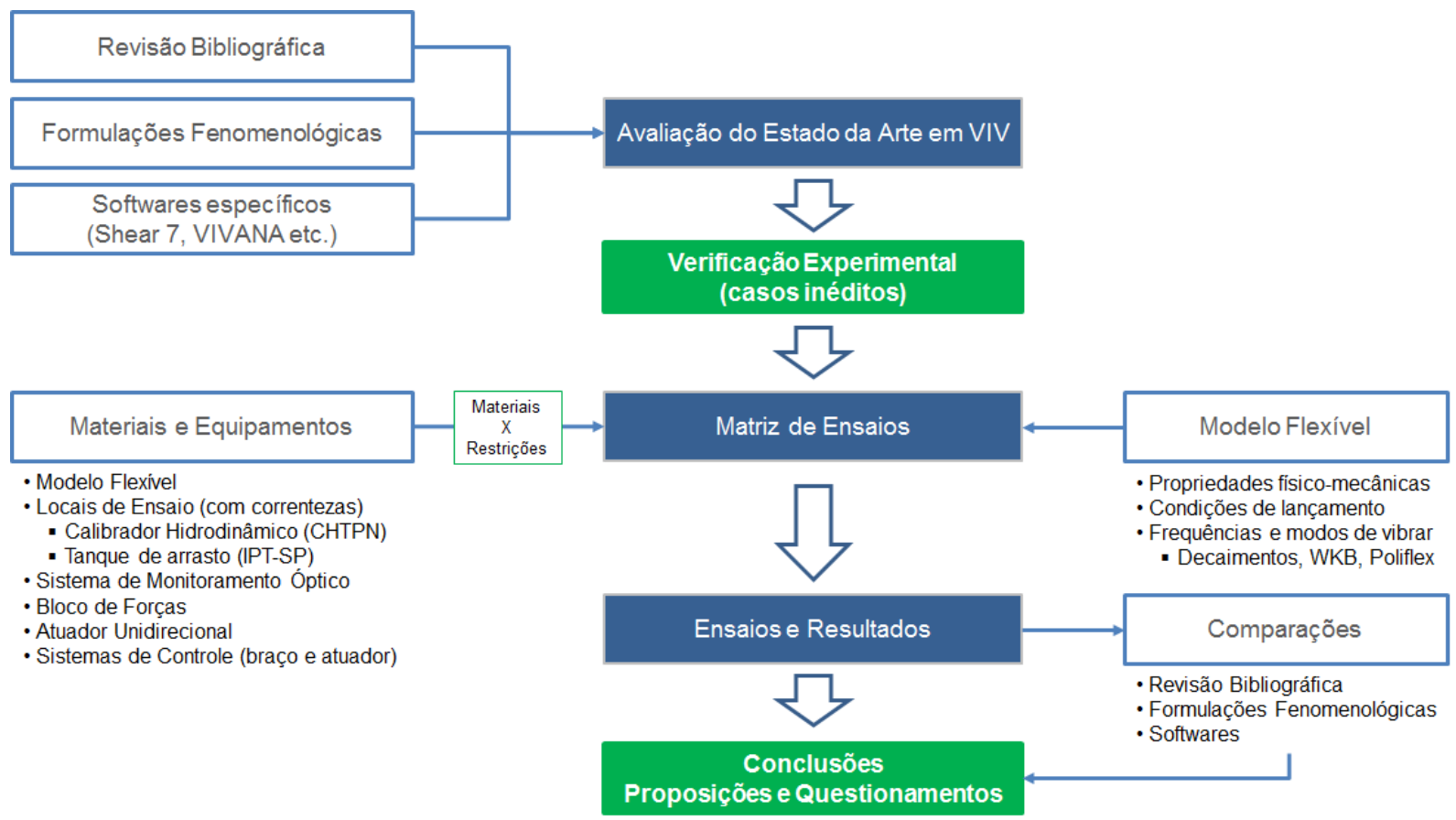

Figura 6.19: Fluxograma de procedimentos, com os materiais e métodos utilizados.

Dado que a principal vertente da presente tese é experimental, foram pesquisados os tipos de ensaios já realizados, buscando juntar um conjunto de informações pertinentes: local de realização, condições de lançamento, tipos de modelos, similaridade com os risers 
ou outras estruturas reais existentes, materiais e métodos empregados, abordagens de análise, códigos utilizados para previsão e, ainda, os pontos pouco explorados ou que carecem investigação.

O conjunto de todas essas informações culminou na delimitação do escopo deste trabalho: a investigação experimental do fenômeno de VIV em linhas flexíveis lançadas em catenária direta, sujeitas a perfis de correnteza variável e ortogonais ao plano de lançamento.

Neste contexo, a escassez de trabalhos e resultados alinhados diretamente com o tema justificam, de per si, seu estudo. A partir dessa definição, o passo seguinte foi a escolha dos materiais e equipamentos a serem utilizados, com vistas às grandezas de interesse, a serem controladas e mensuradas de acordo com descrição feita na seção 6.1.

O intuito do restante desta seção do trabalho é mostrar, de forma sólida e consistente, o encaminhamento das tarefas necessárias à determinação da matriz de ensaios, que é apresentada na seção 6.3 .

\subsubsection{Configurações de lançamento do modelo}

As considerações relativas à determinação das configurações de lançamento do modelo flexível foram divididas em duas partes, visto se tratarem de ensaios realizados em dois locais distintos, cada um deles com suas características e restrições, conforme mencionado e discutido na Seção 6.1.2.

\subsubsection{Configurações de lançamento do modelo no CHTPN}

Conforme mencionado, os experimentos realizados nesta pesquisa foram projetados com foco em duas geometrias de lançamento, a saber: configuração vertical e configuração de catenária direta (quatro geometrias denominadas de Catenária-1, Catenária-2, Catenária3 e Catenária-4.

Como premissas à escolha dessas configurações utilizadas no CHTPN, no entanto, algumas limitações tiveram que ser consideradas, sendo a mais importante delas, relacionada as dimensões do braço giratório, que definiu a distância entre os pontos de ancoragem e topo do modelo, ou raio de lançamento das catenárias.

Assim, embora o raio máximo do braço giratório seja de 3,5m, nas configurações em catenárias direta foi possível contar com uma distância útil de apenas 3,0m entre topo e 
âncora, redução justificada pela dimensão do eixo central e da estrutura trapezoidal de acionamento do braço giratório.

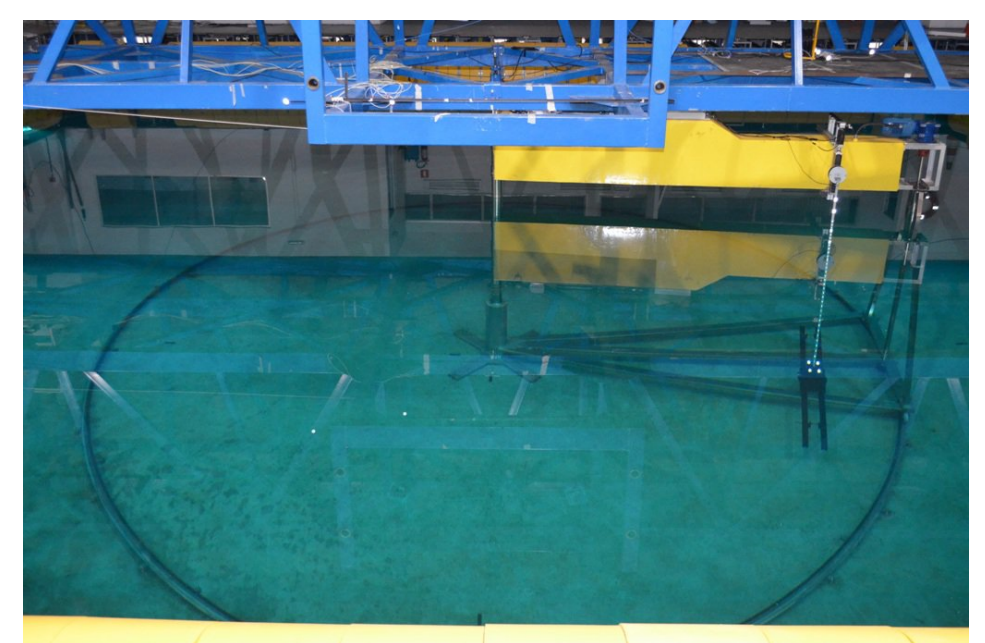

Figura 6.20: Arranjo geral do experimento com a configuração de modelo flexível na vertical.

Para a configuração vertical de lançamento, no entanto, não houve restrição desta natureza. Conforme ilustrado na Figura 6.20, nesta condição, o modelo foi posicionado a uma distância de $3 \mathrm{~m}$ do centro do eixo de rotação do braço giratório.

Por outro lado, no entanto, a verticalidade do lançamento foi garantida pela utilização de um prumo, passível de visualização pela Figura 6.21, posteriormente corroborada pelas imagens geradas pelo sistema de monitoramento óptico. Para essa condição de ensaio foi identificada uma inclinação máxima de aproximadamente $1^{\circ}$ entre a vertical e a reta imaginária ligando as extremidades do modelo (topo e ângora), o que foi considerado dentro das expectativas para as pretensões do experimento de VIV concebido.

Com relação ao sistema de monitoramento por imagens, na Figura 6.22, pode-se ver em detalhe a instalação de duas das câmeras na primeira configuração do arranjo de linha vertical e também para a primeira catenária. A segunda configuração foi um aprimoramento do primeiro arranjo, buscando monitorar um intervalo maior de tempo, o que é imprescindível para avaliar o comportamentodo modelo excitado pelo fenômeno de VIV, ver Figura 6.23. 


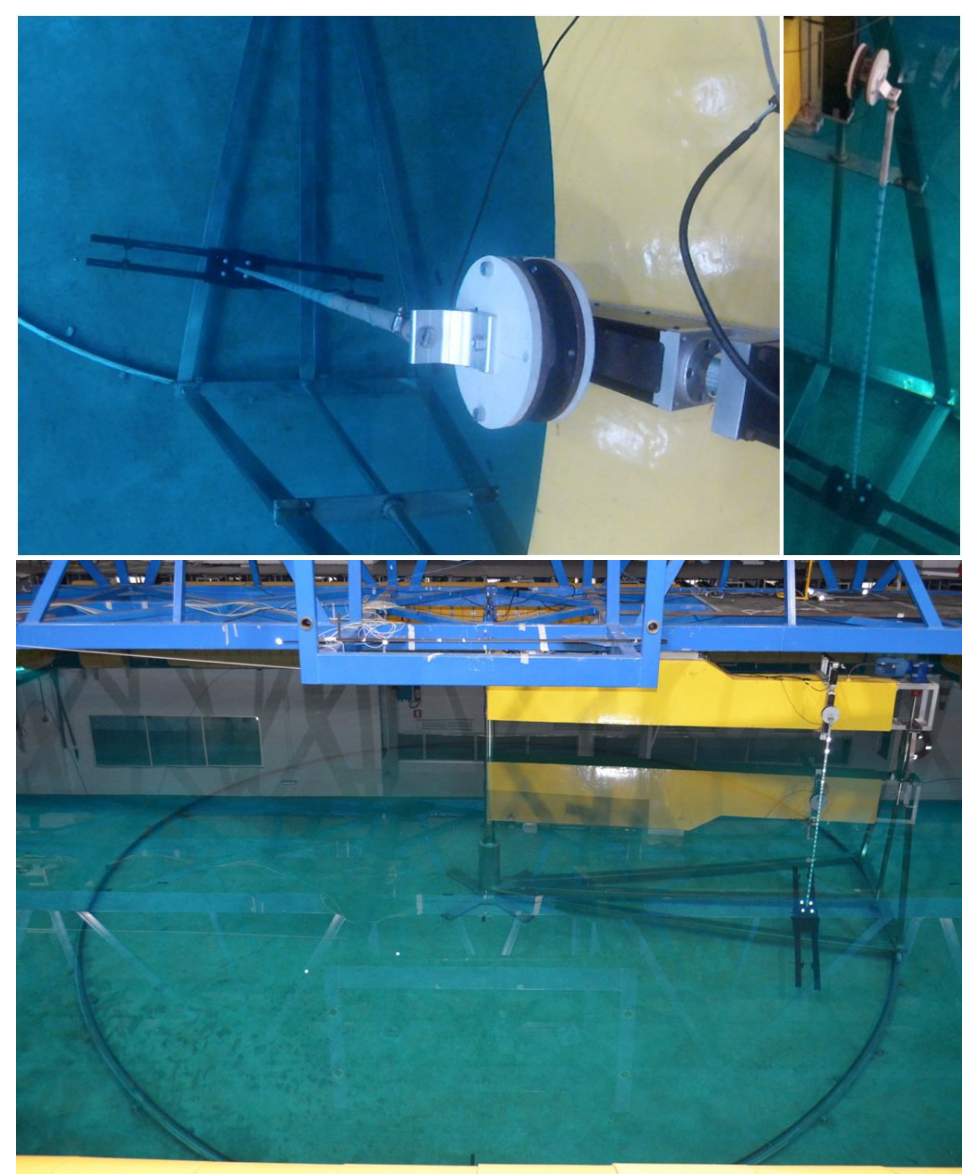

Figura 6.21: Arranjo geral da instalação do modelo vertical no braço giratório.

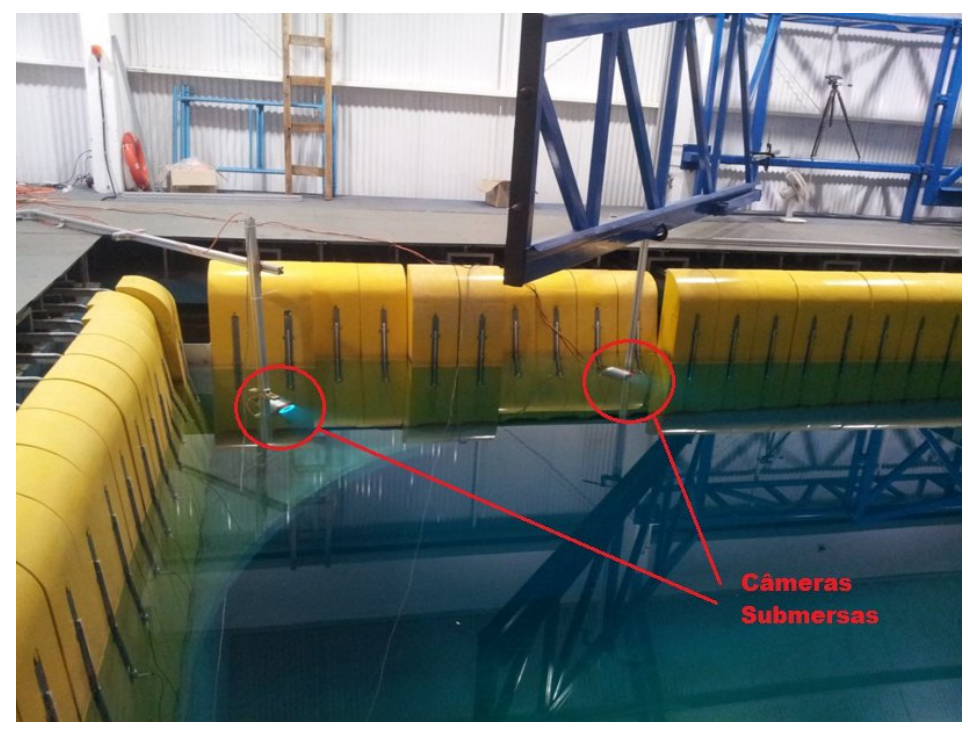

Figura 6.22: Em destaque, duas das cinco câmeras submersas utilizadas na primeira configuração para o monitoramento do movimento do modelo ensaiado no braço giratório. 


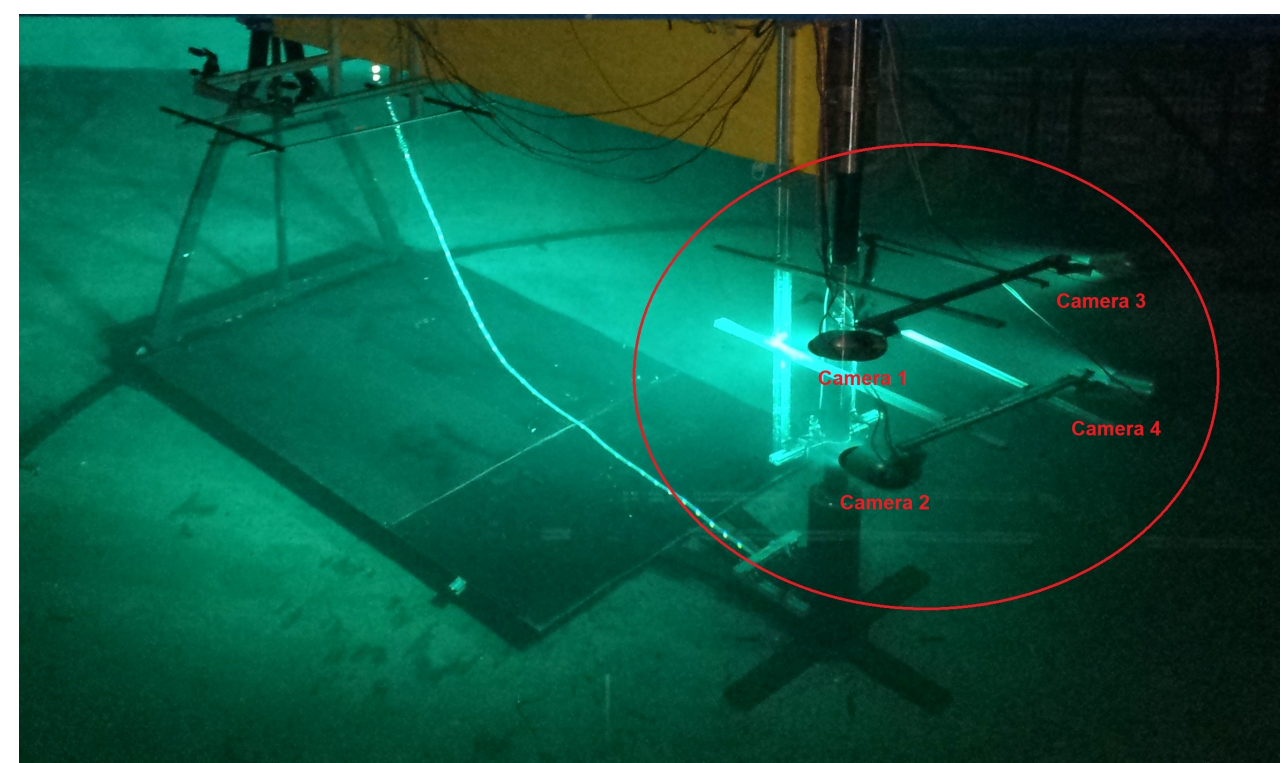

Figura 6.23: Segunda configuração das câmeras submersas, fixas ao eixo central do braço giratório.

A estrutura de ancoragem foi construída com o uso de perfis de alumínio e uma anilha de aço emborrachada com cerca de $10 \mathrm{~kg}$, com o objetivo de garantir o posicionamento da extremidade inferior do modelo, sem a necessidade de elementos de fixação na estrutura inferior imersa do carro.

Em todas as configurações, conforme mencionado, é possível notar que o atuador unidirecional acoplado ao topo permitiu o posicionamento inicial da extremidade superior, permitindo os ajustes para a definição da condição geométrica desejada.

Além dos ajustes no topo, nas configurações em catenárias como, por exemplo, aquela ilustrada na Figura 6.24, a mudança na posição da âncora também foi decisiva na definição da geometria estática. Modificações na posição da âncora, alteram o raio de lançamento, no entanto, sem que a velocidade de correnteza máxima, no topo do modelo, varie substancialmente. 


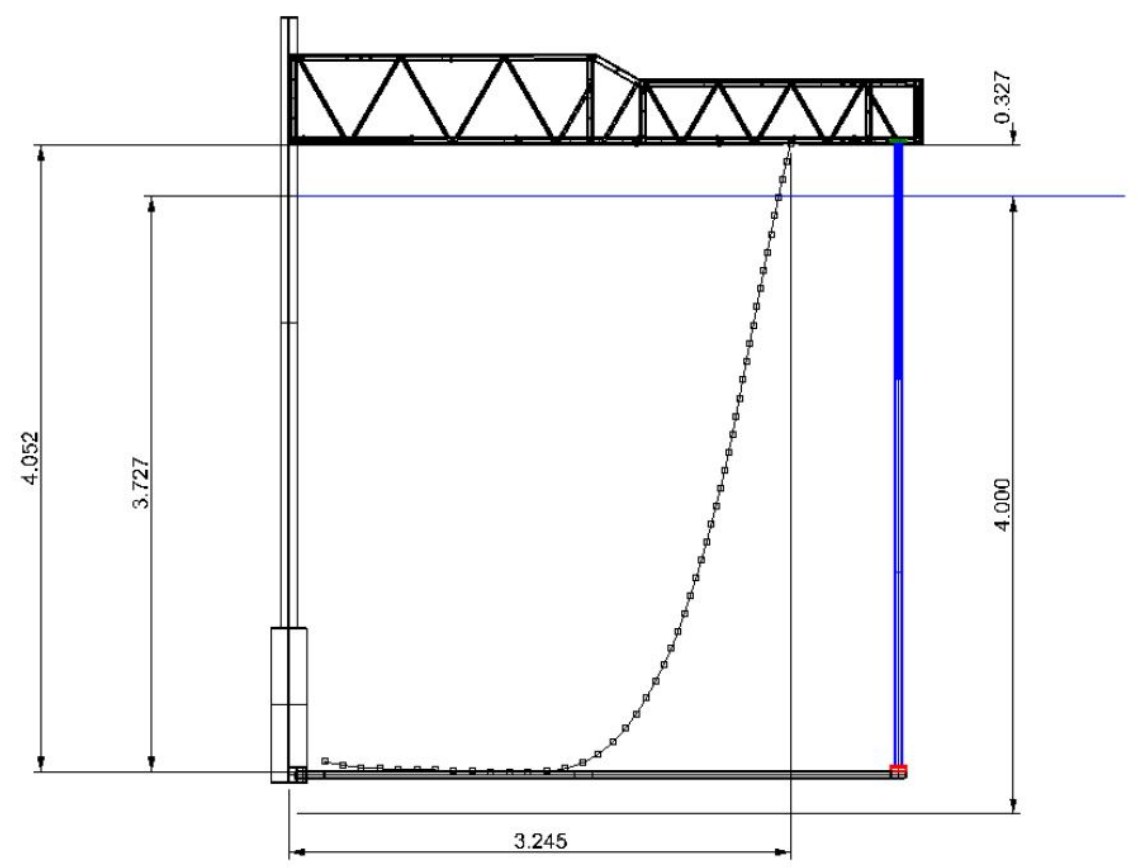

Figura 6.24: Características dimensionais da primeira catenária, ou Catenária-1.

A Figura 6.25, por sua vez, ilustra mais uma das catenárias instaladas no braço giratório. Note o "fundo falso" junto à extremidade inferior, construído a partir de placas de PVC sobre a estrutura inferior do braço giratório, o que aumenta a possibilidade de passeio do TDP, além de facilitar as alterações na posição da âncora. Ver também Figura 6.26 .

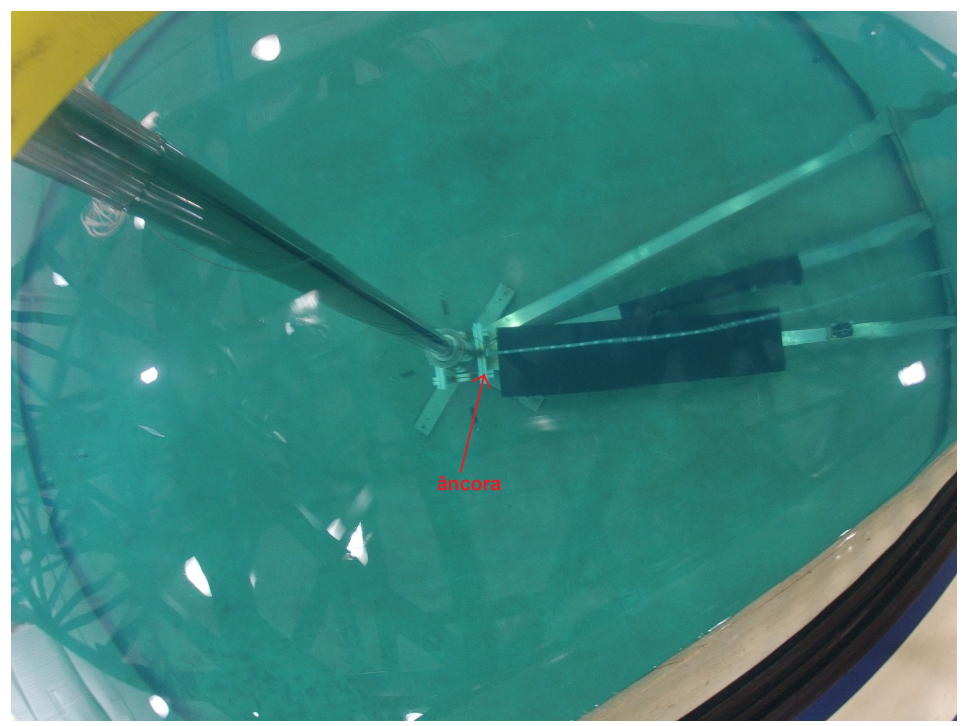

Figura 6.25: Detalhe do posicionamento da âncora próxima ao eixo central do braço giratório. 


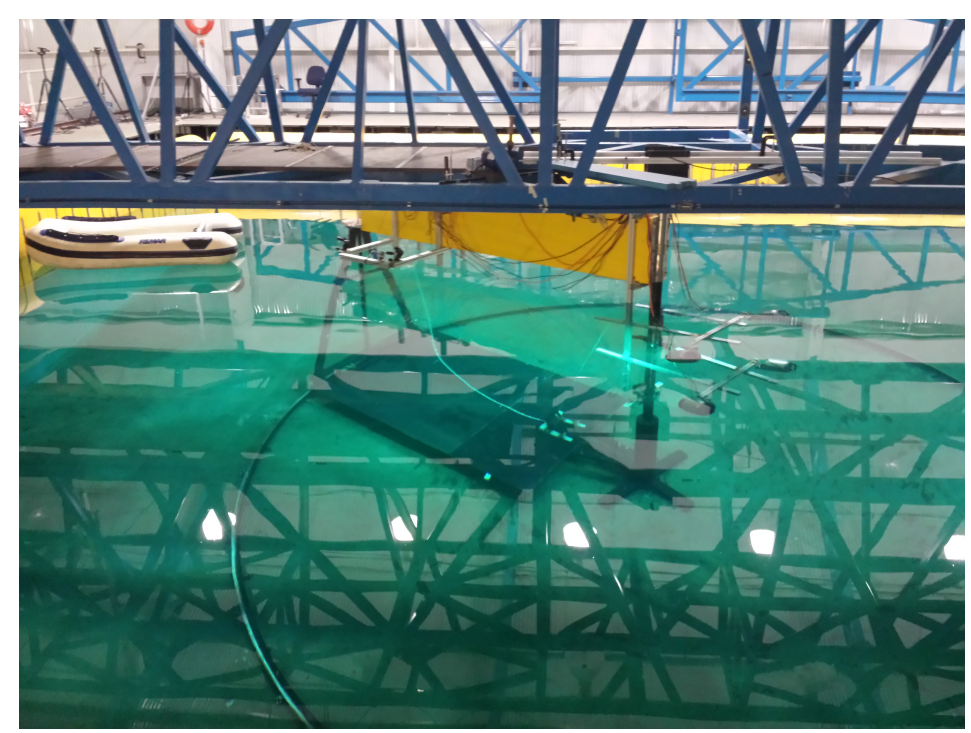

Figura 6.26: Arranjo geral do experimento com as câmeras posicionadas depois do eixo central e fundo falso em toda estrutura inferior do braço- giratório.

Na Figura 6.27 se pode ter uma visão geral do modelo lançado na configurção de Catenária-4, bem como da estrutura que suporta a âncora, "fundo falso". Note que na parte superior esquerda dessa figura também é possível identificar uma das câmeras submersas posicionadas no eixo central do braço giratório.

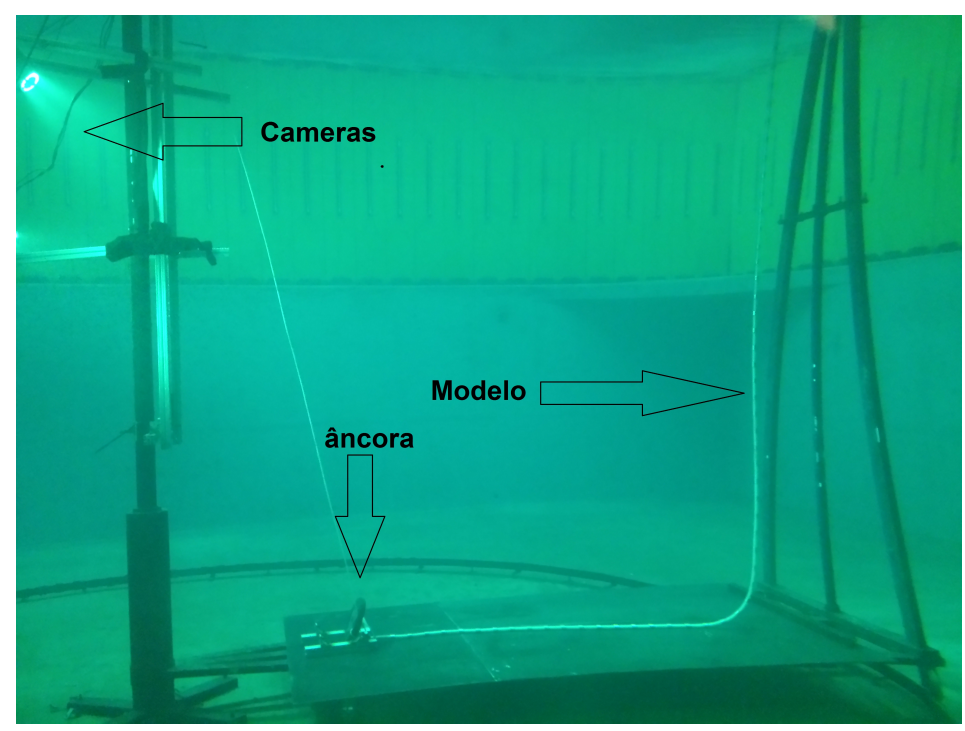

Figura 6.27: Arranjo geral do experimento na condição de lançamento da Catenária-4. 

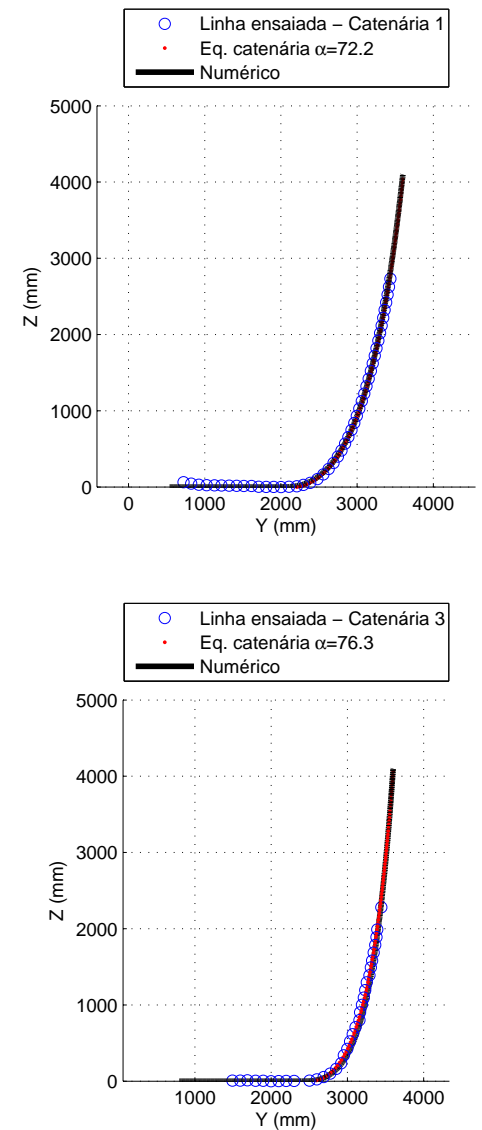
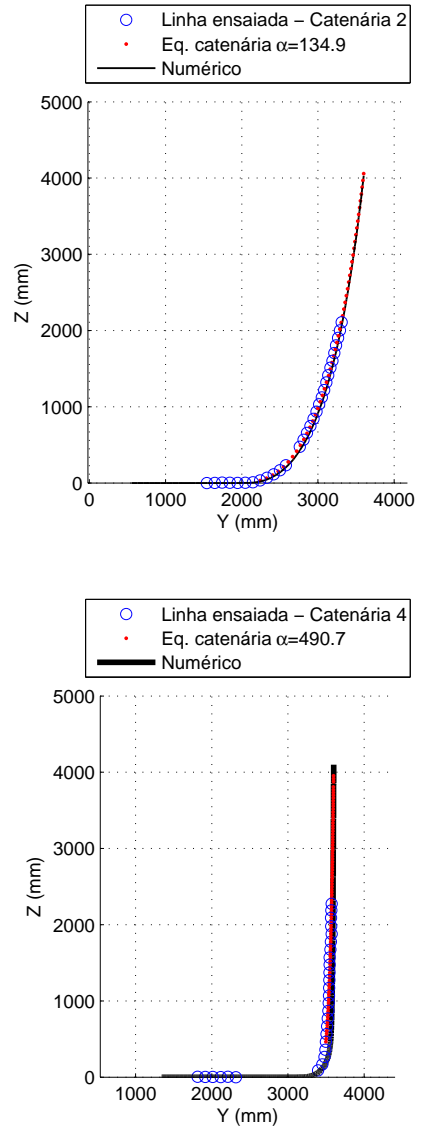

Figura 6.28: Comparação dos arranjos de catenária ensaiadas no braço giratório do

CHTPN. Em azul, a representação dos alvos reconhecidos pelo sistema de monitoramento óptico. Nomenclatura dos arranjos: acima, à esquerda, Catenária-1; acima, à direita, Catenária-2; abaixo, à esquerda, Catenária-3; abaixo, à direita, Catenária-4. Configurações de lançamento em ordem crescente do ângulo de saída no topo.

A variação entre as configurações da linha lançada em catenária pode ser visualizada na Figura 6.28. Note que, conforme descrição anteriormente, mediante a variação do ponto de ancoragem e a manutenção aproximada da posição do topo, o ângulo de topo em relação a horizontal foi variado na faixa $83,5^{\circ} \leq \theta_{0} \leq 90^{\circ}$, resultando em uma variação da frequência natural do primeiro modo de $0,03 \mathrm{~Hz}$ a $0,04 \mathrm{~Hz}$, respectivamente na Catenária-1 e Catenária-4. Na Tabela 6.5 pode ser vista a condição inicial de cada uma das catenárias. 
Tabela 6.5: Propriedades dos arranjos de catenárias realizados no CH-TPN

\begin{tabular}{|c|c|c|c|c|c|}
\hline Arranjo & $\theta_{\text {Topo }}$ & $T_{0}(N)$ & $L(m)$ & No. De alvos & \\
\hline Catenária-1 & 83,5 & $3,60 \mathrm{E}+06$ & 446,6 & 30 & \\
\hline Catenária-2 & 83,4 & $3,43 \mathrm{E}+06$ & 444,5 & 30 & * Valores apresentados na escala \\
\hline Catenária-3 & 86,2 & $2,61 \mathrm{E}+06$ & 434,2 & 29 & \\
\hline Catenária-4 & 89,8 & $7,10 \mathrm{E}+05$ & 379,6 & 23 & \\
\hline
\end{tabular}

\subsubsection{Configurações de lançamento do modelo no tanque do IPT}

Os ensaios realizados no tanque de reboque do IPT foram monitorados por um sistema óptico semelhante ao utilizado no CHTPN, conforme pode ser visualizado na Figura 6.29.

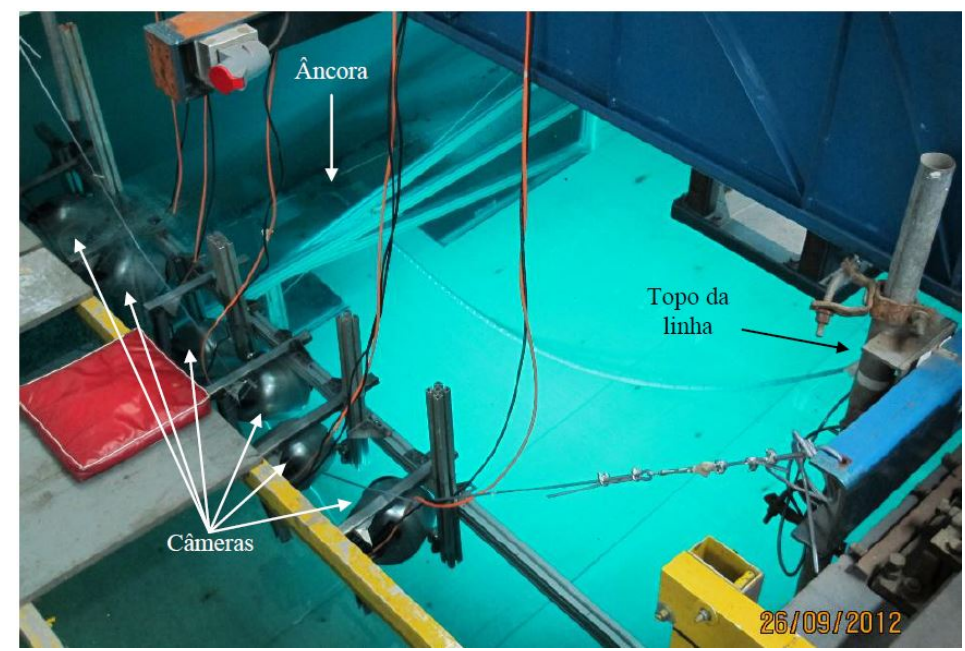

Figura 6.29: Sistema de câmeras submersas utilizado para a monitoração da Catenária-5, ensaiada no IPT.

Os experimentos, realizados com o mesmo modelo de linha flexível em catenária, ocorreram sob velocidade incidente constante, dado que o modelo foi instalado e rebocado no plano transversal à direção longitudinal do tanque do IPT.

A Figura 6.30, por sua vez, apresentada um esquema do arranjo experimental da Catenária-5 ensaiada sob correnteza transversal no tanque de reboque do IPT. Foram monitorados 33 alvos, sendo que quatro deles estavam fora da água. Portanto, foram utilizados dois sistemas de monitoramento óptico: um aéreo, outro submerso. 

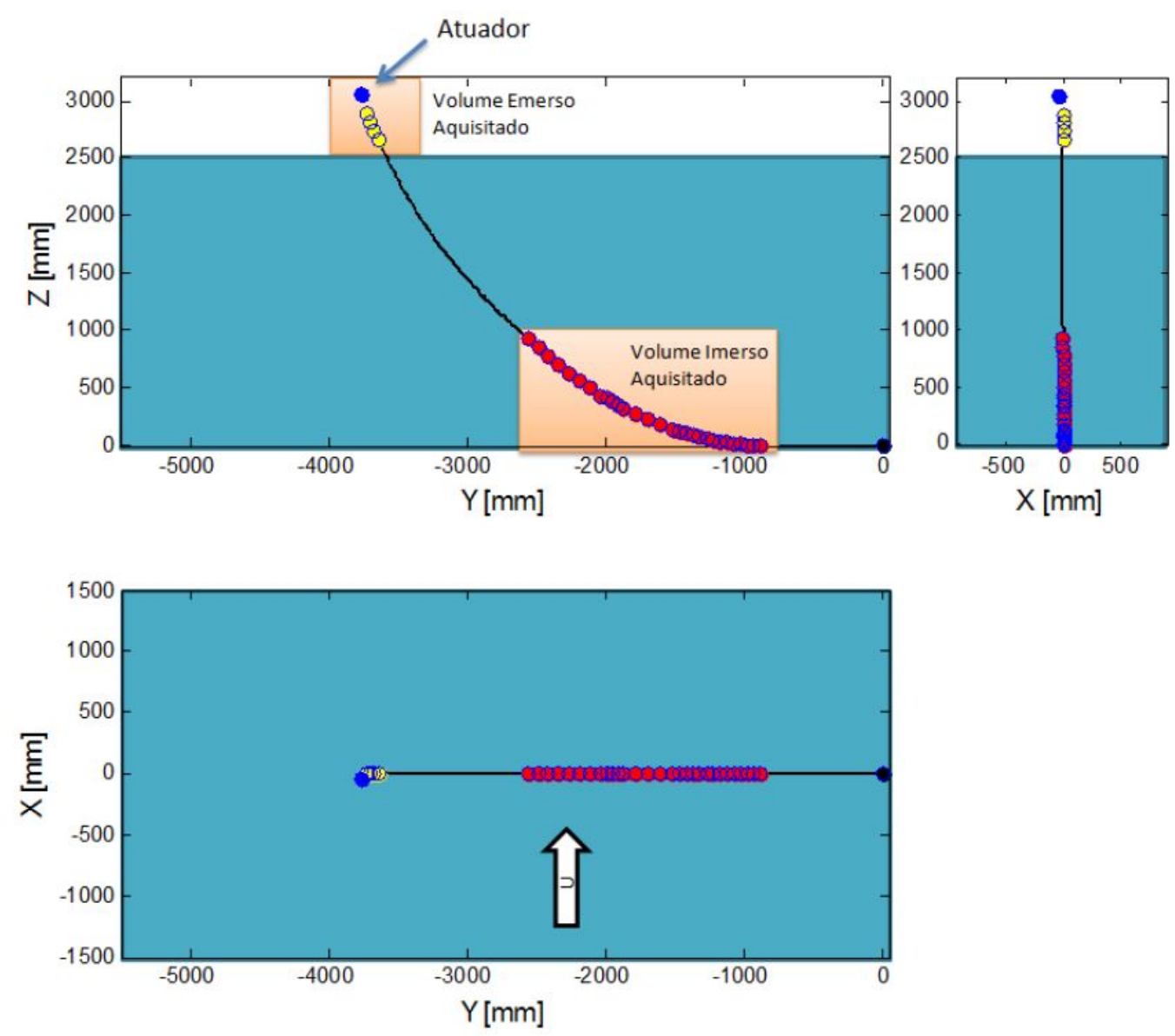

Figura 6.30: Arranjo da Catenária-5 ensaiada em correnteza transversal no tanque de reboque do IPT, extraído de [PETROBRAS \& LMO, 2013].

Tabela 6.6: Características dimensionais da Catenária-5, ensaiada no IPT.

\begin{tabular}{lc}
\hline Raio de lançamento & $3,730 \mathrm{~m}$ \\
Lâmina d'água & $2,500 \mathrm{~m}$ \\
Distância vertical emersa & $0,382 \mathrm{~m}$ \\
Ângulo de saída no topo & $68,1^{\circ}$ \\
Comprimento da linha & $5,080 \mathrm{~m}$ \\
Massa total da linha & $5,715 \mathrm{~kg}$ \\
\hline
\end{tabular}

Já a Tabela 6.6 sintetiza as principais característica geométricas da Catenária-5, rebocada na transversal do tanque de provas do IPT. Importante mencionar que, os ensaios realizados no IPT fizeram parte de um projeto de pesquisa contratado pela Petrobras junto ao Laboratório de Mecânica Offshore (LMO) da USP, compreendendo uma campanha muito mais ampla, da qual a presente tese utilizou como elemento de comparação apenas de uma de suas configurações de ensaio. Maiores detalhes com 
relação àquela campanha podem ser obtidos em [PETROBRAS \& LMO, 2013].

\subsubsection{Ensaios preliminares para caracterização do modelo}

Na seção 6.1, item 6.1.1, foram apresentadas as principais características do modelo flexível utilizado nos ensaios contemplados neste trabalho.

Entretanto, além das informações destacadas anteriormente, foi necessária a realização de ensaios específicos para determinação das frequências naturais do modelo utilizado, dado que essas são de importância vital para o estudo mais adiante descrito.

Para tanto, foram conduzidos ensaios de decaimento, onde a linha, nas diferentes condições de lançamento, foi submetida à aplicação controlada de perturbações a partir de sua condição inicial de equilíbrio, com a medição concomitante da série temporal de oscilações livres amortecidas. Mediante várias condições de excitação (distintas em posição ao longo da linha e intensidade da perturbação), buscou-se identificar o maior número de frequências naturais da estrutura.

Um exemplo da aplicação desse tipo de perturbação, deslocamento lateral da condição inicial de equilíbrio (com o uso de uma haste rígida), é ilustrado na Figura 6.31.

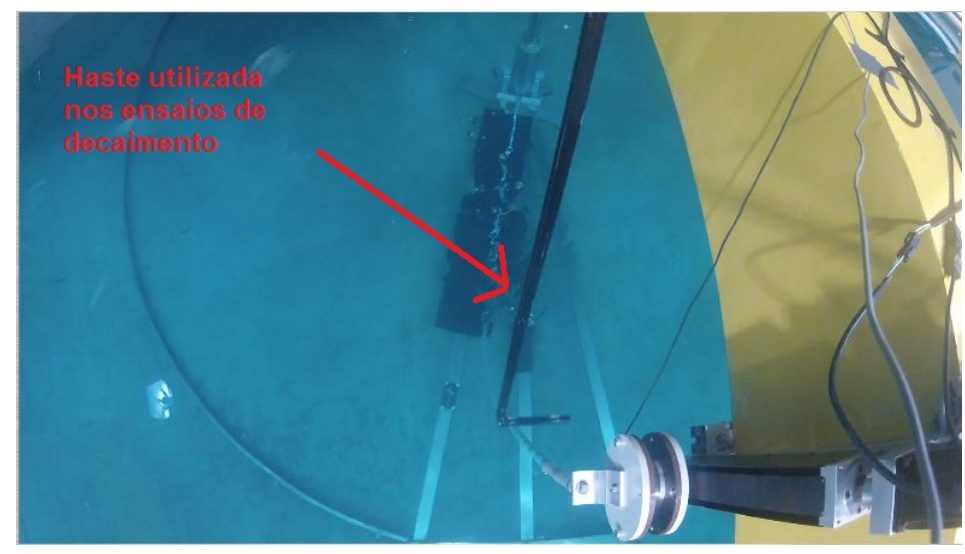

Figura 6.31: Exemplo de ensaio de decaimento para a determinação das frequências naturais de um dos arranjos de lançamento do modelo, no caso, o vertical.

As Figuras 6.32 e 6.33 ilustram gráficos dos ensaios de decaimento, analisados segundo procedimento mais adiante comentado. 

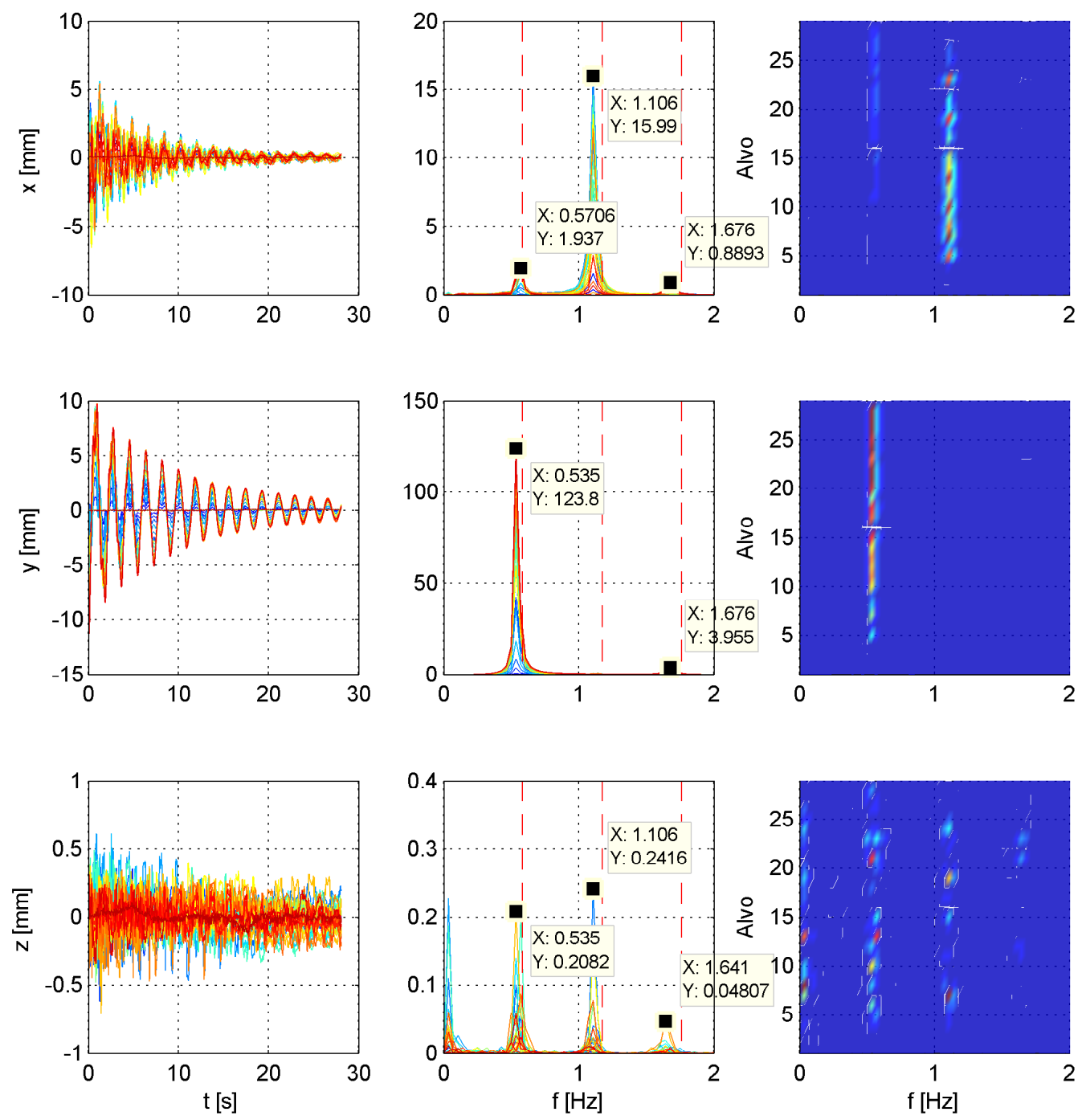

Figura 6.32: Identificação das frequências naturais a partir do deslocamento dos alvos do ensaio de decaimento para a condição Vertical.

As linhas tracejadas vermelhas são as definições de frequência natural segundo funções de Bessel, apresentadas na equação (4.16). Além das frequências também podem ser obtidos os coeficientes de amortecimento, via ajuste de envoltórias aos sinais de decaimento. 

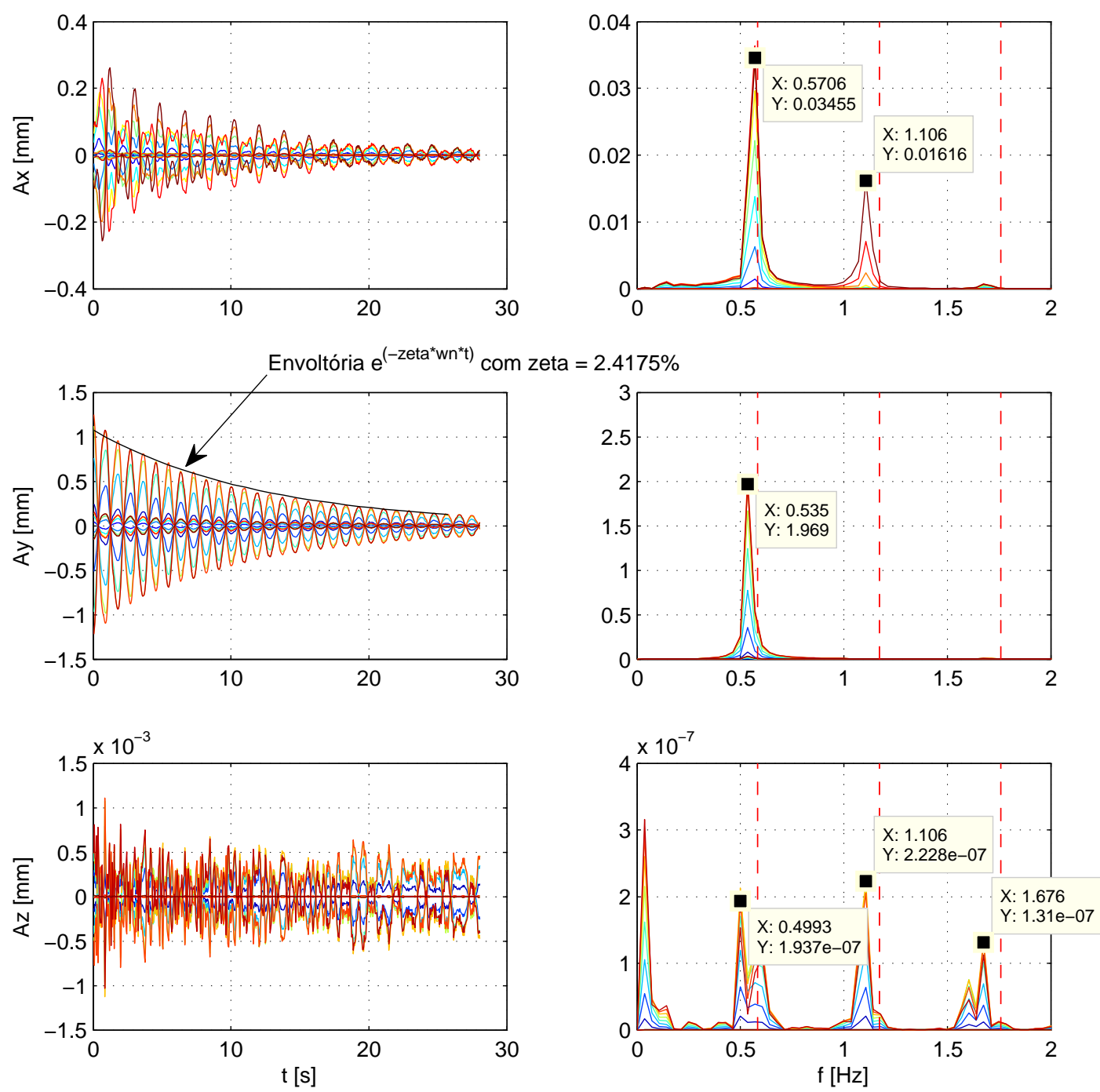

Figura 6.33: Identificação das frequências naturais a partir das amplitudes modais obtidas de decaimento para a condição Vertical. 


\subsection{Matrizes de Ensaios}

Apresentados os materiais e métodos utilizados para o alcance dos objetivos experimentais desta tese, apresentam-se os casos ensaiados nas 6 geometrias de lançamento descritas, apresentados na forma de matrizes de ensaios. concebidas.

Portanto, segundo um descrição geral, para a avaliação experimental das linhas flexíveis em perfis de correnteza ortogonais, foram realizados ensaios segundo 4 baterias, a saber:

- 1a. bateria de ensaios - Linha flexível vertical no braço giratório;

- 2a. bateria de ensaios - Linha flexível em catenária no braço giratório;

- 3a. bateria de ensaios - Linha flexível em catenária no braço giratório com variação do TDP;

- 4a. bateria de ensaios - Linha flexível em catenária no tanque de reboque.

As duas primeiras baterias de ensaios foram realizadas com o sistema de aquisição óptico posicionado nas paredes do CHTPN (Figura 6.22). Esse arranjo, apesar de ter se demonstrado viável, afeta sobremaneira o monitoramento da série temporal, já que, nos instantes em que as estruturas do braço giratório se interpunham entre o modelo e as câmeras, ocorria a oclusão parcial dos alvos.

Para determinar a faixa de velocidades a serem ensaiadas, foram estimadas as velocidades reduzidas $V_{r}$ nos respectivos primeiros modos excitados. Com as primeiras frequências naturais bem definidas, foi possível construir uma matriz de ensaio que incorporasse as regiões de interesse de observação do fenômeno de VIV, de sorte que, para todos os arranjos avaliados, as velocidades reduzidas variaram dentro de uma faixa muito ampla, dependente do valor das primeiras frequências naturais passíveis de excitação..

A Tabela 6.7 apresenta as velocidades ortogonais máximas ensaiadas para o modelo lançado verticalmente no $\mathrm{CHTPN}$, bem como as velocidades reduzidas para os quatro primeiros modos de vibrar $\left(V_{r n}, \operatorname{com} n=1,2,3,4\right)$.

Note que a velocidade máxima que o braço giratório pode atingir não permite a excitação de toda a faixa de sincronização do $3^{\circ}$ e $4^{o}$ modos. Ainda assim, o ensaio foi bastante efetivo, permitindo a obtenção de resultados extremamente valiosos, além da consequente validação do braço giratório como equipamento importante nesta pesquisa. 
As Tabelas 6.8, 6.9, 6.10 e 6.11 apresentam as velocidades angulares utilizadas nos ensaios com as Catenárias-1, -2, -3 e -4, também ensaiadas no CHTPN. Note que a velocidade máxima do braço giratório permitiu a excitação de toda a faixa de sincronização do $6^{\circ}$ modo natural ( $3^{\circ}$ modo natural de vibração da catenária em seu plano de lançamento).

Importante destacar que as velocidades apresentadas nas tabelas se referem às maiores velocidades dos perfis de correnteza variável, ou seja, a velocidade do topo das catenárias. Cabe ressaltar também que, para o cálculo das velocidades reduzidas, foram utilizadas as frequências naturais identificadas nos ensaios de decaimento. 
Tabela 6.7: Matriz de ensaios para o arranjo Vertical, realizada no braço giratório do CHTPN.

\begin{tabular}{|c|c|c|c|c|c|c|c|c|}
\hline Nome do arquivo & $\Omega_{\text {angular }}(\mathrm{rad} / \mathrm{s})$ & $U_{\max }(\mathrm{m} / \mathrm{s})$ & $V r_{1}$ & $V r_{2}$ & $V r_{3}$ & $V r_{4}$ & $V r_{5}$ & $V r_{6}$ \\
\hline Vertical1-1.mat & 0,163 & 0,522 & 4,029 & 4,029 & 2,006 & 2,006 & 1,336 & 1,336 \\
\hline Vertical1-2.mat & 0,180 & 0,575 & 4,441 & 4,441 & 2,211 & 2,211 & 1,473 & 1,473 \\
\hline Vertical1-3.mat & 0,196 & 0,627 & 4,840 & 4,840 & 2,410 & 2,410 & 1,605 & 1,605 \\
\hline Vertical1-4.mat & 0,212 & 0,679 & 5,244 & 5,244 & 2,610 & 2,610 & 1,739 & 1,739 \\
\hline Vertical1-5.mat & 0,227 & 0,727 & 5,617 & 5,617 & 2,796 & 2,796 & 1,863 & 1,863 \\
\hline Vertical1-6.mat & 0,243 & 0,779 & 6,013 & 6,013 & 2,993 & 2,993 & 1,994 & 1,994 \\
\hline Vertical1-7.mat & 0,259 & 0,829 & 6,404 & 6,404 & 3,188 & 3,188 & 2,124 & 2,124 \\
\hline Vertical1-8.mat & 0,274 & 0,878 & 6,784 & 6,784 & 3,377 & 3,377 & 2,249 & 2,249 \\
\hline Vertical1-9.mat & 0,291 & 0,930 & 7,183 & 7,183 & 3,576 & 3,576 & 2,382 & 2,382 \\
\hline Vertical1-10.mat & 0,307 & 0,981 & 7,575 & 7,575 & 3,771 & 3,771 & 2,512 & 2,512 \\
\hline Vertical1-11.mat & 0,322 & 1,032 & 7,968 & 7,968 & 3,967 & 3,967 & 2,642 & 2,642 \\
\hline Vertical1-12.mat & 0,338 & 1,082 & 8,358 & 8,358 & 4,161 & 4,161 & 2,771 & 2,771 \\
\hline Vertical1-13.mat & 0,354 & 1,133 & 8,748 & 8,748 & 4,355 & 4,355 & 2,901 & 2,901 \\
\hline Vertical1-14.mat & 0,370 & 1,185 & 9,155 & 9,155 & 4,558 & 4,558 & 3,036 & 3,036 \\
\hline Vertical1-15.mat & 0,386 & 1,234 & 9,531 & 9,531 & 4,745 & 4,745 & 3,160 & 3,160 \\
\hline Vertical1-16.mat & 0,401 & 1,284 & 9,918 & 9,918 & 4,937 & 4,937 & 3,289 & 3,289 \\
\hline Vertical1-17.mat & 0,417 & 1,334 & 10,304 & 10,304 & 5,129 & 5,129 & 3,417 & 3,417 \\
\hline Vertical1-18.mat & 0,433 & 1,384 & 10,692 & 10,692 & 5,322 & 5,322 & 3,545 & 3,545 \\
\hline Vertical1-19.mat & 0,448 & 1,435 & 11,081 & 11,081 & 5,516 & 5,516 & 3,674 & 3,674 \\
\hline Vertical1-20.mat & 0,464 & 1,485 & 11,472 & 11,472 & 5,711 & 5,711 & 3,804 & 3,804 \\
\hline Vertical1-21.mat & 0,480 & 1,535 & 11,858 & 11,858 & 5,903 & 5,903 & 3,932 & 3,932 \\
\hline Vertical1-23.mat & 0,513 & 1,641 & 12,674 & 12,674 & 6,309 & 6,309 & 4,203 & 4,203 \\
\hline Vertical1-22.mat & 0,513 & 1,642 & 12,681 & 12,681 & 6,313 & 6,313 & 4,205 & 4,205 \\
\hline Vertical1-24.mat & 0,528 & 1,689 & 13,041 & 13,041 & 6,492 & 6,492 & 4,324 & 4,324 \\
\hline Vertical1-25.mat & 0,544 & 1,740 & 13,439 & 13,439 & 6,690 & 6,690 & 4,456 & 4,456 \\
\hline Vertical1-26.mat & 0,559 & 1,790 & 13,827 & 13,827 & 6,883 & 6,883 & 4,585 & 4,585 \\
\hline Vertical1-27.mat & 0,575 & 1,840 & 14,213 & 14,213 & 7,075 & 7,075 & 4,713 & 4,713 \\
\hline Vertical1-28.mat & 0,591 & 1,892 & 14,609 & 14,609 & 7,272 & 7,272 & 4,844 & 4,844 \\
\hline Vertical1-29.mat & 0,607 & 1,941 & 14,993 & 14,993 & 7,464 & 7,464 & 4,972 & 4,972 \\
\hline Vertical1-30.mat & 0,623 & 1,994 & 15,403 & 15,403 & 7,668 & 7,668 & 5,107 & 5,107 \\
\hline Vertical1-31.mat & 0,639 & 2,046 & 15,799 & 15,799 & 7,865 & 7,865 & 5,239 & 5,239 \\
\hline Vertical1-32.mat & 0,656 & 2,098 & 16,200 & 16,200 & 8,065 & 8,065 & 5,372 & 5,372 \\
\hline Vertical1-33.mat & 0,672 & 2,149 & 16,599 & 16,599 & 8,263 & 8,263 & 5,504 & 5,504 \\
\hline Vertical1-34.mat & 0,686 & 2,197 & 16,964 & 16,964 & 8,445 & 8,445 & 5,625 & 5,625 \\
\hline Vertical1-35.mat & 0,707 & 2,261 & 17,465 & 17,465 & 8,694 & 8,694 & 5,791 & 5,791 \\
\hline Vertical1-36.mat & 0,722 & 2,312 & 17,853 & 17,853 & 8,888 & 8,888 & 5,920 & 5,920 \\
\hline Vertical1-37.mat & 0,738 & 2,360 & 18,229 & 18,229 & 9,074 & 9,074 & 6,044 & 6,044 \\
\hline Vertical1-38.mat & 0,754 & 2,414 & 18,645 & 18,645 & 9,282 & 9,282 & 6,182 & 6,182 \\
\hline Vertical1-39.mat & 0,771 & 2,468 & 19,057 & 19,057 & 9,487 & 9,487 & 6,319 & 6,319 \\
\hline Vertical1-40.mat & 0,789 & 2,525 & 19,501 & 19,501 & 9,708 & 9,708 & 6,466 & 6,466 \\
\hline Vertical1-41.mat & 0,804 & 2,573 & 19,871 & 19,871 & 9,892 & 9,892 & 6,589 & 6,589 \\
\hline Vertical1-42.mat & 0,819 & 2,621 & 20,245 & 20,245 & 10,078 & 10,078 & 6,713 & 6,713 \\
\hline Vertical1-45.mat & 0,868 & 2,778 & 21,456 & 21,456 & 10,681 & 10,681 & 7,115 & 7,115 \\
\hline Vertical1-46.mat & 0,881 & 2,819 & 21,774 & 21,774 & 10,839 & 10,839 & 7,220 & 7,220 \\
\hline Vertical1-47.mat & 0,896 & 2,868 & 22,147 & 22,147 & 11,025 & 11,025 & 7,344 & 7,344 \\
\hline Vertical1-49.mat & 0,931 & 2,980 & 23,013 & 23,013 & 11,456 & 11,456 & 7,631 & 7,631 \\
\hline Vertical1-50.mat & 1,026 & 3,284 & 25,359 & 25,359 & 12,624 & 12,624 & 8,409 & 8,409 \\
\hline
\end{tabular}


Tabela 6.8: Matriz de ensaios para o arranjo Catenaria-1, realizada no braço giratório do CHTPN.

\begin{tabular}{|c|c|c|c|c|c|c|c|c|}
\hline Nome do arquivo & $\Omega_{\text {angular }}(\mathrm{rad} / \mathrm{s})$ & $U_{\max }(m / s)$ & $V r_{1}$ & $V r_{2}$ & $V r_{3}$ & $V r_{4}$ & $V r_{5}$ & $V r_{6}$ \\
\hline Catenaria1-1.mat & 0,161 & 0,483 & 6,990 & 4,826 & 3,460 & 2,648 & 2,286 & 1,824 \\
\hline Catenaria1-2.mat & 0,178 & 0,533 & 7,717 & 5,328 & 3,820 & 2,923 & 2,524 & 2,013 \\
\hline Catenaria1-3.mat & 0,194 & 0,582 & 8,428 & 5,819 & 4,172 & 3,192 & 2,757 & 2,199 \\
\hline Catenaria1-4.mat & 0,241 & 0,724 & 10,478 & 7,234 & 5,187 & 3,969 & 3,427 & 2,734 \\
\hline Catenaria1-5.mat & 0,273 & 0,819 & 11,863 & 8,190 & 5,873 & 4,494 & 3,880 & 3,095 \\
\hline Catenaria1-7.mat & 0,305 & 0,914 & 13,239 & 9,140 & 6,554 & 5,015 & 4,330 & 3,454 \\
\hline Catenaria1-8.mat & 0,320 & 0,960 & 13,899 & 9,596 & 6,881 & 5,265 & 4,546 & 3,627 \\
\hline Catenaria1-9.mat & 0,335 & 1,006 & 14,572 & 10,060 & 7,214 & 5,520 & 4,766 & 3,802 \\
\hline Catenaria1-10.mat & 0,367 & 1,101 & 15,947 & 11,010 & 7,894 & 6,040 & 5,216 & 4,161 \\
\hline Catenaria1-11.mat & 0,382 & 1,147 & 16,602 & 11,462 & 8,219 & 6,288 & 5,430 & 4,332 \\
\hline Catenaria1-12.mat & 0,397 & 1,190 & 17,231 & 11,896 & 8,530 & 6,527 & 5,636 & 4,496 \\
\hline Catenaria1-13.mat & 0,410 & 1,231 & 17,831 & 12,311 & 8,827 & 6,754 & 5,832 & 4,653 \\
\hline Catenaria1-14.mat & 0,427 & 1,281 & 18,552 & 12,808 & 9,184 & 7,027 & 6,068 & 4,841 \\
\hline Catenaria1-15.mat & 0,458 & 1,374 & 19,901 & 13,739 & 9,852 & 7,538 & 6,509 & 5,193 \\
\hline Catenaria1-16.mat & 0,488 & 1,465 & 21,218 & 14,649 & 10,504 & 8,037 & 6,940 & 5,536 \\
\hline Catenaria1-17.mat & 0,518 & 1,554 & 22,503 & 15,536 & 11,140 & 8,524 & 7,360 & 5,872 \\
\hline Catenaria1-18.mat & 0,557 & 1,671 & 24,194 & 16,703 & 11,977 & 9,164 & 7,913 & 6,313 \\
\hline Catenaria1-19.mat & 0,573 & 1,719 & 24,892 & 17,186 & 12,323 & 9,429 & 8,142 & 6,495 \\
\hline Catenaria1-20.mat & 0,584 & 1,753 & 25,381 & 17,523 & 12,565 & 9,614 & 8,302 & 6,623 \\
\hline Catenaria1-21.mat & 0,603 & 1,808 & 26,187 & 18,079 & 12,964 & 9,919 & 8,565 & 6,833 \\
\hline Catenaria1-22.mat & 0,620 & 1,861 & 26,954 & 18,609 & 13,344 & 10,210 & 8,816 & 7,033 \\
\hline Catenaria1-24.mat & 0,645 & 1,936 & 28,041 & 19,359 & 13,882 & 10,622 & 9,172 & 7,317 \\
\hline Catenaria1-25.mat & 0,689 & 2,068 & 29,943 & 20,672 & 14,823 & 11,342 & 9,793 & 7,813 \\
\hline Catenaria1-26.mat & 0,708 & 2,123 & 30,739 & 21,222 & 15,217 & 11,644 & 10,054 & 8,021 \\
\hline Catenaria1-27.mat & 0,754 & 2,263 & 32,764 & 22,620 & 16,220 & 12,411 & 10,716 & 8,549 \\
\hline Catenaria1-28.mat & 0,768 & 2,303 & 33,343 & 23,019 & 16,506 & 12,630 & 10,906 & 8,700 \\
\hline Catenaria1-29.mat & 0,778 & 2,335 & 33,819 & 23,348 & 16,742 & 12,810 & 11,061 & 8,824 \\
\hline Catenaria1-30.mat & 0,796 & 2,388 & 34,585 & 23,877 & 17,121 & 13,100 & 11,312 & 9,024 \\
\hline Catenaria1-31.mat & 0,809 & 2,427 & 35,140 & 24,260 & 17,396 & 13,310 & 11,493 & 9,169 \\
\hline Catenaria1-32.mat & 0,832 & 2,497 & 36,160 & 24,965 & 17,901 & 13,697 & 11,827 & 9,435 \\
\hline Catenaria1-33.mat & 0,843 & 2,528 & 36,604 & 25,271 & 18,120 & 13,865 & 11,972 & 9,551 \\
\hline Catenaria1-34.mat & 0,875 & 2,624 & 37,989 & 26,228 & 18,806 & 14,390 & 12,425 & 9,912 \\
\hline Catenaria1-35.mat & 0,899 & 2,698 & 39,066 & 26,971 & 19,340 & 14,798 & 12,778 & 10,193 \\
\hline Catenaria1-36.mat & 0,920 & 2,761 & 39,982 & 27,603 & 19,793 & 15,145 & 13,077 & 10,432 \\
\hline Catenaria1-37.mat & 0,940 & 2,819 & 40,816 & 28,179 & 20,206 & 15,461 & 13,350 & 10,650 \\
\hline Catenaria1-38.mat & 0,967 & 2,902 & 42,022 & 29,012 & 20,803 & 15,917 & 13,744 & 10,964 \\
\hline Catenaria1-39.mat & 1,000 & 3,000 & 43,446 & 29,995 & 21,508 & 16,457 & 14,210 & 11,336 \\
\hline Catenaria1-40.mat & 1,032 & 3,097 & 44,841 & 30,958 & 22,198 & 16,985 & 14,666 & 11,700 \\
\hline
\end{tabular}


Tabela 6.9: Matriz de ensaios para o arranjo Catenaria-2, realizada no braço giratório do CHTPN.

\begin{tabular}{|c|c|c|c|c|c|c|c|c|}
\hline Nome do arquivo & $\Omega_{\text {angular }}(\mathrm{rad} / \mathrm{s})$ & $U_{\max }(\mathrm{m} / \mathrm{s})$ & $V r_{1}$ & $V r_{2}$ & $V r_{3}$ & $V r_{4}$ & $V r_{5}$ & $V r_{6}$ \\
\hline Catenaria2-1.mat & 0,139 & 0,443 & 6,418 & 4,431 & 3,177 & 2,431 & 2,099 & 1,675 \\
\hline Catenaria2-2.mat & 0,161 & 0,515 & 7,460 & 5,151 & 3,693 & 2,826 & 2,440 & 1,947 \\
\hline Catenaria2-3.mat & 0,177 & 0,567 & 8,212 & 5,669 & 4,065 & 3,111 & 2,686 & 2,143 \\
\hline Catenaria2-4.mat & 0,197 & 0,629 & 9,114 & 6,292 & 4,512 & 3,452 & 2,981 & 2,378 \\
\hline Catenaria2-5.mat & 0,215 & 0,690 & 9,985 & 6,894 & 4,943 & 3,782 & 3,266 & 2,605 \\
\hline Catenaria2-6.mat & 0,234 & 0,750 & 10,858 & 7,497 & 5,375 & 4,113 & 3,552 & 2,833 \\
\hline Catenaria2-7.mat & 0,247 & 0,792 & 11,462 & 7,913 & 5,674 & 4,342 & 3,749 & 2,991 \\
\hline Catenaria2-8.mat & 0,264 & 0,846 & 12,250 & 8,458 & 6,064 & 4,640 & 4,007 & 3,196 \\
\hline Catenaria2-9.mat & 0,287 & 0,918 & 13,290 & 9,175 & 6,579 & 5,034 & 4,347 & 3,468 \\
\hline Catenaria2-10.mat & 0,305 & 0,975 & 14,120 & 9,748 & 6,990 & 5,348 & 4,618 & 3,684 \\
\hline Catenaria2-11.mat & 0,320 & 1,023 & 14,813 & 10,227 & 7,333 & 5,611 & 4,845 & 3,865 \\
\hline Catenaria2-12.mat & 0,336 & 1,076 & 15,575 & 10,753 & 7,710 & 5,900 & 5,094 & 4,064 \\
\hline Catenaria2-13.mat & 0,355 & 1,136 & 16,457 & 11,362 & 8,147 & 6,234 & 5,383 & 4,294 \\
\hline Catenaria2-14.mat & 0,369 & 1,181 & 17,106 & 11,810 & 8,468 & 6,479 & 5,595 & 4,463 \\
\hline Catenaria2-15.mat & 0,388 & 1,242 & 17,979 & 12,413 & 8,901 & 6,810 & 5,881 & 4,691 \\
\hline Catenaria2-16.mat & 0,409 & 1,308 & 18,940 & 13,076 & 9,376 & 7,174 & 6,195 & 4,942 \\
\hline Catenaria2-17.mat & 0,420 & 1,343 & 19,453 & 13,430 & 9,630 & 7,369 & 6,363 & 5,076 \\
\hline Catenaria2-18.mat & 0,441 & 1,410 & 20,418 & 14,096 & 10,108 & 7,734 & 6,678 & 5,327 \\
\hline Catenaria2-19.mat & 0,459 & 1,469 & 21,269 & 14,684 & 10,529 & 8,056 & 6,957 & 5,550 \\
\hline Catenaria2-20.mat & 0,474 & 1,517 & 21,960 & 15,161 & 10,871 & 8,318 & 7,183 & 5,730 \\
\hline Catenaria2-21.mat & 0,481 & 1,538 & 22,274 & 15,377 & 11,026 & 8,437 & 7,285 & 5,812 \\
\hline Catenaria2-22.mat & 0,490 & 1,568 & 22,704 & 15,675 & 11,240 & 8,600 & 7,426 & 5,924 \\
\hline Catenaria2-23.mat & 0,511 & 1,634 & 23,661 & 16,336 & 11,713 & 8,963 & 7,739 & 6,174 \\
\hline Catenaria2-24.mat & 0,517 & 1,653 & 23,940 & 16,528 & 11,851 & 9,068 & 7,830 & 6,247 \\
\hline Catenaria2-25.mat & 0,536 & 1,715 & 24,831 & 17,143 & 12,292 & 9,405 & 8,121 & 6,479 \\
\hline Catenaria2-26.mat & 0,548 & 1,755 & 25,412 & 17,544 & 12,580 & 9,626 & 8,312 & 6,631 \\
\hline Catenaria2-27.mat & 0,566 & 1,812 & 26,233 & 18,111 & 12,986 & 9,937 & 8,580 & 6,845 \\
\hline Catenaria2-28.mat & 0,579 & 1,853 & 26,838 & 18,529 & 13,286 & 10,166 & 8,778 & 7,003 \\
\hline Catenaria2-29.mat & 0,597 & 1,911 & 27,672 & 19,104 & 13,699 & 10,482 & 9,051 & 7,220 \\
\hline Catenaria2-30.mat & 0,610 & 1,951 & 28,257 & 19,508 & 13,988 & 10,703 & 9,242 & 7,373 \\
\hline Catenaria2-31.mat & 0,625 & 1,999 & 28,945 & 19,983 & 14,329 & 10,964 & 9,467 & 7,552 \\
\hline Catenaria2-32.mat & 0,639 & 2,045 & 29,617 & 20,447 & 14,662 & 11,218 & 9,687 & 7,728 \\
\hline Catenaria2-33.mat & 0,658 & 2,105 & 30,485 & 21,046 & 15,091 & 11,547 & 9,971 & 7,954 \\
\hline Catenaria2-34.mat & 0,667 & 2,134 & 30,896 & 21,331 & 15,295 & 11,703 & 10,105 & 8,062 \\
\hline Catenaria2-35.mat & 0,688 & 2,201 & 31,872 & 22,004 & 15,778 & 12,072 & 10,424 & 8,316 \\
\hline Catenaria2-36.mat & 0,691 & 2,211 & 32,022 & 22,107 & 15,852 & 12,129 & 10,473 & 8,355 \\
\hline Catenaria2-37.mat & 0,720 & 2,304 & 33,357 & 23,029 & 16,513 & 12,635 & 10,910 & 8,704 \\
\hline Catenaria2-39.mat & 0,723 & 2,314 & 33,507 & 23,133 & 16,587 & 12,692 & 10,959 & 8,743 \\
\hline Catenaria2-38.mat & 0,729 & 2,333 & 33,781 & 23,322 & 16,723 & 12,796 & 11,049 & 8,814 \\
\hline Catenaria2-40.mat & 0,731 & 2,339 & 33,869 & 23,383 & 16,767 & 12,829 & 11,078 & 8,837 \\
\hline
\end{tabular}


Tabela 6.10: Matriz de ensaios para o arranjo Catenaria-3, realizada no braço giratório do CHTPN.

\begin{tabular}{|c|c|c|c|c|c|c|c|c|}
\hline Nome do arquivo & $\Omega_{\text {angular }}(\mathrm{rad} / \mathrm{s})$ & $U_{\max }(\mathrm{m} / \mathrm{s})$ & $V r_{1}$ & $V r_{2}$ & $V r_{3}$ & $V r_{4}$ & $V r_{5}$ & $V r_{6}$ \\
\hline Catenaria3-1.mat & 0,148 & 0,473 & 7,242 & 5,132 & 3,537 & 2,713 & 2,319 & 1,846 \\
\hline Catenaria3-2.mat & 0,163 & 0,522 & 7,986 & 5,659 & 3,900 & 2,992 & 2,557 & 2,035 \\
\hline Catenaria3-3.mat & 0,180 & 0,575 & 8,797 & 6,233 & 4,296 & 3,295 & 2,817 & 2,242 \\
\hline Catenaria3-4.mat & 0,195 & 0,624 & 9,548 & 6,765 & 4,663 & 3,577 & 3,057 & 2,433 \\
\hline Catenaria3-5.mat & 0,216 & 0,692 & 10,583 & 7,498 & 5,168 & 3,964 & 3,388 & 2,697 \\
\hline Catenaria3-6.mat & 0,234 & 0,749 & 11,460 & 8,120 & 5,597 & 4,293 & 3,669 & 2,920 \\
\hline Catenaria3-7.mat & 0,250 & 0,800 & 12,235 & 8,669 & 5,975 & 4,583 & 3,918 & 3,118 \\
\hline Catenaria3-8.mat & 0,267 & 0,855 & 13,083 & 9,270 & 6,389 & 4,901 & 4,189 & 3,334 \\
\hline Catenaria3-9.mat & 0,288 & 0,921 & 14,091 & 9,984 & 6,882 & 5,279 & 4,512 & 3,591 \\
\hline Catenaria3-10.mat & 0,308 & 0,985 & 15,069 & 10,678 & 7,359 & 5,645 & 4,825 & 3,840 \\
\hline Catenaria3-11.mat & 0,324 & 1,036 & 15,853 & 11,233 & 7,742 & 5,939 & 5,076 & 4,040 \\
\hline Catenaria3-12.mat & 0,339 & 1,085 & 16,596 & 11,760 & 8,105 & 6,217 & 5,314 & 4,229 \\
\hline Catenaria3-13.mat & 0,360 & 1,152 & 17,631 & 12,493 & 8,610 & 6,605 & 5,645 & 4,493 \\
\hline Catenaria3-14.mat & 0,379 & 1,213 & 18,569 & 13,158 & 9,069 & 6,956 & 5,946 & 4,732 \\
\hline Catenaria3-15.mat & 0,393 & 1,256 & 19,223 & 13,621 & 9,388 & 7,201 & 6,155 & 4,898 \\
\hline Catenaria3-16.mat & 0,420 & 1,343 & 20,551 & 14,562 & 10,037 & 7,699 & 6,580 & 5,237 \\
\hline Catenaria3-17.mat & 0,430 & 1,376 & 21,058 & 14,921 & 10,284 & 7,888 & 6,743 & 5,366 \\
\hline Catenaria3-18.mat & 0,448 & 1,434 & 21,949 & 15,552 & 10,719 & 8,222 & 7,028 & 5,593 \\
\hline Catenaria3-19.mat & 0,466 & 1,492 & 22,826 & 16,174 & 11,148 & 8,551 & 7,309 & 5,817 \\
\hline Catenaria3-20.mat & 0,482 & 1,542 & 23,602 & 16,723 & 11,526 & 8,841 & 7,557 & 6,014 \\
\hline Catenaria3-21.mat & 0,486 & 1,556 & 23,818 & 16,876 & 11,632 & 8,922 & 7,626 & 6,069 \\
\hline Catenaria3-22.mat & 0,499 & 1,598 & 24,452 & 17,326 & 11,942 & 9,160 & 7,829 & 6,231 \\
\hline Catenaria3-23.mat & 0,520 & 1,664 & 25,465 & 18,044 & 12,436 & 9,539 & 8,154 & 6,489 \\
\hline Catenaria3-24.mat & 0,528 & 1,691 & 25,879 & 18,337 & 12,638 & 9,694 & 8,286 & 6,594 \\
\hline Catenaria3-25.mat & 0,552 & 1,767 & 27,044 & 19,163 & 13,207 & 10,131 & 8,659 & 6,891 \\
\hline Catenaria3-26.mat & 0,558 & 1,785 & 27,317 & 19,356 & 13,341 & 10,233 & 8,747 & 6,961 \\
\hline Catenaria3-27.mat & 0,584 & 1,869 & 28,605 & 20,269 & 13,970 & 10,716 & 9,159 & 7,289 \\
\hline
\end{tabular}


Tabela 6.11: Matriz de ensaios para o arranjo Catenaria-4, realizada no braço giratório do CHTPN.

\begin{tabular}{|c|c|c|c|c|c|c|c|c|}
\hline Nome do arquivo & $\Omega_{\text {angular }}(\mathrm{rad} / \mathrm{s})$ & $U_{\max }(\mathrm{m} / \mathrm{s})$ & $V r_{1}$ & $V r_{2}$ & $V r_{3}$ & $V r_{4}$ & $V r_{5}$ & $V r_{6}$ \\
\hline Catenaria4-1.mat & 0,140 & 0,449 & 8,596 & 5,750 & 3,958 & 2,835 & 2,557 & 1,878 \\
\hline Catenaria4-2.mat & 0,159 & 0,508 & 9,721 & 6,503 & 4,477 & 3,207 & 2,892 & 2,124 \\
\hline Catenaria4-3.mat & 0,179 & 0,572 & 10,935 & 7,315 & 5,035 & 3,607 & 3,253 & 2,389 \\
\hline Catenaria4-4.mat & 0,199 & 0,636 & 12,164 & 8,137 & 5,602 & 4,013 & 3,619 & 2,658 \\
\hline Catenaria4-5.mat & 0,218 & 0,698 & 13,347 & 8,928 & 6,146 & 4,403 & 3,971 & 2,916 \\
\hline Catenaria4-6.mat & 0,235 & 0,751 & 14,364 & 9,608 & 6,615 & 4,738 & 4,274 & 3,139 \\
\hline Catenaria4-7.mat & 0,251 & 0,803 & 15,361 & 10,275 & 7,074 & 5,067 & 4,570 & 3,356 \\
\hline Catenaria4-8.mat & 0,269 & 0,862 & 16,492 & 11,032 & 7,595 & 5,440 & 4,907 & 3,604 \\
\hline Catenaria4-9.mat & 0,289 & 0,925 & 17,692 & 11,835 & 8,147 & 5,836 & 5,264 & 3,866 \\
\hline Catenaria4-10.mat & 0,303 & 0,970 & 18,547 & 12,406 & 8,541 & 6,118 & 5,518 & 4,052 \\
\hline Catenaria4-11.mat & 0,318 & 1,019 & 19,484 & 13,034 & 8,972 & 6,427 & 5,797 & 4,257 \\
\hline Catenaria4-12.mat & 0,338 & 1,082 & 20,700 & 13,847 & 9,532 & 6,828 & 6,159 & 4,523 \\
\hline Catenaria4-13.mat & 0,362 & 1,159 & 22,172 & 14,831 & 10,210 & 7,314 & 6,597 & 4,845 \\
\hline Catenaria4-14.mat & 0,376 & 1,202 & 22,988 & 15,377 & 10,586 & 7,583 & 6,839 & 5,023 \\
\hline Catenaria4-15.mat & 0,394 & 1,262 & 24,139 & 16,147 & 11,116 & 7,962 & 7,182 & 5,274 \\
\hline Catenaria4-16.mat & 0,414 & 1,326 & 25,354 & 16,960 & 11,675 & 8,363 & 7,543 & 5,540 \\
\hline Catenaria4-17.mat & 0,430 & 1,376 & 26,318 & 17,605 & 12,119 & 8,681 & 7,830 & 5,751 \\
\hline Catenaria4-18.mat & 0,450 & 1,441 & 27,564 & 18,438 & 12,693 & 9,093 & 8,201 & 6,023 \\
\hline Catenaria4-19.mat & 0,463 & 1,482 & 28,334 & 18,954 & 13,048 & 9,347 & 8,430 & 6,191 \\
\hline Catenaria4-21.mat & 0,485 & 1,552 & 29,676 & 19,851 & 13,666 & 9,789 & 8,829 & 6,484 \\
\hline Catenaria4-20.mat & 0,485 & 1,553 & 29,693 & 19,862 & 13,673 & 9,795 & 8,834 & 6,488 \\
\hline Catenaria4-22.mat & 0,497 & 1,591 & 30,420 & 20,349 & 14,008 & 10,035 & 9,051 & 6,647 \\
\hline Catenaria4-23.mat & 0,519 & 1,661 & 31,775 & 21,255 & 14,632 & 10,481 & 9,454 & 6,943 \\
\hline Catenaria4-24.mat & 0,528 & 1,688 & 32,288 & 21,598 & 14,868 & 10,651 & 9,606 & 7,055 \\
\hline Catenaria4-25.mat & 0,551 & 1,763 & 33,723 & 22,558 & 15,529 & 11,124 & 10,033 & 7,369 \\
\hline Catenaria4-26.mat & 0,561 & 1,796 & 34,357 & 22,982 & 15,821 & 11,333 & 10,222 & 7,507 \\
\hline Catenaria4-27.mat & 0,581 & 1,860 & 35,566 & 23,791 & 16,378 & 11,732 & 10,582 & 7,771 \\
\hline Catenaria4-28.mat & 0,594 & 1,901 & 36,360 & 24,322 & 16,744 & 11,994 & 10,818 & 7,945 \\
\hline Catenaria4-29.mat & 0,615 & 1,968 & 37,643 & 25,180 & 17,335 & 12,417 & 11,200 & 8,225 \\
\hline Catenaria4-30.mat & 0,621 & 1,987 & 37,994 & 25,415 & 17,496 & 12,533 & 11,304 & 8,302 \\
\hline Catenaria4-31.mat & 0,649 & 2,076 & 39,706 & 26,561 & 18,285 & 13,098 & 11,814 & 8,676 \\
\hline Catenaria4-32.mat & 0,656 & 2,099 & 40,136 & 26,848 & 18,482 & 13,240 & 11,941 & 8,770 \\
\hline Catenaria4-33.mat & 0,673 & 2,155 & 41,213 & 27,568 & 18,978 & 13,595 & 12,262 & 9,005 \\
\hline Catenaria4-34.mat & 0,682 & 2,182 & 41,726 & 27,912 & 19,215 & 13,764 & 12,415 & 9,117 \\
\hline Catenaria4-35.mat & 0,702 & 2,246 & 42,960 & 28,737 & 19,783 & 14,171 & 12,782 & 9,387 \\
\hline Catenaria4-36.mat & 0,720 & 2,304 & 44,058 & 29,472 & 20,289 & 14,533 & 13,108 & 9,627 \\
\hline Catenaria4-37.mat & 0,730 & 2,335 & 44,649 & 29,867 & 20,561 & 14,728 & 13,284 & 9,756 \\
\hline Catenaria4-38.mat & 0,751 & 2,404 & 45,983 & 30,759 & 21,175 & 15,168 & 13,681 & 10,048 \\
\hline Catenaria4-39.mat & 0,759 & 2,430 & 46,470 & 31,085 & 21,399 & 15,329 & 13,826 & 10,154 \\
\hline Catenaria4-40.mat & 0,777 & 2,487 & 47,568 & 31,819 & 21,905 & 15,691 & 14,152 & 10,394 \\
\hline
\end{tabular}


Na Tabela 6.12 são apresentados os nomes dos arquivos, com as velocidades incidentes sobre a catenária instalada no tanque do IPT. A velocidade máxima variou entre $0,242 \mathrm{~m} / \mathrm{s}$ e $2,376 \mathrm{~m} / \mathrm{s}$.

Tabela 6.12: Matriz de ensaios para o arranjo Catenaria-5, realizada no tanque de reboque do IPT.

\begin{tabular}{|c|c|c|c|c|c|c|c|c|}
\hline Nome do arquivo & $\Omega_{\text {angular }}(\mathrm{rad} / \mathrm{s})$ & $U_{\max }(m / s)$ & $V r_{1}$ & $V r_{2}$ & $V r_{3}$ & $V r_{4}$ & $V r_{5}$ & $V r_{6}$ \\
\hline Catenaria5-1.mat & 0,242 & 2,569 & 1,504 & 1,294 & 0,999 & 0,860 & 0,762 & \\
\hline Catenaria5-2.mat & 0,335 & 3,553 & 2,080 & 1,789 & 1,382 & 1,189 & 1,053 & \\
\hline Catenaria5-3.mat & 0,427 & 4,530 & 2,652 & 2,281 & 1,762 & 1,516 & 1,343 & \\
\hline Catenaria5-4.mat & 0,519 & 5,507 & 3,224 & 2,773 & 2,142 & 1,843 & 1,633 & \\
\hline Catenaria5-5.mat & 0,613 & 6,499 & 3,805 & 3,273 & 2,528 & 2,175 & 1,927 & \\
\hline Catenaria5-6.mat & 0,681 & 7,221 & 4,228 & 3,637 & 2,809 & 2,417 & 2,141 & \\
\hline Catenaria5-7.mat & 0,796 & 8,445 & 4,945 & 4,253 & 3,285 & 2,826 & 2,504 & \\
\hline Catenaria5-8.mat & 0,865 & 9,179 & 5,375 & 4,623 & 3,570 & 3,072 & 2,722 & \\
\hline Catenaria5-9.mat & 0,958 & 10,164 & 5,951 & 5,119 & 3,953 & 3,402 & 3,014 & \\
\hline Catenaria5-10.mat & 1,050 & 11,142 & 6,524 & 5,611 & 4,334 & 3,729 & 3,304 & \\
\hline Catenaria5-11.mat & 1,119 & 11,872 & 6,951 & 5,979 & 4,618 & 3,973 & 3,520 & \\
\hline Catenaria5-12.mat & 1,233 & 13,080 & 7,659 & 6,587 & 5,088 & 4,378 & 3,879 & \\
\hline Catenaria5-13.mat & 1,304 & 13,837 & 8,102 & 6,968 & 5,382 & 4,631 & 4,103 & \\
\hline Catenaria5-14.mat & 1,396 & 14,812 & 8,673 & 7,459 & 5,761 & 4,957 & 4,392 & \\
\hline Catenaria5-15.mat & 1,512 & 16,037 & 9,390 & 8,076 & 6,237 & 5,367 & 4,755 & \\
\hline Catenaria5-16.mat & 1,558 & 16,530 & 9,679 & 8,325 & 6,430 & 5,532 & 4,902 & \\
\hline Catenaria5-17.mat & 1,673 & 17,747 & 10,391 & 8,938 & 6,903 & 5,940 & 5,263 & \\
\hline Catenaria5-18.mat & 1,743 & 18,486 & 10,824 & 9,310 & 7,190 & 6,187 & 5,482 & \\
\hline Catenaria5-19.mat & 1,835 & 19,461 & 11,395 & 9,801 & 7,570 & 6,513 & 5,771 & \\
\hline Catenaria5-20.mat & 1,951 & 20,693 & 12,116 & 10,421 & 8,048 & 6,925 & 6,136 & \\
\hline Catenaria5-21.mat & 1,996 & 21,175 & 12,398 & 10,664 & 8,236 & 7,087 & 6,279 & \\
\hline Catenaria5-22.mat & 2,112 & 22,404 & 13,118 & 11,283 & 8,714 & 7,498 & 6,643 & \\
\hline Catenaria5-23.mat & 2,204 & 23,380 & 13,689 & 11,774 & 9,094 & 7,825 & 6,933 & \\
\hline Catenaria5-24.mat & 2,274 & 24,117 & 14,121 & 12,145 & 9,380 & 8,071 & 7,151 & \\
\hline Catenaria5-25.mat & 2,388 & 25,334 & 14,834 & 12,759 & 9,854 & 8,479 & 7,512 & \\
\hline
\end{tabular}




\subsection{Metodologia de análise dos dados}

Na presente seção são descritos os procedimentos adotados para a redução dos dados experimentais e, portanto, obtenção dos gráficos que são utilizados mais adiante, na apresentação dos resultados e respectivas discussões.

De antemão, é importante salientar que as apresentações gráficas aqui descritas são de suma importância na identificação das repostas, amplitudes e frequências, para cada uma das configurações consideradas nos ensaios realizados segundo as matrizes apresentadas na seção anterior.

Desta forma, de maneira recorrente para os diversos casos de ensaio, as apresentações gráficas mencionadas dizem respeito a:

- Curvas de comparação da estática inicial;

- Variação da velocidade reduzida ao longo da linha para cada frequência natural;

- Gráfico de identificação das frequências naturais;

- Curvas de decaimento de amplitude modal;

- Curvas dos modos de vibrar relacionados às frequências naturais;

- Série temporal de cada alvo com os respectivos resultados de PSD;

- Trajetórias de cada alvo nos planos $X Y, Y Z$ e $X Z$;

- Trajetórias de cada alvo na base $(t, n, b)$;

- Série temporal de cada amplitude modal com os respectivos gráficos de PSD;

- Reconstrução das séries temporais por alvo, via somatório das contribuições modais;

- Evolução temporal das séries descritas no sistema de coordenadas $(x, y, z)$;

- Evolução temporal das séries descritas no sistema de coordenadas $(t, n, b)$;

- Variação da amplitude modal com a velocidade reduzida, definida pela frequência natural do primeiro modo de vibrar no plano de lançamento da catenária:

- Variação da amplitude modal obtida segundo a média dos $10 \%$ maiores valores;

- Variação da amplitude modal obtida segundo a média dos 10\% menores valores;

- Variação da amplitude modal obtida segundo o desvio padrão; 
- Variação da amplitude modal com a velocidade reduzida definida pela frequência natural de cada modo de vibrar;

- Identificação das frequências de resposta da amplitude modal.

Em termos de metodologia de análise, o procedimento utilizado seguiu uma cronologia bem similar àquela da lista de gráficos acima, os quais são descritos nos parágrafos que compõem esta seção final do presente capítulo.

Todavia, para compreender quais foram os dados utilizados na confecção de cada gráfico, também são descritos os parâmetros avaliados e de que forma se relacionam à determinação das figuras e informações geradas.

De início, a primeira etapa consistiu na rotação e translação dos resultados relativos às posições dos alvos refletivos identificados pelo sistema de monitoramento óptico. Essas transformações foram utilizadas para que as catenárias sejam apresentadas e analisadas no plano $Y Z$, naturalmente em sua configuração inicial (a de lançamento). De acordo com esta estratégia, a velocidade da correnteza incidirá sempre em uma direção paralela à direção $X$.

Um exemplo de resultado das transformações é apresentado na Figura 6.34, onde a configuração da Catenária-1 é definida a partir dos valores de ângulo e tração no topo e apresentada em conjunto com a variação da velocidade reduzida ao longo de seu comprimento suspenso.
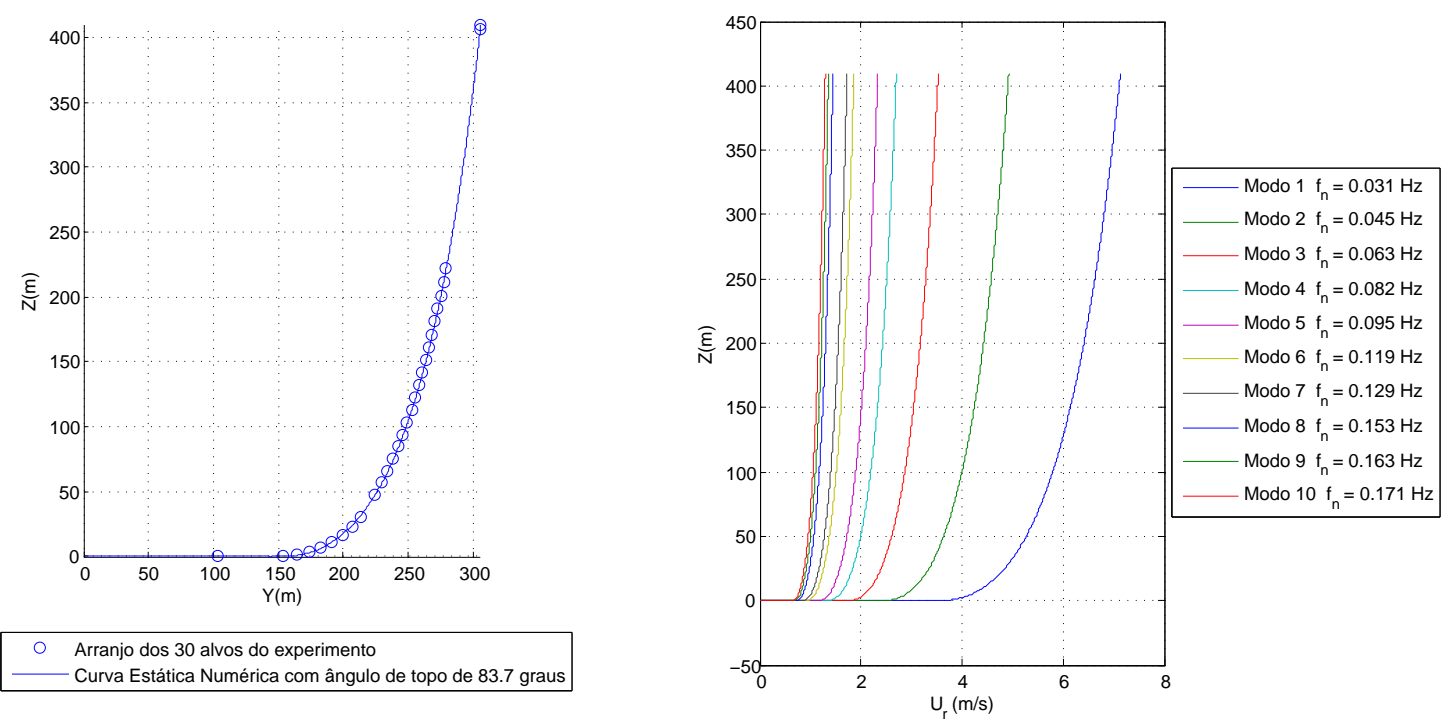

Figura 6.34: Apresentação da Catenária-1 no plano $Y Z$, em conjunto com a variação de velocidade reduzida ao longo de seu comprimento. 
Com as séries temporais de decaimento representadas da maneira descrita acima, ou seja, mediante transformações pertinentes aplicadas nos registros diretamente colhidos pelo sistema de monitoramento óptico, é possível avaliar as frequências naturais de vibrar. Os resultados assim obtidos permitem a identificação das frequências naturais nesses ensaios, como ilustrado na Figura 6.35.

Note que no gráfico, os valores encontrados experimentalmente são comparados com estimativas de frequências naturais teóricas. Neste caso, as linhas tracejadas em preto, nos gráficos de PSD, foram obtidas via PoliFlex, enquanto as linhas tracejadas em vermelho dizem respeito a estimativas feitas com base no método WKB, apresentado na equação (4.24).
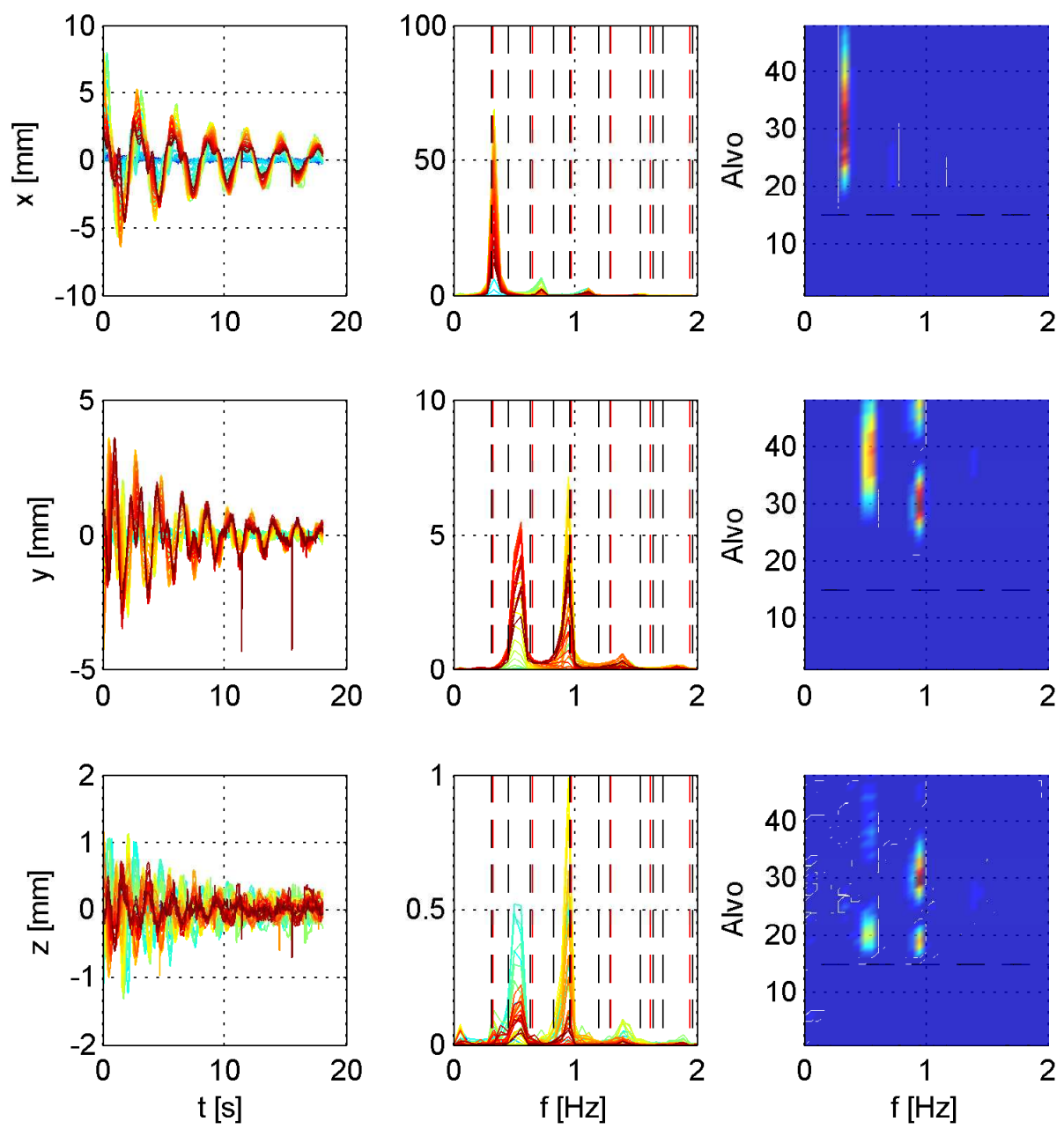

Figura 6.35: Identificação das frequências naturais em exemplo de ensaio de decaimento da Catenária-1.

Na construção dos mapas de frequência, à direita na Figura 6.35, foi utilizada uma 
escala de cores para a definição da posição de cada alvo ao longo do comprimento suspenso da linha. Assim, as chamadas "cores frias", tons de azul, representam os alvos de menor cota vertical, enquanto as "cores quentes", tons de vermelho, estão relacionadas aos alvos próximos ao topo da linha, ou seja, com maiores cotas verticais.

A proximidade entre as curvas verticais que representam as frequências naturais obtidas analítica e/ou numericamente indicam coerência entre as abordagens teórica e experimental.
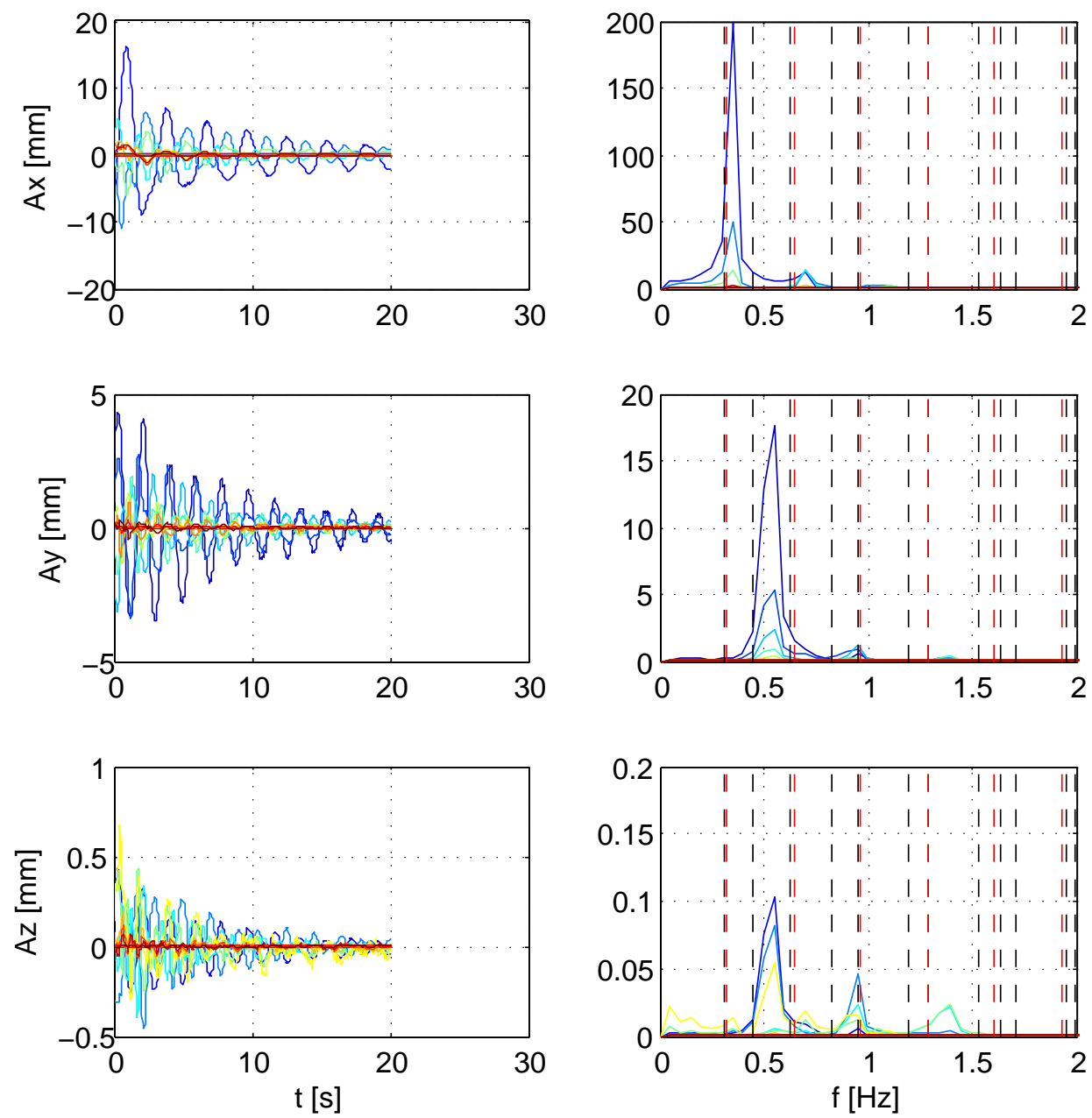

Figura 6.36: Análise das séries modais de decaimento, obtidas com base no procedimento de decomposição modal aplicado às séries de deslocamento dos alvos monitorados para a Catenária-1.

Além de permitir a determinação das frequências naturais do modelo nas diferentes condições de lançamento, os ensaios de decaimento também podem ser utilizados para o cálculo dos coeficientes de amortecimento, no caso, aqueles correspondes à composição 
dos amortecimentos estrutural e viscoso atuantes.

A determinação dos coeficientes de amortecimento pode ser feita a partir da análise das séries temporais de deslocamento diretamente fornecidas pelo sistema de monitoramento dos alvos distribuídos ao londo do modelo. Sabe-se, no entanto, que tal análise não é tarefa fácil, particularmente por conta da inevitável resposta multimodal presente.

Mediante esta característica inerente, a decomposição modal descrita mais adiante, na seção 6.4.1, melhora a análise para determinação dos coeficientes de amortecimento, especialmente no caso do primeiro modo de vibrar. Com base neste procedimento foi possível, portanto, a obtenção de decaimentos modais como os mostrados na Figura 6.36.

A Figura 6.37 ilustra exemplo de análise para a determinação do coeficiente de amortecimento, realizada sobre um sinal de decaimento obtido via procedimento de decomposição modal. Note que, neste caso, trata-se do decaimento em primeiro modo, com decremento logarítmico típico de um amortecimento linear.

Desta forma, no caso da Figura 6.37, de acordo com um ajuste de envoltória via MMQ, chega-se a um coeficiente de amortecimento em primeiro modo natural de $\zeta_{n=1} \cong 4,7 \%$.

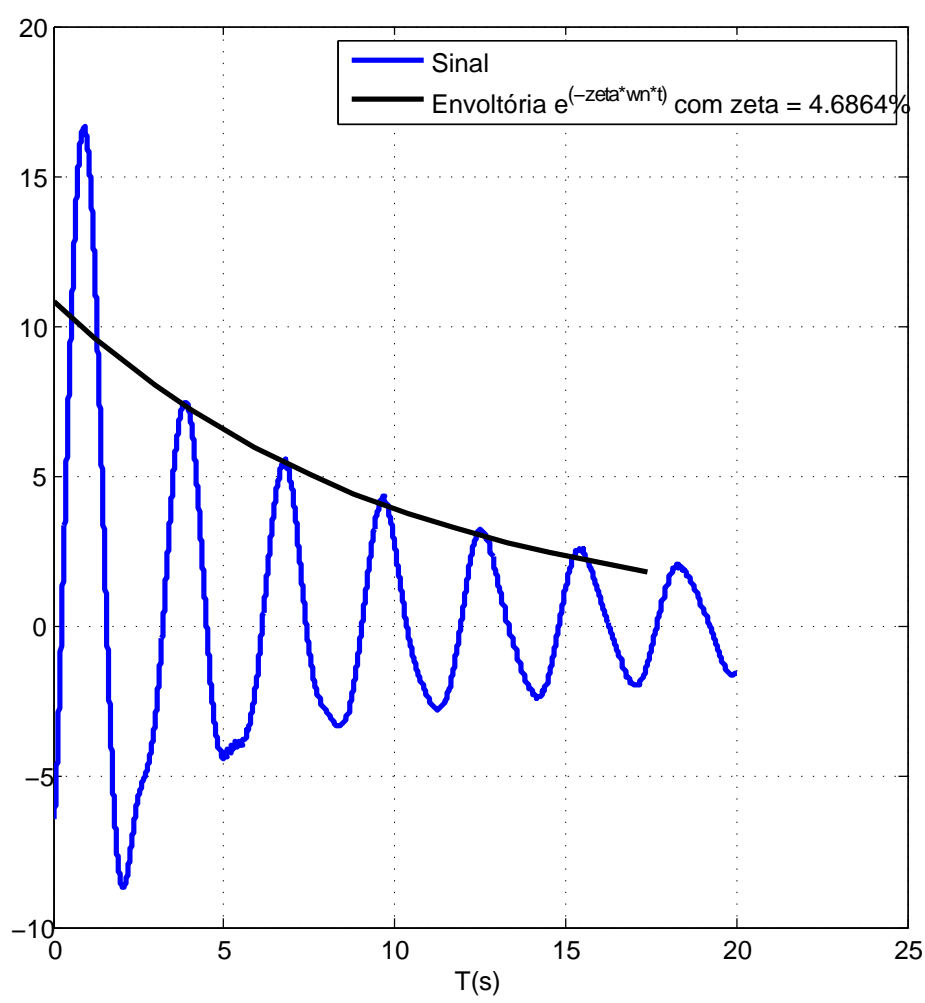

Figura 6.37: Estimativa do coeficiente linear de amortecimento em primeiro modo de vibrar para a Catenária-1. 
A Figura 6.38, por sua vez, ilustrada outro gráfico importante para as análises dos resultados de VIV nas linhas. Trata-se de uma apresentação dos modos de vibrar, onde, no caso do presente trabalho, os marcadores "o" dizem respeito aos movimentos fora do plano de lançamento da linha e os marcadores " $\times$ " aos movimentos no plano de lançamento da mesma.
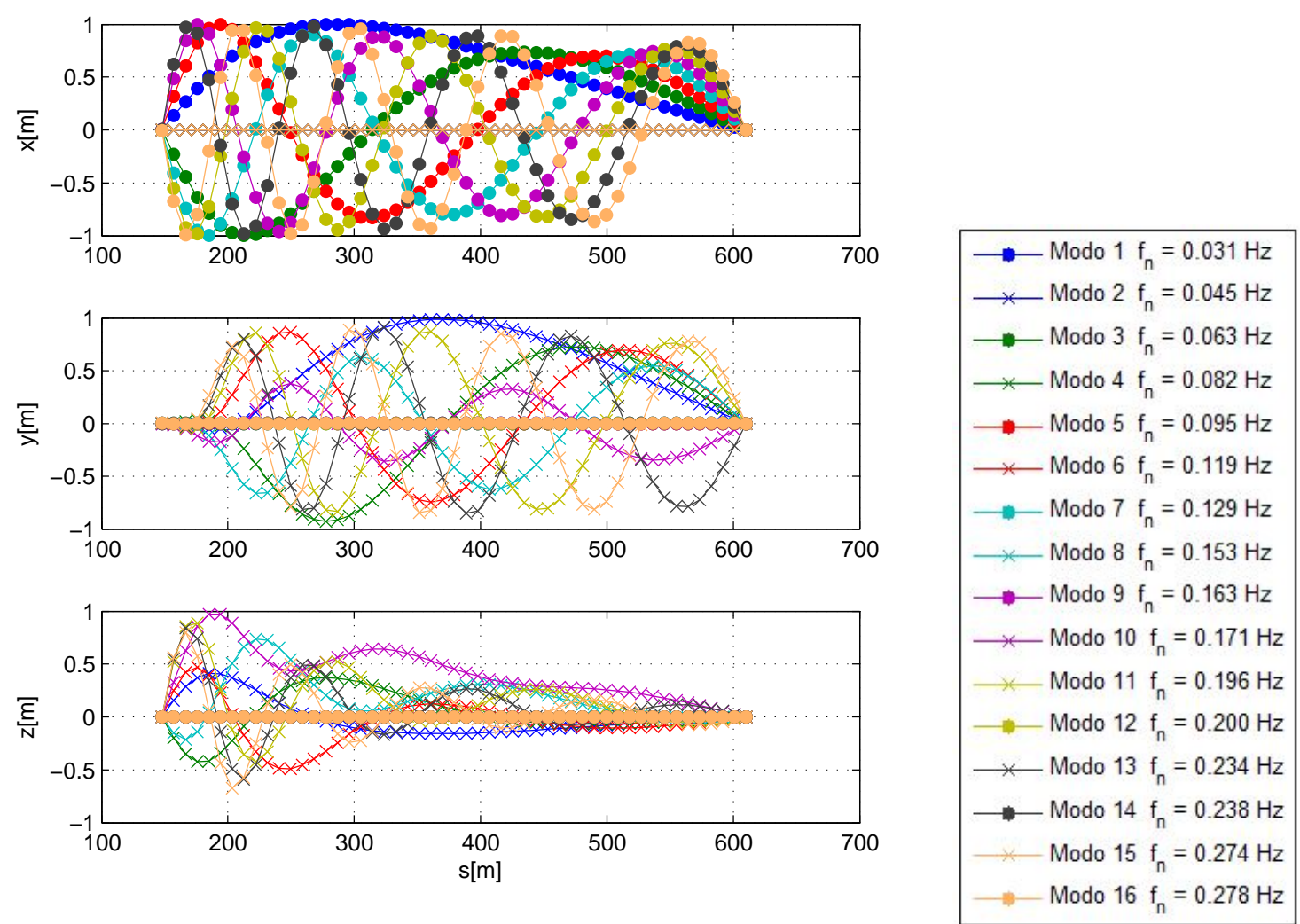

Figura 6.38: Modos de vibrar da linha flexível no arranjo Catenária-1: fora do plano de lançamento marcados com "o" e no plano por " $\times$ ".

Com as séries temporais dos ensaios sob a ação da correnteza, ensaios de VIV foram gerados os primeiros gráficos para a verificação das frequências passíveis de identificação na resposta de cada alvo, também usando gráficos de PSD. Na Figura 6.39, por exemplo, é apresentada um conjunto de séries temporais dos deslocamentos na direção $Y$, onde os sinais de deslocamento são centrados nos números que os identificam. Note que há correspondência entre os sinais temporais, à esquerda, e os gráficos da PSD, à direita.

A identificação dos alvos, nestes gráficos, segue o seguinte padrão: o alvo mais próximo da âncora recebe o rótulo "1"; o alvo seguinte (imediatamente adjacente ao primeiro e na direção crescente das coordenadas curvilíneas) é rotulado como alvo "2" e assim por diante. 
Importante destacar que, gráficos semelhantes também foram construídos para as direções $X$ e $Z$, analisadas mediante conveniência da investigação conduzida.

Além disso, por concisão, foram utilizadas as seguintes nomenclaturas: para os movimentos da linha da direção do escoamento, adotou-se o acrônimo IL (do termo em inglês in line), resultados também identificados nos gráficos pelo uso do marcador "o", e para os movimentos transversais, foi adotado o acrônimo CF (de cross flow), em conjunto com o marcador " $\times$ ".
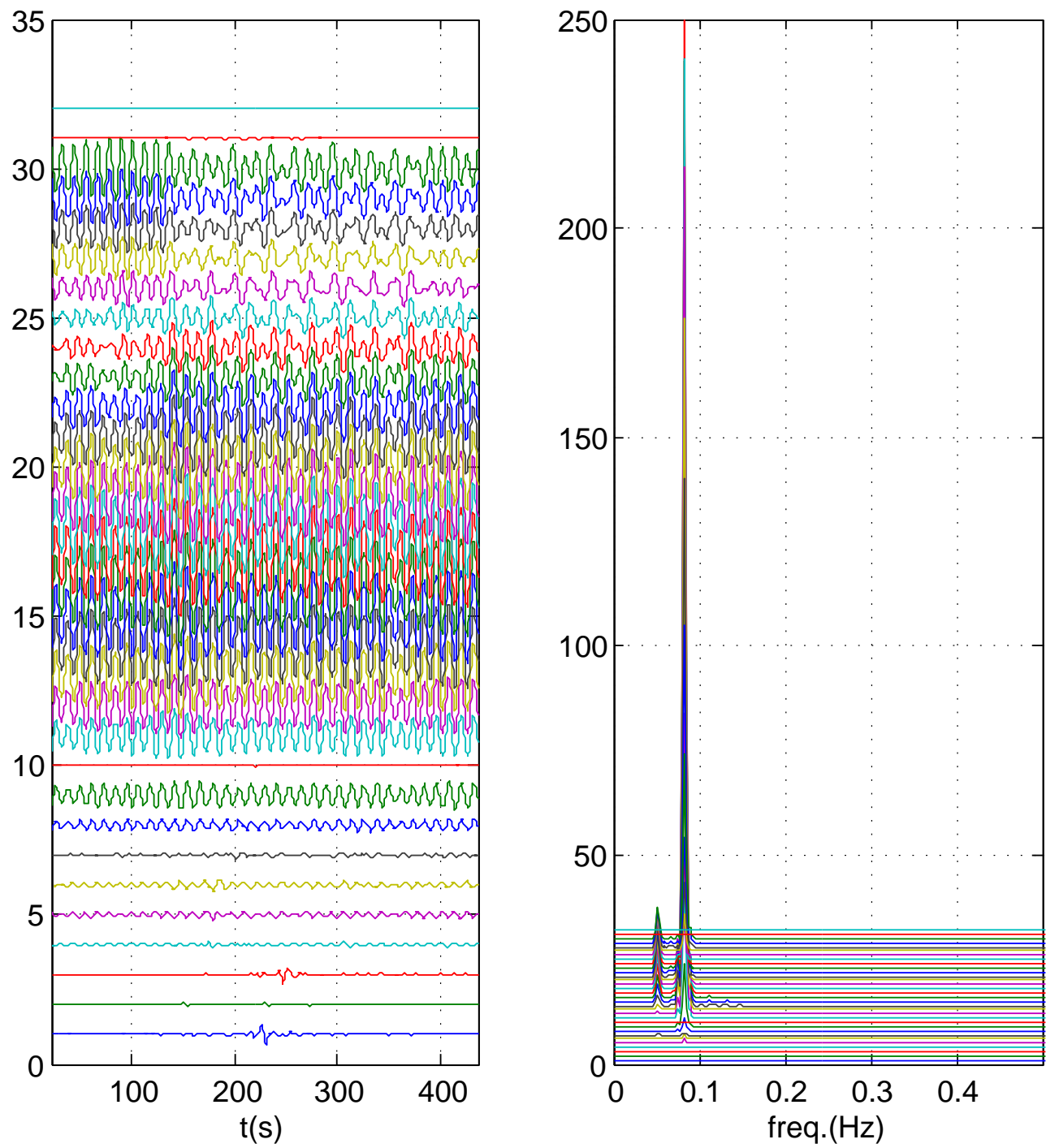

Figura 6.39: Exemplo de séries temporais para a Catenária-1 de deslocamento dos alvos na direção $Y$, avaliados com relação às respectivas $\mathrm{PSD}$, à direita. $\mathrm{O}$ eixo das ordenadas à esquerda em $m$ e à direita em $m^{2} . s$ com a média ajustada para o número do alvo. 
As Figuras 6.40 e 6.41 ilustram exemplo de trajetórias assumidas, alvo a alvo, durante um dos muitos ensaios de VIV realizados, respectivamente descritas com base nos sistemas de coordenadas $(\mathrm{x}, \mathrm{y}, \mathrm{z})$ e $(\mathrm{t}, \mathrm{n}, \mathrm{b})$.

$\mathrm{Na}$ análise e correlação dos comportamentos dinâmicos ao longo das linhas flexíveis longas, gráficos como esses auxiliam na identificação dos modos naturais dominantes. Além disso, permitem estabelecer eventual relação entre amplitudes e frequências de resposta com o comportamento dinâmico da linha ao longo de seu comprimento.
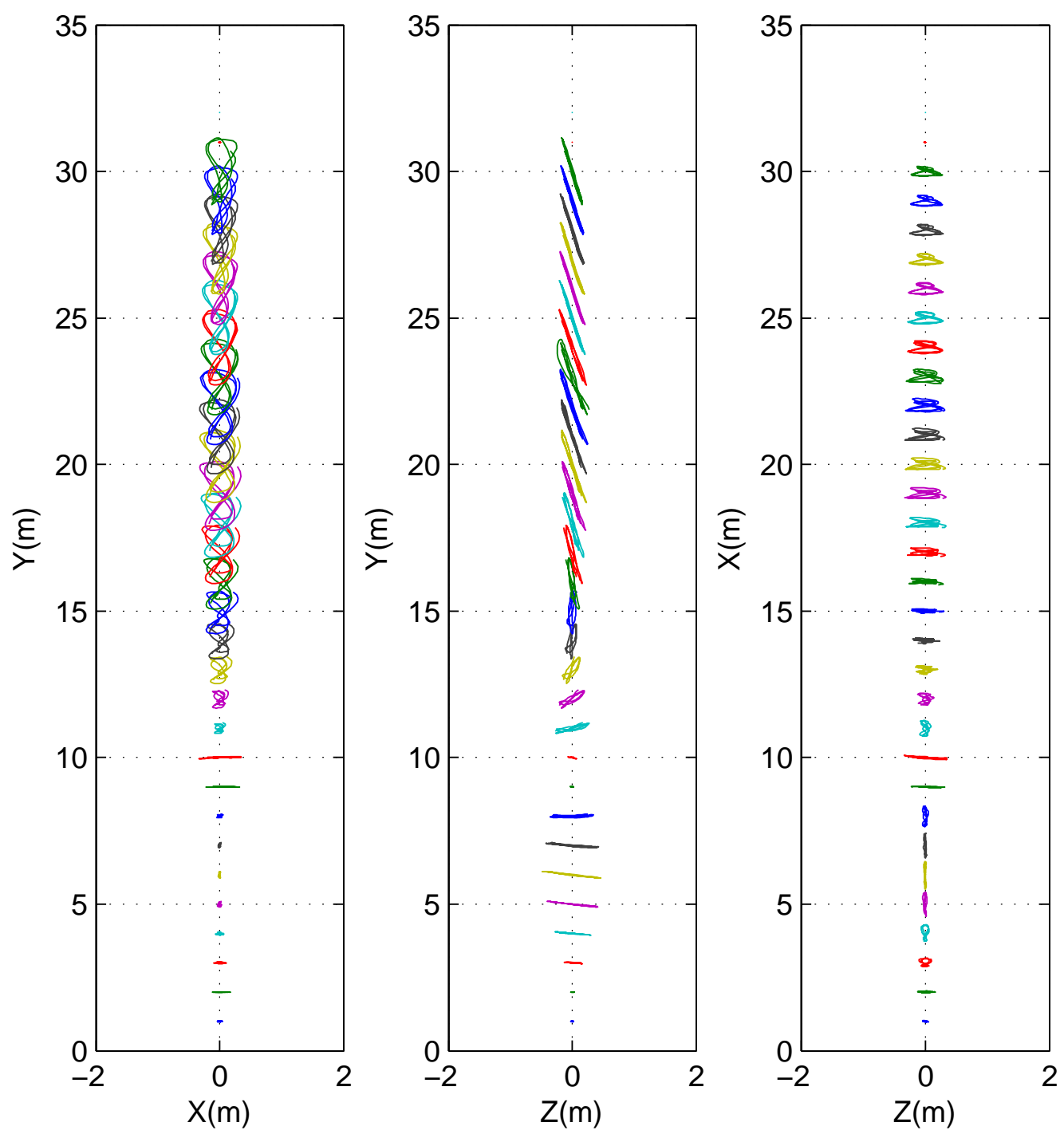

Figura 6.40: Trajetórias dos alvos ao longo da linha Catenária-1, apresentados segundo os planos $X Y, Z Y$ e $Z X$. 

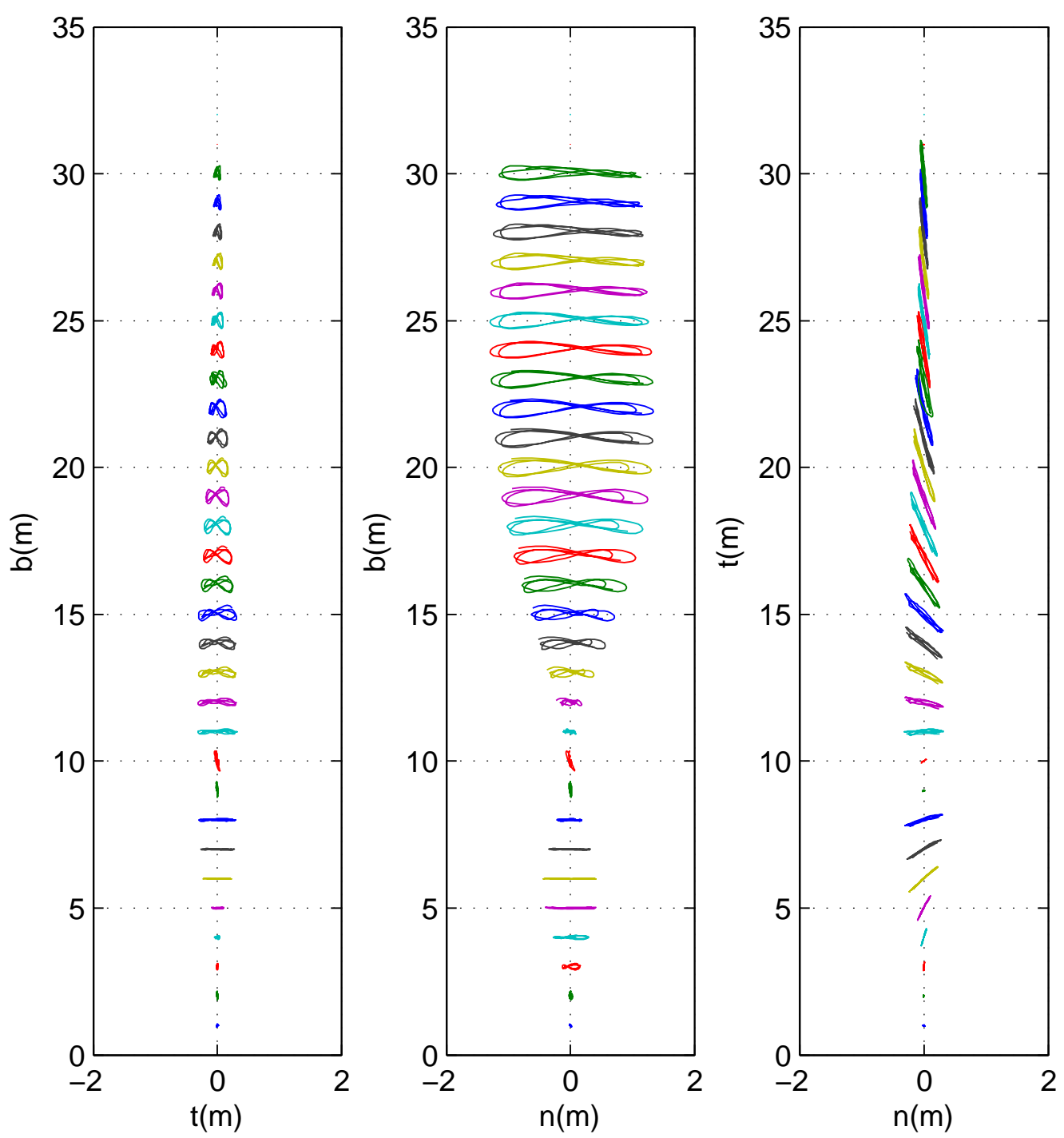

Figura 6.41: Trajetórias dos alvos ao longo da linha Catenária-1, apresentados segundo os planos dados pelas direções $t$ e $b, n$ e $b$, bem como $n$ e $t$.

Na sequência, com base nos mesmos procedimentos de decomposição modal descritos no item 6.4.1, amplitudes de resposta, agora modais, são avaliadas com base nas faixas de excitação estabelecidas pelas matrizes de ensaios da seção anterior deste capítulo, buscando identificar o comportamento vibracional das linhas flexíveis em cada velocidade reduzida.

Este método modal de análise prevê avaliação gráfica de diversas naturezas, de sorte que cada resultado traga em si, ou no conjunto avaliado, informações suficientes para suscitar novas discussões e conclusões relativas ao fenômeno de VIV. 
Portanto, mediante decomposição, as séries temporais modais são analisadas graficamente segundo construção semelhante àquela já descrita quando na análise das séries temporais diretamente registradas pelo sistema de monitoração de cada alvo. Analogamente, as séries temporais modais são, então, apresentadas em torno de valores médios, $n=1,2,3, \ldots$, que representam os respectivos modos naturais a que dizem respeito. Notem que, mais uma vez, há correspondência entre as séries temporais modais e os respectivos gráficos da PSD, à direita da Figura 6.39.

Importante destacar que, com base nas amplitudes modais definidas pelo procedimento de decomposição modal, é possível reconstruir as séries temporais de cada alvo; procedimento adotado para a verificação das próprias decomposições.

Voltando às análises com base nas séries temporais originalmente registradas pelo sistema de monitoramento dos alvos, pode-se, ainda, construir gráfico da evolução temporal dos movimento em cada direção, apresentados como função das coordenadas curvilíneas, conforme exemplifica a Figura 6.42.

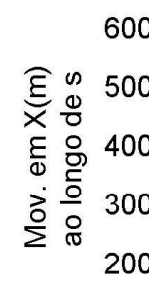

$$
\begin{array}{ll} 
& 600 \\
\text { os } & 500 \\
0 & \\
0 & 400 \\
\text { 흥 } & 400
\end{array}
$$$$
200
$$
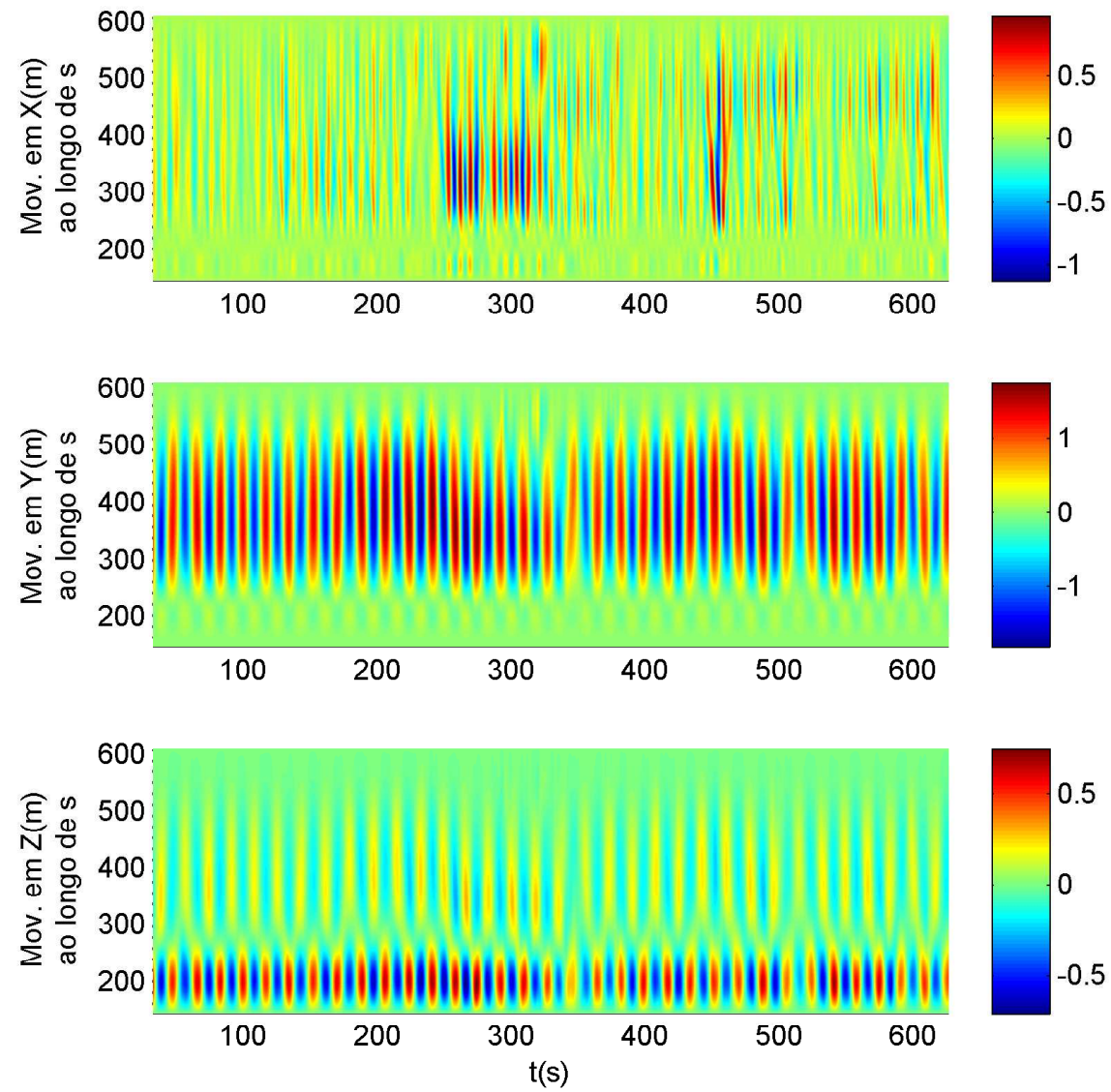

Figura 6.42: Exemplo evolução temporal dos deslocamentos para a Catenária-1 de cada alvo ao longo da linha, apresentados nas direções $X Y$ e $Z$. 
Note, neste tipo de gráfico, que: ordenadas dizem respeito à coordenada $s$ ao longo da linha; abscissas referem-se aos instantes de tempo e a escala de cores refere-se às magnitudes dos deslocamentos instantaneamente registrados.

Evolução temporal análoga também pode ser construída com base em sinais temporais apresentados segundo o sistema de coordenadas $(t, n, b)$, o que é exemplificado na Figura 6.43 .

Estes gráficos de evolução temporal, analisados com relação à condição inicial estática da catenária, permitem a identificação de ondas estacionárias ou progressivas ao longo do tempo. Tal conclusão se faz possível pela verificação da inclinação dos padrões de cores, onde repetições verticais periódicas do mesmo padrão indicam a predominância de ondas estacionárias, enquanto padrões oblíquos sugerem a existência de ondas progressivas.
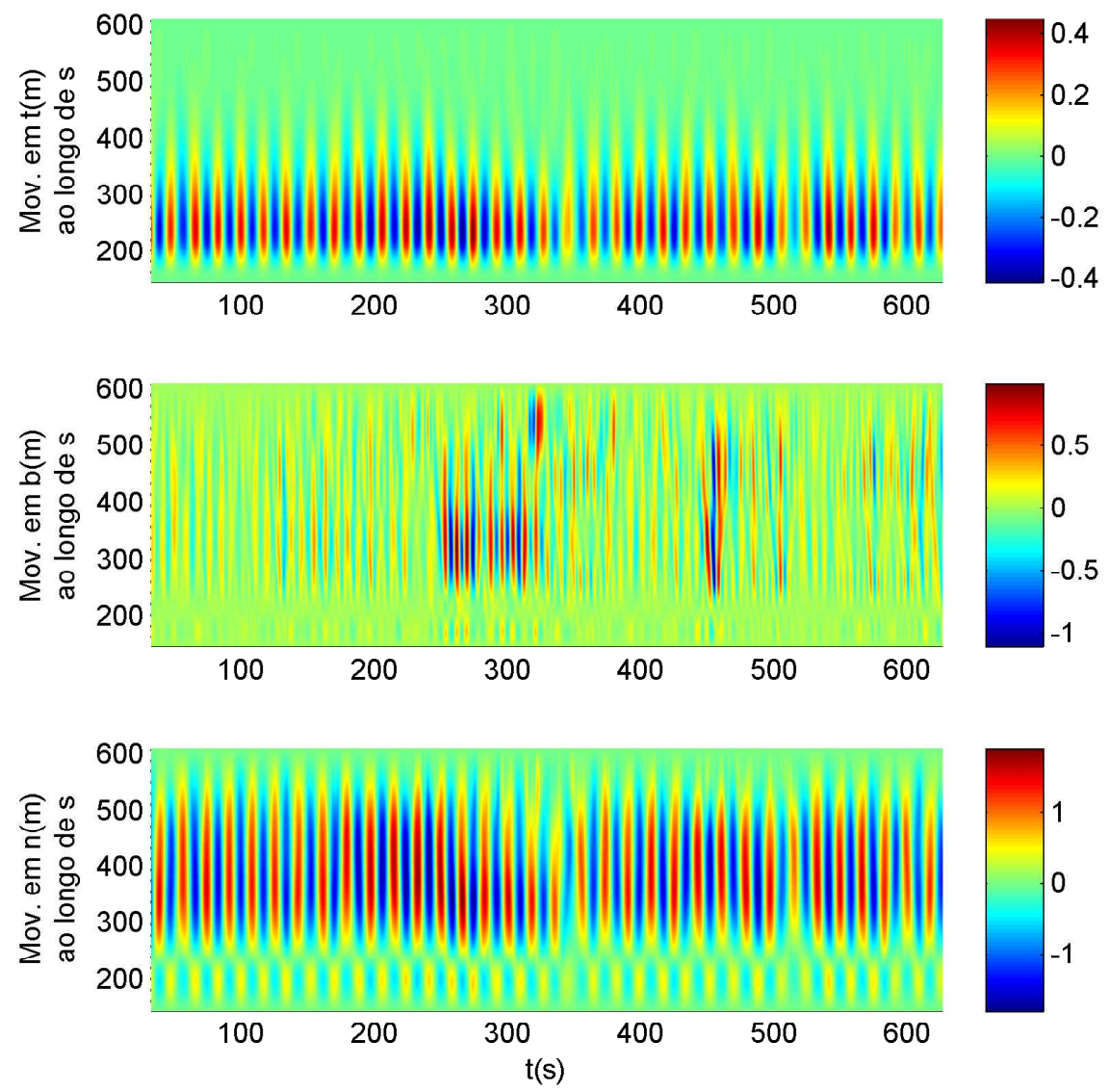

Figura 6.43: Exemplo de visualização de evolução temporal para a Catenária-1 nas direções tnb.

Com base nas análises dos sinais das componentes modais que formam determinada resposta, gráficos de síntese da variação das amplitudes modais como função das 
velocidades reduzidas podem ser construídos segundo três apresentações distintas, a saber: $a_{\max } / D$, média entre os $10 \%$ maiores valores de amplitude modal adimensional; $a_{\text {min }} / D$, média entre os $10 \%$ menores valores de amplitude modal adimensional; e $a_{r m s} / D$, desvio -padrão dos valores de amplitude modal adimensional.

Adicionalmente, esses gráficos também são construídos como função de dois tipos de variável independente: (i) função das velocidades reduzidas calculadas a partir da primeira frequência natural no plano de lançamento da linha e (ii) função das velocidades reduzidas calculadas com base na frequência natural de cada modo de vibrar. Enquanto a primeira serve de indicativo para avaliar a presença de coexistência modal, a segunda representa todas as curvas de amplitude modal em uma mesma faixa de velocidades reduzidas, assim, permitindo comparação direta entre amplitudes na faixa de sincronização de cada modo e a largura de cada uma dessas faixas.

A Figura 6.44 ilustra um exemplo desse tipo de gráfico de síntese, apresentado como função das velocidades reduzidas calculadas com a frequência natural do primeiro modo no plano de lançamento. Lembrar que, no âmbito desta tese, o perfil de velocidades é sempre ortogonal ao plano de lançamento das catenárias. 

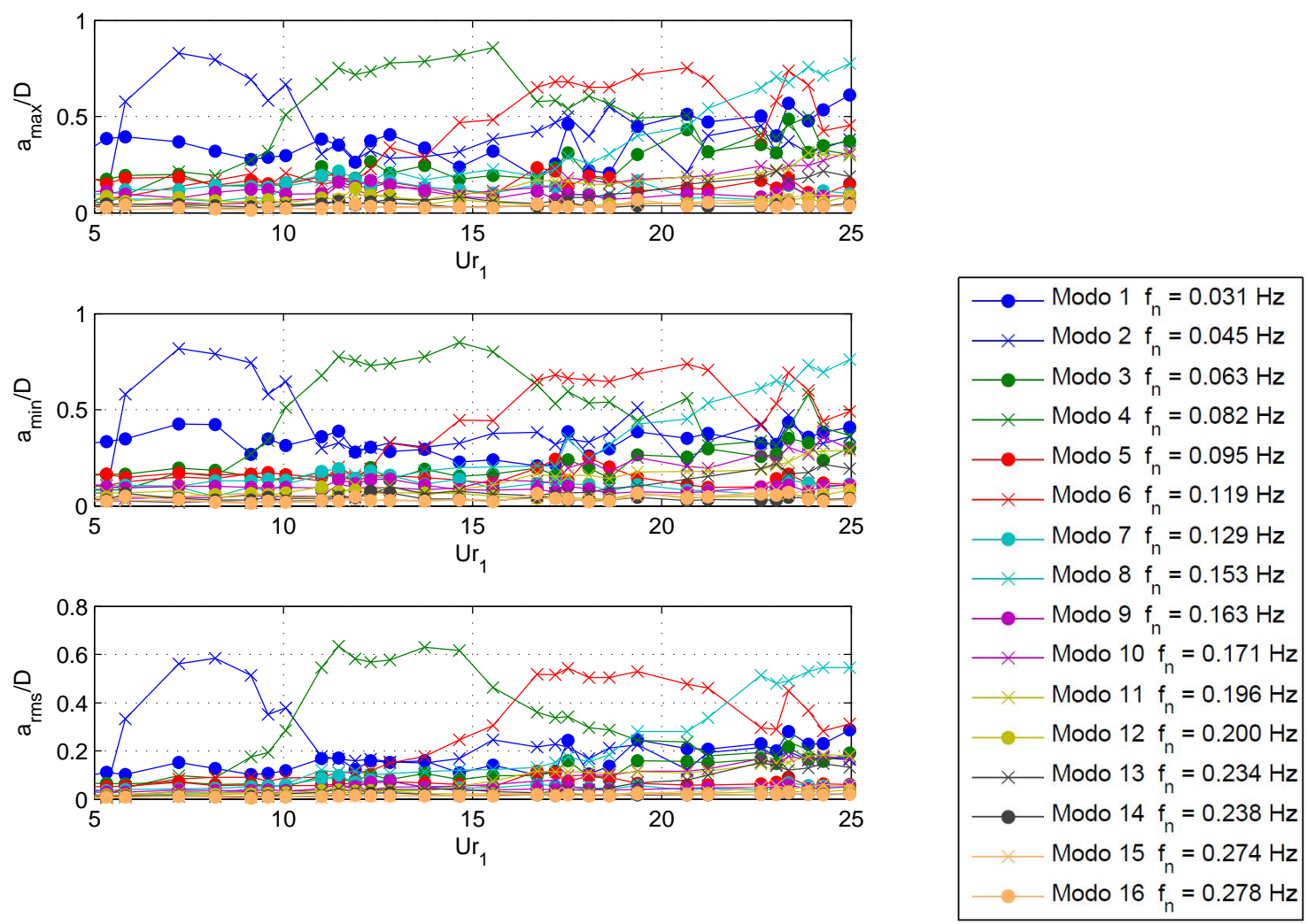

Figura 6.44: Amplitudes modais como função da velocidade reduzida calculada com a frequência natural do primeiro modo no plano de lançamento, $V r_{1}$ para Catenária-1. Ordenadas obtidas via: valores máximos, no alto; valores mínimo, ao centro; e desviospadrão de resposta modal, abaixo.

Os valores de desvio-padrão, no gráfico inferior da Figura 6.44 e demais apresentações semelhantes neste texto, foram multiplicados por $\sqrt{2}$, assumindo, por hipótese, haver relação entre este valor e a amplitude de cada componente modal. Lembrar que, no caso de sinais regulares, a relação entre amplitude de resposta, $A$, e respectivo desvio-padrão, $\sigma$, se faz segundo: $A_{q}=\sqrt{2} \sigma$, onde $q$ diz respeito à grandeza analisada.

Para os gráficos com a velocidade reduzida baseada na frequência natural do primeiro modo no plano, a avaliação de coexistência modal pode ser verificada a partir da existência de contribuições modais distintas em uma mesma velocidade reduzida. Já para as curvas com a velocidade reduzida calculada a partir da frequência natural específica de cada modo, é possível verificar a largura da faixa de sincronização modal, ou seja, para qual faixa de velocidade reduzida existe VIV naquele modo natural; ver exemplo na Figura 6.45 . 

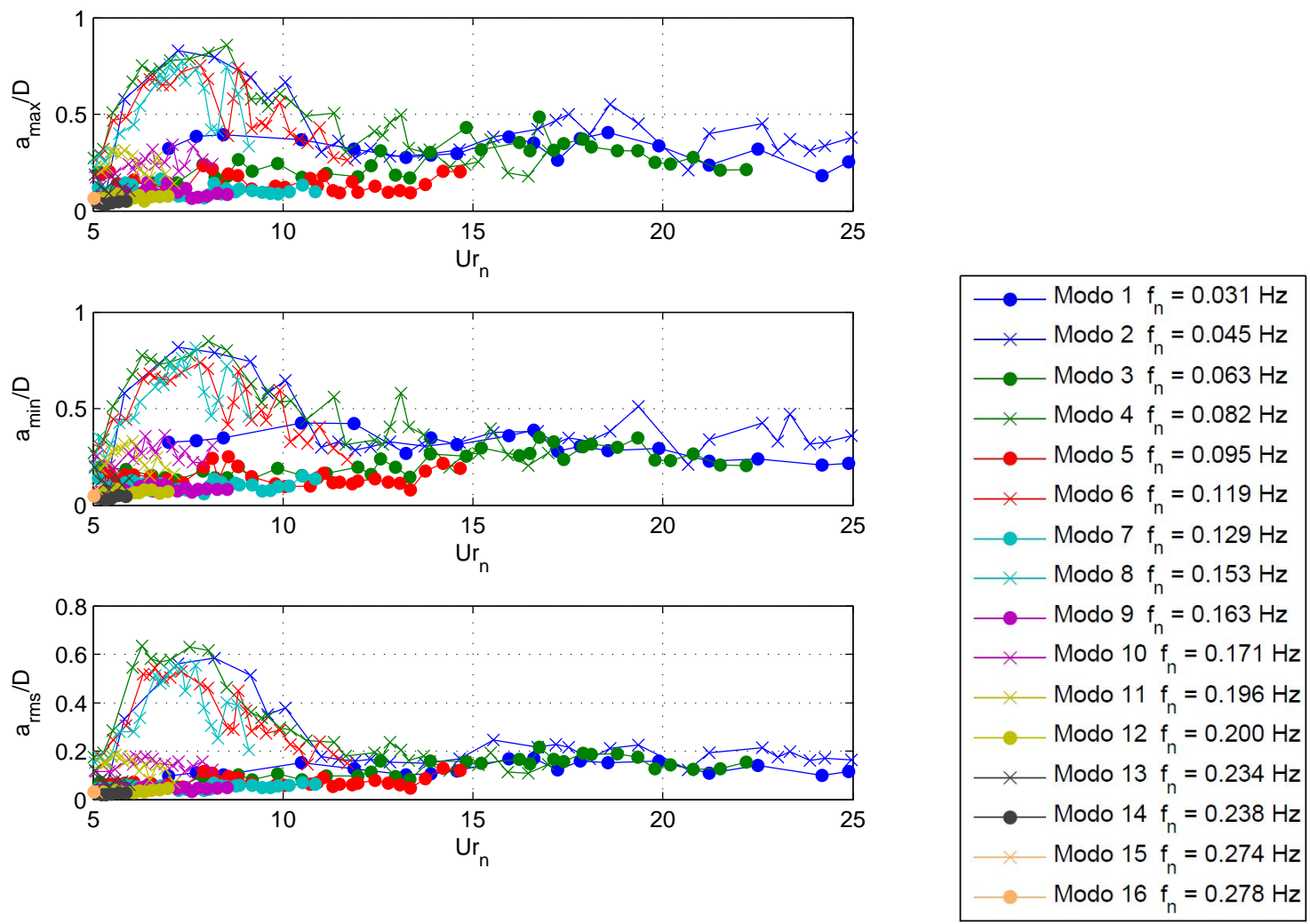

Figura 6.45: Amplitudes modais como função da velocidade reduzida calculada com a frequência natural do primeiro modo no plano de lançamento, $V r_{n}$ para Catenária-1. Ordenadas obtidas via: valores máximos, no alto; valores mínimo, ao centro; e desviospadrão de resposta modal, abaixo.

Finalmente, considerando as curvas de amplitude modal obtidas via desvio padrão, é possível a identificação das frequências de resposta modal, proporcionando avaliação semelhante àquela apresentada na Figura 4.3, onde as estimativas do número de Strouhal característico, $S t$, são confrontadas. Na Figura 6.46 podemos ver um exemplo deste tipo de análise aplicado aos resultados da Catenária-1. 

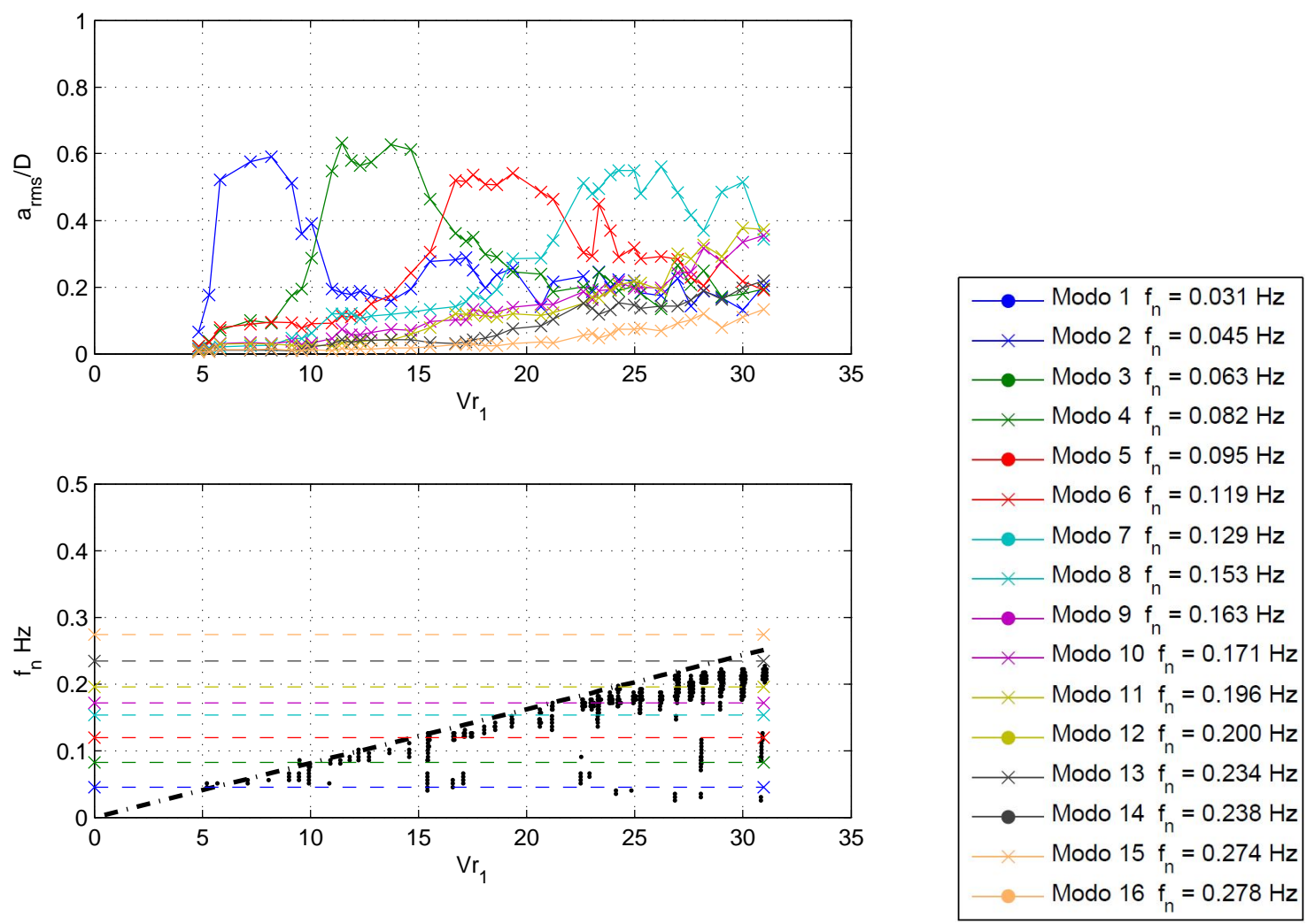

Figura 6.46: Análise conjunta das amplitudes e frequência modais, neste caso, observadas com a execução da matriz de ensaios referentes à Catenária-1.

\subsubsection{Método da decomposição modal}

Em consonância com o que foi exposto no Capítulo 4, com respeito ao cálculo dos modos de vibrar e das respostas de amplitude modal, neste item é apresentada a forma de obtenção das amplitudes modais a partir dos resultados experimentais, mais especificamente, com base nas séries temporais de deslocamento registradas pelo sistema de monitoramento dos alvos. Para estas análises foram utilizados os modos analíticos (segundo [Pesce et al., 1999]) e o código numérico Poliflex.

A decomposição modal pressupõe a ortogonalidade entre os modos de vibrar da estrutura, contudo, devido às não-linearidades intrínseca à resposta nas linha flexíveis, os modos não são exatamente ortogonais.

Ainda assim, com o produto interno definido na equação (6.1), é possível a verificação de valores muito próximos de zero para o produto interno entre autovetores que caracterizam os modos naturais ${ }^{3}$, tanto para os modos de vibração das linhas

\footnotetext{
3 Por definição, o produto interno está relacionado ao cosseno do ângulo entre dois vetores; logo, a nulidade de seu valor implica na ortogonalidade entre os mesmos. Para o caso particular das linhas
} 
verticais, quanto para aquelas lançadas em catenária.

$$
<u(s), v(s)>=\int u v d s
$$

Sendo assim, a despeito dessas considerações, as amplitudes modais serão avaliadas considerando os modos de vibrar como apresentados no capítulo 4.

Para tanto, considerando que os modos de vibrar podem ser caracterizados para as três direções referentes às coordenadas cartesianas $(x, y, z)$, as amplitudes modais podem ser avaliadas de maneira independente segundo equações (6.2).

$$
\begin{aligned}
& A_{x n}(t)=\frac{\int_{0}^{L} x(s, t) \varphi_{x n}(s) d s}{\int_{0}^{L} \varphi_{x n}^{2}(s) d s} \\
& A_{y n}(t)=\frac{\int_{0}^{L} y(s, t) \varphi_{y n}(s) d s}{\int_{0}^{L} \varphi_{y n}^{2}(s) d s} \\
& A_{z n}(t)=\frac{\int_{0}^{L} z(s, t) \varphi_{z n}(s) d s}{\int_{0}^{L} \varphi_{z n}^{2}(s) d s}
\end{aligned}
$$

onde: $\varphi_{n x}, \varphi_{n y}$ e $\varphi_{n z}$ são as funções que caracterizam o n-ésimo modo de vibrar, respectivamente, nas direções $x, y$ e $z$. A Figura 6.47 ilustra um exemplo de resultado obtido a partir dessas componentes, as cores representam cada instante de tempo da deformada da linha Catenária-1 ao longo do comprimento, com a reconstrução a partir das amplitudes modais representada por linhas contínuas e os pontos representam os valores experimentais nas posições dos alvos refletivos monitorados.

verticais, dominadas pela tração, os modos podem ser escritos como $\varphi_{n}=\sin (n \pi s / L)$, funções ortogonais, o que implica produtos internos nulos. 

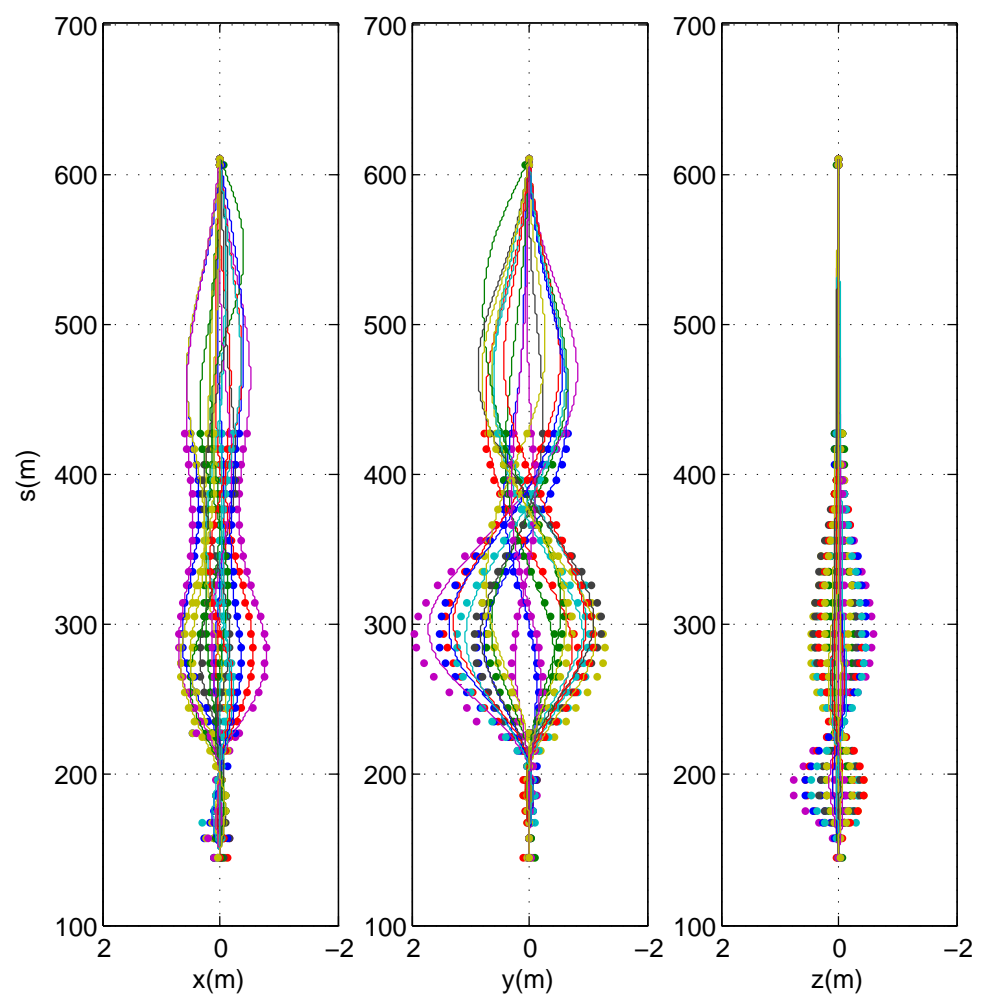

Figura 6.47: Exemplo de resultado da decomposição modal aplicada ao conjunto de séries temporais monitoradas em ensaio de VIV com a Catenária-1. Componentes direcionais definidas com base nas equações (6.2).

Pode-se notar que, para este caso exemplo, a reconstrução ao longo da linha apresenta boa aderência com os valores monitorados nas direções $X$ e $Y$, o mesmo não acontecendo para a direção $Z$; resultado contornado com a composição apresentada a seguir.

Ainda mais interessante que as componentes direcionais consideradas de maneira independente, são os resultados obtidos para a amplitude modal combinada de acordo com a equação (6.3). Neste casos, considerando as três direções para estimativa de uma amplitude modal do n-ésimo modo natural de vibrar, os resultados se mostram aderentes por completo, como pode ser visto na Figura 6.48.

$$
A_{n}(t)=\frac{\int_{0}^{L} x(s, t) \varphi_{x n}(s) d s+\int_{0}^{L} y(s, t) \varphi_{y n}(s) d s+\int_{0}^{L} z(s, t) \varphi_{z n}(s) d s}{\int_{0}^{L} \varphi_{x n}^{2}(s) d s+\int_{0}^{L} \varphi_{y n}^{2}(s) d s+\int_{0}^{L} \varphi_{z n}^{2}(s) d s}
$$



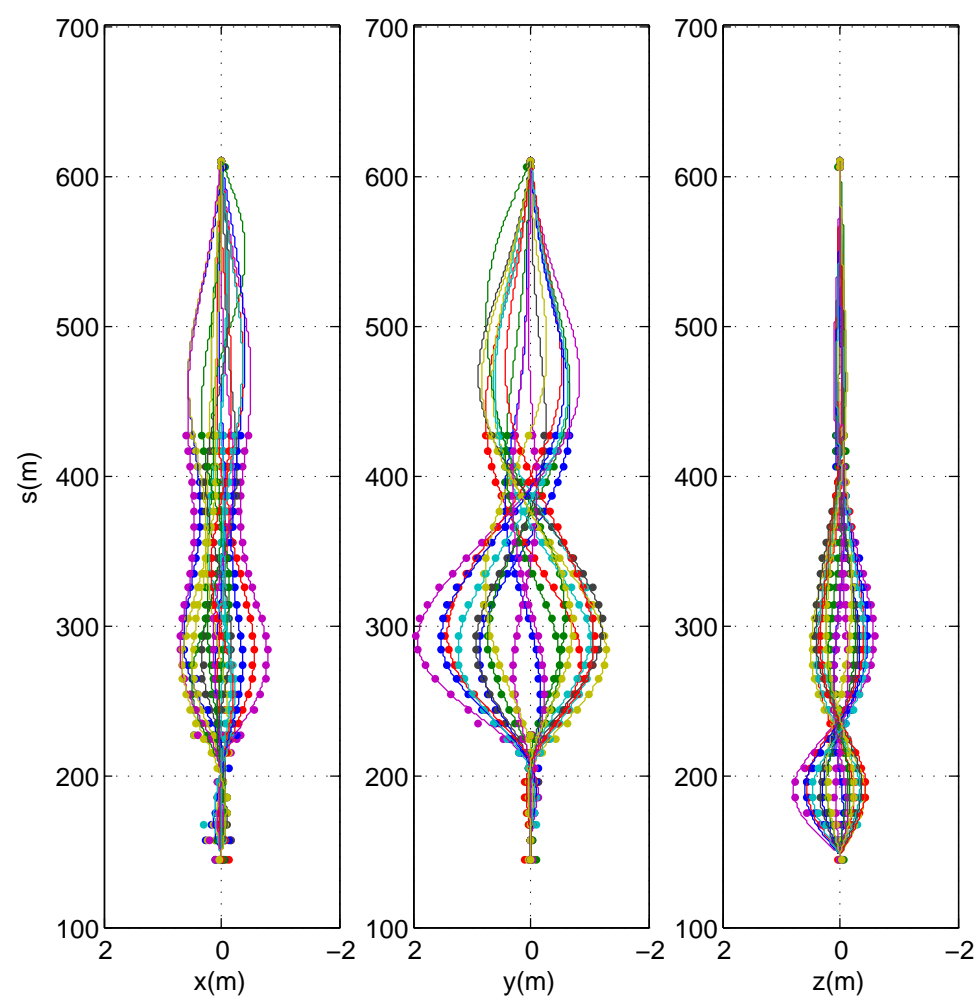

Figura 6.48: Exemplo de resultado da decomposição modal obtida com base nas equações (6.3), posteriormente ponderadas pelos modos naturais da Catenária-1.

Cumpre comentar que o fato de a linha não ter sido monitorada em todo o seu comprimento, devido a limitações laboratoriais, é prejudicial à estimativa via integrais nas equações (6.2) e (6.3). Considerando que no domínio discreto são utilizados somatórios em substituição às integrais do domínio contínuo, a metodologia adotada se completa com as análises experimentais com valores linearmente interpolados na região não monitorada, ou seja, entre o último alvo monitorado e o ponto junto à conexão no topo da catenária. Neste contexto, o somatório dos produtos entre amplitudes modais dadas pela equação (6.3) e os respectivos modos em cada instante melhora a reconstrução nas direções $Y$ e $Z$, contornando a deficiência da decomposição em componentes, apresentada pelas equações $(6.2)$.

Outra forma para avaliação das amplitudes modais é apresentada em [Kaasen, 2002], na tentativa de suprir a ausência de monitoramento em determinados trechos da linha. A decomposição proposta baseia-se no Método dos Mínimos Quadrados (MMQ), a fim de avaliar instantaneamente e de forma independente as amplitudes modais para cada direção. Em resumo, ao invés da decomposição modal ser realizada com um produto interno do tipo (6.1), as amplitudes são calculadas via minimização do erro que melhor 
aproxima a linha elástica instantânea do modo natural conhecido teoricamente. Neste caso, amplitudes modais são obtidas de maneira mais simples, de acordo com as equações (6.4).

$$
\begin{aligned}
& A_{n x}(t)=\left[\varphi_{n x}(s) \varphi_{n x}(s)^{T}\right]^{-1} \varphi_{n x}(s) x(s, t) \\
& A_{n y}(t)=\left[\varphi_{n y}(s) \varphi_{n y}(s)^{T}\right]^{-1} \varphi_{n y}(s) y(s, t) \\
& A_{n z}(t)=\left[\varphi_{n z}(s) \varphi_{n z}(s)^{T}\right]^{-1} \varphi_{n z}(s) z(s, t)
\end{aligned}
$$

Embora mais simples, a decomposição proposta em [Kaasen, 2002] é bastante suscetível a ruídos inerentes à monitoração. No caso de monitorações mais ruidosas, a reconstrução pode incorrer em valores discrepantes, eventualmente muito maiores do que os esperados. Ver comparação apresentada na Figura 6.49, onde as análises são feitas segundo a equação (6.4): à esquerda, com base nos sinais temporais originais de um ensaio com a Catenária-1, e à direita, com base em sinais filtrados (filtro passa baixa).
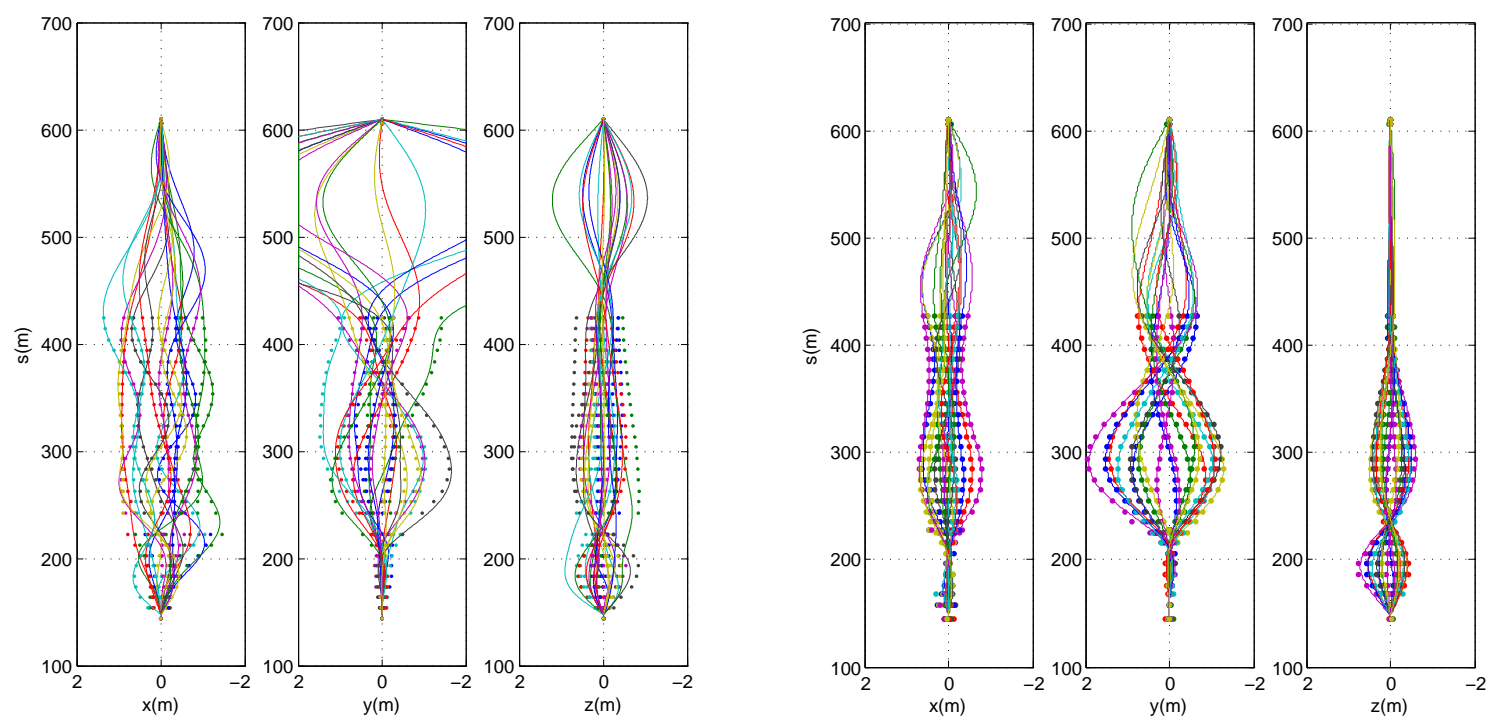

Figura 6.49: Exemplo de resultado da estimativa para as amplitudes modais segundo a equação (6.4): às esquerda, com base em sinais temporais originais de um ensaio com a Catenária-1, e à direita, com sinais filtrados.

Para a avaliação das várias amplitudes modais foi utilizada uma apresentação gráfica semelhante àquela utilizada para a avaliação das séries temporais originais de cada alvo, ou seja, variações temporais das amplitudes modais apresentadas em torno dos respectivos números modais, $n$.

As Figuras 6.50 e 6.51 ilustram as séries temporais de amplitude modal para uma determinada velocidade do braço giratório transportando a Catenária-1. Essas figuras 
foram confeccionadas a partir da avaliação da amplitude modal: (i) de forma independente, segundo equações (6.2); (ii) de forma acoplada, conforme equação (6.3); e (iii) pelo Método dos Mínimos Quadrados, equação (6.4).
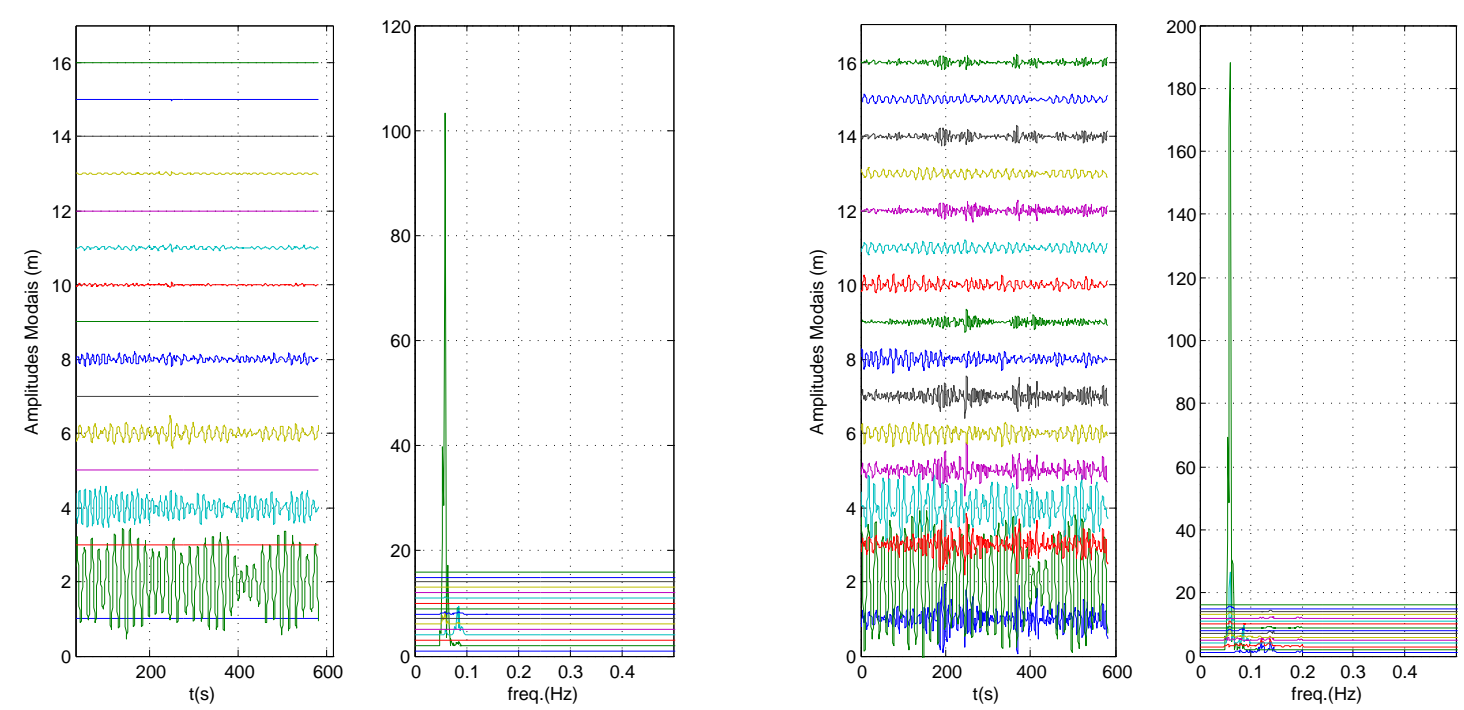

Figura 6.50: Séries temporais das amplitudes modais na direção $Y$ : à esquerda, calculadas com base na equação (6.2), e à direita, com base na equação (6.3) para a

Catenária-1.

É possível notar as diferenças entre amplitudes modais obtidas de forma independente e acoplada, motivadas pela ausência de resposta nos modos ímpares das curvas à esquerda na Figura 6.50. Para o caso onde a avaliação é feita de maneira acoplada, existem respostas tanto nos modos ímpares, quanto nos modos pares, respectivamente, no plano de lançamento e fora dele, o que melhora as curvas à direita da Figura 6.50.

As séries de amplitude modal obtidas via MMQ são apresentadas na Figura 6.51, com diferenças em relação às anteriores, no entanto, mais próximas daquelas calculadas com base na equação (6.3).

Com o intuito de melhor comparar as diferenças entre os métodos definidos pelas equações (6.3) e (6.4), construiu-se a Figura 6.52. Pode-se notar que, embora as amplitudes de resposta sejam similares para os modos dominantes, no caso da estimativa realizada pelo MMQ, também existem amplitudes consideráveis em modos mais altos, o que deve estar associado aos impactos do ruído inerente às monitorações, neste caso, não filtrado. 

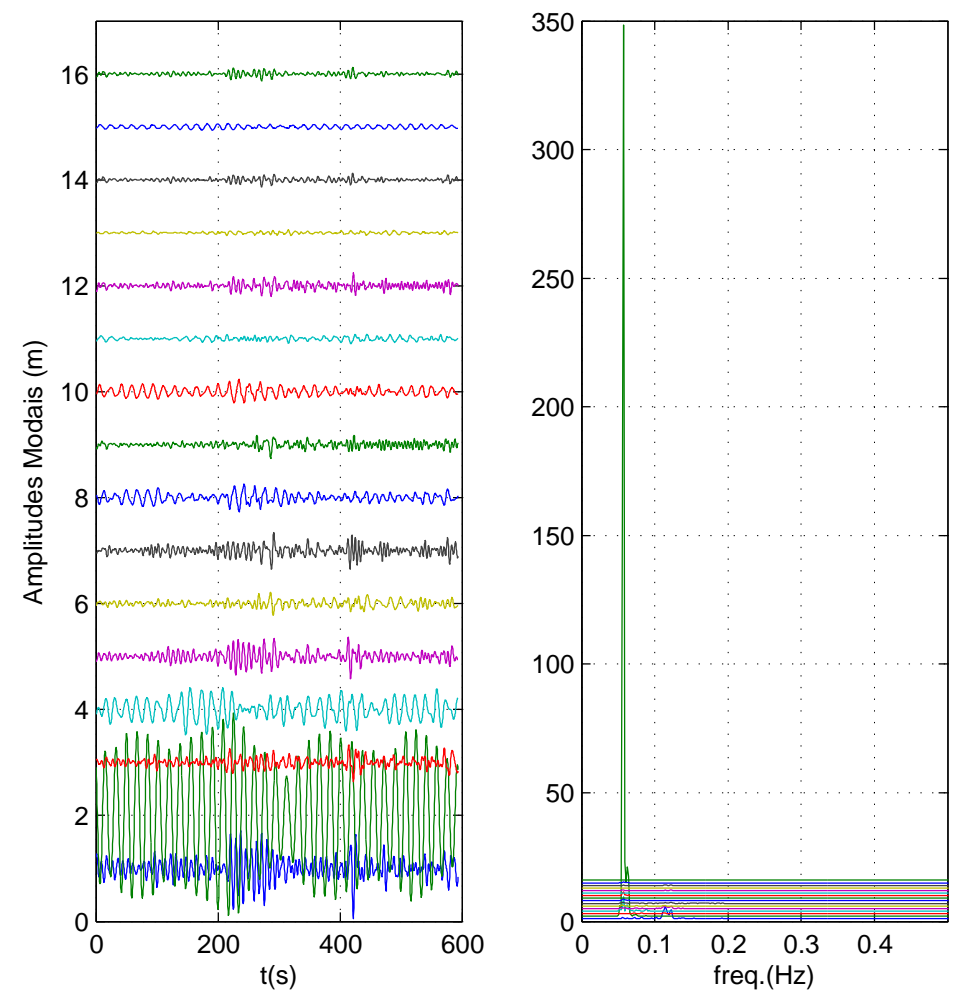

Figura 6.51: Séries temporais das amplitudes modais na direção $Y$, calculadas com base na equação (6.4) para a Catenária-1.
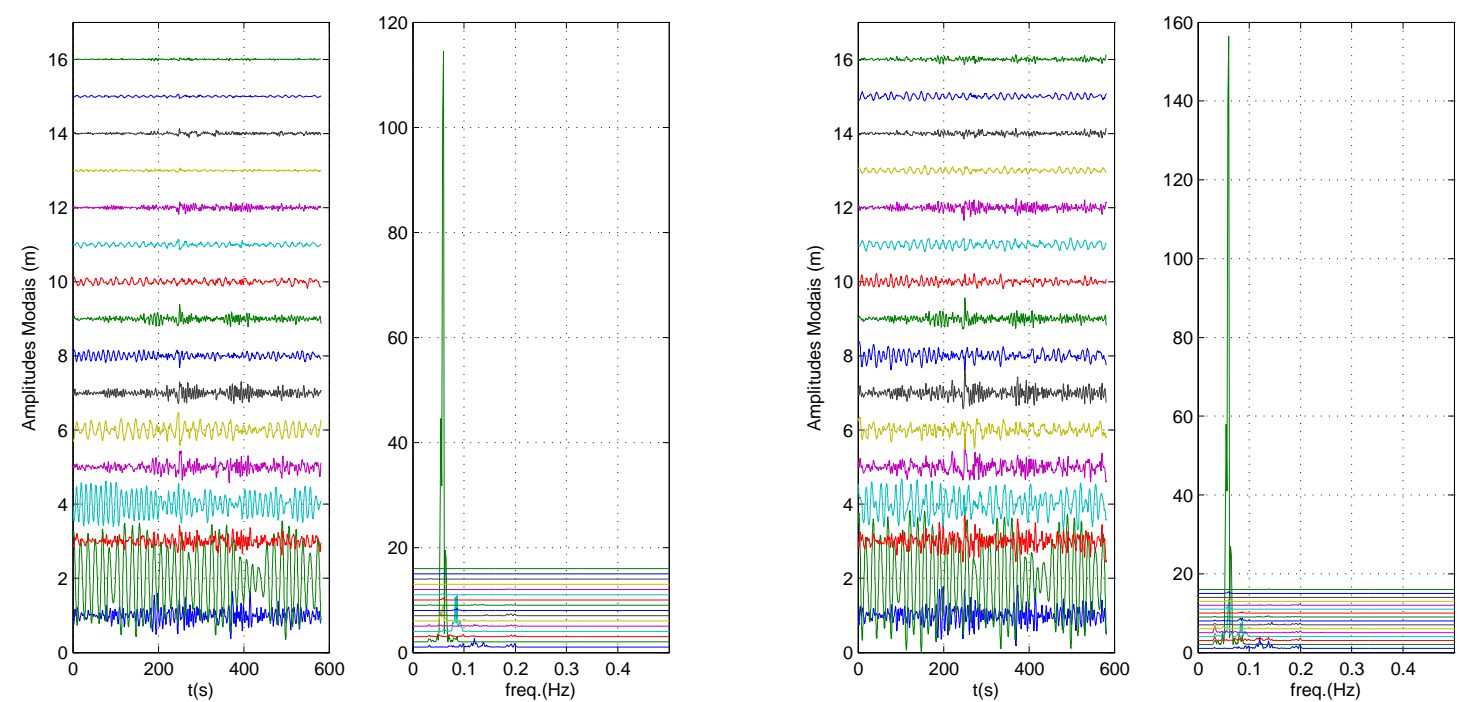

Figura 6.52: Comparação da amplitude modal obtidas de (6.3) e (6.4) com relação a velocidade reduzida variável ao longo da linha para Catenária-1 sob velocidade máxima $U_{\max }=0.914 \mathrm{~m} / \mathrm{s}$

Portanto, para a avaliação de cada ensaio de VIV na catenária sob correnteza variável, 
podem ser realizadas análises das séries temporais das amplitudes modais, identificando os valores máximo médio, mínimo médio, e de desvio- padrão, bem como as respectivas frequências de resposta. Esses valores podem e serão apresentados no próximo capítulo, como funções das velocidades reduzidas.

A Figura 6.53, por sua vez, exemplifica parte desta resultados, no caso, para uma velocidade máxima específica $\left(U_{\max }=0,914 \mathrm{~m} / \mathrm{s}\right)$.
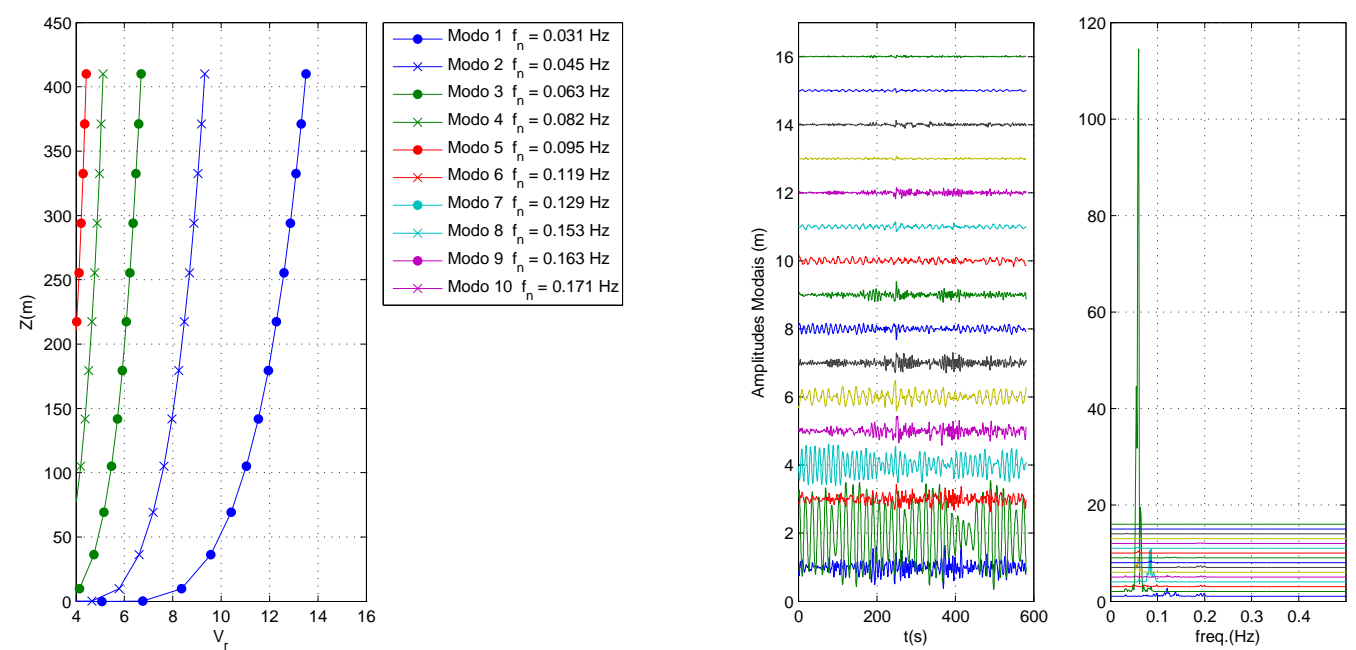

Figura 6.53: Avaliação da amplitude modal com relação a velocidade reduzida variável ao longo da Catenária-1, calculada com base na velocidade nominal máxima de $U_{\text {max }}=0.914 \mathrm{~m} / \mathrm{s}$ e nas respectivas frequências naturais de cada modo.

Na curva à direita da Figura 6.53 pode-se verificar que o segundo modo (primeiro modo no plano) marcado com $\times$, se encontra dentro da região de excitação, entre $5<V_{r}<9$, por esse motivo, apresentando a maior amplitude modal de resposta. Além desse, apenas o quarto modo natural (segundo modo no plano $\times$ ) encontra-se dentro da região teórica de provável sincronização, mesmo assim, pequenas contribuições nos modos com $n>5$ podem ser verificadas.

Em resumo, três métodos foram implementados na tentativa de avaliar de maneira coerente os valores de amplitudes modais, tendo em vista que a linha não foi monitorado em toda a sua extensão. Contudo, nas análises dos resultados apresentados e discutidos no próximo capítulo, apenas o método baseado na equação (6.3) será adotado, por ter resultado em amplitudes modais mais coerentes, sem a necessidade de procedimentos de filtragem dos sinais originais de deslocamento advindos do monitoramento dos alvos. 
Finalizada a apresentação dos materiais e métodos utilizados na condução dos experimentos de VIV definidos com as matrizes de ensaio, no próximo capítulo são sintetizados e discutidos os principais resultados auferidos. 


\section{$7 \quad$ Resultados Experimentais}

Neste capítulo são apresentados, descritos e comparados os resultados obtidos a partir de cada configuração de ensaio dos modelos de linha (vertical e lançados em catenária), mediante as várias condições estabelecidas nas respectivas matrizes de ensaio estabelecidas no capítulo 6.3.

Os resultados auferidos foram analisados em consonância com os procedimentos desenvolvidos e apresentados no Capítulo 6, seção 6.4. Naquela seção são apresentados diversos gráficos, gerados para cada condição ensaiada e com o objetivo de facilitar a avaliação dos resultados experimentais.

Dentre os vários gráficos construídos nesta pesquisa, cumpre destacar a importância daquele referente à variação das amplitudes modais como função da velocidade reduzida. Estes gráficos fazem uma síntese de todas as velocidades ensaiadas, apresentando de forma clara a dinâmica das linhas flexíveis sob ação da correnteza.

Como estrutura de apresentação, o presente capítulo traz, em sua seção 7.1, uma síntese dos principais resultados dos ensaios de VIV na linha vertical. Importante destacar que, dada a extensa abrangência da matriz de ensaios, apenas os resultados importantes para as comparações ao final deste capítulo foram incluídas na seção 7.1. Um conjunto de resultados relativos a cinco valores de velocidade reduzida são trazidos no ANEXO A, podendo servir a eventuais consultas ou comparações teórico-experimentais.

$\mathrm{Na}$ apresentação dos resultados é importante destacar que cada caso de ensaio foi descrito a partir do mesmo conjunto de gráficos, de maneira a facilitar a comparação entre os diferentes resultados e comportamentos dinâmicos de interesse. Assim, a discussão dos resultados com avaliação do movimento de cada alvo baseia-se nos deslocamentos em torno da média de cada série temporal. São determinados o valores máximos de resposta e em qual frequência. Desvios padrão também são avaliados, assim como as evoluções temporais que auxiliam na avaliação do passeio do TDP e na identificação do comportamento estacionário ou progressivo das respostas. 
Adicionalmente, com base na decomposição modal, são avaliadas as magnitudes e frequências das componentes excitadas, largura das faixas de sincronização e evolução dos comportamentos com o aumento da velocidade reduzida.

Seção análoga, a de número 7.2, traz uma síntese dos resultados advindos dos ensaios com as Catenárias. Novamente, conjuntos mais completos de resultados podem ser encontrados nos ANEXOS de B a F.

Finalmente, em sua terceira e última seção, este capítulo se dedica à análise comparativa entre os resultados síntese, identificando padrões de comportamento que permitam o atendimento do objetivos traçados para esta tese.

\subsection{Resultados na linha flexível vertical}

Conforme mencionado, nesta primeira seção são apresentados os resultados para avaliação do fenômeno de VIV no modelo de linha vertical. Essa configuração refere-se à incidência de um perfil de correnteza constante ao longo da linha, de sorte que os resultados também permitem a avaliação da viabilidade do braço giratório como equipamento para a investigação do fenômeno de VIV, via comparação com trabalhos semelhantes obtidos em tanques de reboque, por exemplo, [Chaplin et al., 2005b] ou [Huera-Huarte \& Gharib, 2011], entre outros. Além disso, com base nos resultados desta configuração, os alicerces teórico-experimentais associados são muito bem estabelecidos, criando uma excelente caso de referência.

\subsubsection{Detalhes extras dos ensaios com a linha flexível vertical}

A apresentação dos resultados desse caso específico dizem respeito aos ensaios realizados para avaliação do fenômeno de VIV em modelo de linha flexível vertical na escala 1:100, de comprimento total $L=3,428 \mathrm{~m}$ e diâmetro externo $D=22,2 \mathrm{~mm}$ (na escala do modelo), sujeito à ação de perfil uniforme de correnteza, com intensidades variando de $0,05 \mathrm{~m} / \mathrm{s}$ a $0,33 \mathrm{~m} / \mathrm{s}$.

Não se trata, portanto, do resultado mais importante desta tese de doutorado, com o foco na investigação de catenárias em correnteza variável. Ainda assim, o estudo do modelo lançado verticalmente permitiu o desenvolvimento de uma série de procedimentos e mecanismos capazes de viabilizar as demais atividades, descritas na sequência do texto.

Um ponto a ser ressaltado é o fato da linha vertical em questão possuir frequências 
naturais idênticas nas duas direções e modos de vibrar de determinação mais simples, criando um bom cenário para uma bateria de testes iniciais.

A Figura 7.1 ilustra um trecho da série temporal relativa à condição considerada como exemplo na apresentação da metodologia de análise, seção 6.4. É possível identificar os mesmos padrões de trajetórias em cada alvo, com o cuidado da transformação para um sistema de coordenadas inercial.

De fato, cabe ressaltar que a investigação experimental da linha vertical envolveu dois sistemas de coordenadas: o inercial, que descreve as posições dos alvos obtidas diretamente pelo sistema de monitoramento óptico e o não- inercial, fixo ao braço giratório, que identifica os movimentos pelas direções longitudinal e transversal ao escoamento (correnteza incidente) de maneira direta, sem a interferência no campo visual do equipamento de medição. Estes movimentos, por sua vez, são obtidos a partir de uma simples transformação de coordenadas cartesianas para polares.

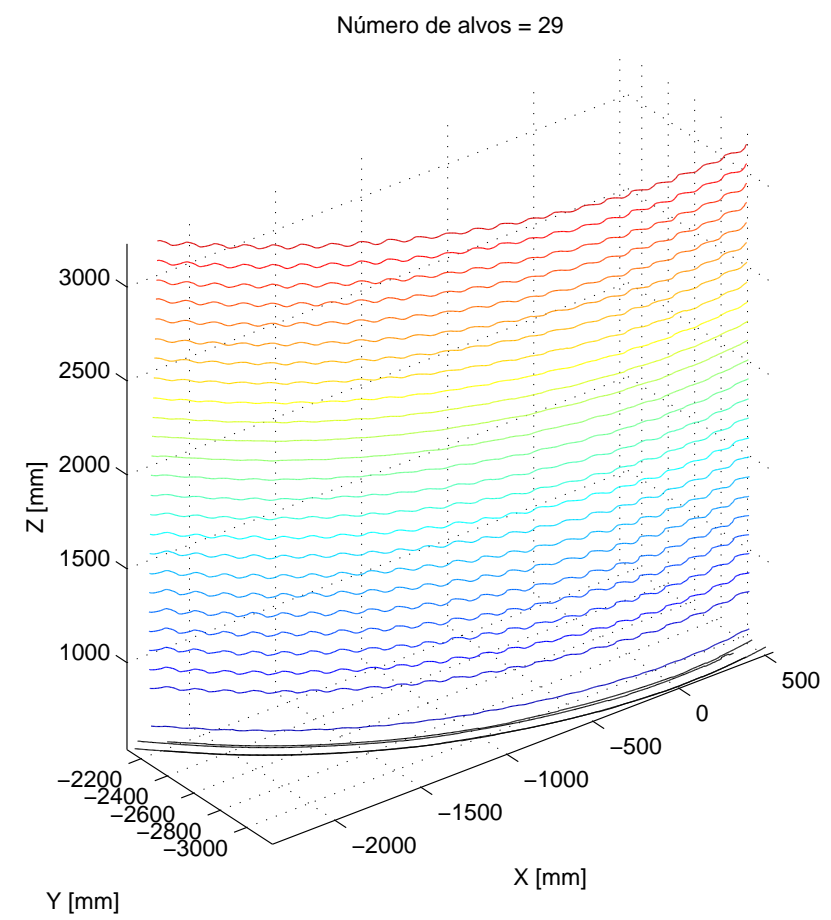

Figura 7.1: Séries temporais de deslocamento ao longo do modelo, obtidas com base no referencial global, na condição de $U_{\max }=0,13 \mathrm{~m} / \mathrm{s}$ e $T_{0}=37 \mathrm{~N}$ (escala do modelo).

Sendo assim, a partir da identificação dos alvos a serem considerados, a transformação mencionada permite o estudo dos movimentos descritos em componentes transversais e longitudinais ao escoamento incidente, conforme prática usual nos estudos do VIV. Neste sentido, ângulos e raios instantâneos são convertidos para deslocamentos nas direções 
longitudinal(in-line) e transversal(cross-flow) ao escoamento, segundo as transformações apresentadas na equação 7.1 .

$$
\begin{aligned}
& X(t)=R(t) \cdot \operatorname{sen} \Theta_{x}(t) \\
& Y(t)=R(t) \cdot \cos \Theta_{x}(t)
\end{aligned}
$$

onde $R(t)$ e $\Theta_{x}(t)$ são, respectivamente, o raio e o ângulo instantâneos, tomados em relação à direção $X$.

A mudança de referencial (do inercial para o não-inercial), possibilitou também a realização de análises complementares. Na Figura 7.2 é apresentada a mesma condição de ensaio ilustrada anteriormente, com os movimentos descritos no referencial não- inercial, ou seja, aquele solidário ao braço giratório.

A seguir são apresentados mais alguns resultados para o caso da linha vertical ensaiada em $U_{\max }=0,13 \mathrm{~m} / \mathrm{s}$. As discussões apresentadas servem a dois propósitos principais: a avaliação da resposta do modelo ensaiado e a verificação do desempenho do braço giratório como equipamento de investigação do fenômeno de VIV.
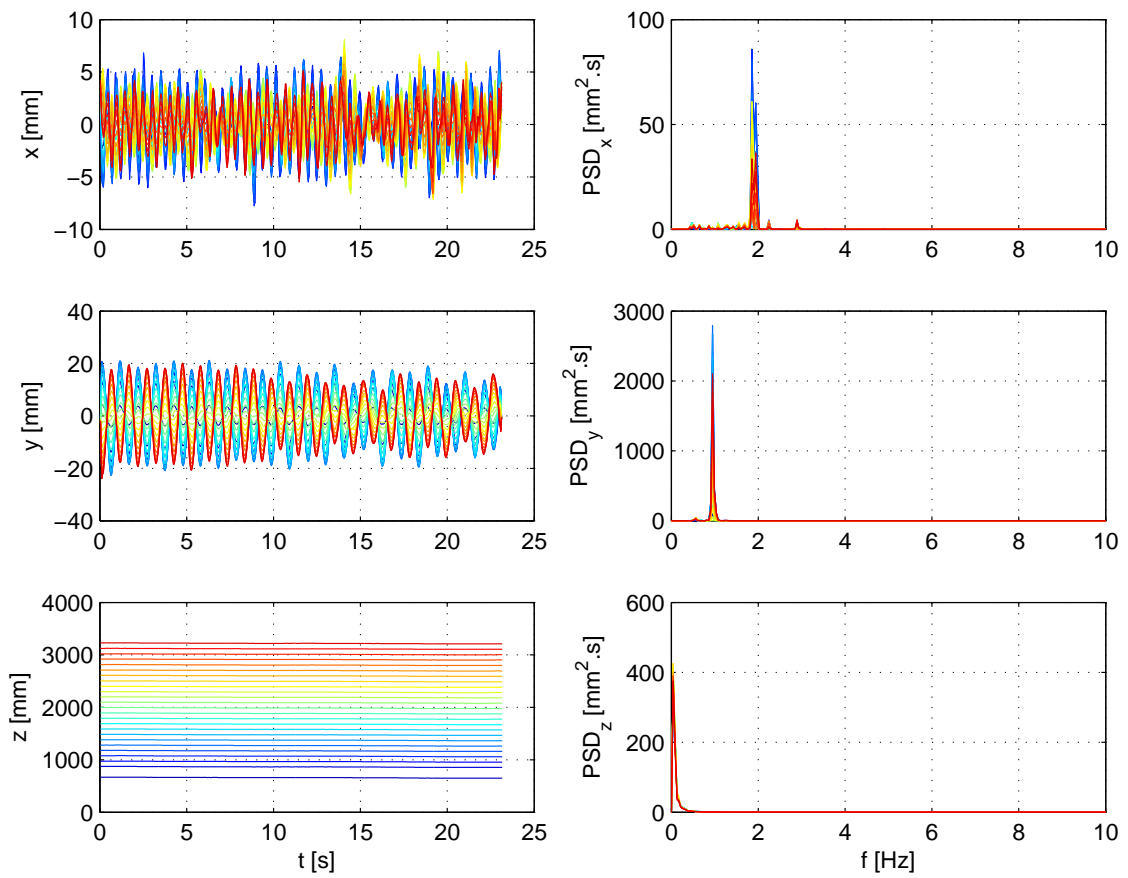

Figura 7.2: Séries temporais de deslocamento ao longo do modelo, nas direções $X, Y$ e $Z$, obtidas com base no referencial local (não-inercial). Caso referente a $U_{\max }=0,13$ $\mathrm{m} / \mathrm{s}$ e $T_{0}=37 \mathrm{~N}$ (escala do modelo). 
As Figuras de 7.3 a 7.5 são apresentadas com o intuito de evidenciar outros resultados relevantes, que possibilitam maior entendimento do caso em estudo.

A partir de gráficos como o ilustrado na Figura 7.3, é possível inspecionar as trajetórias ao longo do comprimento do modelo. Especificamente neste caso, é possível visualizar, junto ao fundo, trajetórias tipicamente em "forma de meia lua" (tons de azul), bastante diferentes daquelas observadas nos alvos mais próximos da superfície livre (trajetórias em "forma de oito", tons de vermelho).
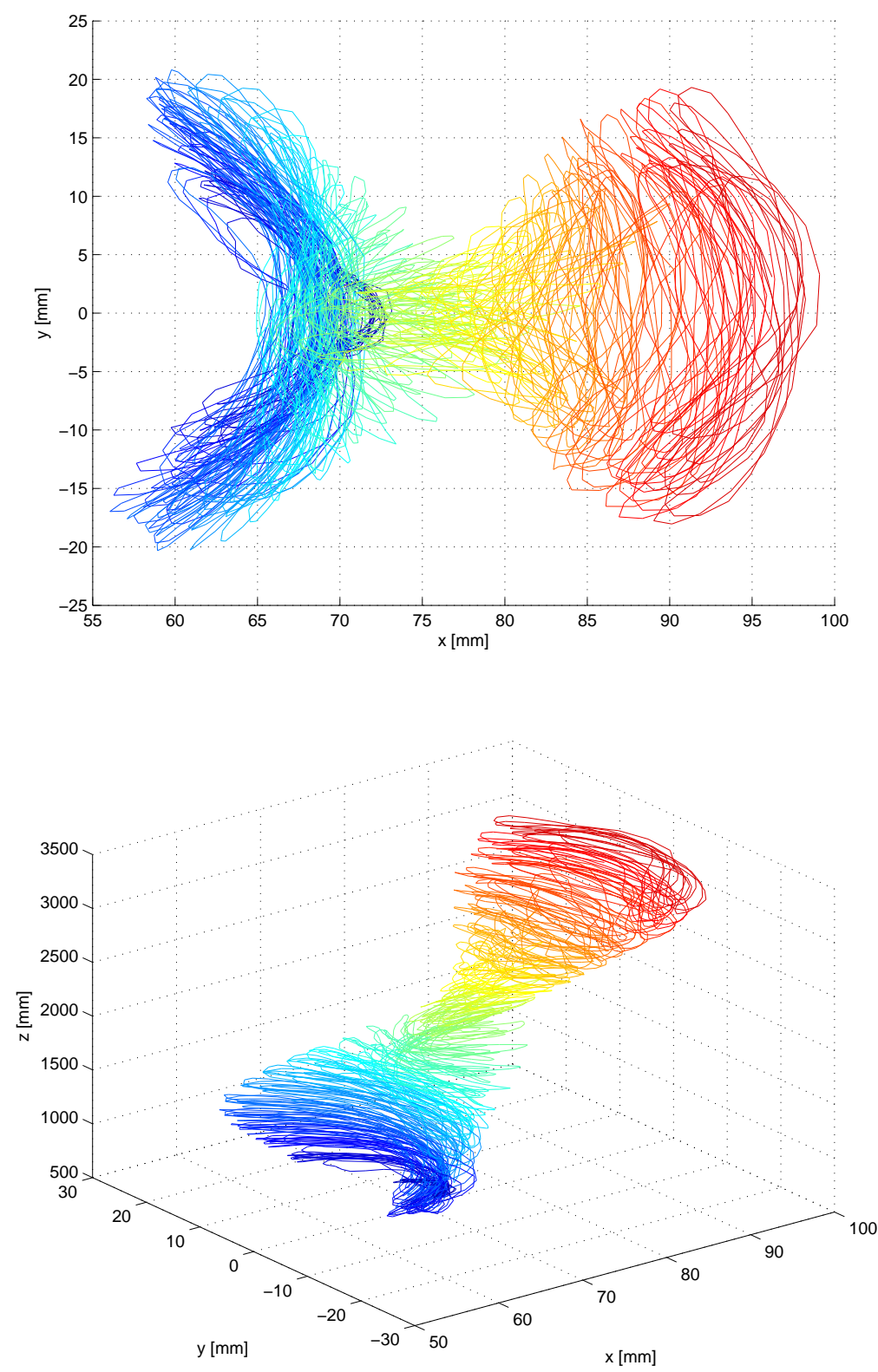

Figura 7.3: Trajetórias ao longo do comprimento do modelo flexível vertical, referentes ao ensaio em $U_{\max }=0,13 \mathrm{~m} / \mathrm{s}$ e $T_{\text {topo }}=37 \mathrm{~N}$ (escala do modelo). Apresentação feita no plano $X Y$. 
A Figura 7.4, adicionalmente, apresenta a evolução temporal dos deslocamentos nas direções longitudinal e transversal ao escoamento. Conforme mencionado, resultados apresentados dessa forma permitem a avaliação da presença de ondas progressivas, traveling waves, ou a ausência das mesmas, como no exemplo considerado.
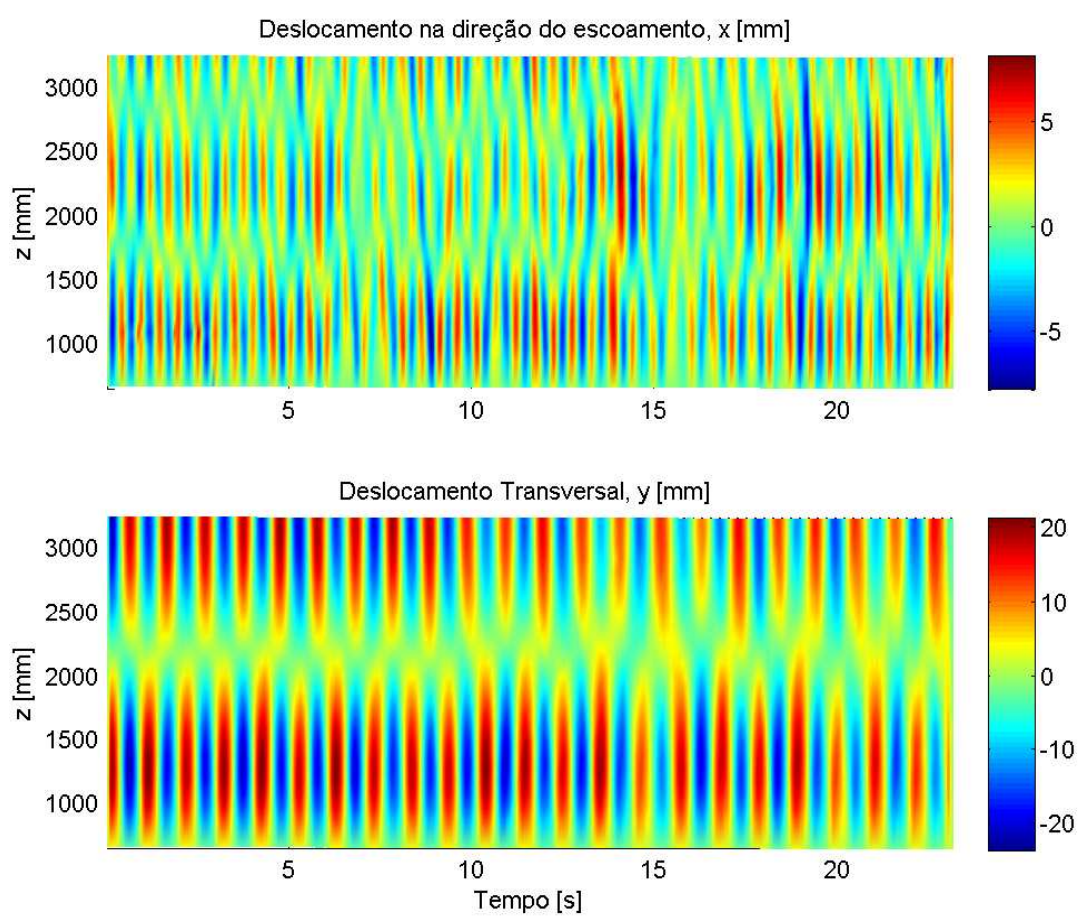

Figura 7.4: Evolução temporal dos deslocamentos ao longo do modelo, nos planos $X Y$, referentes ao ensaio com a linha vertical em $U_{\max }=0,13 \mathrm{~m} / \mathrm{s}$ e $T_{\text {topo }}=37 \mathrm{~N}$ (escala do modelo.
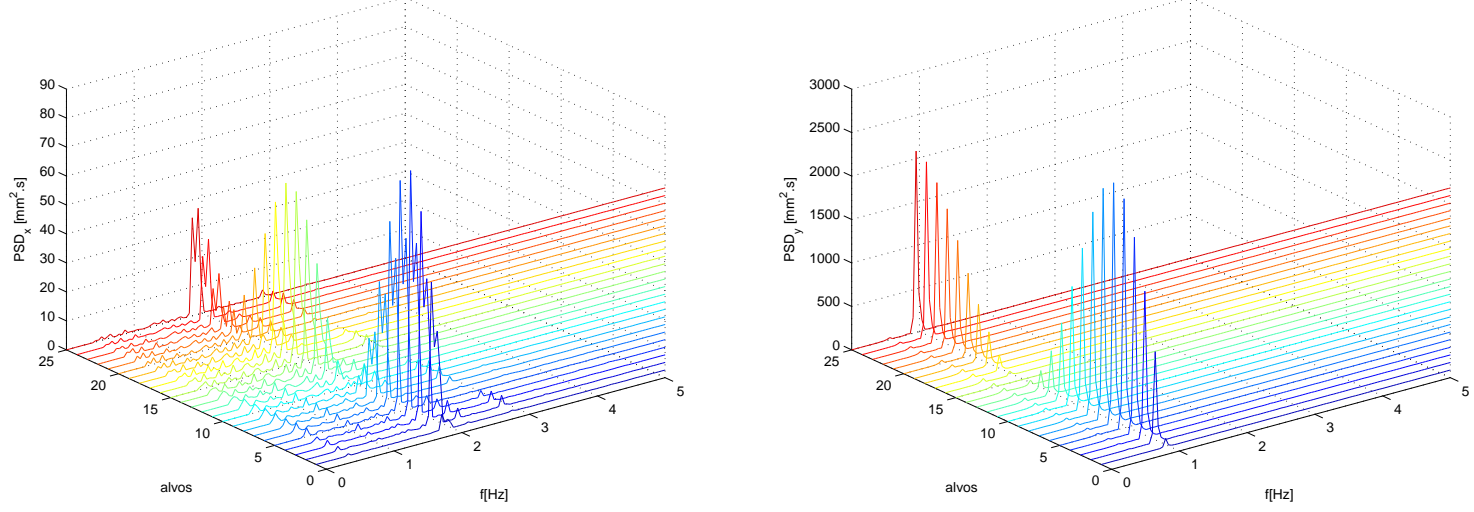

Figura 7.5: À esquerda, PSD na direção $X$ ao longo do modelo vertical em $U_{\text {max }}=0,13 \mathrm{~m} / \mathrm{s}$ e $T_{\text {topo }}=37 \mathrm{kN}$. À direita, respectivos resultados de PSD para a direção $Y$ 
De acordo com a matriz de ensaio (Tabela 6.7), para a velocidade $U_{\max }=1,3 \mathrm{~m} / \mathrm{s}$ o $2^{o}$ modo de vibrar pode coexistir com o $3^{o}$ modo natural $\left(V_{r 2} \cong 10\right.$ e $V_{r 3} \cong 5$ ), que, por sua vez, parece evidenciado com respostas em frequência padrão na direção longitudinal ao escoamento, aproximadamente o dobro das transversais, conforme gráficos de PSD na Figura 7.5 .

Conforme mencionado anteriormente, os demais conjuntos de resultados similares aos apresentados nesta seção encontram-se no ANEXO-A. Dada a quantidade e a qualidade das informações contidas nestes conjuntos é possível afirmar que inúmeros aspectos adicionais podem ser identificados. Além disso, para uma comparação direta com os resultados das linhas lançadas em catenárias os resultados gráficos são sempre apresentados segundo o padrão apresentado na seção de metodologia de análise, item 6.4 .

\subsubsection{Resultados síntese obtidos com a decomposição modal: Linha Vertical}

Nesta seção são apresentados os resultados síntese dos ensaios de VIV na linha flexível vertical, obtidos conforme procedimento da seção 6.4, a partir dos modos apresentados na Figura 7.6. 

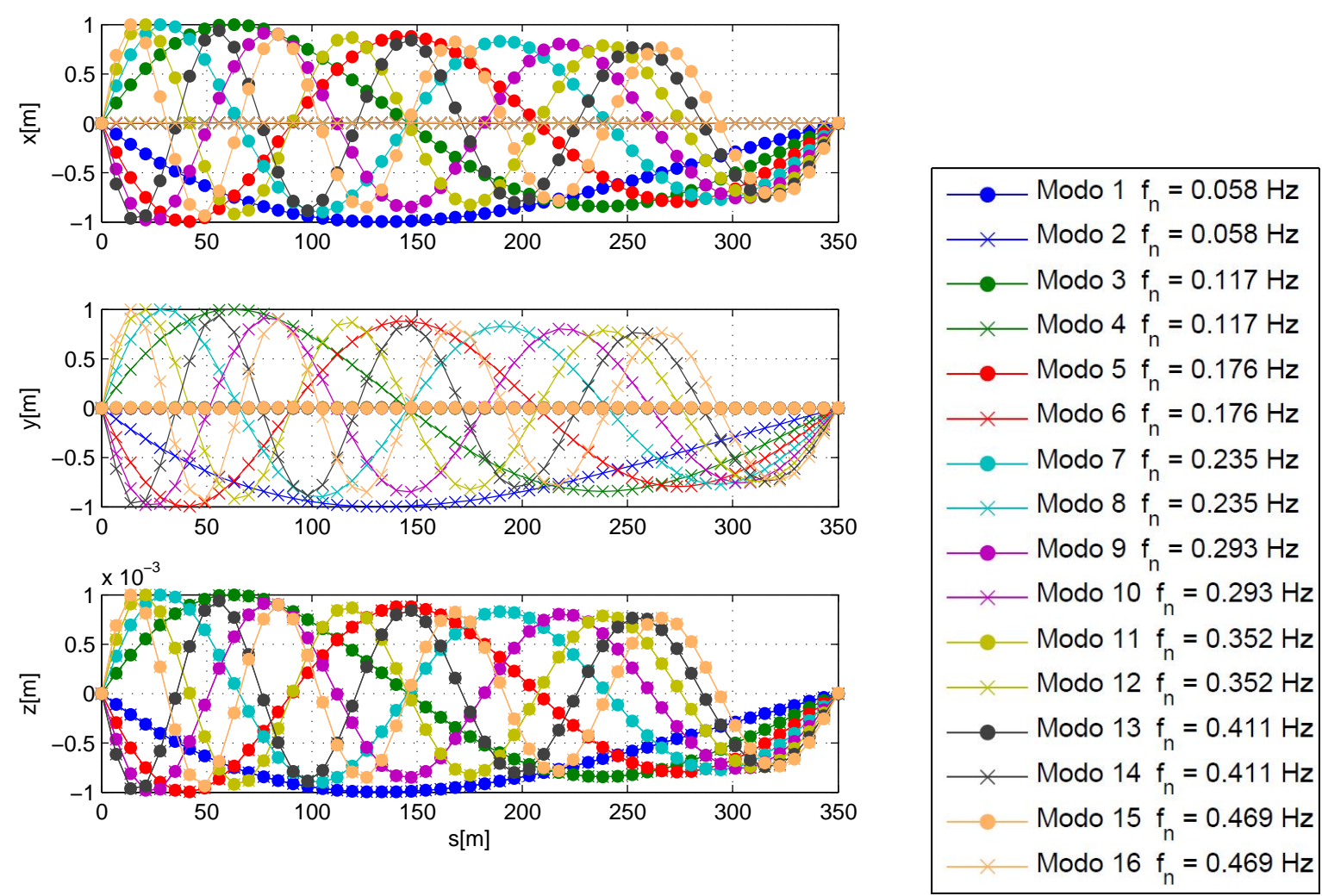

Figura 7.6: Modos naturais de vibrar do modelo de linha vertical, obtidos conforme a equação (4.17).

Importante destacar que discussões e comparações tecidas com base nos gráficos desta seção são trazidos de maneira conjunta mais adiante, na seção 7.3.

Obtida com base na decomposição modal, a Figura 7.7 representa uma síntese dos ensaios realizados em velocidades nominais do braço -giratório na posição de fixação do modelo de linha vertical variando de $0,52 \mathrm{~m} / \mathrm{s}$ a $3,28 \mathrm{~m} / \mathrm{s}$. Estas velocidades correspondem à velocidades reduzidas de 4,0 a 25,4 (calculadas com base na primeira frequência natural transversal ao escoamento incidente na linha). Segundo apresentação usual, os três gráficos da Figura 7.7 apresentam os valores médios dos máximos, mínimos e de desvio padrão das séries temporais de amplitude modal. 

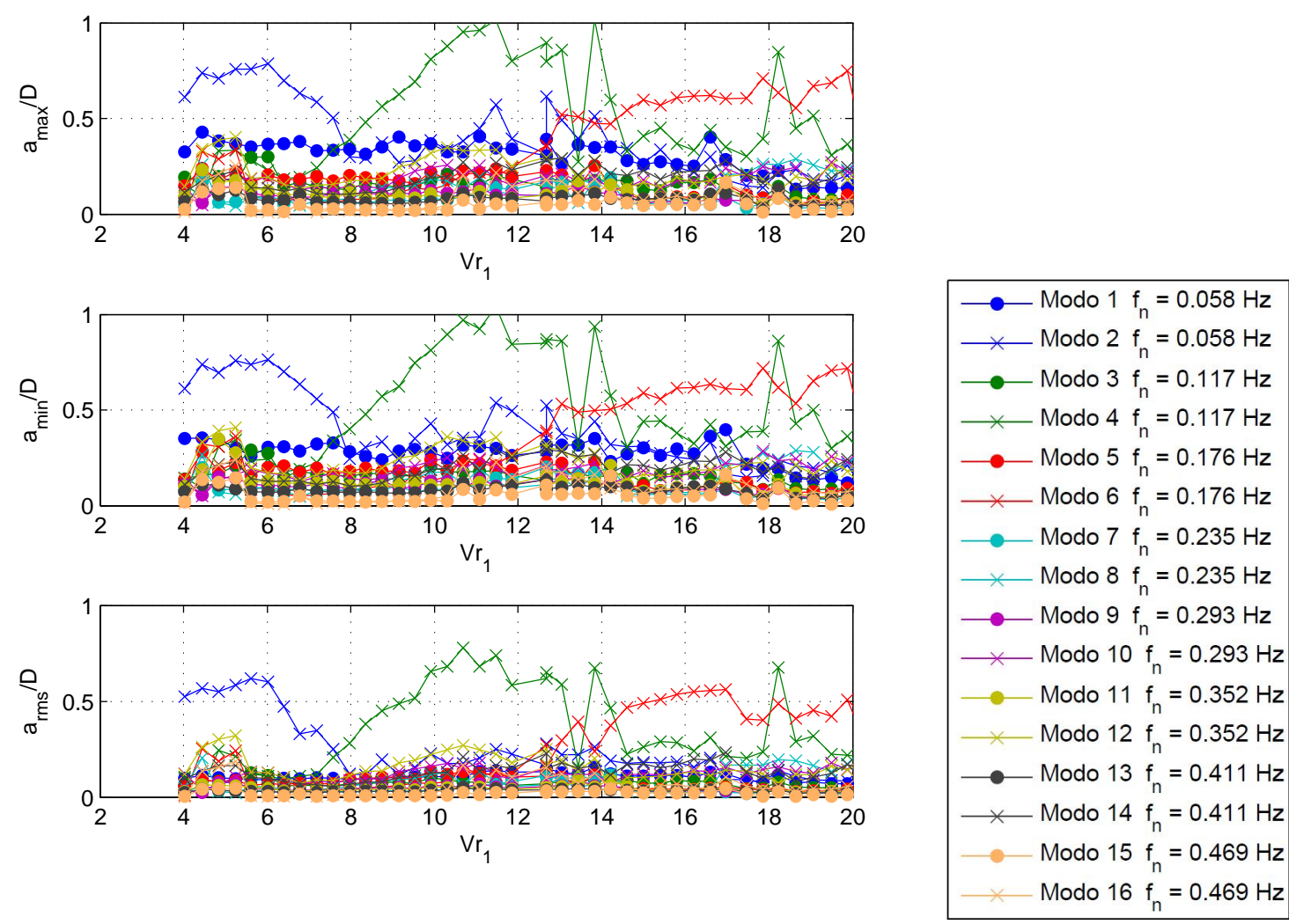

Figura 7.7: Variação das amplitudes modais por velocidade reduzida calculada com a frequência natural do primeiro modo de vibrar transversal da linha vertical. Valores calculados com base na média de máximos, média de mínimos e média dos desvios padrões.

A Figura 7.8, por outro lado, traz os mesmos resultados de amplitude modal, agora apresentados como função das velocidades reduzidas calculadas com base na frequência natural dos respectivos modos de vibrar. Note que, de acordo com essa segunda forma de apresentação dos resultados, há uma sobreposição entre as faixas de sincronização dos primeiros modos naturais pelo fenômeno de VIV.

Naturalmente, as faixas de sincronização dos três primeiros modos transversais ao escoamento incidente na linha vertical são melhor identificados com base nos valores médios de desvio padrão, o que justifica uma apresentação mais detalhada dos resultados com base nos mesmos.

Assim, os resultados obtidos a partir do desvio padrão das séries temporais de amplitude modal são apresentados na Figura 7.9, juntamente com as respectivas frequências dominantes de resposta. Nos gráficos dessa figura, as linhas horizontais tracejadas coloridas representam as frequências naturais de cada modo de vibrar, enquanto as linhas inclinadas (tracejadas em preto) definem as frequências de emissão 
de vórtice segundo proposição baseada no número de Strouhal, bem como as relações de multiplicidade da mesma.
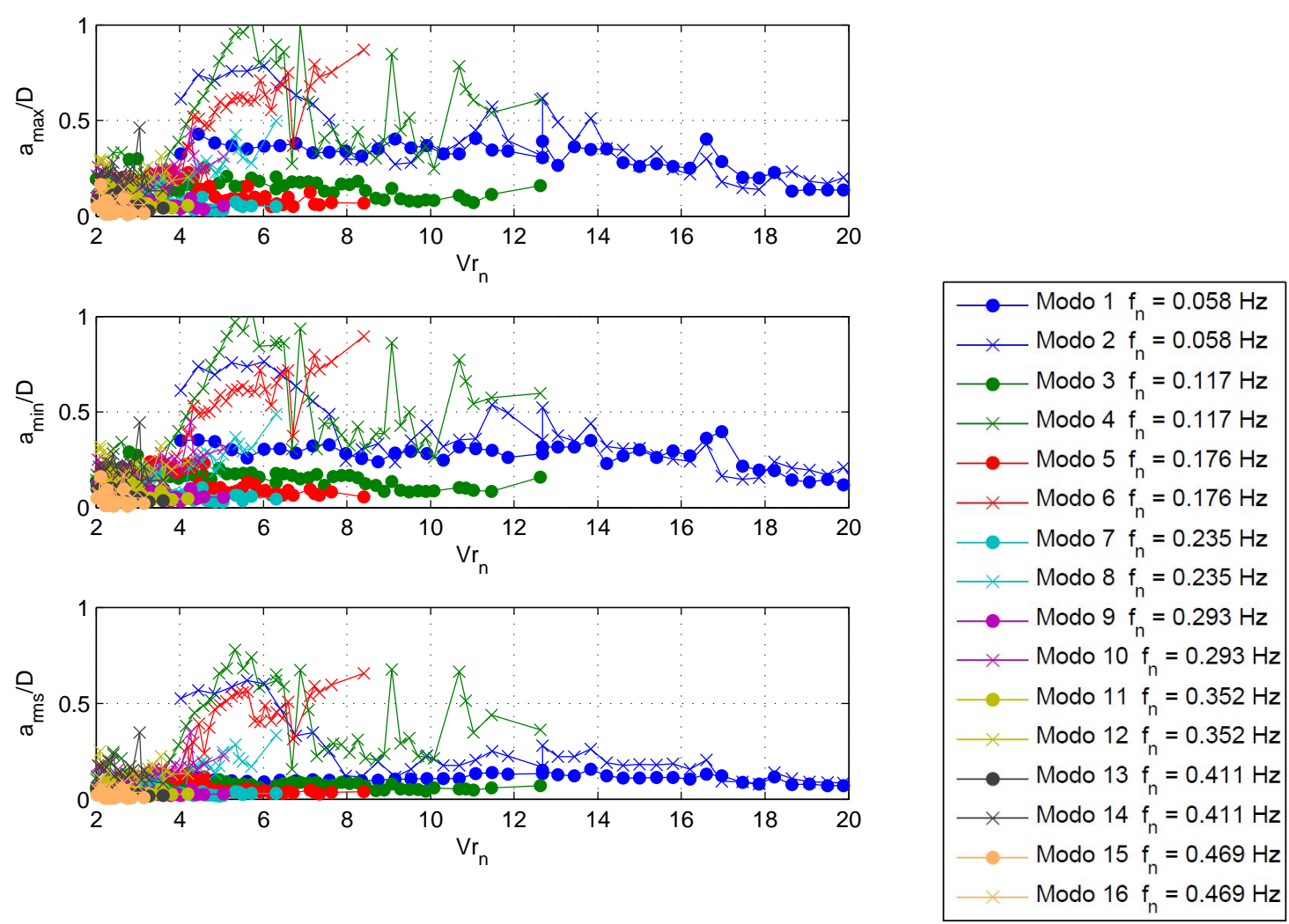

Figura 7.8: Variação das amplitudes modais por velocidade reduzida calculada com a frequência natural de cada modo de vibrar da linha vertical. Valores calculados com base na média de máximos, média de mínimos e média dos desvios padrões. 

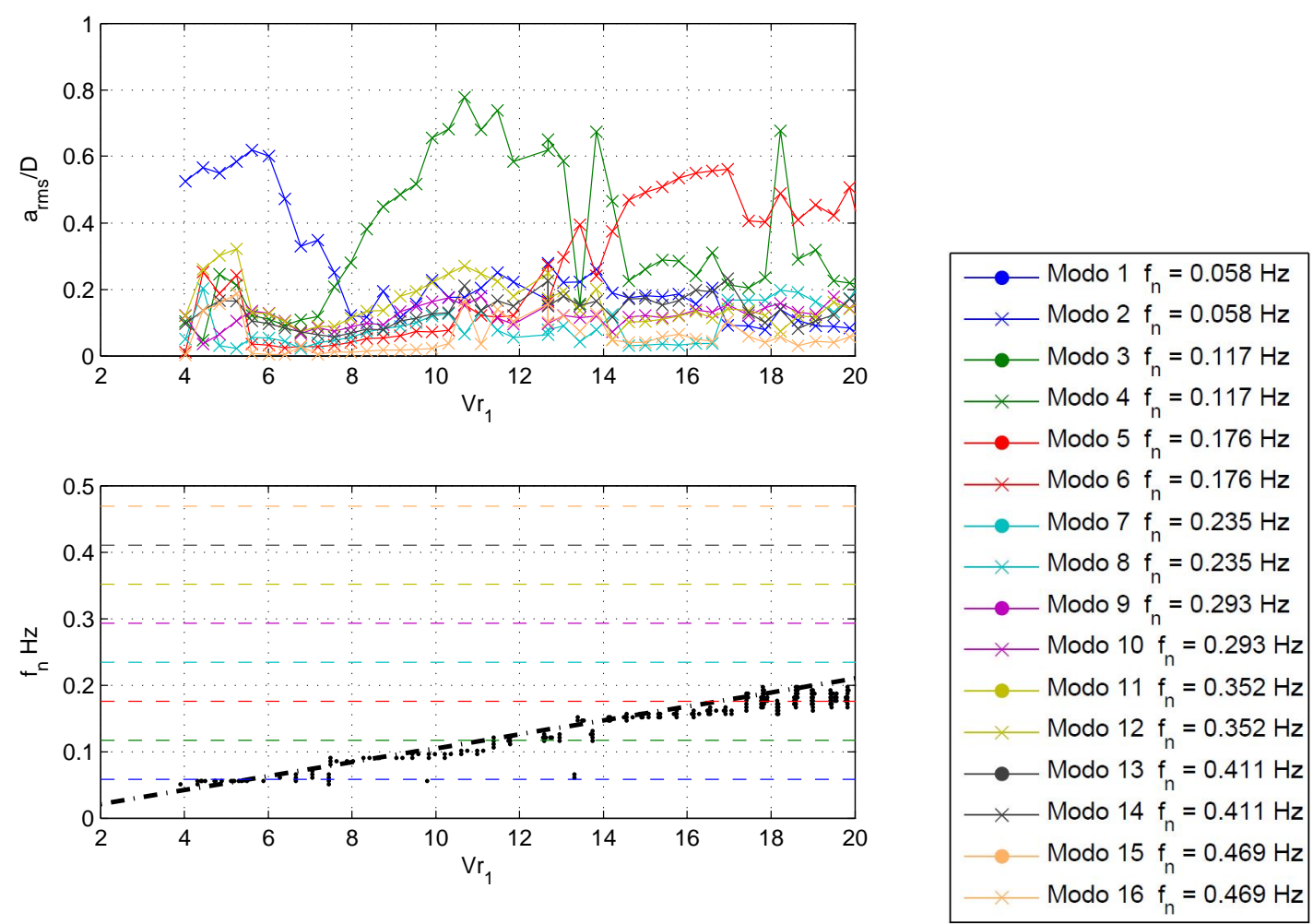

Figura 7.9: Desvio padrão das amplitudes modais e respectivas frequências de resposta dominante na direção transversal ao escoamento incidente (cross flow, CF) da linha vertical. Velocidades reduzidas calculadas com base na frequência natural do primeiro modo de vibrar transversal.

Resultados análogos, porém referentes às respostas longitudinais à direção de incidência do escoamento são apresentados na Figura 7.10.

A próxima seção deste capítulo compila resultados semelhantes obtidos a partir dos ensaios com o modelos de linha lançados em catenária. 

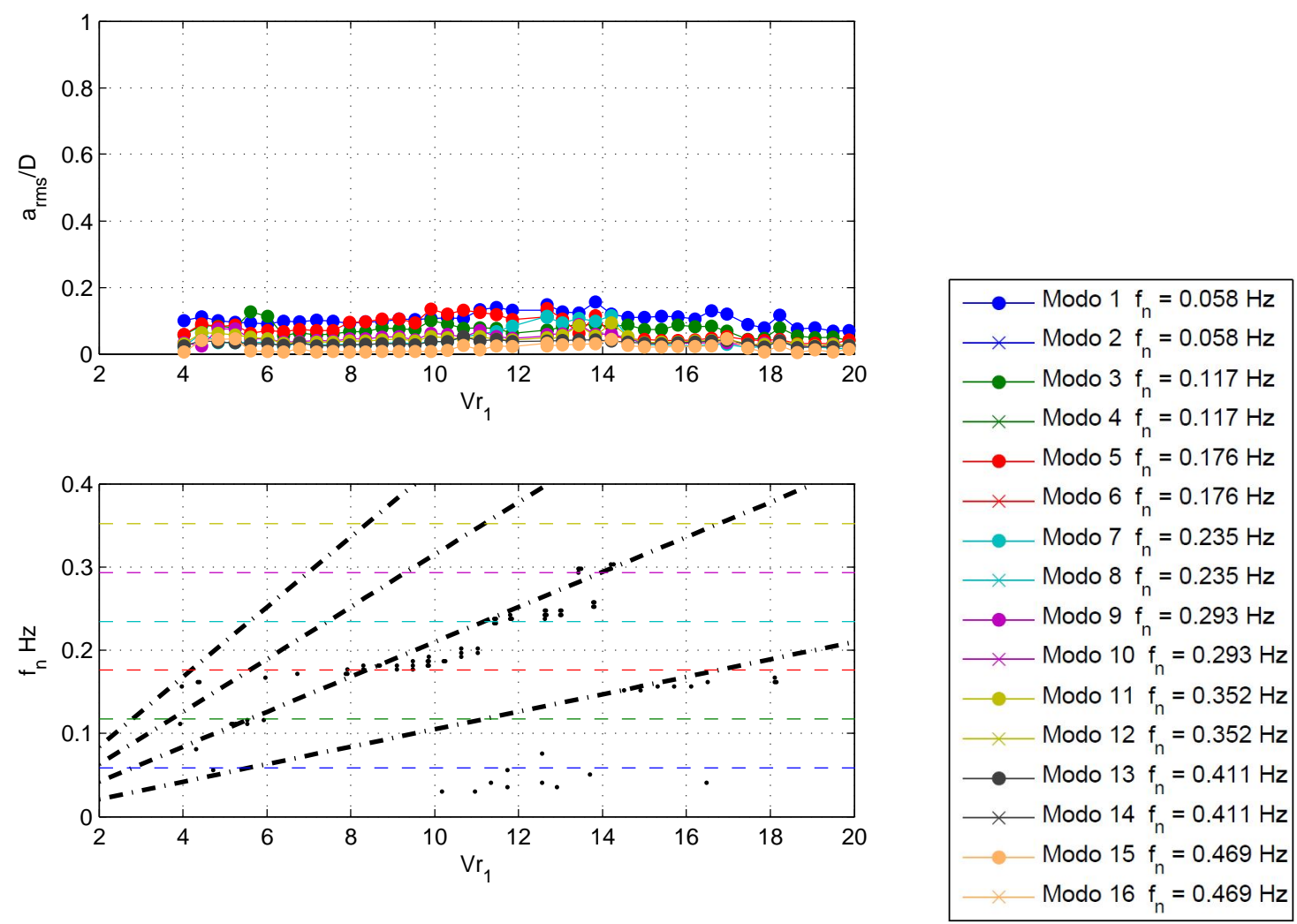

Figura 7.10: Desvio padrão das amplitudes modais e respectivas frequências de resposta dominante na direção longitudinal ao escoamento incidente (inline, IL) da linha vertical. Velocidades reduzidas calculadas com base na frequência natural do primeiro modo de vibrar transversal. 


\subsection{Resultados nas linhas flexíveis lançadas em catenária}

Os resultados que se seguem dizem respeito aos ensaios com as cinco geometrias consideradas para a investigação experimental no âmbito desta pesquisa de doutoramento, conforme descrição detalhada e informações trazidas no Capítulo 6.

Conforme já mencionado, e em favor da concisão, discussões e comparações acerca desses resultados são deixado a cargo da seção 7.3 do presente capítulo.

\subsubsection{Detalhes extras dos ensaios com as linhas flexíveis lançadas em catenária}

Na sequência são apresentados os principais resultados referentes a identificação dos modos de vibrar para os arranjos com o modelo de linha lançado em catenária. Estes resultados visam a caracterização das catenárias ensaiadas com relação as frequências naturais e modos de vibrar, bem como determinar, ao menos para o primeiro modo de vibrar em cada geometria de lançamento, o valor do coeficiente de amortecimento.

Mais uma vez, cumpre destacar que principalmente os modos e as frequências naturais são importantíssimos na determinação dos resultados de decomposição modal, apresentados no item 7.2.2.

Como discutido no capítulo de metodologia da pesquisa, Capítulo 6, as frequências foram obtidas experimentalmente via ensaios de decaimento, posteriormente comparadas com estimativas analítico-numéricas definidas no capítulo de Fundamentos teóricos, Capítulo 4.

Os gráficos nas Figuras de 7.11 a 7.20 apresentam as séries temporais dos decaimentos para cada catenária, antes e depois da decomposição modal. Respectivamente, também fazem apresentação das PSD, segundo as quais, podem ser identificadas as frequências naturais presentes. O gráfico da componente modal em primeiro modo presente nos ensaios de decaimento permite, ainda, a determinação do coeficiente de amortecimento.

As linhas tracejadas vermelhas são estimativas das frequências naturais com base nas equações (4.24) e as linhas tracejadas pretas as respectivas estimativas numéricas.

Modos naturais, por sua vez, são de difícil identificação experimental. Desta forma, foram obtidos teoricamente após identificação das frequências no plano e fora do plano de lançamento das catenárias. 


\subsubsection{Resultados de decaimento com a Catenária-1}
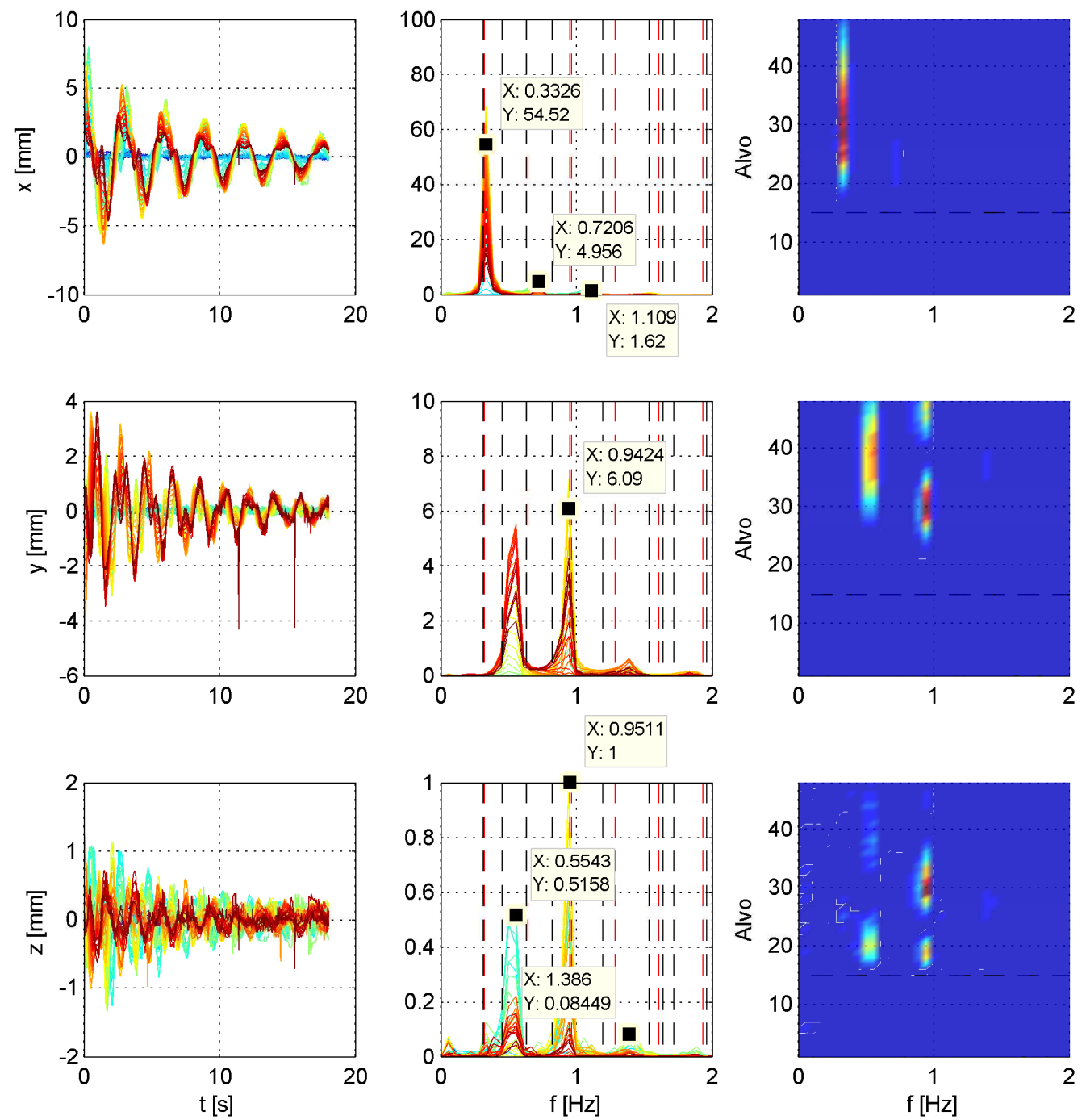

Figura 7.11: Identificação das frequências naturais a partir do deslocamento dos alvos do ensaio de decaimento para a condição Catenária-1. 

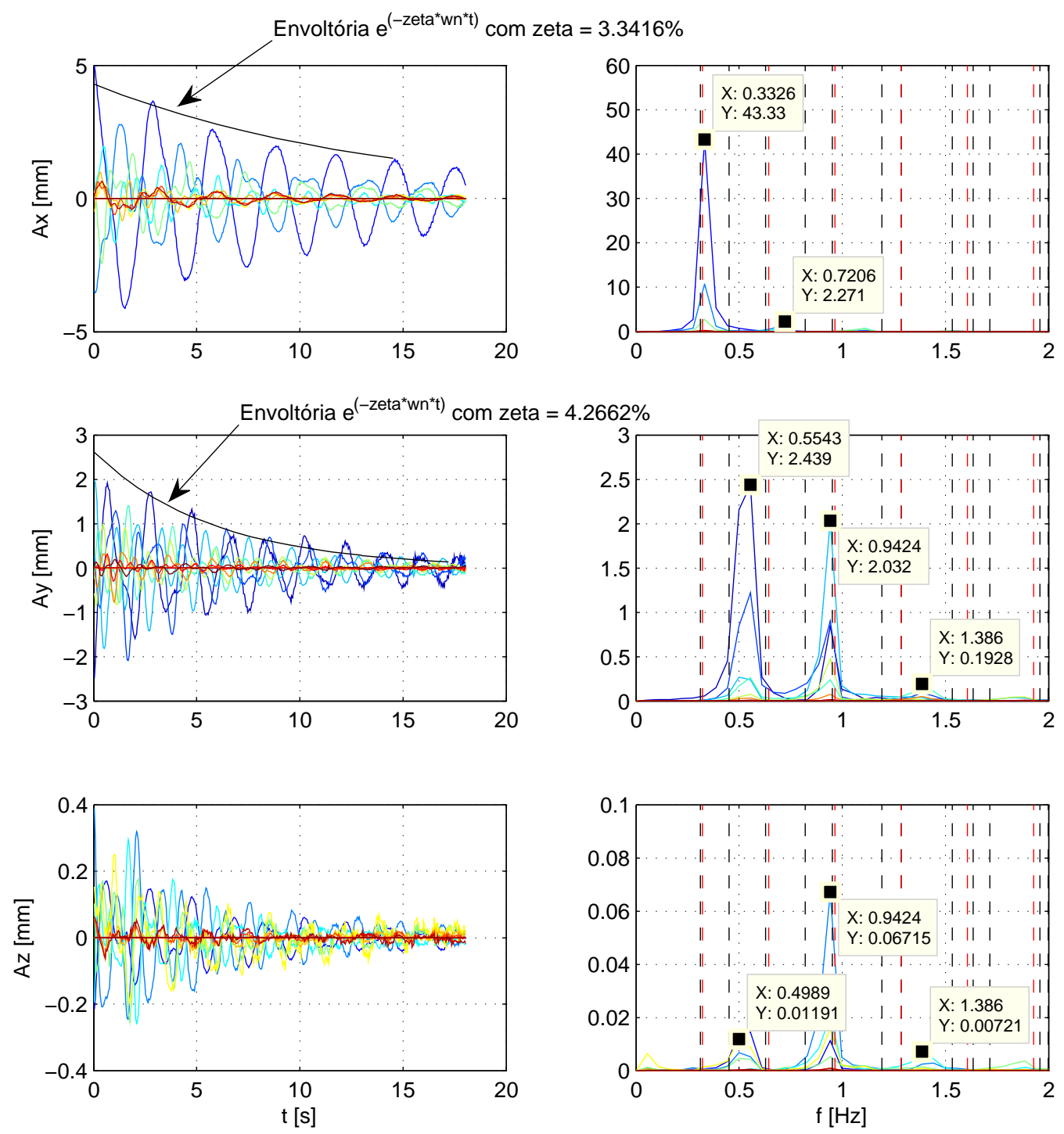

Figura 7.12: Identificação das frequências naturais a partir das amplitudes modais, obtidas de decaimento para a condição Catenária-1. 


\subsubsection{Resultados de decaimento com a Catenária-2}
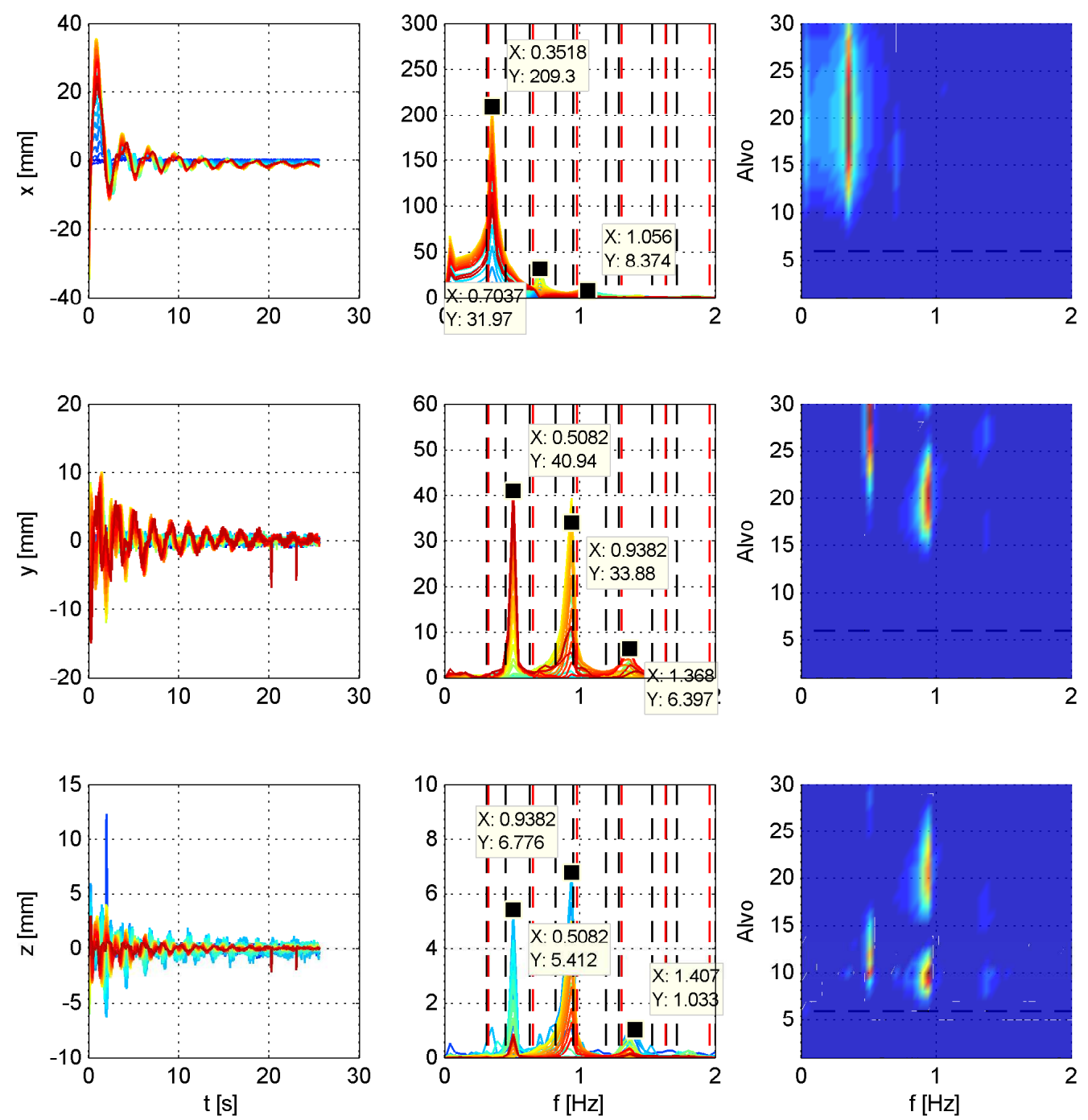

Figura 7.13: Identificação das frequências naturais a partir do deslocamento dos alvos do ensaio de decaimento para a condição Catenária-2. 

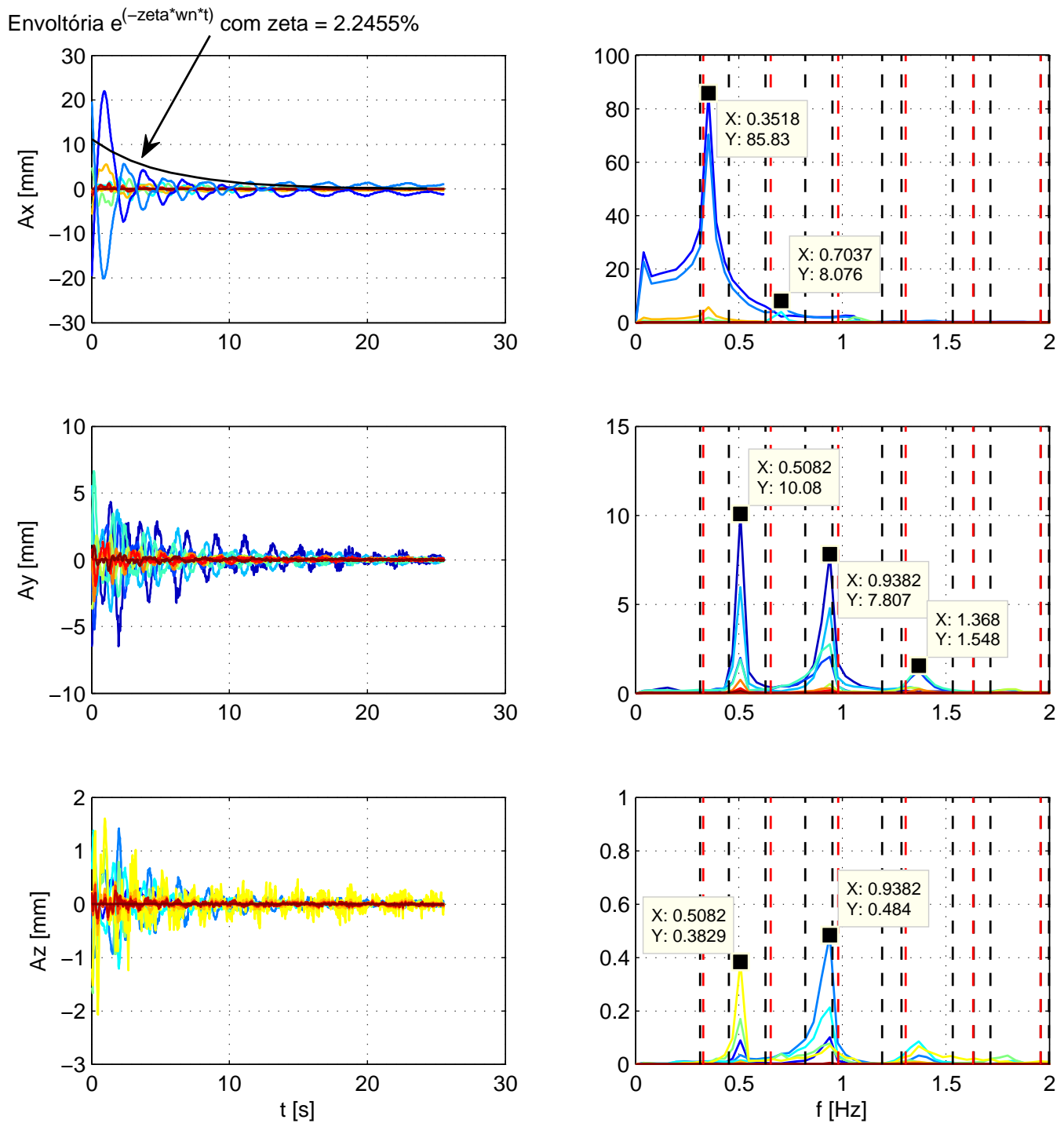

Figura 7.14: Identificação das frequências naturais a partir das amplitudes modais, obtidas de decaimento para a condição Catenária-2. 


\subsubsection{Resultados de decaimento com a Catenária-3}
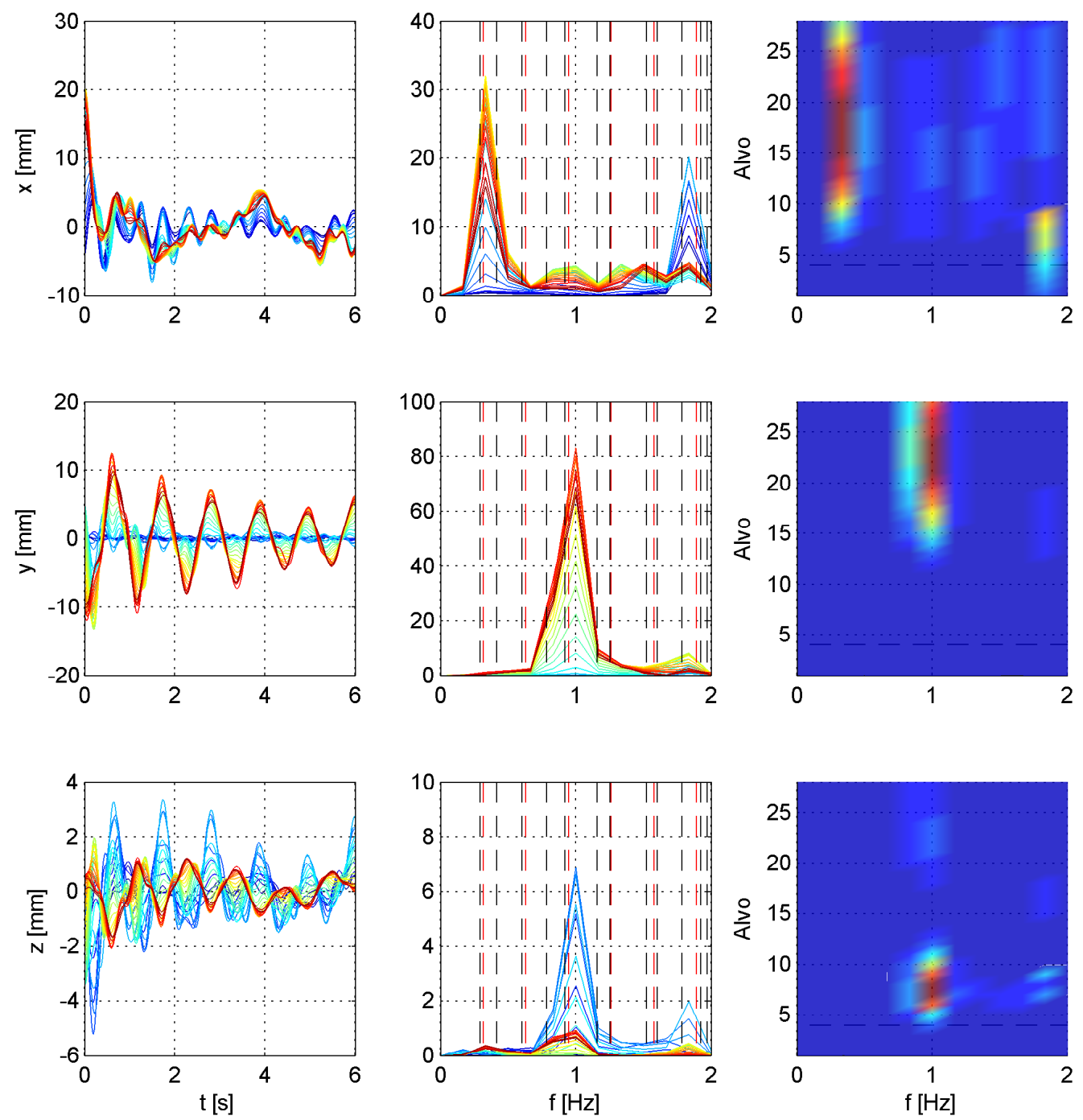

Figura 7.15: Identificação das frequências naturais a partir do deslocamento dos alvos do ensaio de decaimento para a condição Catenária-3. 

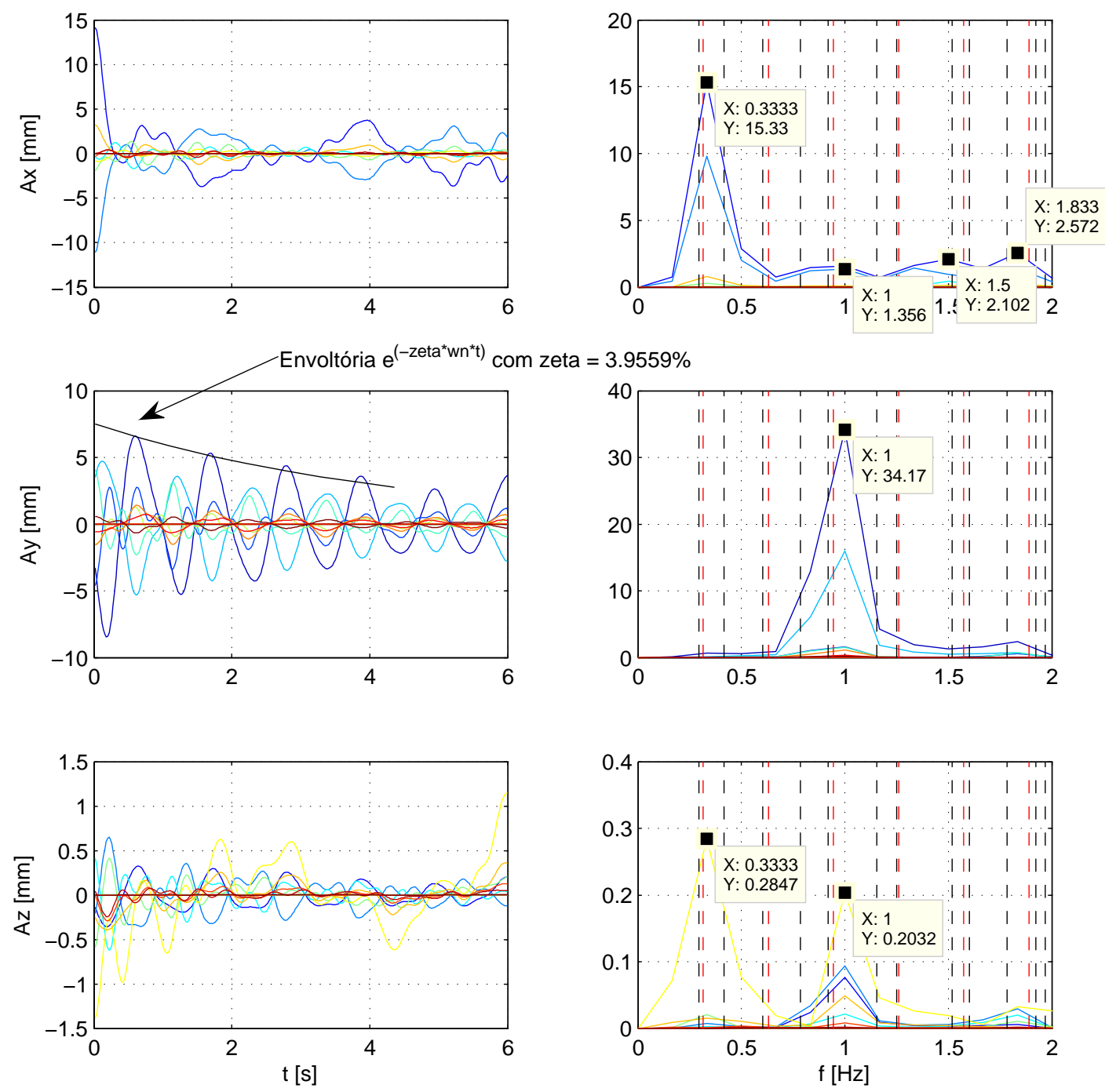

Figura 7.16: Identificação das frequências naturais a partir das amplitudes modais, obtidas de decaimento para a condição Catenária-3. 


\subsubsection{Resultados de decaimento com a Catenária-4}
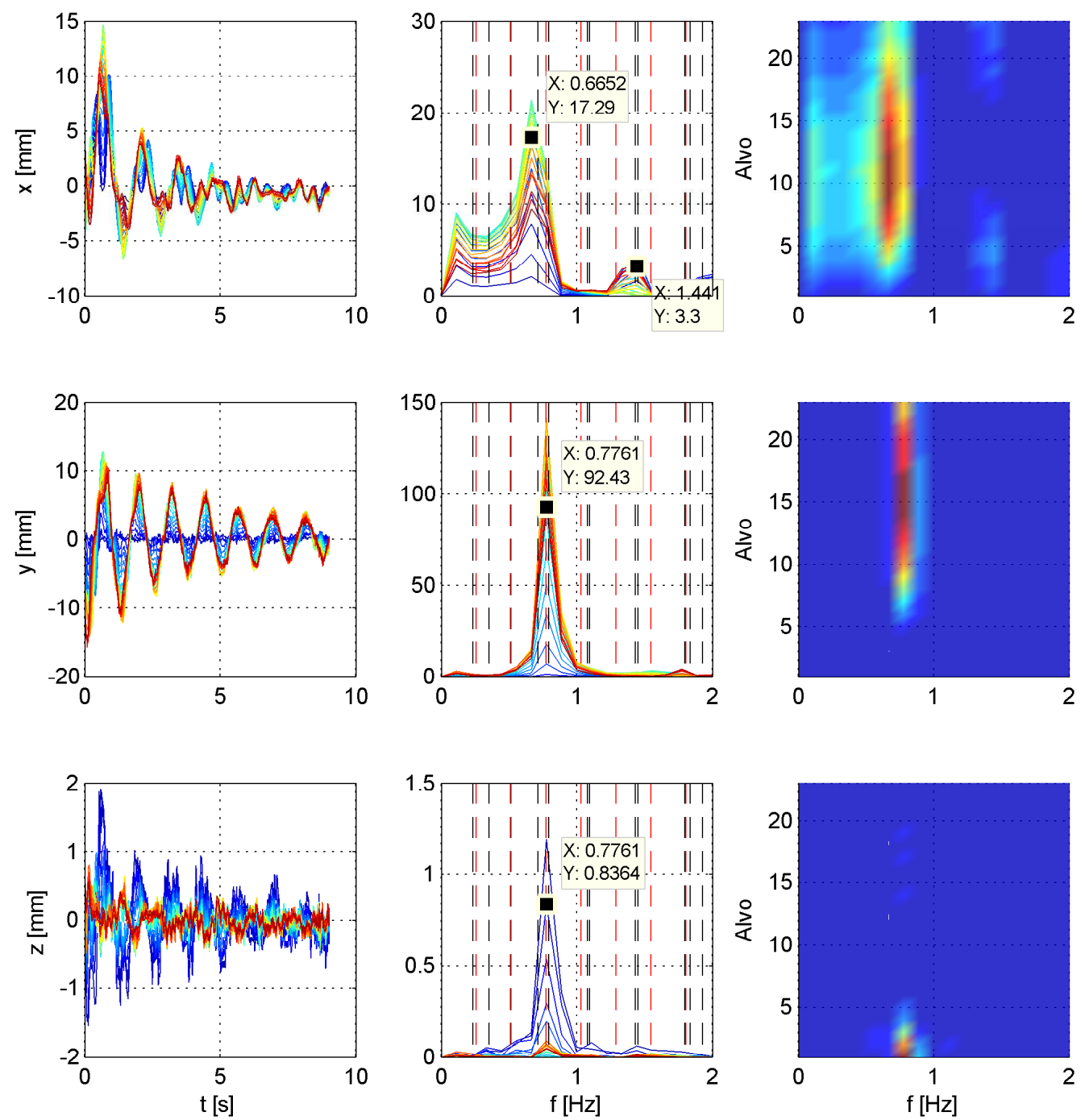

Figura 7.17: Identificação das frequências naturais a partir do deslocamento dos alvos do ensaio de decaimento para a condição Catenária-4. 

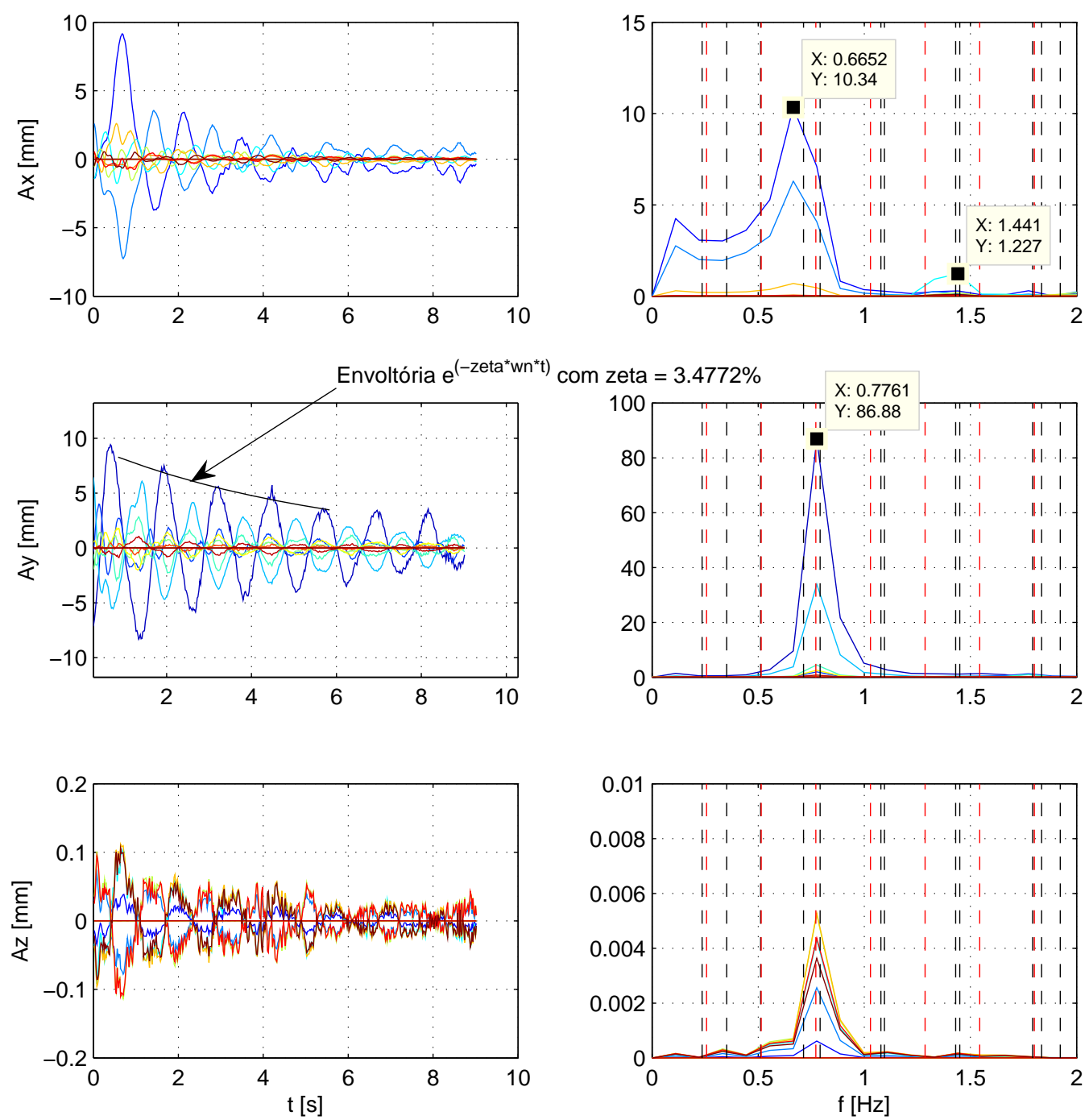

Figura 7.18: Identificação das frequências naturais a partir das amplitudes modais, obtidas de decaimento para a condição Catenária-4. 


\subsubsection{Resultados de decaimento com a Catenária-5}
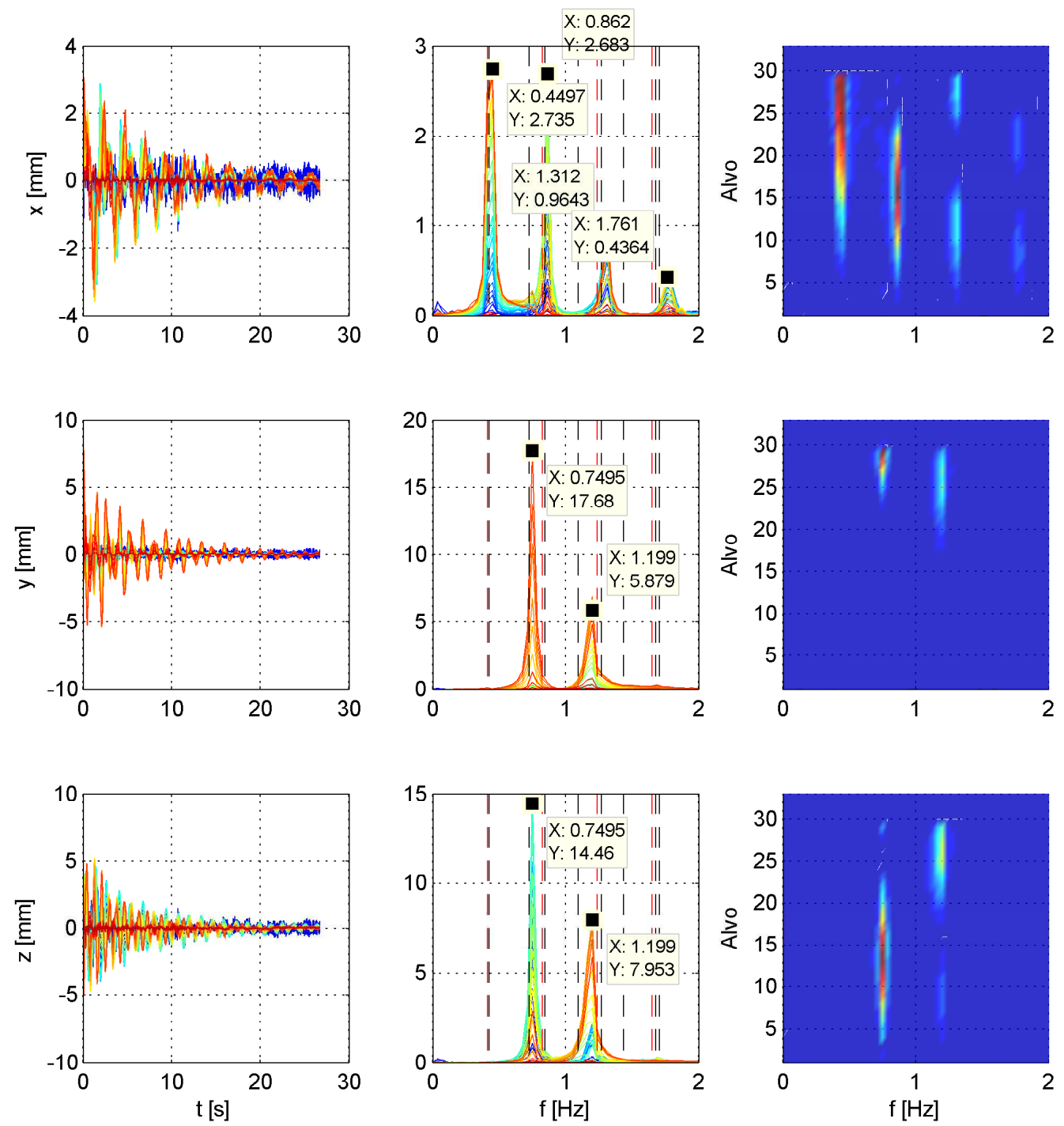

Figura 7.19: Identificação das frequências naturais a partir do deslocamento dos alvos do ensaio de decaimento para a condição Catenária-5. 

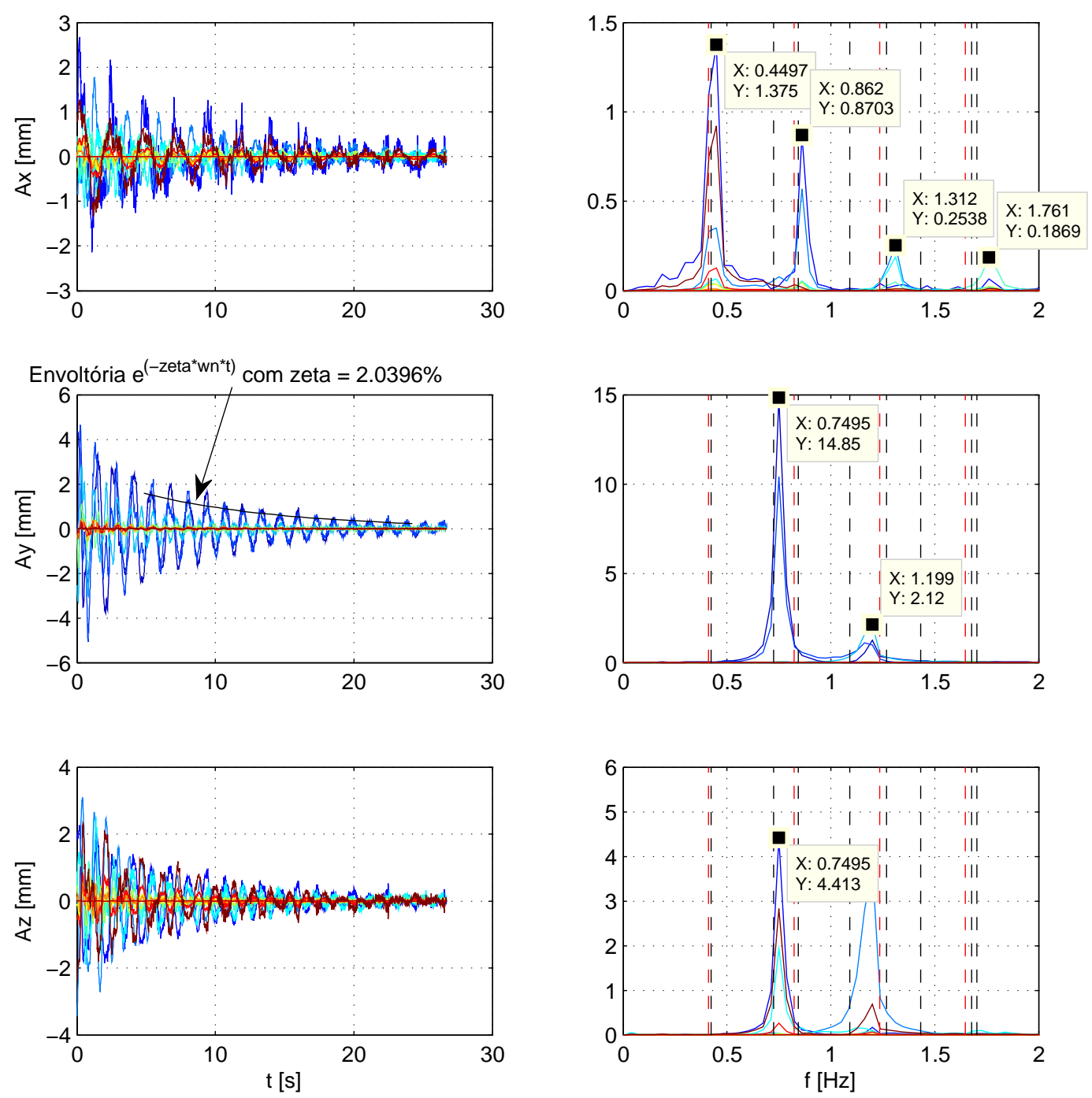

Figura 7.20: Identificação das frequências naturais a partir das amplitudes modais, obtidas de decaimento para a condição Catenária-5. 


\subsubsection{Resultados síntese obtidos com a decomposição modal: Linhas em Catenária}

Nesta seção são apresentados os resultados síntese referentes aos arranjos das linhas flexíveis lançadas em catenária, discutidos e comparados na seção seguinte.

Seguindo o padrão já estabelecido, o primeiro gráfico de cada conjunto diz respeito aos modos naturais passíveis de excitação na catenária consideradas.

Na sequência, são apresentados valores característicos (média dos máximos, média dos mínimos e desvios padrões) obtidos com base na decomposição modal. Neste caso, são feitas duas apresentações gráficas: uma primeira, como função das velocidades reduzidas calculadas a partir da frequência natural do primeiro modo no plano de lançamento da catenária, e uma segunda, onde as velocidades reduzidas são calculadas com base nas respectivas frequências naturais de cada componente modal.

Finalizando cada conjunto, ainda são apresentados dois gráficos das amplitudes modais (CF e IL), calculadas com base nos valores de desvio padrão, e dispostas como função das velocidades reduzidas calculadas pelo primeiro modo no plano de lançamento da catenária em questão. 


\subsubsection{Resultados Síntese da Catenária-1, obtidos mediante decomposição modal}

Nas Figura de 7.21 a 7.25 são apresentados resultados da Catenária-1, segundo ensaios em velocidades que variaram de 0,48 a $3,10 \mathrm{~m} / \mathrm{s}$ (escala real).

Estas velocidades correspondem a velocidade reduzidas de 4,8 a 31,0, baseadas na primeira frequência no plano da catenária, ou seja, a primeira transversal ao perfil variável de correnteza incidente.

Lembrar que, no âmbito desta tese, as catenárias são lançadas na direção radial do braço giratório.
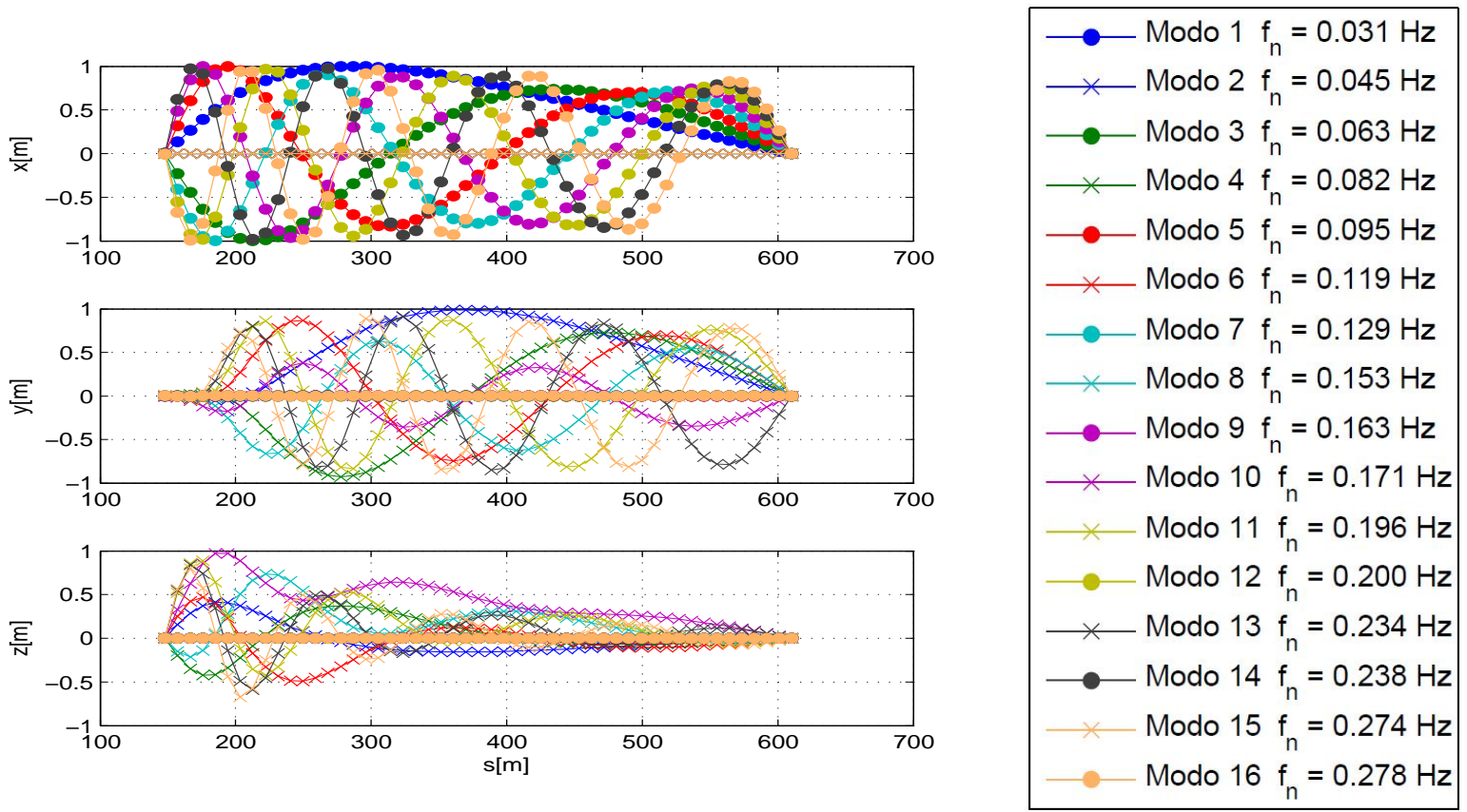

Figura 7.21: Modos de vibrar do arranjo Catenária-1 

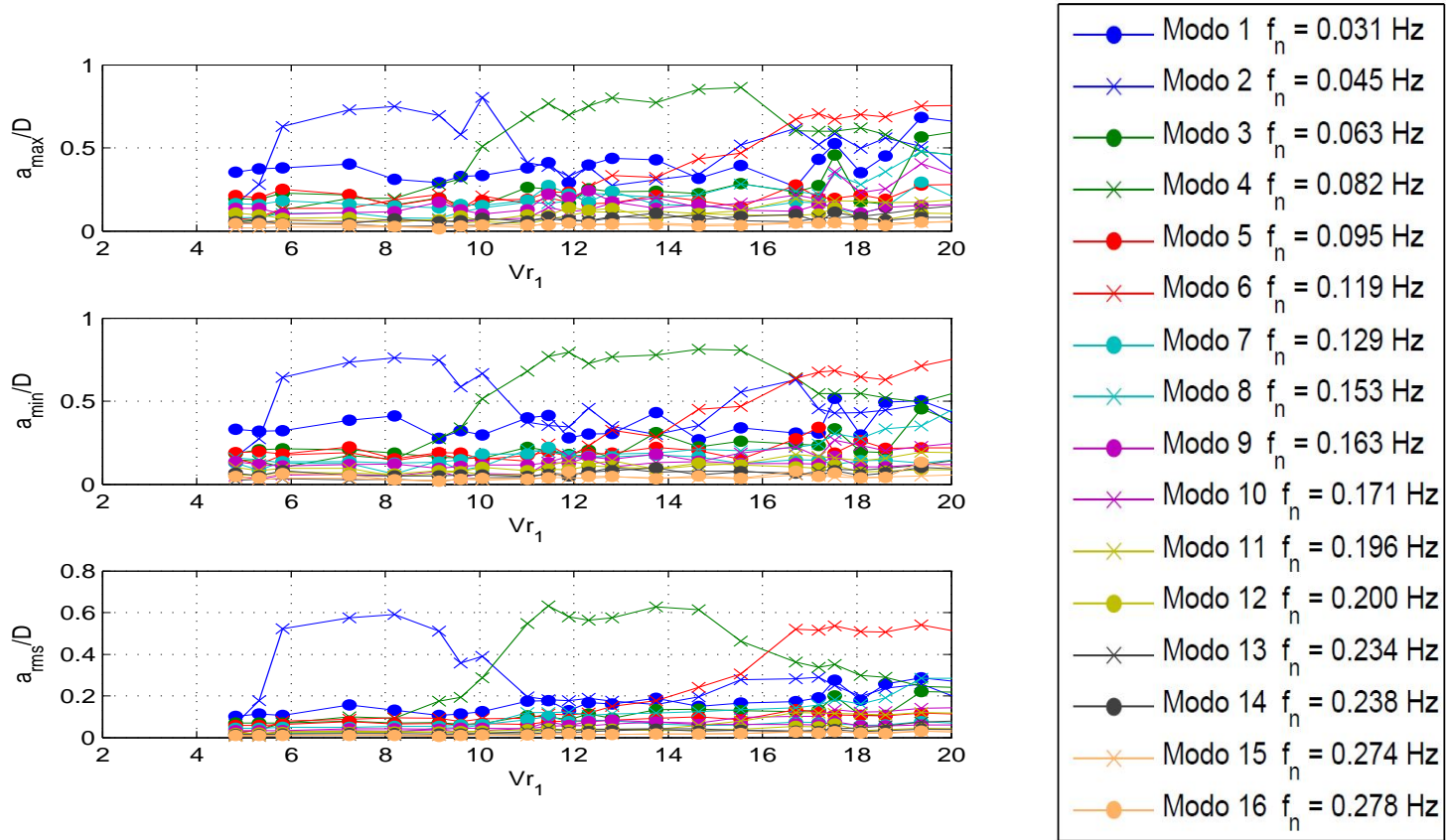

Figura 7.22: Variação das Amplitudes Modais através da interpolação do sinal do ensaio pela velocidade reduzida baseada na frequência natural do primeiro modo de vibrar para o arranjo Catenária-1
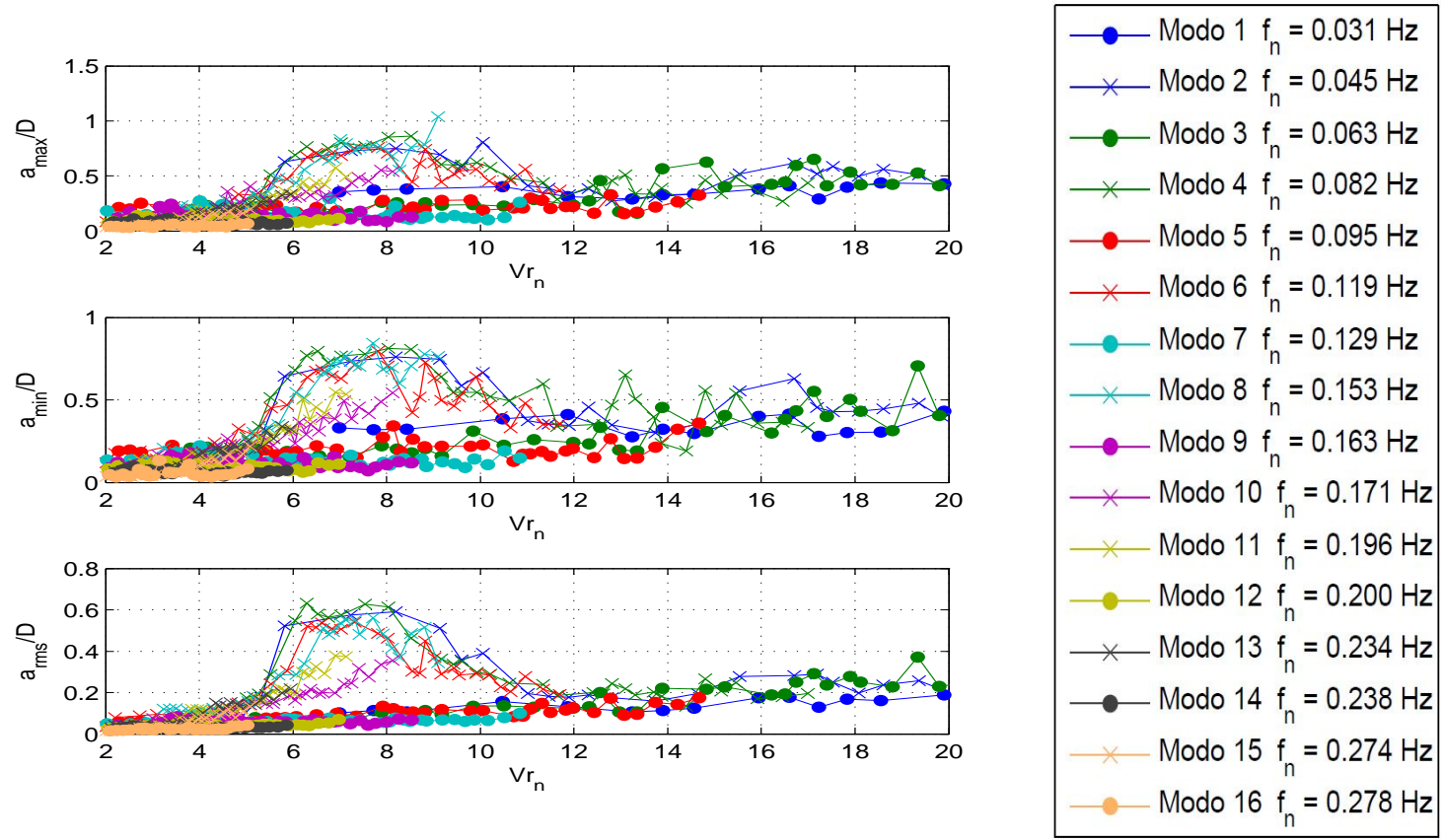

Figura 7.23: Variação das Amplitudes Modais através da interpolação do sinal do ensaio pela velocidade reduzida baseada na frequência natural de cada modo de vibrar para o arranjo Catenária-1 

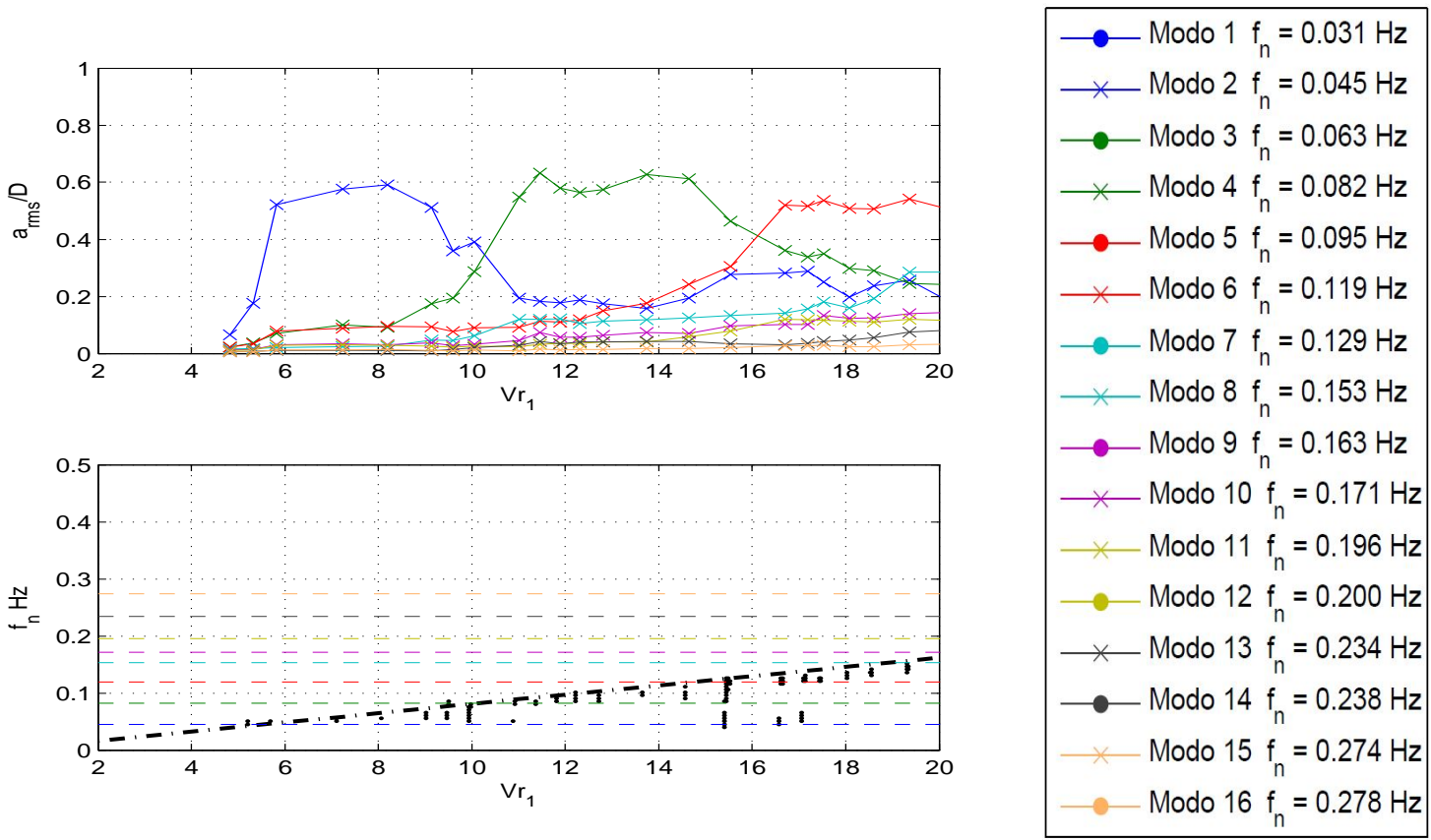

Figura 7.24: Desvio padrão das amplitudes modais através da interpolação do sinal do ensaio e frequência de resposta máxima do movimento cruzado (cross) por Vr baseado na frequência natural do primeiro modo de vibrar para o arranjo Catenária-1
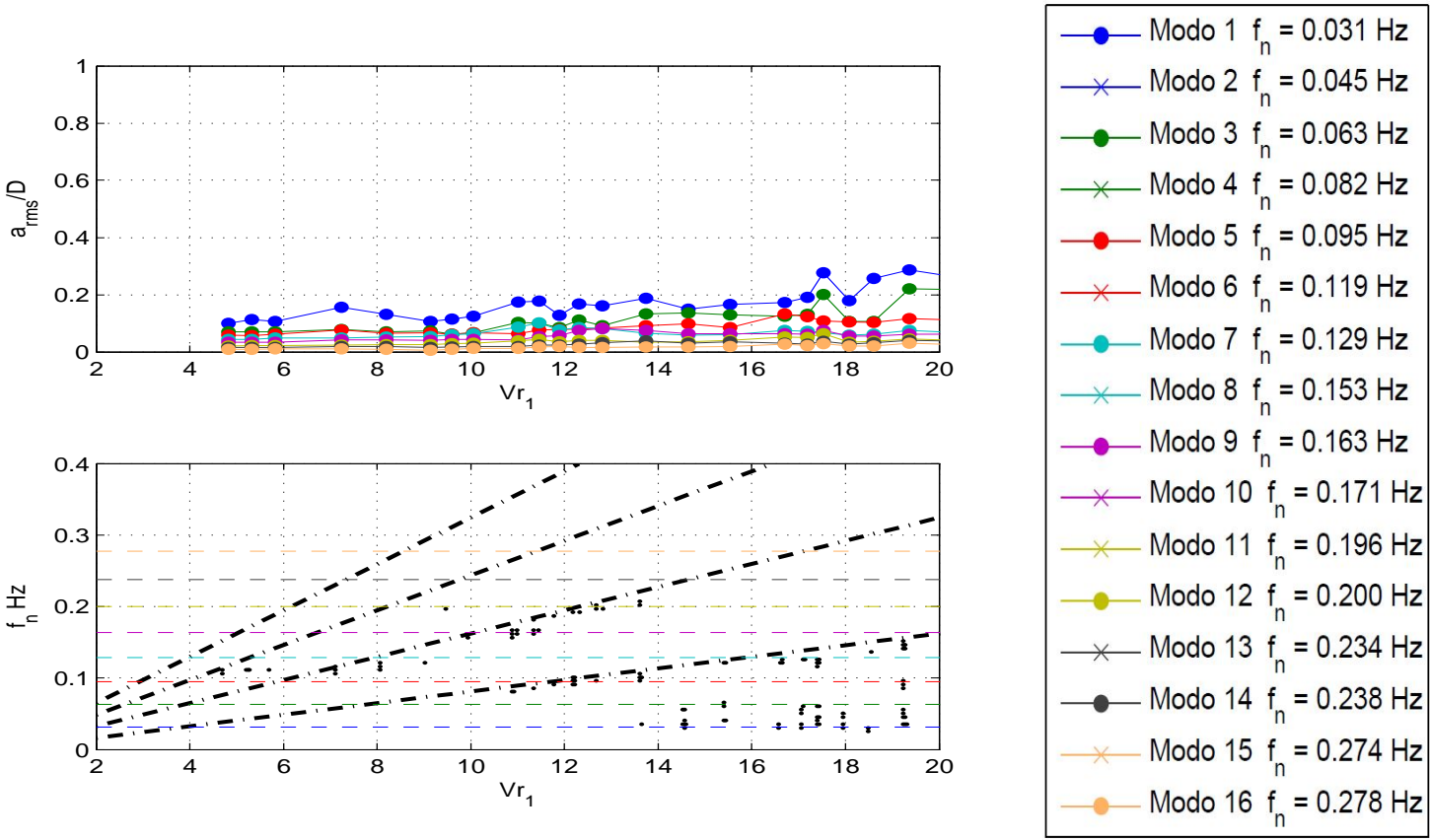

Figura 7.25: Desvio padrão das amplitudes modais através da interpolação do sinal do ensaio e frequência de resposta máxima do movimento na direção do fluxo (in-line) por Vr baseado na frequência natural do primeiro modo de vibrar para o arranjo Catenária-1 


\subsubsection{Resultados Síntese da Catenária-2, obtidos mediante decomposição modal}

Nas Figura de 7.26 a 7.30 são apresentados resultados da Catenária-2, segundo ensaios em velocidades que variaram de 0,37 a $1,97 \mathrm{~m} / \mathrm{s}$ (escala real).

Estas velocidades correspondem a velocidade reduzidas de 3,7 a 19,7 , baseadas na primeira frequência no plano da catenária, ou seja, a primeira transversal ao perfil variável de correnteza incidente.
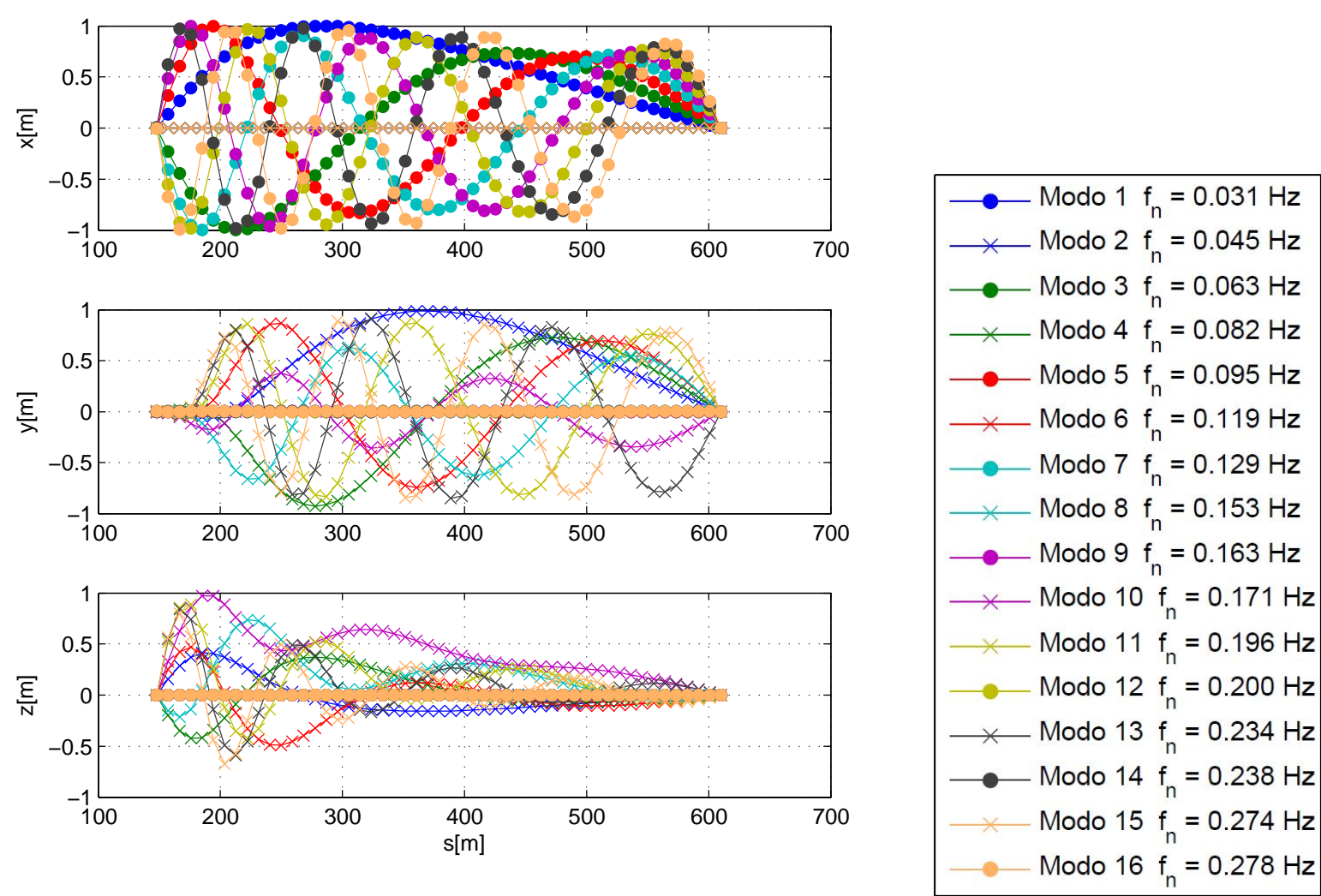

Figura 7.26: Modos de vibrar do arranjo Catenária-2 

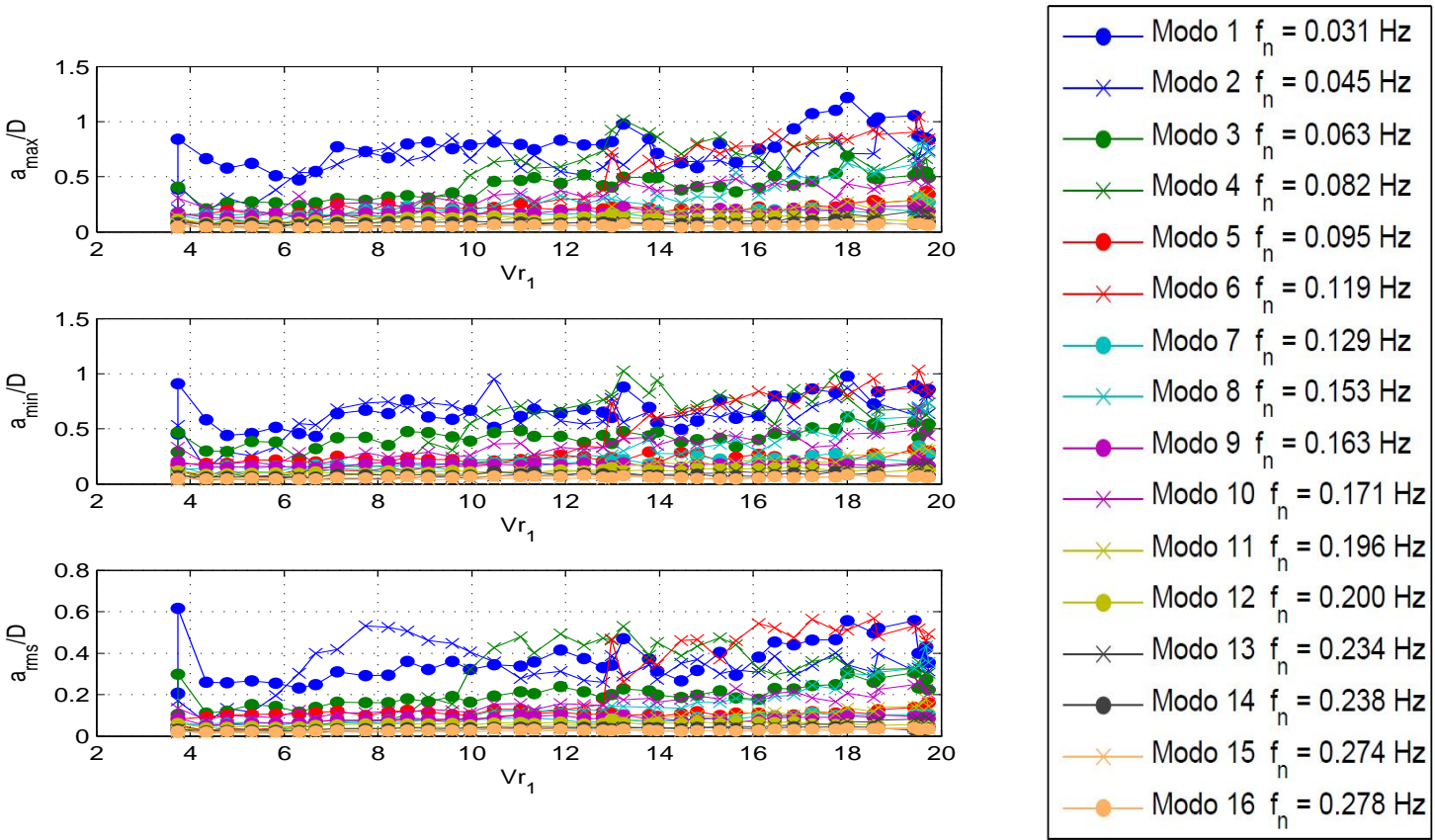

Figura 7.27: Variação das Amplitudes Modais através da interpolação do sinal do ensaio pela velocidade reduzida baseada na frequência natural do primeiro modo de vibrar para o arranjo Catenária-2
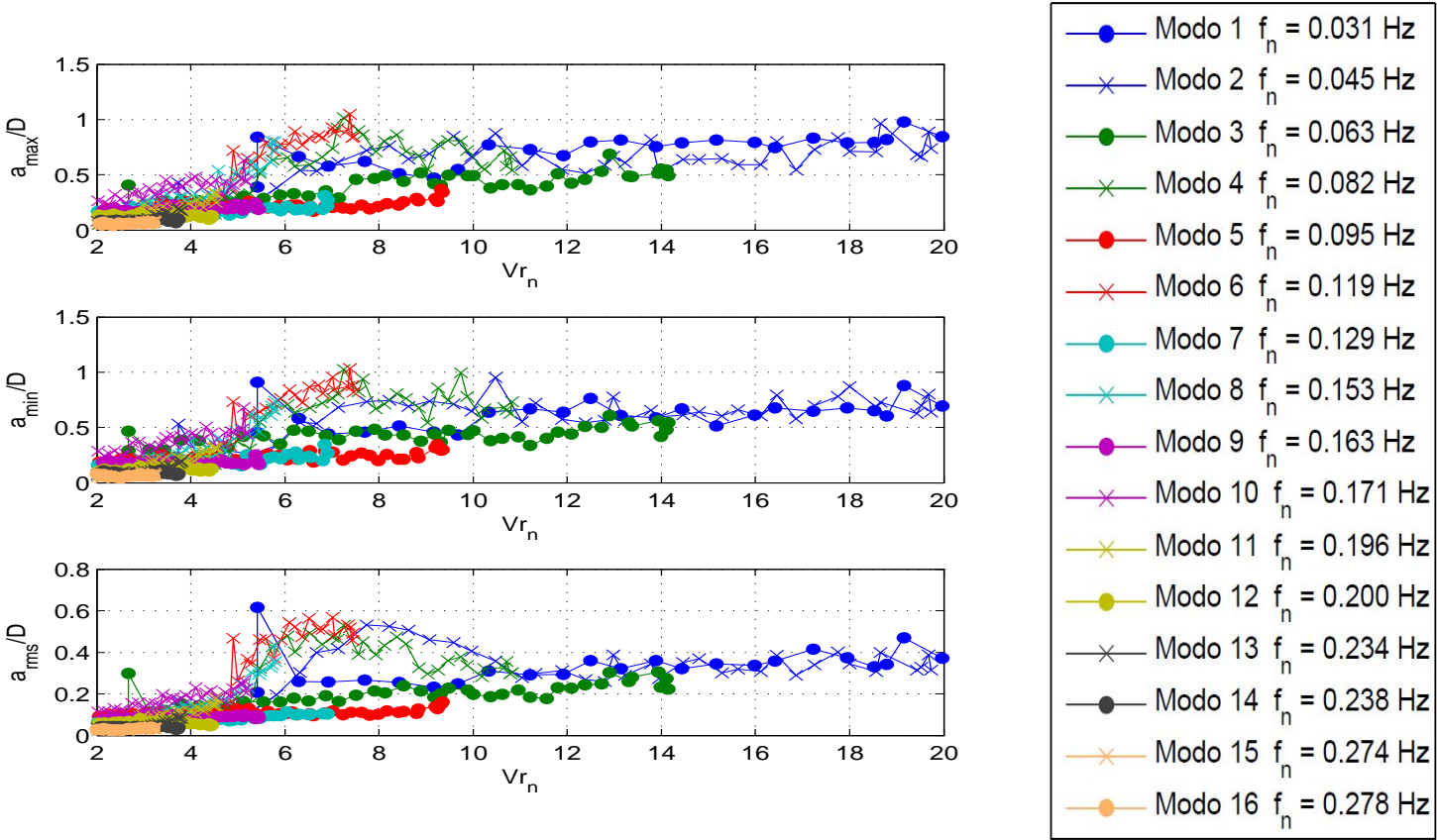

Figura 7.28: Variação das Amplitudes Modais através da interpolação do sinal do ensaio pela velocidade reduzida baseada na frequência natural de cada modo de vibrar para o arranjo Catenária-2 

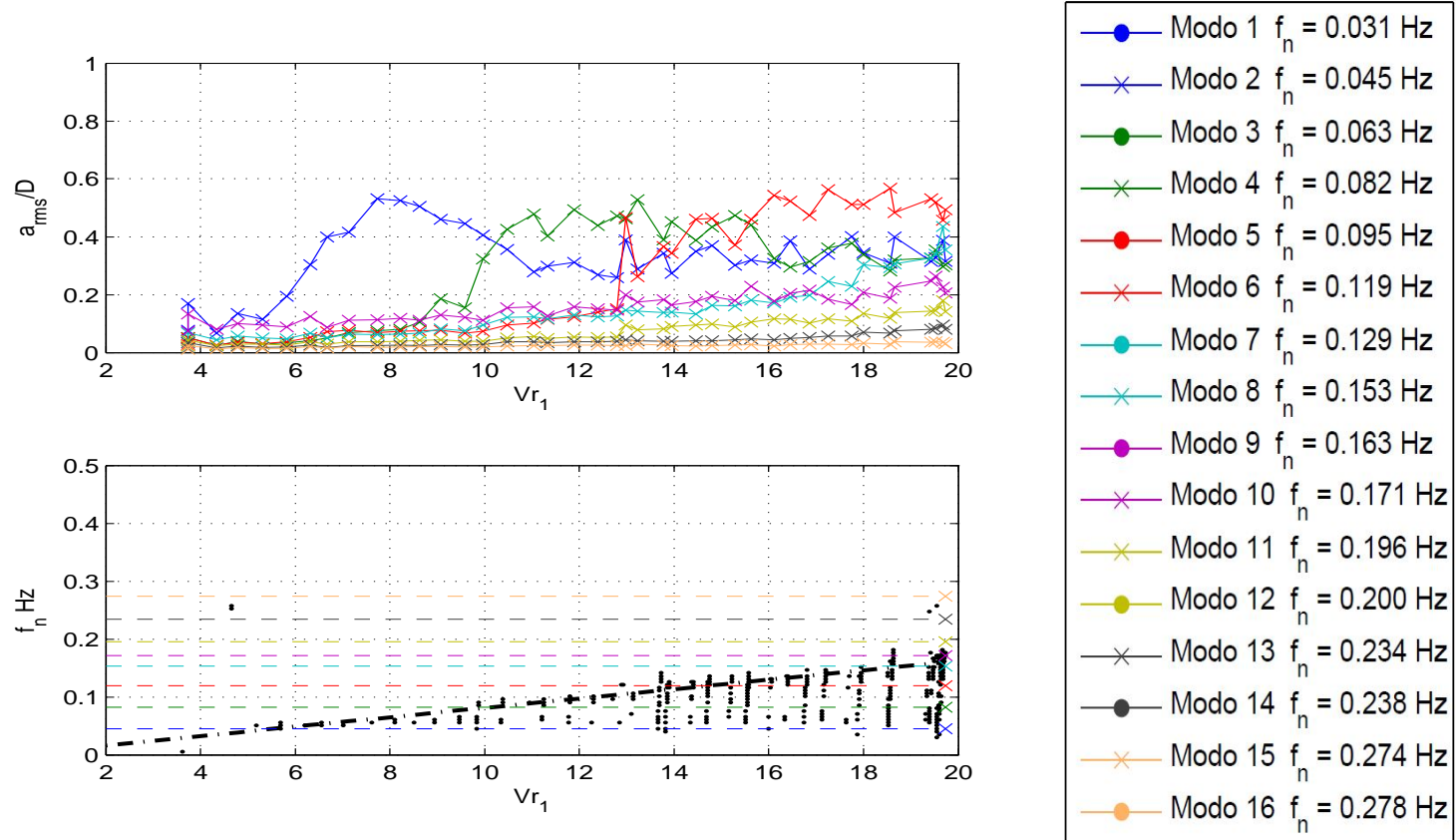

Figura 7.29: Desvio padrão das amplitudes modais através da interpolação do sinal do ensaio e frequência de resposta máxima do movimento cruzado (cross) por Vr baseado na frequência natural do primeiro modo de vibrar para o arranjo Catenária-2
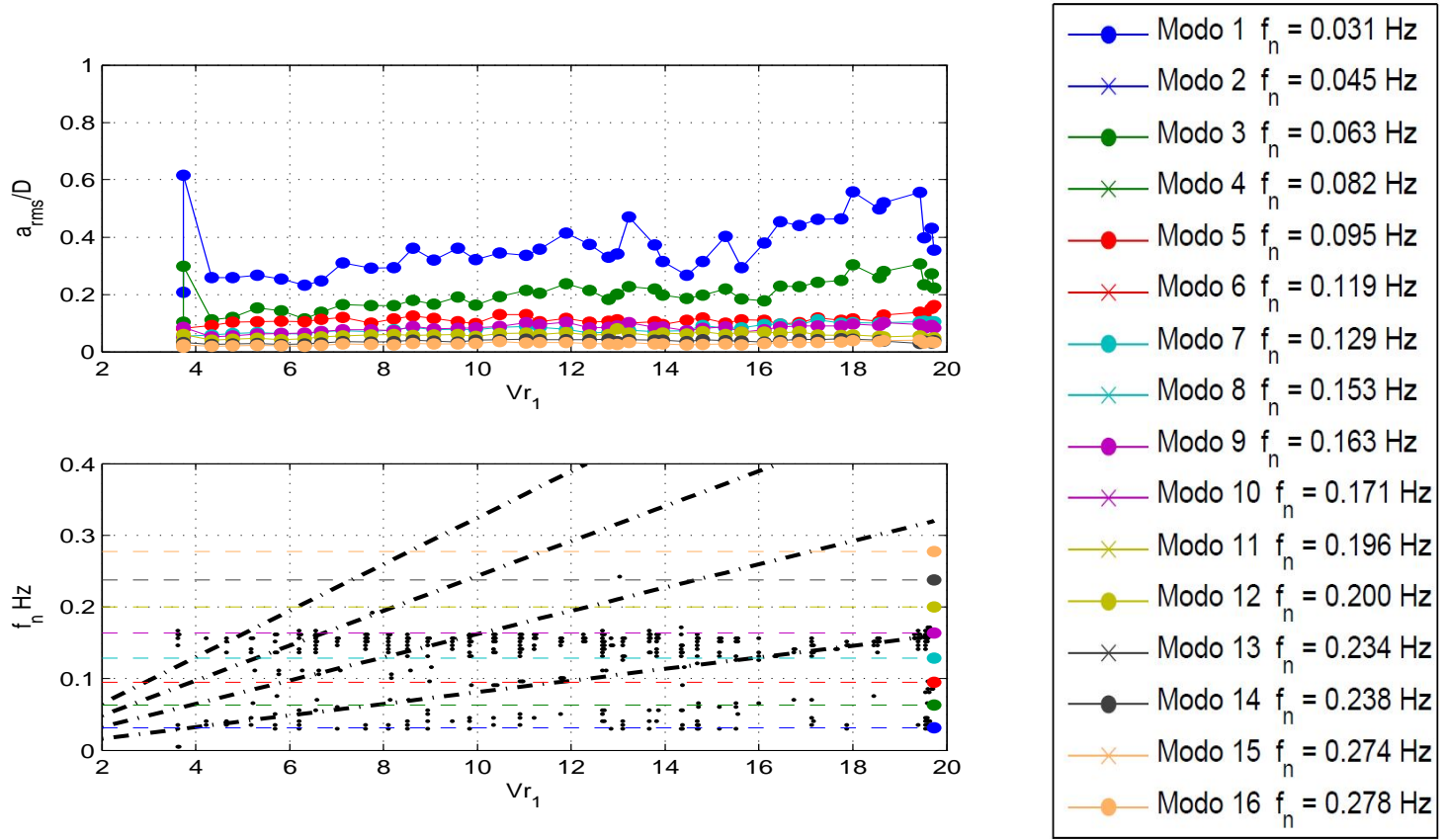

Figura 7.30: Desvio padrão das amplitudes modais através da interpolação do sinal do ensaio e frequência de resposta máxima do movimento na direção do fluxo (in-line) por Vr baseado na frequência natural do primeiro modo de vibrar para o arranjo Catenária-2 


\subsubsection{Resultados Síntese da Catenária-3, obtidos mediante decomposição modal}

Nas Figura de 7.31 a 7.35 são apresentados resultados da Catenária-3, segundo ensaios em velocidades que variaram de 0,40 a $1,58 \mathrm{~m} / \mathrm{s}$ (escala real).

Estas velocidades correspondem a velocidade reduzidas de 4,3 a 17,1, baseadas na primeira frequência no plano da catenária, ou seja, a primeira transversal ao perfil variável de correnteza incidente.
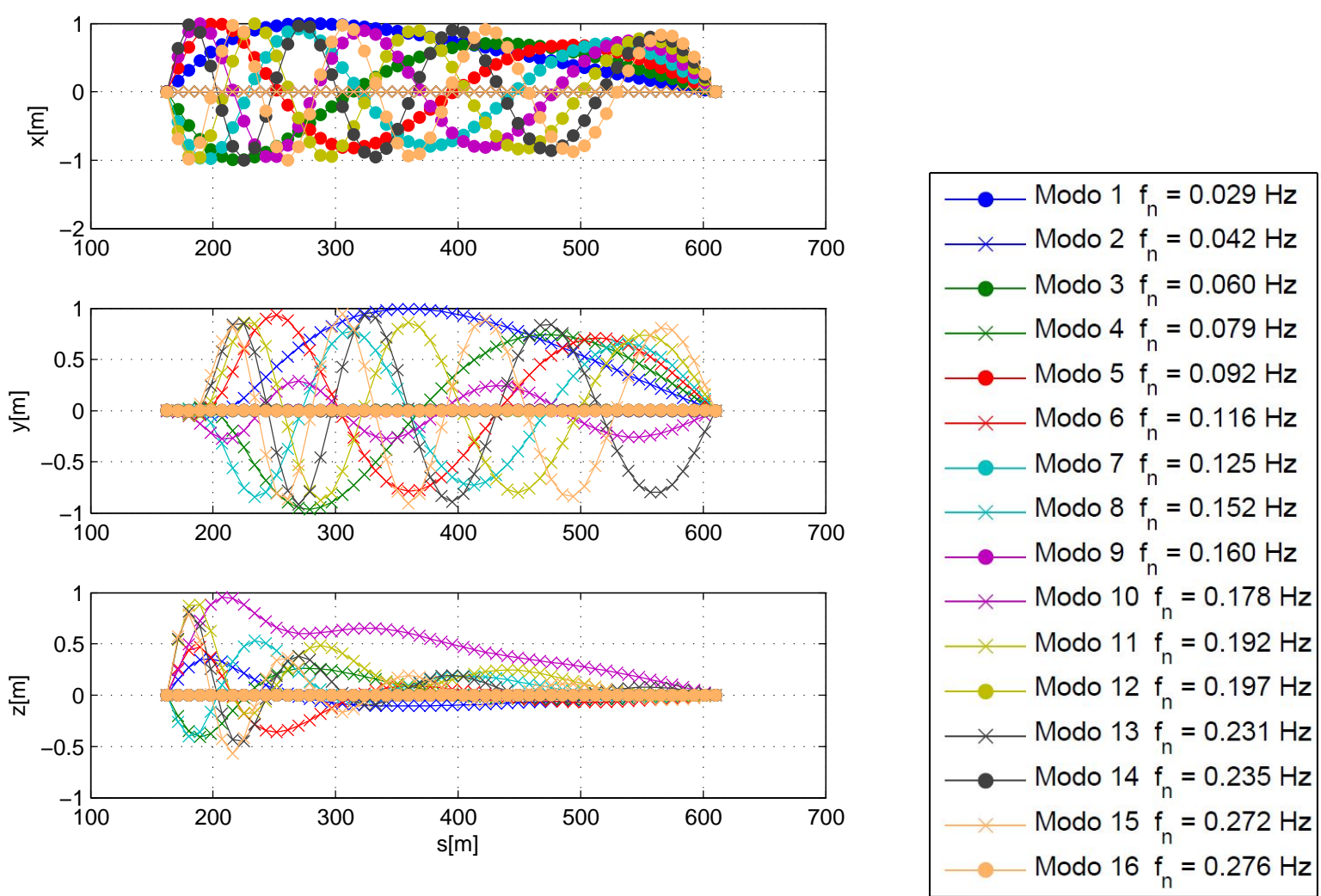

Figura 7.31: Modos de vibrar do arranjo Catenária-3 

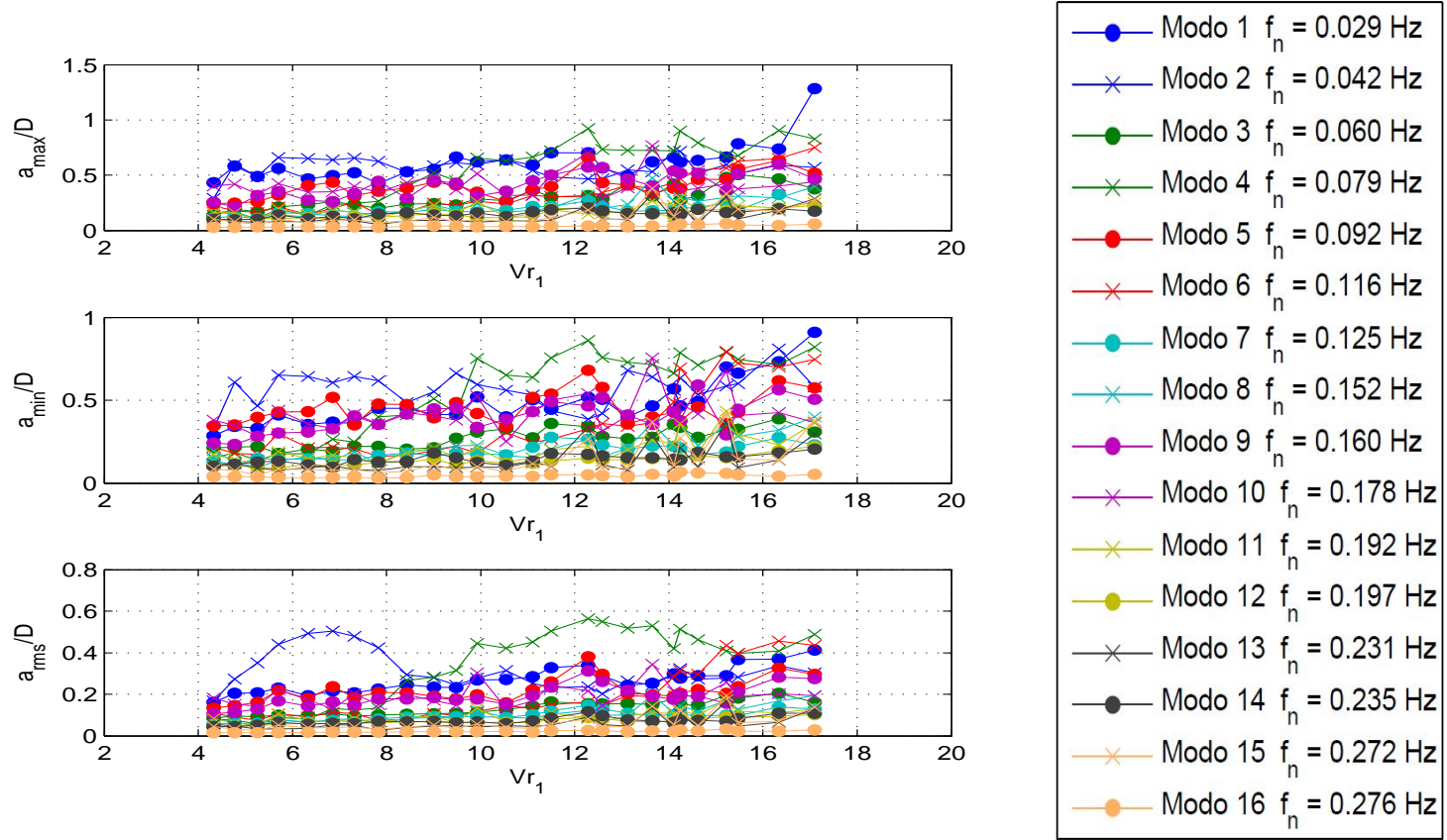

Figura 7.32: Variação das Amplitudes Modais através da interpolação do sinal do ensaio pela velocidade reduzida baseada na frequência natural do primeiro modo de vibrar para o arranjo Catenária-3
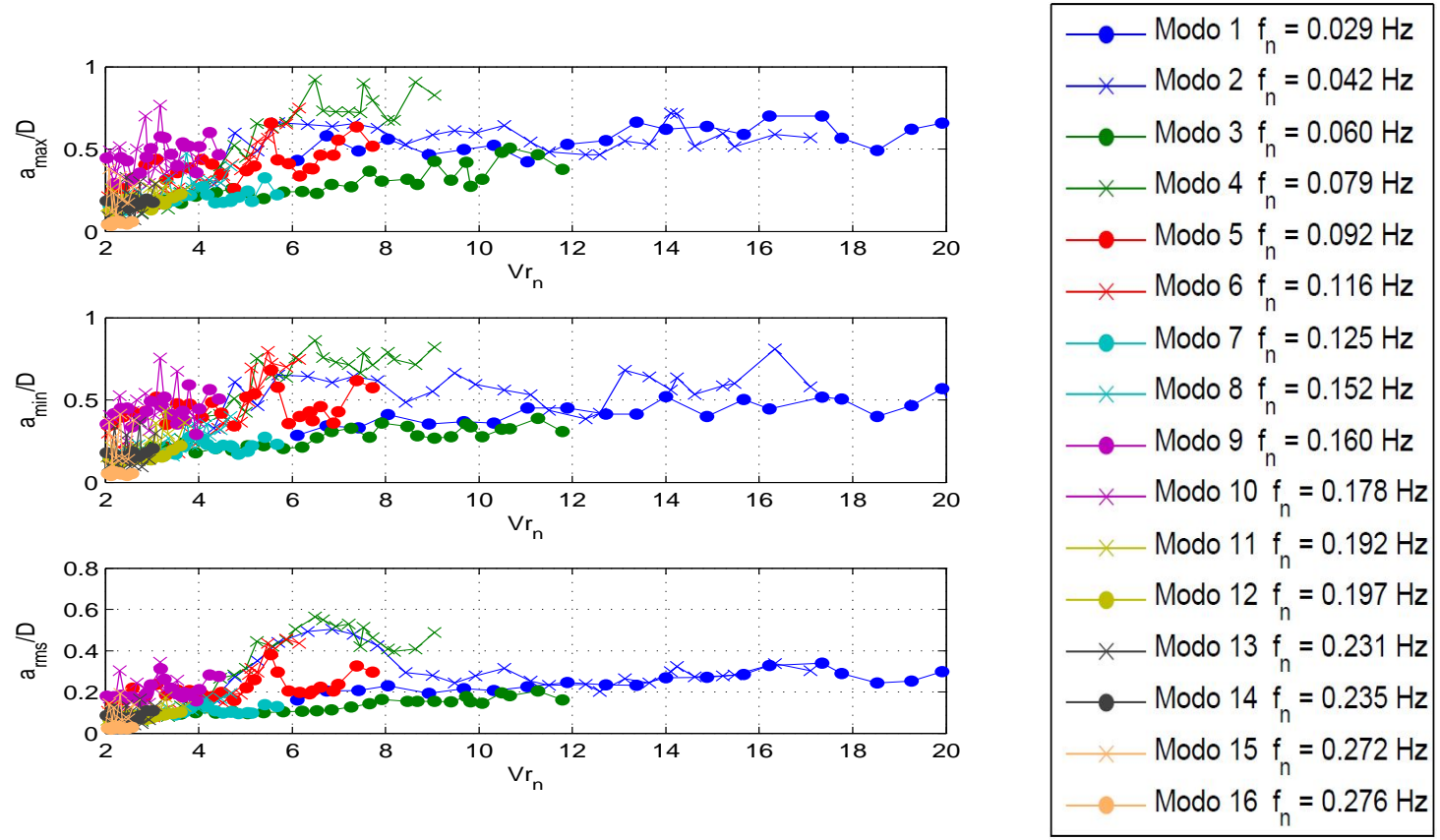

Figura 7.33: Variação das Amplitudes Modais através da interpolação do sinal do ensaio pela velocidade reduzida baseada na frequência natural de cada modo de vibrar para o arranjo Catenária-3 

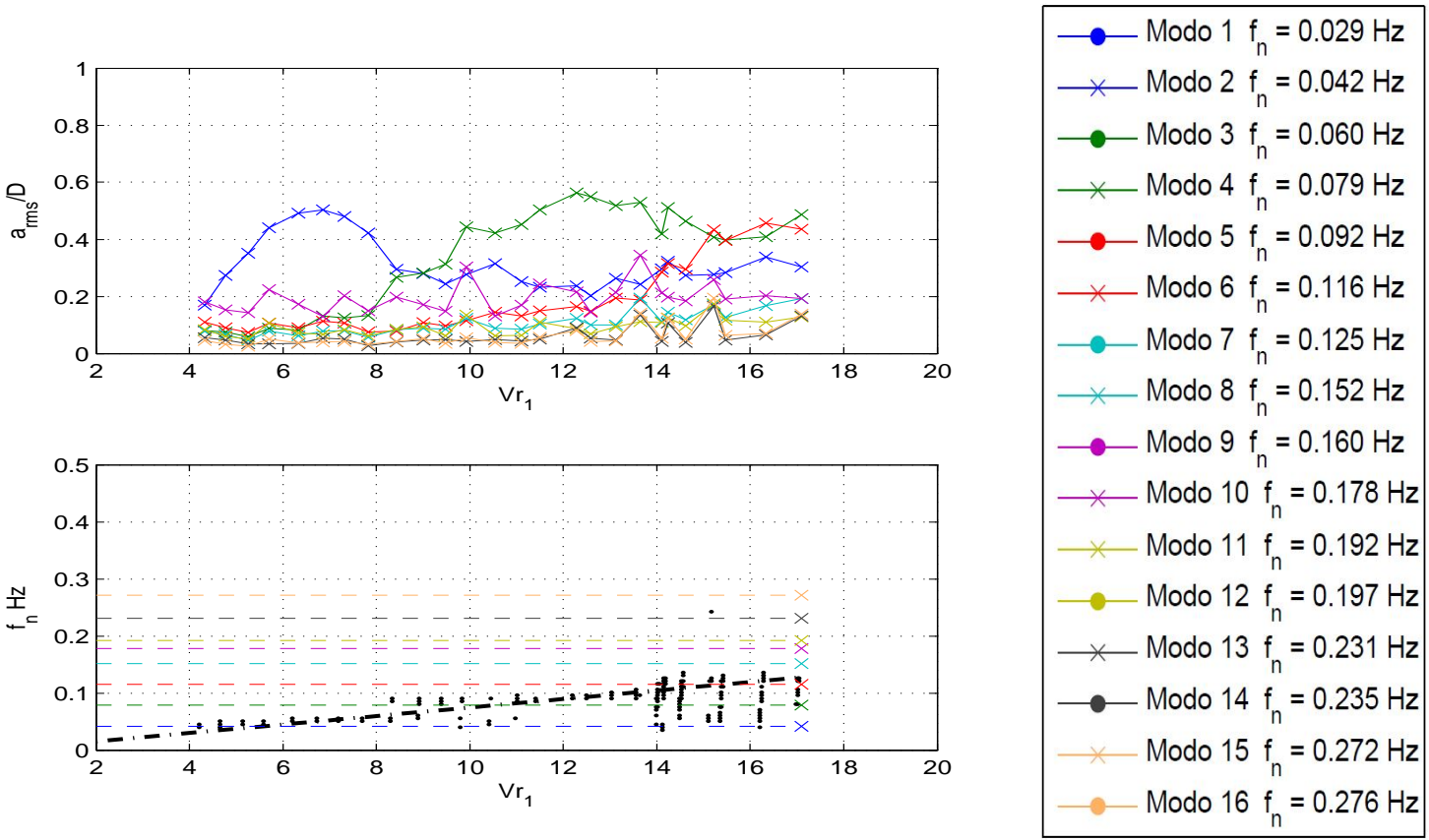

Figura 7.34: Desvio padrão das amplitudes modais através da interpolação do sinal do ensaio e frequência de resposta máxima do movimento cruzado (cross) por Vr baseado na frequência natural do primeiro modo de vibrar para o arranjo Catenária-3
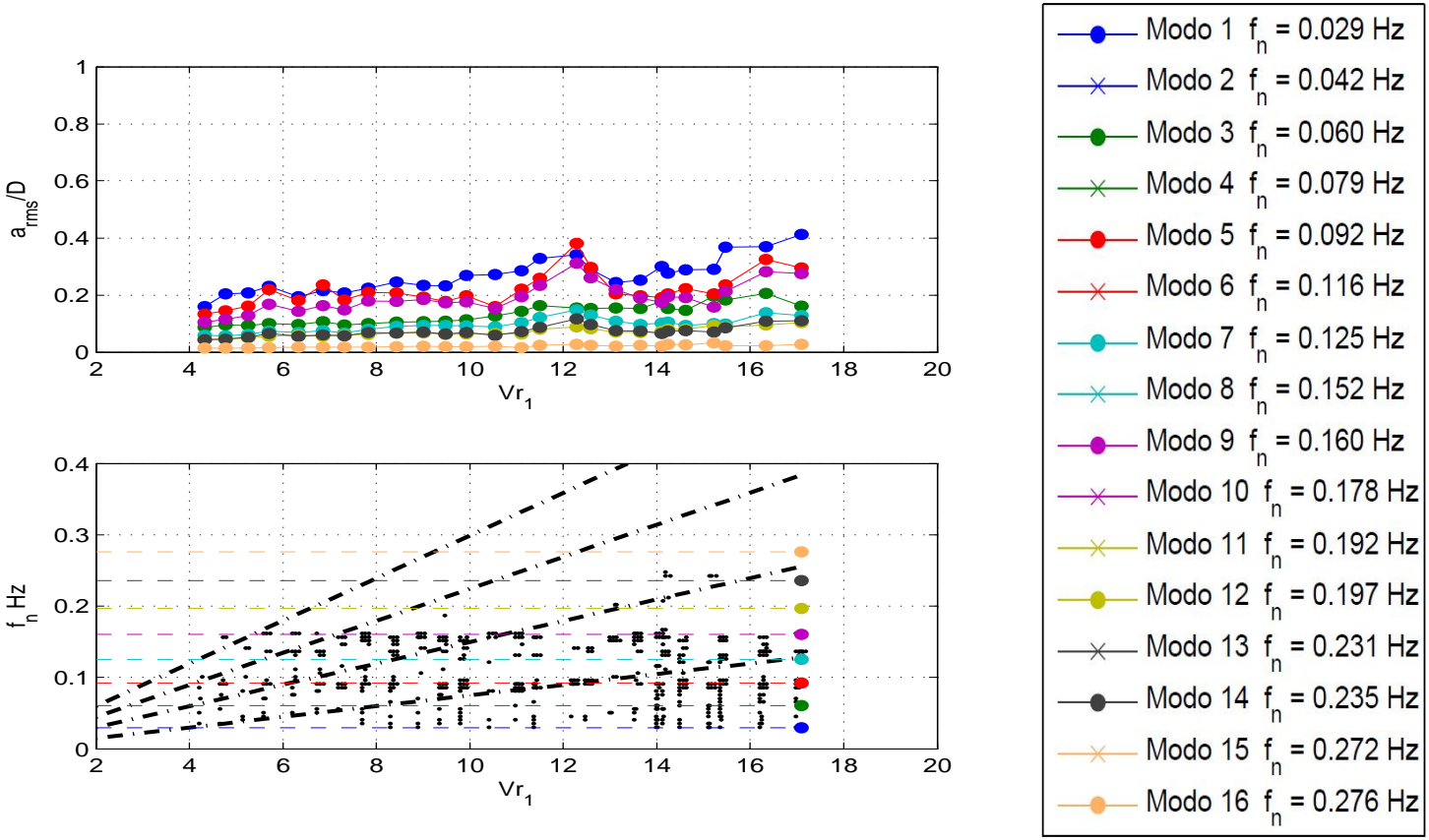

Figura 7.35: Desvio padrão das amplitudes modais através da interpolação do sinal do ensaio e frequência de resposta máxima do movimento na direção do fluxo (in-line) por Vr baseado na frequência natural do primeiro modo de vibrar para o arranjo Catenária-3 


\subsubsection{Resultados Síntese da Catenária-4, obtidos mediante decomposição modal}

Nas Figura de 7.36 a 7.40 são apresentados resultados da Catenária-4, segundo ensaios em velocidades que variaram de 0,38 a $2,10 \mathrm{~m} / \mathrm{s}$ (escala real).

Estas velocidades correspondem a velocidade reduzidas de 4,9 a 26,8, baseadas na primeira frequência no plano da catenária, ou seja, a primeira transversal ao perfil variável de correnteza incidente.
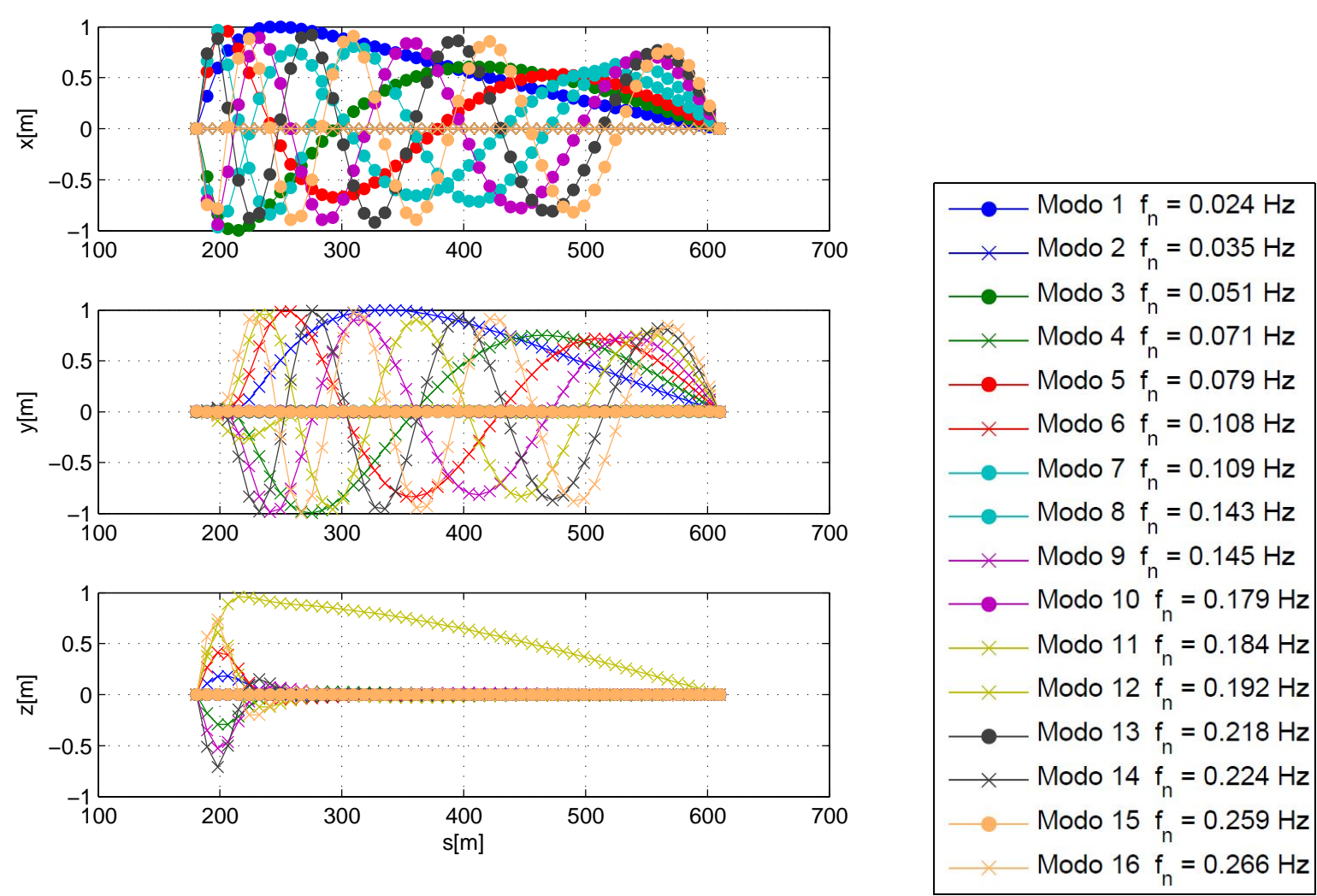

Figura 7.36: Modos de vibrar do arranjo Catenária-4 

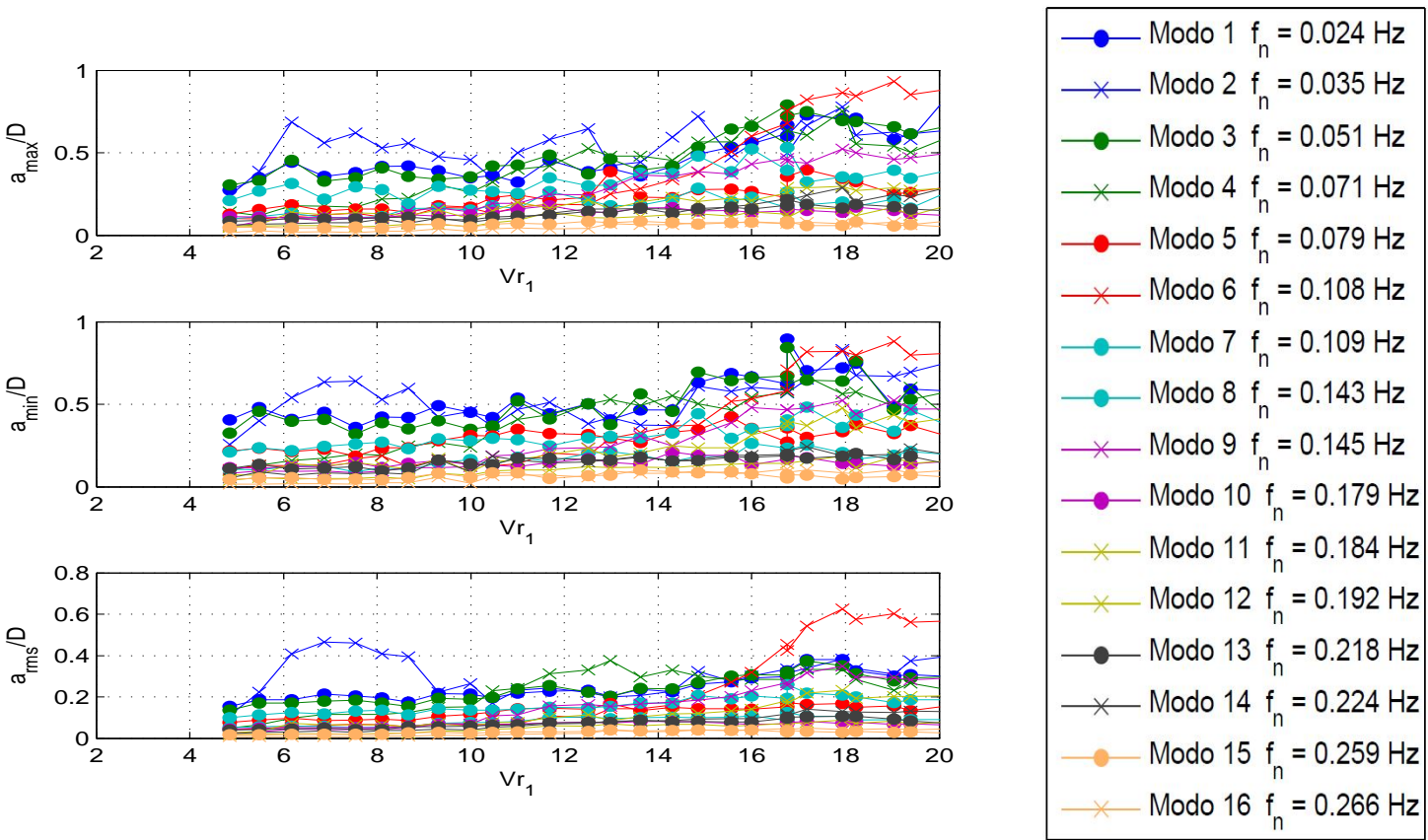

Figura 7.37: Variação das Amplitudes Modais através da interpolação do sinal do ensaio pela velocidade reduzida baseada na frequência natural do primeiro modo de vibrar para o arranjo Catenária-4
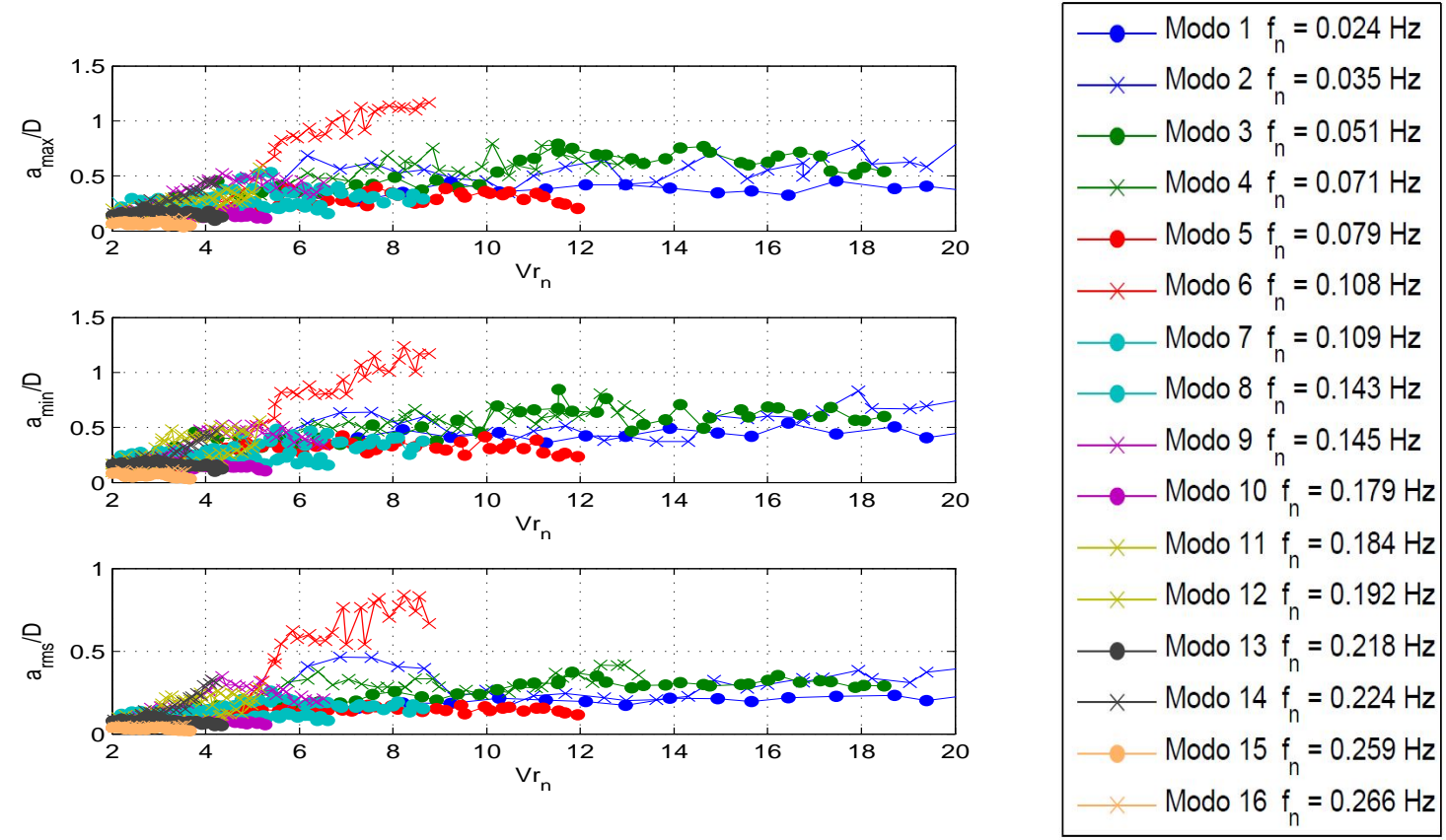

Figura 7.38: Variação das Amplitudes Modais através da interpolação do sinal do ensaio pela velocidade reduzida baseada na frequência natural de cada modo de vibrar para o arranjo Catenária-4 

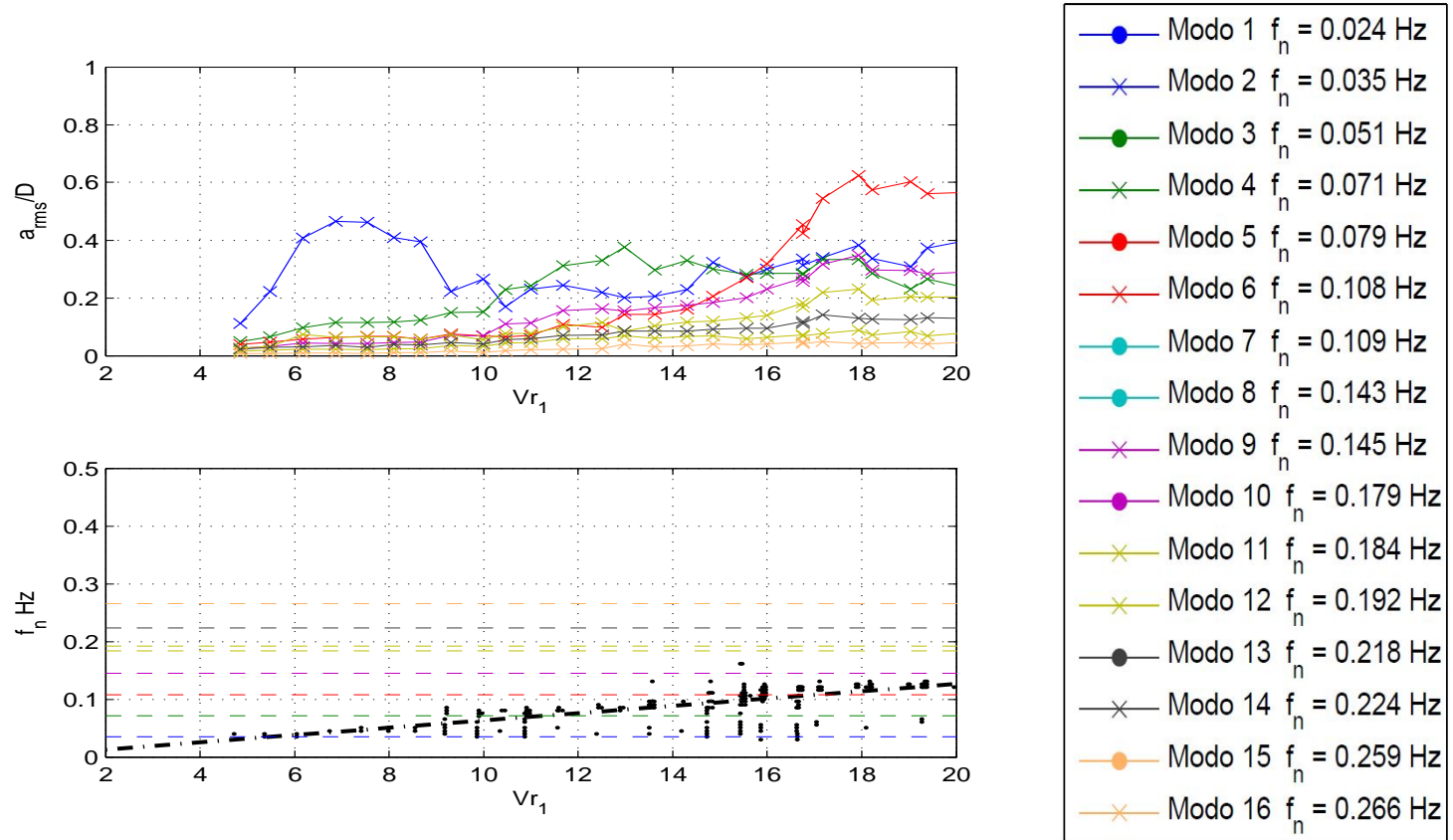

Figura 7.39: Desvio padrão das amplitudes modais através da interpolação do sinal do ensaio e frequência de resposta máxima do movimento cruzado (cross) por Vr baseado na frequência natural do primeiro modo de vibrar para o arranjo Catenária-4
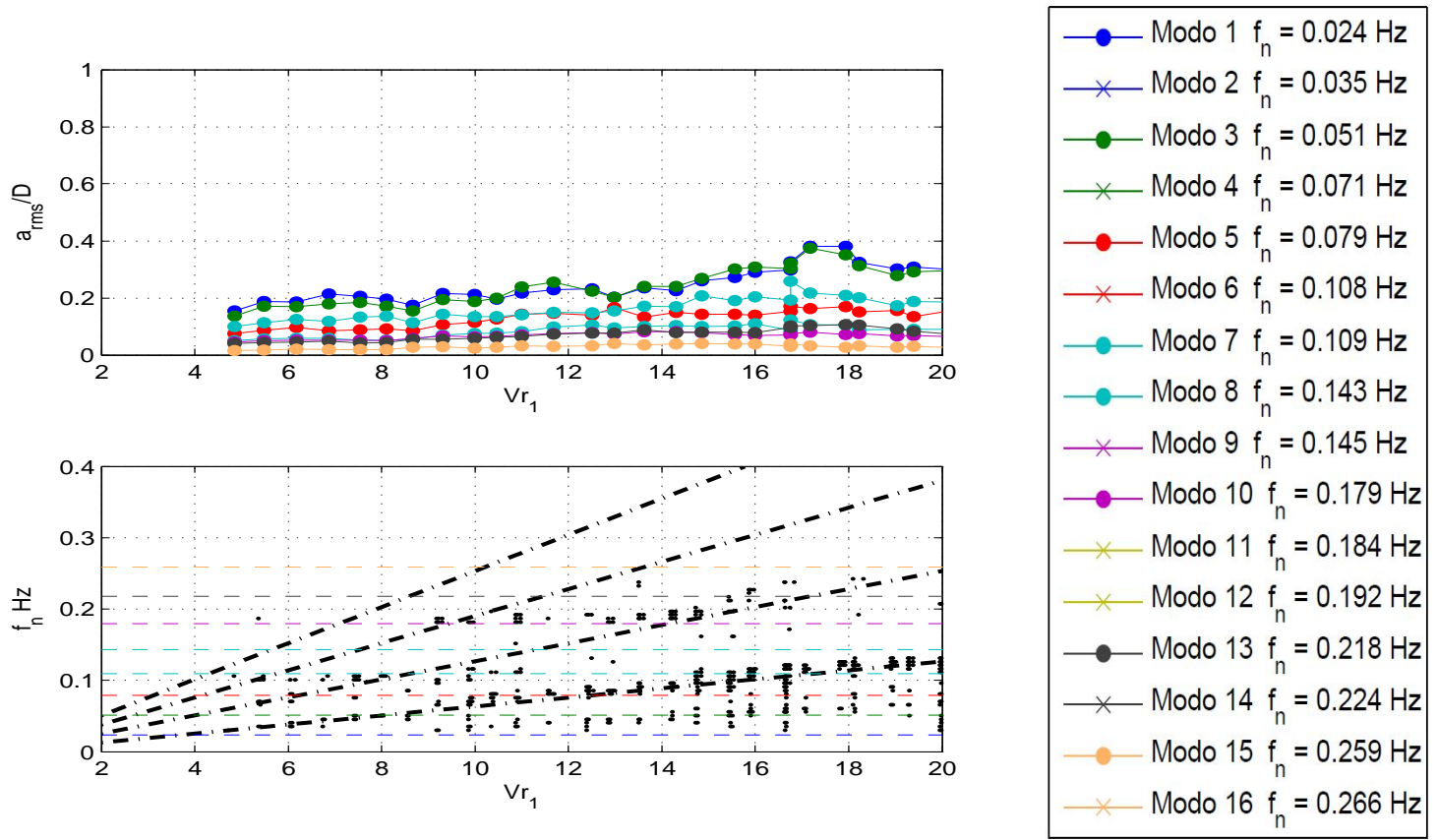

Figura 7.40: Desvio padrão das amplitudes modais através da interpolação do sinal do ensaio e frequência de resposta máxima do movimento na direção do fluxo (in-line) por Vr baseado na frequência natural do primeiro modo de vibrar para o arranjo Catenária-4 


\subsubsection{Resultados Síntese da Catenária-5, obtidos mediante decomposição modal}

Finalmente, para a comparação com o caso estudado no IPT, com velocidade constante ao longo da linha, estão apresentados os resultados referentes ao arranjo Catenaria-5.

Nas Figura de 7.41 a 7.45 são apresentados resultados da Catenária-5, segundo ensaios em velocidades que variaram de 0,24 a $2,39 \mathrm{~m} / \mathrm{s}$ (escala real).

Estas velocidades correspondem a velocidade reduzidas de 1,5 a 14,8, baseadas na primeira frequência no plano da catenária, ou seja, a primeira transversal ao perfil variável de correnteza incidente.
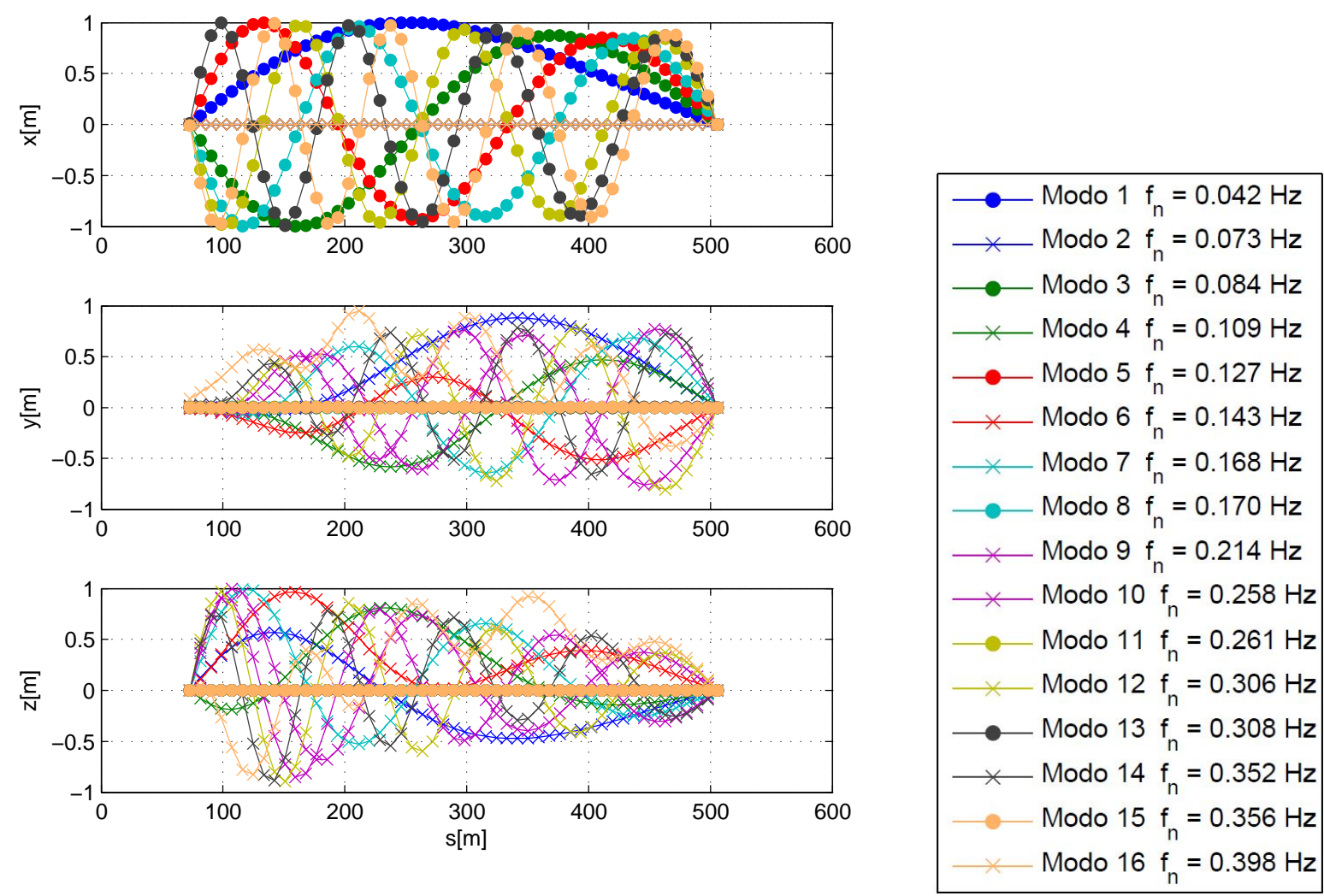

Figura 7.41: Modos de vibrar do arranjo Catenária-5 

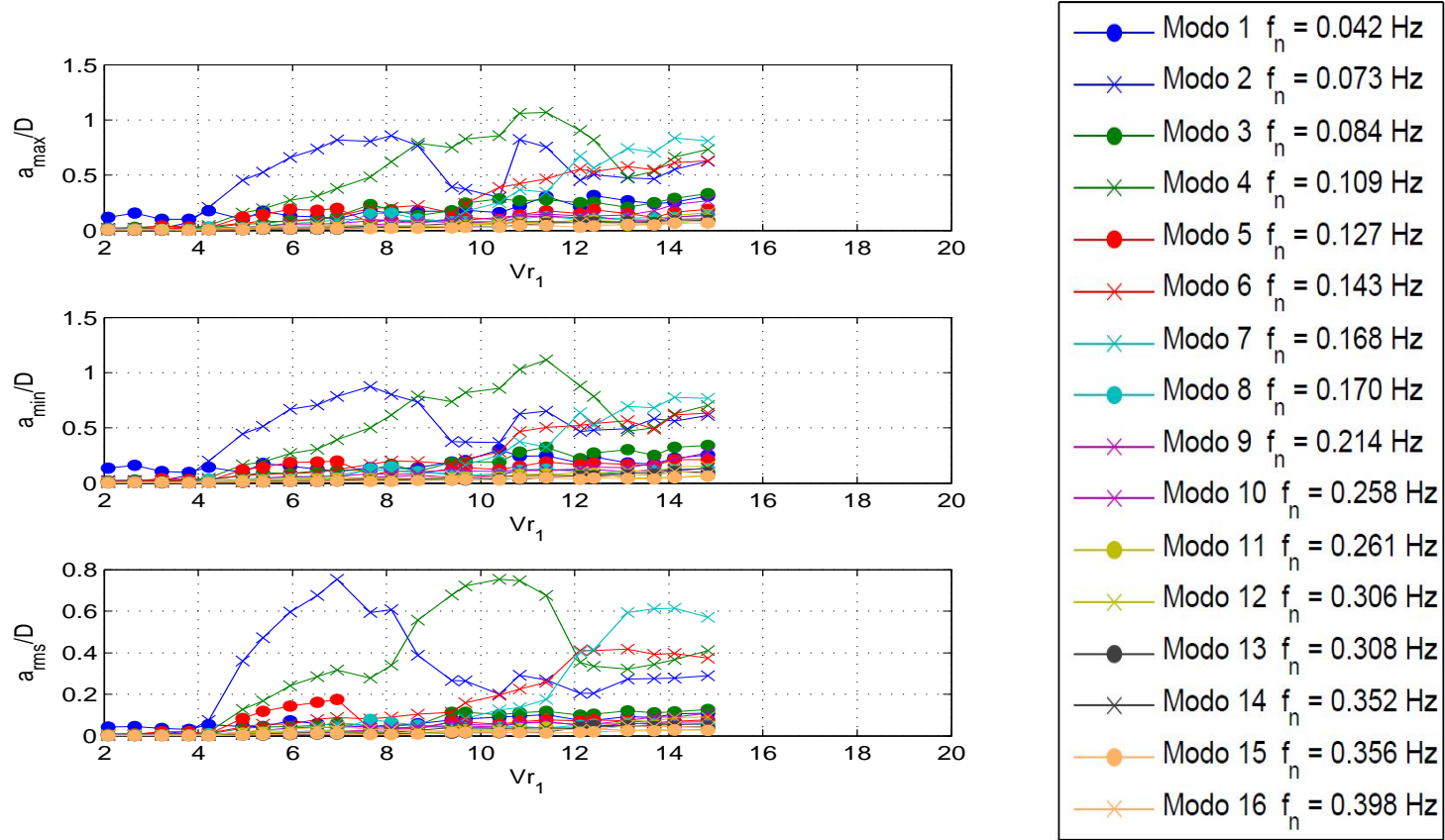

Figura 7.42: Variação das Amplitudes Modais através da interpolação do sinal do ensaio pela velocidade reduzida baseada na frequência natural do primeiro modo de vibrar para o arranjo Catenária-5
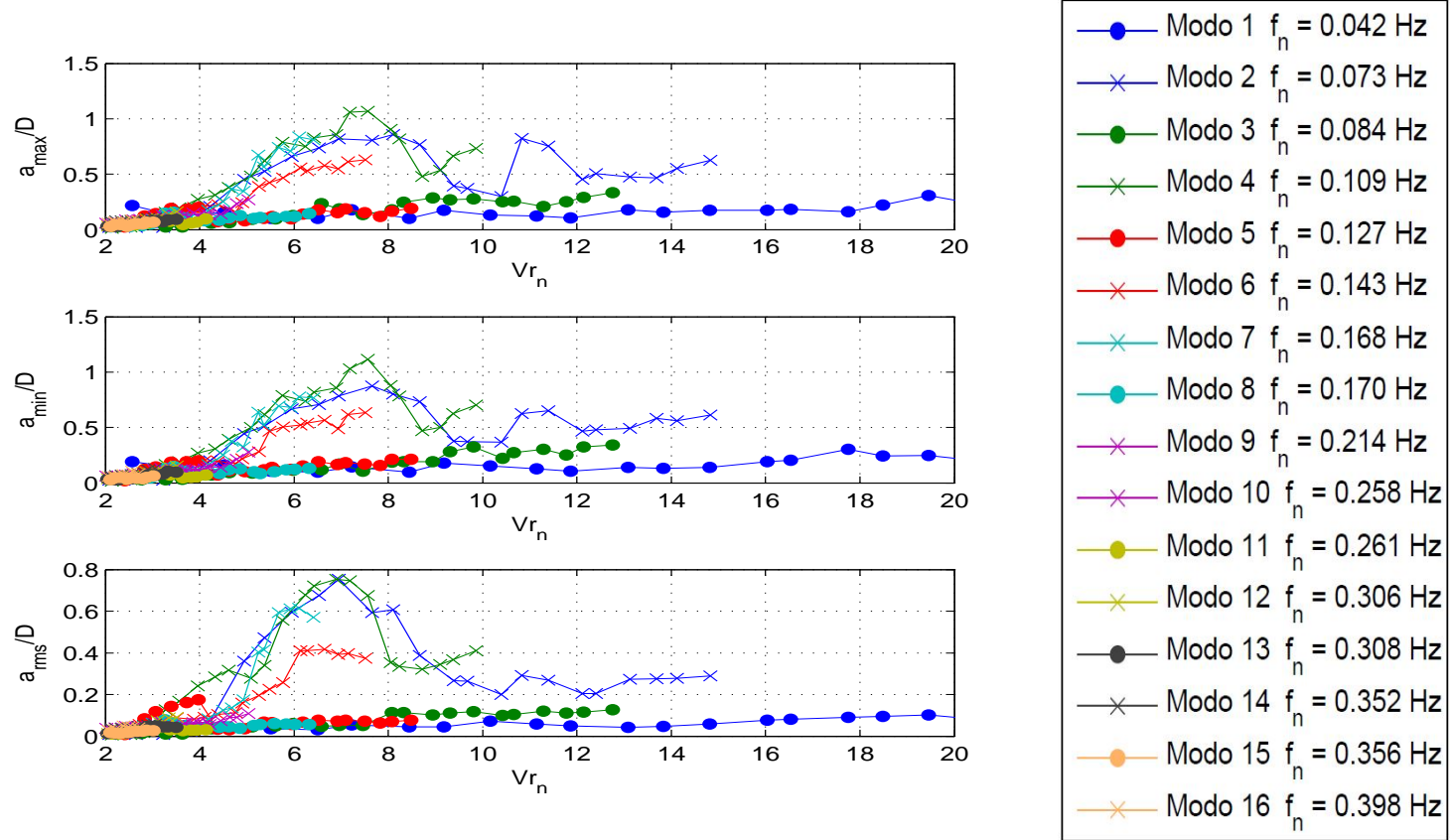

Figura 7.43: Variação das Amplitudes Modais através da interpolação do sinal do ensaio pela velocidade reduzida baseada na frequência natural de cada modo de vibrar para o arranjo Catenária-5 

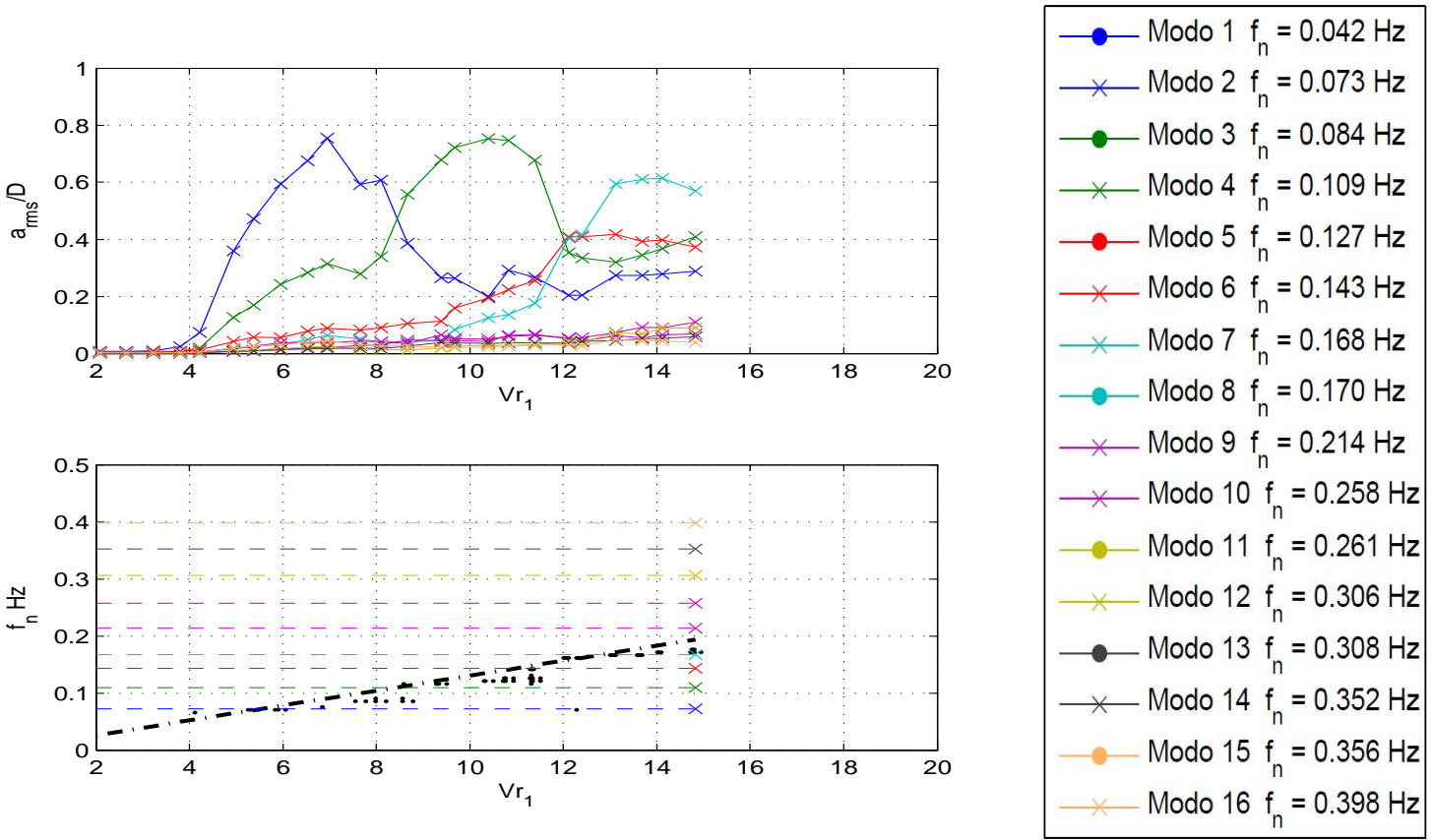

Figura 7.44: Desvio padrão das amplitudes modais através da interpolação do sinal do ensaio e frequência de resposta máxima do movimento cruzado (cross) por Vr baseado na frequência natural do primeiro modo de vibrar para o arranjo Catenária-5
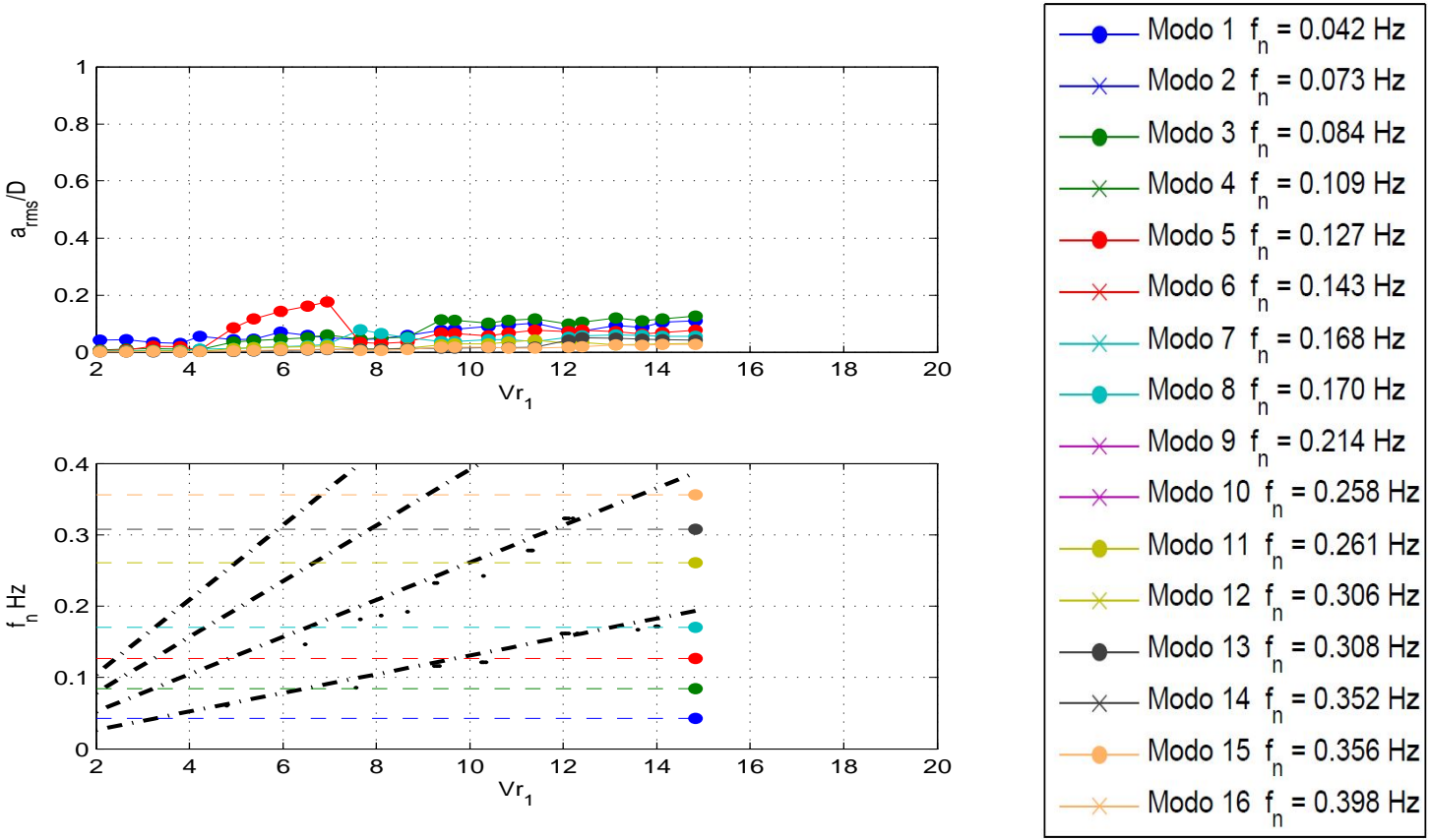

Figura 7.45: Desvio padrão das amplitudes modais através da interpolação do sinal do ensaio e frequência de resposta máxima do movimento na direção do fluxo (in-line) por Vr baseado na frequência natural do primeiro modo de vibrar para o arranjo Catenária-5

Assim como no caso da linha vertical, também para as catenárias foram construídos anexos onde são apresentados mais resultados das séries temporais e as respectivas amplitudes modais nos principais ensaios de VIV, ANEXOS de B a F. 


\subsection{Análises comparativas e discussões sobre os resultados experimentais}

Neste capítulo são comparados e discutidos os principais resultados obtidos ao longo de toda pesquisa, com foco na identificação de padrões de respostas, tendo em vista os objetivos almejados.

Um dos resultados mais importantes da presente tese, no que tange ao objetivo principal e às análises referentes aos avanços com respeito ao "estado da arte" sobre o fenômeno de VIV, foi apresentado nas Seções 7.1.2 e 7.2.2. Naquelas seções foram apresentados os gráficos correspondentes às variações das amplitudes modais em termos das velocidades reduzidas para o conjunto de ensaios realizados utilizando o modelo de linha flexível.

Foram cinco conjuntos de experimentos realizados: no CH-TPN - um lançamento vertical e quatro em catenária, todos com perfis de correnteza variável e ortogonal ao plano de lançamento; e no IPT - um lançamento em catenária rebocado em perfil uniforme de velocidades, também ortogonal ao plano da catenária. Na busca por comparações mais precisas e contundentes, e para facilidade do leitor em compreender as análises efetuadas, na presente seção os resultados gráficos serão recuperados e ilustrados lado-a-lado.

A análise será iniciada pela avaliação dos resultados relativos ao modelo lançado verticalmente, tanto pela sua importância com relação ao atual " estado da arte", como pela maior quantidade de trabalhos publicados sobre o fenômeno de VIV em linhas sob essa configuração.

Esse último argumento, entenda-se, implica uma boa disponibilidade de dados de comparação, bem como resulta em uma maior compreensão fenomenológica do problema em questão. Dessa forma, o modelo ensaiado verticalmente é considerado como referência para as análises comparativas e discussões aqui desenvolvidas.

O VIV, como definido anteriormente, refere-se aos movimentos periódicos produzidos pela ação de um escoamento sobre um corpo elástico (ou rígido elasticamente suportado). Cabe, então, recobrar as principais características do fenômeno das vibração induzidas por vórtices, quais sejam: autoexcitação e autocontrole.

Além disso, é válido recuperar as informações que concernem à resposta esperada de modelos flexíveis verticais sujeitos ao fenômeno de VIV. A baixos valores de velocidades reduzidas $\left(V_{r} \lesssim 5\right)$ as frequências de excitação são menores que as frequências naturais da estrutura. Conforme a velocidade reduzida aumenta, existe uma tendência desta 
frequência de excitação em se sincronizar com uma das frequências naturais do corpo, caracterizando a ocorrência de uma ressonância, autocontrolada, para uma faixa de $V_{r}$ conhecida como lock-in.
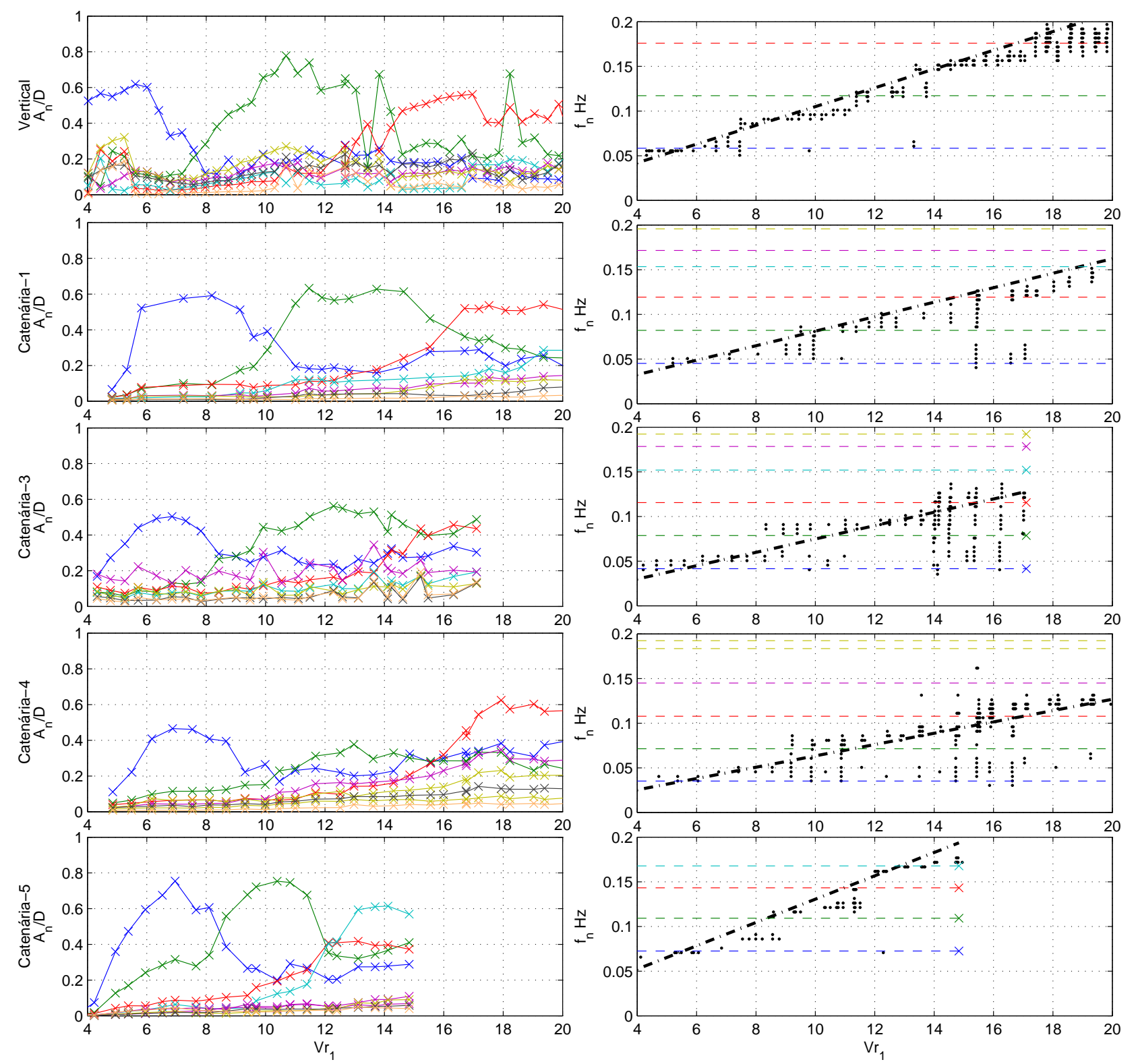

Figura 7.46: Variação nas amplitudes modais CF para todos os modelos considerados nos ensaios com o braço giratório, no $\mathrm{CH}-\mathrm{TPN}$.

No caso de cilindros longos (grande razão de aspecto), como é o presente caso, as vibrações produzidas na estrutura são da ordem de um diâmetro. Como mencionado anteriormente no texto, existem relatos de que a magnitude das amplitudes modais, adimensional pelo diâmetro hidrodinâmico, podem chegar a valores até $50 \%$ maiores que um diâmetro em casos específicos. Nesse ponto, cabe relembrar a importância de certas variáveis-chave como a razão de aspecto, o parâmetro de massa-amortecimento, direção 
e módulo da velocidade incidente, entre outros.

Recuperadas essas informações e características é possível analisar os gráficos da Figura 7.46, tomando como referência aquele advindo do VIV na linha vertical. Ressalte-se que essa figura ilustra as amplitudes modais em função da velocidade reduzida para os dezesseis primeiros modos globais da linha.

De uma maneira geral, as amplitudes modais que podem ser avaliadas apresentam um padrão bastante coerentes com o esperado: inexistem para baixos valores de velocidade reduzida $\left(V_{r}<4\right)$; são bastante diminutas para a boa parte dos modos globais mais altos em toda a faixa $0<V_{r 1} \leq 20$ para modos que não atingiram a zona de excitação e são de amplitude limitada a valores menores que a unidade nas situações em que ocorre o lock-in $\left(5<V_{r n} \leq 10\right)$.

Além disso, é interessante perceber a excitação dos modos de vibrar naturais sucessivos, o que é naturalmente esperado, com maiores amplitudes de resposta adimensional para os modos no plano da linha e, portanto, na condição chamada de cross-flow.

Nesse sentido, cumpre notar que os máximos de amplitude para o $1^{o}$ modo no plano da linha ocorrem para $4 \lesssim V_{r 1} \lesssim 6$; para o $2^{\circ}$ modo, também no plano, a faixa com o ramo de respostas mais amplificadas está em $10 \lesssim V_{r 1} \lesssim 13$; e para o $3^{\circ}$ modo no plano da linha, os picos de amplitudes são visualizados na faixa em que $15 \lesssim V_{r 1} \lesssim 17$. Esses três modos foram os que apresentaram maiores amplitudes modais e, desta forma, dominaram a dinâmica dos ensaios conduzidos no braço giratório do CHTPN.

É possível comentar, também, que as maiores amplitude de resposta fora do plano da linha, na direção do escoamento incidente (ou inline, ocorreram para o primeiro modo correspondente, embora em amplitudes adimensionais de, no máximo, 0,5, sem que fossem notados picos ressonantes de resposta.

Para determinados valores de velocidade reduzida é possível notar coexistência modal, tanto na mesma direção (por exemplo, para $V_{r 1} \approx 18$, onde aparecem picos de resposta dos $2^{\circ}$ e $3^{o}$ modos no plano da linha), quanto em direções perpendiculares entre si (salienta-se, a título de informação, que nas proximidades de $V_{r 1} \approx 16,5$ existem picos de respostas da mesma ordem de magnitude, tanto para o $2^{o}$ modo (no plano) quanto para o $1^{o}$ modo (ortogonal ao plano).

Estabelecido o caso de referência, com a evidenciação de suas particularidades mais relevantes em termos de comportamento da resposta modal, é possível avaliar os demais 
casos, todos referentes a configurações de lançamento em catenária direta.

Para todos os casos em catenária, respostas, mesmo que sutis, aparecem nos gráficos de variação das amplitudes modais para $V_{r 1} \gtrsim 4$, exatamente como no caso da linha vertical.

Cabe, no entanto, apenas uma ressalva: o modelo ensaiado no IPT apresentou respostas para $V_{r 1} \gtrsim 2$ em níveis relativamente baixos, muito provavelmente relacionadas à configuração de lançamento com ângulo de topo de cerca de $70^{\circ}$ (em relação à horizontal). Esse ângulo de topo, bem menor que os dos demais lançamentos, apresentou o menor nível de amortecimento $\zeta \approx 2 \%$, enquanto as demais condições apresentaram $\zeta \approx 4 \%$, possivelmente facilitando a ocorrência de maiores amplitudes, ver respostas da Catenária-5 na Figura 7.46 e também no ANEXO F.

Os ensaios realizados no IPT não permitiram o alcance de velocidades relativas da magnitude das auferidas no CH-TPN, limitando-se a $V_{r} \lesssim 15$. Por outro lado, a linha apresentou diferentes padrões de resposta para faixas de velocidade restritas, próximas ao limite superior atingido nos ensaios: foi percebido um aumento significativo das respostas das amplitudes modais até cerca de 0,8, apontando para o fato de que a faixa de lock-in estava próxima de ser excitada.

Ainda com relação à Catenária-5, é interessante notar que, no entorno de $V_{r 1}=14$, os dois primeiros gráficos, relativos aos valores máximo e mínimo da amplitude modal, apontam para respostas significativas da linha nos seus $2^{\circ}, 3^{\circ}$ e $4^{o}$ modos no plano da linha (CF ou cross-flow). Os modos fora do plano mantiveram respostas em amplitude essencialmente baixas.

Esse é outro ponto de semelhança com o comportamento da linha vertical, evidenciado a partir das respostas de baixas amplitudes adimensionais relativas aos modos de vibrar mais altos, em particular para a Catenária-5, indicando a não-ocorrência de ressonância. Essas frequências tendem a ser excitadas apenas para velocidades reduzidas substancialmente maiores.

Adicionalmente, e mais importante no que tange às regiões de lock-in, nota-se que os patamares mais evidentes ocorrem para os mesmos modos de vibrar, em particular os três primeiros no plano da linha, aparecendo sequencialmente e na ordem, com o aumento da velocidade reduzida. Esse comportamento foi mais nítido na Catenária-1; compare esse padrão com aquele apresentado pela linha Vertical, ambos na Figura 7.46.

Com relação à sequência dos experimentos denominados Catenária-1 a Catenária-4, 
todos realizados no CH-TPN, onde a linha estava sujeita a perfis variáveis de correnteza, uma diferença significativa é passível de ser visualizada: conforme os ângulos de topo foram modificados, tendendo aproximar o modelo da configuração vertical, os modos fora do plano passaram a responder com amplitudes modais crescentes.

Outro ponto de particular interesse, relativamente ao cerne do presente texto, é a coexistência modal percebida também nos casos em catenária, mais acentuadamente, inclusive, que no caso vertical. Essa característica é nítida para modos no plano da catenária dos ensaios no IPT, enquanto que nos demais casos esse fenômeno chegou a ocorrer entre modos dentro e fora do plano, concomitantemente, novamente exibindo um padrão de respostas bastante similar ao caso em que o modelo foi ensaiado verticalmente.

Um dos objetivos traçados para a presente tese foi a proposição de uma metodologia eficiente de análise, capaz de revelar comportamentos dinâmicos conhecidos, frente a respostas resultantes de uma excitação complexa multimodal sobre a linha flexível. Diante dos resultados apresentados até aqui, é possível perceber que a metodologia de análise proposta foi capaz de alcançar esse objetivo, permitindo, inclusive, prover informações inéditas a partir dos ensaios realizados.

A fim de abalizar essa informação e agregar valor aos resultados concebidos proceder-se-á aqui o detalhamento da reconstrução de uma série temporal experimental, para uma dada velocidade, a partir das informações relativas às respostas de amplitude advindas da decomposição modal, com vistas na descrição apresentada no Capítulo 5, no qual foi descrita a metodologia de identificação de zonas de excitação, que faz parte dos códigos/programas comercias mais utilizados nos projetos de risers.

Cabe lembrar que, nesses códigos/programas, os coeficientes de amortecimento e massa adicional são calculados de maneira iterativa resultando nas amplitudes modais como apresentado na equação (5.4). Estes coeficientes são empíricos e utilizados, indistintamente, para todos os modos, de maneira a gerar uma amplitude para cada um deles. O procedimento por trás dessa metodologia é baseado no balanço energético, com a utilização de coeficientes como os apresentados em [Gopalkrishnan, 1993], provenientes de ensaios com modelos rígidos em oscilação forçada.

Além disso, esses códigos/programas encerram a hipótese de cilindro finito, dado que no caso de cilindros infinitos as amplitudes poderiam ser variáveis ao longo do comprimento, sugerindo a existência de ondas progressivas como as ilustradas na Figura 5.3, extraída de [Vandiver \& Marcollo, 2003]. Resultado desta natureza não foi plenamente evidenciado nas condições aqui ensaiadas, sendo parcialmente identificado 
como resultado da alternância entre modos simultaneamente passíveis de excitação e que, portanto, competem pela dominância na dinâmica global das linhas.

Considerando a escala de 1:100, como maneira de permitir a analogia com um caso real descrito em [Rateiro et al., 2012], nos ensaios realizados, o modelo guarda analogia com um riser de aproximadamente $600 \mathrm{~m}$ de comprimento, com aproximadamente $450 \mathrm{~m}$ suspensos. Ademais, as respostas obtidas foram identificadas como sendo referentes aos seus primeiros 10 modos de vibrar, sob velocidades máximas próximas a reais de $2 \mathrm{~m} / \mathrm{s}$. Desta forma, a hipótese de cilindro finito parece bem satisfatória.
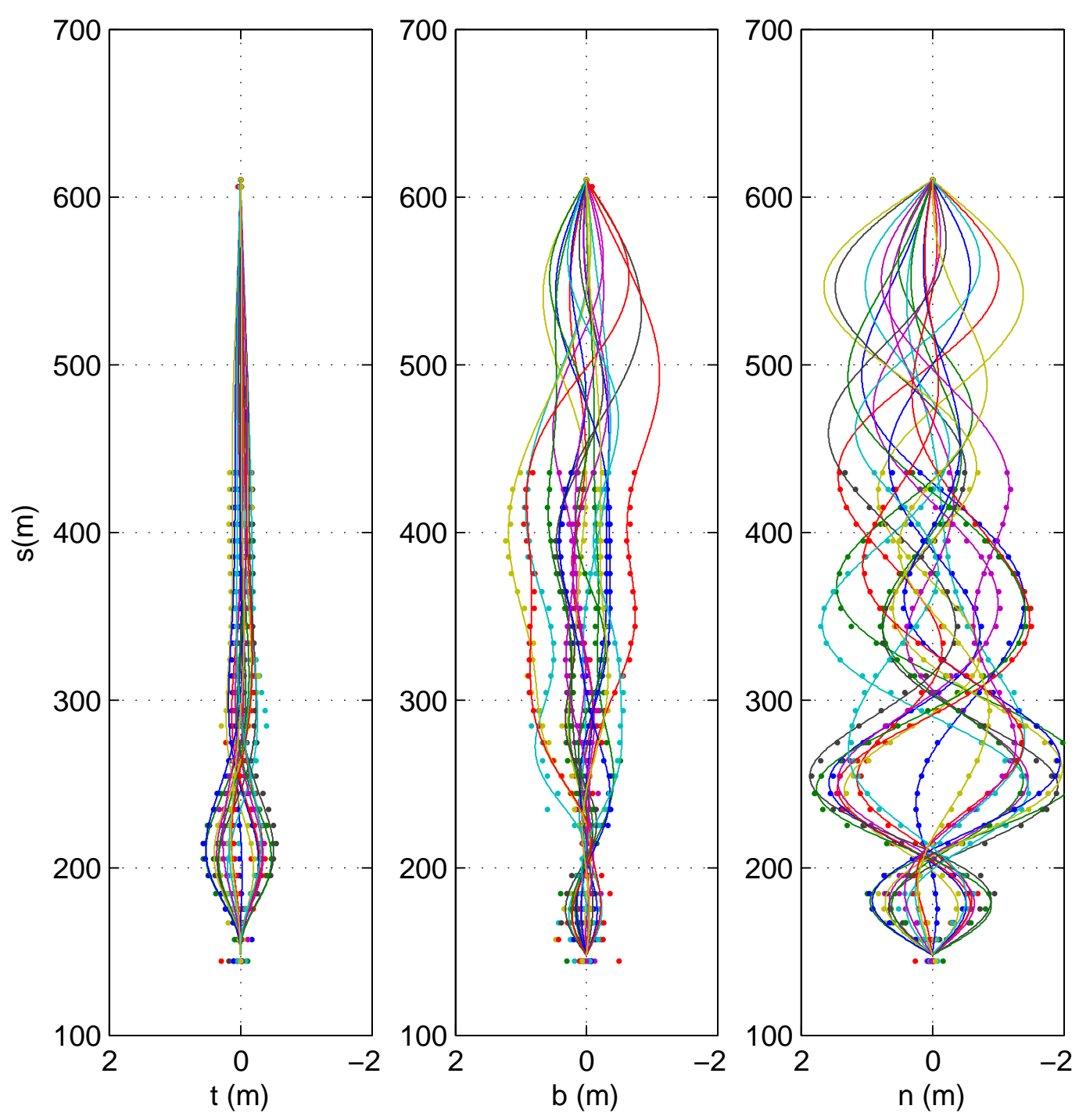

Figura 7.47: Reconstrução da deformada da Catenária-1 no sistema de coordenadas $(\mathrm{t}, \mathrm{n}, \mathrm{b})$, sob velocidade $U_{\max }=1,94 \mathrm{~m} / \mathrm{s}$.

Apresentadas essas considerações, a verificação do comportamento da linha flexível 
para as configurações em catenária parece bastante plausível, neste contexto, permitindo a obtenção das frequências naturais e modos de vibrar baseados nas suas condições estáticas iniciais, o que pode ser feito de maneira analítica ou numérica.

A partir das análises realizadas ao longo do texto e dos comentários tecidos com relação às considerações mesmo sobre a incidência de perfis de correnteza variável e a maneira como esses afetam as zonas de excitação definidas por $V_{r}$, pode-se concluir que a avaliação das amplitudes de resposta, advindas da decomposição modal, permite a reconstrução das séries temporais experimentais com boa aderência, utilizando os modos de vibrar obtidos com um código PoliFlex, que possibilitou considerações de extensibilidade e avaliações das diversas escalas de tempo envolvidas nos modos de vibrar, conforme ilustrado na Figura 7.47 .

Ainda para essa condição específica, também foram considerados os modos e as frequências obtidas a partir das formulações apresentadas em [Pesce et al., 1999], a fim de tornar mais expedita a recomposição da assinatura temporal. Independente da abordagem para a obtenção de modos e frequências naturais, há que se considerar a existência de modos associados à extensibilidade da linha, o que afeta a ordem como os modos naturais se suscedem e, portanto, são excitados com o gradativo aumento da velocidade de reboque.
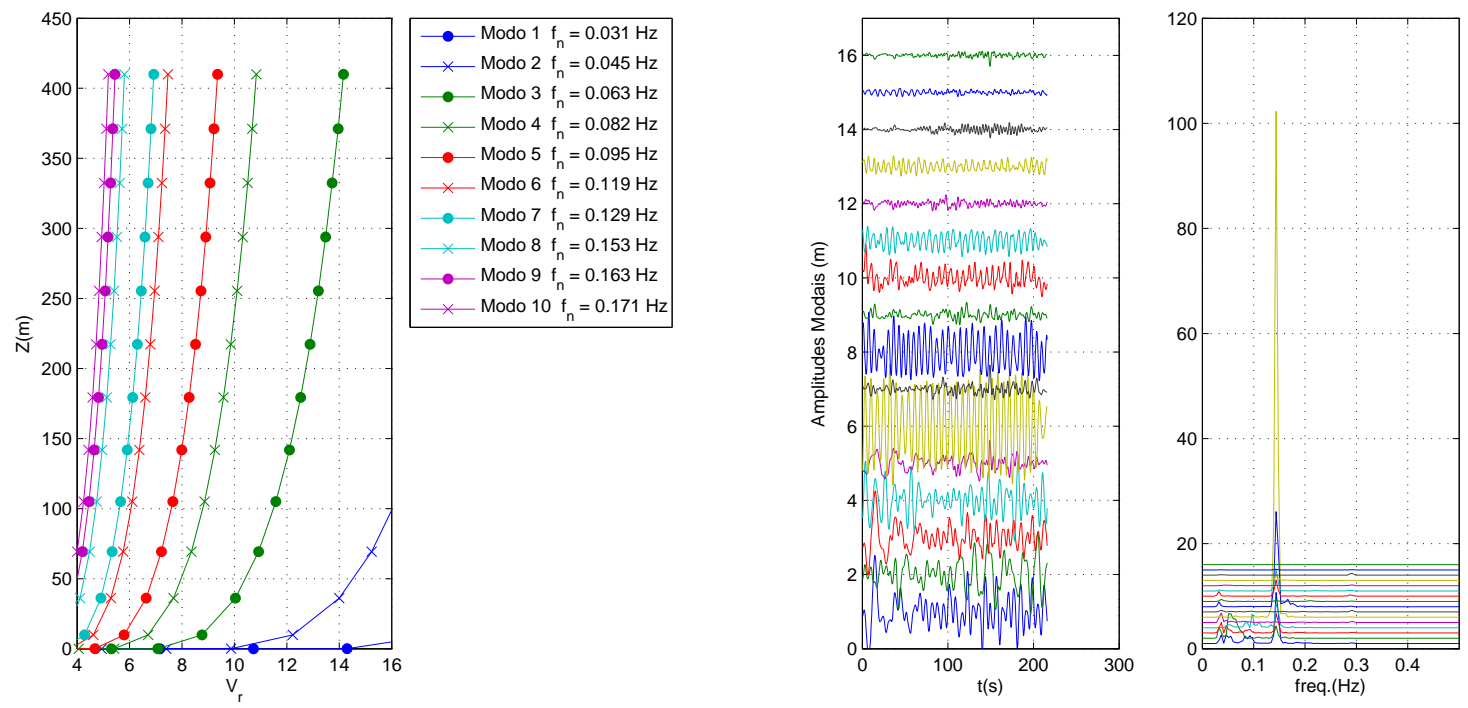

Figura 7.48: Amplitudes modais acopladas obtidas para o ensaio da Catenária-1 $\left(U_{\max }\right.$ $=1,94 \mathrm{~m} / \mathrm{s})$.

Sendo assim, como última comparação a ser feita a partir dos resultados oriundos dos trabalhos da presente tese, obtidos para uma certa velocidade com resultado 
multimodal, amplitudes acopladas, bem como frequências e modos naturais de vibrar como os apresentados no Capítulo 4, são apresentados os seguintes comentários acerca da Catenária-1 sob velocidade de correnteza $U_{\max }=1,94 \mathrm{~m} / \mathrm{s}$, conforme detalhes apresentados na Figura B.16, do ANEXO B.

O caráter multimodal pode ser visualizado na Figura 7.48, que apresenta amplitudes modais em todos os 16 primeiros modos, com as maiores amplitudes observadas nos $6^{\circ}$ e $8^{\circ}$ modos.

Um resumo dos valores das frequências naturais obtidos analiticamente segundo as equações (4.22) e (4.24), e numericamente pelo PoliFlex pode ser visto na Tabela 7.1.

Tabela 7.1: Comparação das frequências analíticas e numéricas em Hz na escala real.

\begin{tabular}{ccccc}
\hline & & & \multicolumn{2}{c}{ PoliFlex } \\
ID. WKB/Bessel & WKB & Bessel & ID \& Freq. In-Line & ID \& Freq. Cross-Flow \\
\hline 1 & 0,032 & 0,033 & $1-0,031$ & $2-0,045$ \\
2 & 0,064 & 0,067 & $3-0,063$ & $4-0,082$ \\
3 & 0,096 & 0,101 & $5-0,095$ & $6-0,119$ \\
4 & 0,128 & 0,134 & $7-0,129$ & $8-0,153$ \\
5 & 0,16 & 0,168 & $9-0,163$ & $10-0,171$ \\
6 & 0,192 & 0,202 & $11-0,200$ & $12-0,196$ \\
7 & 0,224 & 0,235 & $13-0,238$ & $14-0,234$ \\
8 & 0,255 & 0,269 & $15-0,278$ & $16-0,274$ \\
\hline
\end{tabular}

Para realizar a comparação com os modos obtidos analiticamente, os valores numéricos correspondentes foram transformados para o sistema de coordenadas ( $\mathrm{t}, \mathrm{n}, \mathrm{b})$, dado que a metodologia analítica avalia a deformação na direção normal à curva estática da linha flexível.

Na Figura 7.49 é apresentada uma comparação do modo de vibrar obtido numericamente para Catenária-1 e os modos por WKB. Para o caso da velocidade de $U_{\max }=1,94 \mathrm{~m} / \mathrm{s}$, estes modos analíticos podem representar o movimento tanto no $6^{\circ}$ quanto no $8^{\circ}$ modos com as amplitudes mostradas na Figura 7.48. 

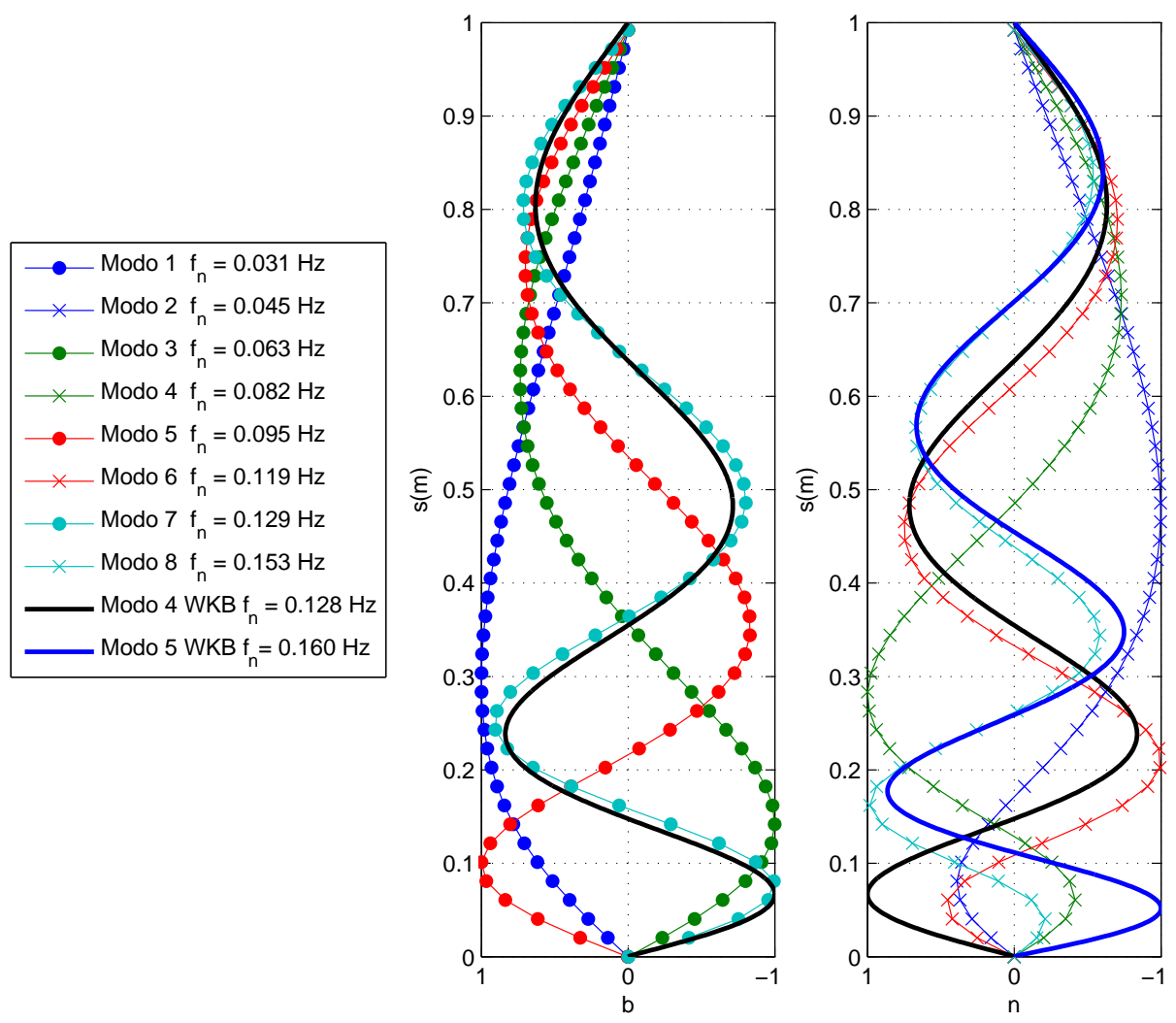

Figura 7.49: Comparação do modo de vibrar obtido numericamente para Catenária-1 e modelo analítico.

Para chegar no resultado acima, foram considerados coeficientes de massa adicional unitários e as frequências apresentadas na Tabela 7.1, as quais também se mostraram próximas às frequências numéricas, com os valores de $0,128 \mathrm{~Hz}$ para o $4^{\circ}$ modo via $\mathrm{WKB}$, comparados a $0,12 \mathrm{~Hz}$ para o $6^{\circ}$ e $0,16 \mathrm{~Hz}$ para o $5^{\circ}$ modo via $\mathrm{WKB}$ com $0,15 \mathrm{~Hz}$ para $8^{\circ}$ modos obtidos numericamente via código PoliFlex. Interessante notar como o $4^{\circ}$ modo via WKB se assemelha em forma e frequência do $7^{\circ}$ modo numérico, contudo a bi-normal não é a direção predominate do VIV.

Este tipo de comparação possui as suas limitações, mas sugere que para esse caso em específico, mesmo na presença de respostas multimodais, resultaria em resposta muito similar àquela dos códigos, como os apresentados em [Vandiver \& Li, 2005] e [Larsen et al., 2001b].

Cabe ressaltar que o intuito dessa comparação foi avaliar de que maneira o padrão de resposta poderia ser estimado a partir de equações analíticas que avaliam os modos de vibrar de maneira expedita. Esse resultado poderia, ainda, ser utilizado para avaliação dos 
coeficientes de amortecimento, como os descritos na equação 5.3. Esta metodologia tem um potencial maior de extrapolação para outras configurações reais e em linhas flexíveis de comprimentos maiores, além das dimensões das condições investigadas experimentalmente neste doutorado.

Finalizando assim, duas sugestões bem pertinentes são apresentadas para trabalhos futuros: (i) avaliar os coeficientes hidrodinâmicos necessários para obtenção numérica de resultados similares aos das matrizes de ensaio apresentadas nesta pesquisa e (ii) investigação do comportamento de linhas de comprimentos ainda maiores, buscando uma riqueza maior na sucessão de faixas de sincronização do modos. 


\section{Conclusões}

Nesta pesquisa foi apresentada uma série de ensaios para avaliar o fenômeno de VIV em linhas flexíveis longas, em particular naquelas lançadas em catenária. O estudo focou principalmente na avaliação experimental da influência das velocidades de correnteza variável e incidindo de maneira ortogonal ao plano de lançamento. Consideradas em um ambiente controlado como é do tanque de provas, estas condições são de grande importância para validar modelos teóricos e semi- empíricos utilizados no projeto de risers.

Em grande parte, a investigação experimental conduzida no âmbito desta tese aconteceu no braço giratório instalado no Calibrador Hidrodinâmico do Tanque de Provas Numérico (CHTPN), da USP, e a metodologia de análise foi baseada

principalmente na técnica de decomposição modal das respostas auferidas nas várias condições de ensaio. Um conjunto de ensaios realizados no tanque de reboque do Instituto de Pesquisas Tecnológicas do Estado de São Paulo (IPT) também fez parte das análises conduzidas nesta pesquisa.

O modelo de linha utilizado foi desenvolvido para viabilizar o estudo do VIV em uma faixa de velocidades e dimensões compatíveis com os dois tanques de prova, sem, contudo, abrir mão de certa equivalência com um problema em escala real. Em termos da similaridade conseguida, pode-se dizer que a dinâmica de VIV foi equivalente àquela presente em uma linha com $600 \mathrm{~m}$ de comprimento, sujeita a velocidades entre 0,50 a 2,50 $\mathrm{m} / \mathrm{s}$.

Portanto, foram analisados 6 arranjos, sendo um vertical e cinco lançamentos em catenária direta. Para as condições em catenária o angulo de topo variou entre $70^{\circ}$ e $89^{\circ}$, o que, além da variação do comprimento suspenso da catenária, também gerou um efeito na variação da correnteza ao longo das linhas.

Com relação a aspectos de ordem fenomenológica, explorando o intervalo de velocidades angulares do braço giratório, foi possível a excitação isolada, ou em muitos 
casos combinada, de um ou mais modos naturais da catenária.

Não fosse a aplicação da técnica de decomposição modal, não seria possível, por exemplo, chegar à conclusão de que: "os comportamentos típicos do fenômeno de VIV na catenária são bastante parecidos com aqueles conhecidos nas linhas flexíveis longas, com a sucessão de regimes de sincronização, gradativamente sobrepostos na medida em que aumenta-se a ordem dos modos naturais excitados".

Além desta importante constatação experimental, mais interessante ainda foi identificar que o padrão de comportamento descrito acima se mantém mesmo na condição de um perfil de velocidades de excitação (perfil de correnteza) ortogonal ao plano de lançamento das catenárias e, mais, aparentemente independente da variação da intensidade ao longo do comprimento suspenso.

Independente da condição de lançamento das linhas (vertical ou catenária), e do modo natural excitado, a decomposição modal também mostrou que as faixas de sincronização, em geral, se iniciam no entorno de $V_{r}=4$. O limite superior em termos da velocidade reduzida máxima nas faixas de sincronização, por outro lado, foi consideravelmente diferente nas várias condições de lançamento e modo natural excitado, o que, certamente, está associado a parâmetros de inércia, de amortecimento e até mesmo ao ângulo de topo das linhas.

Com relação a este último aspecto, de fato, as linhas mais verticais, ou seja, com ângulos maiores de saída no topo (tomados em relação à direção horizontal), exibem um comportamento mais parecido com a linha vertical, com faixas de sincronização melhor identificadas e alternância de regimes ressonantes mais nítidos, inclusive na direção do escoamento incidente.

"A decomposição modal, portanto, caracteriza-se como o método buscado para viabilizar as análises do comportamento multimodal antecipadamente conhecido, representando um ganho substancial na compreensão dos mecanismos de interação entre as faixas de sincronização excitadas pelo VIV". Ficou claro, no entanto, que o ganho só é conseguido se um profundo trabalho de caracterização teórico-experimental das frequências e modos naturais da linha flexível longa for realizado antecipadamente. Sem essa caracterização, a decomposição modal perde grande parte de seu poder de identificação dos comportamentos imersos na dinâmica global observada e monitorada.

Falando em monitoração, esta também é outra contribuição original desta pesquisa de doutorado, na medida em que: "um sistema de rastreamento por aquisição e tratamento de imagens submersas foi devidamente adaptado e intensamente aplicado à 
investigação da dinâmica de linhas flexíveis longas". Se uma busca por técnicas de medição em experimentos de VIV como os realizados nesta pesquisa for realizada, praticamente nada será encontrado em termos de monitoração direta de deslocamentos na discretização aqui realizada. A utilização deste tipo de recursos não é de todo complicada, mas requer um esforço no sentido de viabilizar uma série de aspectos relacionados à qualidade das imagens colhidas durante o processo de monitoramento. Após este trabalho, pode-se dizer que hoje as equipes de pesquisa envolvidas, do CHTPN e do Laboratório de Mecânica Offshore (LMO), ambos da USP, dispõem de um grande experiência no assunto.

Na mesma linha avanços originais, há que se destacar o braço giratório instalado no CHTPN. Mediante a campanha bastante abrangente de ensaios conduzidos para o desenvolvimento desta teste, conclui-se que: "o braço - giratório é um equipamento bastante adequado às pesquisas de VIV", obviamente, sob cuidados descritos no capítulo que descreve a metodologia desta pesquisa. Destacar que este equipamento foi concebido no âmbito de um projeto de pesquisa desenvolvido pelos laboratórios supracitados em parceria com a PETROBRAS, profundamente melhorado e equipado com os esforços e recursos da presente pesquisa.

Como parte final destas conclusões, cumpre destacar aqueles pontos que se destacam como possíveis desdobramentos sugeridos para trabalhos futuros, conduzidos a partir dos avanços promovidos por esta tese.

Um primeiro desdobramento seria a condução de análises ainda mais elaboradas, baseadas em balanço de energia, com a finalidade de auferir resultados modais das contribuições inerciais e dissipativas durante a ação do VIV sobre as estruturas flexíveis longas. Se obtivesse êxito, esta abordagem mais aprofundada traria uma valoração mais precisa dos parâmetros utilizados pela abordagem teórica na predição do fenômeno de VIV, especialmente no que se refere à determinação de parâmetros modais inerentes (massas reduzidas, coeficientes de amortecimento, entre outros).

Infelizmente, dada a extensão das matrizes aqui ensaiadas, não foi possível a investigação de algumas condições de lançamento que, listadas abaixo, ficam como sugestão para outros programas de pesquisa. São elas:

- Linhas flexíveis horizontalmente instaladas na radial no braço- giratório, portanto, sob excitação de um perfil linearmente variável ao longo do comprimento;

- Linhas flexíveis inclinadas, lançadas no plano radial do braço- giratório, nestes casos, 
combinando os efeitos da velocidade variável segundo a posição radial e a própria inclinação da linha (sugere-se aplicar diferentes ângulos de inclinação);

- Catenárias ensaiadas no braço giratório segundo um lançamento onde o topo se encontre próximo ao eixo central de rotação, portanto, em perfis de velocidade onde a magnitude cresce com a profundidade. Apesar de não refletir situações reais de operação dos risers, esta condição permite a investigação do VIV na catenária, com intensificação da excitação junto ao fundo;

- Executar os casos anteriores promovendo a simultânea variação da tração pela imposição de movimentos no topo, lembrando que o arranjo experimental no braço giratório já dispõe de atuador que permite esta condição extra de ensaio.

Também seria interessante a condução de experimentos com linhas flexíveis longas de razão de aspecto ainda maiores que as ensaiadas nesta pesquisa, buscando, desta forma, ampliar o espectro de frequências naturais passíveis de excitação. Há que se cuidar, no entanto, para que esta ampliação seja associada à manutenção dos níveis de controle da excitação e níveis de monitoração aqui praticados.

Finalmente, como comentário geral desta tese conclui-se os trabalhos, destacando que a tese e objetivos estabelecidos foram atingidos dentro das possibilidades e restrições impostas pela infraestrutura e recursos disponíveis, acreditando ter contribuído para o avanço na fronteira de compreensão do fenômeno de VIV agindo nas linhas flexíveis longas. 


\section{Referências}

[Assi, 2009] Assi, G. R. (2009). Mechanisms for flow-induced vibration of interfering bluff bodies. PhD thesis, Imperial College London. v, 10, 11

[Assi et al., 2014] Assi, G. R. S., Srinil, N., Freire, C. M., \& Korkischko, I. (2014). Experimental investigation of the flow-induced vibration of a curved cylinder in convex and concave configurations. Journal of Fluids and Structures, 44, 52-66. 15

[Blevins, 1990] Blevins, R. D. (1990). Flow-induced vibration. Van Nostrand Reinhold. $\mathrm{v}, 10$

[Chaplin et al., 2005a] Chaplin, J., Bearman, P., Cheng, Y., Fontaine, E., Graham, J., Herfjord, K., Huera Huarte, F., Isherwood, M., Lambrakos, K., Larsen, C., Meneghini, J., Moe, G., Pattenden, R., Triantafyllou, M., \& Willden, R. (2005a). Blind predictions of laboratory measurements of vortex-induced vibrations of a tension riser. Journal of Fluids and Structures, 21(1 SPEC. ISS.), 25-40. 34

[Chaplin et al., 2005b] Chaplin, J., Bearman, P., Huera Huarte, F., \& Pattenden, R. (2005b). Laboratory measurements of vortex-induced vibrations of a vertical tension riser in a stepped current. Journal of Fluids and Structures, 21(1 SPEC. ISS.), 3-24. 34,110

[Chatjigeorgiou, 2008a] Chatjigeorgiou, I. (2008a). Application of the wkb method to catenary-shaped slender structures. Mathematical and Computer Modelling, 48(1), 249257. 22

[Chatjigeorgiou, 2008b] Chatjigeorgiou, I. (2008b). Solution of the boundary layer problems for calculating the natural modes of riser-type slender structures. Journal of Offshore Mechanics and Arctic Engineering, 130(1). 22, 25

[Da Silveira et al., 2007] Da Silveira, L., Cunha, L., De Martins, C., \& Pesce, C. (2007). An investigation on the effect of tension variation on VIV of risers. In Proceedings of the International Conference on Offshore Mechanics and Arctic Engineering - OMAE, volume 1 (pp. 267-275). vii, 41, 42

[Dantas et al., 2010] Dantas, C. M. S., Siqueira, M. Q. d., Pereira, V. M. d. S., Sousa, F. J. M. d., Sousa, J. R. M. d., \& Masetti, I. Q. (2010). Parametric study on the axial vibrations of riser suspended and moored by chains (RSAA) configurations. Marine Systems $\&$ Ocean Technology. 2

[Franzini et al., 2009] Franzini, G., Fujarra, A., Meneghini, J., Korkischko, I., \& Franciss, R. (2009). Experimental investigation of Vortex-Induced vibration on rigid, smooth and inclined cylinders. Journal of Fluids and Structures, 25(4), 742-750. 15 
[Fujarra, 2002] Fujarra, A. L. C. (2002). Estudos Experimentais e Analíticos das Vibrações Induzidas pela Emissão de Vórtices em Cilindros Flexiveis e Rígidos. Tese de doutorado, USP. vi, 33, 34

[Gabbai \& Benaroya, 2005] Gabbai, R. \& Benaroya, H. (2005). An overview of modeling and experiments of vortex-induced vibration of circular cylinders. Journal of Sound and Vibration, 282(3-5), 575-616. Arquivo. 31

[Gopalkrishnan, 1993] Gopalkrishnan, R. (1993). Vortex-induced forces on oscillating bluff cylinders. Technical report, DTIC Document. v, vi, 14, 16, 17, 18, 152

[Halse, 2000] Halse, K. H. (2000). Norwegian deepwater program: improved predictions of vortex-induced vibrations. In Proceedings of the Annual Offshore Technology Conference, volume 2 (pp. 557-564). 43

[Hong et al., 2002] Hong, Y., Nakamura, M., Koterayama, W., \& Osawa, H. (2002). An experimental and numerical study on dynamics of flexible free hanging riser. In Proceedings of ISOPE Pacific/Asia Offshore Mechanics Symposium (pp. 131-137). 41

[Huera-Huarte \& Bearman, 2009a] Huera-Huarte, F. \& Bearman, P. (2009a). Wake structures and vortex-induced vibrations of a long flexible cylinder-Part 1: Dynamic response. Journal of Fluids and Structures, 25(6), 969-990. 34

[Huera-Huarte \& Bearman, 2009b] Huera-Huarte, F. \& Bearman, P. (2009b). Wake structures and vortex-induced vibrations of a long flexible cylinder-Part 2: Drag coefficients and vortex modes. Journal of Fluids and Structures, 25(6), 991-1006. 34

[Huera-Huarte \& Gharib, 2011] Huera-Huarte, F. \& Gharib, M. (2011). Flow-induced vibrations of a side-by-side arrangement of two flexible circular cylinders. Journal of Fluids and Structures, 27(3), 354-366. 110

[Jauvtis \& Williamson, 2004] Jauvtis, N. \& Williamson, C. H. K. (2004). The effect of two degrees of freedom on vortex-induced vibration at low mass and damping. Journal of Fluid Mechanics, 509, 23-62. vi, 32

[Josefsson \& Dalton, 2010] Josefsson, $\quad$ P. \& Dalton, $\quad$ C. (2010). An analytical/computational approach in assessing vortex-induced vibration of a variable tension riser. Journal of Offshore Mechanics and Arctic Engineering, 132(3), $1-7.43$

[Kaasen, 2002] Kaasen, K. E. (2002). On identification of viv modes from measurements. In 12th International Offshore and Polar Engineering Conference, volume 3 (pp. 827833). 103, 104

[Larsen et al., 2001a] Larsen, C. M., Vikestad, K., Yttervik, R., \& Passano, E. (2001a). Empirical model for analysis of vortex induced vibrations-theoretical background and case studies. In Proceedings of 20th International Conference on Offshore Mechanics and Arctic Engineering, OMAE, volume 1. v, 15

[Larsen et al., 2001b] Larsen, C. M., Vikestad, K., Yttervik, R., Passano, E., \& Baarholm, G. (2001b). Vivana-theory manual. Marintek, Trondheim, Norway. vi, $19,20,44,156$ 
[Larsen et al., 2010] Larsen, C. M., Wu, J., \& Lie, H. (2010). On the understanding of non-stationary viv of slender beams. In ASME 2010 29th International Conference on Ocean, Offshore and Arctic Engineering (pp. 607-612).: American Society of Mechanical Engineers. vi, 19

[Lehn, 2003] Lehn, E. (2003). VIV Suppression Tests on High L/D Flexible Cylinders. Technical Report 512382.00.01, MARINTEK. Arquivo. 43

[Lie \& Kaasen, 2006] Lie, H. \& Kaasen, K. (2006). Modal analysis of measurements from a large-scale VIV model test of a riser in linearly sheared flow. Journal of Fluids and Structures, 22(4), 557-575. vii, 39, 40, 41

[Lie et al., 1997] Lie, H., Larsen, C. M., \& Vandiver, J. (1997). Vortex induced vibrations of long marine risers; model test in a rotating rig. In Proceedings of the International Conference on Offshore Mechanics and Arctic Engineering - OMAE, volume 1 (pp. 241-252). vii, 38

[Lie et al., 1998] Lie, H., Mo, K., \& Vandiver, J. (1998). VIV model test of a bare- and a staggered buoyancy riser in a rotating rig. In Proceedings of the Annual Offshore Technology Conference, volume 2 (pp. 177-187). vii, 38, 39

[Malta, 2010] Malta, E. B. (2010). Métodos e processos para a análise experimental de sistemas oceânicos de produção de petróleo e gás. Dissertação de mestrado, Escola Politécnica da USP, São Paulo. Arquivo. v, 1

[Masetti \& Costa, 2009] Masetti, I. Q. \& Costa, A. P. d. S. (2009). Inovação tecnológica no escoamento - configuração de riser suspenso e ancorado por amarras. TN Petroleo, (66). v, 2

[Pereira, 2011] Pereira, V. M. d. S. (2011). Análise da resposta dinâmica do tubo vertical do sistema de riser suspenso e ancorado por amarras ( $R S A A)$. Dissertação de mestrado, UFRJ. 2

[Pesce et al., 2006] Pesce, C., Fujarra, A., \& Kubota, L. (2006). The hilbert-huang spectral analysis method applied to VIV. In Proceedings of the International Conference on Offshore Mechanics and Arctic Engineering - OMAE, volume 2006. 41

[Pesce \& Martins, 2005] Pesce, C. \& Martins, C. (2005). Numerical computation of riser dynamics. Numerical Models in Fluid Structure Interaction, 42, 253-309. vi, 23, 27, 28,34

[Pesce et al., 1999] Pesce, C. P., Fujarra, A. L. C., Simos, A. N., \& Tannuri, E. A. (1999). Analytical and closed form solutions for deep water riser-like eigenvalue problem. The Ninth International Offshore and Polar Engineering Conference. 22, 26, 27, 100, 154

[PETROBRAS \& LMO, 2013] PETROBRAS \& LMO (2013). Relatório final do projeto de Dinâmica Não-Linear de Risers. Technical report, São Paulo, Brasil. ix, 74, 75

[Rateiro, 2010] Rateiro, F. (2010). Análise dinâmica acoplada de risers e linhas de ancoragem em sistemas flutuantes de produção de petróleo e gás natural. Dissertação de mestrado, Escola Politécnica da USP, São Paulo. Arquivo. v, 1 
[Rateiro et al., 2012] Rateiro, F., Pesce, C. P., Gonçalves, R. T., Franzini, G. R., Fujarra, A. L. C., Salles, R., \& Mendes, P. (2012). Risers model tests: Scaling methodology and dynamic similarity. In Proceedings of the 22nd International Ocean and Polar Engineering Conference (ISOPE 2012), Rhodes: ISOPE-2012-TPC-06633. xvii, 35, $47,48,49,153,170,202,228,254,280,306$

[Sarpkaya, 2004] Sarpkaya, T. (2004). A critical review of the intrinsic nature of vortexinduced vibrations. Journal of Fluids and Structures, 19(4), 389-447. Arquivo. 31

[Schiller et al., 2014] Schiller, R. V., Caire, M., Nóbrega, P. H. A., Passano, E., \& Lie, H. (2014). Vortex induced vibrations of deep water risers: Sensitivity to current profile, shear and directionality. In ASME $201433 \mathrm{rd}$ International Conference on Ocean, Offshore and Arctic Engineering (pp. V002T08A065-V002T08A065).: American Society of Mechanical Engineers. 20

[Srinil, 2010] Srinil, N. (2010). Multi-mode interactions in vortex-induced vibrations of flexible curved straight structures with geometric nonlinearities. Journal of Fluids and Structures, 26(7), 1098-1122. vi, 29

[Srinil et al., 2009] Srinil, N., Wiercigroch, M., \& OBrien, P. (2009). Reduced-order modelling of vortex-induced vibration of catenary riser. Ocean Engineering, 36(17), 1404-1414. vi, 20, 21

[Tellier \& Thethi, 2009] Tellier, E. \& Thethi, R. (2009). The evolution of freestanding risers. In Proceedings of the International Conference on Offshore Mechanics and Arctic Engineering - OMAE, volume 3 (pp. 381-390). Arquivo. 2

[Vandiver, 1993] Vandiver, J. K. (1993). Dimensionless parameters important to the prediction of vortex-induced vibration of long, flexible cylinders in ocean currents. Journal of Fluids and Structures, 7(5), 423-455. vi, 21, 33, 34, 35, 36, 37

[Vandiver et al., 1996] Vandiver, J. K., Allen, D., \& Li, L. (1996). The occurrence of lockin under highly sheared conditions. Journal of Fluids and Structures, 10(5), 555-561. vi, 36,37

[Vandiver \& Li, 2005] Vandiver, J. K. \& Li, L. (2005). SHEAR7 PROGRAM THEORETICAL MANUAL. vi, 19, 20, 21, 25, 44, 156

[Vandiver \& Marcollo, 2003] Vandiver, J. K. \& Marcollo, A. (2003). High mode number VIV experiments. In H. Benaroya \& T. J. Wei (Eds.), IUTAM Symposium on Integrated Modeling of Fully Coupled Fluid Structure Interactions Using Analysis, Computations and Experiments, number 75 in Fluid Mechanics and its Applications (pp. 211-231). Springer Netherlands. vi, 36, 152

[Venugopal, 1996] Venugopal, M. (1996). Damping and response prediction of a flexible cylinder in a current. Thesis, Massachusetts Institute of Technology. Thesis (Ph. D.)Massachusetts Institute of Technology, Dept. of Ocean Engineering, 1996. 43, 44

[Vikestad, 1998] Vikestad, K. (1998). Multi-frequency response of a cylinder subjected to vortex shedding and support motions. Department of Marine Structures, Faculty of Marine Technology, Norwegian University of Science and Technology. vi, 14, 17, 18 
[Williamson \& Govardhan, 2004] Williamson, C. \& Govardhan, R. (2004). Vortexinduced vibrations, volume 36. Book. 21, 31

[Williamson \& Govardhan, 2008] Williamson, C. \& Govardhan, R. (2008). A brief review of recent results in vortex-induced vibrations. Journal of Wind Engineering and Industrial Aerodynamics, 96(6-7), 713-735. v, 11, 13, 14 
Anexo A - Resultados de VIV na linha vertical 
Neste anexo é apresentado um conjunto mais completo de resultados do VIV na linha flexível vertical, particularmente aqueles referentes às velocidades reduzidas mais importantes. Vale lembrar que todos os resultados estão apresentados na escala real (1:100) conforme definido em [Rateiro et al., 2012]. Neste sentido, as seções que se seguem dizem respeito a:

- Na seção A.1: Velocidade de $0,779 \mathrm{~m} / \mathrm{s}$ e $V_{r 1}=6,01$

- Na seção A.2: Velocidade de $0,981 \mathrm{~m} / \mathrm{s}$ e $V_{r 1}=7,57$

- Na seção A.3: Velocidade de $1,380 \mathrm{~m} / \mathrm{s}$ e $V_{r 1}=10,69$

- Na seção A.4: Velocidade de $1,740 \mathrm{~m} / \mathrm{s}$ e $V_{r 1}=13,44$

- Na seção A.5: Velocidade de 2,200 m/s e $V_{r 1}=16,96$ 


\section{A.1 Vertical - Velocidade de $0,779 \mathrm{~m} / \mathrm{s}$ e $V_{r 1}=6,01$}

A seguir são apresentados gráficos e tabelas com detalhes da análise referente à linha vertical em velocidade de $0,779 \mathrm{~m} / \mathrm{s}$ e $V_{r 1}=6,01$. Como pode ser visto na Tabela A.1 e nas Figuras de A.1 a A.3, os maiores deslocamentos nas direções $X, Y$ e $Z$ foram de 0,340, 1,414 e 0,107 m, respectivamente. Estes valores ocorreram para os alvos 5, 14 e 20. Nestes alvos, as frequências de resposta com maior energia foram de 0,0299, 0,0567 e $0,115 \mathrm{~Hz}$.

Considerando a decomposição modal, de acordo com a Tabela A.2, as maiores amplitudes modais apresentadas nas direções $X, Y$ e $Z$ foram de 3,511, 1,700 e 0,029 m, respectivamente. Estes valores ocorreram aos modos 2 e 7 . Nestes modos, as frequências de resposta com maior energia foram de 0,0567, 0,0731 e 0,0955 Hz.

A Tabela A.3 apresenta resultados dos movimentos referentes ao deslocamento no plano transversal à correnteza, onde a maior amplitude foi de 1,691 m. Este valor ocorreu para o modo 2. Neste modo, a frequência de resposta com maior energia foi de 0,057 Hz.

Por sua vez, a Tabela A.4 apresenta resultados dos movimentos no plano longitudinal à correnteza, onde a maior amplitude foi de $3,458 \mathrm{~m}$. Este valor ocorreu para o modo 7 . Neste modo, a frequência de resposta com maior energia foi de 0,096 Hz. 

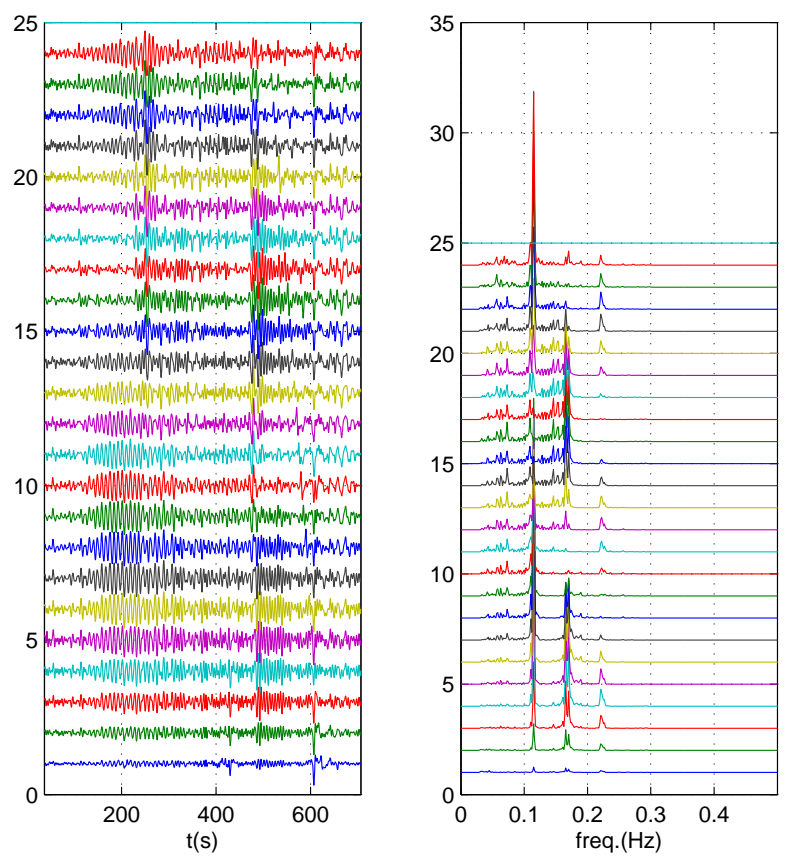

Figura A.1: Séries temporais de deslocamento na direção $X$ e respectivas PSD da linha vertical na $U_{\max }=0,779 \mathrm{~m} / \mathrm{s}$ e $V_{r 1}=6,013$.
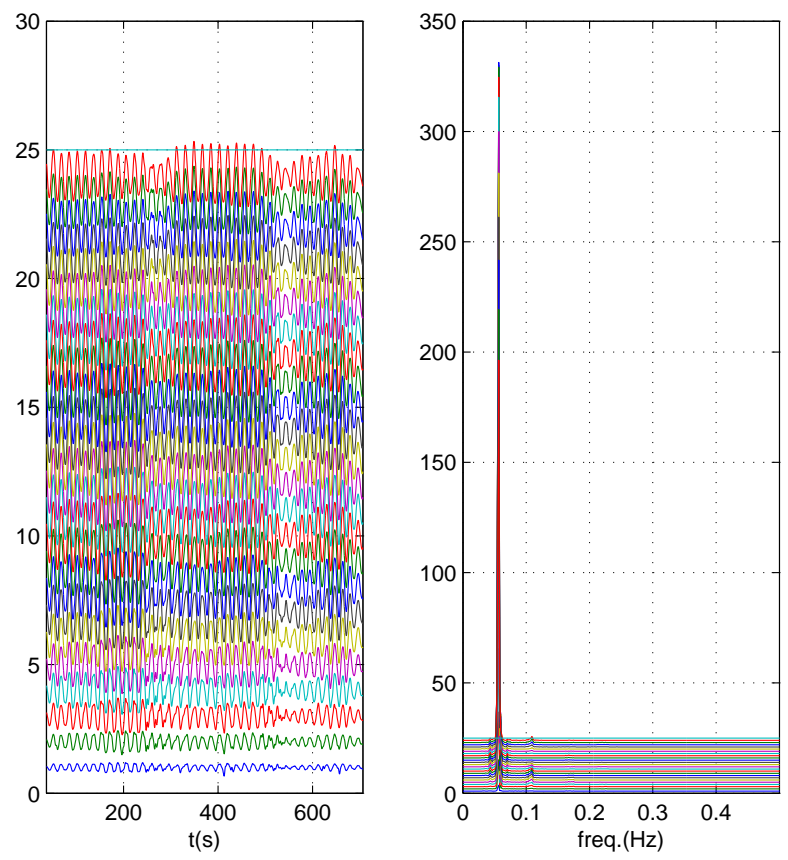

Figura A.2: Séries temporais de deslocamento na direção $Y$ e respectivas PSD da linha vertical na $U_{\max }=0,779 \mathrm{~m} / \mathrm{s}$ e $V_{r 1}=6,013$. 

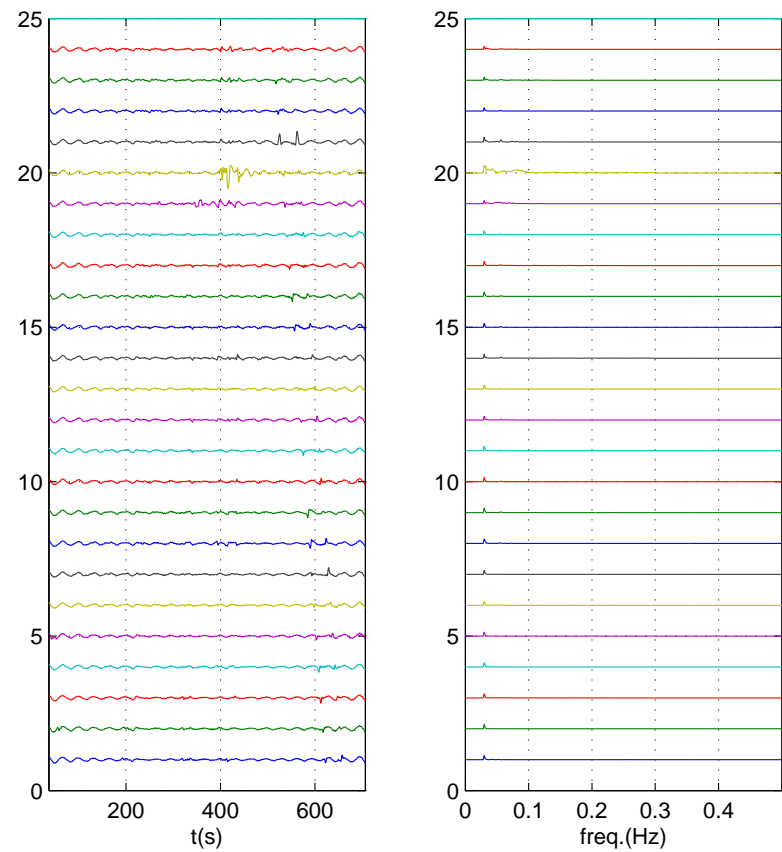

Figura A.3: Séries temporais de deslocamento na direção $Z$ e respectivas PSD da linha vertical na $U_{\max }=0,779 \mathrm{~m} / \mathrm{s}$ e $V_{r 1}=6,013$.
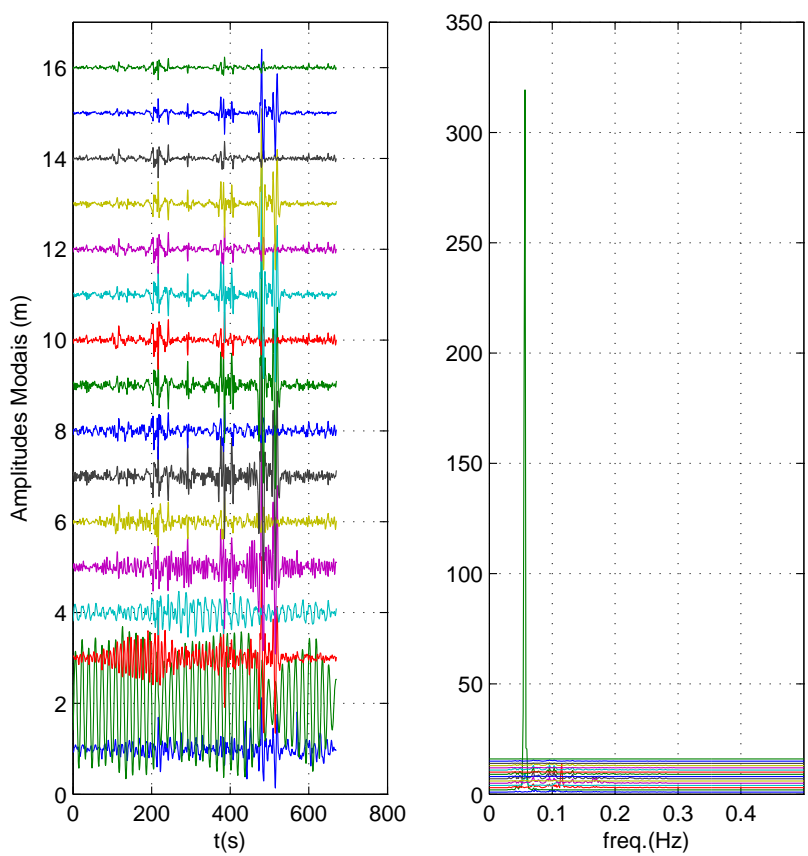

Figura A.4: Séries temporais de amplitude modal e respectivas PSD da linha vertical na $U_{\max }=0,779 \mathrm{~m} / \mathrm{s}$ e $V_{r 1}=6,013$. 
Tabela A.1: Resultados das séries temporais de deslocamento na linha vertical em

$$
U_{\text {max }}=0,779 \mathrm{~m} / \mathrm{s} \text {. }
$$

\begin{tabular}{|c|c|c|c|c|c|c|c|c|c|c|c|c|}
\hline \multirow[b]{2}{*}{ ID. Alvo } & \multirow[b]{2}{*}{$\mathrm{X}(\mathrm{m})$} & \multicolumn{2}{|c|}{ Máximo } & \multirow[b]{2}{*}{$\mathrm{X}(\mathrm{m})$} & \multirow{2}{*}{$\begin{array}{l}\text { Mínimo } \\
\mathrm{Y}(\mathrm{m})\end{array}$} & \multirow{2}{*}{$\mathrm{Z}(\mathrm{m})$} & \multicolumn{3}{|c|}{ Desvio padrão } & \multicolumn{3}{|c|}{ Freq. máxima em Hz } \\
\hline & & $\mathrm{Y}(\mathrm{m})$ & $\mathrm{Z}(\mathrm{m})$ & & & & $\mathrm{X}(\mathrm{m})$ & $\mathrm{Y}(\mathrm{m})$ & $\mathrm{Z}(\mathrm{m})$ & $\mathrm{X}$ & $\mathrm{Y}$ & $\mathrm{Z}$ \\
\hline 1 & 0,077 & 0,144 & 0,093 & $-0,066$ & $-0,153$ & $-0,108$ & 0,032 & 0,088 & 0,063 & 0,115 & 0,057 & 0,030 \\
\hline 2 & 0,098 & 0,291 & 0,095 & $-0,098$ & $-0,304$ & $-0,112$ & 0,052 & 0,180 & 0,060 & 0,115 & 0,057 & 0,030 \\
\hline 3 & 0,206 & 0,500 & 0,090 & $-0,172$ & $-0,517$ & $-0,097$ & 0,077 & 0,308 & 0,058 & 0,115 & 0,057 & 0,030 \\
\hline 4 & 0,257 & 0,671 & 0,086 & $-0,228$ & $-0,687$ & $-0,095$ & 0,095 & 0,412 & 0,056 & 0,115 & 0,057 & 0,030 \\
\hline 5 & 0,340 & 0,810 & 0,093 & $-0,216$ & $-0,836$ & $-0,101$ & 0,127 & 0,502 & 0,057 & 0,115 & 0,057 & 0,030 \\
\hline 6 & 0,278 & 0,960 & 0,087 & $-0,217$ & $-0,969$ & $-0,091$ & 0,099 & 0,595 & 0,056 & 0,115 & 0,057 & 0,030 \\
\hline 7 & 0,282 & 1,085 & 0,096 & $-0,194$ & $-1,074$ & $-0,088$ & 0,091 & 0,671 & 0,056 & 0,115 & 0,057 & 0,030 \\
\hline 8 & 0,268 & 1,191 & 0,093 & $-0,153$ & $-1,174$ & $-0,095$ & 0,085 & 0,739 & 0,059 & 0,115 & 0,057 & 0,030 \\
\hline 9 & 0,263 & 1,260 & 0,095 & $-0,143$ & $-1,245$ & $-0,096$ & 0,082 & 0,791 & 0,059 & 0,115 & 0,057 & 0,030 \\
\hline 10 & 0,263 & 1,315 & 0,096 & $-0,173$ & $-1,301$ & $-0,099$ & 0,086 & 0,833 & 0,059 & 0,115 & 0,057 & 0,030 \\
\hline 11 & 0,246 & 1,365 & 0,096 & $-0,208$ & $-1,345$ & $-0,113$ & 0,089 & 0,867 & 0,059 & 0,115 & 0,057 & 0,030 \\
\hline 12 & 0,235 & 1,394 & 0,093 & $-0,221$ & $-1,377$ & $-0,091$ & 0,093 & 0,888 & 0,058 & 0,115 & 0,057 & 0,030 \\
\hline 13 & 0,214 & 1,412 & 0,095 & $-0,229$ & $-1,398$ & $-0,092$ & 0,092 & 0,900 & 0,058 & 0,115 & 0,057 & 0,030 \\
\hline 14 & 0,183 & 1,414 & 0,098 & $-0,208$ & $-1,411$ & $-0,092$ & 0,084 & 0,904 & 0,059 & 0,166 & 0,057 & 0,030 \\
\hline 15 & 0,161 & 1,405 & 0,100 & $-0,183$ & $-1,399$ & $-0,099$ & 0,073 & 0,902 & 0,058 & 0,166 & 0,057 & 0,030 \\
\hline 16 & 0,131 & 1,400 & 0,105 & $-0,149$ & $-1,399$ & $-0,096$ & 0,062 & 0,896 & 0,060 & 0,166 & 0,057 & 0,030 \\
\hline 17 & 0,141 & 1,374 & 0,100 & $-0,125$ & $-1,369$ & $-0,092$ & 0,058 & 0,883 & 0,060 & 0,166 & 0,057 & 0,030 \\
\hline 18 & 0,147 & 1,335 & 0,100 & $-0,116$ & $-1,331$ & $-0,090$ & 0,063 & 0,862 & 0,058 & 0,166 & 0,057 & 0,030 \\
\hline 19 & 0,170 & 1,299 & 0,087 & $-0,151$ & $-1,288$ & $-0,090$ & 0,072 & 0,837 & 0,058 & 0,166 & 0,057 & 0,030 \\
\hline 20 & 0,187 & 1,250 & 0,107 & $-0,166$ & $-1,241$ & $-0,087$ & 0,080 & 0,809 & 0,060 & 0,115 & 0,057 & 0,030 \\
\hline 21 & 0,205 & 1,174 & 0,104 & $-0,191$ & $-1,208$ & $-0,090$ & 0,087 & 0,784 & 0,060 & 0,115 & 0,057 & 0,030 \\
\hline 22 & 0,204 & 1,119 & 0,090 & $-0,207$ & $-1,127$ & $-0,093$ & 0,088 & 0,738 & 0,058 & 0,115 & 0,057 & 0,030 \\
\hline 23 & 0,193 & 1,064 & 0,084 & $-0,194$ & $-1,069$ & $-0,089$ & 0,085 & 0,699 & 0,058 & 0,115 & 0,057 & 0,030 \\
\hline 24 & 0,190 & 1,008 & 0,088 & $-0,187$ & $-1,008$ & $-0,088$ & 0,078 & 0,658 & 0,055 & 0,115 & 0,057 & 0,030 \\
\hline 25 & 0,000 & 0,000 & 0,000 & 0,000 & 0,000 & 0,000 & 0,000 & 0,000 & 0,000 & 0,000 & 0,000 & 0,000 \\
\hline
\end{tabular}


Tabela A.2: Resultados das séries temporais de amplitude modal na linha vertical em $U_{\max }=0,779 \mathrm{~m} / \mathrm{s}$.

\begin{tabular}{|c|c|c|c|c|c|c|c|c|c|c|c|c|}
\hline \multirow[b]{2}{*}{ Modo } & \multirow[b]{2}{*}{$\mathrm{X}(\mathrm{m})$} & \multicolumn{3}{|c|}{ Máximo } & \multicolumn{2}{|l|}{ Mínimo } & \multicolumn{3}{|c|}{ Desvio padrão } & \multicolumn{3}{|c|}{ Freq. máxima em $\mathrm{Hz}$} \\
\hline & & $\mathrm{Y}(\mathrm{m})$ & $\mathrm{Z}(\mathrm{m})$ & $\mathrm{X}(\mathrm{m})$ & $\mathrm{Y}(\mathrm{m})$ & $\mathrm{Z}(\mathrm{m})$ & $\mathrm{X}(\mathrm{m})$ & $\mathrm{Y}(\mathrm{m})$ & $\mathrm{Z}(\mathrm{m})$ & $\mathrm{X}$ & $\mathrm{Y}$ & $\mathrm{Z}$ \\
\hline 1 & 1,138 & 0,148 & 0,015 & $-0,873$ & $-0,145$ & $-0,025$ & 0,180 & 0,080 & 0,005 & 0,073 & 0,057 & 0,030 \\
\hline 2 & 0,197 & 1,700 & 0,000 & $-0,151$ & $-1,667$ & $-0,000$ & 0,031 & 0,917 & 0,000 & 0,073 & 0,057 & 0,030 \\
\hline 3 & 2,262 & 0,034 & 0,022 & $-1,680$ & $-0,040$ & $-0,040$ & 0,295 & 0,012 & 0,006 & 0,115 & 0,057 & 0,073 \\
\hline 4 & 0,328 & 0,470 & 0,000 & $-0,244$ & $-0,544$ & $-0,001$ & 0,043 & 0,168 & 0,000 & 0,115 & 0,057 & 0,073 \\
\hline 5 & 3,384 & 0,038 & 0,027 & $-1,943$ & $-0,036$ & $-0,051$ & 0,346 & 0,007 & 0,007 & 0,166 & 0,058 & 0,073 \\
\hline 6 & 0,459 & 0,552 & 0,000 & $-0,264$ & $-0,525$ & $-0,001$ & 0,047 & 0,106 & 0,000 & 0,166 & 0,058 & 0,073 \\
\hline 7 & 3,511 & 0,040 & 0,029 & $-2,336$ & $-0,042$ & $-0,055$ & 0,356 & 0,007 & 0,007 & 0,096 & 0,057 & 0,073 \\
\hline 8 & 0,460 & 0,612 & 0,000 & $-0,306$ & $-0,630$ & $-0,001$ & 0,047 & 0,106 & 0,000 & 0,096 & 0,057 & 0,073 \\
\hline 9 & 3,313 & 0,040 & 0,028 & $-2,312$ & $-0,042$ & $-0,052$ & 0,334 & 0,006 & 0,007 & 0,096 & 0,049 & 0,073 \\
\hline 10 & 0,424 & 0,627 & 0,000 & $-0,296$ & $-0,648$ & $-0,001$ & 0,043 & 0,095 & 0,000 & 0,096 & 0,049 & 0,073 \\
\hline 11 & 2,837 & 0,032 & 0,024 & $-1,951$ & $-0,034$ & $-0,044$ & 0,284 & 0,005 & 0,006 & 0,096 & 0,049 & 0,073 \\
\hline 12 & 0,358 & 0,507 & 0,000 & $-0,246$ & $-0,538$ & $-0,001$ & 0,036 & 0,080 & 0,000 & 0,096 & 0,049 & 0,073 \\
\hline 13 & 2,127 & 0,024 & 0,019 & $-1,477$ & $-0,027$ & $-0,033$ & 0,214 & 0,004 & 0,004 & 0,096 & 0,070 & 0,073 \\
\hline 14 & 0,265 & 0,380 & 0,000 & $-0,184$ & $-0,428$ & $-0,001$ & 0,027 & 0,060 & 0,000 & 0,096 & 0,070 & 0,073 \\
\hline 15 & 1,424 & 0,015 & 0,012 & $-1,024$ & $-0,017$ & $-0,022$ & 0,144 & 0,003 & 0,003 & 0,096 & 0,049 & 0,073 \\
\hline 16 & 0,176 & 0,233 & 0,000 & $-0,127$ & $-0,273$ & $-0,000$ & 0,018 & 0,041 & 0,000 & 0,096 & 0,049 & 0,073 \\
\hline
\end{tabular}

Tabela A.3: Resultados para os modos transversais da linha vertical em $U_{\text {max }}=0,779 \mathrm{~m} / \mathrm{s}$.

Amplitudes

Modo Máxima(m) Mínima(m) Desvio Padrão(m) Freq. máxima $(\mathrm{Hz})$

\begin{tabular}{lllll}
\hline 2 & 1,691 & $-1,658$ & 0,912 & 0,057 \\
4 & 0,467 & $-0,540$ & 0,167 & 0,057 \\
6 & 0,546 & $-0,521$ & 0,105 & 0,058 \\
8 & 0,605 & $-0,625$ & 0,105 & 0,057 \\
10 & 0,620 & $-0,642$ & 0,094 & 0,049 \\
12 & 0,501 & $-0,533$ & 0,080 & 0,049 \\
14 & 0,375 & $-0,424$ & 0,060 & 0,070 \\
16 & 0,230 & $-0,270$ & 0,041 & 0,049 \\
\hline
\end{tabular}


Tabela A.4: Resultados para os modos longitudinais da linha vertical em $U_{\max }=0,779 \mathrm{~m} / \mathrm{s}$.

Amplitudes

Modo Máxima(m) Mínima(m) Desvio Padrão(m) Freq. máxima (Hz)

\begin{tabular}{lllll}
\hline 1 & 1,125 & $-0,862$ & 0,178 & 0,073 \\
3 & 2,230 & $-1,657$ & 0,291 & 0,115 \\
5 & 3,334 & $-1,914$ & 0,341 & 0,166 \\
7 & 3,458 & $-2,300$ & 0,351 & 0,096 \\
9 & 3,261 & $-2,276$ & 0,329 & 0,096 \\
11 & 2,792 & $-1,920$ & 0,279 & 0,096 \\
13 & 2,092 & $-1,453$ & 0,211 & 0,096 \\
15 & 1,401 & $-1,008$ & 0,142 & 0,096 \\
\hline
\end{tabular}




\section{A.2 Vertical - Velocidade de $0,981 \mathrm{~m} / \mathrm{s}$ e $V_{r 1}=7,57$}

A seguir são apresentados gráficos e tabelas com detalhes da análise referente à linha vertical em velocidade de $0,981 \mathrm{~m} / \mathrm{s}$ e $V_{r 1}=7,57$. Como pode ser visto na Tabela A.5 e nas Figuras de A.5 a A.7, os maiores deslocamentos nas direções $X, Y$ e $Z$ foram de 0,271, 1,277 e $0,167 \mathrm{~m}$, respectivamente. Estes valores ocorreram para os alvos 4 e 8 . Nestes alvos, as frequências de resposta com maior energia foram de 0,0302, 0,0869 e 0,168 Hz.

Considerando a decomposição modal, de acordo com a Tabela A.6, as maiores amplitudes modais apresentadas nas direções $X, Y$ e $Z$ foram de 2,617, 1,111 e 0,036 m, respectivamente. Estes valores ocorreram aos modos 2 e 7 . Nestes modos, as frequências de resposta com maior energia foram de 0,0567, 0,0926 e 0,121 Hz.

A Tabela A.7 apresenta resultados dos movimentos referentes ao deslocamento no plano transversal à correnteza, onde a maior amplitude foi de 1,105 m. Este valor ocorreu para o modo 2. Neste modo, a frequência de resposta com maior energia foi de 0,057 Hz.

Por sua vez, a Tabela A.8 apresenta resultados dos movimentos no plano longitudinal à correnteza, onde a maior amplitude foi de $2,577 \mathrm{~m}$. Este valor ocorreu para o modo 7 . Neste modo, a frequência de resposta com maior energia foi de 0,121 Hz. 

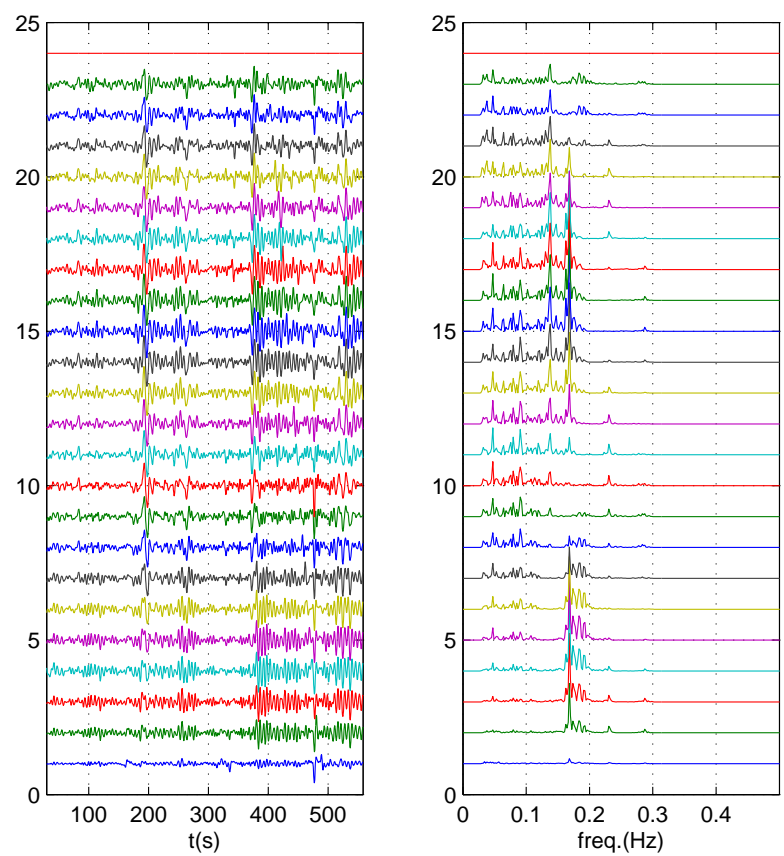

Figura A.5: Séries temporais de deslocamento na direção $X$ e respectivas PSD da linha vertical na $U_{\max }=0,981 \mathrm{~m} / \mathrm{s}$ e $V_{r 1}=7,575$.
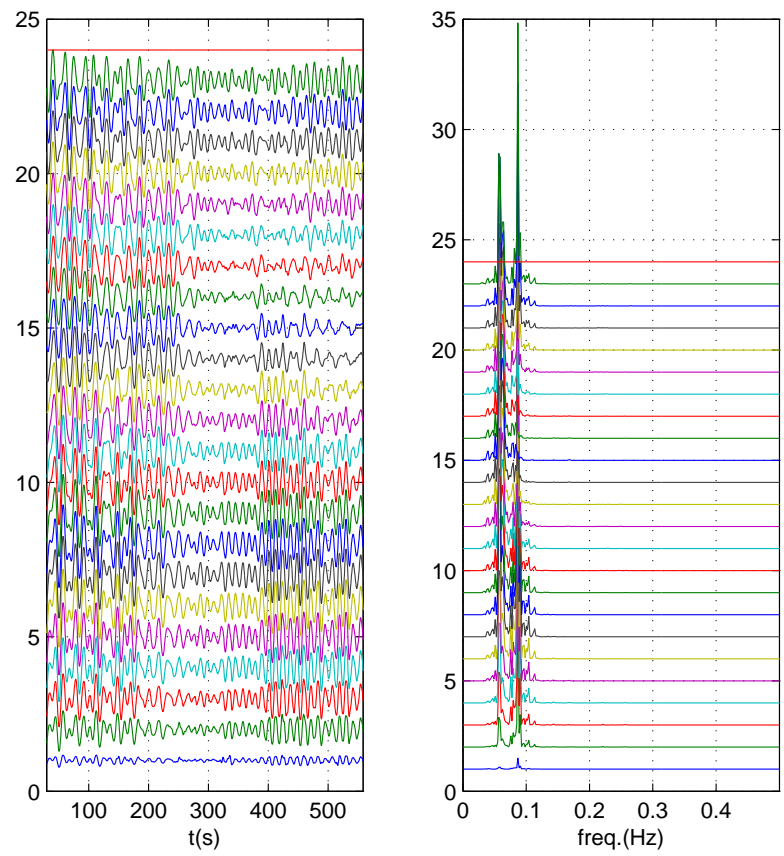

Figura A.6: Séries temporais de deslocamento na direção $Y$ e respectivas PSD da linha vertical na $U_{\max }=0,981 \mathrm{~m} / \mathrm{s}$ e $V_{r 1}=7,575$. 

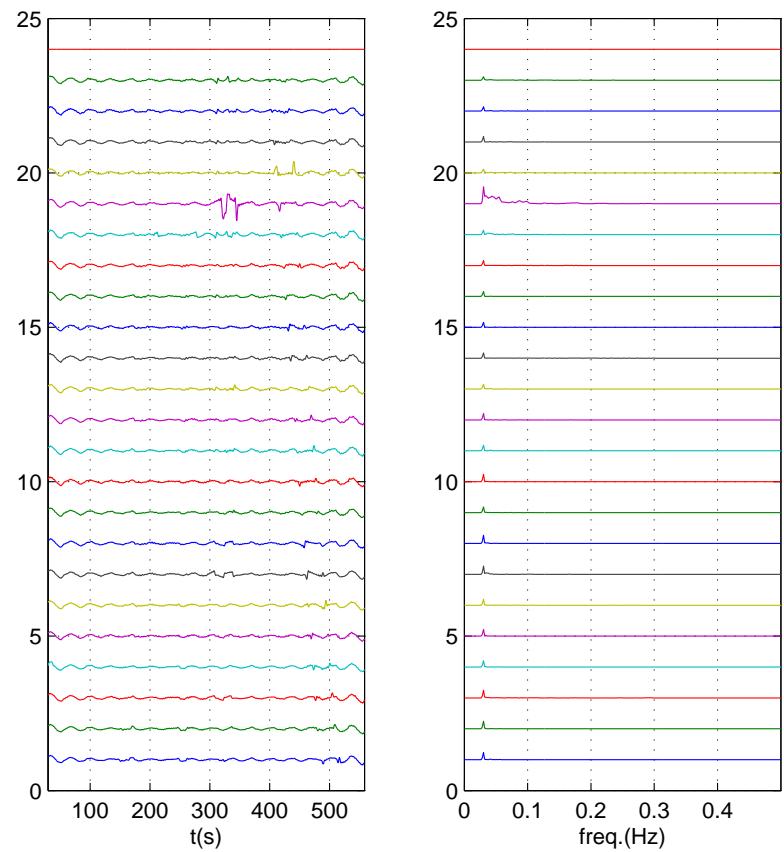

Figura A.7: Séries temporais de deslocamento na direção $Z$ e respectivas PSD da linha vertical na $U_{\max }=0,981 \mathrm{~m} / \mathrm{s}$ e $V_{r 1}=7,575$.
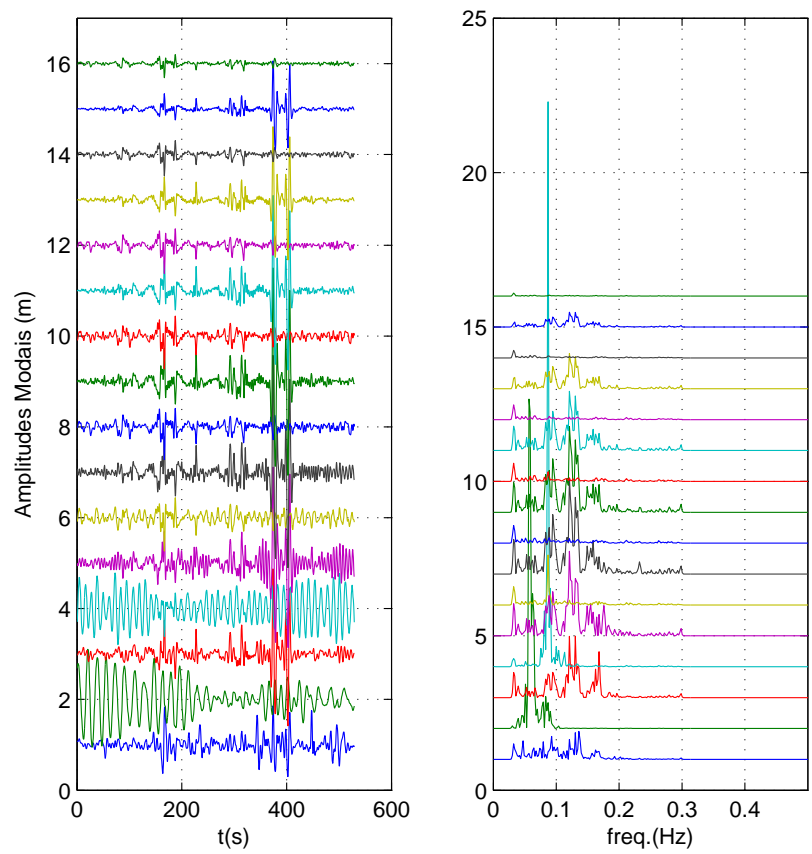

Figura A.8: Séries temporais de amplitude modal e respectivas PSD da linha vertical na $U_{\max }=0,981 \mathrm{~m} / \mathrm{s}$ e $V_{r 1}=7,575$. 
Tabela A.5: Resultados das séries temporais de deslocamento na linha vertical em

$$
U_{\text {max }}=0,981 \mathrm{~m} / \mathrm{s} \text {. }
$$

\begin{tabular}{|c|c|c|c|c|c|c|c|c|c|c|c|c|}
\hline \multirow[b]{2}{*}{ ID. Alvo } & \multirow[b]{2}{*}{$\mathrm{X}(\mathrm{m})$} & \multicolumn{2}{|l|}{ Máximo } & \multirow[b]{2}{*}{$\mathrm{X}(\mathrm{m})$} & \multirow{2}{*}{$\begin{array}{l}\text { Mínimo } \\
\mathrm{Y}(\mathrm{m})\end{array}$} & \multirow[b]{2}{*}{$\mathrm{Z}(\mathrm{m})$} & \multicolumn{3}{|c|}{ Desvio padrão } & \multicolumn{3}{|c|}{ Freq. máxima em $\mathrm{H}$} \\
\hline & & $\mathrm{Y}(\mathrm{m})$ & $\mathrm{Z}(\mathrm{m})$ & & & & $\mathrm{X}(\mathrm{m})$ & $\mathrm{Y}(\mathrm{m})$ & $\mathrm{Z}(\mathrm{m})$ & $\mathrm{X}$ & $\mathrm{Y}$ & $\mathrm{Z}$ \\
\hline 1 & 0,052 & 0,169 & 0,138 & $-0,037$ & $-0,223$ & $-0,095$ & 0,019 & 0,095 & 0,074 & 0,168 & 0,087 & 0,030 \\
\hline 2 & 0,150 & 0,606 & 0,141 & $-0,094$ & $-0,706$ & $-0,100$ & 0,057 & 0,320 & 0,074 & 0,168 & 0,087 & 0,030 \\
\hline 3 & 0,192 & 0,801 & 0,148 & $-0,114$ & $-0,915$ & $-0,105$ & 0,070 & 0,420 & 0,078 & 0,168 & 0,087 & 0,030 \\
\hline 4 & 0,271 & 0,964 & 0,167 & $-0,188$ & $-1,102$ & $-0,106$ & 0,104 & 0,505 & 0,081 & 0,168 & 0,087 & 0,030 \\
\hline 5 & 0,215 & 1,100 & 0,143 & $-0,127$ & $-1,234$ & $-0,118$ & 0,082 & 0,574 & 0,078 & 0,168 & 0,087 & 0,030 \\
\hline 6 & 0,195 & 1,194 & 0,146 & $-0,148$ & $-1,333$ & $-0,117$ & 0,081 & 0,622 & 0,079 & 0,168 & 0,087 & 0,030 \\
\hline 7 & 0,175 & 1,253 & 0,145 & $-0,164$ & $-1,392$ & $-0,120$ & 0,078 & 0,653 & 0,080 & 0,168 & 0,087 & 0,030 \\
\hline 8 & 0,136 & 1,277 & 0,152 & $-0,168$ & $-1,405$ & $-0,118$ & 0,075 & 0,670 & 0,080 & 0,091 & 0,087 & 0,030 \\
\hline 9 & 0,137 & 1,261 & 0,148 & $-0,164$ & $-1,398$ & $-0,120$ & 0,076 & 0,677 & 0,081 & 0,091 & 0,087 & 0,030 \\
\hline 10 & 0,128 & 1,229 & 0,156 & $-0,157$ & $-1,369$ & $-0,128$ & 0,075 & 0,680 & 0,081 & 0,047 & 0,087 & 0,030 \\
\hline 11 & 0,147 & 1,179 & 0,157 & $-0,153$ & $-1,310$ & $-0,122$ & 0,076 & 0,676 & 0,081 & 0,047 & 0,057 & 0,030 \\
\hline 12 & 0,156 & 1,125 & 0,148 & $-0,163$ & $-1,234$ & $-0,121$ & 0,077 & 0,674 & 0,081 & 0,168 & 0,057 & 0,030 \\
\hline 13 & 0,165 & 1,042 & 0,142 & $-0,146$ & $-1,152$ & $-0,124$ & 0,075 & 0,670 & 0,081 & 0,168 & 0,059 & 0,030 \\
\hline 14 & 0,159 & 0,992 & 0,152 & $-0,139$ & $-1,077$ & $-0,132$ & 0,075 & 0,672 & 0,080 & 0,168 & 0,059 & 0,030 \\
\hline 15 & 0,160 & 0,943 & 0,156 & $-0,162$ & $-0,973$ & $-0,115$ & 0,075 & 0,671 & 0,080 & 0,168 & 0,057 & 0,030 \\
\hline 16 & 0,166 & 0,969 & 0,142 & $-0,154$ & $-1,040$ & $-0,123$ & 0,073 & 0,678 & 0,081 & 0,168 & 0,057 & 0,030 \\
\hline 17 & 0,171 & 0,977 & 0,138 & $-0,153$ & $-1,105$ & $-0,121$ & 0,072 & 0,679 & 0,080 & 0,168 & 0,059 & 0,030 \\
\hline 18 & 0,174 & 0,997 & 0,149 & $-0,150$ & $-1,147$ & $-0,123$ & 0,074 & 0,680 & 0,081 & 0,168 & 0,059 & 0,030 \\
\hline 19 & 0,158 & 1,016 & 0,143 & $-0,137$ & $-1,190$ & $-0,114$ & 0,076 & 0,681 & 0,082 & 0,168 & 0,057 & 0,030 \\
\hline 20 & 0,159 & 1,022 & 0,126 & $-0,131$ & $-1,200$ & $-0,107$ & 0,076 & 0,669 & 0,076 & 0,138 & 0,059 & 0,030 \\
\hline 21 & 0,128 & 1,031 & 0,144 & $-0,147$ & $-1,233$ & $-0,116$ & 0,071 & 0,673 & 0,082 & 0,138 & 0,087 & 0,030 \\
\hline 22 & 0,111 & 1,029 & 0,144 & $-0,182$ & $-1,228$ & $-0,129$ & 0,071 & 0,662 & 0,082 & 0,138 & 0,087 & 0,030 \\
\hline 23 & 0,115 & 1,008 & 0,134 & $-0,207$ & $-1,215$ & $-0,112$ & 0,072 & 0,649 & 0,078 & 0,138 & 0,087 & 0,030 \\
\hline 24 & $-0,000$ & $-0,000$ & 0,000 & $-0,000$ & $-0,000$ & 0,000 & 0,000 & 0,000 & 0,000 & 0,000 & 0,000 & 0,000 \\
\hline
\end{tabular}


Tabela A.6: Resultados das séries temporais de amplitude modal na linha vertical em $U_{\max }=0,981 \mathrm{~m} / \mathrm{s}$.

\begin{tabular}{|c|c|c|c|c|c|c|c|c|c|c|c|c|}
\hline \multirow[b]{2}{*}{ Modo } & \multirow[b]{2}{*}{$\mathrm{X}(\mathrm{m})$} & \multicolumn{3}{|c|}{ Máximo } & \multicolumn{2}{|l|}{ Mínimo } & \multicolumn{3}{|c|}{ Desvio padrão } & \multicolumn{3}{|c|}{ Freq. máxima em $\mathrm{Hz}$} \\
\hline & & $\mathrm{Y}(\mathrm{m})$ & $\mathrm{Z}(\mathrm{m})$ & $\mathrm{X}(\mathrm{m})$ & $\mathrm{Y}(\mathrm{m})$ & $\mathrm{Z}(\mathrm{m})$ & $\mathrm{X}(\mathrm{m})$ & $\mathrm{Y}(\mathrm{m})$ & $\mathrm{Z}(\mathrm{m})$ & $\mathrm{X}$ & $\mathrm{Y}$ & $\mathrm{Z}$ \\
\hline 1 & 0,868 & 0,097 & 0,019 & $-0,710$ & $-0,092$ & $-0,018$ & 0,183 & 0,033 & 0,005 & 0,136 & 0,057 & 0,030 \\
\hline 2 & 0,150 & 1,111 & 0,000 & $-0,123$ & $-1,057$ & $-0,000$ & 0,032 & 0,383 & 0,000 & 0,136 & 0,057 & 0,030 \\
\hline 3 & 1,901 & 0,058 & 0,027 & $-1,605$ & $-0,059$ & $-0,025$ & 0,244 & 0,025 & 0,005 & 0,130 & 0,087 & 0,093 \\
\hline 4 & 0,276 & 0,788 & 0,000 & $-0,233$ & $-0,802$ & $-0,000$ & 0,035 & 0,336 & 0,000 & 0,130 & 0,087 & 0,093 \\
\hline 5 & 2,145 & 0,031 & 0,033 & $-1,886$ & $-0,051$ & $-0,032$ & 0,311 & 0,009 & 0,007 & 0,121 & 0,087 & 0,093 \\
\hline 6 & 0,291 & 0,447 & 0,000 & $-0,256$ & $-0,742$ & $-0,000$ & 0,042 & 0,125 & 0,000 & 0,121 & 0,087 & 0,093 \\
\hline 7 & 2,617 & 0,027 & 0,036 & $-2,134$ & $-0,048$ & $-0,034$ & 0,327 & 0,007 & 0,007 & 0,121 & 0,032 & 0,093 \\
\hline 8 & 0,343 & 0,413 & 0,001 & $-0,279$ & $-0,723$ & $-0,001$ & 0,043 & 0,105 & 0,000 & 0,121 & 0,032 & 0,093 \\
\hline 9 & 2,540 & 0,029 & 0,034 & $-2,098$ & $-0,047$ & $-0,033$ & 0,310 & 0,007 & 0,007 & 0,121 & 0,032 & 0,093 \\
\hline 10 & 0,325 & 0,445 & 0,001 & $-0,269$ & $-0,729$ & $-0,001$ & 0,040 & 0,102 & 0,000 & 0,121 & 0,032 & 0,093 \\
\hline 11 & 2,129 & 0,023 & 0,029 & $-1,776$ & $-0,040$ & $-0,027$ & 0,264 & 0,005 & 0,006 & 0,121 & 0,032 & 0,093 \\
\hline 12 & 0,269 & 0,365 & 0,000 & $-0,224$ & $-0,629$ & $-0,000$ & 0,033 & 0,085 & 0,000 & 0,121 & 0,032 & 0,093 \\
\hline 13 & 1,639 & 0,019 & 0,024 & $-1,344$ & $-0,030$ & $-0,021$ & 0,202 & 0,004 & 0,004 & 0,121 & 0,032 & 0,093 \\
\hline 14 & 0,204 & 0,307 & 0,000 & $-0,168$ & $-0,479$ & $-0,000$ & 0,025 & 0,064 & 0,000 & 0,121 & 0,032 & 0,093 \\
\hline 15 & 1,077 & 0,012 & 0,016 & $-0,907$ & $-0,020$ & $-0,014$ & 0,136 & 0,003 & 0,003 & 0,121 & 0,032 & 0,093 \\
\hline 16 & 0,133 & 0,200 & 0,000 & $-0,112$ & $-0,315$ & $-0,000$ & 0,017 & 0,042 & 0,000 & 0,121 & 0,032 & 0,093 \\
\hline
\end{tabular}

Tabela A.7: Resultados para os modos transversais da linha vertical em $U_{\text {max }}=0,981 \mathrm{~m} / \mathrm{s}$.

Amplitudes

Modo Máxima(m) Mínima(m) Desvio Padrão(m) Freq. máxima $(\mathrm{Hz})$

\begin{tabular}{lllll}
\hline 2 & 1,105 & $-1,051$ & 0,381 & 0,057 \\
4 & 0,783 & $-0,796$ & 0,334 & 0,087 \\
6 & 0,443 & $-0,735$ & 0,124 & 0,087 \\
8 & 0,410 & $-0,717$ & 0,104 & 0,032 \\
10 & 0,441 & $-0,723$ & 0,101 & 0,032 \\
12 & 0,362 & $-0,624$ & 0,084 & 0,032 \\
14 & 0,304 & $-0,474$ & 0,063 & 0,032 \\
16 & 0,198 & $-0,312$ & 0,042 & 0,032 \\
\hline
\end{tabular}


Tabela A.8: Resultados para os modos longitudinais da linha vertical em $U_{\max }=0,981 \mathrm{~m} / \mathrm{s}$.

Amplitudes

Modo Máxima(m) Mínima(m) Desvio Padrão(m) Freq. máxima (Hz)

\begin{tabular}{lllll}
\hline 1 & 0,857 & $-0,701$ & 0,181 & 0,136 \\
3 & 1,875 & $-1,583$ & 0,240 & 0,130 \\
5 & 2,113 & $-1,858$ & 0,307 & 0,121 \\
7 & 2,577 & $-2,102$ & 0,322 & 0,121 \\
9 & 2,500 & $-2,065$ & 0,305 & 0,121 \\
11 & 2,095 & $-1,748$ & 0,259 & 0,121 \\
13 & 1,612 & $-1,323$ & 0,198 & 0,121 \\
15 & 1,059 & $-0,892$ & 0,133 & 0,121 \\
\hline
\end{tabular}




\section{A.3 Vertical - Velocidade de $1,380 \mathrm{~m} / \mathrm{s}$ e $V_{r 1}=10,69$}

A seguir são apresentados gráficos e tabelas com detalhes da análise referente à linha vertical em velocidade de $1,380 \mathrm{~m} / \mathrm{s}$ e $V_{r 1}=10,69$. Como pode ser visto na Tabela A.9 e nas Figuras de A.9 a A.11, os maiores deslocamentos nas direções $X, Y$ e $Z$ foram de 0,501, 1,734 e 0,175 m, respectivamente. Estes valores ocorreram para os alvos 1, 6 e 10. Nestes alvos, as frequências de resposta com maior energia foram de 0,0295, 0,0456 e 0,0994 Hz.

Considerando a decomposição modal, de acordo com a Tabela A.10, as maiores amplitudes modais apresentadas nas direções $X, Y$ e $Z$ foram de 2,691, 2,155 e 0,035 m, respectivamente. Estes valores ocorreram aos modos 9, 4 e 7 . Nestes modos, as frequências de resposta com maior energia foram de 0,0349, 0,0994 e 0,0349 Hz.

A Tabela A.11 apresenta resultados dos movimentos referentes ao deslocamento no plano transversal à correnteza, onde a maior amplitude foi de 2,141 m. Este valor ocorreu para o modo 4. Neste modo, a frequência de resposta com maior energia foi de 0,099 Hz.

Por sua vez, a Tabela A.12 apresenta resultados dos movimentos no plano longitudinal à correnteza, onde a maior amplitude foi de 2,650 m. Este valor ocorreu para o modo 9 . Neste modo, a frequência de resposta com maior energia foi de 0,035 Hz. 

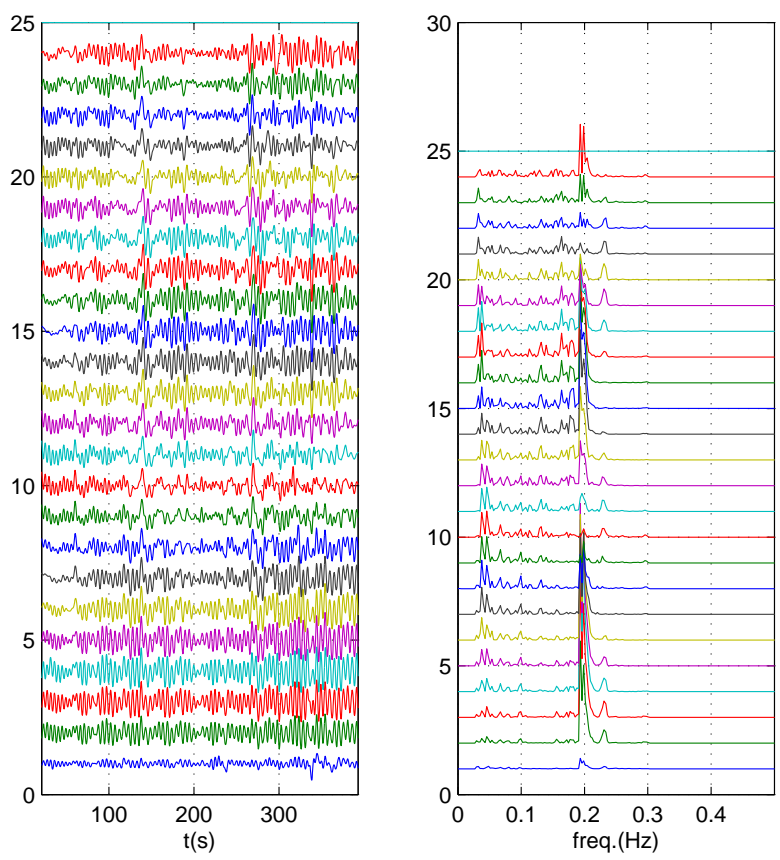

Figura A.9: Séries temporais de deslocamento na direção $X$ e respectivas PSD da linha vertical na $U_{\max }=1,380 \mathrm{~m} / \mathrm{s}$ e $V_{r 1}=10,692$.
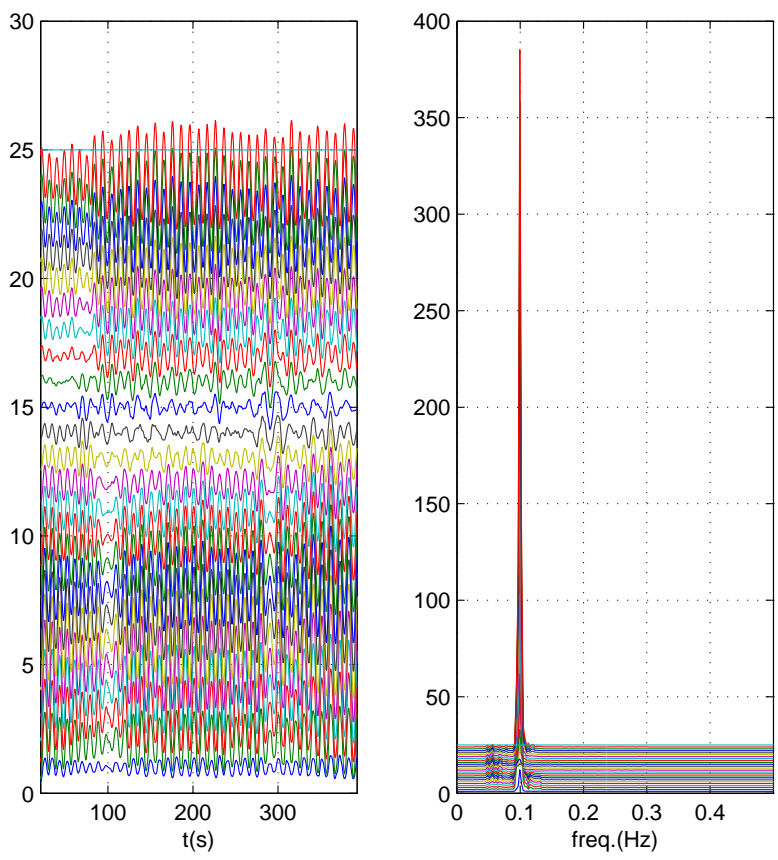

Figura A.10: Séries temporais de deslocamento na direção $Y$ e respectivas PSD da linha vertical na $U_{\max }=1,380 \mathrm{~m} / \mathrm{s}$ e $V_{r 1}=10,692$. 

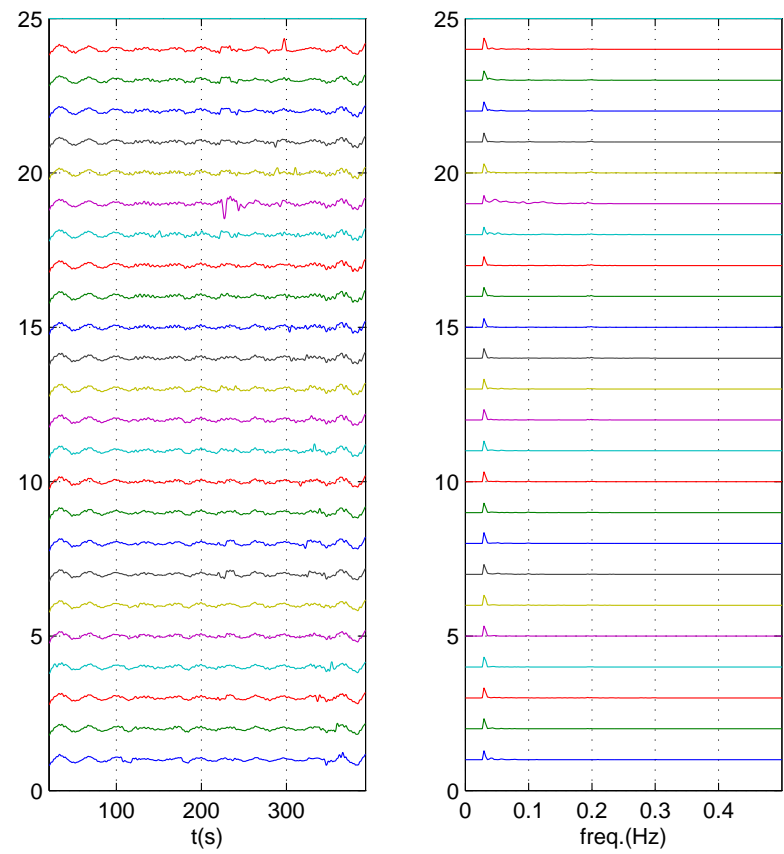

Figura A.11: Séries temporais de deslocamento na direção $Z$ e respectivas PSD da linha vertical na $U_{\max }=1,380 \mathrm{~m} / \mathrm{s}$ e $V_{r 1}=10,692$.
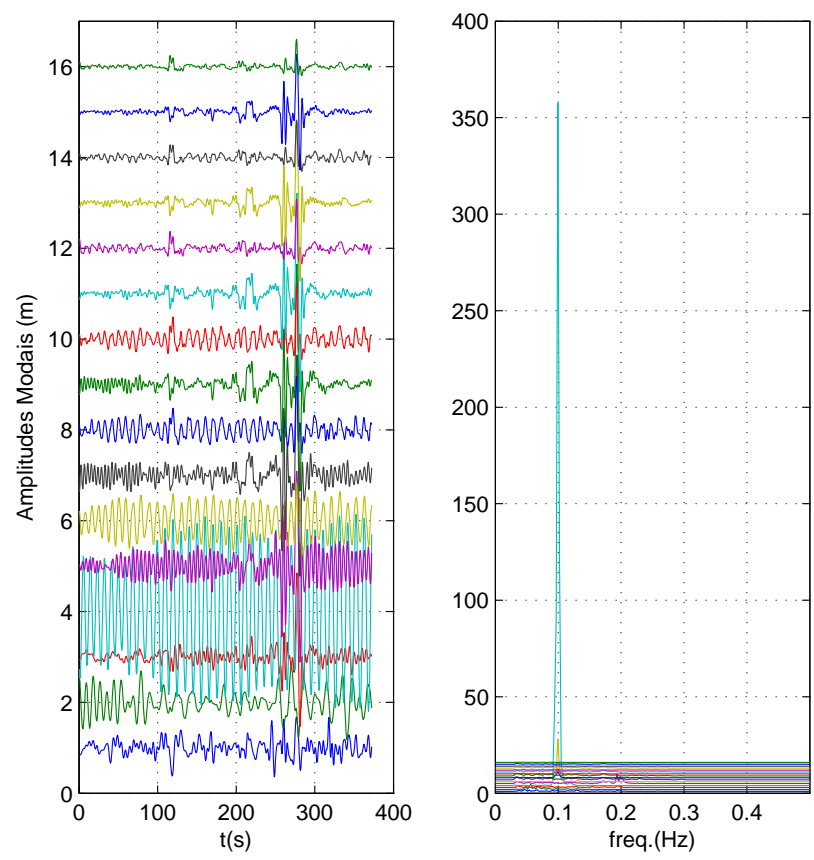

Figura A.12: Séries temporais de amplitude modal e respectivas PSD da linha vertical na $U_{\max }=1,380 \mathrm{~m} / \mathrm{s}$ e $V_{r 1}=10.692$. 
Tabela A.9: Resultados das séries temporais de deslocamento na linha vertical em

$$
U_{\text {max }}=1,380 \mathrm{~m} / \mathrm{s} \text {. }
$$

\begin{tabular}{|c|c|c|c|c|c|c|c|c|c|c|c|c|}
\hline \multirow[b]{2}{*}{ ID. Alvo } & \multirow[b]{2}{*}{$\mathrm{X}(\mathrm{m})$} & \multicolumn{2}{|c|}{ Máximo } & \multirow[b]{2}{*}{$\mathrm{X}(\mathrm{m})$} & \multirow{2}{*}{$\begin{array}{l}\text { Mínimo } \\
\mathrm{Y}(\mathrm{m})\end{array}$} & \multirow[b]{2}{*}{$\mathrm{Z}(\mathrm{m})$} & \multicolumn{3}{|c|}{ Desvio padrão } & \multicolumn{3}{|c|}{ Freq. máxima em Hz } \\
\hline & & $\mathrm{Y}(\mathrm{m})$ & $\mathrm{Z}(\mathrm{m})$ & & & & $\mathrm{X}(\mathrm{m})$ & $\mathrm{Y}(\mathrm{m})$ & $\mathrm{Z}(\mathrm{m})$ & $\mathrm{X}$ & $\mathrm{Y}$ & $\mathrm{Z}$ \\
\hline 1 & 0,128 & 0,364 & 0,175 & $-0,176$ & $-0,519$ & $-0,187$ & 0,067 & 0,239 & 0,090 & 0,193 & 0,099 & 0,030 \\
\hline 2 & 0,329 & 1,145 & 0,144 & $-0,321$ & $-1,451$ & $-0,206$ & 0,164 & 0,756 & 0,089 & 0,193 & 0,099 & 0,030 \\
\hline 3 & 0,372 & 1,434 & 0,149 & $-0,362$ & $-1,760$ & $-0,213$ & 0,183 & 0,941 & 0,088 & 0,193 & 0,099 & 0,030 \\
\hline 4 & 0,440 & 1,595 & 0,137 & $-0,367$ & $-1,966$ & $-0,207$ & 0,185 & 1,055 & 0,081 & 0,193 & 0,099 & 0,030 \\
\hline 5 & 0,316 & 1,726 & 0,146 & $-0,317$ & $-2,017$ & $-0,222$ & 0,149 & 1,116 & 0,087 & 0,193 & 0,099 & 0,030 \\
\hline 6 & 0,336 & 1,734 & 0,150 & $-0,237$ & $-1,975$ & $-0,217$ & 0,115 & 1,108 & 0,087 & 0,193 & 0,099 & 0,030 \\
\hline 7 & 0,401 & 1,656 & 0,149 & $-0,148$ & $-1,839$ & $-0,223$ & 0,104 & 1,048 & 0,089 & 0,199 & 0,099 & 0,030 \\
\hline 8 & 0,452 & 1,514 & 0,154 & $-0,194$ & $-1,632$ & $-0,237$ & 0,130 & 0,948 & 0,093 & 0,199 & 0,099 & 0,030 \\
\hline 9 & 0,495 & 1,328 & 0,154 & $-0,270$ & $-1,387$ & $-0,232$ & 0,172 & 0,828 & 0,091 & 0,046 & 0,099 & 0,030 \\
\hline 10 & 0,501 & 1,139 & 0,160 & $-0,320$ & $-1,128$ & $-0,227$ & 0,197 & 0,696 & 0,092 & 0,046 & 0,099 & 0,030 \\
\hline 11 & 0,487 & 0,926 & 0,153 & $-0,338$ & $-0,878$ & $-0,230$ & 0,205 & 0,565 & 0,091 & 0,046 & 0,099 & 0,030 \\
\hline 12 & 0,449 & 0,739 & 0,165 & $-0,324$ & $-0,685$ & $-0,231$ & 0,189 & 0,444 & 0,092 & 0,193 & 0,099 & 0,030 \\
\hline 13 & 0,383 & 0,544 & 0,157 & $-0,274$ & $-0,557$ & $-0,228$ & 0,155 & 0,326 & 0,093 & 0,193 & 0,099 & 0,030 \\
\hline 14 & 0,305 & 0,370 & 0,160 & $-0,215$ & $-0,442$ & $-0,223$ & 0,120 & 0,221 & 0,092 & 0,193 & 0,056 & 0,030 \\
\hline 15 & 0,210 & 0,198 & 0,154 & $-0,195$ & $-0,304$ & $-0,222$ & 0,097 & 0,125 & 0,091 & 0,193 & 0,056 & 0,030 \\
\hline 16 & 0,201 & 0,244 & 0,157 & $-0,256$ & $-0,174$ & $-0,214$ & 0,107 & 0,101 & 0,093 & 0,193 & 0,099 & 0,030 \\
\hline 17 & 0,285 & 0,390 & 0,155 & $-0,303$ & $-0,227$ & $-0,215$ & 0,140 & 0,172 & 0,091 & 0,193 & 0,099 & 0,030 \\
\hline 18 & 0,341 & 0,556 & 0,158 & $-0,341$ & $-0,374$ & $-0,209$ & 0,170 & 0,269 & 0,093 & 0,193 & 0,099 & 0,030 \\
\hline 19 & 0,372 & 0,700 & 0,148 & $-0,357$ & $-0,502$ & $-0,202$ & 0,186 & 0,364 & 0,087 & 0,193 & 0,099 & 0,030 \\
\hline 20 & 0,359 & 0,816 & 0,154 & $-0,378$ & $-0,623$ & $-0,197$ & 0,191 & 0,451 & 0,087 & 0,193 & 0,099 & 0,030 \\
\hline 21 & 0,319 & 0,928 & 0,149 & $-0,380$ & $-0,713$ & $-0,198$ & 0,180 & 0,522 & 0,089 & 0,164 & 0,099 & 0,030 \\
\hline 22 & 0,262 & 1,043 & 0,149 & $-0,358$ & $-0,802$ & $-0,200$ & 0,160 & 0,586 & 0,090 & 0,193 & 0,099 & 0,030 \\
\hline 23 & 0,232 & 1,131 & 0,146 & $-0,302$ & $-0,912$ & $-0,177$ & 0,130 & 0,640 & 0,085 & 0,193 & 0,099 & 0,030 \\
\hline 24 & 0,238 & 1,223 & 0,161 & $-0,235$ & $-1,006$ & $-0,182$ & 0,108 & 0,677 & 0,088 & 0,193 & 0,099 & 0,030 \\
\hline 25 & 0,000 & 0,000 & 0,000 & 0,000 & 0,000 & 0,000 & 0,000 & 0,000 & 0,000 & 0,000 & 0,000 & 0,000 \\
\hline
\end{tabular}


Tabela A.10: Resultados das séries temporais de amplitude modal na linha vertical em $U_{\max }=1,380 \mathrm{~m} / \mathrm{s}$.

\begin{tabular}{|c|c|c|c|c|c|c|c|c|c|c|c|c|}
\hline \multirow[b]{2}{*}{ Modo } & \multirow[b]{2}{*}{$\mathrm{X}(\mathrm{m})$} & \multicolumn{3}{|c|}{ Máximo } & \multicolumn{2}{|l|}{ Mínimo } & \multicolumn{3}{|c|}{ Desvio padrão } & \multicolumn{3}{|c|}{ Freq. máxima em $\mathrm{Hz}$} \\
\hline & & $\mathrm{Y}(\mathrm{m})$ & $\mathrm{Z}(\mathrm{m})$ & $\mathrm{X}(\mathrm{m})$ & $\mathrm{Y}(\mathrm{m})$ & $\mathrm{Z}(\mathrm{m})$ & $\mathrm{X}(\mathrm{m})$ & $\mathrm{Y}(\mathrm{m})$ & $\mathrm{Z}(\mathrm{m})$ & $\mathrm{X}$ & $\mathrm{Y}$ & $\mathrm{Z}$ \\
\hline 1 & 0,680 & 0,069 & 0,025 & $-0,645$ & $-0,072$ & $-0,030$ & 0,186 & 0,024 & 0,007 & 0,048 & 0,056 & 0,030 \\
\hline 2 & 0,118 & 0,791 & 0,000 & $-0,112$ & $-0,826$ & $-0,000$ & 0,032 & 0,274 & 0,000 & 0,048 & 0,056 & 0,030 \\
\hline 3 & 1,874 & 0,158 & 0,025 & $-1,558$ & $-0,162$ & $-0,039$ & 0,232 & 0,089 & 0,005 & 0,035 & 0,099 & 0,035 \\
\hline 4 & 0,272 & 2,155 & 0,000 & $-0,226$ & $-2,215$ & $-0,001$ & 0,034 & 1,224 & 0,000 & 0,035 & 0,099 & 0,035 \\
\hline 5 & 2,119 & 0,056 & 0,031 & $-2,147$ & $-0,051$ & $-0,051$ & 0,376 & 0,023 & 0,006 & 0,193 & 0,099 & 0,032 \\
\hline 6 & 0,288 & 0,817 & 0,000 & $-0,291$ & $-0,753$ & $-0,001$ & 0,051 & 0,339 & 0,000 & 0,193 & 0,099 & 0,032 \\
\hline 7 & 2,685 & 0,078 & 0,035 & $-2,255$ & $-0,034$ & $-0,052$ & 0,355 & 0,012 & 0,006 & 0,035 & 0,099 & 0,035 \\
\hline 8 & 0,352 & 1,189 & 0,001 & $-0,295$ & $-0,516$ & $-0,001$ & 0,046 & 0,187 & 0,000 & 0,035 & 0,099 & 0,035 \\
\hline 9 & 2,691 & 0,080 & 0,034 & $-2,384$ & $-0,030$ & $-0,050$ & 0,331 & 0,011 & 0,006 & 0,035 & 0,099 & 0,083 \\
\hline 10 & 0,345 & 1,233 & 0,001 & $-0,305$ & $-0,459$ & $-0,001$ & 0,042 & 0,170 & 0,000 & 0,035 & 0,099 & 0,083 \\
\hline 11 & 2,245 & 0,069 & 0,031 & $-2,193$ & $-0,022$ & $-0,043$ & 0,287 & 0,007 & 0,005 & 0,172 & 0,032 & 0,035 \\
\hline 12 & 0,283 & 1,088 & 0,000 & $-0,277$ & $-0,347$ & $-0,001$ & 0,036 & 0,111 & 0,000 & 0,172 & 0,032 & 0,035 \\
\hline 13 & 1,811 & 0,052 & 0,025 & $-1,751$ & $-0,019$ & $-0,033$ & 0,232 & 0,006 & 0,004 & 0,035 & 0,099 & 0,035 \\
\hline 14 & 0,226 & 0,827 & 0,000 & $-0,219$ & $-0,310$ & $-0,001$ & 0,029 & 0,095 & 0,000 & 0,035 & 0,099 & 0,035 \\
\hline 15 & 1,294 & 0,038 & 0,018 & $-1,294$ & $-0,013$ & $-0,023$ & 0,172 & 0,004 & 0,003 & 0,035 & 0,043 & 0,038 \\
\hline 16 & 0,160 & 0,604 & 0,000 & $-0,160$ & $-0,204$ & $-0,000$ & 0,021 & 0,065 & 0,000 & 0,035 & 0,043 & 0,038 \\
\hline
\end{tabular}

Tabela A.11: Resultados para os modos transversais da linha vertical em $U_{\max }=1,380 \mathrm{~m} / \mathrm{s}$.

Amplitudes

Modo Máxima(m) Mínima(m) Desvio Padrão(m) Freq. máxima (Hz)

\begin{tabular}{lllll}
\hline 2 & 0,786 & $-0,822$ & 0,273 & 0,056 \\
4 & 2,141 & $-2,200$ & 1,216 & 0,099 \\
6 & 0,812 & $-0,747$ & 0,337 & 0,099 \\
8 & 1,182 & $-0,512$ & 0,186 & 0,099 \\
10 & 1,225 & $-0,455$ & 0,169 & 0,099 \\
12 & 1,081 & $-0,344$ & 0,111 & 0,032 \\
14 & 0,822 & $-0,307$ & 0,095 & 0,099 \\
16 & 0,600 & $-0,202$ & 0,064 & 0,043 \\
\hline
\end{tabular}


Tabela A.12: Resultados para os modos longitudinais da linha vertical em

$$
U_{\text {max }}=1,380 \mathrm{~m} / \mathrm{s} \text {. }
$$

Amplitudes

Modo Máxima(m) Mínima(m) Desvio Padrão(m) Freq. máxima (Hz)

\begin{tabular}{lllll}
\hline 1 & 0,672 & $-0,638$ & 0,184 & 0,048 \\
3 & 1,848 & $-1,536$ & 0,229 & 0,035 \\
5 & 2,089 & $-2,115$ & 0,370 & 0,193 \\
7 & 2,644 & $-2,221$ & 0,350 & 0,035 \\
9 & 2,650 & $-2,347$ & 0,326 & 0,035 \\
11 & 2,210 & $-2,159$ & 0,283 & 0,172 \\
13 & 1,783 & $-1,723$ & 0,228 & 0,035 \\
15 & 1,273 & $-1,274$ & 0,169 & 0,035 \\
\hline
\end{tabular}




\section{A.4 Vertical - Velocidade de $1,740 \mathrm{~m} / \mathrm{s}$ e $V_{r 1}=13,44$}

A seguir são apresentados gráficos e tabelas com detalhes da análise referente à linha vertical em velocidade de $1,740 \mathrm{~m} / \mathrm{s}$ e $V_{r 1}=13,44$. Como pode ser visto na Tabela A.13 e nas Figuras de A.13 a A.15, os maiores deslocamentos nas direções $X, Y$ e $Z$ foram de 0,508, 1,339 e 0,214 m, respectivamente. Estes valores ocorreram para os alvos 10, 24 e 25. Nestes alvos, as frequências de resposta com maior energia foram de 0,0327, 0,147 e $0,298 \mathrm{~Hz}$.

Considerando a decomposição modal, de acordo com a Tabela A.14, as maiores amplitudes modais apresentadas nas direções $X, Y$ e $Z$ foram de 1,743, 1,393 e 0,034 m, respectivamente. Estes valores ocorreram aos modos 1, 6 e 9. Nestes modos, as frequências de resposta com maior energia foram de 0,0327, 0,147 e 0,298 Hz.

A Tabela A.15 apresenta resultados dos movimentos referentes ao deslocamento no plano transversal à correnteza, onde a maior amplitude foi de 1,383 m. Este valor ocorreu para o modo 6. Neste modo, a frequência de resposta com maior energia foi de 0,147 Hz.

Por sua vez, a Tabela A.16 apresenta resultados dos movimentos no plano longitudinal à correnteza, onde a maior amplitude foi de 1,717 $\mathrm{m}$. Este valor ocorreu para o modo 9 . Neste modo, a frequência de resposta com maior energia foi de 0,298 Hz. 

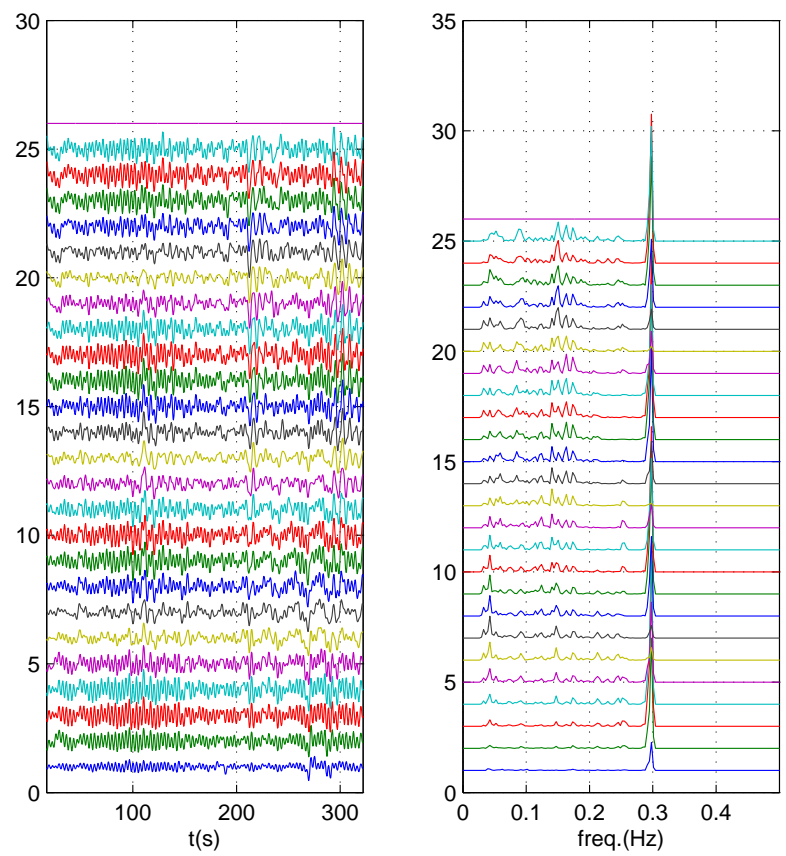

Figura A.13: Séries temporais de deslocamento na direção $X$ e respectivas PSD da linha vertical na $U_{\max }=1,740 \mathrm{~m} / \mathrm{s}$ e $V_{r 1}=13,439$.
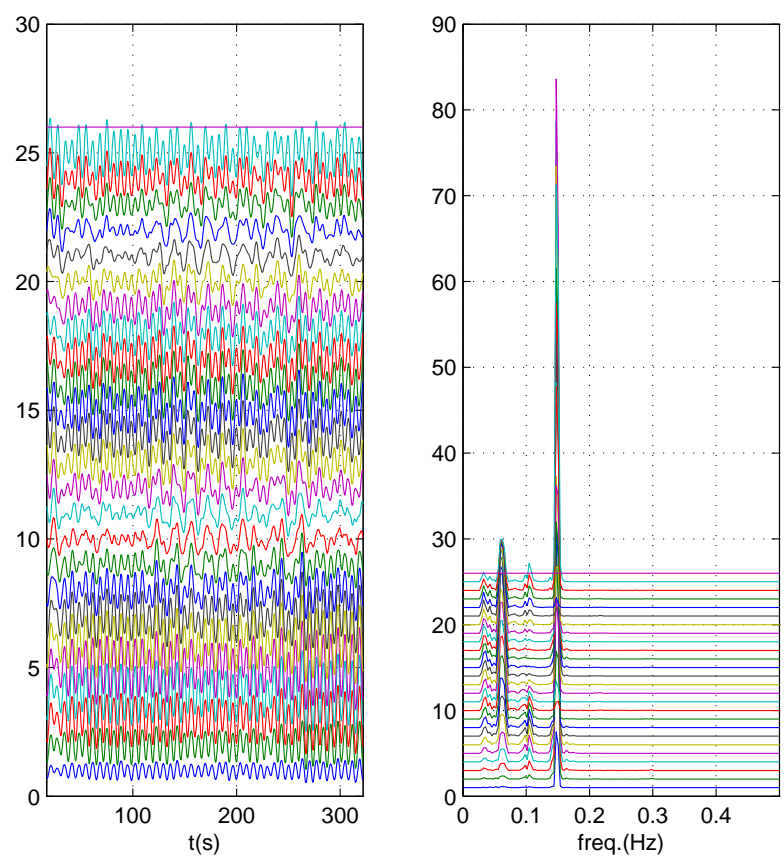

Figura A.14: Séries temporais de deslocamento na direção $Y$ e respectivas PSD da linha vertical na $U_{\max }=1,740 \mathrm{~m} / \mathrm{s}$ e $V_{r 1}=13,439$. 

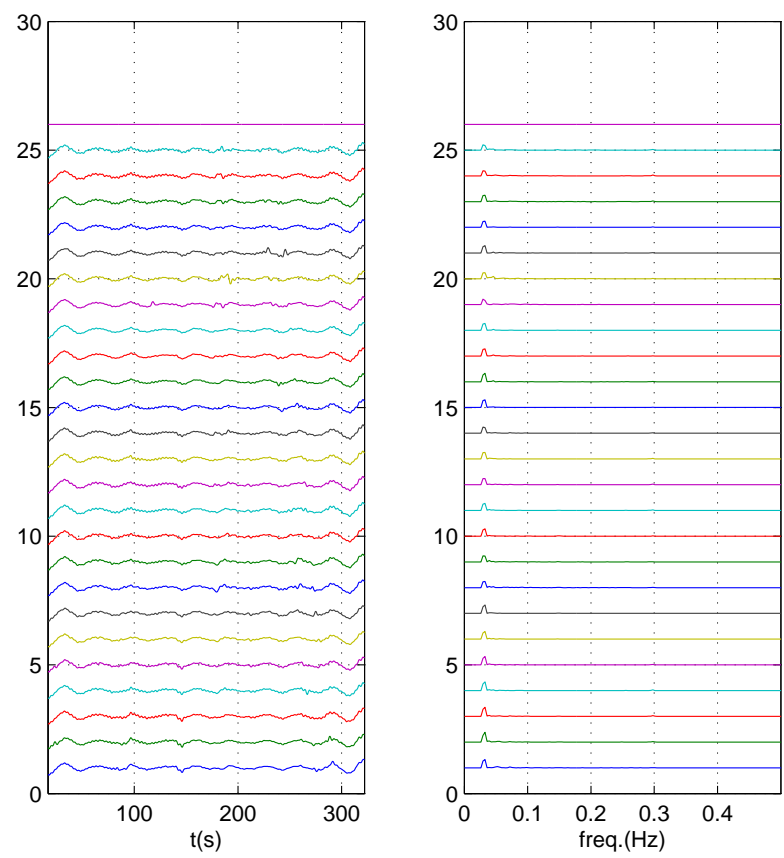

Figura A.15: Séries temporais de deslocamento na direção $Z$ e respectivas PSD da linha vertical na $U_{\max }=1,740 \mathrm{~m} / \mathrm{s}$ e $V_{r 1}=13,439$.
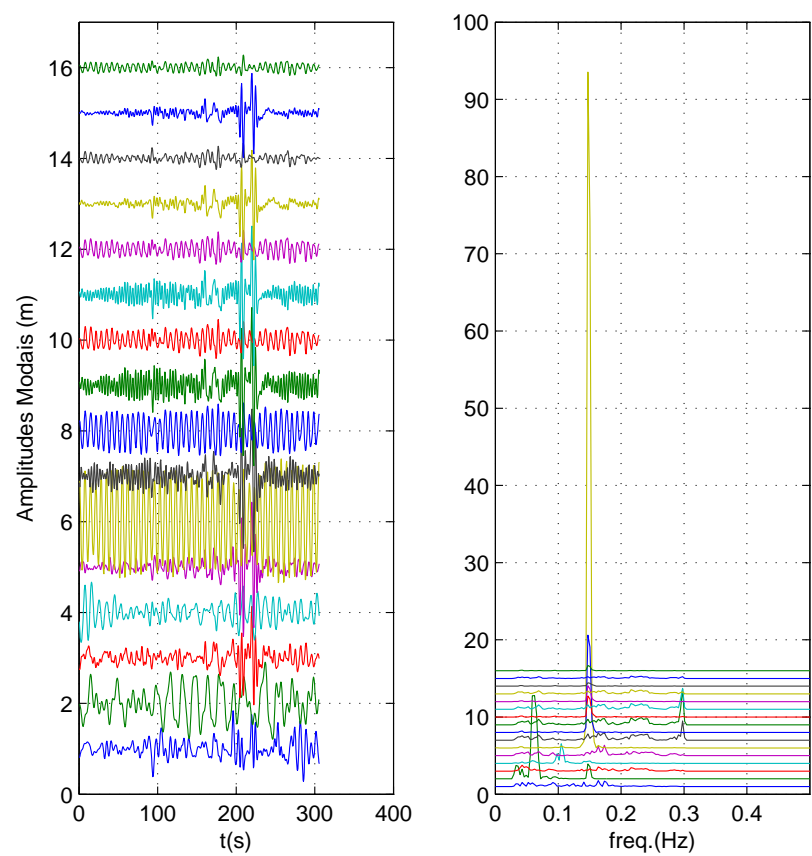

Figura A.16: Séries temporais de amplitude modal e respectivas PSD da linha vertical na $U_{\max }=1,740 \mathrm{~m} / \mathrm{s}$ e $V_{r 1}=13,439$. 
Tabela A.13: Resultados das séries temporais de deslocamento na linha vertical em

$$
U_{\text {max }}=1,740 \mathrm{~m} / \mathrm{s} \text {. }
$$

\begin{tabular}{|c|c|c|c|c|c|c|c|c|c|c|c|c|}
\hline \multirow[b]{2}{*}{ ID. Alvo } & \multirow[b]{2}{*}{$\mathrm{X}(\mathrm{m})$} & \multicolumn{2}{|l|}{ Máximo } & \multirow[b]{2}{*}{$\mathrm{X}(\mathrm{m})$} & \multirow{2}{*}{$\begin{array}{l}\text { Mínimo } \\
\mathrm{Y}(\mathrm{m})\end{array}$} & \multirow[b]{2}{*}{$\mathrm{Z}(\mathrm{m})$} & \multicolumn{3}{|c|}{ Desvio padrão } & \multicolumn{3}{|c|}{ Freq. máxima em $\mathrm{H}$} \\
\hline & & $\mathrm{Y}(\mathrm{m})$ & $\mathrm{Z}(\mathrm{m})$ & & & & $\mathrm{X}(\mathrm{m})$ & $\mathrm{Y}(\mathrm{m})$ & $\mathrm{Z}(\mathrm{m})$ & $\mathrm{X}$ & $\mathrm{Y}$ & $\mathrm{Z}$ \\
\hline 1 & 0,143 & 0,287 & 0,191 & $-0,159$ & $-0,306$ & $-0,283$ & 0,074 & 0,172 & 0,124 & 0,298 & 0,147 & 0,033 \\
\hline 2 & 0,420 & 0,567 & 0,164 & $-0,385$ & $-0,670$ & $-0,259$ & 0,193 & 0,362 & 0,105 & 0,298 & 0,147 & 0,033 \\
\hline 3 & 0,370 & 0,868 & 0,205 & $-0,416$ & $-0,899$ & $-0,299$ & 0,195 & 0,518 & 0,129 & 0,298 & 0,147 & 0,033 \\
\hline 4 & 0,409 & 1,044 & 0,200 & $-0,424$ & $-1,056$ & $-0,304$ & 0,194 & 0,606 & 0,128 & 0,298 & 0,147 & 0,033 \\
\hline 5 & 0,451 & 1,094 & 0,201 & $-0,407$ & $-1,107$ & $-0,276$ & 0,197 & 0,628 & 0,118 & 0,298 & 0,147 & 0,033 \\
\hline 6 & 0,323 & 1,066 & 0,201 & $-0,238$ & $-1,032$ & $-0,300$ & 0,113 & 0,592 & 0,127 & 0,043 & 0,147 & 0,033 \\
\hline 7 & 0,341 & 0,943 & 0,204 & $-0,267$ & $-0,890$ & $-0,304$ & 0,121 & 0,516 & 0,128 & 0,043 & 0,147 & 0,033 \\
\hline 8 & 0,369 & 0,752 & 0,202 & $-0,329$ & $-0,715$ & $-0,307$ & 0,153 & 0,423 & 0,129 & 0,298 & 0,147 & 0,033 \\
\hline 9 & 0,436 & 0,651 & 0,210 & $-0,321$ & $-0,681$ & $-0,312$ & 0,183 & 0,350 & 0,130 & 0,298 & 0,147 & 0,029 \\
\hline 10 & 0,463 & 0,828 & 0,214 & $-0,325$ & $-0,640$ & $-0,317$ & 0,193 & 0,322 & 0,133 & 0,298 & 0,062 & 0,033 \\
\hline 11 & 0,404 & 0,969 & 0,212 & $-0,290$ & $-0,608$ & $-0,313$ & 0,175 & 0,340 & 0,133 & 0,298 & 0,062 & 0,033 \\
\hline 12 & 0,338 & 1,090 & 0,211 & $-0,256$ & $-0,613$ & $-0,321$ & 0,146 & 0,396 & 0,134 & 0,298 & 0,147 & 0,029 \\
\hline 13 & 0,302 & 1,146 & 0,205 & $-0,268$ & $-0,674$ & $-0,317$ & 0,131 & 0,458 & 0,132 & 0,141 & 0,147 & 0,033 \\
\hline 14 & 0,358 & 1,138 & 0,201 & $-0,328$ & $-0,767$ & $-0,312$ & 0,148 & 0,507 & 0,132 & 0,298 & 0,147 & 0,029 \\
\hline 15 & 0,390 & 1,089 & 0,201 & $-0,356$ & $-0,810$ & $-0,310$ & 0,177 & 0,528 & 0,132 & 0,298 & 0,147 & 0,033 \\
\hline 16 & 0,381 & 0,979 & 0,195 & $-0,374$ & $-0,772$ & $-0,299$ & 0,195 & 0,517 & 0,131 & 0,298 & 0,147 & 0,033 \\
\hline 17 & 0,354 & 0,882 & 0,197 & $-0,384$ & $-0,746$ & $-0,304$ & 0,197 & 0,478 & 0,133 & 0,298 & 0,147 & 0,033 \\
\hline 18 & 0,352 & 0,788 & 0,194 & $-0,361$ & $-0,697$ & $-0,300$ & 0,180 & 0,415 & 0,131 & 0,298 & 0,147 & 0,033 \\
\hline 19 & 0,331 & 0,695 & 0,195 & $-0,358$ & $-0,650$ & $-0,303$ & 0,162 & 0,346 & 0,131 & 0,298 & 0,147 & 0,029 \\
\hline 20 & 0,284 & 0,589 & 0,203 & $-0,366$ & $-0,655$ & $-0,295$ & 0,155 & 0,300 & 0,132 & 0,164 & 0,062 & 0,033 \\
\hline 21 & 0,329 & 0,633 & 0,171 & $-0,420$ & $-0,683$ & $-0,278$ & 0,172 & 0,299 & 0,127 & 0,151 & 0,062 & 0,033 \\
\hline 22 & 0,412 & 0,834 & 0,181 & $-0,472$ & $-0,827$ & $-0,287$ & 0,199 & 0,366 & 0,126 & 0,298 & 0,062 & 0,033 \\
\hline 23 & 0,475 & 1,037 & 0,189 & $-0,508$ & $-0,964$ & $-0,305$ & 0,224 & 0,467 & 0,129 & 0,298 & 0,147 & 0,033 \\
\hline 24 & 0,508 & 1,187 & 0,198 & $-0,497$ & $-1,089$ & $-0,293$ & 0,229 & 0,570 & 0,126 & 0,298 & 0,147 & 0,029 \\
\hline 25 & 0,507 & 1,339 & 0,202 & $-0,464$ & $-1,248$ & $-0,299$ & 0,218 & 0,690 & 0,127 & 0,298 & 0,147 & 0,029 \\
\hline 26 & $-0,000$ & $-0,000$ & 0,000 & $-0,000$ & $-0,000$ & 0,000 & 0,000 & 0,000 & 0,000 & 0,000 & 0,000 & 0,000 \\
\hline
\end{tabular}


Tabela A.14: Resultados das séries temporais de amplitude modal na linha vertical em $U_{\max }=1,740 \mathrm{~m} / \mathrm{s}$.

\begin{tabular}{|c|c|c|c|c|c|c|c|c|c|c|c|c|}
\hline \multirow[b]{2}{*}{ Modo } & \multirow[b]{2}{*}{$\mathrm{X}(\mathrm{m})$} & \multicolumn{3}{|c|}{ Máximo } & \multicolumn{2}{|l|}{ Mínimo } & \multicolumn{3}{|c|}{ Desvio padrão } & \multicolumn{3}{|c|}{ Freq. máxima em $\mathrm{Hz}$} \\
\hline & & $\mathrm{Y}(\mathrm{m})$ & $\mathrm{Z}(\mathrm{m})$ & $\mathrm{X}(\mathrm{m})$ & $\mathrm{Y}(\mathrm{m})$ & $\mathrm{Z}(\mathrm{m})$ & $\mathrm{X}(\mathrm{m})$ & $\mathrm{Y}(\mathrm{m})$ & $\mathrm{Z}(\mathrm{m})$ & $\mathrm{X}$ & $\mathrm{Y}$ & $\mathrm{Z}$ \\
\hline 1 & 0,848 & 0,079 & 0,034 & $-0,724$ & $-0,069$ & $-0,034$ & 0,209 & 0,031 & 0,009 & 0,164 & 0,062 & 0,033 \\
\hline 2 & 0,147 & 0,911 & 0,000 & $-0,125$ & $-0,794$ & $-0,000$ & 0,036 & 0,352 & 0,000 & 0,164 & 0,062 & 0,033 \\
\hline 3 & 1,151 & 0,049 & 0,016 & $-1,045$ & $-0,048$ & $-0,023$ & 0,197 & 0,016 & 0,003 & 0,043 & 0,105 & 0,177 \\
\hline 4 & 0,167 & 0,677 & 0,000 & $-0,152$ & $-0,661$ & $-0,000$ & 0,029 & 0,222 & 0,000 & 0,043 & 0,105 & 0,177 \\
\hline 5 & 1,452 & 0,095 & 0,021 & $-1,551$ & $-0,092$ & $-0,032$ & 0,240 & 0,053 & 0,005 & 0,173 & 0,147 & 0,033 \\
\hline 6 & 0,197 & 1,393 & 0,000 & $-0,210$ & $-1,353$ & $-0,000$ & 0,033 & 0,780 & 0,000 & 0,173 & 0,147 & 0,033 \\
\hline 7 & 1,505 & 0,041 & 0,023 & $-1,685$ & $-0,036$ & $-0,035$ & 0,289 & 0,020 & 0,005 & 0,298 & 0,147 & 0,177 \\
\hline 8 & 0,197 & 0,622 & 0,000 & $-0,221$ & $-0,551$ & $-0,001$ & 0,038 & 0,299 & 0,000 & 0,298 & 0,147 & 0,177 \\
\hline 9 & 1,743 & 0,029 & 0,022 & $-1,795$ & $-0,026$ & $-0,033$ & 0,296 & 0,010 & 0,005 & 0,298 & 0,147 & 0,177 \\
\hline 10 & 0,223 & 0,455 & 0,000 & $-0,230$ & $-0,409$ & $-0,001$ & 0,038 & 0,155 & 0,000 & 0,298 & 0,147 & 0,177 \\
\hline 11 & 1,533 & 0,026 & 0,020 & $-1,587$ & $-0,021$ & $-0,030$ & 0,254 & 0,009 & 0,004 & 0,298 & 0,147 & 0,049 \\
\hline 12 & 0,193 & 0,415 & 0,000 & $-0,200$ & $-0,333$ & $-0,000$ & 0,032 & 0,136 & 0,000 & 0,298 & 0,147 & 0,049 \\
\hline 13 & 1,198 & 0,021 & 0,017 & $-1,253$ & $-0,015$ & $-0,024$ & 0,189 & 0,005 & 0,003 & 0,216 & 0,147 & 0,049 \\
\hline 14 & 0,149 & 0,337 & 0,000 & $-0,156$ & $-0,243$ & $-0,000$ & 0,024 & 0,079 & 0,000 & 0,216 & 0,147 & 0,049 \\
\hline 15 & 0,888 & 0,017 & 0,012 & $-1,000$ & $-0,012$ & $-0,016$ & 0,146 & 0,005 & 0,002 & 0,216 & 0,147 & 0,052 \\
\hline 16 & 0,110 & 0,279 & 0,000 & $-0,124$ & $-0,186$ & $-0,000$ & 0,018 & 0,080 & 0,000 & 0,216 & 0,147 & 0,052 \\
\hline
\end{tabular}

Tabela A.15: Resultados para os modos transversais da linha vertical em $U_{\max }=1,740 \mathrm{~m} / \mathrm{s}$.

Amplitudes

Modo Máxima(m) Mínima(m) Desvio Padrão(m) Freq. máxima (Hz)

\begin{tabular}{lllll}
\hline 2 & 0,906 & $-0,789$ & 0,350 & 0,062 \\
4 & 0,672 & $-0,657$ & 0,221 & 0,105 \\
6 & 1,383 & $-1,343$ & 0,775 & 0,147 \\
8 & 0,615 & $-0,547$ & 0,297 & 0,147 \\
10 & 0,452 & $-0,406$ & 0,154 & 0,147 \\
12 & 0,411 & $-0,330$ & 0,135 & 0,147 \\
14 & 0,333 & $-0,241$ & 0,078 & 0,147 \\
16 & 0,276 & $-0,185$ & 0,079 & 0,147 \\
\hline
\end{tabular}


Tabela A.16: Resultados para os modos longitudinais da linha vertical em

$$
U_{\text {max }}=1,740 \mathrm{~m} / \mathrm{s} \text {. }
$$

Amplitudes

Modo Máxima(m) Mínima(m) Desvio Padrão(m) Freq. máxima (Hz)

\begin{tabular}{lllll}
\hline 1 & 0,838 & $-0,716$ & 0,207 & 0,164 \\
3 & 1,136 & $-1,032$ & 0,194 & 0,043 \\
5 & 1,431 & $-1,527$ & 0,236 & 0,173 \\
7 & 1,482 & $-1,659$ & 0,285 & 0,298 \\
9 & 1,717 & $-1,767$ & 0,291 & 0,298 \\
11 & 1,509 & $-1,561$ & 0,250 & 0,298 \\
13 & 1,179 & $-1,233$ & 0,186 & 0,216 \\
15 & 0,874 & $-0,984$ & 0,143 & 0,216 \\
\hline
\end{tabular}




\section{A.5 Vertical - velocidade de $2,200 \mathrm{~m} / \mathrm{s}$ e $V_{r 1}=16,96$}

A seguir são apresentados gráficos e tabelas com detalhes da análise referente à linha vertical em velocidade de $2,200 \mathrm{~m} / \mathrm{s}$ e $V_{r 1}=16,96$. Como pode ser visto na Tabela A.17 e nas Figuras de A.17 a A.19, os maiores deslocamentos nas direções $X, Y$ e $Z$ foram de $0,669,1,786$ e 0,742 m, respectivamente. Estes valores ocorreram para os alvos 1 e 4 . Nestes alvos, as frequências de resposta com maior energia foram de 0,0388 e 0,159 Hz.

Considerando a decomposição modal, de acordo com a Tabela A.18, as maiores amplitudes modais apresentadas nas direções $X, Y$ e $Z$ foram de 0,599, 1,714 e 0,028 m, respectivamente. Estes valores ocorreram aos modos 1 e 6 . Nestes modos, as frequências de resposta com maior energia foram de 0,0388, 0,108 e 0,159 Hz.

A Tabela A.19 apresenta resultados dos movimentos referentes ao deslocamento no plano transversal à correnteza, onde a maior amplitude foi de 1,701 m. Este valor ocorreu para o modo 6. Neste modo, a frequência de resposta com maior energia foi de 0,159 Hz.

Por sua vez, a Tabela A.20 apresenta resultados dos movimentos no plano longitudinal à correnteza, onde a maior amplitude foi de $0,592 \mathrm{~m}$. Este valor ocorreu para o modo 1 . Neste modo, a frequência de resposta com maior energia foi de 0,108 Hz. 

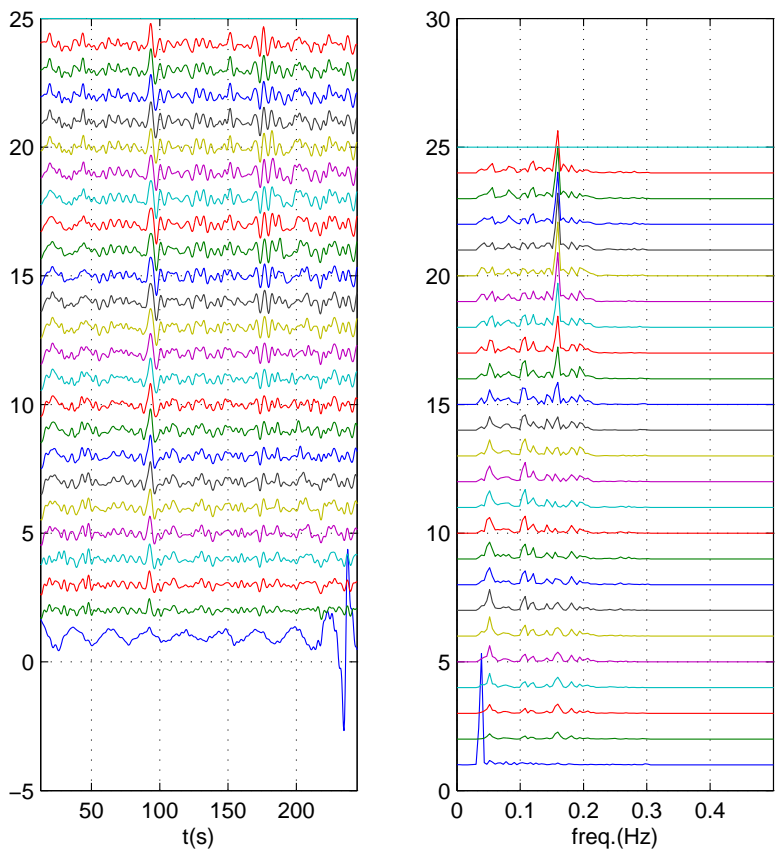

Figura A.17: Séries temporais de deslocamento na direção $X$ e respectivas PSD da linha vertical na $U_{\max }=2,200 \mathrm{~m} / \mathrm{s}$ e $V_{r 1}=16,964$.
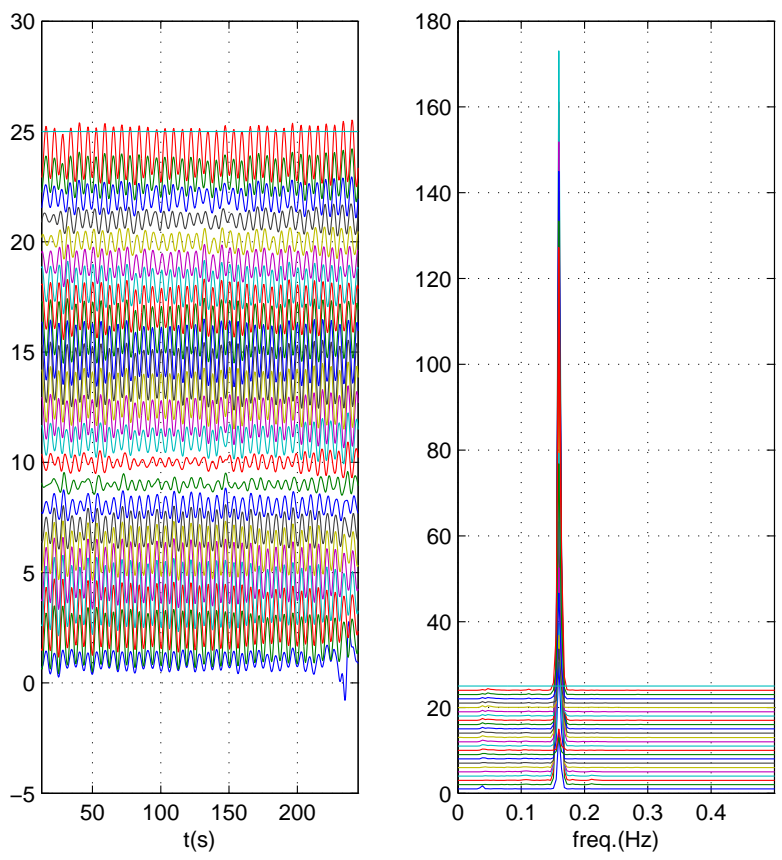

Figura A.18: Séries temporais de deslocamento na direção $Y$ e respectivas PSD da linha vertical na $U_{\max }=2,200 \mathrm{~m} / \mathrm{s}$ e $V_{r 1}=16,964$. 

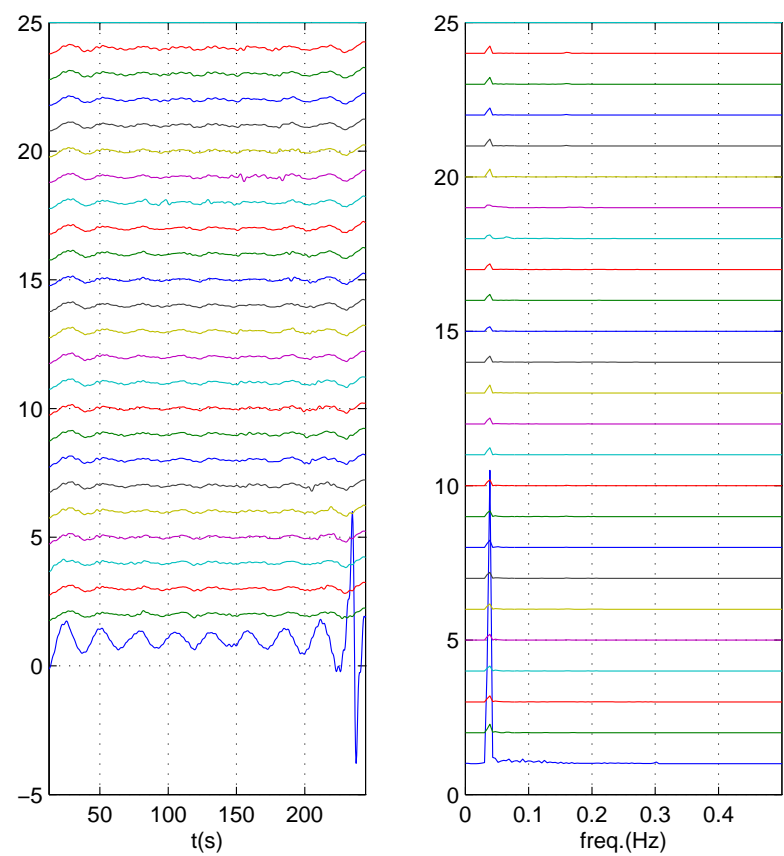

Figura A.19: Séries temporais de deslocamento na direção $Z$ e respectivas PSD da linha vertical na $U_{\max }=2,200 \mathrm{~m} / \mathrm{s}$ e $V_{r 1}=16,964$.
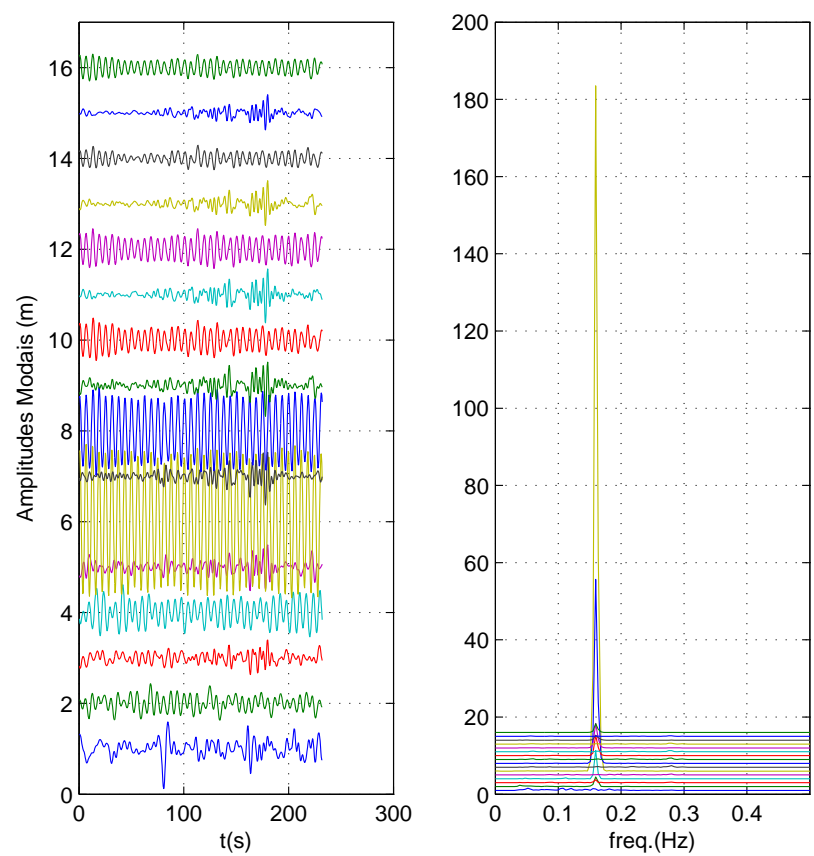

Figura A.20: Séries temporais de amplitude modal e respectivas PSD da linha vertical na $U_{\max }=2,200 \mathrm{~m} / \mathrm{s}$ e $V_{r 1}=16,964$. 
Tabela A.17: Resultados das séries temporais de deslocamento na linha vertical em

$$
U_{\text {max }}=2,200 \mathrm{~m} / \mathrm{s} \text {. }
$$

\begin{tabular}{|c|c|c|c|c|c|c|c|c|c|c|c|c|}
\hline \multirow[b]{2}{*}{ ID. Alvo } & \multirow[b]{2}{*}{$\mathrm{X}(\mathrm{m})$} & \multicolumn{2}{|l|}{ Máximo } & \multirow[b]{2}{*}{$\mathrm{X}(\mathrm{m})$} & \multicolumn{2}{|l|}{ Mínimo } & \multicolumn{3}{|c|}{ Desvio padrão } & \multicolumn{3}{|c|}{ Freq. máxima em $\mathrm{Hz}$} \\
\hline & & $\mathrm{Y}(\mathrm{m})$ & $\mathrm{Z}(\mathrm{m})$ & & $\mathrm{Y}(\mathrm{m})$ & $\mathrm{Z}(\mathrm{m})$ & $\mathrm{X}(\mathrm{m})$ & $\mathrm{Y}(\mathrm{m})$ & $\mathrm{Z}(\mathrm{m})$ & $\mathrm{X}$ & $\mathrm{Y}$ & Z \\
\hline 1 & 0,669 & 0,520 & 0,742 & $-0,568$ & $-0,734$ & $-1,125$ & 0,305 & 0,341 & 0,475 & 0,039 & 0,159 & 0,039 \\
\hline 2 & 0,304 & 1,487 & 0,134 & $-0,311$ & $-1,579$ & $-0,237$ & 0,128 & 0,949 & 0,098 & 0,159 & 0,159 & 0,039 \\
\hline 3 & 0,369 & 1,709 & 0,133 & $-0,400$ & $-1,833$ & $-0,247$ & 0,158 & 1,089 & 0,100 & 0,159 & 0,159 & 0,039 \\
\hline 4 & 0,393 & 1,786 & 0,144 & $-0,337$ & $-1,860$ & $-0,326$ & 0,160 & 1,098 & 0,103 & 0,052 & 0,159 & 0,039 \\
\hline 5 & 0,383 & 1,601 & 0,146 & $-0,479$ & $-1,662$ & $-0,266$ & 0,184 & 0,989 & 0,103 & 0,052 & 0,159 & 0,039 \\
\hline 6 & 0,366 & 1,343 & 0,141 & $-0,492$ & $-1,360$ & $-0,258$ & 0,191 & 0,795 & 0,102 & 0,052 & 0,159 & 0,039 \\
\hline 7 & 0,343 & 1,036 & 0,152 & $-0,505$ & $-0,997$ & $-0,260$ & 0,192 & 0,566 & 0,107 & 0,052 & 0,159 & 0,039 \\
\hline 8 & 0,328 & 0,750 & 0,152 & $-0,491$ & $-0,686$ & $-0,274$ & 0,194 & 0,362 & 0,110 & 0,052 & 0,159 & 0,039 \\
\hline 9 & 0,321 & 0,537 & 0,148 & $-0,494$ & $-0,456$ & $-0,257$ & 0,196 & 0,222 & 0,106 & 0,052 & 0,159 & 0,039 \\
\hline 10 & 0,338 & 0,437 & 0,152 & $-0,470$ & $-0,502$ & $-0,252$ & 0,190 & 0,269 & 0,104 & 0,108 & 0,159 & 0,039 \\
\hline 11 & 0,376 & 0,773 & 0,149 & $-0,465$ & $-0,794$ & $-0,248$ & 0,189 & 0,463 & 0,107 & 0,108 & 0,159 & 0,039 \\
\hline 12 & 0,388 & 1,080 & 0,154 & $-0,437$ & $-1,072$ & $-0,245$ & 0,182 & 0,662 & 0,106 & 0,108 & 0,159 & 0,039 \\
\hline 13 & 0,388 & 1,334 & 0,156 & $-0,418$ & $-1,321$ & $-0,243$ & 0,177 & 0,837 & 0,107 & 0,108 & 0,159 & 0,039 \\
\hline 14 & 0,379 & 1,454 & 0,141 & $-0,393$ & $-1,476$ & $-0,230$ & 0,170 & 0,935 & 0,103 & 0,108 & 0,159 & 0,039 \\
\hline 15 & 0,363 & 1,455 & 0,144 & $-0,360$ & $-1,509$ & $-0,223$ & 0,165 & 0,954 & 0,100 & 0,159 & 0,159 & 0,039 \\
\hline 16 & 0,333 & 1,415 & 0,148 & $-0,334$ & $-1,501$ & $-0,228$ & 0,162 & 0,919 & 0,105 & 0,159 & 0,159 & 0,039 \\
\hline 17 & 0,329 & 1,282 & 0,144 & $-0,275$ & $-1,425$ & $-0,223$ & 0,162 & 0,807 & 0,104 & 0,159 & 0,159 & 0,039 \\
\hline 18 & 0,380 & 1,115 & 0,145 & $-0,248$ & $-1,273$ & $-0,227$ & 0,163 & 0,659 & 0,106 & 0,159 & 0,159 & 0,039 \\
\hline 19 & 0,424 & 0,861 & 0,137 & $-0,274$ & $-1,032$ & $-0,215$ & 0,167 & 0,488 & 0,099 & 0,159 & 0,159 & 0,034 \\
\hline 20 & 0,458 & 0,693 & 0,139 & $-0,289$ & $-0,785$ & $-0,228$ & 0,167 & 0,357 & 0,101 & 0,159 & 0,159 & 0,039 \\
\hline 21 & 0,493 & 0,563 & 0,129 & $-0,279$ & $-0,624$ & $-0,216$ & 0,170 & 0,316 & 0,101 & 0,159 & 0,159 & 0,039 \\
\hline 22 & 0,470 & 0,781 & 0,146 & $-0,277$ & $-0,771$ & $-0,223$ & 0,169 & 0,428 & 0,103 & 0,159 & 0,159 & 0,039 \\
\hline 23 & 0,461 & 1,068 & 0,135 & $-0,294$ & $-1,000$ & $-0,218$ & 0,170 & 0,600 & 0,100 & 0,159 & 0,159 & 0,039 \\
\hline 24 & 0,436 & 1,395 & 0,144 & $-0,273$ & $-1,267$ & $-0,224$ & 0,167 & 0,827 & 0,106 & 0,159 & 0,159 & 0,039 \\
\hline 25 & $-0,000$ & $-0,000$ & 0,000 & $-0,000$ & $-0,000$ & 0,000 & 0,000 & 0,000 & 0,000 & 0,000 & 0,000 & 0,000 \\
\hline
\end{tabular}


Tabela A.18: Resultados das séries temporais de amplitude modal na linha vertical em $U_{\max }=2,200 \mathrm{~m} / \mathrm{s}$.

\begin{tabular}{|c|c|c|c|c|c|c|c|c|c|c|c|c|}
\hline \multirow[b]{2}{*}{ Modo } & \multirow[b]{2}{*}{$\mathrm{X}(\mathrm{m})$} & \multicolumn{3}{|c|}{ Máximo } & \multicolumn{2}{|l|}{ Mínimo } & \multicolumn{3}{|c|}{ Desvio padrão } & \multicolumn{3}{|c|}{ Freq. máxima em $\mathrm{Hz}$} \\
\hline & & $\mathrm{Y}(\mathrm{m})$ & $\mathrm{Z}(\mathrm{m})$ & $\mathrm{X}(\mathrm{m})$ & $\mathrm{Y}(\mathrm{m})$ & $\mathrm{Z}(\mathrm{m})$ & $\mathrm{X}(\mathrm{m})$ & $\mathrm{Y}(\mathrm{m})$ & $\mathrm{Z}(\mathrm{m})$ & $\mathrm{X}$ & $\mathrm{Y}$ & $\mathrm{Z}$ \\
\hline 1 & 0,599 & 0,038 & 0,028 & $-0,885$ & $-0,032$ & $-0,027$ & 0,185 & 0,014 & 0,008 & 0,108 & 0,159 & 0,039 \\
\hline 2 & 0,104 & 0,436 & 0,000 & $-0,153$ & $-0,371$ & $-0,000$ & 0,032 & 0,156 & 0,000 & 0,108 & 0,159 & 0,039 \\
\hline 3 & 0,404 & 0,045 & 0,012 & $-0,371$ & $-0,039$ & $-0,008$ & 0,113 & 0,018 & 0,003 & 0,159 & 0,159 & 0,052 \\
\hline 4 & 0,059 & 0,619 & 0,000 & $-0,054$ & $-0,537$ & $-0,000$ & 0,016 & 0,251 & 0,000 & 0,159 & 0,159 & 0,052 \\
\hline 5 & 0,498 & 0,117 & 0,014 & $-0,525$ & $-0,115$ & $-0,012$ & 0,129 & 0,075 & 0,004 & 0,280 & 0,159 & 0,039 \\
\hline 6 & 0,068 & 1,714 & 0,000 & $-0,071$ & $-1,684$ & $-0,000$ & 0,017 & 1,102 & 0,000 & 0,280 & 0,159 & 0,039 \\
\hline 7 & 0,534 & 0,064 & 0,018 & $-0,641$ & $-0,065$ & $-0,013$ & 0,123 & 0,037 & 0,004 & 0,280 & 0,159 & 0,052 \\
\hline 8 & 0,070 & 0,965 & 0,000 & $-0,084$ & $-0,981$ & $-0,000$ & 0,016 & 0,568 & 0,000 & 0,280 & 0,159 & 0,052 \\
\hline 9 & 0,523 & 0,032 & 0,017 & $-0,687$ & $-0,029$ & $-0,018$ & 0,128 & 0,013 & 0,004 & 0,280 & 0,159 & 0,052 \\
\hline 10 & 0,067 & 0,489 & 0,000 & $-0,088$ & $-0,453$ & $-0,000$ & 0,016 & 0,204 & 0,000 & 0,280 & 0,159 & 0,052 \\
\hline 11 & 0,575 & 0,029 & 0,016 & $-0,632$ & $-0,027$ & $-0,015$ & 0,113 & 0,014 & 0,004 & 0,276 & 0,159 & 0,052 \\
\hline 12 & 0,073 & 0,462 & 0,000 & $-0,080$ & $-0,427$ & $-0,000$ & 0,014 & 0,218 & 0,000 & 0,276 & 0,159 & 0,052 \\
\hline 13 & 0,517 & 0,018 & 0,017 & $-0,482$ & $-0,016$ & $-0,017$ & 0,101 & 0,007 & 0,004 & 0,280 & 0,159 & 0,052 \\
\hline 14 & 0,065 & 0,293 & 0,000 & $-0,060$ & $-0,251$ & $-0,000$ & 0,013 & 0,112 & 0,000 & 0,280 & 0,159 & 0,052 \\
\hline 15 & 0,410 & 0,019 & 0,013 & $-0,379$ & $-0,018$ & $-0,013$ & 0,079 & 0,008 & 0,003 & 0,280 & 0,159 & 0,052 \\
\hline 16 & 0,051 & 0,300 & 0,000 & $-0,047$ & $-0,296$ & $-0,000$ & 0,010 & 0,136 & 0,000 & 0,280 & 0,159 & 0,052 \\
\hline
\end{tabular}

Tabela A.19: Resultados para os modos transversais da linha vertical em $U_{\max }=2,200 \mathrm{~m} / \mathrm{s}$.

Amplitudes

Modo Máxima(m) Mínima(m) Desvio Padrão(m) Freq. máxima $(\mathrm{Hz})$

\begin{tabular}{lllll}
\hline 2 & 0,434 & $-0,369$ & 0,155 & 0,159 \\
4 & 0,615 & $-0,533$ & 0,249 & 0,159 \\
6 & 1,701 & $-1,672$ & 1,094 & 0,159 \\
8 & 0,958 & $-0,974$ & 0,564 & 0,159 \\
10 & 0,485 & $-0,450$ & 0,202 & 0,159 \\
12 & 0,458 & $-0,424$ & 0,217 & 0,159 \\
14 & 0,291 & $-0,249$ & 0,111 & 0,159 \\
16 & 0,298 & $-0,294$ & 0,135 & 0,159 \\
\hline
\end{tabular}


Tabela A.20: Resultados para os modos longitudinais da linha vertical em

$$
U_{\text {max }}=2,200 \mathrm{~m} / \mathrm{s} \text {. }
$$

\section{Amplitudes}

Modo Máxima(m) Mínima(m) Desvio Padrão(m) Freq. máxima (Hz)

\begin{tabular}{lllll}
\hline 1 & 0,592 & $-0,875$ & 0,183 & 0,108 \\
3 & 0,399 & $-0,366$ & 0,112 & 0,159 \\
5 & 0,491 & $-0,516$ & 0,127 & 0,280 \\
7 & 0,526 & $-0,632$ & 0,121 & 0,280 \\
9 & 0,515 & $-0,676$ & 0,126 & 0,280 \\
11 & 0,566 & $-0,622$ & 0,112 & 0,276 \\
13 & 0,509 & $-0,475$ & 0,099 & 0,280 \\
15 & 0,404 & $-0,373$ & 0,077 & 0,280 \\
\hline
\end{tabular}


Anexo B - Resultados de VIV nas linhas em Catenária-1 
Neste anexo é apresentado um conjunto mais completo de resultados do VIV na linha flexível para a Catenária-1, particularmente aqueles referentes às velocidades reduzidas mais importantes. Vale lembrar que todos os resultados estão apresentados na escala real (1:100) conforme definido em [Rateiro et al., 2012]. Neste sentido, as seções que se seguem dizem respeito a:

- Na seção B.1: Velocidade de $0,819 \mathrm{~m} / \mathrm{s}$ e $V_{r 1}=8,19$

- Na seção B.2: Velocidade de $1,101 \mathrm{~m} / \mathrm{s}$ e $V_{r 1}=11,01$

- Na seção B.3: Velocidade de $1,374 \mathrm{~m} / \mathrm{s}$ e $V_{r 1}=13,74$

- Na seção B.4: Velocidade de $1,936 \mathrm{~m} / \mathrm{s}$ e $V_{r 1}=19,36$

\section{B.1 Catenária-1 - Velocidade de $0,819 \mathrm{~m} / \mathrm{s}$ e $V_{r 1}=$ 8,19}

Abaixo serão apresentados os gráficos com alguns detalhes da análise referentes ao arranjo Catenária-1 para a velocidade de $0,819 \mathrm{~m} / \mathrm{s}$ e $V_{r 1}=8,19$.
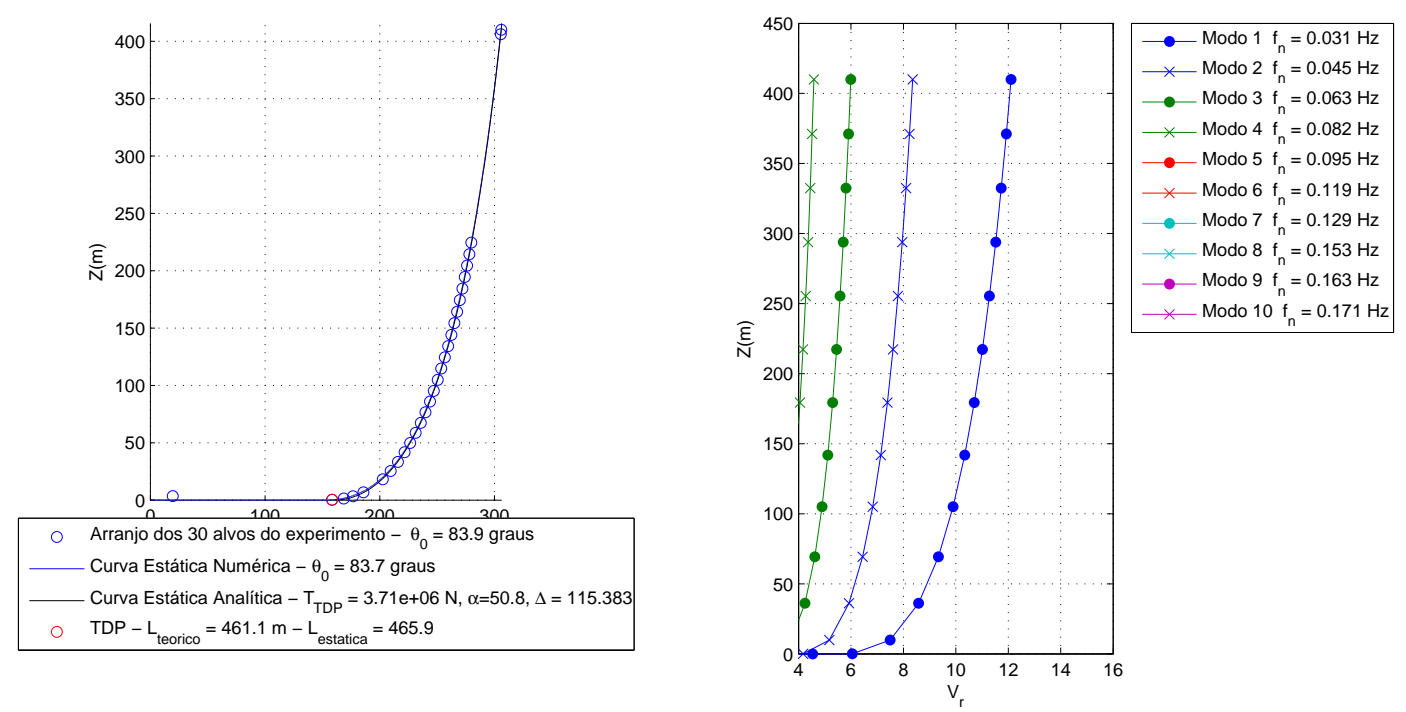

Figura B.1: Variação da velocidade no modelo durante o ensaio para Catenária-1 na

$$
U_{\text {max }}=0,819 \mathrm{~m} / \mathrm{s} \text { e } V_{r 1}=8,190 .
$$

Como pode ser visto na Tabela B.1 e nas Figuras de B.2 a B.4, os maiores deslocamentos máximos apresentados na direção X, Y e Z foram de 0,324, 1,447 e 0,533 
$\mathrm{m}$, respectivamente. Estes valores ocorreram para os alvos 6, 21 e 22. Nestes alvos, as suas frequências de resposta com maior energia foram de 0,0573 e 0,115 Hz.
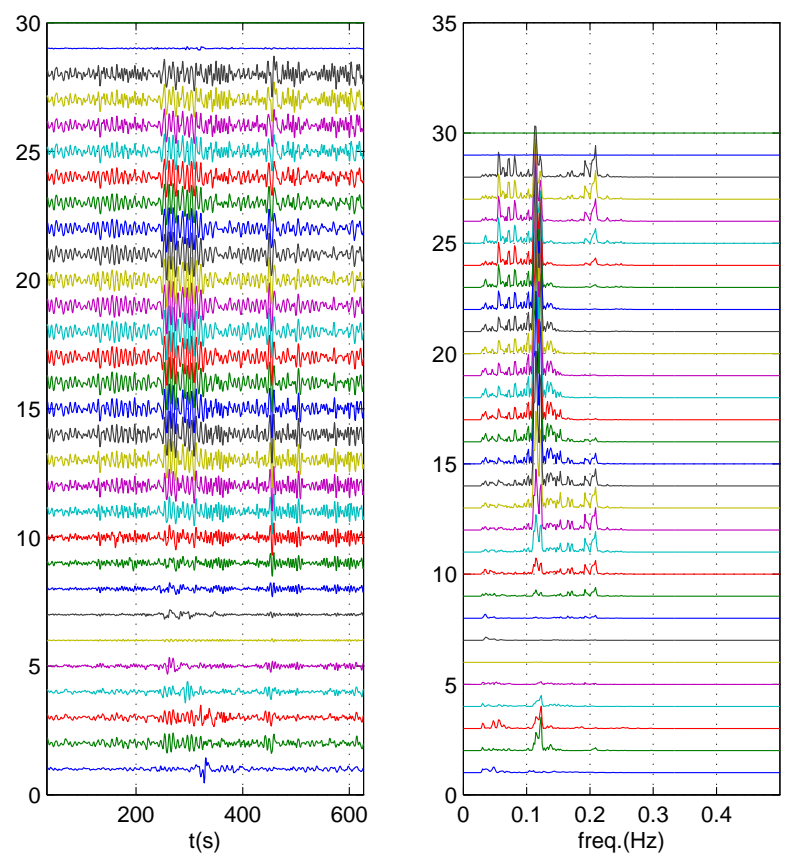

Figura B.2: Série temporal com frequências de resposta para X obtida experimentalmente por alvo para o arranjo de Catenária-1 na $U_{\max }=0,819 \mathrm{~m} / \mathrm{s}$ e $V_{r 1}=8,190$. 

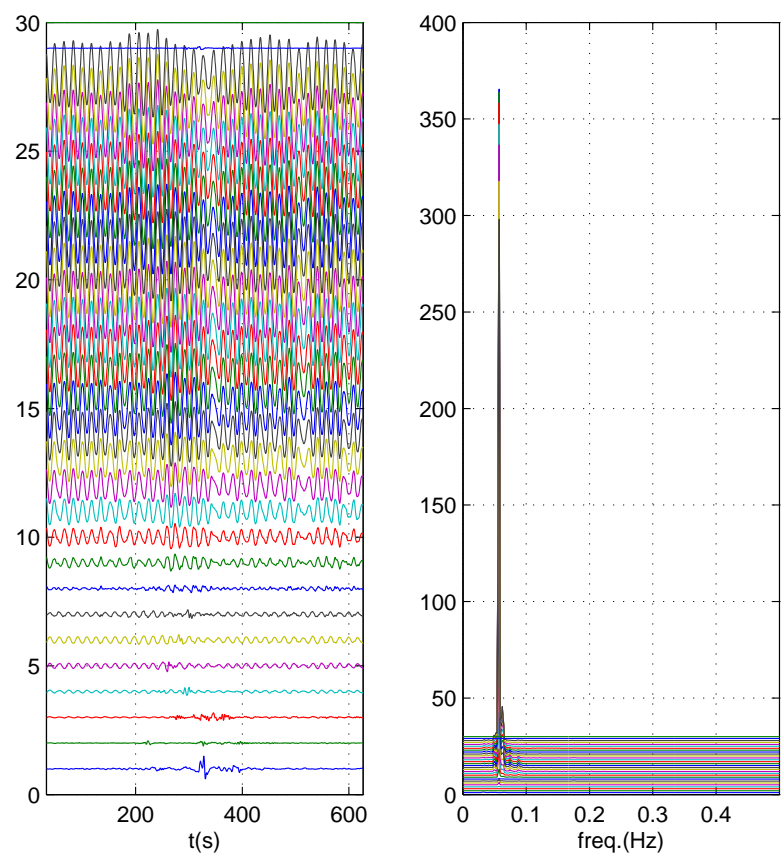

Figura B.3: Série temporal com frequências de resposta para Y obtida experimentalmente por alvo para o arranjo de Catenária-1 na $U_{\max }=0,819 \mathrm{~m} / \mathrm{s}$ e $V_{r 1}=8,190$.
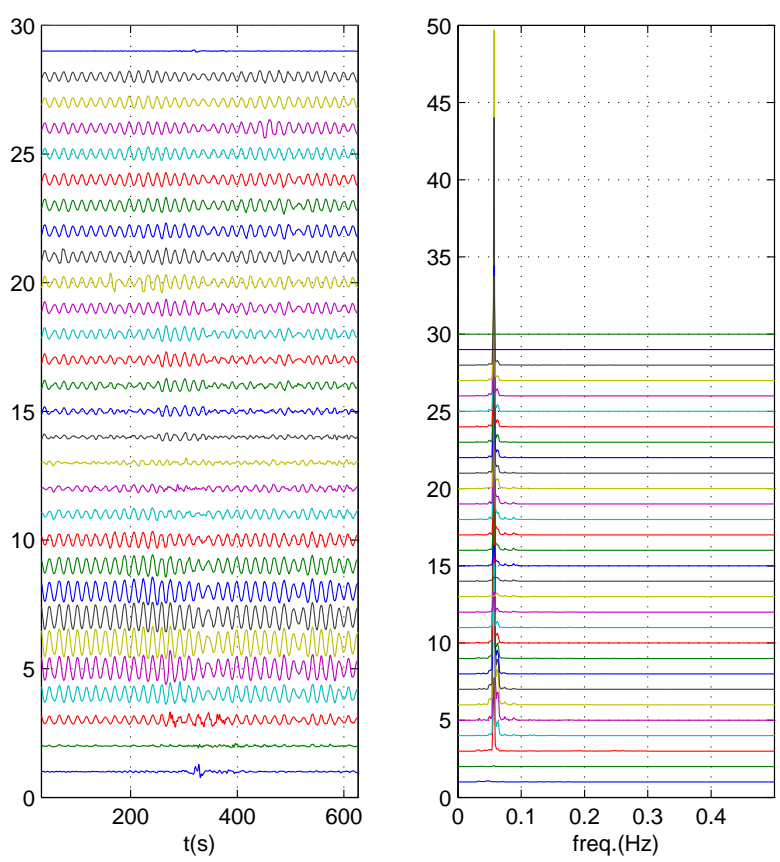

Figura B.4: Série temporal com frequências de resposta para Z obtida experimentalmente por alvo para o arranjo de Catenária-1 na $U_{\max }=0,819 \mathrm{~m} / \mathrm{s}$ e $V_{r 1}=8,190$. 
Tabela B.1: Propriedades da série temporal do ensaio Catenária-1 para a

$$
U_{\max }=0,819 \mathrm{~m} / \mathrm{s} \text {. }
$$

\begin{tabular}{|c|c|c|c|c|c|c|c|c|c|c|c|c|}
\hline \multirow[b]{2}{*}{ ID. Alvo } & \multirow[b]{2}{*}{$\mathrm{X}(\mathrm{m})$} & \multicolumn{2}{|c|}{ Máximo } & \multirow[b]{2}{*}{$\mathrm{X}(\mathrm{m})$} & \multirow{2}{*}{$\begin{array}{l}\text { Mínimo } \\
\mathrm{Y}(\mathrm{m})\end{array}$} & \multirow[b]{2}{*}{$\mathrm{Z}(\mathrm{m})$} & \multicolumn{3}{|c|}{ Desvio padrão } & \multicolumn{3}{|c|}{ Freq. máxima em $\mathrm{Hz}$} \\
\hline & & $\mathrm{Y}(\mathrm{m})$ & $\mathrm{Z}(\mathrm{m})$ & & & & $\mathrm{X}(\mathrm{m})$ & $\mathrm{Y}(\mathrm{m})$ & $\mathrm{Z}(\mathrm{m})$ & $\mathrm{X}$ & $\mathrm{Y}$ & Z \\
\hline 1 & 0,075 & 0,011 & 0,019 & $-0,056$ & $-0,019$ & $-0,020$ & 0,033 & 0,008 & 0,012 & 0,047 & 0,032 & 0,047 \\
\hline 2 & 0,201 & 0,011 & 0,055 & $-0,129$ & $-0,016$ & $-0,035$ & 0,086 & 0,006 & 0,023 & 0,123 & 0,039 & 0,057 \\
\hline 3 & 0,142 & 0,025 & 0,197 & $-0,100$ & $-0,027$ & $-0,142$ & 0,066 & 0,014 & 0,109 & 0,123 & 0,052 & 0,057 \\
\hline 4 & 0,102 & 0,059 & 0,344 & $-0,061$ & $-0,062$ & $-0,303$ & 0,047 & 0,037 & 0,207 & 0,123 & 0,057 & 0,057 \\
\hline 5 & 0,049 & 0,100 & 0,477 & $-0,030$ & $-0,104$ & $-0,445$ & 0,024 & 0,068 & 0,298 & 0,123 & 0,057 & 0,057 \\
\hline 6 & 0,017 & 0,127 & 0,533 & $-0,019$ & $-0,122$ & $-0,522$ & 0,008 & 0,086 & 0,350 & 0,209 & 0,057 & 0,057 \\
\hline 7 & 0,025 & 0,105 & 0,498 & $-0,027$ & $-0,089$ & $-0,469$ & 0,013 & 0,055 & 0,318 & 0,035 & 0,057 & 0,057 \\
\hline 8 & 0,040 & 0,092 & 0,404 & $-0,042$ & $-0,057$ & $-0,378$ & 0,022 & 0,037 & 0,267 & 0,034 & 0,057 & 0,057 \\
\hline 9 & 0,071 & 0,218 & 0,322 & $-0,100$ & $-0,203$ & $-0,303$ & 0,045 & 0,116 & 0,208 & 0,209 & 0,057 & 0,057 \\
\hline 10 & 0,105 & 0,360 & 0,242 & $-0,135$ & $-0,348$ & $-0,250$ & 0,063 & 0,208 & 0,157 & 0,115 & 0,057 & 0,057 \\
\hline 11 & 0,169 & 0,500 & 0,165 & $-0,181$ & $-0,517$ & $-0,194$ & 0,084 & 0,314 & 0,104 & 0,115 & 0,057 & 0,057 \\
\hline 12 & 0,190 & 0,625 & 0,095 & $-0,221$ & $-0,688$ & $-0,137$ & 0,105 & 0,415 & 0,060 & 0,115 & 0,057 & 0,057 \\
\hline 13 & 0,252 & 0,768 & 0,066 & $-0,242$ & $-0,830$ & $-0,117$ & 0,120 & 0,505 & 0,047 & 0,115 & 0,057 & 0,062 \\
\hline 14 & 0,256 & 0,917 & 0,120 & $-0,287$ & $-1,009$ & $-0,078$ & 0,138 & 0,613 & 0,050 & 0,115 & 0,057 & 0,057 \\
\hline 15 & 0,278 & 1,050 & 0,177 & $-0,300$ & $-1,153$ & $-0,122$ & 0,155 & 0,701 & 0,081 & 0,115 & 0,057 & 0,057 \\
\hline 16 & 0,289 & 1,159 & 0,209 & $-0,310$ & $-1,274$ & $-0,147$ & 0,166 & 0,774 & 0,100 & 0,115 & 0,057 & 0,057 \\
\hline 17 & 0,286 & 1,242 & 0,235 & $-0,321$ & $-1,358$ & $-0,164$ & 0,176 & 0,829 & 0,117 & 0,115 & 0,057 & 0,057 \\
\hline 18 & 0,293 & 1,314 & 0,254 & $-0,316$ & $-1,406$ & $-0,192$ & 0,178 & 0,869 & 0,130 & 0,115 & 0,057 & 0,057 \\
\hline 19 & 0,316 & 1,371 & 0,256 & $-0,326$ & $-1,438$ & $-0,194$ & 0,179 & 0,899 & 0,134 & 0,115 & 0,057 & 0,057 \\
\hline 20 & 0,305 & 1,420 & 0,256 & $-0,311$ & $-1,436$ & $-0,204$ & 0,179 & 0,918 & 0,136 & 0,115 & 0,057 & 0,057 \\
\hline 21 & 0,324 & 1,434 & 0,318 & $-0,301$ & $-1,437$ & $-0,244$ & 0,173 & 0,926 & 0,156 & 0,115 & 0,057 & 0,057 \\
\hline 22 & 0,314 & 1,447 & 0,246 & $-0,294$ & $-1,416$ & $-0,216$ & 0,167 & 0,931 & 0,143 & 0,115 & 0,057 & 0,057 \\
\hline 23 & 0,302 & 1,437 & 0,248 & $-0,280$ & $-1,366$ & $-0,211$ & 0,159 & 0,923 & 0,143 & 0,115 & 0,057 & 0,057 \\
\hline 24 & 0,293 & 1,424 & 0,240 & $-0,280$ & $-1,328$ & $-0,204$ & 0,149 & 0,912 & 0,140 & 0,115 & 0,057 & 0,057 \\
\hline 25 & 0,289 & 1,404 & 0,217 & $-0,262$ & $-1,310$ & $-0,200$ & 0,143 & 0,899 & 0,135 & 0,115 & 0,057 & 0,057 \\
\hline 26 & 0,269 & 1,366 & 0,203 & $-0,251$ & $-1,291$ & $-0,198$ & 0,135 & 0,875 & 0,131 & 0,115 & 0,057 & 0,057 \\
\hline 27 & 0,266 & 1,316 & 0,184 & $-0,250$ & $-1,267$ & $-0,190$ & 0,129 & 0,850 & 0,125 & 0,115 & 0,057 & 0,057 \\
\hline 28 & 0,266 & 1,259 & 0,169 & $-0,255$ & $-1,250$ & $-0,182$ & 0,125 & 0,823 & 0,117 & 0,113 & 0,057 & 0,057 \\
\hline 29 & 0,017 & 0,003 & 0,004 & $-0,017$ & $-0,004$ & $-0,004$ & 0,008 & 0,002 & 0,002 & 0,123 & 0,056 & 0,057 \\
\hline 30 & 0,000 & 0,000 & 0,000 & 0,000 & 0,000 & 0,000 & 0,000 & 0,000 & 0,000 & 0,000 & 0,000 & 0,000 \\
\hline
\end{tabular}

Considerando agora a decomposição modal, na Tabela B.2 através da interpolação do sinal do ensaio, correspondente a uma velocade reduzida do primeiro modo $V_{r 1}=8,19$, as maiores amplitudes máximas apresentadas na direção X, Y e Z foram de 0,700, 1,583 e $0,135 \mathrm{~m}$, respectivamente. Estes valores ocorreram para os modos 1, 2 e 10. Nestes modos, as suas frequências de resposta com maior energia foram de 0,0573 e 0,115 Hz. 

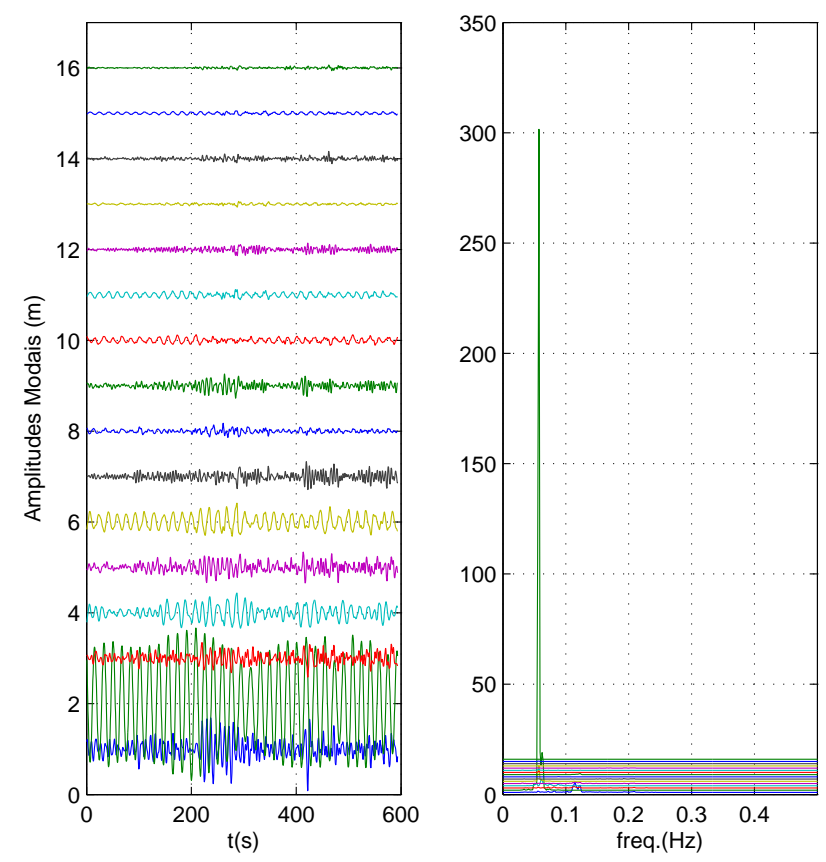

Figura B.5: Variação da amplitude modal acoplada ao longo do tempo através da interpolação do sinal do ensaio para Catenária-1 na $U_{\max }=0,819 \mathrm{~m} / \mathrm{s}$ e $V_{r 1}=8,190$.

Tabela B.2: Propriedades das amplitudes modais do ensaio Catenária-1 através da interpolação do sinal do ensaio para a $V_{\max }=0,819 \mathrm{~m} / \mathrm{s}$.

\begin{tabular}{lccccccccccccc}
\hline \multicolumn{1}{c}{ Máximo } & \multicolumn{1}{c}{ Mínimo } & \multicolumn{3}{c}{ Desvio padrão } & \multicolumn{2}{c}{ Freq. máxima em Hz } \\
\multicolumn{1}{c}{ Modo } & $\mathrm{X}(\mathrm{m})$ & $\mathrm{Y}(\mathrm{m})$ & $\mathrm{Z}(\mathrm{m})$ & $\mathrm{X}(\mathrm{m})$ & $\mathrm{Y}(\mathrm{m})$ & $\mathrm{Z}(\mathrm{m})$ & $\mathrm{X}(\mathrm{m})$ & $\mathrm{Y}(\mathrm{m})$ & $\mathrm{Z}(\mathrm{m})$ & $\mathrm{X}$ & $\mathrm{Y}$ & $\mathrm{Z}$ \\
& & & & & & & & & & & & \\
\hline 1 & 0,700 & 0,000 & 0,000 & $-0,923$ & $-0,000$ & $-0,000$ & 0,209 & 0,000 & 0,000 & 0,115 & 0,057 & 0,057 \\
2 & 0,000 & 1,583 & 0,099 & $-0,000$ & $-1,603$ & $-0,099$ & 0,000 & 0,878 & 0,054 & 0,115 & 0,057 & 0,057 \\
3 & 0,351 & 0,000 & 0,000 & $-0,421$ & $-0,000$ & $-0,000$ & 0,112 & 0,000 & 0,000 & 0,113 & 0,057 & 0,057 \\
4 & 0,000 & 0,398 & 0,079 & $-0,000$ & $-0,340$ & $-0,079$ & 0,000 & 0,140 & 0,032 & 0,115 & 0,061 & 0,057 \\
5 & 0,345 & 0,000 & 0,000 & $-0,347$ & $-0,000$ & $-0,000$ & 0,105 & 0,000 & 0,000 & 0,115 & 0,057 & 0,057 \\
6 & 0,000 & 0,431 & 0,037 & $-0,000$ & $-0,303$ & $-0,035$ & 0,000 & 0,139 & 0,016 & 0,057 & 0,057 & 0,057 \\
7 & 0,336 & 0,000 & 0,000 & $-0,289$ & $-0,000$ & $-0,000$ & 0,084 & 0,000 & 0,000 & 0,192 & 0,057 & 0,057 \\
8 & 0,000 & 0,136 & 0,106 & $-0,000$ & $-0,137$ & $-0,091$ & 0,000 & 0,051 & 0,047 & 0,123 & 0,057 & 0,057 \\
9 & 0,263 & 0,000 & 0,000 & $-0,275$ & $-0,000$ & $-0,000$ & 0,068 & 0,000 & 0,000 & 0,123 & 0,088 & 0,057 \\
10 & 0,000 & 0,058 & 0,135 & $-0,000$ & $-0,082$ & $-0,109$ & 0,000 & 0,015 & 0,054 & 0,123 & 0,057 & 0,057 \\
11 & 0,000 & 0,106 & 0,030 & $-0,000$ & $-0,089$ & $-0,026$ & 0,000 & 0,037 & 0,012 & 0,209 & 0,057 & 0,057 \\
12 & 0,142 & 0,000 & 0,000 & $-0,136$ & $-0,000$ & $-0,000$ & 0,041 & 0,000 & 0,000 & 0,209 & 0,057 & 0,057 \\
13 & 0,000 & 0,074 & 0,032 & $-0,000$ & $-0,093$ & $-0,029$ & 0,000 & 0,028 & 0,016 & 0,121 & 0,057 & 0,057 \\
14 & 0,162 & 0,000 & 0,000 & $-0,112$ & $-0,000$ & $-0,000$ & 0,029 & 0,000 & 0,000 & 0,121 & 0,057 & 0,057 \\
15 & 0,000 & 0,028 & 0,040 & $-0,000$ & $-0,034$ & $-0,040$ & 0,000 & 0,008 & 0,020 & 0,123 & 0,034 & 0,057 \\
16 & 0,064 & 0,000 & 0,000 & $-0,064$ & $-0,000$ & $-0,000$ & 0,015 & 0,000 & 0,000 & 0,123 & 0,034 & 0,057 \\
\hline
\end{tabular}

A Tabela B.3 apresenta para o ensaio Catenária-1 apenas os movimentos referentes a 
deslocamento no plano da catenária através da interpolação do sinal do ensaio, a maior amplitude acoplada máxima foi de 1,666 m. Este valor ocorreu para o modo 2. Neste modo, a sua frequência de resposta com maior energia foi de 0,057 Hz.

Tabela B.3: Propriedades das amplitudes modais acopladas no plano da catenária do ensaio Catenária-1 através da interpolação do sinal do ensaio para a $V_{\max }=0,819 \mathrm{~m} / \mathrm{s}$.

Amplitude

Modo Máxima(m) Mínima(m) Desvio Padrão(m) Freq. máxima (Hz)

\begin{tabular}{lllll}
\hline 2 & 1,666 & $-1,687$ & 0,928 & 0,057 \\
4 & 0,437 & $-0,337$ & 0,144 & 0,061 \\
6 & 0,418 & $-0,314$ & 0,149 & 0,057 \\
8 & 0,175 & $-0,138$ & 0,039 & 0,088 \\
10 & 0,126 & $-0,110$ & 0,048 & 0,057 \\
11 & 0,118 & $-0,105$ & 0,046 & 0,057 \\
13 & 0,061 & $-0,067$ & 0,016 & 0,057 \\
15 & 0,053 & $-0,054$ & 0,022 & 0,057 \\
\hline
\end{tabular}

A Tabela B.4 para o ensaio Catenária-1 com apenas as amplitudes correspondentes a movimentos fora do plano através da interpolação do sinal do ensaio, a maior amplitude acoplada máxima apresentada foi de 0,693 m. Este valor ocorreu para o modo 1 . Neste modo, a sua frequência de resposta com maior energia foi de 0,115 Hz.

Tabela B.4: Propriedades das amplitudes modais acopladas fora do plano da catenária do ensaio Catenária-1 através da interpolação do sinal do ensaio para a

$$
V_{\max }=0,819 \mathrm{~m} / \mathrm{s} \text {. }
$$

\begin{tabular}{lllll}
\hline \multicolumn{5}{c}{ Amplitude } \\
Modo & Máxima(m) & Mínima(m) & Desvio Padrão(m) & Freq. máxima $(\mathrm{Hz})$ \\
\hline 1 & 0,693 & $-0,914$ & 0,207 & 0,115 \\
3 & 0,346 & $-0,416$ & 0,110 & 0,113 \\
5 & 0,341 & $-0,342$ & 0,103 & 0,115 \\
7 & 0,331 & $-0,286$ & 0,083 & 0,192 \\
9 & 0,260 & $-0,272$ & 0,067 & 0,123 \\
12 & 0,141 & $-0,134$ & 0,040 & 0,209 \\
14 & 0,160 & $-0,111$ & 0,029 & 0,121 \\
16 & 0,063 & $-0,063$ & 0,015 & 0,123 \\
\hline
\end{tabular}




\section{B.2 Catenária-1 - Velocidade de $1,1 \mathrm{~m} / \mathrm{s} \quad \mathrm{e}$ $V_{r 1}=11,01$}

Abaixo serão apresentados os gráficos com alguns detalhes da análise referentes ao arranjo Catenária-1 para a velocidade de $1,1 \mathrm{~m} / \mathrm{s}$ e $V_{r 1}=11,01$.
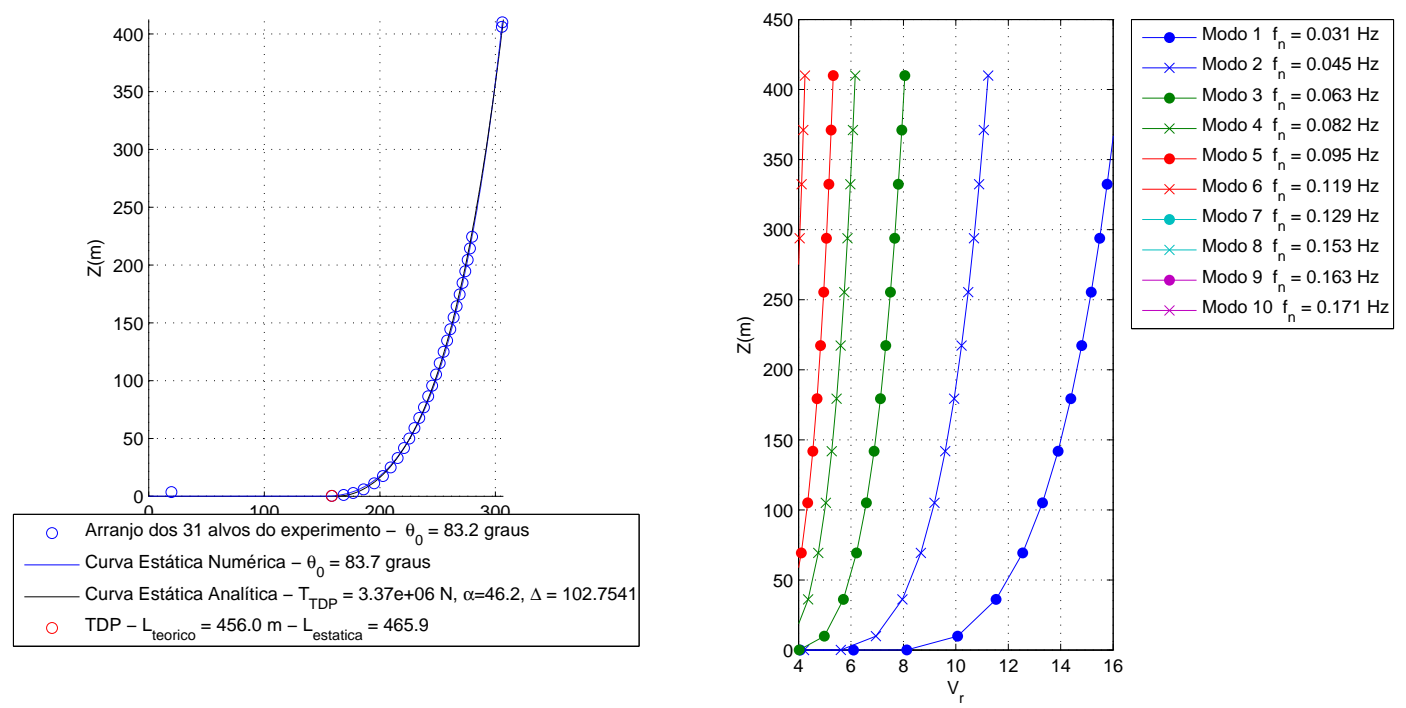

Figura B.6: Variação da velocidade no modelo durante o ensaio para Catenária-1 na $U_{\text {max }}=1,1 \mathrm{~m} / \mathrm{s}$ e $V_{r 1}=11,010$.

Como pode ser visto na Tabela B.5 e nas Figuras de B.7 a B.9, os maiores deslocamentos máximos apresentados na direção X, Y e Z foram de 0,519, 1,445 e 0,518 $\mathrm{m}$, respectivamente. Estes valores ocorreram para os alvos 16 e 29. Nestes alvos, as suas frequências de resposta com maior energia foi de 0,0823 Hz. 

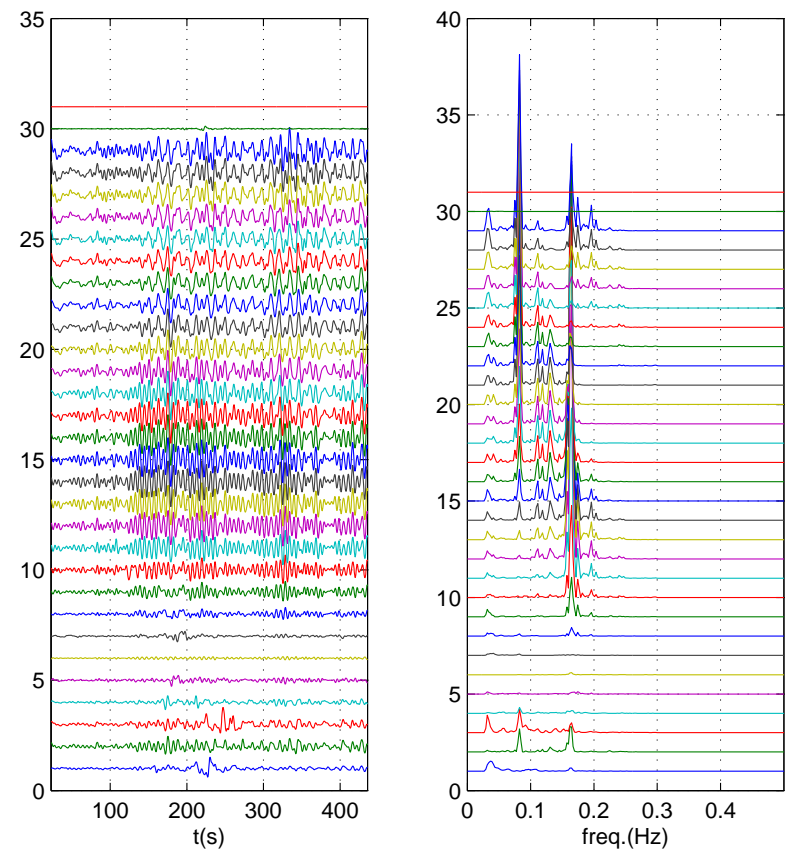

Figura B.7: Série temporal com frequências de resposta para X obtida experimentalmente por alvo para o arranjo de Catenária-1 na $U_{\max }=1,1 \mathrm{~m} / \mathrm{s}$ e $V_{r 1}=11,010$.
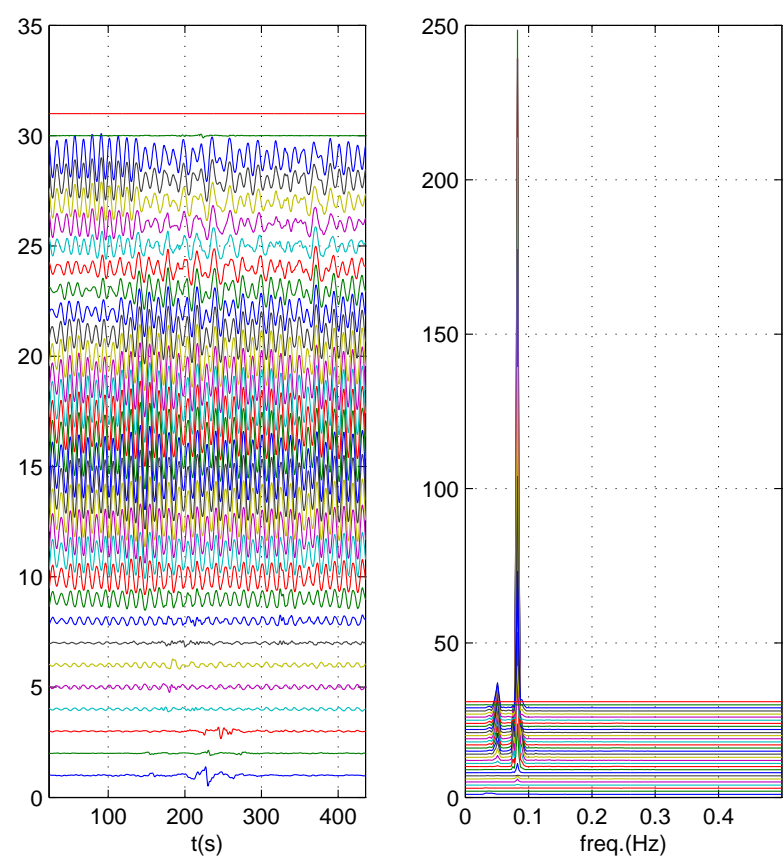

Figura B.8: Série temporal com frequências de resposta para Y obtida experimentalmente por alvo para o arranjo de Catenária-1 na $U_{\max }=1,1 \mathrm{~m} / \mathrm{s}$ e $V_{r 1}=11,010$. 

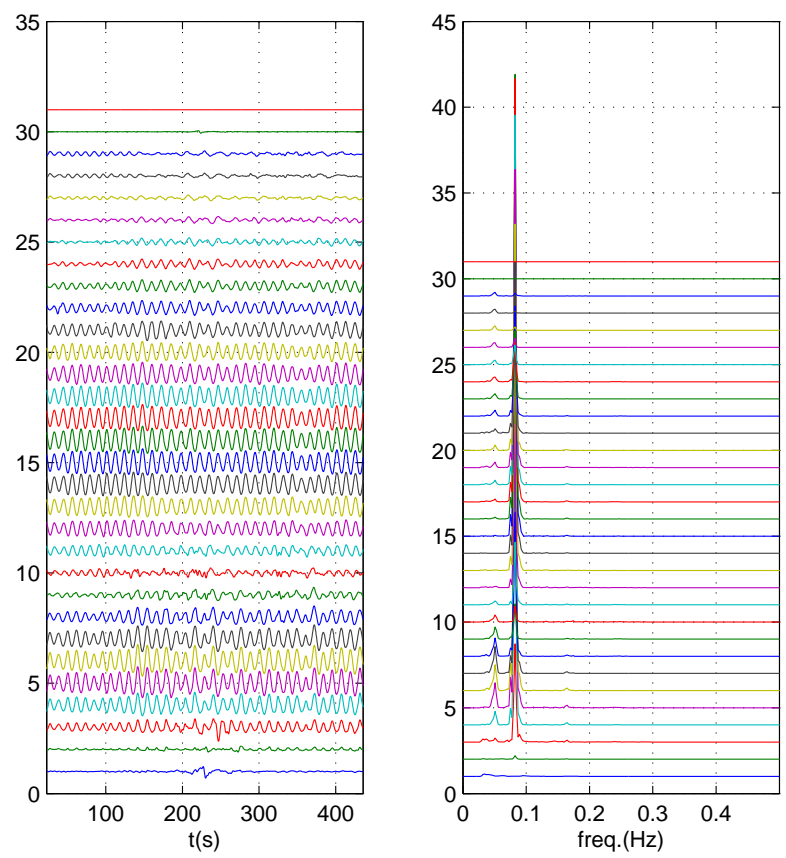

Figura B.9: Série temporal com frequências de resposta para Z obtida experimentalmente por alvo para o arranjo de Catenária- 1 na $U_{\max }=1,1 \mathrm{~m} / \mathrm{s}$ e $V_{r 1}=11,010$. 
Tabela B.5: Propriedades da série temporal do ensaio Catenária-1 para a

$$
U_{\max }=1,1 \mathrm{~m} / \mathrm{s} \text {. }
$$

\begin{tabular}{|c|c|c|c|c|c|c|c|c|c|c|c|c|}
\hline \multirow[b]{2}{*}{ ID. Alvo } & \multirow[b]{2}{*}{$\mathrm{X}(\mathrm{m})$} & \multicolumn{3}{|c|}{ Máximo } & \multicolumn{2}{|l|}{ Mínimo } & \multicolumn{3}{|c|}{ Desvio padrão } & \multicolumn{3}{|c|}{ Freq. máxima em $\mathrm{Hz}$} \\
\hline & & $\mathrm{Y}(\mathrm{m})$ & $\mathrm{Z}(\mathrm{m})$ & $\mathrm{X}(\mathrm{m})$ & $\mathrm{Y}(\mathrm{m})$ & $\mathrm{Z}(\mathrm{m})$ & $\mathrm{X}(\mathrm{m})$ & $\mathrm{Y}(\mathrm{m})$ & $\mathrm{Z}(\mathrm{m})$ & $\mathrm{X}$ & $\mathrm{Y}$ & $\mathrm{Z}$ \\
\hline 1 & 0,045 & 0,030 & 0,020 & $-0,047$ & $-0,031$ & $-0,025$ & 0,024 & 0,013 & 0,011 & 0,036 & 0,034 & 0,034 \\
\hline 2 & 0,165 & 0,013 & 0,062 & $-0,094$ & $-0,012$ & $-0,034$ & 0,054 & 0,007 & 0,025 & 0,162 & 0,039 & 0,082 \\
\hline 3 & 0,126 & 0,024 & 0,207 & $-0,069$ & $-0,030$ & $-0,169$ & 0,044 & 0,016 & 0,113 & 0,082 & 0,031 & 0,082 \\
\hline 4 & 0,062 & 0,050 & 0,378 & $-0,038$ & $-0,064$ & $-0,300$ & 0,024 & 0,035 & 0,206 & 0,082 & 0,082 & 0,082 \\
\hline 5 & 0,075 & 0,076 & 0,494 & $-0,059$ & $-0,090$ & $-0,408$ & 0,027 & 0,053 & 0,277 & 0,174 & 0,082 & 0,082 \\
\hline 6 & 0,019 & 0,080 & 0,501 & $-0,027$ & $-0,083$ & $-0,411$ & 0,011 & 0,051 & 0,280 & 0,165 & 0,082 & 0,082 \\
\hline 7 & 0,040 & 0,040 & 0,409 & $-0,055$ & $-0,046$ & $-0,326$ & 0,027 & 0,024 & 0,226 & 0,041 & 0,082 & 0,082 \\
\hline 8 & 0,049 & 0,175 & 0,256 & $-0,046$ & $-0,177$ & $-0,214$ & 0,025 & 0,104 & 0,144 & 0,165 & 0,082 & 0,082 \\
\hline 9 & 0,082 & 0,384 & 0,114 & $-0,086$ & $-0,361$ & $-0,119$ & 0,044 & 0,229 & 0,063 & 0,165 & 0,082 & 0,082 \\
\hline 10 & 0,097 & 0,607 & 0,140 & $-0,133$ & $-0,571$ & $-0,130$ & 0,064 & 0,366 & 0,075 & 0,165 & 0,082 & 0,082 \\
\hline 11 & 0,134 & 0,818 & 0,245 & $-0,165$ & $-0,790$ & $-0,221$ & 0,077 & 0,495 & 0,139 & 0,165 & 0,082 & 0,082 \\
\hline 12 & 0,159 & 1,047 & 0,346 & $-0,207$ & $-1,003$ & $-0,324$ & 0,092 & 0,630 & 0,207 & 0,165 & 0,082 & 0,082 \\
\hline 13 & 0,196 & 1,218 & 0,436 & $-0,268$ & $-1,174$ & $-0,400$ & 0,113 & 0,735 & 0,258 & 0,165 & 0,082 & 0,082 \\
\hline 14 & 0,193 & 1,361 & 0,486 & $-0,258$ & $-1,301$ & $-0,459$ & 0,108 & 0,809 & 0,287 & 0,165 & 0,082 & 0,082 \\
\hline 15 & 0,207 & 1,439 & 0,513 & $-0,266$ & $-1,387$ & $-0,492$ & 0,107 & 0,856 & 0,307 & 0,165 & 0,082 & 0,082 \\
\hline 16 & 0,203 & 1,445 & 0,518 & $-0,267$ & $-1,402$ & $-0,497$ & 0,105 & 0,863 & 0,311 & 0,165 & 0,082 & 0,082 \\
\hline 17 & 0,184 & 1,382 & 0,492 & $-0,250$ & $-1,340$ & $-0,469$ & 0,099 & 0,827 & 0,297 & 0,165 & 0,082 & 0,082 \\
\hline 18 & 0,164 & 1,253 & 0,457 & $-0,230$ & $-1,211$ & $-0,439$ & 0,096 & 0,757 & 0,274 & 0,165 & 0,082 & 0,082 \\
\hline 19 & 0,156 & 1,144 & 0,410 & $-0,224$ & $-1,065$ & $-0,451$ & 0,100 & 0,666 & 0,247 & 0,162 & 0,082 & 0,082 \\
\hline 20 & 0,174 & 0,927 & 0,404 & $-0,238$ & $-0,959$ & $-0,364$ & 0,105 & 0,572 & 0,241 & 0,082 & 0,082 & 0,082 \\
\hline 21 & 0,171 & 0,698 & 0,289 & $-0,235$ & $-0,771$ & $-0,258$ & 0,105 & 0,428 & 0,174 & 0,082 & 0,082 & 0,082 \\
\hline 22 & 0,247 & 0,492 & 0,246 & $-0,253$ & $-0,581$ & $-0,256$ & 0,114 & 0,296 & 0,134 & 0,082 & 0,082 & 0,082 \\
\hline 23 & 0,295 & 0,361 & 0,167 & $-0,234$ & $-0,428$ & $-0,145$ & 0,116 & 0,201 & 0,092 & 0,082 & 0,082 & 0,082 \\
\hline 24 & 0,346 & 0,296 & 0,109 & $-0,248$ & $-0,315$ & $-0,095$ & 0,128 & 0,192 & 0,053 & 0,082 & 0,082 & 0,082 \\
\hline 25 & 0,399 & 0,444 & 0,075 & $-0,257$ & $-0,459$ & $-0,083$ & 0,138 & 0,266 & 0,035 & 0,082 & 0,051 & 0,082 \\
\hline 26 & 0,441 & 0,639 & 0,067 & $-0,301$ & $-0,625$ & $-0,059$ & 0,150 & 0,372 & 0,031 & 0,082 & 0,051 & 0,082 \\
\hline 27 & 0,472 & 0,789 & 0,084 & $-0,342$ & $-0,742$ & $-0,076$ & 0,159 & 0,467 & 0,042 & 0,082 & 0,082 & 0,051 \\
\hline 28 & 0,512 & 0,909 & 0,103 & $-0,380$ & $-0,833$ & $-0,091$ & 0,175 & 0,547 & 0,055 & 0,082 & 0,082 & 0,051 \\
\hline 29 & 0,519 & 1,015 & 0,108 & $-0,386$ & $-0,934$ & $-0,105$ & 0,176 & 0,615 & 0,065 & 0,082 & 0,082 & 0,051 \\
\hline 30 & 0,012 & 0,006 & 0,004 & $-0,010$ & $-0,005$ & $-0,004$ & 0,005 & 0,003 & 0,002 & 0,162 & 0,031 & 0,046 \\
\hline 31 & 0,000 & 0,000 & 0,000 & 0,000 & 0,000 & 0,000 & 0,000 & 0,000 & 0,000 & 0,000 & 0,000 & 0,000 \\
\hline
\end{tabular}

Considerando agora a decomposição modal, na Tabela B.6 através da interpolação do sinal do ensaio, correspondente a uma velocade reduzida do primeiro modo $V_{r 1}=11.01$, as maiores amplitudes máximas apresentadas na direção X, Y e Z foram de 0,853, 1,363 e 0,177 m, respectivamente. Estes valores ocorreram para os modos 1 e 4 . Nestes modos, as suas frequências de resposta com maior energia foram de 0,0823 e 0,165 Hz. 

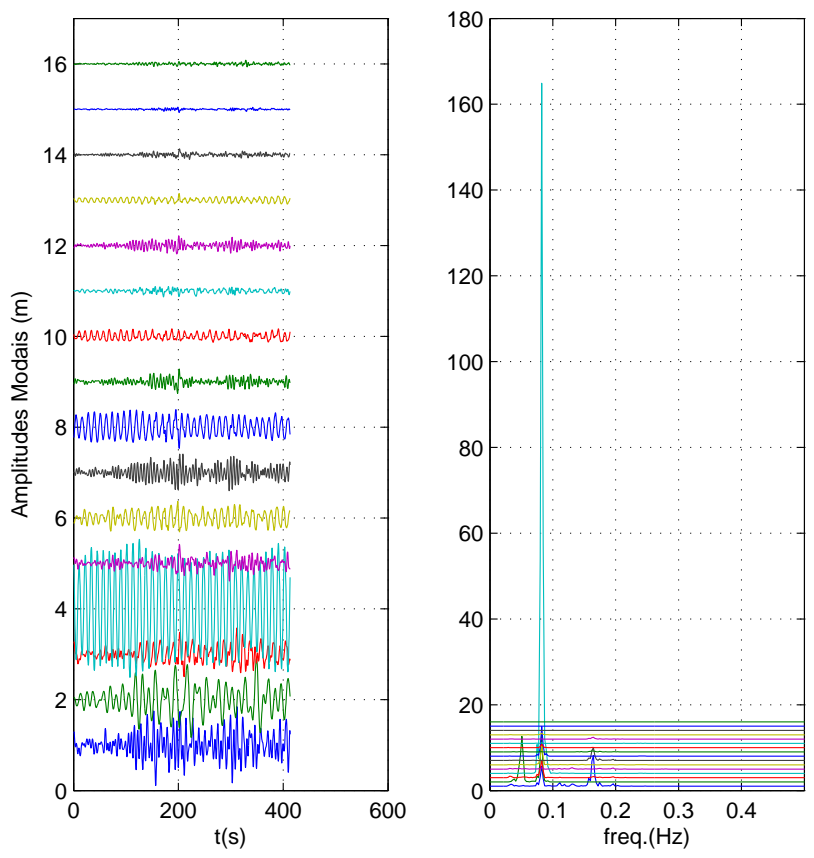

Figura B.10: Variação da amplitude modal acoplada ao longo do tempo através da interpolação do sinal do ensaio para Catenária-1 na $U_{\max }=1,1 \mathrm{~m} / \mathrm{s}$ e $V_{r 1}=11,010$.

Tabela B.6: Propriedades das amplitudes modais do ensaio Catenária-1 através da interpolação do sinal do ensaio para a $V_{\max }=1,1 \mathrm{~m} / \mathrm{s}$.

\begin{tabular}{lccccccccccccc}
\hline \multicolumn{1}{c}{ Máximo } & \multicolumn{1}{c}{ Mínimo } & \multicolumn{3}{c}{ Desvio padrão } & \multicolumn{2}{c}{ Freq. máxima em Hz } \\
\multicolumn{1}{c}{ Modo } & $\mathrm{X}(\mathrm{m})$ & $\mathrm{Y}(\mathrm{m})$ & $\mathrm{Z}(\mathrm{m})$ & $\mathrm{X}(\mathrm{m})$ & $\mathrm{Y}(\mathrm{m})$ & $\mathrm{Z}(\mathrm{m})$ & $\mathrm{X}(\mathrm{m})$ & $\mathrm{Y}(\mathrm{m})$ & $\mathrm{Z}(\mathrm{m})$ & $\mathrm{X}$ & $\mathrm{Y}$ & $\mathrm{Z}$ \\
& & & & & & & & & & & & \\
\hline 1 & 0,853 & 0,000 & 0,000 & $-0,897$ & $-0,000$ & $-0,000$ & 0,277 & 0,000 & 0,000 & 0,165 & 0,051 & 0,082 \\
2 & 0,000 & 0,833 & 0,090 & $-0,000$ & $-0,748$ & $-0,089$ & 0,000 & 0,275 & 0,043 & 0,165 & 0,051 & 0,082 \\
3 & 0,588 & 0,000 & 0,000 & $-0,497$ & $-0,000$ & $-0,000$ & 0,165 & 0,000 & 0,000 & 0,082 & 0,051 & 0,082 \\
4 & 0,000 & 1,363 & 0,177 & $-0,000$ & $-1,364$ & $-0,175$ & 0,000 & 0,770 & 0,097 & 0,082 & 0,082 & 0,082 \\
5 & 0,428 & 0,000 & 0,000 & $-0,392$ & $-0,000$ & $-0,000$ & 0,101 & 0,000 & 0,000 & 0,131 & 0,082 & 0,082 \\
6 & 0,000 & 0,426 & 0,097 & $-0,000$ & $-0,308$ & $-0,094$ & 0,000 & 0,154 & 0,054 & 0,165 & 0,082 & 0,082 \\
7 & 0,413 & 0,000 & 0,000 & $-0,406$ & $-0,000$ & $-0,000$ & 0,138 & 0,000 & 0,000 & 0,165 & 0,082 & 0,082 \\
8 & 0,000 & 0,395 & 0,070 & $-0,000$ & $-0,458$ & $-0,093$ & 0,000 & 0,204 & 0,029 & 0,162 & 0,082 & 0,082 \\
9 & 0,284 & 0,000 & 0,000 & $-0,262$ & $-0,000$ & $-0,000$ & 0,067 & 0,000 & 0,000 & 0,162 & 0,082 & 0,082 \\
10 & 0,000 & 0,160 & 0,128 & $-0,000$ & $-0,107$ & $-0,132$ & 0,000 & 0,038 & 0,048 & 0,162 & 0,082 & 0,082 \\
11 & 0,000 & 0,108 & 0,047 & $-0,000$ & $-0,145$ & $-0,040$ & 0,000 & 0,042 & 0,021 & 0,165 & 0,082 & 0,082 \\
12 & 0,216 & 0,000 & 0,000 & $-0,186$ & $-0,000$ & $-0,000$ & 0,061 & 0,000 & 0,000 & 0,165 & 0,082 & 0,082 \\
13 & 0,000 & 0,133 & 0,047 & $-0,000$ & $-0,072$ & $-0,037$ & 0,000 & 0,028 & 0,022 & 0,240 & 0,082 & 0,082 \\
14 & 0,131 & 0,000 & 0,000 & $-0,104$ & $-0,000$ & $-0,000$ & 0,029 & 0,000 & 0,000 & 0,240 & 0,082 & 0,082 \\
15 & 0,000 & 0,056 & 0,048 & $-0,000$ & $-0,093$ & $-0,041$ & 0,000 & 0,023 & 0,022 & 0,165 & 0,082 & 0,082 \\
16 & 0,081 & 0,000 & 0,000 & $-0,066$ & $-0,000$ & $-0,000$ & 0,020 & 0,000 & 0,000 & 0,165 & 0,082 & 0,082 \\
\hline
\end{tabular}

A Tabela B.7 apresenta para o ensaio Catenária-1 apenas os movimentos referentes a 
deslocamento no plano da catenária através da interpolação do sinal do ensaio, a maior amplitude acoplada máxima foi de 1,531 m. Este valor ocorreu para o modo 4. Neste modo, a sua frequência de resposta com maior energia foi de 0,082 Hz.

Tabela B.7: Propriedades das amplitudes modais acopladas no plano da catenária do ensaio Catenária-1 através da interpolação do sinal do ensaio para a $V_{\max }=1,1 \mathrm{~m} / \mathrm{s}$.

\begin{tabular}{lllll}
\hline \multicolumn{5}{c}{ Amplitude } \\
Modo & Máxima(m) & Mínima(m) & Desvio Padrão(m) & Freq. máxima $(\mathrm{Hz})$ \\
& & & & \\
\hline 2 & 0,910 & $-0,832$ & 0,306 & 0,082 \\
4 & 1,531 & $-1,508$ & 0,860 & 0,082 \\
6 & 0,368 & $-0,305$ & 0,144 & 0,082 \\
8 & 0,386 & $-0,464$ & 0,189 & 0,082 \\
10 & 0,168 & $-0,132$ & 0,072 & 0,082 \\
11 & 0,097 & $-0,132$ & 0,038 & 0,082 \\
13 & 0,144 & $-0,094$ & 0,046 & 0,082 \\
15 & 0,047 & $-0,071$ & 0,013 & 0,240 \\
\hline
\end{tabular}

A Tabela B.8 para o ensaio Catenária-1 com apenas as amplitudes correspondentes a movimentos fora do plano através da interpolação do sinal do ensaio, a maior amplitude acoplada máxima apresentada foi de 0,845 m. Este valor ocorreu para o modo 1. Neste modo, a sua frequência de resposta com maior energia foi de 0,165 Hz.

Tabela B.8: Propriedades das amplitudes modais acopladas fora do plano da catenária do ensaio Catenária-1 através da interpolação do sinal do ensaio para a $V_{\max }=1,1 \mathrm{~m} / \mathrm{s}$.

\section{Amplitude}

Modo Máxima(m) Mínima(m) Desvio Padrão(m) Freq. máxima (Hz)

\begin{tabular}{lllll}
\hline 1 & 0,845 & $-0,889$ & 0,275 & 0,165 \\
3 & 0,580 & $-0,491$ & 0,163 & 0,082 \\
5 & 0,423 & $-0,387$ & 0,100 & 0,131 \\
7 & 0,408 & $-0,401$ & 0,136 & 0,165 \\
9 & 0,280 & $-0,259$ & 0,067 & 0,162 \\
12 & 0,214 & $-0,184$ & 0,060 & 0,165 \\
14 & 0,130 & $-0,103$ & 0,029 & 0,240 \\
16 & 0,080 & $-0,066$ & 0,019 & 0,165 \\
\hline
\end{tabular}


B.3 Catenária-1 - Velocidade de $1,37 \mathrm{~m} / \mathrm{s}$ e $V_{r 1}=$ 13,74 
Abaixo serão apresentados os gráficos com alguns detalhes da análise referentes ao arranjo Catenária-1 para a velocidade de $1,37 \mathrm{~m} / \mathrm{s}$ e $V_{r 1}=13,74$.
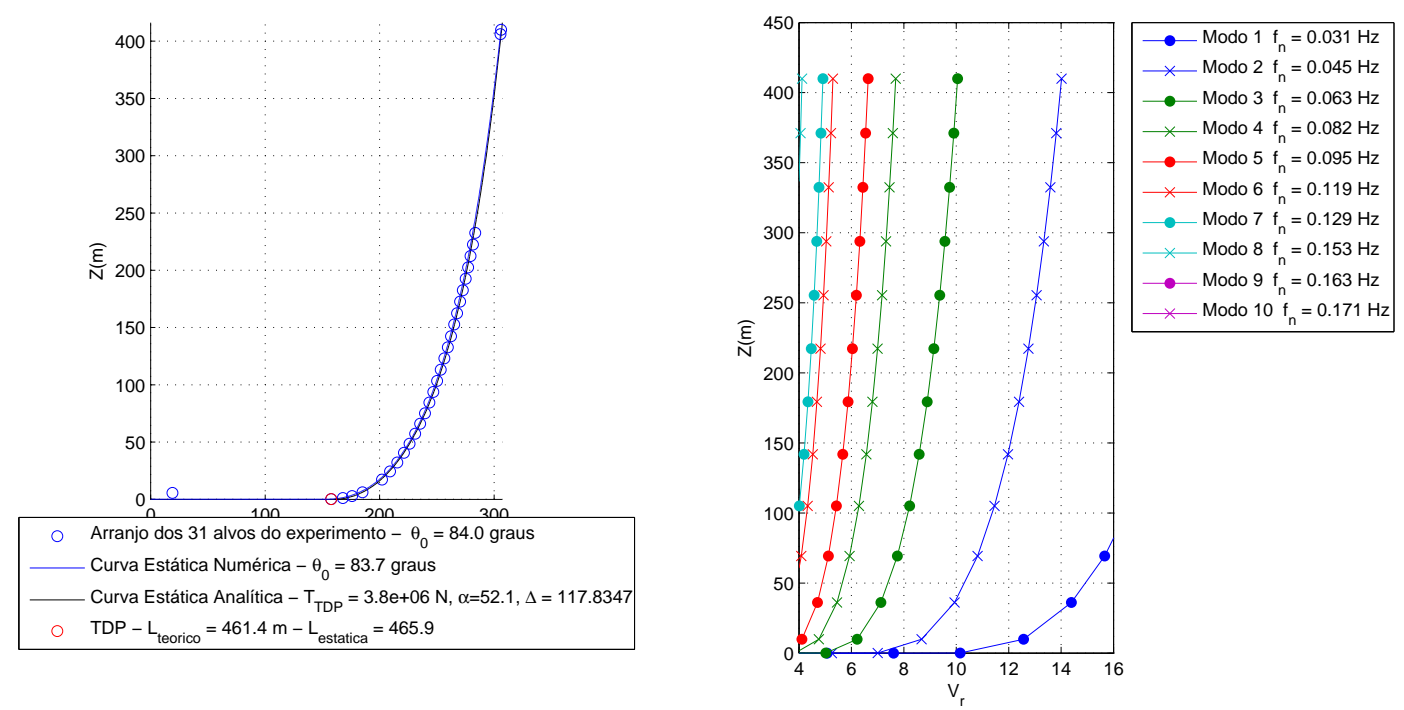

Figura B.11: Variação da velocidade no modelo durante o ensaio para Catenária-1 na $U_{\text {max }}=1,37 \mathrm{~m} / \mathrm{s}$ e $V_{r 1}=13,739$.

Como pode ser visto na Tabela B.9 e nas Figuras de B.12 a B.14, os maiores deslocamentos máximos apresentados na direção X, Y e Z foram de 0,399, 1,610 e 0,842 $\mathrm{m}$, respectivamente. Estes valores ocorreram para os alvos 11 e 14. Nestes alvos, as suas frequências de resposta com maior energia foram de 0,0986 e 0,207 Hz. 

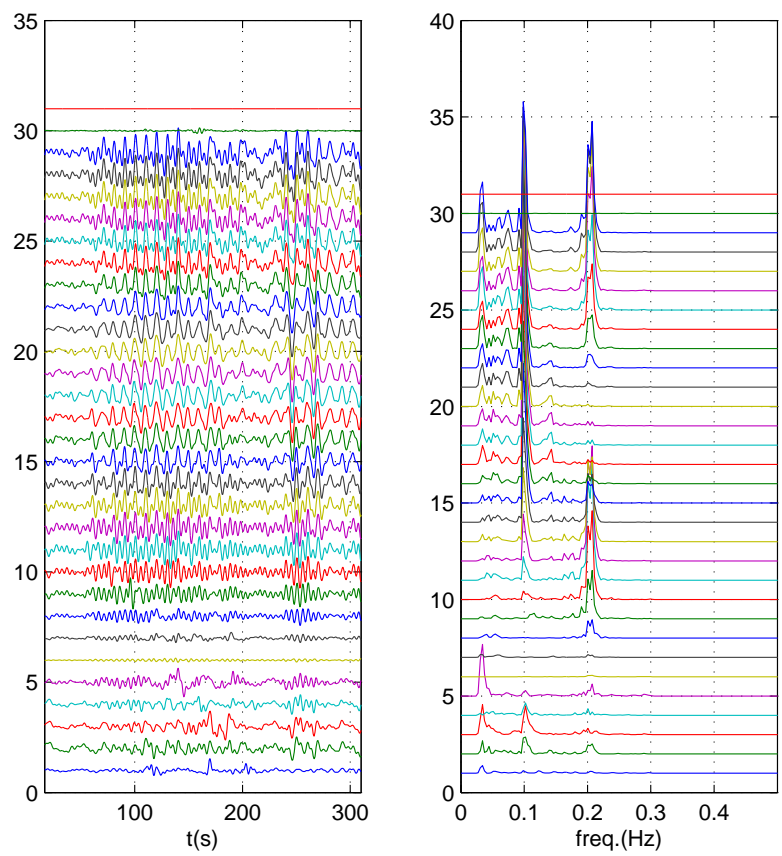

Figura B.12: Série temporal com frequências de resposta para X obtida experimentalmente por alvo para o arranjo de Catenária-1 na $U_{\max }=1,37 \mathrm{~m} / \mathrm{s}$ e $V_{r 1}=13,739$.
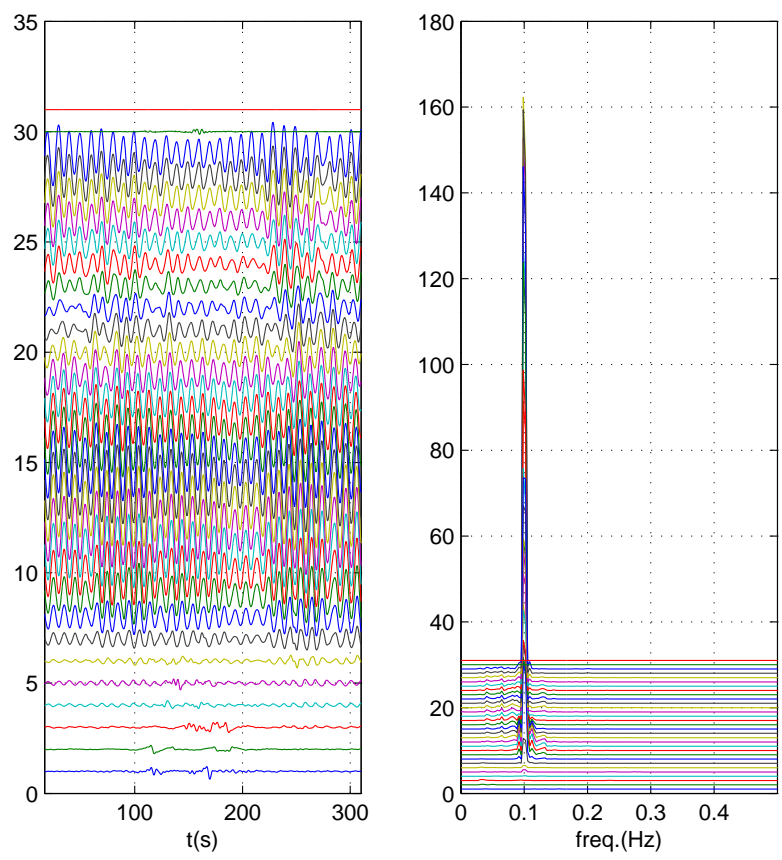

Figura B.13: Série temporal com frequências de resposta para Y obtida experimentalmente por alvo para o arranjo de Catenária- 1 na $U_{\max }=1,37 \mathrm{~m} / \mathrm{s}$ e $V_{r 1}=13,739$. 

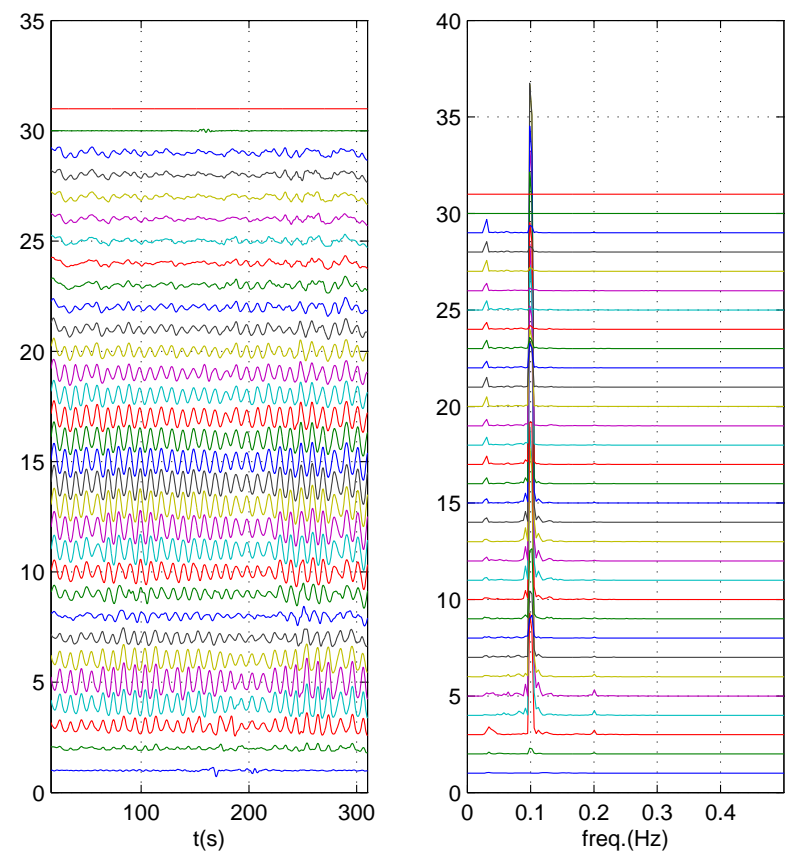

Figura B.14: Série temporal com frequências de resposta para Z obtida experimentalmente por alvo para o arranjo de Catenária-1 na $U_{\max }=1,37 \mathrm{~m} / \mathrm{s}$ e $V_{r 1}=13,739$. 
Tabela B.9: Propriedades da série temporal do ensaio Catenária-1 para a

$$
U_{\max }=1,37 \mathrm{~m} / \mathrm{s} \text {. }
$$

\begin{tabular}{|c|c|c|c|c|c|c|c|c|c|c|c|c|}
\hline \multirow[b]{2}{*}{ ID. Alvo } & \multirow[b]{2}{*}{$\mathrm{X}(\mathrm{m})$} & \multicolumn{2}{|l|}{ Máximo } & \multicolumn{3}{|c|}{ Mínimo } & \multicolumn{3}{|c|}{ Desvio padrão } & \multicolumn{3}{|c|}{ Freq. máxima em $\mathrm{Hz}$} \\
\hline & & $\mathrm{Y}(\mathrm{m})$ & $\mathrm{Z}(\mathrm{m})$ & $\mathrm{X}(\mathrm{m})$ & $\mathrm{Y}(\mathrm{m})$ & $\mathrm{Z}(\mathrm{m})$ & $\mathrm{X}(\mathrm{m})$ & $\mathrm{Y}(\mathrm{m})$ & $\mathrm{Z}(\mathrm{m})$ & $\mathrm{X}$ & $\mathrm{Y}$ & $\mathrm{Z}$ \\
\hline 1 & 0,074 & 0,021 & 0,020 & $-0,065$ & $-0,017$ & $-0,018$ & 0,036 & 0,009 & 0,009 & 0,034 & 0,041 & 0,034 \\
\hline 2 & 0,274 & 0,021 & 0,099 & $-0,170$ & $-0,024$ & $-0,086$ & 0,129 & 0,010 & 0,057 & 0,102 & 0,034 & 0,099 \\
\hline 3 & 0,228 & 0,041 & 0,299 & $-0,117$ & $-0,039$ & $-0,243$ & 0,087 & 0,022 & 0,165 & 0,034 & 0,034 & 0,099 \\
\hline 4 & 0,228 & 0,070 & 0,480 & $-0,121$ & $-0,065$ & $-0,425$ & 0,081 & 0,040 & 0,277 & 0,102 & 0,102 & 0,099 \\
\hline 5 & 0,144 & 0,115 & 0,613 & $-0,121$ & $-0,102$ & $-0,568$ & 0,054 & 0,064 & 0,364 & 0,034 & 0,099 & 0,099 \\
\hline 6 & 0,018 & 0,076 & 0,439 & $-0,020$ & $-0,067$ & $-0,439$ & 0,009 & 0,043 & 0,258 & 0,207 & 0,099 & 0,099 \\
\hline 7 & 0,073 & 0,287 & 0,246 & $-0,074$ & $-0,281$ & $-0,264$ & 0,034 & 0,183 & 0,140 & 0,201 & 0,099 & 0,099 \\
\hline 8 & 0,111 & 0,540 & 0,208 & $-0,147$ & $-0,547$ & $-0,196$ & 0,055 & 0,356 & 0,097 & 0,207 & 0,099 & 0,102 \\
\hline 9 & 0,170 & 0,821 & 0,396 & $-0,225$ & $-0,828$ & $-0,289$ & 0,087 & 0,541 & 0,186 & 0,207 & 0,099 & 0,102 \\
\hline 10 & 0,193 & 1,065 & 0,540 & $-0,272$ & $-1,072$ & $-0,437$ & 0,102 & 0,705 & 0,277 & 0,207 & 0,099 & 0,099 \\
\hline 11 & 0,399 & 1,298 & 0,663 & $-0,300$ & $-1,328$ & $-0,562$ & 0,126 & 0,860 & 0,353 & 0,207 & 0,099 & 0,099 \\
\hline 12 & 0,214 & 1,461 & 0,740 & $-0,290$ & $-1,473$ & $-0,644$ & 0,126 & 0,970 & 0,399 & 0,207 & 0,099 & 0,099 \\
\hline 13 & 0,235 & 1,566 & 0,797 & $-0,250$ & $-1,574$ & $-0,688$ & 0,110 & & 0,436 & 0,207 & 0,099 & 0,099 \\
\hline 14 & 0,225 & 1,610 & 0,842 & $-0,237$ & $-1,598$ & $-0,711$ & 0,105 & 1,043 & 0,450 & 0,099 & 0,099 & 0,099 \\
\hline 15 & 0,204 & 1,597 & 0,836 & $-0,227$ & $-1,612$ & $-0,707$ & 0,097 & 1,030 & 0,443 & 0,099 & 0,099 & 0,099 \\
\hline 16 & 0,170 & 1,511 & 0,806 & $-0,231$ & $-1,530$ & $-0,679$ & 0,093 & 0,966 & 0,418 & 0,099 & 0,099 & 0,099 \\
\hline 17 & 0,160 & 1,363 & 0,763 & $-0,195$ & $-1,367$ & $-0,634$ & 0,089 & 0,850 & 0,390 & 0,099 & 0,099 & 0,099 \\
\hline 18 & 0,164 & 1,204 & 0,687 & $-0,261$ & $-1,161$ & $-0,659$ & 0,102 & 0,716 & 0,363 & 0,099 & 0,099 & 0,099 \\
\hline 19 & 0,187 & 0,949 & 0,640 & $-0,192$ & $-0,947$ & $-0,544$ & 0,084 & 0,553 & 0,316 & 0,099 & 0,099 & 0,099 \\
\hline 20 & 0,131 & 0,668 & 0,597 & $-0,173$ & $-0,713$ & $-0,410$ & 0,074 & 0,361 & 0,239 & 0,099 & 0,099 & 0,099 \\
\hline 21 & 0,152 & 0,404 & 0,509 & $-0,166$ & $-0,458$ & $-0,354$ & 0,072 & 0,206 & 0,201 & 0,099 & 0,099 & 0,099 \\
\hline 22 & 0,182 & 0,374 & 0,394 & $-0,165$ & $-0,339$ & $-0,261$ & 0,076 & 0,183 & 0,153 & 0,099 & 0,099 & 0,099 \\
\hline 23 & 0,193 & 0,599 & 0,323 & $-0,144$ & $-0,625$ & $-0,197$ & 0,078 & 0,299 & 0,134 & 0,099 & 0,099 & 0,099 \\
\hline 24 & 0,209 & 0,813 & 0,267 & $-0,155$ & $-0,866$ & $-0,165$ & 0,085 & 0,431 & 0,122 & 0,099 & 0,099 & 0,031 \\
\hline 25 & 0,218 & 0,991 & 0,277 & $-0,165$ & $-1,062$ & $-0,191$ & 0,090 & 0,553 & 0,134 & 0,099 & 0,099 & 0,031 \\
\hline 26 & 0,234 & 1,116 & 0,270 & $-0,163$ & $-1,218$ & $-0,210$ & 0,098 & 0,652 & 0,137 & 0,099 & 0,099 & 0,031 \\
\hline 27 & 0,237 & 1,199 & 0,265 & $-0,171$ & $-1,318$ & $-0,227$ & 0,101 & 0,721 & 0,148 & 0,099 & 0,099 & 0,031 \\
\hline 28 & 0,230 & 1,274 & 0,250 & $-0,181$ & $-1,387$ & $-0,233$ & 0,103 & 0,776 & 0,149 & 0,099 & 0,099 & 0,031 \\
\hline 29 & 0,250 & 1,303 & 0,263 & $-0,206$ & $-1,449$ & $-0,237$ & 0,107 & 0,815 & 0,158 & 0,099 & 0,099 & 0,031 \\
\hline 30 & 0,018 & 0,004 & 0,007 & $-0,018$ & $-0,004$ & $-0,005$ & 0,009 & 0,002 & 0,003 & 0,034 & 0,041 & 0,037 \\
\hline 31 & 0,000 & 0,000 & 0,000 & 0,000 & 0,000 & 0,000 & 0,000 & 0,000 & 0,000 & 0,000 & 0,000 & 0,000 \\
\hline
\end{tabular}

Considerando agora a decomposição modal, na Tabela B.10 através da interpolação do sinal do ensaio, correspondente a uma velocade reduzida do primeiro modo $V_{r 1}=13,74$, as maiores amplitudes máximas apresentadas na direção X, Y e Z foram de 0,958, 1,526 e 0,399 m, respectivamente. Estes valores ocorreram para os modos 1, 4 e 10. Nestes modos, as suas frequências de resposta com maior energia foram de 0,0306 e 0,0986 Hz. 

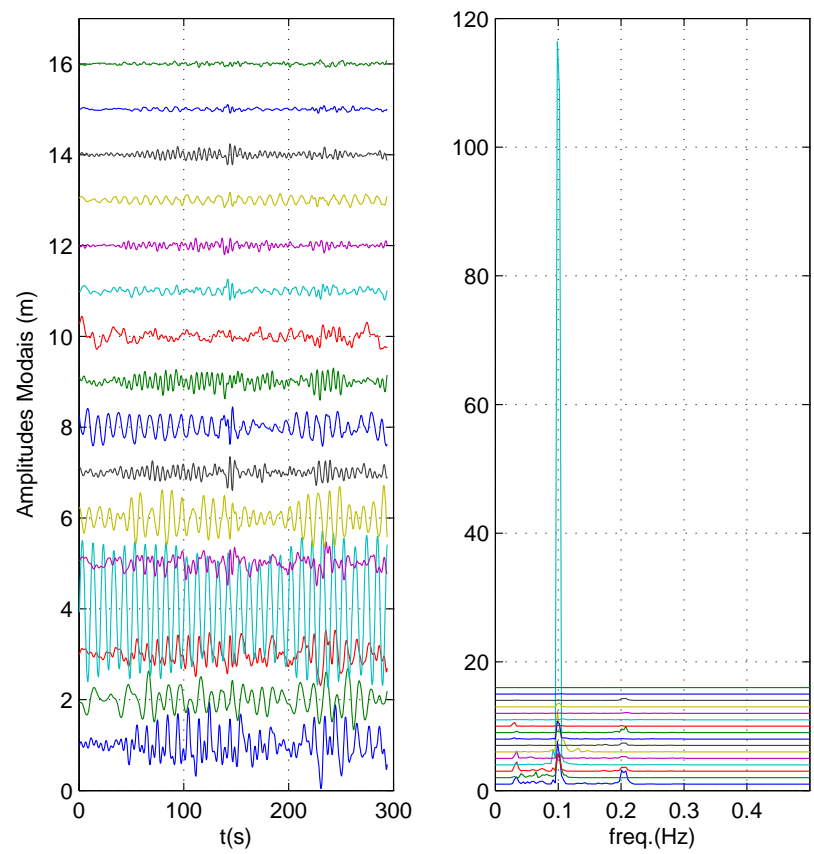

Figura B.15: Variação da amplitude modal acoplada ao longo do tempo através da interpolação do sinal do ensaio para Catenária-1 na $U_{\max }=1,37 \mathrm{~m} / \mathrm{s}$ e $V_{r 1}=13,739$.

Tabela B.10: Propriedades das amplitudes modais do ensaio Catenária-1 através da interpolação do sinal do ensaio para a $V_{\max }=1,37 \mathrm{~m} / \mathrm{s}$.

\begin{tabular}{lcccccccccccccc}
\hline \multicolumn{1}{c}{ Máximo } & \multicolumn{1}{c}{ Mínimo } & & \multicolumn{3}{c}{ Desvio padrão } & \multicolumn{3}{c}{ Freq. máxima em Hz } \\
\multicolumn{1}{c}{ Modo } & $\mathrm{X}(\mathrm{m})$ & $\mathrm{Y}(\mathrm{m})$ & $\mathrm{Z}(\mathrm{m})$ & $\mathrm{X}(\mathrm{m})$ & $\mathrm{Y}(\mathrm{m})$ & $\mathrm{Z}(\mathrm{m})$ & $\mathrm{X}(\mathrm{m})$ & $\mathrm{Y}(\mathrm{m})$ & $\mathrm{Z}(\mathrm{m})$ & $\mathrm{X}$ & $\mathrm{Y}$ & $\mathrm{Z}$ \\
& & & & & & & & & & & & \\
\hline 1 & 0,958 & 0,000 & 0,000 & $-0,966$ & $-0,000$ & $-0,000$ & 0,297 & 0,000 & 0,000 & 0,099 & 0,102 & 0,099 \\
2 & 0,000 & 0,597 & 0,112 & $-0,000$ & $-0,584$ & $-0,087$ & 0,000 & 0,229 & 0,045 & 0,099 & 0,102 & 0,099 \\
3 & 0,539 & 0,000 & 0,000 & $-0,697$ & $-0,000$ & $-0,000$ & 0,212 & 0,000 & 0,000 & 0,099 & 0,102 & 0,099 \\
4 & 0,000 & 1,526 & 0,233 & $-0,000$ & $-1,500$ & $-0,239$ & 0,000 & 0,869 & 0,125 & 0,099 & 0,099 & 0,099 \\
5 & 0,481 & 0,000 & 0,000 & $-0,499$ & $-0,000$ & $-0,000$ & 0,147 & 0,000 & 0,000 & 0,034 & 0,099 & 0,099 \\
6 & 0,000 & 0,518 & 0,227 & $-0,000$ & $-0,482$ & $-0,200$ & 0,000 & 0,209 & 0,097 & 0,102 & 0,099 & 0,099 \\
7 & 0,355 & 0,000 & 0,000 & $-0,394$ & $-0,000$ & $-0,000$ & 0,103 & 0,000 & 0,000 & 0,201 & 0,099 & 0,099 \\
8 & 0,000 & 0,461 & 0,220 & $-0,000$ & $-0,511$ & $-0,278$ & 0,000 & 0,216 & 0,078 & 0,207 & 0,099 & 0,102 \\
9 & 0,307 & 0,000 & 0,000 & $-0,407$ & $-0,000$ & $-0,000$ & 0,119 & 0,000 & 0,000 & 0,207 & 0,099 & 0,031 \\
10 & 0,000 & 0,151 & 0,399 & $-0,000$ & $-0,167$ & $-0,346$ & 0,000 & 0,042 & 0,112 & 0,207 & 0,099 & 0,031 \\
11 & 0,000 & 0,226 & 0,106 & $-0,000$ & $-0,205$ & $-0,077$ & 0,000 & 0,056 & 0,030 & 0,207 & 0,105 & 0,031 \\
12 & 0,164 & 0,000 & 0,000 & $-0,206$ & $-0,000$ & $-0,000$ & 0,054 & 0,000 & 0,000 & 0,207 & 0,105 & 0,031 \\
13 & 0,000 & 0,177 & 0,064 & $-0,000$ & $-0,166$ & $-0,054$ & 0,000 & 0,050 & 0,025 & 0,207 & 0,102 & 0,102 \\
14 & 0,243 & 0,000 & 0,000 & $-0,224$ & $-0,000$ & $-0,000$ & 0,063 & 0,000 & 0,000 & 0,207 & 0,102 & 0,102 \\
15 & 0,000 & 0,073 & 0,061 & $-0,000$ & $-0,093$ & $-0,057$ & 0,000 & 0,023 & 0,027 & 0,102 & 0,102 & 0,099 \\
16 & 0,089 & 0,000 & 0,000 & $-0,076$ & $-0,000$ & $-0,000$ & 0,027 & 0,000 & 0,000 & 0,102 & 0,102 & 0,099 \\
\hline
\end{tabular}

A Tabela B.11 apresenta para o ensaio Catenária-1 apenas os movimentos referentes 
a deslocamento no plano da catenária através da interpolação do sinal do ensaio, a maior amplitude acoplada máxima foi de $1,715 \mathrm{~m}$. Este valor ocorreu para o modo 4 . Neste modo, a sua frequência de resposta com maior energia foi de 0,099 Hz.

Tabela B.11: Propriedades das amplitudes modais acopladas no plano da catenária do ensaio Catenária-1 através da interpolação do sinal do ensaio para a $V_{\max }=1,37 \mathrm{~m} / \mathrm{s}$.

\begin{tabular}{lllll}
\hline \multicolumn{5}{c}{ Amplitude } \\
Modo & Máxima(m) & Mínima(m) & Desvio Padrão(m) & Freq. máxima (Hz) \\
& & & & \\
\hline 2 & 0,685 & $-0,665$ & 0,249 & 0,102 \\
4 & 1,715 & $-1,728$ & 0,985 & 0,099 \\
6 & 0,717 & $-0,631$ & 0,277 & 0,099 \\
8 & 0,451 & $-0,419$ & 0,186 & 0,099 \\
10 & 0,442 & $-0,287$ & 0,116 & 0,031 \\
11 & 0,262 & $-0,202$ & 0,064 & 0,105 \\
13 & 0,171 & $-0,163$ & 0,067 & 0,102 \\
15 & 0,104 & $-0,086$ & 0,028 & 0,105 \\
\hline
\end{tabular}

A Tabela B.12 para o ensaio Catenária-1 com apenas as amplitudes correspondentes a movimentos fora do plano através da interpolação do sinal do ensaio, a maior amplitude acoplada máxima apresentada foi de 0,949 m. Este valor ocorreu para o modo 1. Neste modo, a sua frequência de resposta com maior energia foi de 0,099 Hz.

Tabela B.12: Propriedades das amplitudes modais acopladas fora do plano da catenária do ensaio Catenária-1 através da interpolação do sinal do ensaio para a

$$
V_{\text {max }}=1,37 \mathrm{~m} / \mathrm{s} \text {. }
$$

\begin{tabular}{lllll}
\hline \multicolumn{5}{c}{ Amplitude } \\
Modo & Máxima(m) & Mínima(m) & Desvio Padrão(m) & Freq. máxima (Hz) \\
& & & & \\
\hline 1 & 0,949 & $-0,957$ & 0,295 & 0,099 \\
3 & 0,533 & $-0,688$ & 0,209 & 0,099 \\
5 & 0,475 & $-0,493$ & 0,145 & 0,034 \\
7 & 0,351 & $-0,389$ & 0,102 & 0,201 \\
9 & 0,304 & $-0,402$ & 0,117 & 0,207 \\
12 & 0,162 & $-0,204$ & 0,053 & 0,207 \\
14 & 0,241 & $-0,222$ & 0,062 & 0,207 \\
16 & 0,088 & $-0,075$ & 0,027 & 0,102 \\
\hline
\end{tabular}




\section{B.4 Catenária-1 - Velocidade de $1,94 \mathrm{~m} / \mathrm{s}$ e $V_{r 1}=$ 19,36}

Abaixo serão apresentados os gráficos com alguns detalhes da análise referentes ao arranjo Catenária-1 para a velocidade de $1,94 \mathrm{~m} / \mathrm{s}$ e $V_{r 1}=19,36$.
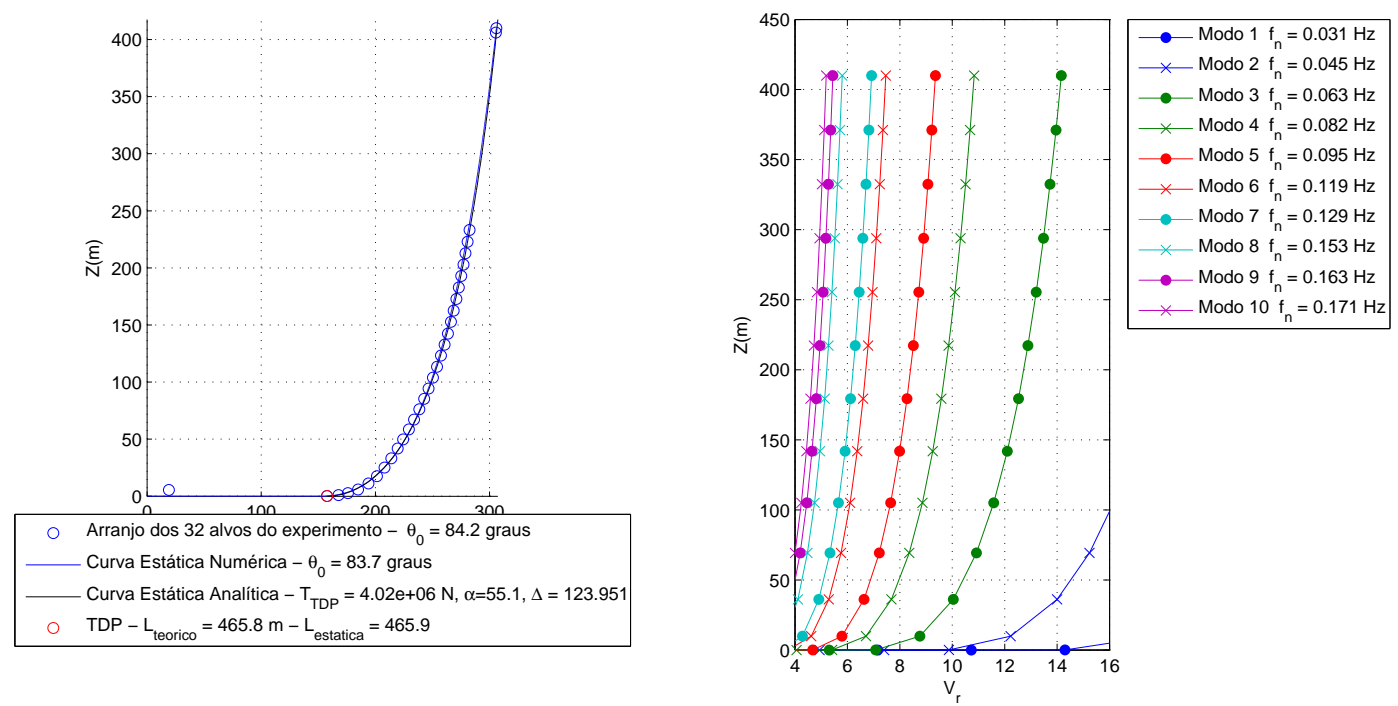

Figura B.16: Variação da velocidade no modelo durante o ensaio para Catenária-1 na $U_{\text {max }}=1,94 \mathrm{~m} / \mathrm{s}$ e $V_{r 1}=19,359$.

Como pode ser visto na Tabela B.13 e nas Figuras de B.17 a B.19, os maiores deslocamentos máximos apresentados na direção X, Y e Z foram de 1,914, 2,137 e 1,338 $\mathrm{m}$, respectivamente. Estes valores ocorreram para os alvos 12 e 30. Nestes alvos, as suas frequências de resposta com maior energia foi de 0,144 Hz. 

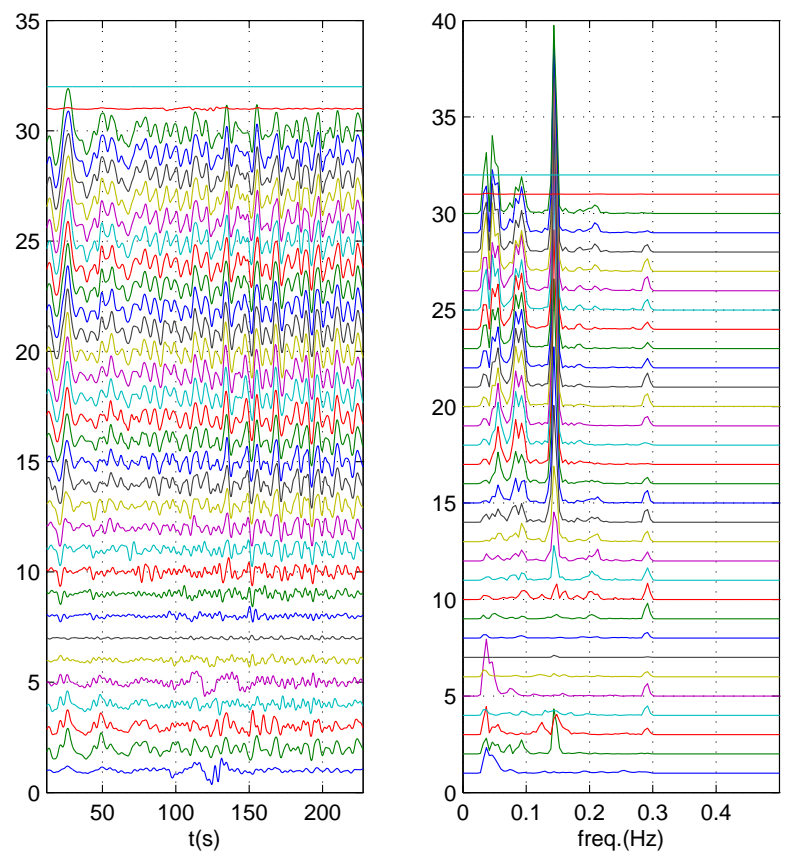

Figura B.17: Série temporal com frequências de resposta para X obtida experimentalmente por alvo para o arranjo de Catenária-1 na $U_{\max }=1,94 \mathrm{~m} / \mathrm{s}$ e $V_{r 1}=19,359$.
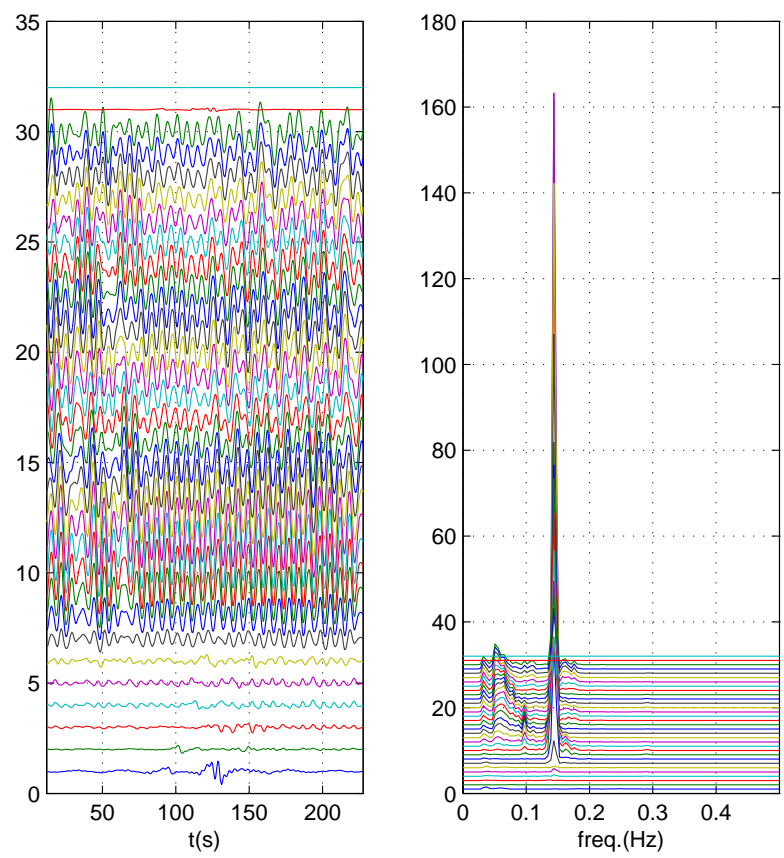

Figura B.18: Série temporal com frequências de resposta para Y obtida experimentalmente por alvo para o arranjo de Catenária-1 na $U_{\max }=1,94 \mathrm{~m} / \mathrm{s}$ e $V_{r 1}=19,359$. 

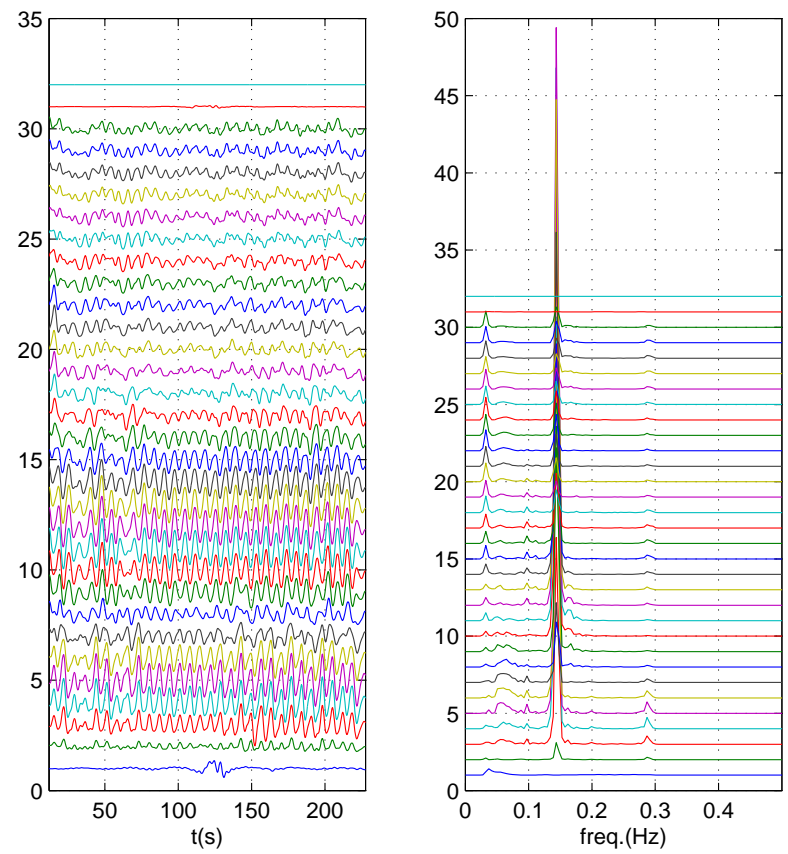

Figura B.19: Série temporal com frequências de resposta para Z obtida experimentalmente por alvo para o arranjo de Catenária-1 na $U_{\max }=1,94 \mathrm{~m} / \mathrm{s}$ e $V_{r 1}=19,359$. 
Tabela B.13: Propriedades da série temporal do ensaio Catenária-1 para a

$$
U_{\max }=1,94 \mathrm{~m} / \mathrm{s} \text {. }
$$

\begin{tabular}{|c|c|c|c|c|c|c|c|c|c|c|c|c|}
\hline \multirow[b]{2}{*}{ ID. Alvo } & \multirow[b]{2}{*}{$\mathrm{X}(\mathrm{m})$} & \multicolumn{2}{|c|}{ Máximo } & \multirow[b]{2}{*}{$\mathrm{X}(\mathrm{m})$} & \multirow{2}{*}{$\begin{array}{l}\text { Mínimo } \\
\text { Y(m) }\end{array}$} & \multirow[b]{2}{*}{$\mathrm{Z}(\mathrm{m})$} & \multicolumn{3}{|c|}{ Desvio padrão } & \multicolumn{3}{|c|}{ Freq. máxima em $\mathrm{Hz}$} \\
\hline & & $\mathrm{Y}(\mathrm{m})$ & $\mathrm{Z}(\mathrm{m})$ & & & & $\mathrm{X}(\mathrm{m})$ & $\mathrm{Y}(\mathrm{m})$ & $\mathrm{Z}(\mathrm{m})$ & $\mathrm{X}$ & $\mathrm{Y}$ & $\mathrm{Z}$ \\
\hline 1 & 0,195 & 0,062 & 0,035 & $-0,131$ & $-0,066$ & $-0,038$ & 0,091 & 0,031 & 0,018 & 0,037 & 0,037 & 0,037 \\
\hline 2 & 0,908 & 0,021 & 0,328 & $-0,482$ & $-0,033$ & $-0,143$ & 0,377 & 0,015 & 0,116 & 0,144 & 0,079 & 0,144 \\
\hline 3 & 0,751 & 0,059 & 0,802 & $-0,396$ & $-0,068$ & $-0,416$ & 0,310 & 0,034 & 0,304 & 0,037 & 0,134 & 0,144 \\
\hline 4 & 0,603 & 0,123 & 1,082 & $-0,331$ & $-0,113$ & $-0,682$ & 0,243 & 0,062 & 0,451 & 0,292 & 0,144 & 0,144 \\
\hline 5 & 0,353 & 0,158 & 1,201 & $-0,251$ & $-0,146$ & $-0,803$ & 0,167 & 0,074 & 0,511 & 0,037 & 0,144 & 0,144 \\
\hline 6 & 0,216 & 0,124 & 0,967 & $-0,133$ & $-0,286$ & $-0,603$ & 0,079 & 0,092 & 0,399 & 0,032 & 0,037 & 0,144 \\
\hline 7 & 0,049 & 0,468 & 0,553 & $-0,056$ & $-0,591$ & $-0,422$ & 0,023 & 0,254 & 0,258 & 0,144 & 0,144 & 0,144 \\
\hline 8 & 0,128 & 0,979 & 0,712 & $-0,255$ & $-1,019$ & $-0,407$ & 0,083 & 0,505 & 0,268 & 0,292 & 0,144 & 0,144 \\
\hline 9 & 0,209 & 1,460 & 1,016 & $-0,469$ & $-1,492$ & $-0,585$ & 0,138 & 0,766 & 0,412 & 0,292 & 0,144 & 0,144 \\
\hline 10 & 0,239 & 1,847 & 1,241 & $-0,651$ & $-1,865$ & $-0,861$ & 0,186 & 0,973 & 0,535 & 0,292 & 0,144 & 0,144 \\
\hline 11 & 0,261 & 2,089 & 1,326 & $-0,711$ & $-2,061$ & $-0,950$ & 0,210 & 1,069 & 0,579 & 0,144 & 0,144 & 0,144 \\
\hline 12 & 0,422 & 2,137 & 1,338 & $-0,835$ & $-2,079$ & $-0,955$ & 0,259 & 1,066 & 0,582 & 0,144 & 0,144 & 0,144 \\
\hline 13 & 0,640 & 2,010 & 1,274 & $-0,868$ & $-1,844$ & $-0,959$ & 0,339 & 0,983 & 0,549 & 0,144 & 0,144 & 0,144 \\
\hline 14 & 1,104 & 1,818 & 0,997 & $-0,895$ & $-1,479$ & $-0,784$ & 0,389 & 0,838 & 0,466 & 0,144 & 0,144 & 0,144 \\
\hline 15 & 0,955 & 1,573 & 0,748 & $-0,879$ & $-1,155$ & $-0,672$ & 0,383 & 0,694 & 0,367 & 0,144 & 0,144 & 0,144 \\
\hline 16 & 1,171 & 1,374 & 0,667 & $-0,963$ & $-1,048$ & $-0,578$ & 0,451 & 0,629 & 0,297 & 0,144 & 0,144 & 0,144 \\
\hline 17 & 1,363 & 1,336 & 0,783 & $-1,106$ & $-1,355$ & $-0,508$ & 0,509 & 0,668 & 0,266 & 0,144 & 0,144 & 0,144 \\
\hline 18 & 1,550 & 1,499 & 0,880 & $-1,197$ & $-1,594$ & $-0,495$ & 0,561 & 0,754 & 0,273 & 0,144 & 0,144 & 0,144 \\
\hline 19 & 1,655 & 1,616 & 0,908 & $-1,269$ & $-1,649$ & $-0,388$ & 0,595 & 0,833 & 0,274 & 0,144 & 0,144 & 0,032 \\
\hline 20 & 1,760 & 1,593 & 0,856 & $-1,318$ & $-1,622$ & $-0,400$ & 0,642 & 0,887 & 0,278 & 0,144 & 0,144 & 0,144 \\
\hline 21 & 1,832 & 1,481 & 1,012 & $-1,333$ & $-1,557$ & $-0,412$ & 0,672 & 0,893 & 0,296 & 0,144 & 0,144 & 0,144 \\
\hline 22 & 1,878 & 1,497 & 0,916 & $-1,370$ & $-1,361$ & $-0,420$ & 0,708 & 0,864 & 0,278 & 0,144 & 0,144 & 0,144 \\
\hline 23 & 1,892 & 1,550 & 0,667 & $-1,411$ & $-1,426$ & $-0,414$ & 0,740 & 0,795 & 0,244 & 0,144 & 0,144 & 0,144 \\
\hline 24 & 1,892 & 1,571 & 0,531 & $-1,452$ & $-1,375$ & $-0,392$ & 0,771 & 0,714 & 0,227 & 0,144 & 0,144 & 0,144 \\
\hline 25 & 1,881 & 1,578 & 0,404 & $-1,501$ & $-1,327$ & $-0,361$ & 0,797 & 0,649 & 0,205 & 0,144 & 0,144 & 0,144 \\
\hline 26 & 1,874 & 1,495 & 0,428 & $-1,528$ & $-1,166$ & $-0,374$ & 0,821 & 0,583 & 0,202 & 0,144 & 0,144 & 0,144 \\
\hline 27 & 1,860 & 1,390 & 0,437 & $-1,564$ & $-1,034$ & $-0,333$ & 0,839 & 0,542 & 0,190 & 0,144 & 0,144 & 0,144 \\
\hline 28 & 1,869 & 1,218 & 0,478 & $-1,564$ & $-0,881$ & $-0,307$ & 0,859 & 0,525 & 0,188 & 0,144 & 0,144 & 0,144 \\
\hline 29 & 1,895 & 1,355 & 0,502 & $-1,587$ & $-1,020$ & $-0,267$ & 0,883 & 0,547 & 0,183 & 0,144 & 0,144 & 0,144 \\
\hline 30 & 1,914 & 1,537 & 0,524 & $-1,559$ & $-1,033$ & $-0,236$ & 0,896 & 0,580 & 0,187 & 0,144 & 0,144 & 0,144 \\
\hline 31 & 0,049 & 0,009 & 0,006 & $-0,029$ & $-0,010$ & $-0,007$ & 0,023 & 0,006 & 0,003 & 0,037 & 0,037 & 0,037 \\
\hline 32 & 0,000 & 0,000 & 0,000 & 0,000 & 0,000 & 0,000 & 0,000 & 0,000 & 0,000 & 0,000 & 0,000 & 0,000 \\
\hline
\end{tabular}

Considerando agora a decomposição modal, na Tabela B.14 através da interpolação do sinal do ensaio, correspondente a uma velocade reduzida do primeiro modo $V_{r 1}=19.36$, as maiores amplitudes máximas apresentadas na direção X, Y e Z foram de 1,531, 1,395 e 0,546 m, respectivamente. Estes valores ocorreram para os modos 1, 6 e 10. Nestes modos, as suas frequências de resposta com maior energia foram de 0,0324 e 0,144 Hz. 

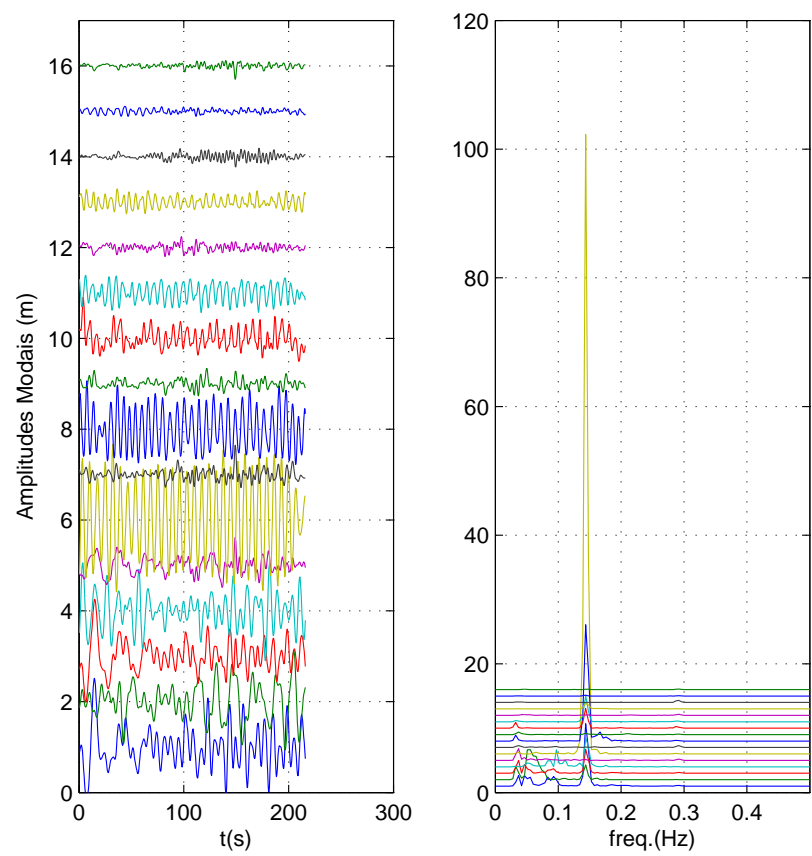

Figura B.20: Variação da amplitude modal acoplada ao longo do tempo através da interpolação do sinal do ensaio para Catenária-1 na $U_{\max }=1,94 \mathrm{~m} / \mathrm{s}$ e $V_{r 1}=19,359$.

Tabela B.14: Propriedades das amplitudes modais do ensaio Catenária-1 através da interpolação do sinal do ensaio para a $V_{\max }=1,94 \mathrm{~m} / \mathrm{s}$.

\begin{tabular}{lcccccccccccccc}
\hline \multicolumn{1}{c}{ Máximo } & \multicolumn{1}{c}{ Mínimo } & & \multicolumn{3}{c}{ Desvio padrão } & \multicolumn{3}{c}{ Freq. máxima em Hz } \\
\multicolumn{1}{c}{ Modo } & $\mathrm{X}(\mathrm{m})$ & $\mathrm{Y}(\mathrm{m})$ & $\mathrm{Z}(\mathrm{m})$ & $\mathrm{X}(\mathrm{m})$ & $\mathrm{Y}(\mathrm{m})$ & $\mathrm{Z}(\mathrm{m})$ & $\mathrm{X}(\mathrm{m})$ & $\mathrm{Y}(\mathrm{m})$ & $\mathrm{Z}(\mathrm{m})$ & $\mathrm{X}$ & $\mathrm{Y}$ & $\mathrm{Z}$ \\
& & & & & & & & & & & & \\
\hline 1 & 1,531 & 0,000 & 0,000 & $-1,126$ & $-0,000$ & $-0,000$ & 0,454 & 0,000 & 0,000 & 0,144 & 0,051 & 0,144 \\
2 & 0,000 & 1,071 & 0,087 & $-0,000$ & $-0,983$ & $-0,088$ & 0,000 & 0,376 & 0,038 & 0,144 & 0,051 & 0,144 \\
3 & 1,270 & 0,000 & 0,000 & $-1,021$ & $-0,000$ & $-0,000$ & 0,351 & 0,000 & 0,000 & 0,144 & 0,051 & 0,144 \\
4 & 0,000 & 1,027 & 0,212 & $-0,000$ & $-0,950$ & $-0,210$ & 0,000 & 0,326 & 0,105 & 0,144 & 0,097 & 0,144 \\
5 & 0,624 & 0,000 & 0,000 & $-0,492$ & $-0,000$ & $-0,000$ & 0,186 & 0,000 & 0,000 & 0,037 & 0,144 & 0,144 \\
6 & 0,000 & 1,395 & 0,285 & $-0,000$ & $-1,340$ & $-0,293$ & 0,000 & 0,711 & 0,153 & 0,046 & 0,144 & 0,144 \\
7 & 0,658 & 0,000 & 0,000 & $-0,288$ & $-0,000$ & $-0,000$ & 0,120 & 0,000 & 0,000 & 0,292 & 0,144 & 0,144 \\
8 & 0,000 & 0,697 & 0,467 & $-0,000$ & $-0,736$ & $-0,352$ & 0,000 & 0,333 & 0,162 & 0,037 & 0,144 & 0,144 \\
9 & 0,344 & 0,000 & 0,000 & $-0,267$ & $-0,000$ & $-0,000$ & 0,097 & 0,000 & 0,000 & 0,037 & 0,144 & 0,032 \\
10 & 0,000 & 0,361 & 0,546 & $-0,000$ & $-0,383$ & $-0,353$ & 0,000 & 0,189 & 0,157 & 0,037 & 0,144 & 0,032 \\
11 & 0,000 & 0,353 & 0,154 & $-0,000$ & $-0,408$ & $-0,112$ & 0,000 & 0,194 & 0,047 & 0,292 & 0,144 & 0,032 \\
12 & 0,242 & 0,000 & 0,000 & $-0,199$ & $-0,000$ & $-0,000$ & 0,071 & 0,000 & 0,000 & 0,292 & 0,144 & 0,032 \\
13 & 0,000 & 0,247 & 0,060 & $-0,000$ & $-0,230$ & $-0,055$ & 0,000 & 0,114 & 0,023 & 0,292 & 0,144 & 0,032 \\
14 & 0,186 & 0,000 & 0,000 & $-0,226$ & $-0,000$ & $-0,000$ & 0,065 & 0,000 & 0,000 & 0,292 & 0,144 & 0,032 \\
15 & 0,000 & 0,097 & 0,058 & $-0,000$ & $-0,110$ & $-0,045$ & 0,000 & 0,039 & 0,022 & 0,292 & 0,292 & 0,144 \\
16 & 0,118 & 0,001 & 0,000 & $-0,297$ & $-0,001$ & $-0,000$ & 0,050 & 0,000 & 0,000 & 0,292 & 0,292 & 0,144 \\
\hline
\end{tabular}

A Tabela B.15 apresenta para o ensaio Catenária-1 apenas os movimentos referentes 
a deslocamento no plano da catenária através da interpolação do sinal do ensaio, a maior amplitude acoplada máxima foi de $1,668 \mathrm{~m}$. Este valor ocorreu para o modo 6 . Neste modo, a sua frequência de resposta com maior energia foi de $0,144 \mathrm{~Hz}$.

Tabela B.15: Propriedades das amplitudes modais acopladas no plano da catenária do ensaio Catenária-1 através da interpolação do sinal do ensaio para a $V_{\max }=1,94 \mathrm{~m} / \mathrm{s}$.

\begin{tabular}{lllll}
\hline \multicolumn{5}{c}{ Amplitude } \\
Modo & Máxima(m) & Mínima(m) & Desvio Padrão(m) & Freq. máxima (Hz) \\
& & & & \\
\hline 2 & 1,127 & $-1,063$ & 0,403 & 0,056 \\
4 & 1,059 & $-1,097$ & 0,385 & 0,144 \\
6 & 1,668 & $-1,579$ & 0,849 & 0,144 \\
8 & 1,063 & $-0,777$ & 0,448 & 0,144 \\
10 & 0,900 & $-0,508$ & 0,219 & 0,144 \\
11 & 0,385 & $-0,427$ & 0,189 & 0,144 \\
13 & 0,294 & $-0,258$ & 0,118 & 0,144 \\
15 & 0,111 & $-0,113$ & 0,048 & 0,144 \\
\hline
\end{tabular}

A Tabela B.16 para o ensaio Catenária-1 com apenas as amplitudes correspondentes a movimentos fora do plano através da interpolação do sinal do ensaio, a maior amplitude acoplada máxima apresentada foi de 1,517 m. Este valor ocorreu para o modo 1 . Neste modo, a sua frequência de resposta com maior energia foi de 0,144 Hz.

Tabela B.16: Propriedades das amplitudes modais acopladas fora do plano da catenária do ensaio Catenária-1 através da interpolação do sinal do ensaio para a

$$
V_{\text {max }}=1,94 \mathrm{~m} / \mathrm{s} \text {. }
$$

\begin{tabular}{llccc}
\hline \multicolumn{5}{c}{ Amplitude } \\
Modo & Máxima(m) & Mínima(m) & Desvio Padrão(m) & Freq. máxima $(\mathrm{Hz})$ \\
\hline 1 & 1,517 & $-1,116$ & 0,450 & 0,144 \\
3 & 1,254 & $-1,009$ & 0,347 & 0,144 \\
5 & 0,616 & $-0,485$ & 0,183 & 0,037 \\
7 & 0,650 & $-0,285$ & 0,119 & 0,292 \\
9 & 0,340 & $-0,264$ & 0,096 & 0,037 \\
12 & 0,239 & $-0,197$ & 0,070 & 0,292 \\
14 & 0,184 & $-0,224$ & 0,065 & 0,292 \\
16 & 0,116 & $-0,294$ & 0,049 & 0,292 \\
\hline
\end{tabular}


Anexo C - Resultados de VIV nas linhas em Catenária-2 
Neste anexo é apresentado um conjunto mais completo de resultados do VIV na linha flexível para a Catenária-2, particularmente aqueles referentes às velocidades reduzidas mais importantes. Vale lembrar que todos os resultados estão apresentados na escala real (1:100) conforme definido em [Rateiro et al., 2012]. Neste sentido, as seções que se seguem dizem respeito a:

- Na seção C.1: Velocidade de $0,774 \mathrm{~m} / \mathrm{s}$ e $V_{r 1}=7,74$

- Na seção C.2: Velocidade de $1,047 \mathrm{~m} / \mathrm{s}$ e $V_{r 1}=10,47$

- Na seção C.3: Velocidade de $1,279 \mathrm{~m} / \mathrm{s}$ e $V_{r 1}=12,79$

- Na seção C.4: Velocidade de $1,395 \mathrm{~m} / \mathrm{s}$ e $V_{r 1}=13,95$

\section{C.1 Catenária-2 - Velocidade de $0,774 \mathrm{~m} / \mathrm{s}$ e $V_{r 1}=$ 7,74}

Abaixo serão apresentados os gráficos com alguns detalhes da análise referentes ao arranjo Catenária-2 para a velocidade de $0,774 \mathrm{~m} / \mathrm{s}$ e $V_{r 1}=7,74$.
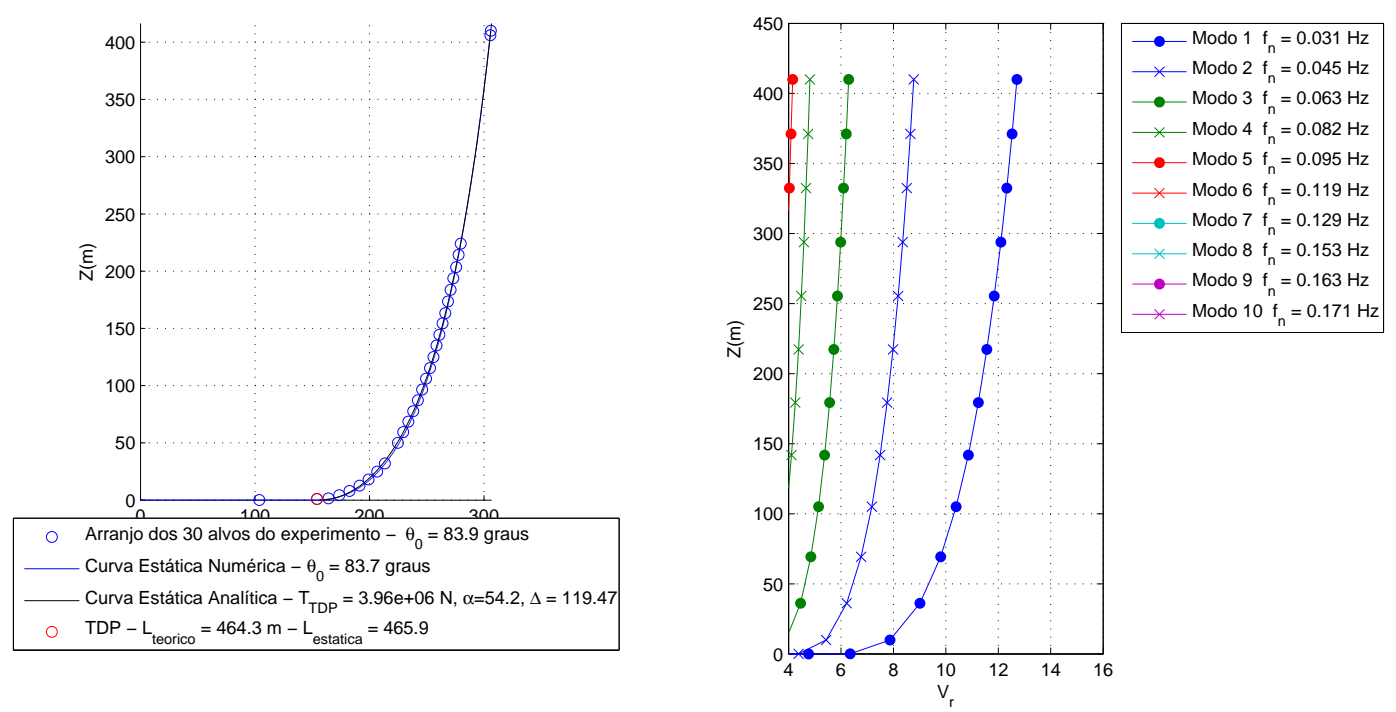

Figura C.1: Variação da velocidade no modelo durante o ensaio para Catenária-2 na $U_{\max }=0,774 \mathrm{~m} / \mathrm{s}$ e $V_{r 1}=7,741$.

Como pode ser visto na Tabela C.1 e nas Figuras de C.2 a C.4, os maiores deslocamentos máximos apresentados na direção X, Y e Z foram de 0,754, 1,332 e 0,556 
$\mathrm{m}$, respectivamente. Estes valores ocorreram para os alvos 6, 19 e 24. Nestes alvos, as suas frequências de resposta com maior energia foram de 0,0545 e 0,159 Hz.
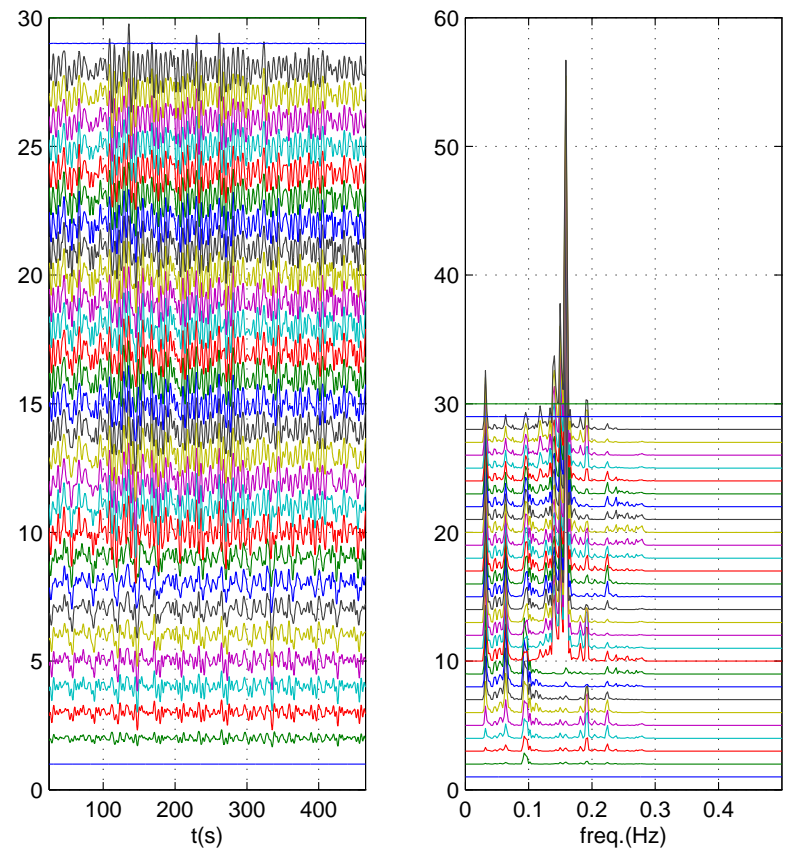

Figura C.2: Série temporal com frequências de resposta para X obtida experimentalmente por alvo para o arranjo de Catenária-2 na $U_{\max }=0,774 \mathrm{~m} / \mathrm{s}$ e $V_{r 1}=7,741$. 

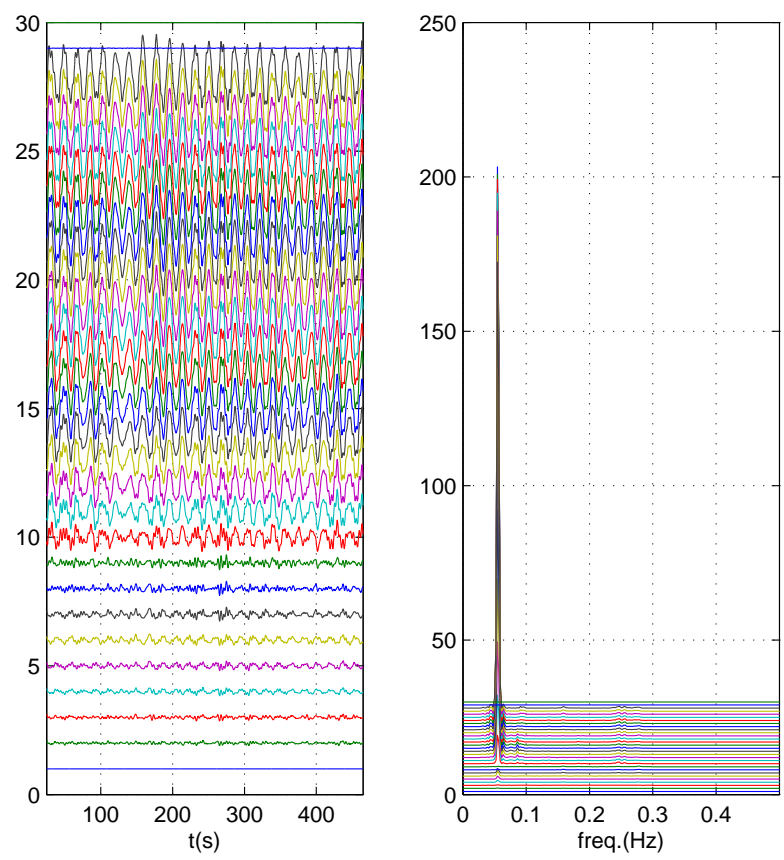

Figura C.3: Série temporal com frequências de resposta para Y obtida experimentalmente por alvo para o arranjo de Catenária-2 na $U_{\max }=0,774 \mathrm{~m} / \mathrm{s}$ e $V_{r 1}=7,741$.
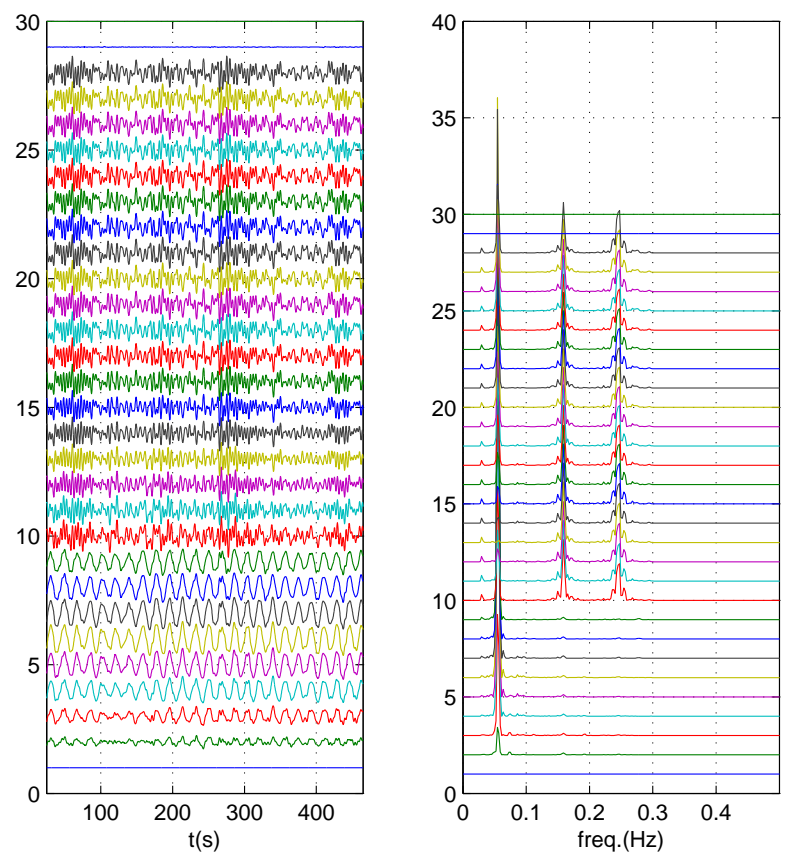

Figura C.4: Série temporal com frequências de resposta para Z obtida experimentalmente por alvo para o arranjo de Catenária-2 na $U_{\max }=0,774 \mathrm{~m} / \mathrm{s}$ e $V_{r 1}=7,741$. 
Tabela C.1: Propriedades da série temporal do ensaio Catenária-2 para a $U_{\max }=0,774 \mathrm{~m} / \mathrm{s}$.

\begin{tabular}{|c|c|c|c|c|c|c|c|c|c|c|c|c|}
\hline \multirow[b]{2}{*}{ ID. Alvo } & \multirow[b]{2}{*}{$\mathrm{X}(\mathrm{m})$} & \multicolumn{2}{|c|}{ Máximo } & \multirow[b]{2}{*}{$\mathrm{X}(\mathrm{m})$} & \multirow{2}{*}{$\begin{array}{l}\text { Mínimo } \\
\mathrm{Y}(\mathrm{m})\end{array}$} & \multirow[b]{2}{*}{$\mathrm{Z}(\mathrm{m})$} & \multicolumn{3}{|c|}{ Desvio padrão } & \multicolumn{3}{|c|}{ Freq. máxima em $\mathrm{Hz}$} \\
\hline & & $\mathrm{Y}(\mathrm{m})$ & $\mathrm{Z}(\mathrm{m})$ & & & & $\mathrm{X}(\mathrm{m})$ & $\mathrm{Y}(\mathrm{m})$ & $\mathrm{Z}(\mathrm{m})$ & $\mathrm{X}$ & $\mathrm{Y}$ & Z \\
\hline 1 & 0,000 & 0,000 & 0,000 & 0,000 & 0,000 & $-0,000$ & 0,000 & 0,000 & 0,000 & 0,000 & 0,000 & 0,032 \\
\hline 2 & 0,148 & 0,085 & 0,160 & $-0,182$ & $-0,063$ & $-0,184$ & 0,070 & 0,034 & 0,092 & 0,093 & 0,054 & 0,054 \\
\hline 3 & 0,282 & 0,106 & 0,262 & $-0,389$ & $-0,055$ & $-0,305$ & 0,139 & 0,039 & 0,167 & 0,093 & 0,054 & 0,054 \\
\hline 4 & 0,359 & 0,115 & 0,367 & $-0,536$ & $-0,067$ & $-0,399$ & 0,189 & 0,052 & 0,262 & 0,193 & 0,054 & 0,054 \\
\hline 5 & 0,369 & 0,132 & 0,449 & $-0,618$ & $-0,081$ & $-0,496$ & 0,215 & 0,068 & 0,319 & 0,193 & 0,054 & 0,054 \\
\hline 6 & 0,302 & 0,136 & 0,556 & $-0,626$ & $-0,160$ & $-0,514$ & 0,216 & 0,079 & 0,359 & 0,064 & 0,054 & 0,054 \\
\hline 7 & 0,189 & 0,110 & 0,496 & $-0,602$ & $-0,101$ & $-0,504$ & 0,210 & 0,062 & 0,337 & 0,064 & 0,054 & 0,054 \\
\hline 8 & 0,221 & 0,108 & 0,464 & $-0,612$ & $-0,075$ & $-0,477$ & 0,213 & 0,049 & 0,300 & 0,064 & 0,054 & 0,054 \\
\hline 9 & 0,347 & 0,225 & 0,389 & $-0,680$ & $-0,119$ & $-0,367$ & 0,236 & 0,092 & 0,238 & 0,064 & 0,159 & 0,054 \\
\hline 10 & 0,720 & 0,584 & 0,322 & $-0,855$ & $-0,468$ & $-0,479$ & 0,364 & 0,282 & 0,232 & 0,159 & 0,054 & 0,054 \\
\hline 11 & 0,665 & 0,733 & 0,307 & $-0,714$ & $-0,638$ & $-0,483$ & 0,341 & 0,383 & 0,210 & 0,159 & 0,054 & 0,159 \\
\hline 12 & 0,693 & 0,868 & 0,333 & $-0,574$ & $-0,790$ & $-0,488$ & 0,327 & 0,479 & 0,198 & 0,159 & 0,054 & 0,159 \\
\hline 13 & 0,710 & 0,984 & 0,348 & $-0,531$ & $-0,941$ & $-0,488$ & 0,331 & 0,568 & 0,199 & 0,159 & 0,054 & 0,159 \\
\hline 14 & 0,709 & 1,091 & 0,354 & $-0,596$ & $-1,068$ & $-0,491$ & 0,348 & 0,650 & 0,207 & 0,159 & 0,054 & 0,159 \\
\hline 15 & 0,698 & 1,175 & 0,374 & $-0,682$ & $-1,173$ & $-0,488$ & 0,370 & 0,717 & 0,216 & 0,159 & 0,054 & 0,159 \\
\hline 16 & 0,679 & 1,229 & 0,393 & $-0,750$ & $-1,256$ & $-0,493$ & 0,387 & 0,773 & 0,226 & 0,159 & 0,054 & 0,159 \\
\hline 17 & 0,665 & 1,285 & 0,406 & $-0,798$ & $-1,323$ & $-0,493$ & 0,396 & 0,821 & 0,235 & 0,159 & 0,054 & 0,159 \\
\hline 18 & 0,661 & 1,305 & 0,419 & $-0,812$ & $-1,344$ & $-0,495$ & 0,399 & 0,852 & 0,245 & 0,159 & 0,054 & 0,054 \\
\hline 19 & 0,666 & 1,332 & 0,421 & $-0,806$ & $-1,377$ & $-0,489$ & 0,398 & 0,875 & 0,244 & 0,159 & 0,054 & 0,054 \\
\hline 20 & 0,680 & 1,308 & 0,415 & $-0,782$ & $-1,347$ & $-0,487$ & 0,396 & 0,874 & 0,245 & 0,159 & 0,054 & 0,054 \\
\hline 21 & 0,702 & 1,291 & 0,411 & $-0,752$ & $-1,325$ & $-0,487$ & 0,393 & 0,873 & 0,246 & 0,159 & 0,054 & 0,054 \\
\hline 22 & 0,725 & 1,293 & 0,407 & $-0,711$ & $-1,324$ & $-0,494$ & 0,390 & 0,880 & 0,249 & 0,159 & 0,054 & 0,054 \\
\hline 23 & 0,745 & 1,238 & 0,391 & $-0,658$ & $-1,251$ & $-0,491$ & 0,383 & 0,853 & 0,245 & 0,159 & 0,054 & 0,054 \\
\hline 24 & 0,754 & 1,189 & 0,378 & $-0,649$ & $-1,199$ & $-0,492$ & 0,375 & 0,833 & 0,243 & 0,159 & 0,054 & 0,054 \\
\hline 25 & 0,753 & 1,147 & 0,361 & $-0,648$ & $-1,159$ & $-0,486$ & 0,371 & 0,800 & 0,238 & 0,159 & 0,054 & 0,054 \\
\hline 26 & 0,737 & 1,151 & 0,345 & $-0,638$ & $-1,152$ & $-0,486$ & 0,370 & 0,771 & 0,234 & 0,159 & 0,054 & 0,054 \\
\hline 27 & 0,705 & 1,134 & 0,332 & $-0,638$ & $-1,127$ & $-0,486$ & 0,375 & 0,738 & 0,228 & 0,159 & 0,054 & 0,054 \\
\hline 28 & 0,662 & 1,096 & 0,332 & $-0,651$ & $-1,104$ & $-0,480$ & 0,381 & 0,697 & 0,223 & 0,159 & 0,054 & 0,054 \\
\hline 29 & 0,005 & 0,004 & 0,007 & $-0,004$ & $-0,006$ & $-0,006$ & 0,002 & 0,003 & 0,003 & 0,093 & 0,127 & 0,093 \\
\hline 30 & 0,000 & 0,000 & 0,000 & 0,000 & 0,000 & 0,000 & 0,000 & 0,000 & 0,000 & 0,000 & 0,000 & 0,000 \\
\hline
\end{tabular}

Considerando agora a decomposição modal, na Tabela C.2 através da interpolação do sinal do ensaio, correspondente a uma velocade reduzida do primeiro modo $V_{r 1}=7,74$, as maiores amplitudes máximas apresentadas na direção X, Y e Z foram de 1,629, 1,529 e 0,574 m, respectivamente. Estes valores ocorreram para os modos 1, 2 e 10, Nestes modos, as suas frequências de resposta com maior energia foram de 0,0545 e 0,159 Hz. 

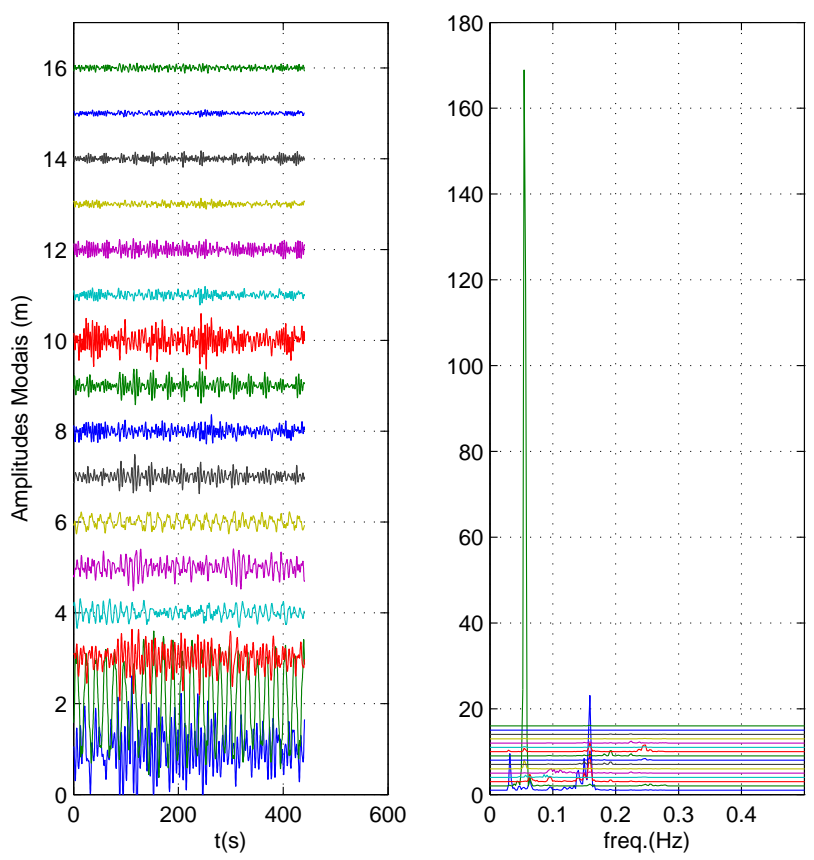

Figura C.5: Variação da amplitude modal acoplada ao longo do tempo através da interpolação do sinal do ensaio para Catenária-2 na $U_{\max }=0,774 \mathrm{~m} / \mathrm{s}$ e $V_{r 1}=7,741$.

Tabela C.2: Propriedades das amplitudes modais do ensaio Catenária-2 através da interpolação do sinal do ensaio para a $V_{\max }=0,774 \mathrm{~m} / \mathrm{s}$.

\begin{tabular}{lccccccccccccc}
\hline \multicolumn{1}{c}{ Máximo } & \multicolumn{1}{c}{ Mínimo } & \multicolumn{3}{c}{ Desvio padrão } & \multicolumn{3}{c}{ Freq. máxima em Hz } \\
\multicolumn{1}{c}{ Modo } & $\mathrm{X}(\mathrm{m})$ & $\mathrm{Y}(\mathrm{m})$ & $\mathrm{Z}(\mathrm{m})$ & $\mathrm{X}(\mathrm{m})$ & $\mathrm{Y}(\mathrm{m})$ & $\mathrm{Z}(\mathrm{m})$ & $\mathrm{X}(\mathrm{m})$ & $\mathrm{Y}(\mathrm{m})$ & $\mathrm{Z}(\mathrm{m})$ & $\mathrm{X}$ & $\mathrm{Y}$ & $\mathrm{Z}$ \\
& & & & & & & & & & & & \\
\hline 1 & 1,629 & 0,000 & 0,000 & $-1,500$ & $-0,000$ & $-0,000$ & 0,461 & 0,000 & 0,000 & 0,159 & 0,054 & 0,054 \\
2 & 0,000 & 1,529 & 0,145 & $-0,000$ & $-1,533$ & $-0,143$ & 0,000 & 0,784 & 0,063 & 0,159 & 0,054 & 0,054 \\
3 & 0,645 & 0,000 & 0,000 & $-0,949$ & $-0,000$ & $-0,000$ & 0,256 & 0,000 & 0,000 & 0,159 & 0,054 & 0,054 \\
4 & 0,000 & 0,339 & 0,171 & $-0,000$ & $-0,285$ & $-0,179$ & 0,000 & 0,111 & 0,060 & 0,159 & 0,057 & 0,054 \\
5 & 0,413 & 0,000 & 0,000 & $-0,520$ & $-0,000$ & $-0,000$ & 0,158 & 0,000 & 0,000 & 0,098 & 0,054 & 0,159 \\
6 & 0,000 & 0,238 & 0,107 & $-0,000$ & $-0,264$ & $-0,103$ & 0,000 & 0,104 & 0,035 & 0,150 & 0,054 & 0,159 \\
7 & 0,491 & 0,000 & 0,000 & $-0,379$ & $-0,000$ & $-0,000$ & 0,111 & 0,000 & 0,000 & 0,150 & 0,054 & 0,159 \\
8 & 0,000 & 0,127 & 0,333 & $-0,000$ & $-0,146$ & $-0,363$ & 0,000 & 0,044 & 0,104 & 0,193 & 0,054 & 0,159 \\
9 & 0,391 & 0,000 & 0,000 & $-0,420$ & $-0,000$ & $-0,000$ & 0,123 & 0,000 & 0,000 & 0,193 & 0,182 & 0,159 \\
10 & 0,000 & 0,048 & 0,574 & $-0,000$ & $-0,041$ & $-0,621$ & 0,000 & 0,015 & 0,179 & 0,193 & 0,182 & 0,159 \\
11 & 0,000 & 0,115 & 0,148 & $-0,000$ & $-0,081$ & $-0,157$ & 0,000 & 0,034 & 0,047 & 0,225 & 0,054 & 0,159 \\
12 & 0,241 & 0,000 & 0,000 & $-0,213$ & $-0,000$ & $-0,000$ & 0,093 & 0,000 & 0,000 & 0,225 & 0,054 & 0,159 \\
13 & 0,000 & 0,071 & 0,089 & $-0,000$ & $-0,053$ & $-0,104$ & 0,000 & 0,025 & 0,030 & 0,225 & 0,054 & 0,159 \\
14 & 0,177 & 0,000 & 0,000 & $-0,192$ & $-0,000$ & $-0,000$ & 0,055 & 0,000 & 0,000 & 0,225 & 0,054 & 0,159 \\
15 & 0,000 & 0,028 & 0,079 & $-0,000$ & $-0,029$ & $-0,084$ & 0,000 & 0,010 & 0,025 & 0,159 & 0,281 & 0,159 \\
16 & 0,106 & 0,000 & 0,000 & $-0,118$ & $-0,000$ & $-0,000$ & 0,040 & 0,000 & 0,000 & 0,159 & 0,281 & 0,159 \\
\hline
\end{tabular}

A Tabela C.3 apresenta para o ensaio Catenária-2 apenas os movimentos referentes a 
deslocamento no plano da catenária através da interpolação do sinal do ensaio, a maior amplitude acoplada máxima foi de 1,603 m. Este valor ocorreu para o modo 2. Neste modo, a sua frequência de resposta com maior energia foi de $0,054 \mathrm{~Hz}$.

Tabela C.3: Propriedades das amplitudes modais acopladas no plano da catenária do ensaio Catenária-2 através da interpolação do sinal do ensaio para a $V_{\max }=0,774 \mathrm{~m} / \mathrm{s}$.

Amplitude

Modo Máxima(m) Mínima(m) Desvio Padrão(m) Freq. máxima (Hz)

\begin{tabular}{lllll}
\hline 2 & 1,603 & $-1,628$ & 0,833 & 0,054 \\
4 & 0,312 & $-0,344$ & 0,119 & 0,086 \\
6 & 0,240 & $-0,263$ & 0,109 & 0,054 \\
8 & 0,365 & $-0,282$ & 0,098 & 0,159 \\
10 & 0,590 & $-0,632$ & 0,179 & 0,159 \\
11 & 0,186 & $-0,219$ & 0,059 & 0,159 \\
13 & 0,130 & $-0,111$ & 0,038 & 0,159 \\
15 & 0,078 & $-0,088$ & 0,028 & 0,159 \\
\hline
\end{tabular}

A Tabela C.4 para o ensaio Catenária-2 com apenas as amplitudes correspondentes a movimentos fora do plano através da interpolação do sinal do ensaio, a maior amplitude acoplada máxima apresentada foi de 1,613 m. Este valor ocorreu para o modo 1 . Neste modo, a sua frequência de resposta com maior energia foi de 0,159 Hz.

Tabela C.4: Propriedades das amplitudes modais acopladas fora do plano da catenária do ensaio Catenária-2 através da interpolação do sinal do ensaio para a

$$
V_{\text {max }}=0,774 \mathrm{~m} / \mathrm{s} \text {. }
$$

\begin{tabular}{lllll}
\hline \multicolumn{5}{c}{ Amplitude } \\
Modo & Máxima(m) & Mínima(m) & Desvio Padrão(m) & Freq. máxima (Hz) \\
& & & & \\
\hline 1 & 1,613 & $-1,486$ & 0,457 & 0,159 \\
3 & 0,637 & $-0,938$ & 0,253 & 0,159 \\
5 & 0,408 & $-0,513$ & 0,156 & 0,098 \\
7 & 0,484 & $-0,374$ & 0,110 & 0,150 \\
9 & 0,386 & $-0,415$ & 0,121 & 0,193 \\
12 & 0,239 & $-0,211$ & 0,092 & 0,225 \\
14 & 0,175 & $-0,190$ & 0,054 & 0,225 \\
16 & 0,105 & $-0,116$ & 0,040 & 0,159 \\
\hline
\end{tabular}




\section{C.2 Catenária-2 - Velocidade de $1,05 \mathrm{~m} / \mathrm{s}$ e $V_{r 1}=$ 10,47}

Abaixo serão apresentados os gráficos com alguns detalhes da análise referentes ao arranjo Catenária-2 para a velocidade de $1,05 \mathrm{~m} / \mathrm{s}$ e $V_{r 1}=10,47$.
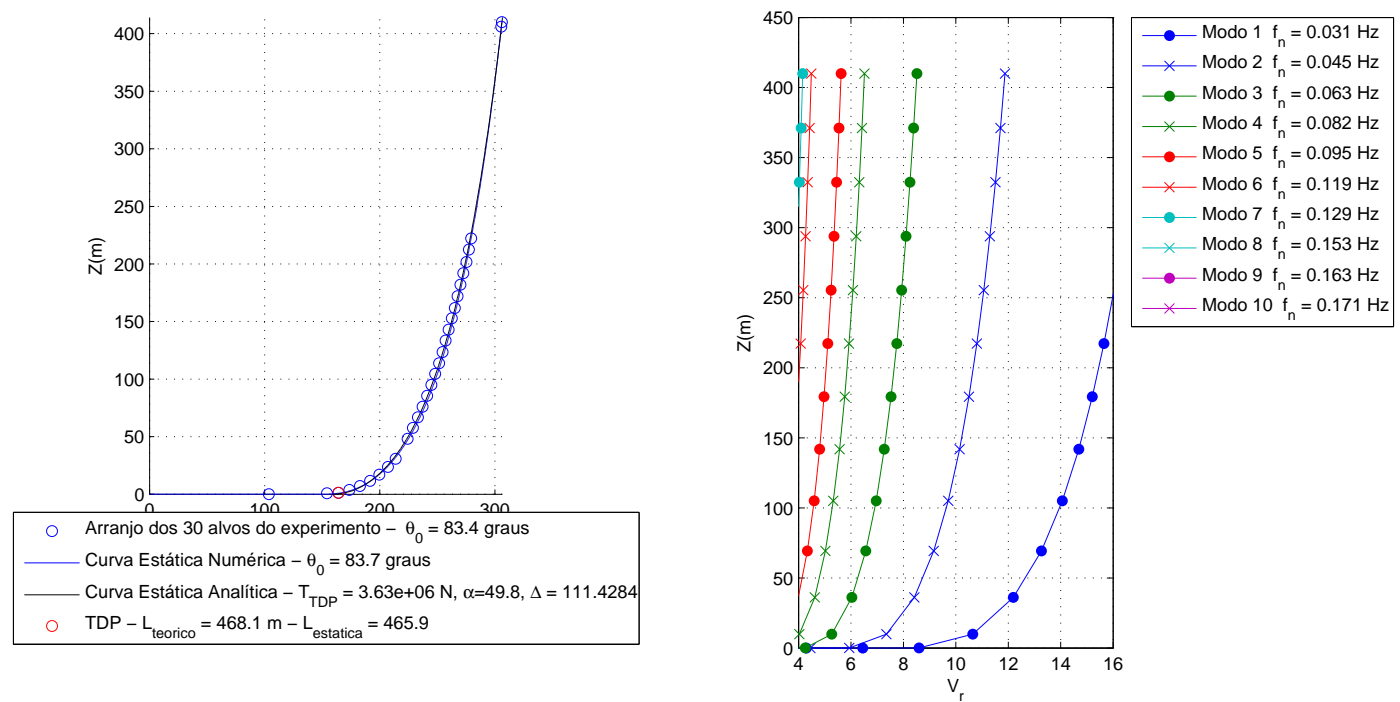

Figura C.6: Variação da velocidade no modelo durante o ensaio para Catenária-2 na

$$
U_{\text {max }}=1,05 \mathrm{~m} / \mathrm{s} \text { e } V_{r 1}=10,473 .
$$

Como pode ser visto na Tabela C.5 e nas Figuras de C.7 a C.9, os maiores deslocamentos máximos apresentados na direção X, Y e Z foram de 1,810, 2,083 e 0,933 $\mathrm{m}$, respectivamente. Estes valores ocorreram para os alvos 6, 19 e 27. Nestes alvos, as suas frequências de resposta com maior energia foram de 0,0903 e 0,135 Hz. 

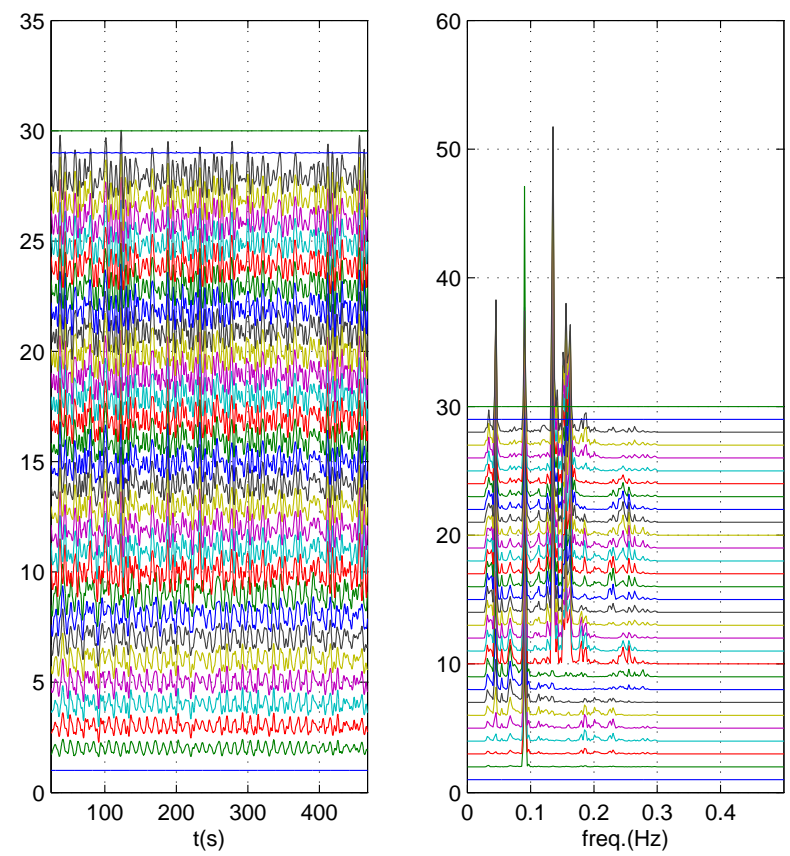

Figura C.7: Série temporal com frequências de resposta para $\mathrm{X}$ obtida experimentalmente por alvo para o arranjo de Catenária-2 na $U_{\max }=1,05 \mathrm{~m} / \mathrm{s}$ e $V_{r 1}=10,473$.
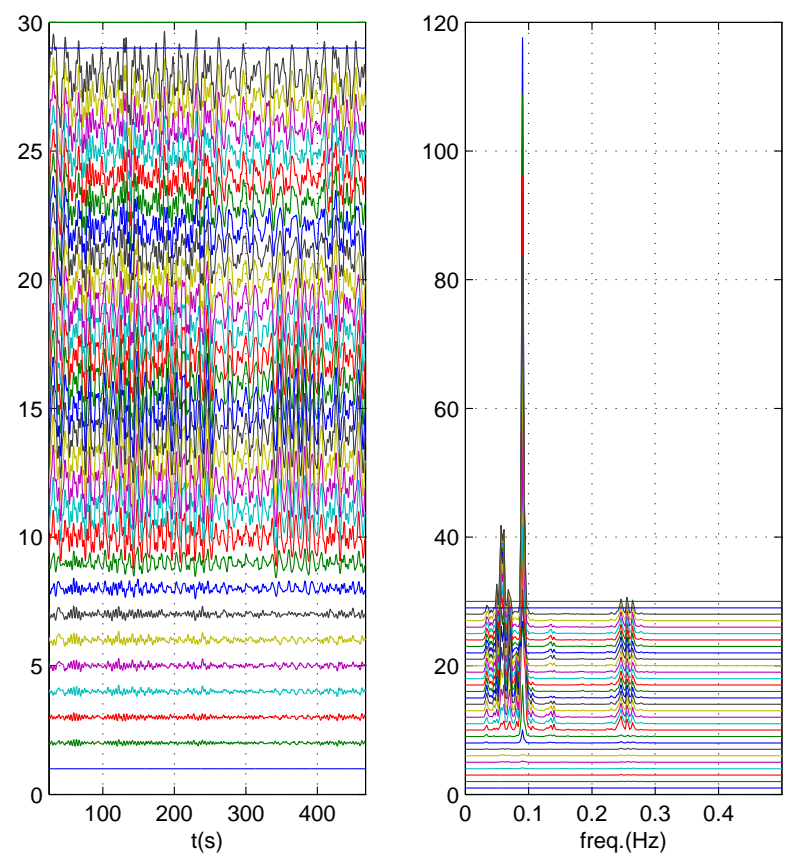

Figura C.8: Série temporal com frequências de resposta para Y obtida experimentalmente por alvo para o arranjo de Catenária-2 na $U_{\max }=1,05 \mathrm{~m} / \mathrm{s}$ e $V_{r 1}=10,473$. 

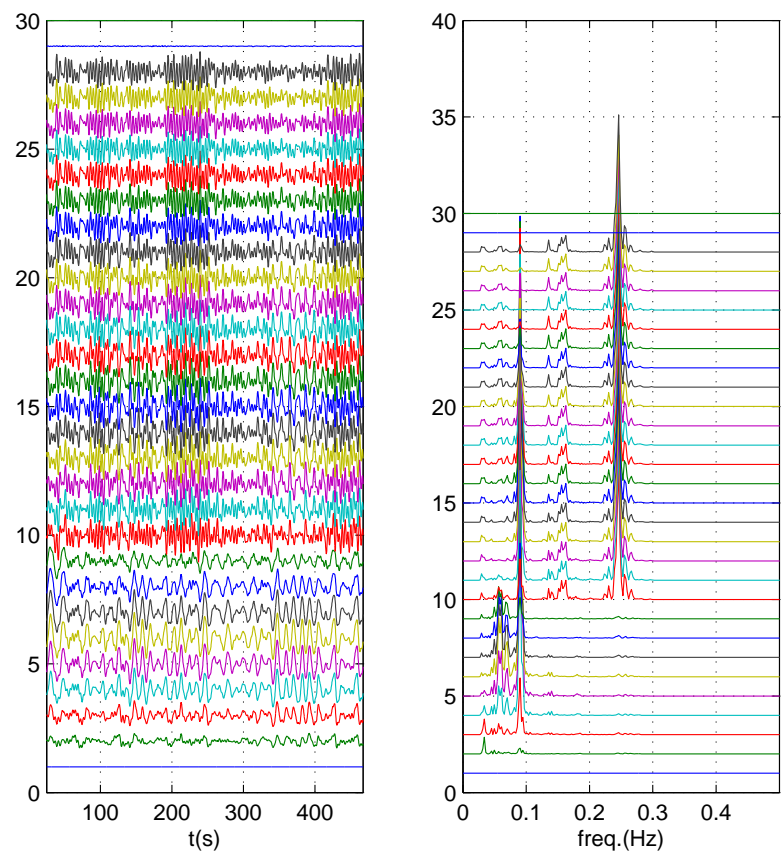

Figura C.9: Série temporal com frequências de resposta para Z obtida experimentalmente por alvo para o arranjo de Catenária-2 na $U_{\max }=1,05 \mathrm{~m} / \mathrm{s}$ e $V_{r 1}=10,473$. 
Tabela C.5: Propriedades da série temporal do ensaio Catenária-2 para a

$$
U_{\max }=1,05 \mathrm{~m} / \mathrm{s} \text {. }
$$

\begin{tabular}{|c|c|c|c|c|c|c|c|c|c|c|c|c|}
\hline \multirow[b]{2}{*}{ ID. Alvo } & \multirow[b]{2}{*}{$\mathrm{X}(\mathrm{m})$} & \multicolumn{2}{|c|}{ Máximo } & \multirow[b]{2}{*}{$\mathrm{X}(\mathrm{m})$} & \multirow{2}{*}{$\begin{array}{l}\text { Mínimo } \\
\mathrm{Y}(\mathrm{m})\end{array}$} & \multirow{2}{*}{$\mathrm{Z}(\mathrm{m})$} & \multicolumn{3}{|c|}{ Desvio padrão } & \multicolumn{3}{|c|}{ Freq. máxima em $\mathrm{Hz}$} \\
\hline & & $\mathrm{Y}(\mathrm{m})$ & $\mathrm{Z}(\mathrm{m})$ & & & & $\mathrm{X}(\mathrm{m})$ & $\mathrm{Y}(\mathrm{m})$ & $\mathrm{Z}(\mathrm{m})$ & $\mathrm{X}$ & $\mathrm{Y}$ & $\mathrm{Z}$ \\
\hline 1 & 0,000 & 0,000 & 0,000 & 0,000 & 0,000 & $-0,000$ & 0,000 & 0,000 & 0,000 & 0,000 & 0,000 & 0,244 \\
\hline 2 & 0,414 & 0,089 & 0,195 & $-0,358$ & $-0,072$ & $-0,197$ & 0,212 & 0,042 & 0,109 & 0,090 & 0,257 & 0,034 \\
\hline 3 & 0,619 & 0,098 & 0,410 & $-0,462$ & $-0,070$ & $-0,333$ & 0,278 & 0,044 & 0,212 & 0,090 & 0,246 & 0,090 \\
\hline 4 & 0,840 & 0,136 & 0,717 & $-0,559$ & $-0,144$ & $-0,530$ & 0,357 & 0,073 & 0,374 & 0,090 & 0,090 & 0,090 \\
\hline 5 & 1,057 & 0,169 & 0,880 & $-0,636$ & $-0,175$ & $-0,679$ & 0,438 & 0,101 & 0,478 & 0,090 & 0,090 & 0,090 \\
\hline 6 & 1,225 & 0,236 & 0,933 & $-0,719$ & $-0,204$ & $-0,773$ & 0,517 & 0,125 & 0,531 & 0,090 & 0,090 & 0,090 \\
\hline 7 & 1,324 & 0,262 & 0,856 & $-0,815$ & $-0,235$ & $-0,775$ & 0,581 & 0,128 & 0,518 & 0,090 & 0,246 & 0,090 \\
\hline 8 & 1,368 & 0,275 & 0,713 & $-0,911$ & $-0,306$ & $-0,733$ & 0,633 & 0,148 & 0,472 & 0,090 & 0,090 & 0,090 \\
\hline 9 & 1,359 & 0,377 & 0,541 & $-1,005$ & $-0,354$ & $-0,696$ & 0,671 & 0,188 & 0,399 & 0,090 & 0,090 & 0,056 \\
\hline 10 & 1,502 & 1,035 & 0,408 & $-1,112$ & $-0,936$ & $-0,968$ & 0,724 & 0,445 & 0,370 & 0,135 & 0,090 & 0,246 \\
\hline 11 & 1,557 & 1,328 & 0,423 & $-1,000$ & $-1,147$ & $-0,855$ & 0,713 & 0,595 & 0,314 & 0,135 & 0,090 & 0,246 \\
\hline 12 & 1,636 & 1,574 & 0,450 & $-0,880$ & $-1,360$ & $-0,744$ & 0,704 & 0,746 & 0,281 & 0,135 & 0,090 & 0,090 \\
\hline 13 & 1,716 & 1,757 & 0,470 & $-0,766$ & $-1,541$ & $-0,654$ & 0,695 & 0,883 & 0,270 & 0,135 & 0,090 & 0,090 \\
\hline 14 & 1,778 & 1,889 & 0,478 & $-0,673$ & $-1,711$ & $-0,585$ & 0,687 & 1,013 & 0,275 & 0,135 & 0,090 & 0,090 \\
\hline 15 & 1,810 & 1,992 & 0,495 & $-0,644$ & $-1,850$ & $-0,542$ & 0,681 & 1,124 & 0,293 & 0,135 & 0,090 & 0,090 \\
\hline 16 & 1,805 & 2,033 & 0,543 & $-0,682$ & $-1,951$ & $-0,581$ & 0,680 & 1,211 & 0,311 & 0,135 & 0,090 & 0,090 \\
\hline 17 & 1,793 & 2,077 & 0,603 & $-0,748$ & $-2,028$ & $-0,604$ & 0,686 & 1,282 & 0,328 & 0,045 & 0,090 & 0,090 \\
\hline 18 & 1,760 & 2,064 & 0,644 & $-0,822$ & $-2,089$ & $-0,604$ & 0,697 & 1,328 & 0,336 & 0,045 & 0,090 & 0,090 \\
\hline 19 & 1,709 & 2,083 & 0,703 & $-0,874$ & $-2,133$ & $-0,614$ & 0,709 & 1,363 & 0,350 & 0,045 & 0,090 & 0,090 \\
\hline 20 & 1,665 & 2,020 & 0,730 & $-0,897$ & $-2,169$ & $-0,596$ & 0,719 & 1,369 & 0,353 & 0,045 & 0,090 & 0,246 \\
\hline 21 & 1,631 & 1,988 & 0,758 & $-0,909$ & $-2,195$ & $-0,599$ & 0,729 & 1,375 & 0,356 & 0,135 & 0,056 & 0,246 \\
\hline 22 & 1,622 & 2,005 & 0,763 & $-0,989$ & $-2,229$ & $-0,602$ & 0,737 & 1,374 & 0,355 & 0,135 & 0,056 & 0,246 \\
\hline 23 & 1,648 & 1,907 & 0,770 & $-1,056$ & $-2,248$ & $-0,602$ & 0,744 & 1,345 & 0,351 & 0,135 & 0,056 & 0,246 \\
\hline 24 & 1,690 & 1,842 & 0,768 & $-1,099$ & $-2,244$ & $-0,597$ & 0,751 & 1,316 & 0,346 & 0,135 & 0,056 & 0,246 \\
\hline 25 & 1,746 & 1,777 & 0,741 & $-1,132$ & $-2,226$ & $-0,585$ & 0,759 & 1,276 & 0,334 & 0,135 & 0,090 & 0,246 \\
\hline 26 & 1,790 & 1,699 & 0,737 & $-1,144$ & $-2,196$ & $-0,578$ & 0,762 & 1,232 & 0,330 & 0,135 & 0,090 & 0,246 \\
\hline 27 & 1,810 & 1,626 & 0,708 & $-1,138$ & $-2,147$ & $-0,565$ & 0,758 & 1,176 & 0,318 & 0,135 & 0,090 & 0,246 \\
\hline 28 & 1,798 & 1,549 & 0,688 & $-1,108$ & $-2,084$ & $-0,551$ & 0,745 & 1,125 & 0,309 & 0,135 & 0,090 & 0,246 \\
\hline 29 & 0,017 & 0,006 & 0,014 & $-0,014$ & $-0,008$ & $-0,012$ & 0,009 & 0,004 & 0,008 & 0,090 & 0,135 & 0,090 \\
\hline 30 & 0,000 & 0,000 & 0,000 & 0,000 & 0,000 & 0,000 & 0,000 & 0,000 & 0,000 & 0,000 & 0,000 & 0,000 \\
\hline
\end{tabular}

Considerando agora a decomposição modal, na Tabela C.6 através da interpolação do sinal do ensaio, correspondente a uma velocade reduzida do primeiro modo $V_{r 1}=10,47$, as maiores amplitudes máximas apresentadas na direção X, Y e Z foram de 1,822, 1,830 e 0,741 m, respectivamente. Estes valores ocorreram para os modos 1, 2 e 10, Nestes modos, as suas frequências de resposta com maior energia foram de 0,0564, 0,135 e 0,246 $\mathrm{Hz}$. 

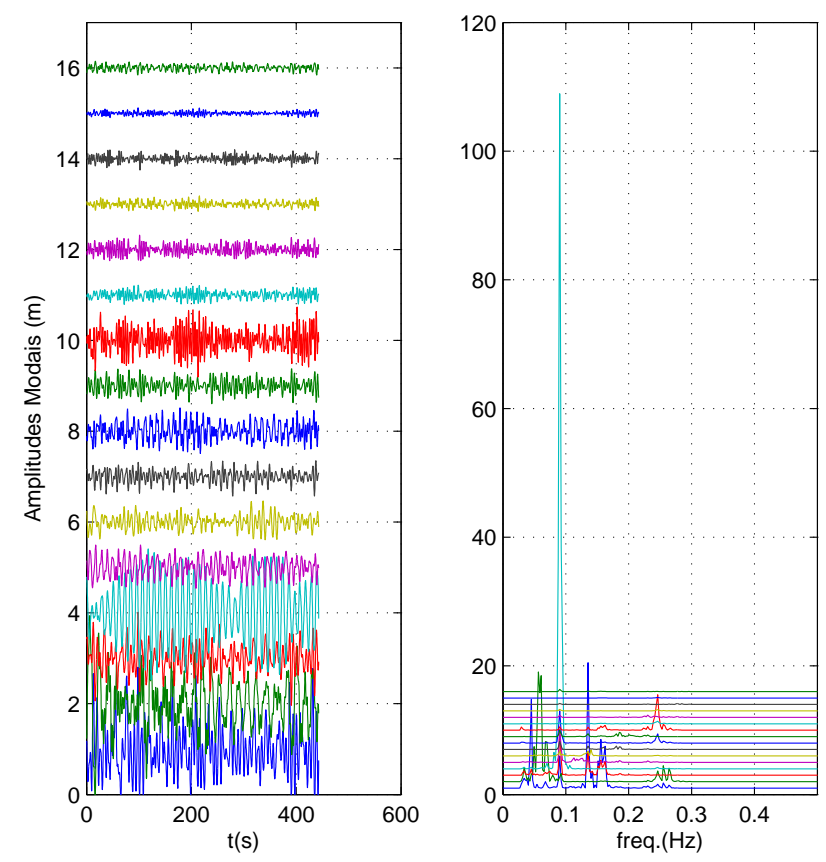

Figura C.10: Variação da amplitude modal acoplada ao longo do tempo através da interpolação do sinal do ensaio para Catenária-2 na $U_{\max }=1,05 \mathrm{~m} / \mathrm{s}$ e $V_{r 1}=10,473$.

Tabela C.6: Propriedades das amplitudes modais do ensaio Catenária-2 através da interpolação do sinal do ensaio para a $V_{\max }=1,05 \mathrm{~m} / \mathrm{s}$.

\begin{tabular}{lcccccccccccccc}
\hline \multicolumn{1}{c}{ Máximo } & \multicolumn{1}{c}{ Mínimo } & & \multicolumn{3}{c}{ Desvio padrão } & \multicolumn{7}{c}{ Freq. máxima em Hz } \\
\multicolumn{1}{c}{ Modo } & $\mathrm{X}(\mathrm{m})$ & $\mathrm{Y}(\mathrm{m})$ & $\mathrm{Z}(\mathrm{m})$ & $\mathrm{X}(\mathrm{m})$ & $\mathrm{Y}(\mathrm{m})$ & $\mathrm{Z}(\mathrm{m})$ & $\mathrm{X}(\mathrm{m})$ & $\mathrm{Y}(\mathrm{m})$ & $\mathrm{Z}(\mathrm{m})$ & $\mathrm{X}$ & $\mathrm{Y}$ & $\mathrm{Z}$ \\
& & & & & & & & & & & & \\
\hline 1 & 1,822 & 0,000 & 0,000 & $-1,152$ & $-0,000$ & $-0,000$ & 0,547 & 0,000 & 0,000 & 0,135 & 0,056 & 0,090 \\
2 & 0,000 & 1,830 & 0,164 & $-0,000$ & $-2,104$ & $-0,193$ & 0,000 & 0,537 & 0,061 & 0,135 & 0,056 & 0,090 \\
3 & 1,025 & 0,000 & 0,000 & $-1,047$ & $-0,000$ & $-0,000$ & 0,307 & 0,000 & 0,000 & 0,090 & 0,056 & 0,090 \\
4 & 0,000 & 1,179 & 0,292 & $-0,000$ & $-1,222$ & $-0,284$ & 0,000 & 0,595 & 0,101 & 0,090 & 0,090 & 0,090 \\
5 & 0,501 & 0,000 & 0,000 & $-0,467$ & $-0,000$ & $-0,000$ & 0,206 & 0,000 & 0,000 & 0,090 & 0,090 & 0,090 \\
6 & 0,000 & 0,414 & 0,193 & $-0,000$ & $-0,346$ & $-0,178$ & 0,000 & 0,138 & 0,069 & 0,090 & 0,090 & 0,090 \\
7 & 0,356 & 0,000 & 0,000 & $-0,434$ & $-0,000$ & $-0,000$ & 0,134 & 0,000 & 0,000 & 0,090 & 0,090 & 0,090 \\
8 & 0,000 & 0,313 & 0,417 & $-0,000$ & $-0,408$ & $-0,482$ & 0,000 & 0,162 & 0,139 & 0,090 & 0,090 & 0,246 \\
9 & 0,381 & 0,000 & 0,000 & $-0,400$ & $-0,000$ & $-0,000$ & 0,140 & 0,000 & 0,000 & 0,090 & 0,090 & 0,246 \\
10 & 0,000 & 0,088 & 0,741 & $-0,000$ & $-0,093$ & $-0,800$ & 0,000 & 0,031 & 0,237 & 0,090 & 0,090 & 0,246 \\
11 & 0,000 & 0,134 & 0,196 & $-0,000$ & $-0,125$ & $-0,202$ & 0,000 & 0,046 & 0,064 & 0,230 & 0,090 & 0,246 \\
12 & 0,322 & 0,000 & 0,000 & $-0,249$ & $-0,000$ & $-0,000$ & 0,101 & 0,000 & 0,000 & 0,230 & 0,090 & 0,246 \\
13 & 0,000 & 0,083 & 0,144 & $-0,000$ & $-0,079$ & $-0,128$ & 0,000 & 0,030 & 0,043 & 0,278 & 0,090 & 0,246 \\
14 & 0,199 & 0,000 & 0,000 & $-0,252$ & $-0,000$ & $-0,000$ & 0,067 & 0,000 & 0,000 & 0,278 & 0,090 & 0,246 \\
15 & 0,000 & 0,059 & 0,127 & $-0,000$ & $-0,066$ & $-0,098$ & 0,000 & 0,020 & 0,036 & 0,090 & 0,090 & 0,246 \\
16 & 0,146 & 0,000 & 0,001 & $-0,160$ & $-0,000$ & $-0,001$ & 0,056 & 0,000 & 0,000 & 0,090 & 0,090 & 0,246 \\
\hline
\end{tabular}

A Tabela C.7 apresenta para o ensaio Catenária-2 apenas os movimentos referentes a 
deslocamento no plano da catenária através da interpolação do sinal do ensaio, a maior amplitude acoplada máxima foi de 1,941 m. Este valor ocorreu para o modo 2. Neste modo, a sua frequência de resposta com maior energia foi de 0,056 Hz.

Tabela C.7: Propriedades das amplitudes modais acopladas no plano da catenária do ensaio Catenária-2 através da interpolação do sinal do ensaio para a $V_{\max }=1,05 \mathrm{~m} / \mathrm{s}$.

Amplitude

Modo Máxima(m) Mínima(m) Desvio Padrão(m) Freq. máxima (Hz)

\begin{tabular}{lllll}
\hline 2 & 1,941 & $-2,115$ & 0,560 & 0,056 \\
4 & 1,408 & $-1,472$ & 0,668 & 0,090 \\
6 & 0,466 & $-0,393$ & 0,150 & 0,140 \\
8 & 0,513 & $-0,491$ & 0,192 & 0,090 \\
10 & 0,736 & $-0,807$ & 0,243 & 0,246 \\
11 & 0,217 & $-0,210$ & 0,078 & 0,246 \\
13 & 0,181 & $-0,161$ & 0,057 & 0,090 \\
15 & 0,120 & $-0,097$ & 0,036 & 0,246 \\
\hline
\end{tabular}

A Tabela C.8 para o ensaio Catenária-2 com apenas as amplitudes correspondentes a movimentos fora do plano através da interpolação do sinal do ensaio, a maior amplitude acoplada máxima apresentada foi de 1,805 m. Este valor ocorreu para o modo 1 . Neste modo, a sua frequência de resposta com maior energia foi de 0,135 Hz.

Tabela C.8: Propriedades das amplitudes modais acopladas fora do plano da catenária do ensaio Catenária-2 através da interpolação do sinal do ensaio para a $V_{\max }=1,05 \mathrm{~m} / \mathrm{s}$.

Amplitude

Modo Máxima(m) Mínima $(\mathrm{m})$ Desvio Padrão(m) Freq. máxima $(\mathrm{Hz})$

\begin{tabular}{lllll}
\hline 1 & 1,805 & $-1,142$ & 0,542 & 0,135 \\
3 & 1,012 & $-1,034$ & 0,303 & 0,090 \\
5 & 0,495 & $-0,461$ & 0,203 & 0,090 \\
7 & 0,352 & $-0,428$ & 0,132 & 0,090 \\
9 & 0,376 & $-0,395$ & 0,139 & 0,090 \\
12 & 0,319 & $-0,247$ & 0,099 & 0,230 \\
14 & 0,197 & $-0,249$ & 0,066 & 0,278 \\
16 & 0,144 & $-0,159$ & 0,055 & 0,090 \\
\hline
\end{tabular}




\section{C.3 Catenária-2 - Velocidade de $1,28 \mathrm{~m} / \mathrm{s}$ e $V_{r 1}=$ 12,79}

Abaixo serão apresentados os gráficos com alguns detalhes da análise referentes ao arranjo Catenária-2 para a velocidade de $1,28 \mathrm{~m} / \mathrm{s}$ e $V_{r 1}=12,79$.
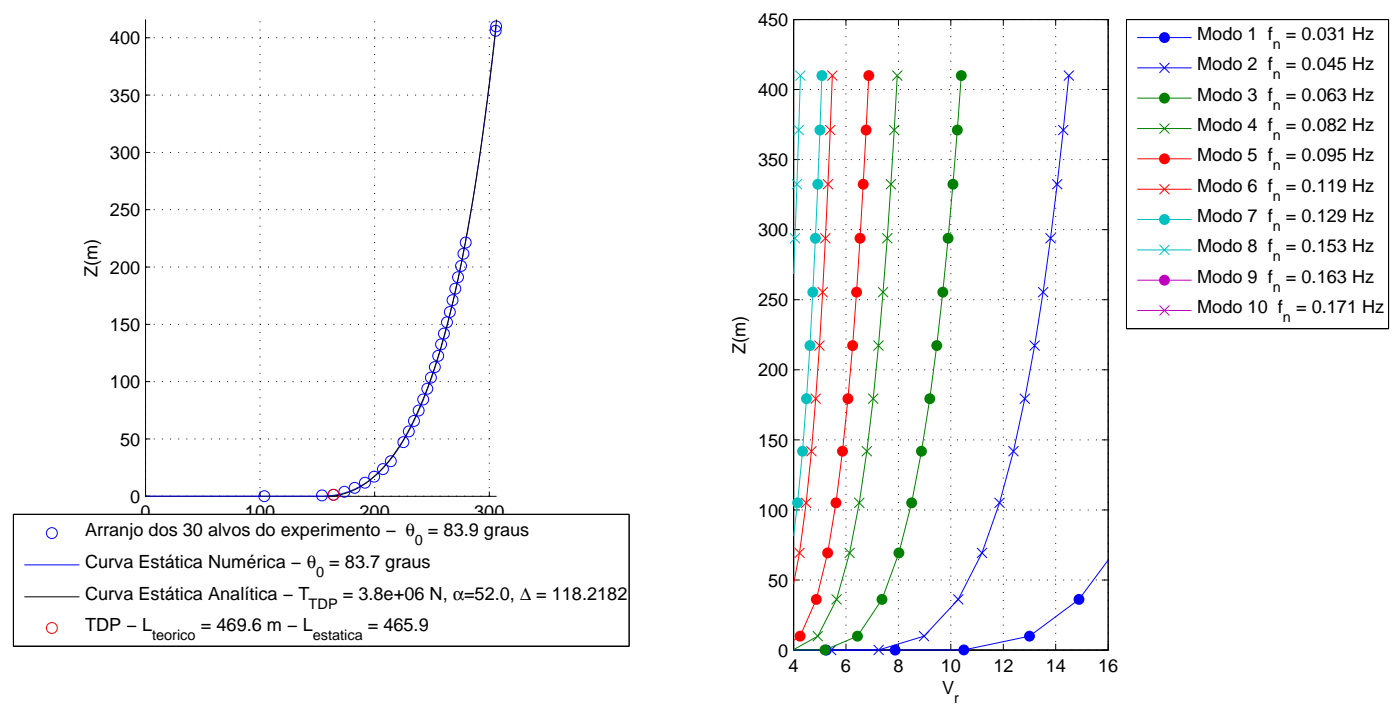

Figura C.11: Variação da velocidade no modelo durante o ensaio para Catenária-2 na

$$
U_{\text {max }}=1,28 \mathrm{~m} / \mathrm{s} \text { e } V_{r 1}=12,792 \text {. }
$$

Como pode ser visto na Tabela C.9 e nas Figuras de C.12 a C.14, os maiores deslocamentos máximos apresentados na direção X, Y e Z foram de 1,472, 1,588 e 0,659 $\mathrm{m}$, respectivamente. Estes valores ocorreram para os alvos 10, 20 e 25. Nestes alvos, as suas frequências de resposta com maior energia foram de 0,0961, 0,161 e 0,246 Hz. 

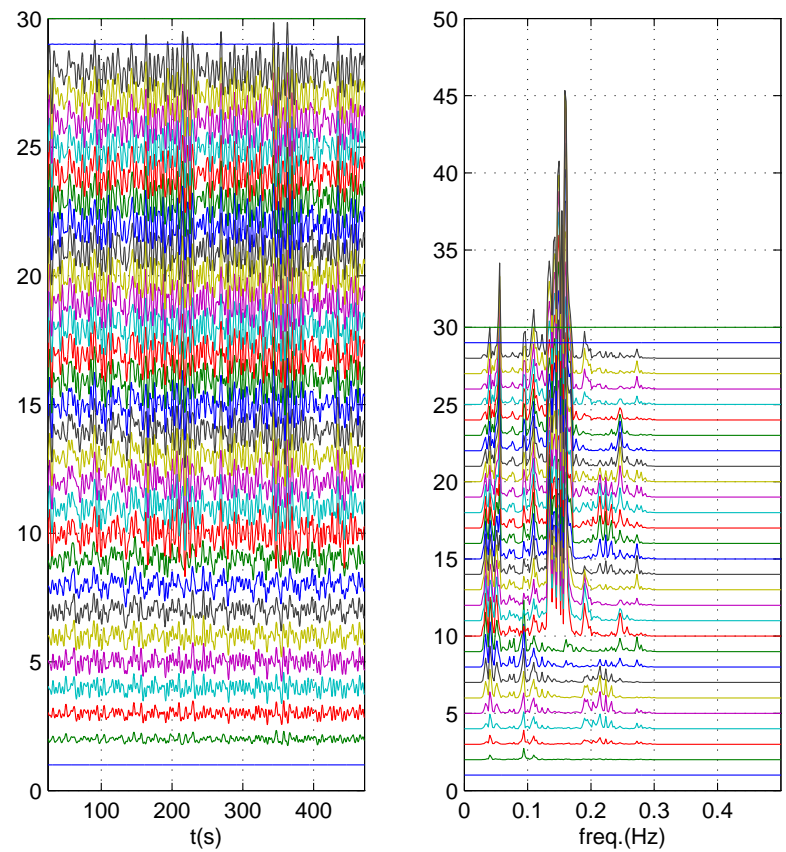

Figura C.12: Série temporal com frequências de resposta para X obtida experimentalmente por alvo para o arranjo de Catenária-2 na $U_{\max }=1,28 \mathrm{~m} / \mathrm{s}$ e $V_{r 1}=12,792$.
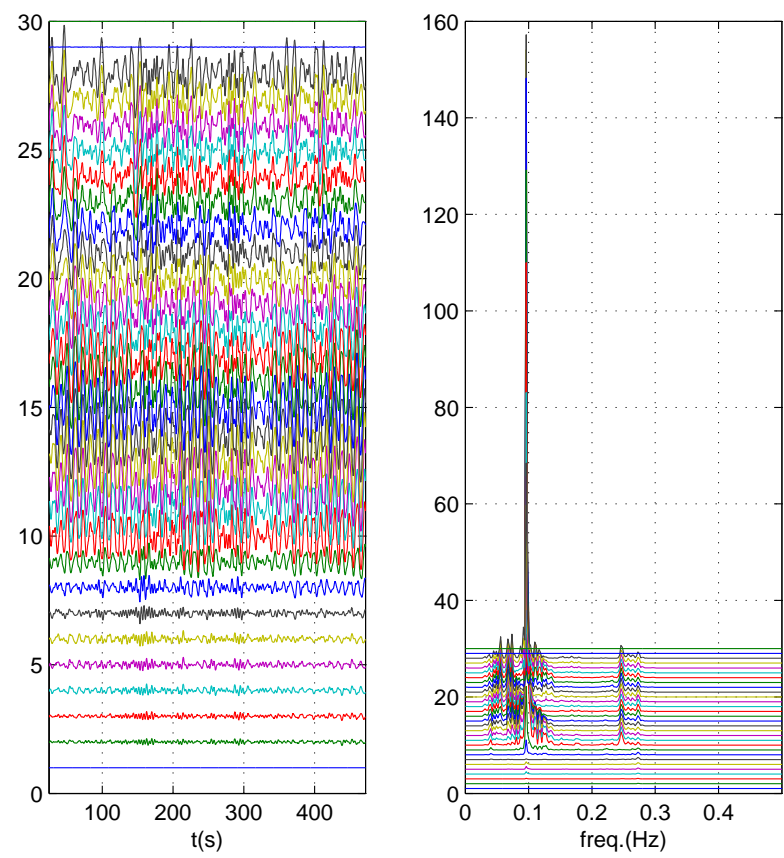

Figura C.13: Série temporal com frequências de resposta para Y obtida experimentalmente por alvo para o arranjo de Catenária-2 na $U_{\max }=1,28 \mathrm{~m} / \mathrm{s} \mathrm{e}$ $V_{r 1}=12,792$. 

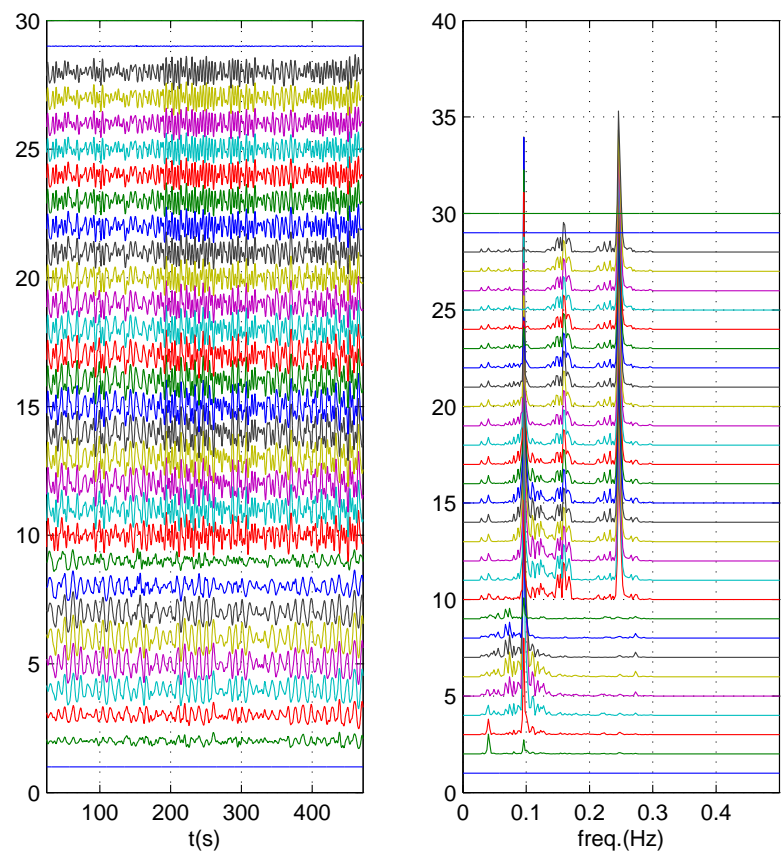

Figura C.14: Série temporal com frequências de resposta para Z obtida experimentalmente por alvo para o arranjo de Catenária-2 na $U_{\max }=1,28 \mathrm{~m} / \mathrm{s}$ e $V_{r 1}=12,792$. 
Tabela C.9: Propriedades da série temporal do ensaio Catenária-2 para a

$$
U_{\max }=1,28 \mathrm{~m} / \mathrm{s} \text {. }
$$

\begin{tabular}{|c|c|c|c|c|c|c|c|c|c|c|c|c|}
\hline \multirow[b]{2}{*}{ ID. Alvo } & \multirow[b]{2}{*}{$\mathrm{X}(\mathrm{m})$} & \multicolumn{2}{|c|}{ Máximo } & \multirow[b]{2}{*}{$\mathrm{X}(\mathrm{m})$} & \multirow{2}{*}{$\begin{array}{l}\text { Mínimo } \\
\mathrm{Y}(\mathrm{m})\end{array}$} & \multirow{2}{*}{$\mathrm{Z}(\mathrm{m})$} & \multicolumn{3}{|c|}{ Desvio padrão } & \multicolumn{3}{|c|}{ Freq. máxima em $\mathrm{Hz}$} \\
\hline & & $\mathrm{Y}(\mathrm{m})$ & $\mathrm{Z}(\mathrm{m})$ & & & & $\mathrm{X}(\mathrm{m})$ & $\mathrm{Y}(\mathrm{m})$ & $\mathrm{Z}(\mathrm{m})$ & $\mathrm{X}$ & $\mathrm{Y}$ & $\mathrm{Z}$ \\
\hline 1 & 0,000 & 0,000 & 0,000 & 0,000 & 0,000 & $-0,000$ & 0,000 & 0,000 & 0,000 & 0,000 & 0,000 & 0,246 \\
\hline 2 & 0,110 & 0,054 & 0,130 & $-0,141$ & $-0,040$ & $-0,105$ & 0,074 & 0,023 & 0,064 & 0,094 & 0,273 & 0,040 \\
\hline 3 & 0,204 & 0,070 & 0,228 & $-0,174$ & $-0,043$ & $-0,209$ & 0,103 & 0,027 & 0,112 & 0,094 & 0,273 & 0,096 \\
\hline 4 & 0,271 & 0,106 & 0,325 & $-0,259$ & $-0,110$ & $-0,415$ & 0,138 & 0,052 & 0,205 & 0,094 & 0,096 & 0,096 \\
\hline 5 & 0,296 & 0,113 & 0,360 & $-0,328$ & $-0,143$ & $-0,538$ & 0,163 & 0,066 & 0,264 & 0,215 & 0,096 & 0,096 \\
\hline 6 & 0,274 & 0,197 & 0,357 & $-0,355$ & $-0,162$ & $-0,670$ & 0,173 & 0,088 & 0,312 & 0,040 & 0,096 & 0,096 \\
\hline 7 & 0,244 & 0,157 & 0,366 & $-0,394$ & $-0,196$ & $-0,571$ & 0,168 & 0,090 & 0,298 & 0,040 & 0,273 & 0,096 \\
\hline 8 & 0,212 & 0,183 & 0,353 & $-0,385$ & $-0,201$ & $-0,463$ & 0,160 & 0,108 & 0,268 & 0,040 & 0,096 & 0,096 \\
\hline 9 & 0,205 & 0,302 & 0,383 & $-0,398$ & $-0,246$ & $-0,406$ & 0,170 & 0,149 & 0,235 & 0,040 & 0,096 & 0,096 \\
\hline 10 & 0,916 & 0,612 & 0,659 & $-0,898$ & $-0,687$ & $-0,601$ & 0,432 & 0,347 & 0,317 & 0,159 & 0,096 & 0,246 \\
\hline 11 & 0,834 & 0,749 & 0,655 & $-0,973$ & $-0,891$ & $-0,678$ & 0,416 & 0,443 & 0,322 & 0,161 & 0,096 & 0,096 \\
\hline 12 & 0,829 & 0,852 & 0,638 & $-1,066$ & $-1,079$ & $-0,725$ & 0,416 & 0,528 & 0,328 & 0,161 & 0,096 & 0,096 \\
\hline 13 & 0,882 & 0,916 & 0,620 & $-1,151$ & $-1,229$ & $-0,742$ & 0,430 & 0,595 & 0,333 & 0,161 & 0,096 & 0,096 \\
\hline 14 & 0,963 & 0,925 & 0,611 & $-1,234$ & $-1,350$ & $-0,735$ & 0,458 & 0,649 & 0,336 & 0,161 & 0,096 & 0,096 \\
\hline 15 & 1,051 & 0,895 & 0,601 & $-1,296$ & $-1,450$ & $-0,713$ & 0,495 & 0,689 & 0,336 & 0,161 & 0,096 & 0,096 \\
\hline 16 & 1,150 & 0,960 & 0,578 & $-1,326$ & $-1,488$ & $-0,679$ & 0,536 & 0,708 & 0,330 & 0,161 & 0,096 & 0,096 \\
\hline 17 & 1,253 & 1,061 & 0,576 & $-1,346$ & $-1,497$ & $-0,642$ & 0,576 & 0,718 & 0,327 & 0,161 & 0,096 & 0,096 \\
\hline 18 & 1,346 & 1,193 & 0,552 & $-1,348$ & $-1,441$ & $-0,599$ & 0,610 & 0,713 & 0,319 & 0,161 & 0,096 & 0,096 \\
\hline 19 & 1,438 & 1,280 & 0,536 & $-1,342$ & $-1,371$ & $-0,553$ & 0,641 & 0,712 & 0,310 & 0,161 & 0,096 & 0,096 \\
\hline 20 & 1,472 & 1,374 & 0,508 & $-1,339$ & $-1,230$ & $-0,525$ & 0,656 & 0,692 & 0,297 & 0,161 & 0,096 & 0,246 \\
\hline 21 & 1,456 & 1,458 & 0,497 & $-1,355$ & $-1,061$ & $-0,514$ & 0,662 & 0,691 & 0,292 & 0,159 & 0,096 & 0,246 \\
\hline 22 & 1,426 & 1,517 & 0,475 & $-1,377$ & $-0,928$ & $-0,492$ & 0,668 & 0,698 & 0,282 & 0,159 & 0,074 & 0,246 \\
\hline 23 & 1,334 & 1,553 & 0,446 & $-1,425$ & $-0,714$ & $-0,480$ & 0,660 & 0,699 & 0,276 & 0,159 & 0,074 & 0,246 \\
\hline 24 & 1,225 & 1,582 & 0,426 & $-1,483$ & $-0,728$ & $-0,480$ & 0,653 & 0,717 & 0,269 & 0,159 & 0,074 & 0,246 \\
\hline 25 & 1,119 & 1,588 & 0,408 & $-1,556$ & $-0,875$ & $-0,475$ & 0,645 & 0,737 & 0,263 & 0,159 & 0,096 & 0,246 \\
\hline 26 & 1,032 & 1,533 & 0,399 & $-1,627$ & $-1,004$ & $-0,468$ & 0,639 & 0,743 & 0,258 & 0,159 & 0,096 & 0,246 \\
\hline 27 & 0,980 & 1,456 & 0,401 & $-1,673$ & $-1,120$ & $-0,454$ & 0,633 & 0,740 & 0,253 & 0,159 & 0,096 & 0,246 \\
\hline 28 & 0,970 & 1,380 & 0,396 & $-1,695$ & $-1,191$ & $-0,440$ & 0,630 & 0,727 & 0,246 & 0,159 & 0,096 & 0,246 \\
\hline 29 & 0,007 & 0,011 & 0,009 & $-0,007$ & $-0,008$ & $-0,006$ & 0,004 & 0,004 & 0,004 & 0,094 & 0,134 & 0,246 \\
\hline 30 & 0,000 & 0,000 & 0,000 & 0,000 & 0,000 & 0,000 & 0,000 & 0,000 & 0,000 & 0,000 & 0,000 & 0,000 \\
\hline
\end{tabular}

Considerando agora a decomposição modal, na Tabela C.10 através da interpolação do sinal do ensaio, correspondente a uma velocade reduzida do primeiro modo $V_{r 1}=12,79$, as maiores amplitudes máximas apresentadas na direção X, Y e Z foram de 1,776, 1,389 e 0,674 m, respectivamente. Estes valores ocorreram para os modos 1, 4 e 10, Nestes modos, as suas frequências de resposta com maior energia foram de 0,0961, 0,161 e 0,246 $\mathrm{Hz}$. 

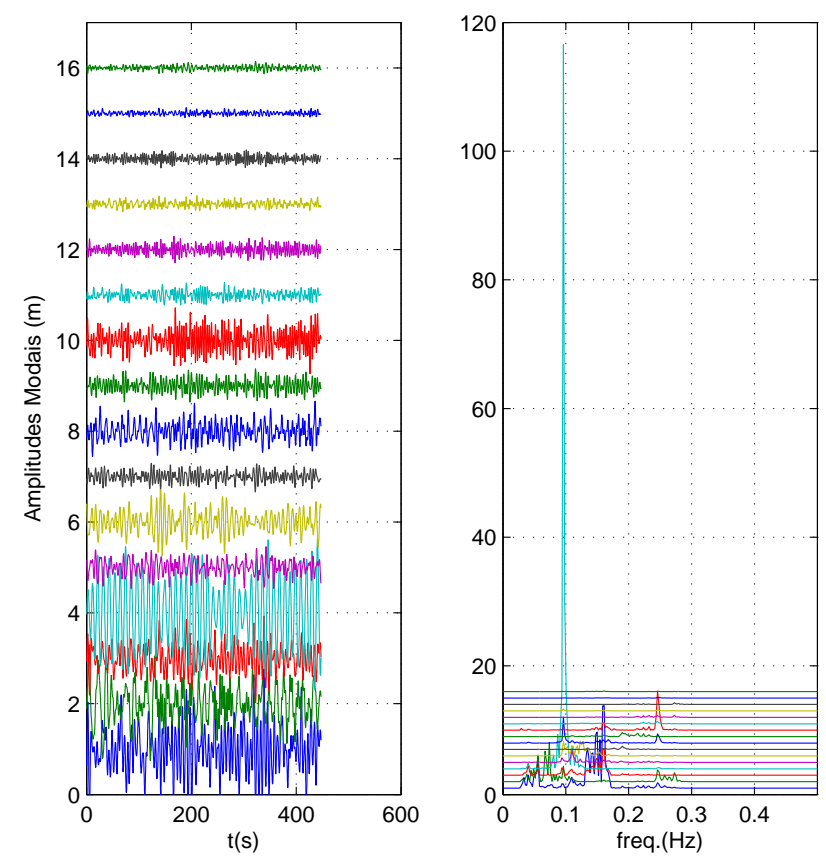

Figura C.15: Variação da amplitude modal acoplada ao longo do tempo através da interpolação do sinal do ensaio para Catenária-2 na $U_{\max }=1,28 \mathrm{~m} / \mathrm{s}$ e $V_{r 1}=12,792$.

Tabela C.10: Propriedades das amplitudes modais do ensaio Catenária-2 através da interpolação do sinal do ensaio para a $V_{\max }=1,28 \mathrm{~m} / \mathrm{s}$.

\begin{tabular}{|c|c|c|c|c|c|c|c|c|c|c|c|c|}
\hline \multirow[b]{2}{*}{ Modo } & \multirow[b]{2}{*}{$\mathrm{X}(\mathrm{m})$} & \multicolumn{2}{|c|}{ Máximo } & \multirow[b]{2}{*}{$\mathrm{X}(\mathrm{m})$} & \multirow{2}{*}{$\begin{array}{l}\text { Mínimo } \\
\mathrm{Y}(\mathrm{m})\end{array}$} & \multirow[b]{2}{*}{$\mathrm{Z}(\mathrm{m})$} & \multicolumn{3}{|c|}{ Desvio padrão } & \multicolumn{3}{|c|}{ Freq. máxima em $\mathrm{Hz}$} \\
\hline & & $\mathrm{Y}(\mathrm{m})$ & $\mathrm{Z}(\mathrm{m})$ & & & & $\mathrm{X}(\mathrm{m})$ & $\mathrm{Y}(\mathrm{m})$ & $\mathrm{Z}(\mathrm{m})$ & $\mathrm{X}$ & $\mathrm{Y}$ & Z \\
\hline 1 & 1,776 & 0,000 & 0,000 & $-1,464$ & $-0,000$ & $-0,000$ & 0,523 & 0,000 & 0,000 & 0,161 & 0,074 & 0,096 \\
\hline 2 & 0,000 & 1,216 & 0,152 & $-0,000$ & $-1,241$ & $-0,169$ & 0,000 & 0,385 & 0,058 & 0,161 & 0,074 & 0,096 \\
\hline 3 & 0,943 & 0,000 & 0,000 & $-0,989$ & $-0,000$ & $-0,000$ & 0,291 & 0,000 & 0,000 & 0,161 & 0,074 & 0,096 \\
\hline 4 & 0,000 & 1,389 & 0,356 & $-0,000$ & $-1,529$ & $-0,284$ & 0,000 & 0,650 & 0,115 & 0,161 & 0,096 & 0,096 \\
\hline 5 & 0,466 & 0,000 & 0,000 & $-0,465$ & $-0,000$ & $-0,000$ & 0,170 & 0,000 & 0,000 & 0,110 & 0,096 & 0,096 \\
\hline 6 & 0,000 & 0,682 & 0,221 & $-0,000$ & $-0,659$ & $-0,259$ & 0,000 & 0,189 & 0,085 & 0,110 & 0,127 & 0,096 \\
\hline 7 & 0,299 & 0,000 & 0,000 & $-0,344$ & $-0,000$ & $-0,000$ & 0,110 & 0,000 & 0,000 & 0,190 & 0,127 & 0,096 \\
\hline 8 & 0,000 & 0,417 & 0,400 & $-0,000$ & $-0,418$ & $-0,462$ & 0,000 & 0,180 & 0,137 & 0,190 & 0,096 & 0,246 \\
\hline 9 & 0,382 & 0,000 & 0,000 & $-0,364$ & $-0,000$ & $-0,000$ & 0,136 & 0,000 & 0,000 & 0,190 & 0,096 & 0,246 \\
\hline 10 & 0,000 & 0,095 & 0,674 & $-0,000$ & $-0,117$ & $-0,726$ & 0,000 & 0,031 & 0,225 & 0,190 & 0,096 & 0,246 \\
\hline 11 & 0,000 & 0,202 & 0,183 & $-0,000$ & $-0,188$ & $-0,176$ & 0,000 & 0,054 & 0,061 & 0,232 & 0,127 & 0,246 \\
\hline 12 & 0,297 & 0,000 & 0,000 & $-0,294$ & $-0,000$ & $-0,000$ & 0,096 & 0,000 & 0,000 & 0,273 & 0,127 & 0,246 \\
\hline 13 & 0,000 & 0,150 & 0,117 & $-0,000$ & $-0,101$ & $-0,114$ & 0,000 & 0,038 & 0,041 & 0,273 & 0,096 & 0,246 \\
\hline 14 & 0,197 & 0,000 & 0,000 & $-0,209$ & $-0,000$ & $-0,000$ & 0,069 & 0,000 & 0,000 & 0,273 & 0,096 & 0,246 \\
\hline 15 & 0,000 & 0,058 & 0,107 & $-0,000$ & $-0,055$ & $-0,091$ & 0,000 & 0,019 & 0,035 & 0,161 & 0,273 & 0,246 \\
\hline 16 & 0,142 & 0,000 & 0,001 & $-0,139$ & $-0,000$ & $-0,000$ & 0,044 & 0,000 & 0,000 & 0,161 & 0,273 & 0,246 \\
\hline
\end{tabular}

A Tabela C.11 apresenta para o ensaio Catenária-2 apenas os movimentos referentes 
a deslocamento no plano da catenária através da interpolação do sinal do ensaio, a maior amplitude acoplada máxima foi de 1,638 m. Este valor ocorreu para o modo 4. Neste modo, a sua frequência de resposta com maior energia foi de 0,096 Hz.

Tabela C.11: Propriedades das amplitudes modais acopladas no plano da catenária do ensaio Catenária-2 através da interpolação do sinal do ensaio para a $V_{\max }=1,28 \mathrm{~m} / \mathrm{s}$.

Amplitude

Modo Máxima(m) Mínima(m) Desvio Padrão(m) Freq. máxima (Hz)

\begin{tabular}{lllll}
\hline 2 & 1,301 & $-1,251$ & 0,407 & 0,074 \\
4 & 1,638 & $-1,697$ & 0,740 & 0,096 \\
6 & 0,843 & $-0,743$ & 0,238 & 0,123 \\
8 & 0,663 & $-0,559$ & 0,198 & 0,096 \\
10 & 0,718 & $-0,735$ & 0,230 & 0,246 \\
11 & 0,271 & $-0,221$ & 0,085 & 0,246 \\
13 & 0,187 & $-0,170$ & 0,061 & 0,096 \\
15 & 0,123 & $-0,095$ & 0,038 & 0,246 \\
\hline
\end{tabular}

A Tabela C.12 para o ensaio Catenária-2 com apenas as amplitudes correspondentes a movimentos fora do plano através da interpolação do sinal do ensaio, a maior amplitude acoplada máxima apresentada foi de 1,759 m. Este valor ocorreu para o modo 1. Neste modo, a sua frequência de resposta com maior energia foi de 0,161 Hz.

Tabela C.12: Propriedades das amplitudes modais acopladas fora do plano da catenária do ensaio Catenária-2 através da interpolação do sinal do ensaio para a

$$
V_{\max }=1,28 \mathrm{~m} / \mathrm{s} \text {. }
$$

Amplitude

Modo Máxima(m) Mínima(m) Desvio Padrão(m) Freq. máxima (Hz)

\begin{tabular}{lllll}
\hline 1 & 1,759 & $-1,450$ & 0,518 & 0,161 \\
3 & 0,932 & $-0,977$ & 0,288 & 0,161 \\
5 & 0,460 & $-0,459$ & 0,168 & 0,110 \\
7 & 0,296 & $-0,340$ & 0,109 & 0,190 \\
9 & 0,377 & $-0,360$ & 0,135 & 0,190 \\
12 & 0,294 & $-0,291$ & 0,095 & 0,273 \\
14 & 0,195 & $-0,207$ & 0,068 & 0,273 \\
16 & 0,141 & $-0,137$ & 0,044 & 0,161 \\
\hline
\end{tabular}




\section{C.4 Catenária-2 - Velocidade de $1,39 \mathrm{~m} / \mathrm{s}$ e $V_{r 1}=$ 13,95}

Abaixo serão apresentados os gráficos com alguns detalhes da análise referentes ao arranjo Catenária-2 para a velocidade de $1,39 \mathrm{~m} / \mathrm{s}$ e $V_{r 1}=13,95$.
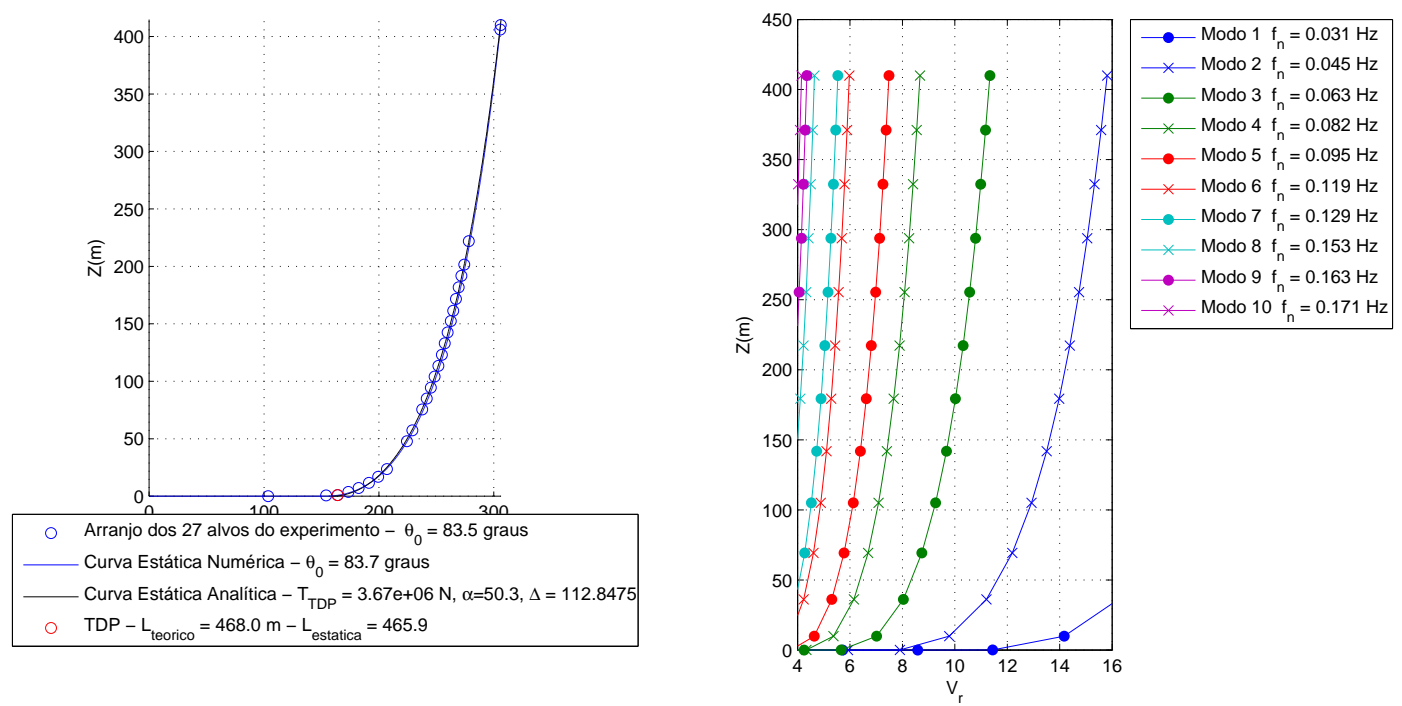

Figura C.16: Variação da velocidade no modelo durante o ensaio para Catenária-2 na

$$
U_{\text {max }}=1,39 \mathrm{~m} / \mathrm{s} \text { e } V_{r 1}=13,946 \text {. }
$$

Como pode ser visto na Tabela C.13 e nas Figuras de C.17 a C.19, os maiores deslocamentos máximos apresentados na direção X, Y e Z foram de 1,586, 1,316 e 0,918 $\mathrm{m}$, respectivamente. Estes valores ocorreram para os alvos 11, 14 e 19. Nestes alvos, as suas frequências de resposta com maior energia foram de 0,121 e 0,159 Hz. 

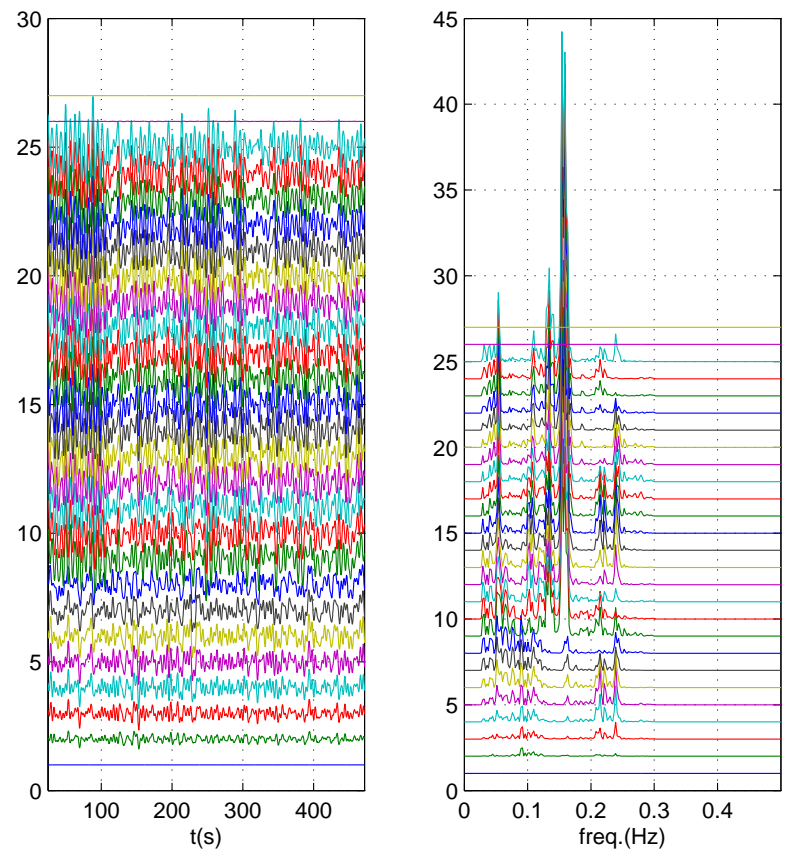

Figura C.17: Série temporal com frequências de resposta para X obtida experimentalmente por alvo para o arranjo de Catenária-2 na $U_{\max }=1,39 \mathrm{~m} / \mathrm{s}$ e $V_{r 1}=13,946$.
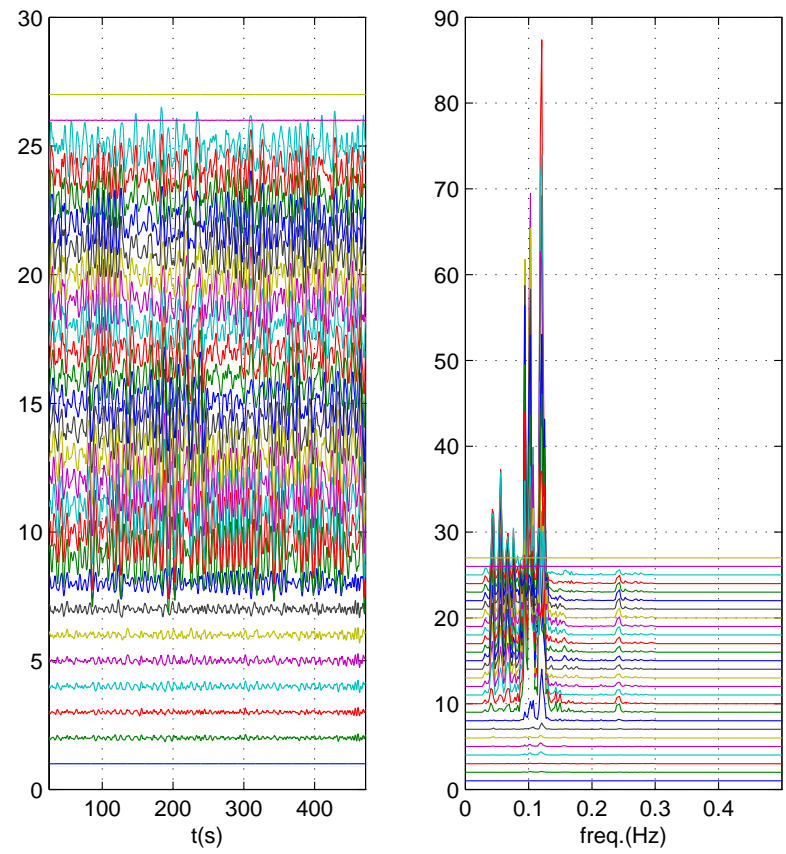

Figura C.18: Série temporal com frequências de resposta para Y obtida experimentalmente por alvo para o arranjo de Catenária-2 na $U_{\max }=1,39 \mathrm{~m} / \mathrm{s}$ e $V_{r 1}=13,946$. 

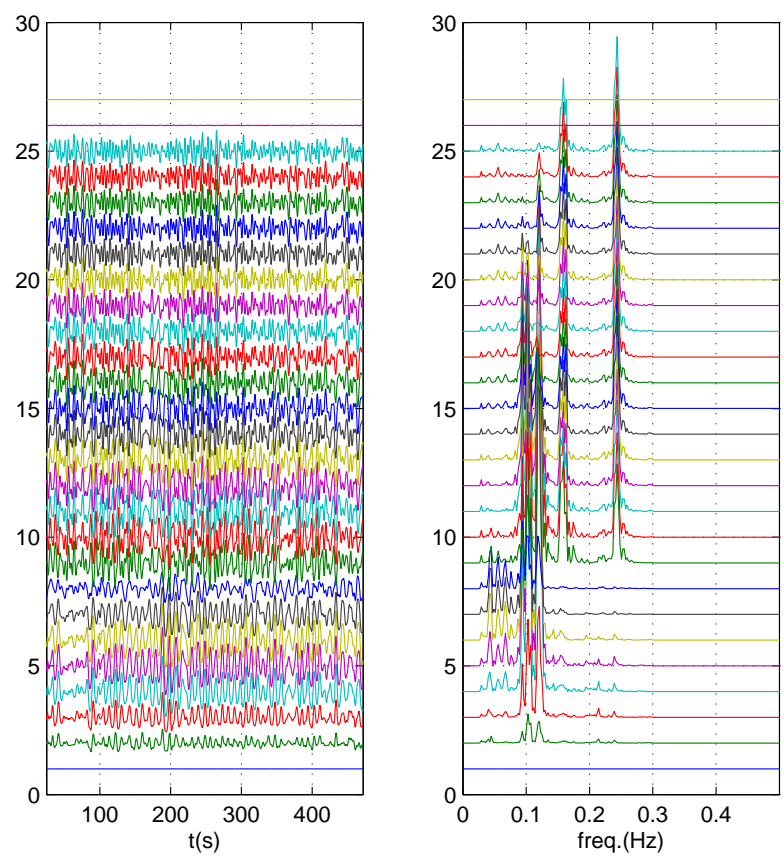

Figura C.19: Série temporal com frequências de resposta para Z obtida experimentalmente por alvo para o arranjo de Catenária-2 na $U_{\max }=1,39 \mathrm{~m} / \mathrm{s}$ e $V_{r 1}=13,946$. 
Tabela C.13: Propriedades da série temporal do ensaio Catenária-2 para a

$$
U_{\max }=1,39 \mathrm{~m} / \mathrm{s} \text {. }
$$

\begin{tabular}{|c|c|c|c|c|c|c|c|c|c|c|c|c|}
\hline \multirow[b]{2}{*}{ ID. Alvo } & \multirow[b]{2}{*}{$\mathrm{X}(\mathrm{m})$} & \multicolumn{2}{|c|}{ Máximo } & \multirow[b]{2}{*}{$\mathrm{X}(\mathrm{m})$} & \multirow{2}{*}{$\begin{array}{l}\text { Mínimo } \\
\mathrm{Y}(\mathrm{m})\end{array}$} & \multirow[b]{2}{*}{$\mathrm{Z}(\mathrm{m})$} & \multicolumn{3}{|c|}{ Desvio padrão } & \multicolumn{3}{|c|}{ Freq. máxima em $\mathrm{Hz}$} \\
\hline & & $\mathrm{Y}(\mathrm{m})$ & $\mathrm{Z}(\mathrm{m})$ & & & & $\mathrm{X}(\mathrm{m})$ & $\mathrm{Y}(\mathrm{m})$ & $\mathrm{Z}(\mathrm{m})$ & $\mathrm{X}$ & $\mathrm{Y}$ & Z \\
\hline 1 & $-0,000$ & $-0,000$ & 0,000 & $-0,000$ & $-0,000$ & $-0,000$ & 0,000 & 0,000 & 0,000 & 0,000 & 0,000 & 0,054 \\
\hline 2 & 0,196 & 0,096 & 0,387 & $-0,151$ & $-0,099$ & $-0,172$ & 0,093 & 0,048 & 0,149 & 0,092 & 0,103 & 0,103 \\
\hline 3 & 0,425 & 0,109 & 0,614 & $-0,286$ & $-0,098$ & $-0,331$ & 0,169 & 0,049 & 0,252 & 0,239 & 0,118 & 0,121 \\
\hline 4 & 0,605 & 0,143 & 0,806 & $-0,358$ & $-0,138$ & $-0,494$ & 0,233 & 0,065 & 0,345 & 0,239 & 0,118 & 0,121 \\
\hline 5 & 0,715 & 0,142 & 0,832 & $-0,406$ & $-0,110$ & $-0,553$ & 0,274 & 0,064 & 0,370 & 0,239 & 0,118 & 0,121 \\
\hline 6 & 0,761 & 0,150 & 0,767 & $-0,490$ & $-0,125$ & $-0,513$ & 0,297 & 0,066 & 0,344 & 0,239 & 0,118 & 0,121 \\
\hline 7 & 0,758 & 0,219 & 0,598 & $-0,551$ & $-0,145$ & $-0,404$ & 0,308 & 0,102 & 0,275 & 0,051 & 0,121 & 0,118 \\
\hline 8 & 0,754 & 0,396 & 0,362 & $-0,612$ & $-0,274$ & $-0,379$ & 0,325 & 0,212 & 0,186 & 0,051 & 0,121 & 0,094 \\
\hline 9 & 1,143 & 1,218 & 0,792 & $-0,871$ & $-1,006$ & $-0,578$ & 0,570 & 0,563 & 0,404 & 0,154 & 0,121 & 0,121 \\
\hline 10 & 1,248 & 1,295 & 0,889 & $-0,958$ & $-1,178$ & $-0,693$ & 0,593 & 0,632 & 0,436 & 0,154 & 0,121 & 0,121 \\
\hline 11 & 1,452 & 1,177 & 0,918 & $-1,094$ & $-1,202$ & $-0,758$ & 0,624 & 0,623 & 0,428 & 0,159 & 0,121 & 0,121 \\
\hline 12 & 1,524 & 1,065 & 0,898 & $-1,134$ & $-1,151$ & $-0,744$ & 0,632 & 0,598 & 0,412 & 0,159 & 0,103 & 0,121 \\
\hline 13 & 1,581 & 0,926 & 0,845 & $-1,144$ & $-1,020$ & $-0,709$ & 0,633 & 0,551 & 0,388 & 0,159 & 0,103 & 0,103 \\
\hline 14 & 1,586 & 0,948 & 0,769 & $-1,127$ & $-0,857$ & $-0,648$ & 0,624 & 0,510 & 0,358 & 0,159 & 0,094 & 0,103 \\
\hline 15 & 1,548 & 0,988 & 0,733 & $-1,096$ & $-0,737$ & $-0,598$ & 0,608 & 0,495 & 0,342 & 0,159 & 0,094 & 0,103 \\
\hline 16 & 1,470 & 1,080 & 0,670 & $-1,077$ & $-0,554$ & $-0,568$ & 0,591 & 0,493 & 0,320 & 0,159 & 0,094 & 0,244 \\
\hline 17 & 1,368 & 1,163 & 0,605 & $-1,057$ & $-0,648$ & $-0,580$ & 0,580 & 0,519 & 0,302 & 0,159 & 0,094 & 0,244 \\
\hline 18 & 1,283 & 1,281 & 0,536 & $-1,038$ & $-0,781$ & $-0,598$ & 0,576 & 0,575 & 0,287 & 0,159 & 0,094 & 0,244 \\
\hline 19 & 1,222 & 1,316 & 0,474 & $-1,028$ & $-0,887$ & $-0,617$ & 0,579 & 0,626 & 0,279 & 0,159 & 0,121 & 0,244 \\
\hline 20 & 1,172 & 1,261 & 0,463 & $-1,025$ & $-0,944$ & $-0,635$ & 0,592 & 0,613 & 0,280 & 0,159 & 0,121 & 0,244 \\
\hline 21 & 1,159 & 1,218 & 0,422 & $-1,013$ & $-1,070$ & $-0,663$ & 0,605 & 0,645 & 0,280 & 0,159 & 0,121 & 0,244 \\
\hline 22 & 1,175 & 1,126 & 0,423 & $-0,986$ & $-1,127$ & $-0,675$ & 0,616 & 0,628 & 0,280 & 0,159 & 0,121 & 0,244 \\
\hline 23 & 1,216 & 1,062 & 0,417 & $-0,948$ & $-1,124$ & $-0,681$ & 0,620 & 0,571 & 0,282 & 0,154 & 0,121 & 0,244 \\
\hline 24 & 1,253 & 1,022 & 0,430 & $-0,896$ & $-1,084$ & $-0,679$ & 0,618 & 0,493 & 0,283 & 0,154 & 0,056 & 0,244 \\
\hline 25 & 1,270 & 0,923 & 0,460 & $-1,008$ & $-0,924$ & $-0,655$ & 0,610 & 0,357 & 0,285 & 0,154 & 0,103 & 0,244 \\
\hline 26 & 0,005 & 0,006 & 0,010 & $-0,005$ & $-0,005$ & $-0,008$ & 0,003 & 0,003 & 0,005 & 0,089 & 0,107 & 0,230 \\
\hline 27 & 0,000 & 0,000 & 0,000 & 0,000 & 0,000 & 0,000 & 0,000 & 0,000 & 0,000 & 0,000 & 0,000 & 0,000 \\
\hline
\end{tabular}

Considerando agora a decomposição modal, na Tabela C.14 através da interpolação do sinal do ensaio, correspondente a uma velocade reduzida do primeiro modo $V_{r 1}=13,95$, as maiores amplitudes máximas apresentadas na direção X, Y e Z foram de 1,593, 1,740 e 0,734 m, respectivamente. Estes valores ocorreram para os modos 1, 4 e 10, Nestes modos, as suas frequências de resposta com maior energia foram de 0,103, 0,154 e 0,244 $\mathrm{Hz}$. 

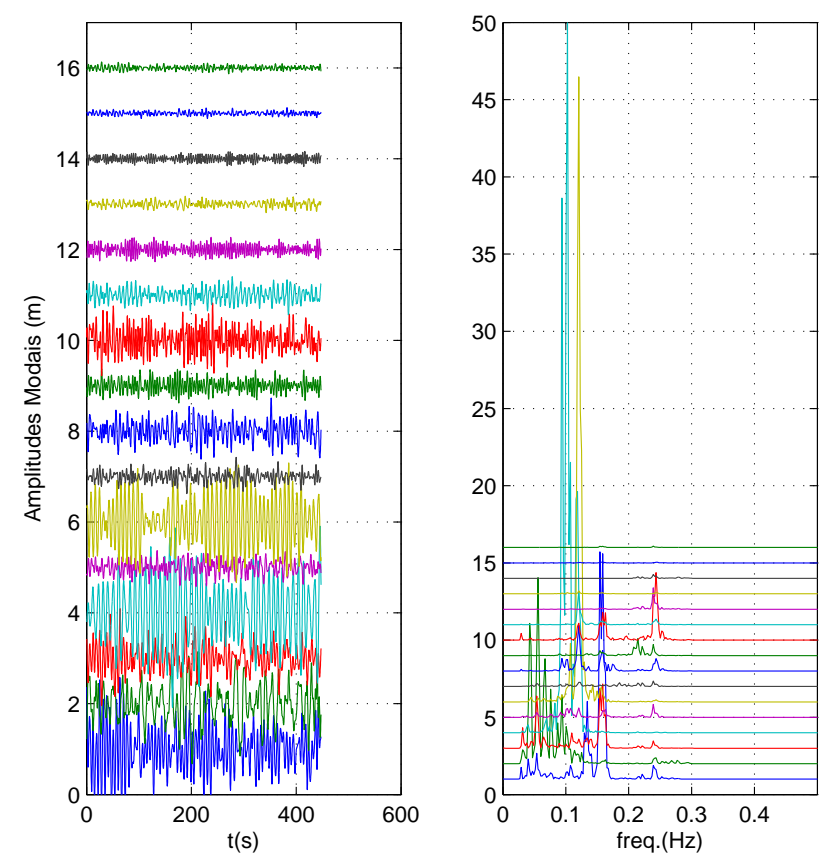

Figura C.20: Variação da amplitude modal acoplada ao longo do tempo através da interpolação do sinal do ensaio para Catenária-2 na $U_{\max }=1,39 \mathrm{~m} / \mathrm{s}$ e $V_{r 1}=13,946$.

Tabela C.14: Propriedades das amplitudes modais do ensaio Catenária-2 através da interpolação do sinal do ensaio para a $V_{\max }=1,39 \mathrm{~m} / \mathrm{s}$.

\begin{tabular}{lcccccccccccccc}
\hline \multicolumn{1}{c}{ Máximo } & \multicolumn{1}{c}{ Mínimo } & & \multicolumn{3}{c}{ Desvio padrão } & \multicolumn{3}{c}{ Freq. máxima em Hz } \\
\multicolumn{1}{c}{ Modo } & $\mathrm{X}(\mathrm{m})$ & $\mathrm{Y}(\mathrm{m})$ & $\mathrm{Z}(\mathrm{m})$ & $\mathrm{X}(\mathrm{m})$ & $\mathrm{Y}(\mathrm{m})$ & $\mathrm{Z}(\mathrm{m})$ & $\mathrm{X}(\mathrm{m})$ & $\mathrm{Y}(\mathrm{m})$ & $\mathrm{Z}(\mathrm{m})$ & $\mathrm{X}$ & $\mathrm{Y}$ & $\mathrm{Z}$ \\
& & & & & & & & & & & & \\
\hline 1 & 1,593 & 0,000 & 0,000 & $-1,250$ & $-0,000$ & $-0,000$ & 0,499 & 0,000 & 0,000 & 0,154 & 0,056 & 0,103 \\
2 & 0,000 & 1,108 & 0,156 & $-0,000$ & $-1,236$ & $-0,172$ & 0,000 & 0,403 & 0,059 & 0,154 & 0,056 & 0,103 \\
3 & 1,109 & 0,000 & 0,000 & $-1,058$ & $-0,000$ & $-0,000$ & 0,313 & 0,000 & 0,000 & 0,159 & 0,056 & 0,103 \\
4 & 0,000 & 1,740 & 0,308 & $-0,000$ & $-1,789$ & $-0,353$ & 0,000 & 0,613 & 0,128 & 0,159 & 0,103 & 0,103 \\
5 & 0,379 & 0,000 & 0,000 & $-0,423$ & $-0,000$ & $-0,000$ & 0,151 & 0,000 & 0,000 & 0,239 & 0,103 & 0,121 \\
6 & 0,000 & 1,126 & 0,327 & $-0,000$ & $-1,094$ & $-0,288$ & 0,000 & 0,446 & 0,120 & 0,121 & 0,121 & 0,121 \\
7 & 0,429 & 0,000 & 0,000 & $-0,379$ & $-0,000$ & $-0,000$ & 0,114 & 0,000 & 0,000 & 0,239 & 0,121 & 0,121 \\
8 & 0,000 & 0,494 & 0,453 & $-0,000$ & $-0,480$ & $-0,458$ & 0,000 & 0,184 & 0,159 & 0,215 & 0,121 & 0,244 \\
9 & 0,380 & 0,000 & 0,000 & $-0,382$ & $-0,000$ & $-0,000$ & 0,137 & 0,000 & 0,000 & 0,215 & 0,121 & 0,244 \\
10 & 0,000 & 0,176 & 0,734 & $-0,000$ & $-0,184$ & $-0,698$ & 0,000 & 0,066 & 0,245 & 0,215 & 0,121 & 0,244 \\
11 & 0,000 & 0,306 & 0,193 & $-0,000$ & $-0,391$ & $-0,178$ & 0,000 & 0,128 & 0,063 & 0,239 & 0,121 & 0,244 \\
12 & 0,277 & 0,000 & 0,000 & $-0,274$ & $-0,000$ & $-0,000$ & 0,103 & 0,000 & 0,000 & 0,239 & 0,121 & 0,244 \\
13 & 0,000 & 0,128 & 0,114 & $-0,000$ & $-0,160$ & $-0,112$ & 0,000 & 0,044 & 0,040 & 0,239 & 0,121 & 0,244 \\
14 & 0,163 & 0,000 & 0,000 & $-0,175$ & $-0,000$ & $-0,000$ & 0,063 & 0,000 & 0,000 & 0,239 & 0,121 & 0,244 \\
15 & 0,000 & 0,074 & 0,106 & $-0,000$ & $-0,063$ & $-0,103$ & 0,000 & 0,021 & 0,035 & 0,239 & 0,103 & 0,244 \\
16 & 0,127 & 0,000 & 0,001 & $-0,132$ & $-0,000$ & $-0,001$ & 0,042 & 0,000 & 0,000 & 0,239 & 0,103 & 0,244 \\
\hline
\end{tabular}

A Tabela C.15 apresenta para o ensaio Catenária-2 apenas os movimentos referentes 
a deslocamento no plano da catenária através da interpolação do sinal do ensaio, a maior amplitude acoplada máxima foi de 1,912 m. Este valor ocorreu para o modo 4. Neste modo, a sua frequência de resposta com maior energia foi de 0,103 Hz.

Tabela C.15: Propriedades das amplitudes modais acopladas no plano da catenária do ensaio Catenária-2 através da interpolação do sinal do ensaio para a $V_{\max }=1,39 \mathrm{~m} / \mathrm{s}$.

\begin{tabular}{llccc}
\hline \multicolumn{5}{c}{ Amplitude } \\
Modo & Máxima(m) & Mínima(m) & Desvio Padrão(m) & Freq. máxima $(\mathrm{Hz})$ \\
& & & & \\
\hline 2 & 1,150 & $-1,326$ & 0,430 & 0,056 \\
4 & 1,912 & $-2,081$ & 0,710 & 0,103 \\
6 & 1,304 & $-1,332$ & 0,539 & 0,121 \\
8 & 0,729 & $-0,615$ & 0,219 & 0,121 \\
10 & 0,824 & $-0,780$ & 0,257 & 0,244 \\
11 & 0,401 & $-0,442$ & 0,141 & 0,121 \\
13 & 0,174 & $-0,189$ & 0,060 & 0,121 \\
15 & 0,125 & $-0,117$ & 0,038 & 0,159 \\
\hline
\end{tabular}

A Tabela C.16 para o ensaio Catenária-2 com apenas as amplitudes correspondentes a movimentos fora do plano através da interpolação do sinal do ensaio, a maior amplitude acoplada máxima apresentada foi de 1,578 m. Este valor ocorreu para o modo 1. Neste modo, a sua frequência de resposta com maior energia foi de 0,154 Hz.

Tabela C.16: Propriedades das amplitudes modais acopladas fora do plano da catenária do ensaio Catenária-2 através da interpolação do sinal do ensaio para a

$$
V_{\max }=1,39 \mathrm{~m} / \mathrm{s} \text {. }
$$

Amplitude

Modo Máxima(m) Mínima(m) Desvio Padrão(m) Freq. máxima (Hz)

\begin{tabular}{lllll}
\hline 1 & 1,578 & $-1,238$ & 0,495 & 0,154 \\
3 & 1,095 & $-1,045$ & 0,309 & 0,159 \\
5 & 0,374 & $-0,417$ & 0,149 & 0,239 \\
7 & 0,424 & $-0,375$ & 0,113 & 0,239 \\
9 & 0,376 & $-0,378$ & 0,136 & 0,215 \\
12 & 0,274 & $-0,271$ & 0,102 & 0,239 \\
14 & 0,162 & $-0,174$ & 0,063 & 0,239 \\
16 & 0,126 & $-0,131$ & 0,042 & 0,239 \\
\hline
\end{tabular}


Anexo D - Resultados de VIV nas linhas em Catenária-3 
Neste anexo é apresentado um conjunto mais completo de resultados do VIV na linha flexível para a Catenária-3, particularmente aqueles referentes às velocidades reduzidas mais importantes. Vale lembrar que todos os resultados estão apresentados na escala real (1:100) conforme definido em [Rateiro et al., 2012]. Neste sentido, as seções que se seguem dizem respeito a:

- Na seção D.1: Velocidade de $0,632 \mathrm{~m} / \mathrm{s}$ e $V_{r 1}=6,85$

- Na seção D.2: Velocidade de $0,915 \mathrm{~m} / \mathrm{s}$ e $V_{r 1}=9,92$

- Na seção D.3: Velocidade de $1,13 \mathrm{~m} / \mathrm{s}$ e $V_{r 1}=12,29$

- Na seção D.4: Velocidade de $1,43 \mathrm{~m} / \mathrm{s}$ e $V_{r 1}=15,47$

\section{D.1 Catenária-3 - Velocidade de $0,632 \mathrm{~m} / \mathrm{s}$ e $V_{r 1}=$ 6,85}

Abaixo serão apresentados os gráficos com alguns detalhes da análise referentes ao arranjo Catenária-3 para a velocidade de $0,632 \mathrm{~m} / \mathrm{s}$ e $V_{r 1}=6,85$,
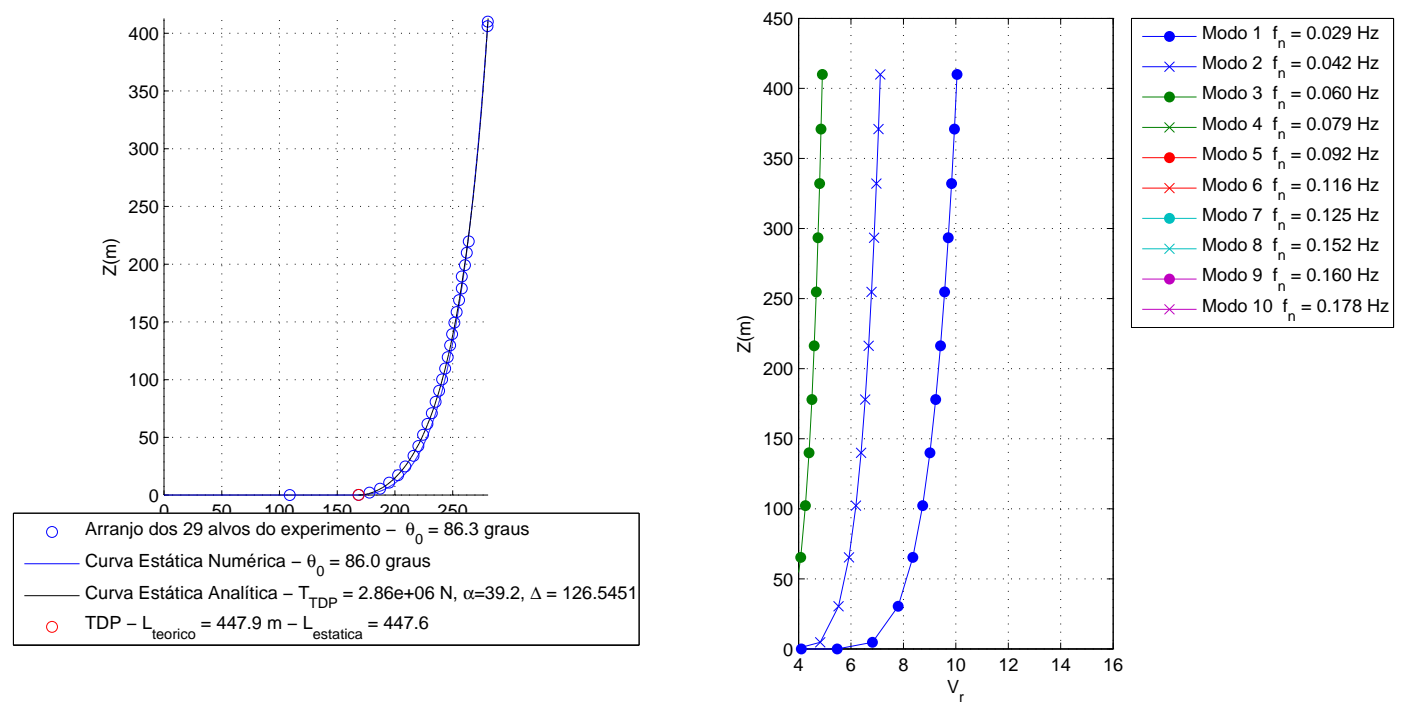

Figura D.1: Variação da velocidade no modelo durante o ensaio para Catenária-3 na

$$
U_{\text {max }}=0,632 \mathrm{~m} / \mathrm{s} \text { e } V_{r 1}=6,851 \text {. }
$$

Como pode ser visto na Tabela D.1 e nas Figuras de D.2 a D.4, os maiores deslocamentos máximos apresentados na direção X, Y e Z foram de 1,243, 2,679 e 0,970 
$\mathrm{m}$, respectivamente. Estes valores ocorreram para os alvos 7 e 24 . Nestes alvos, as suas frequências de resposta com maior energia foi de 0,053 Hz.
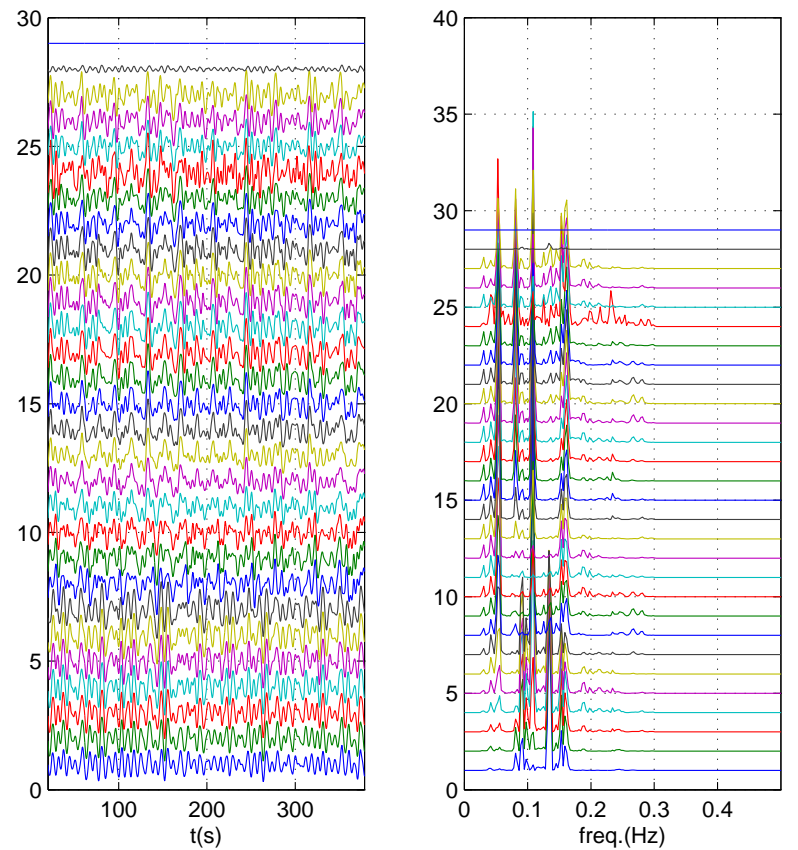

Figura D.2: Série temporal com frequências de resposta para X obtida experimentalmente por alvo para o arranjo de Catenária-3 na $U_{\max }=0,632 \mathrm{~m} / \mathrm{s}$ e $V_{r 1}=6,851$. 

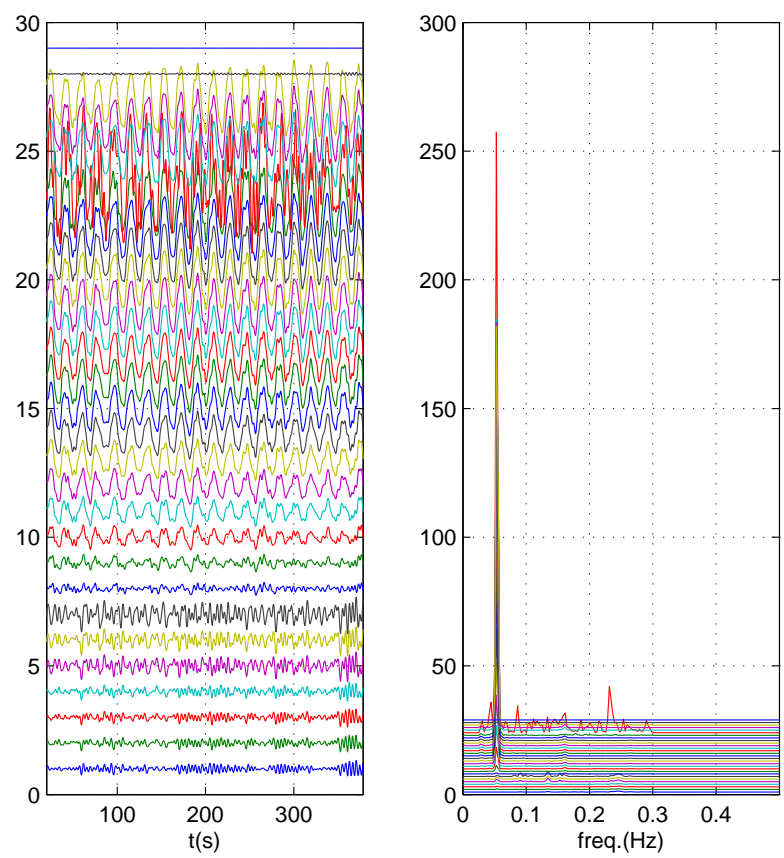

Figura D.3: Série temporal com frequências de resposta para Y obtida experimentalmente por alvo para o arranjo de Catenária-3 na $U_{\max }=0,632 \mathrm{~m} / \mathrm{s}$ e $V_{r 1}=6,851$.
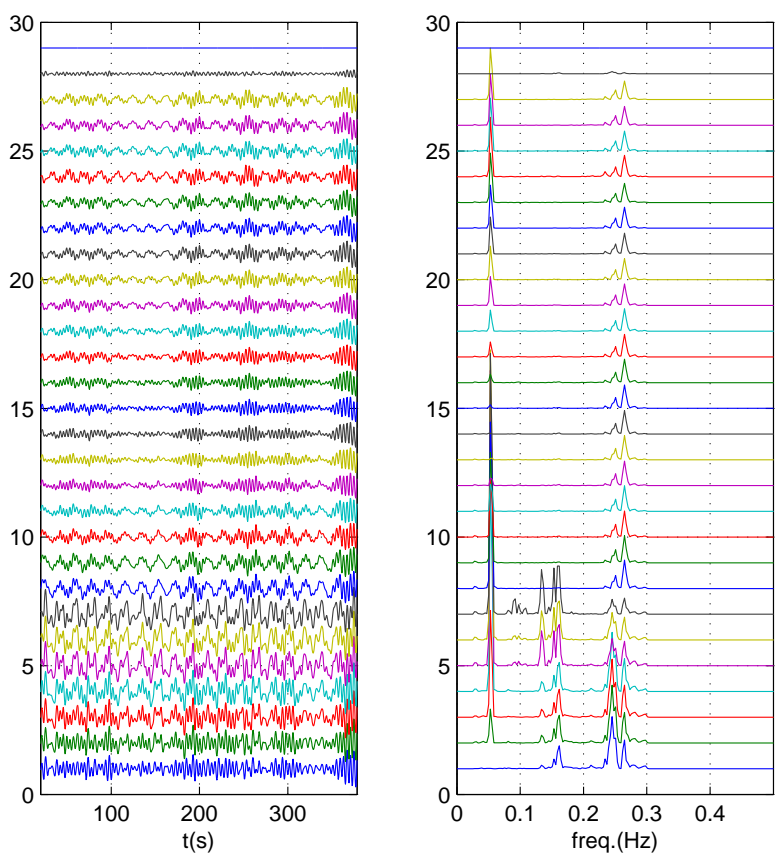

Figura D.4: Série temporal com frequências de resposta para Z obtida experimentalmente por alvo para o arranjo de Catenária-3 na $U_{\max }=0,632 \mathrm{~m} / \mathrm{s}$ e $V_{r 1}=6,851$. 
Tabela D.1: Propriedades da série temporal do ensaio Catenária-3 para a

$$
U_{\max }=0,632 \mathrm{~m} / \mathrm{s} \text {. }
$$

\begin{tabular}{|c|c|c|c|c|c|c|c|c|c|c|c|c|}
\hline \multirow[b]{2}{*}{ ID. Alvo } & \multirow[b]{2}{*}{$\mathrm{X}(\mathrm{m})$} & \multicolumn{2}{|c|}{ Máximo } & \multirow[b]{2}{*}{$\mathrm{X}(\mathrm{m})$} & \multirow{2}{*}{$\begin{array}{l}\text { Mínimo } \\
\mathrm{Y}(\mathrm{m})\end{array}$} & \multirow{2}{*}{$\mathrm{Z}(\mathrm{m})$} & \multicolumn{3}{|c|}{ Desvio padrão } & \multicolumn{3}{|c|}{ Freq. máxima em $\mathrm{Hz}$} \\
\hline & & $\mathrm{Y}(\mathrm{m})$ & $\mathrm{Z}(\mathrm{m})$ & & & & $\mathrm{X}(\mathrm{m})$ & $\mathrm{Y}(\mathrm{m})$ & $\mathrm{Z}(\mathrm{m})$ & $\mathrm{X}$ & $\mathrm{Y}$ & Z \\
\hline 1 & 0,658 & 0,115 & 0,468 & $-0,459$ & $-0,239$ & $-0,414$ & 0,295 & 0,055 & 0,193 & 0,134 & 0,245 & 0,245 \\
\hline 2 & 0,706 & 0,133 & 0,593 & $-0,693$ & $-0,302$ & $-0,421$ & 0,369 & 0,072 & 0,221 & 0,134 & 0,245 & 0,245 \\
\hline 3 & 0,783 & 0,123 & 0,720 & $-0,768$ & $-0,295$ & $-0,453$ & 0,399 & 0,071 & 0,251 & 0,134 & 0,245 & 0,053 \\
\hline 4 & 0,860 & 0,171 & 0,777 & $-0,811$ & $-0,324$ & $-0,526$ & 0,435 & 0,082 & 0,283 & 0,109 & 0,053 & 0,053 \\
\hline 5 & 0,849 & 0,257 & 0,938 & $-0,720$ & $-0,540$ & $-0,533$ & 0,431 & 0,170 & 0,327 & 0,109 & 0,134 & 0,053 \\
\hline 6 & 0,887 & 0,257 & 0,931 & $-0,688$ & $-0,587$ & $-0,524$ & 0,452 & 0,168 & 0,320 & 0,109 & 0,134 & 0,053 \\
\hline 7 & 0,891 & 0,404 & 0,970 & $-0,617$ & $-0,681$ & $-0,519$ & 0,439 & 0,233 & 0,330 & 0,109 & 0,134 & 0,053 \\
\hline 8 & 0,769 & 0,203 & 0,393 & $-0,822$ & $-0,192$ & $-0,359$ & 0,347 & 0,099 & 0,199 & 0,109 & 0,053 & 0,053 \\
\hline 9 & 0,777 & 0,287 & 0,371 & $-0,746$ & $-0,248$ & $-0,308$ & 0,333 & 0,143 & 0,169 & 0,109 & 0,053 & 0,053 \\
\hline 10 & 0,715 & 0,410 & 0,322 & $-0,663$ & $-0,383$ & $-0,262$ & 0,317 & 0,233 & 0,138 & 0,053 & 0,053 & 0,053 \\
\hline 11 & 0,679 & 0,513 & 0,290 & $-0,575$ & $-0,481$ & $-0,209$ & 0,304 & 0,301 & 0,115 & 0,053 & 0,053 & 0,053 \\
\hline 12 & 0,787 & 0,663 & 0,254 & $-0,474$ & $-0,609$ & $-0,169$ & 0,302 & 0,385 & 0,101 & 0,053 & 0,053 & 0,265 \\
\hline 13 & 0,867 & 0,803 & 0,244 & $-0,441$ & $-0,680$ & $-0,163$ & 0,311 & 0,447 & 0,097 & 0,053 & 0,053 & 0,265 \\
\hline 14 & 0,902 & 0,927 & 0,217 & $-0,462$ & $-0,746$ & $-0,160$ & 0,327 & 0,507 & 0,095 & 0,109 & 0,053 & 0,265 \\
\hline 15 & 0,904 & 1,023 & 0,224 & $-0,505$ & $-0,813$ & $-0,175$ & 0,347 & 0,563 & 0,097 & 0,109 & 0,053 & 0,265 \\
\hline 16 & 0,911 & 1,092 & 0,229 & $-0,560$ & $-0,814$ & $-0,207$ & 0,366 & 0,599 & 0,098 & 0,109 & 0,053 & 0,265 \\
\hline 17 & 0,925 & 1,160 & 0,233 & $-0,602$ & $-0,865$ & $-0,214$ & 0,379 & 0,643 & 0,100 & 0,109 & 0,053 & 0,265 \\
\hline 18 & 0,923 & 1,191 & 0,237 & $-0,627$ & $-0,946$ & $-0,222$ & 0,390 & 0,686 & 0,106 & 0,109 & 0,053 & 0,265 \\
\hline 19 & 0,905 & 1,208 & 0,242 & $-0,636$ & $-1,009$ & $-0,241$ & 0,397 & 0,717 & 0,108 & 0,109 & 0,053 & 0,053 \\
\hline 20 & 0,885 & 1,221 & 0,235 & $-0,621$ & $-1,039$ & $-0,230$ & 0,395 & 0,739 & 0,109 & 0,109 & 0,053 & 0,053 \\
\hline 21 & 0,883 & 1,213 & 0,234 & $-0,633$ & $-1,056$ & $-0,234$ & 0,389 & 0,747 & 0,108 & 0,109 & 0,053 & 0,053 \\
\hline 22 & 0,910 & 1,227 & 0,244 & $-0,650$ & $-1,124$ & $-0,236$ & 0,383 & 0,781 & 0,110 & 0,081 & 0,053 & 0,053 \\
\hline 23 & 0,899 & 1,313 & 0,228 & $-0,669$ & $-1,096$ & $-0,213$ & 0,363 & 0,762 & 0,107 & 0,081 & 0,053 & 0,053 \\
\hline 24 & 1,243 & 2,679 & 0,292 & $-1,022$ & $-2,604$ & $-0,240$ & 0,506 & 1,435 & 0,135 & 0,053 & 0,053 & 0,053 \\
\hline 25 & 0,961 & 1,196 & 0,243 & $-0,702$ & $-1,108$ & $-0,240$ & 0,366 & 0,761 & 0,109 & 0,081 & 0,053 & 0,053 \\
\hline 26 & 0,934 & 1,188 & 0,237 & $-0,701$ & $-1,094$ & $-0,235$ & 0,362 & 0,744 & 0,106 & 0,081 & 0,053 & 0,053 \\
\hline 27 & 0,900 & 1,169 & 0,228 & $-0,687$ & $-1,095$ & $-0,237$ & 0,360 & 0,726 & 0,104 & 0,109 & 0,053 & 0,053 \\
\hline 28 & 0,148 & 0,024 & 0,097 & $-0,110$ & $-0,051$ & $-0,088$ & 0,066 & 0,012 & 0,042 & 0,134 & 0,245 & 0,245 \\
\hline 29 & 0,000 & 0,000 & 0,000 & 0,000 & 0,000 & 0,000 & 0,000 & 0,000 & 0,000 & 0,000 & 0,000 & 0,000 \\
\hline
\end{tabular}

Considerando agora a decomposição modal, na Tabela D.2 através da interpolação do sinal do ensaio, correspondente a uma velocade reduzida do primeiro modo $V_{r 1}=6.85$, as maiores amplitudes máximas apresentadas na direção X, Y e Z foram de 1,113, 1,383 e 0,804 m, respectivamente. Estes valores ocorreram para os modos 1, 2 e 10. Nestes modos, as suas frequências de resposta com maior energia foram de 0,053 e 0,265 Hz. 

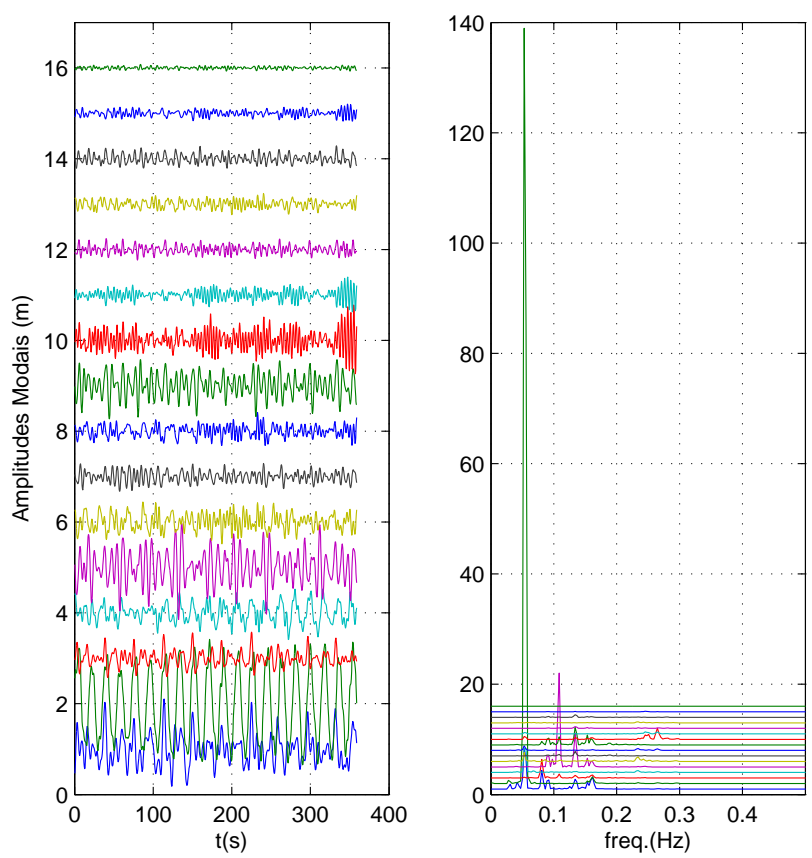

Figura D.5: Variação da amplitude modal acoplada ao longo do tempo através da interpolação do sinal do ensaio para Catenária-3 na $U_{\max }=0,632 \mathrm{~m} / \mathrm{s}$ e $V_{r 1}=6,851$.

Tabela D.2: Propriedades das amplitudes modais do ensaio Catenária-3 através da interpolação do sinal do ensaio para a $V_{\max }=0,632 \mathrm{~m} / \mathrm{s}$.

\begin{tabular}{lccccccccccccc}
\hline \multicolumn{1}{c}{ Máximo } & \multicolumn{1}{c}{ Mínimo } & \multicolumn{3}{c}{ Desvio padrão } & \multicolumn{3}{c}{ Freq. máxima em Hz } \\
\multicolumn{1}{c}{ Modo } & $\mathrm{X}(\mathrm{m})$ & $\mathrm{Y}(\mathrm{m})$ & $\mathrm{Z}(\mathrm{m})$ & $\mathrm{X}(\mathrm{m})$ & $\mathrm{Y}(\mathrm{m})$ & $\mathrm{Z}(\mathrm{m})$ & $\mathrm{X}(\mathrm{m})$ & $\mathrm{Y}(\mathrm{m})$ & $\mathrm{Z}(\mathrm{m})$ & $\mathrm{X}$ & $\mathrm{Y}$ & $\mathrm{Z}$ \\
& & & & & & & & & & & & \\
\hline 1 & 1,113 & 0,000 & 0,000 & $-0,825$ & $-0,000$ & $-0,000$ & 0,341 & 0,000 & 0,000 & 0,053 & 0,053 & 0,053 \\
2 & 0,002 & 1,383 & 0,073 & $-0,002$ & $-1,310$ & $-0,059$ & 0,001 & 0,767 & 0,029 & 0,053 & 0,053 & 0,053 \\
3 & 0,585 & 0,000 & 0,000 & $-0,436$ & $-0,000$ & $-0,000$ & 0,170 & 0,000 & 0,000 & 0,081 & 0,053 & 0,053 \\
4 & 0,000 & 0,534 & 0,083 & $-0,000$ & $-0,615$ & $-0,101$ & 0,000 & 0,217 & 0,032 & 0,109 & 0,053 & 0,053 \\
5 & 0,981 & 0,000 & 0,000 & $-1,164$ & $-0,000$ & $-0,000$ & 0,375 & 0,000 & 0,000 & 0,109 & 0,053 & 0,053 \\
6 & 0,000 & 0,458 & 0,046 & $-0,000$ & $-0,475$ & $-0,051$ & 0,000 & 0,182 & 0,017 & 0,134 & 0,053 & 0,265 \\
7 & 0,295 & 0,000 & 0,000 & $-0,327$ & $-0,000$ & $-0,000$ & 0,119 & 0,000 & 0,000 & 0,134 & 0,053 & 0,265 \\
8 & 0,000 & 0,340 & 0,101 & $-0,000$ & $-0,330$ & $-0,111$ & 0,000 & 0,115 & 0,031 & 0,134 & 0,053 & 0,265 \\
9 & 0,581 & 0,000 & 0,000 & $-0,736$ & $-0,000$ & $-0,000$ & 0,258 & 0,000 & 0,000 & 0,134 & 0,053 & 0,245 \\
10 & 0,000 & 0,101 & 0,804 & $-0,000$ & $-0,089$ & $-0,801$ & 0,000 & 0,033 & 0,212 & 0,134 & 0,053 & 0,265 \\
11 & 0,000 & 0,180 & 0,270 & $-0,000$ & $-0,181$ & $-0,262$ & 0,000 & 0,069 & 0,071 & 0,134 & 0,053 & 0,265 \\
12 & 0,245 & 0,000 & 0,000 & $-0,234$ & $-0,000$ & $-0,000$ & 0,088 & 0,000 & 0,000 & 0,134 & 0,053 & 0,265 \\
13 & 0,000 & 0,192 & 0,133 & $-0,000$ & $-0,176$ & $-0,124$ & 0,000 & 0,079 & 0,034 & 0,134 & 0,231 & 0,265 \\
14 & 0,289 & 0,000 & 0,000 & $-0,216$ & $-0,000$ & $-0,000$ & 0,097 & 0,000 & 0,000 & 0,134 & 0,231 & 0,265 \\
15 & 0,000 & 0,130 & 0,085 & $-0,000$ & $-0,132$ & $-0,080$ & 0,000 & 0,050 & 0,022 & 0,159 & 0,134 & 0,265 \\
16 & 0,075 & 0,000 & 0,000 & $-0,074$ & $-0,000$ & $-0,000$ & 0,026 & 0,000 & 0,000 & 0,159 & 0,134 & 0,265 \\
\hline
\end{tabular}

A Tabela D.3 apresenta para o ensaio Catenária-3 apenas os movimentos referentes a 
deslocamento no plano da catenária através da interpolação do sinal do ensaio, a maior amplitude acoplada máxima foi de 1,416 m. Este valor ocorreu para o modo 2. Neste modo, a sua frequência de resposta com maior energia foi de 0,053 Hz.

Tabela D.3: Propriedades das amplitudes modais acopladas no plano da catenária do ensaio Catenária-3 através da interpolação do sinal do ensaio para a $V_{\max }=0,632 \mathrm{~m} / \mathrm{s}$.

Amplitude

Modo Máxima(m) Mínima(m) Desvio Padrão(m) Freq. máxima (Hz)

\begin{tabular}{lllll}
\hline 2 & 1,416 & $-1,346$ & 0,790 & 0,053 \\
4 & 0,524 & $-0,588$ & 0,207 & 0,053 \\
6 & 0,442 & $-0,481$ & 0,178 & 0,053 \\
8 & 0,414 & $-0,315$ & 0,122 & 0,053 \\
10 & 0,778 & $-0,733$ & 0,204 & 0,265 \\
11 & 0,395 & $-0,372$ & 0,106 & 0,245 \\
13 & 0,235 & $-0,233$ & 0,084 & 0,234 \\
15 & 0,201 & $-0,172$ & 0,063 & 0,245 \\
\hline
\end{tabular}

A Tabela D.4 para o ensaio Catenária-3 com apenas as amplitudes correspondentes a movimentos fora do plano através da interpolação do sinal do ensaio, a maior amplitude acoplada máxima apresentada foi de 1,102 m. Este valor ocorreu para o modo 1 . Neste modo, a sua frequência de resposta com maior energia foi de 0,053 Hz.

Tabela D.4: Propriedades das amplitudes modais acopladas fora do plano da catenária do ensaio Catenária-3 através da interpolação do sinal do ensaio para a

$$
V_{\text {max }}=0,632 \mathrm{~m} / \mathrm{s} \text {. }
$$

\begin{tabular}{lllll}
\hline \multicolumn{5}{c}{ Amplitude } \\
Modo & Máxima(m) & Mínima(m) & Desvio Padrão(m) & Freq. máxima $(\mathrm{Hz})$ \\
& & & & \\
\hline 1 & 1,102 & $-0,817$ & 0,338 & 0,053 \\
3 & 0,577 & $-0,430$ & 0,167 & 0,081 \\
5 & 0,967 & $-1,148$ & 0,370 & 0,109 \\
7 & 0,291 & $-0,323$ & 0,118 & 0,134 \\
9 & 0,574 & $-0,727$ & 0,255 & 0,134 \\
12 & 0,242 & $-0,231$ & 0,087 & 0,134 \\
14 & 0,285 & $-0,214$ & 0,096 & 0,134 \\
16 & 0,074 & $-0,073$ & 0,026 & 0,159 \\
\hline
\end{tabular}




\section{D.2 Catenária-3 - Velocidade de $0,915 \mathrm{~m} / \mathrm{s}$ e $V_{r 1}=$ 9,92}

Abaixo serão apresentados os gráficos com alguns detalhes da análise referentes ao arranjo Catenária-3 para a velocidade de $0,915 \mathrm{~m} / \mathrm{s}$ e $V_{r 1}=9,92$.
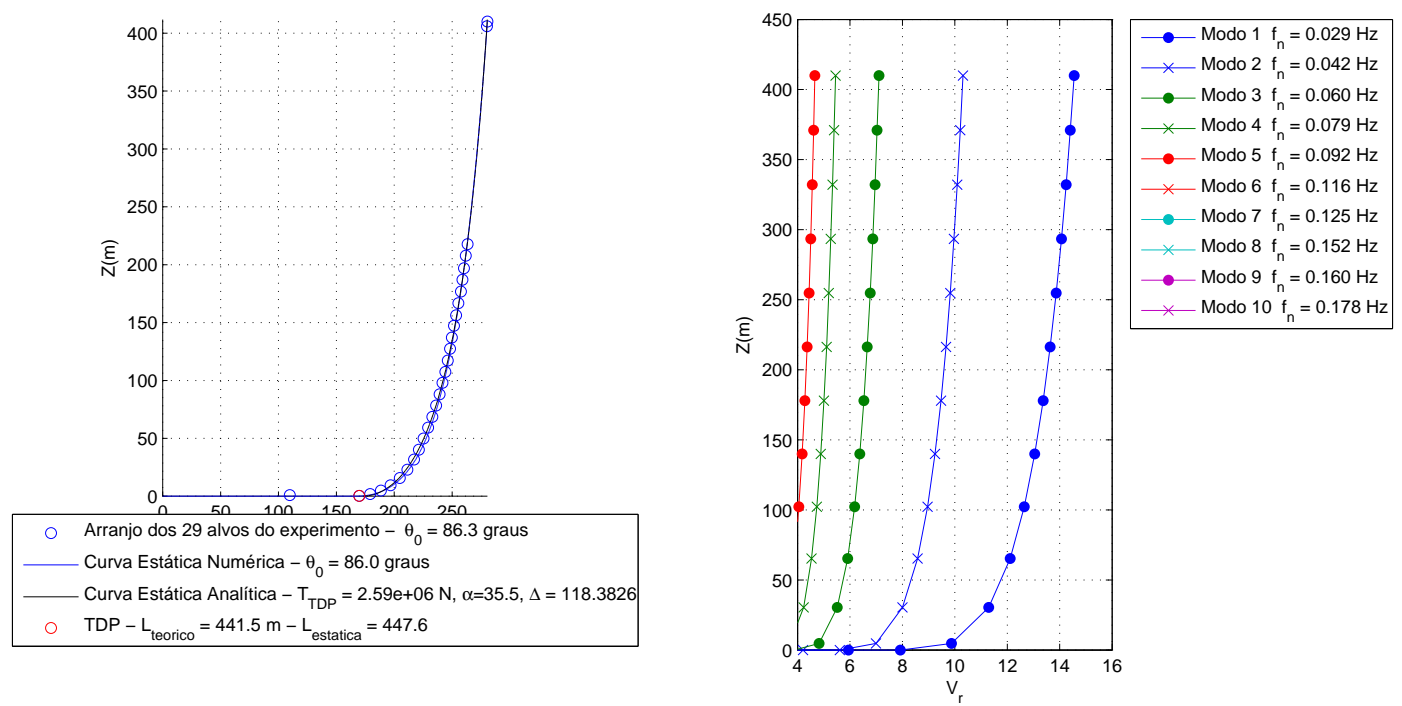

Figura D.6: Variação da velocidade no modelo durante o ensaio para Catenária-3 na

$$
U_{\text {max }}=0,915 \mathrm{~m} / \mathrm{s} \text { e } V_{r 1}=9,922 \text {. }
$$

Como pode ser visto na Tabela D.5 e nas Figuras de D.7 a D.9, os maiores deslocamentos máximos apresentados na direção X, Y e Z foram de 1,294, 1,520 e 1,109 $\mathrm{m}$, respectivamente. Estes valores ocorreram para os alvos 4, 19 e 24. Nestes alvos, as suas frequências de resposta com maior energia foram de 0,0407, 0,0871 e 0,261 Hz. 

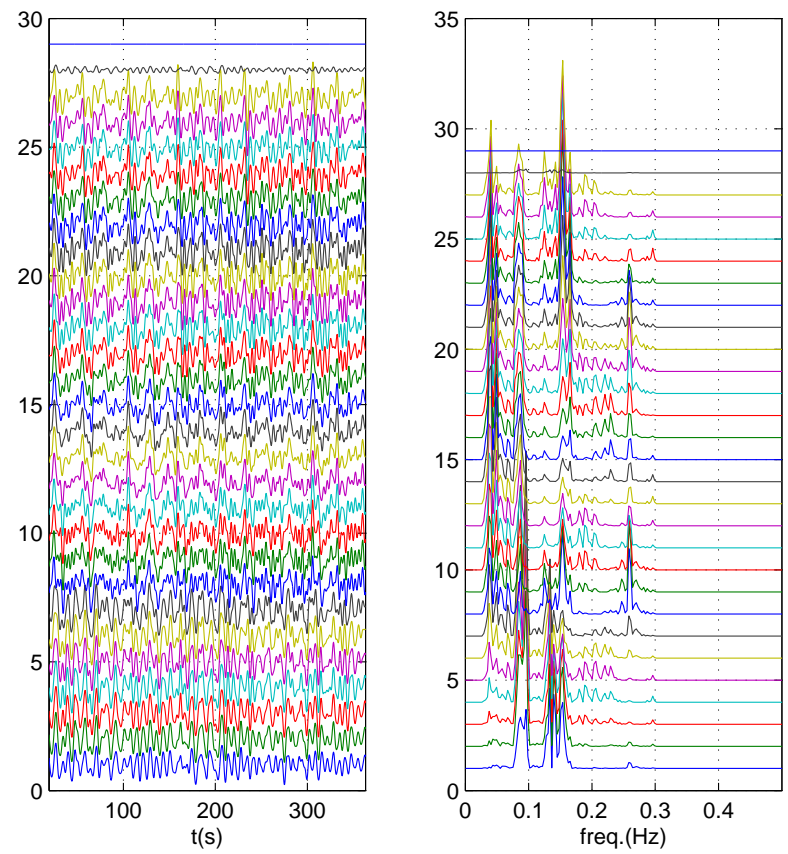

Figura D.7: Série temporal com frequências de resposta para X obtida experimentalmente por alvo para o arranjo de Catenária-3 na $U_{\max }=0,915 \mathrm{~m} / \mathrm{s}$ e $V_{r 1}=9,922$.
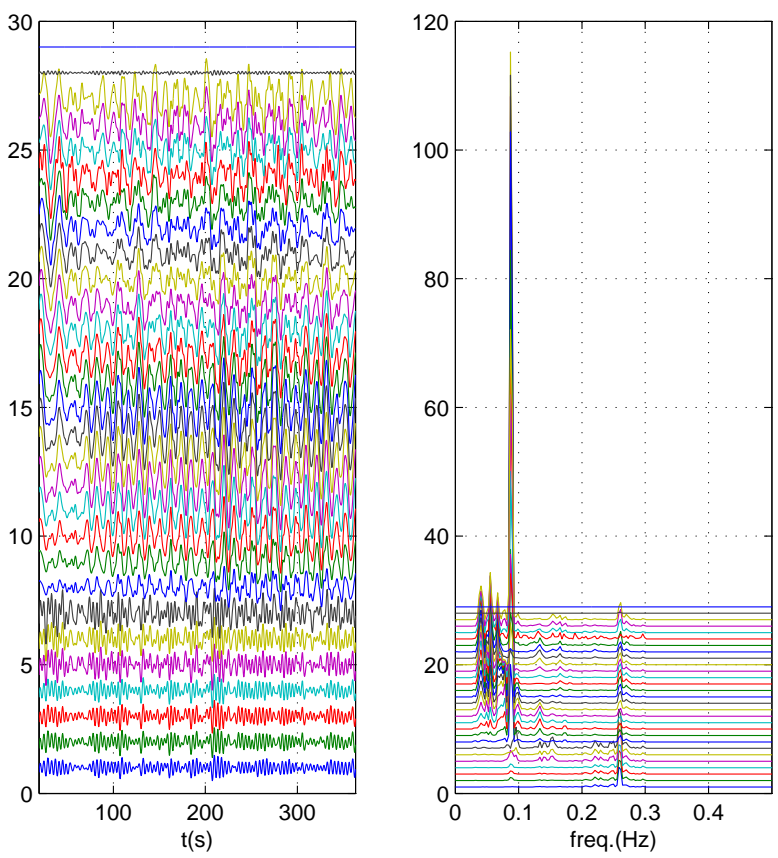

Figura D.8: Série temporal com frequências de resposta para Y obtida experimentalmente por alvo para o arranjo de Catenária-3 na $U_{\max }=0,915 \mathrm{~m} / \mathrm{s}$ e $V_{r 1}=9,922$. 

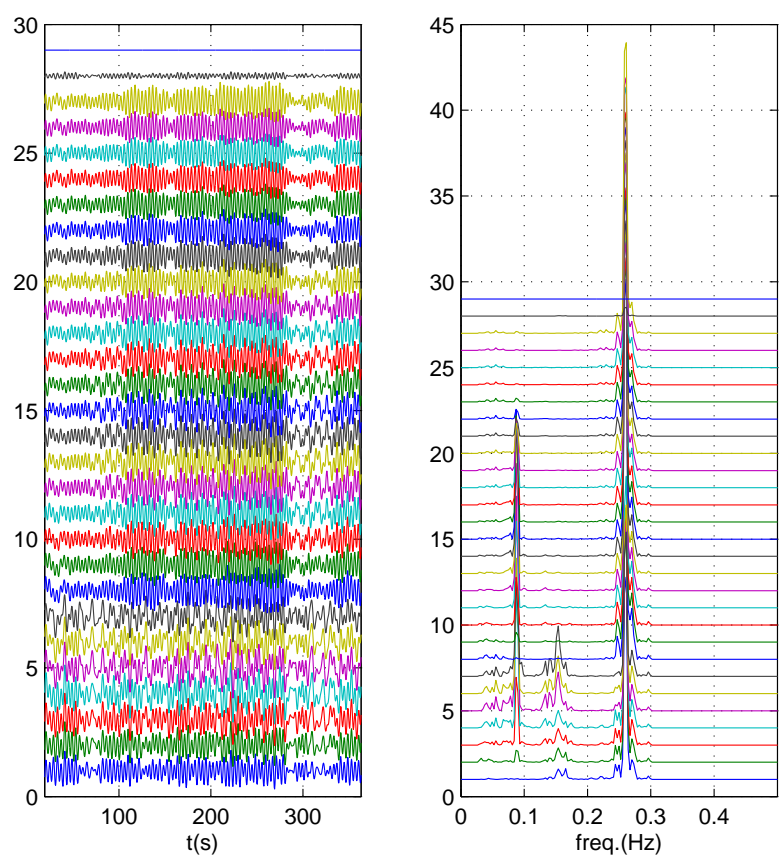

Figura D.9: Série temporal com frequências de resposta para Z obtida experimentalmente por alvo para o arranjo de Catenária-3 na $U_{\max }=0,915 \mathrm{~m} / \mathrm{s}$ e $V_{r 1}=9,922$. 
Tabela D.5: Propriedades da série temporal do ensaio Catenária-3 para a $U_{\max }=0,915 \mathrm{~m} / \mathrm{s}$.

\begin{tabular}{|c|c|c|c|c|c|c|c|c|c|c|c|c|}
\hline \multirow[b]{2}{*}{ ID. Alvo } & \multirow[b]{2}{*}{$\mathrm{X}(\mathrm{m})$} & \multicolumn{2}{|c|}{ Máximo } & \multirow[b]{2}{*}{$\mathrm{X}(\mathrm{m})$} & \multirow{2}{*}{$\begin{array}{l}\text { Mínimo } \\
\mathrm{Y}(\mathrm{m})\end{array}$} & \multirow[b]{2}{*}{$\mathrm{Z}(\mathrm{m})$} & \multicolumn{3}{|c|}{ Desvio padrão } & \multicolumn{3}{|c|}{ Freq. máxima em $\mathrm{Hz}$} \\
\hline & & $\mathrm{Y}(\mathrm{m})$ & $\mathrm{Z}(\mathrm{m})$ & & & & $\mathrm{X}(\mathrm{m})$ & $\mathrm{Y}(\mathrm{m})$ & $\mathrm{Z}(\mathrm{m})$ & $\mathrm{X}$ & $\mathrm{Y}$ & Z \\
\hline 1 & 0,843 & 0,376 & 0,758 & $-0,636$ & $-0,325$ & $-0,599$ & 0,377 & 0,184 & 0,354 & 0,134 & 0,258 & 0,261 \\
\hline 2 & 1,036 & 0,430 & 0,903 & $-0,876$ & $-0,409$ & $-0,645$ & 0,498 & 0,199 & 0,375 & 0,096 & 0,258 & 0,261 \\
\hline 3 & 1,046 & 0,440 & 1,012 & $-0,932$ & $-0,412$ & $-0,683$ & 0,524 & 0,204 & 0,392 & 0,096 & 0,258 & 0,261 \\
\hline 4 & 1,035 & 0,440 & 1,109 & $-0,988$ & $-0,410$ & $-0,713$ & 0,556 & 0,208 & 0,415 & 0,096 & 0,258 & 0,261 \\
\hline 5 & 0,928 & 0,635 & 1,003 & $-0,911$ & $-0,807$ & $-0,789$ & 0,535 & 0,326 & 0,370 & 0,096 & 0,258 & 0,087 \\
\hline 6 & 1,009 & 0,647 & 0,984 & $-0,907$ & $-0,863$ & $-0,797$ & 0,557 & 0,336 & 0,370 & 0,096 & 0,258 & 0,261 \\
\hline 7 & 0,979 & 0,907 & 0,839 & $-0,838$ & $-1,192$ & $-0,816$ & 0,545 & 0,452 & 0,355 & 0,096 & 0,258 & 0,261 \\
\hline 8 & 1,079 & 0,296 & 0,552 & $-1,115$ & $-0,289$ & $-0,474$ & 0,379 & 0,146 & 0,245 & 0,154 & 0,087 & 0,261 \\
\hline 9 & 1,096 & 0,444 & 0,455 & $-1,210$ & $-0,394$ & $-0,452$ & 0,398 & 0,208 & 0,230 & 0,038 & 0,087 & 0,261 \\
\hline 10 & 1,102 & 0,677 & 0,416 & $-1,178$ & $-0,547$ & $-0,430$ & 0,405 & 0,301 & 0,213 & 0,038 & 0,087 & 0,261 \\
\hline 11 & 1,106 & 0,903 & 0,401 & $-1,085$ & $-0,612$ & $-0,380$ & 0,401 & 0,378 & 0,204 & 0,038 & 0,087 & 0,261 \\
\hline 12 & 1,113 & 1,094 & 0,367 & $-0,921$ & $-0,692$ & $-0,340$ & 0,398 & 0,453 & 0,194 & 0,038 & 0,087 & 0,261 \\
\hline 13 & 1,129 & 1,259 & 0,339 & $-0,761$ & $-0,712$ & $-0,378$ & 0,401 & 0,521 & 0,189 & 0,041 & 0,087 & 0,261 \\
\hline 14 & 1,179 & 1,356 & 0,318 & $-0,648$ & $-0,689$ & $-0,402$ & 0,410 & 0,569 & 0,184 & 0,041 & 0,087 & 0,261 \\
\hline 15 & 1,226 & 1,437 & 0,298 & $-0,622$ & $-0,693$ & $-0,425$ & 0,421 & 0,610 & 0,184 & 0,041 & 0,087 & 0,261 \\
\hline 16 & 1,267 & 1,438 & 0,293 & $-0,684$ & $-0,776$ & $-0,437$ & 0,433 & 0,631 & 0,183 & 0,041 & 0,087 & 0,261 \\
\hline 17 & 1,284 & 1,447 & 0,313 & $-0,784$ & $-0,853$ & $-0,454$ & 0,444 & 0,663 & 0,183 & 0,041 & 0,087 & 0,261 \\
\hline 18 & 1,293 & 1,401 & 0,324 & $-0,862$ & $-0,966$ & $-0,460$ & 0,456 & 0,675 & 0,187 & 0,041 & 0,087 & 0,261 \\
\hline 19 & 1,294 & 1,360 & 0,334 & $-0,904$ & $-1,115$ & $-0,460$ & 0,464 & 0,685 & 0,188 & 0,041 & 0,087 & 0,261 \\
\hline 20 & 1,271 & 1,260 & 0,336 & $-0,879$ & $-1,251$ & $-0,441$ & 0,466 & 0,685 & 0,184 & 0,041 & 0,055 & 0,261 \\
\hline 21 & 1,236 & 1,160 & 0,337 & $-0,863$ & $-1,326$ & $-0,422$ & 0,463 & 0,679 & 0,182 & 0,041 & 0,055 & 0,261 \\
\hline 22 & 1,179 & 1,231 & 0,335 & $-0,887$ & $-1,470$ & $-0,416$ & 0,453 & 0,697 & 0,184 & 0,154 & 0,055 & 0,261 \\
\hline 23 & 1,087 & 1,188 & 0,333 & $-0,870$ & $-1,500$ & $-0,382$ & 0,440 & 0,684 & 0,184 & 0,154 & 0,055 & 0,261 \\
\hline 24 & 1,154 & 1,520 & 0,372 & $-0,916$ & $-1,659$ & $-0,339$ & 0,459 & 0,791 & 0,181 & 0,154 & 0,087 & 0,261 \\
\hline 25 & 1,025 & 1,152 & 0,335 & $-0,931$ & $-1,541$ & $-0,349$ & 0,431 & 0,672 & 0,181 & 0,154 & 0,087 & 0,261 \\
\hline 26 & 1,006 & 1,132 & 0,331 & $-0,888$ & $-1,519$ & $-0,346$ & 0,425 & 0,663 & 0,181 & 0,154 & 0,087 & 0,261 \\
\hline 27 & 1,016 & 1,149 & 0,332 & $-0,803$ & $-1,493$ & $-0,360$ & 0,419 & 0,654 & 0,181 & 0,154 & 0,087 & 0,261 \\
\hline 28 & 0,191 & 0,081 & 0,157 & $-0,146$ & $-0,075$ & $-0,118$ & 0,087 & 0,039 & 0,072 & 0,096 & 0,258 & 0,261 \\
\hline 29 & 0,000 & 0,000 & 0,000 & 0,000 & 0,000 & 0,000 & 0,000 & 0,000 & 0,000 & 0,000 & 0,000 & 0,000 \\
\hline
\end{tabular}

Considerando agora a decomposição modal, na Tabela D.6 através da interpolação do sinal do ensaio, correspondente a uma velocade reduzida do primeiro modo $V_{r 1}=9.92$, as maiores amplitudes máximas apresentadas na direção X, Y e Z foram de 1,393, 1,350 e 1,182 m, respectivamente. Estes valores ocorreram para os modos 1, 4 e 10. Nestes modos, as suas frequências de resposta com maior energia foram de 0,0407, 0,0871 e 0,261 $\mathrm{Hz}$. 

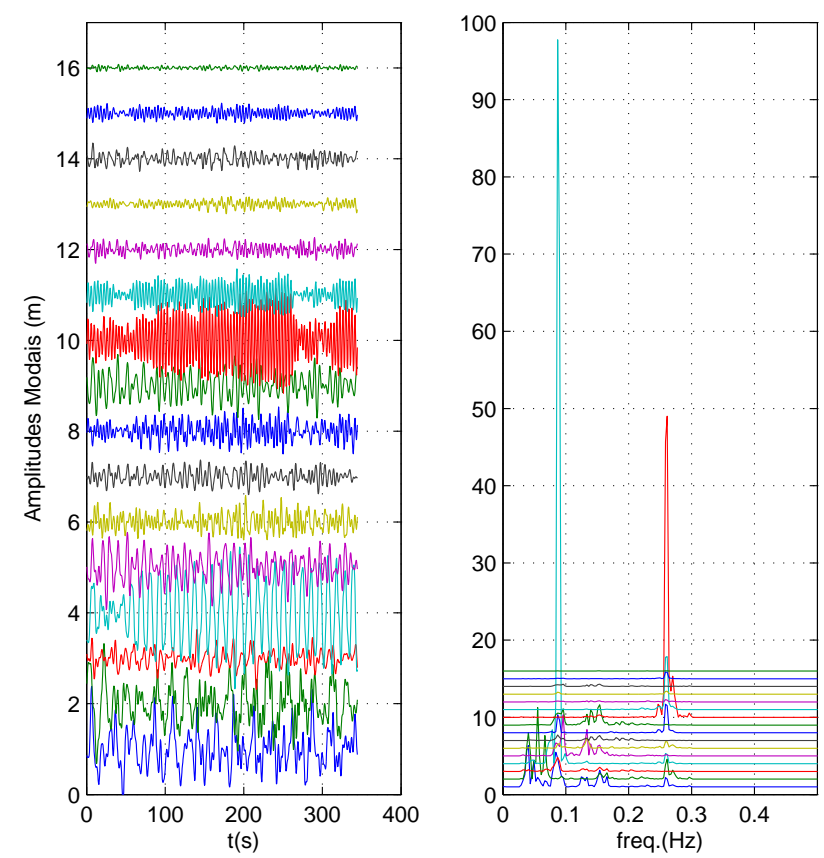

Figura D.10: Variação da amplitude modal acoplada ao longo do tempo através da interpolação do sinal do ensaio para Catenária-3 na $U_{\max }=0,915 \mathrm{~m} / \mathrm{s}$ e $V_{r 1}=9,922$.

Tabela D.6: Propriedades das amplitudes modais do ensaio Catenária-3 através da interpolação do sinal do ensaio para a $V_{\max }=0,915 \mathrm{~m} / \mathrm{s}$.

\begin{tabular}{lccccccccccccc}
\hline \multicolumn{1}{c}{ Máximo } & \multicolumn{1}{c}{ Mínimo } & \multicolumn{3}{c}{ Desvio padrão } & \multicolumn{2}{c}{ Freq. máxima em Hz } \\
\multicolumn{1}{c}{ Modo } & $\mathrm{X}(\mathrm{m})$ & $\mathrm{Y}(\mathrm{m})$ & $\mathrm{Z}(\mathrm{m})$ & $\mathrm{X}(\mathrm{m})$ & $\mathrm{Y}(\mathrm{m})$ & $\mathrm{Z}(\mathrm{m})$ & $\mathrm{X}(\mathrm{m})$ & $\mathrm{Y}(\mathrm{m})$ & $\mathrm{Z}(\mathrm{m})$ & $\mathrm{X}$ & $\mathrm{Y}$ & $\mathrm{Z}$ \\
& & & & & & & & & & & & \\
\hline 1 & 1,393 & 0,000 & 0,000 & $-1,164$ & $-0,000$ & $-0,000$ & 0,427 & 0,000 & 0,000 & 0,041 & 0,055 & 0,087 \\
2 & 0,003 & 1,273 & 0,092 & $-0,002$ & $-1,272$ & $-0,075$ & 0,001 & 0,422 & 0,031 & 0,041 & 0,055 & 0,087 \\
3 & 0,642 & 0,000 & 0,000 & $-0,692$ & $-0,000$ & $-0,000$ & 0,181 & 0,000 & 0,000 & 0,087 & 0,055 & 0,087 \\
4 & 0,000 & 1,350 & 0,166 & $-0,000$ & $-1,510$ & $-0,172$ & 0,000 & 0,652 & 0,062 & 0,096 & 0,087 & 0,087 \\
5 & 0,782 & 0,000 & 0,000 & $-0,943$ & $-0,000$ & $-0,000$ & 0,316 & 0,000 & 0,000 & 0,096 & 0,087 & 0,087 \\
6 & 0,000 & 0,540 & 0,167 & $-0,000$ & $-0,425$ & $-0,164$ & 0,000 & 0,181 & 0,056 & 0,087 & 0,258 & 0,087 \\
7 & 0,371 & 0,000 & 0,000 & $-0,401$ & $-0,000$ & $-0,000$ & 0,146 & 0,000 & 0,000 & 0,087 & 0,258 & 0,261 \\
8 & 0,000 & 0,401 & 0,244 & $-0,000$ & $-0,401$ & $-0,266$ & 0,000 & 0,155 & 0,101 & 0,154 & 0,087 & 0,261 \\
9 & 0,698 & 0,000 & 0,000 & $-0,753$ & $-0,000$ & $-0,000$ & 0,280 & 0,000 & 0,000 & 0,154 & 0,087 & 0,261 \\
10 & 0,000 & 0,183 & 1,182 & $-0,000$ & $-0,164$ & $-1,175$ & 0,000 & 0,052 & 0,502 & 0,154 & 0,258 & 0,261 \\
11 & 0,000 & 0,328 & 0,371 & $-0,000$ & $-0,240$ & $-0,389$ & 0,000 & 0,084 & 0,158 & 0,258 & 0,258 & 0,261 \\
12 & 0,269 & 0,000 & 0,000 & $-0,306$ & $-0,000$ & $-0,000$ & 0,101 & 0,000 & 0,000 & 0,258 & 0,258 & 0,261 \\
13 & 0,000 & 0,130 & 0,162 & $-0,000$ & $-0,116$ & $-0,156$ & 0,000 & 0,045 & 0,066 & 0,096 & 0,087 & 0,261 \\
14 & 0,348 & 0,000 & 0,000 & $-0,282$ & $-0,000$ & $-0,000$ & 0,108 & 0,000 & 0,000 & 0,096 & 0,087 & 0,261 \\
15 & 0,000 & 0,153 & 0,102 & $-0,000$ & $-0,149$ & $-0,097$ & 0,000 & 0,055 & 0,044 & 0,154 & 0,258 & 0,261 \\
16 & 0,076 & 0,000 & 0,000 & $-0,089$ & $-0,000$ & $-0,000$ & 0,030 & 0,000 & 0,000 & 0,154 & 0,258 & 0,261 \\
\hline
\end{tabular}

A Tabela D.7 apresenta para o ensaio Catenária-3 apenas os movimentos referentes a 
deslocamento no plano da catenária através da interpolação do sinal do ensaio, a maior amplitude acoplada máxima foi de 1,451 m. Este valor ocorreu para o modo 4. Neste modo, a sua frequência de resposta com maior energia foi de 0,087 Hz.

Tabela D.7: Propriedades das amplitudes modais acopladas no plano da catenária do ensaio Catenária-3 através da interpolação do sinal do ensaio para a $V_{\max }=0,915 \mathrm{~m} / \mathrm{s}$.

Amplitude

Modo Máxima(m) Mínima(m) Desvio Padrão(m) Freq. máxima (Hz)

\begin{tabular}{lllll}
\hline 2 & 1,326 & $-1,317$ & 0,434 & 0,055 \\
4 & 1,451 & $-1,671$ & 0,696 & 0,087 \\
6 & 0,585 & $-0,396$ & 0,181 & 0,134 \\
8 & 0,534 & $-0,503$ & 0,193 & 0,258 \\
10 & 1,144 & $-1,164$ & 0,476 & 0,261 \\
11 & 0,575 & $-0,477$ & 0,210 & 0,261 \\
13 & 0,169 & $-0,214$ & 0,067 & 0,261 \\
15 & 0,222 & $-0,219$ & 0,087 & 0,258 \\
\hline
\end{tabular}

A Tabela D.8 para o ensaio Catenária-3 com apenas as amplitudes correspondentes a movimentos fora do plano através da interpolação do sinal do ensaio, a maior amplitude acoplada máxima apresentada foi de 1,380 m. Este valor ocorreu para o modo 1 . Neste modo, a sua frequência de resposta com maior energia foi de 0,041 Hz.

Tabela D.8: Propriedades das amplitudes modais acopladas fora do plano da catenária do ensaio Catenária-3 através da interpolação do sinal do ensaio para a

$$
V_{\text {max }}=0,915 \mathrm{~m} / \mathrm{s} \text {. }
$$

\begin{tabular}{lllll}
\hline \multicolumn{5}{c}{ Amplitude } \\
Modo & Máxima(m) & Mínima(m) & Desvio Padrão(m) & Freq. máxima (Hz) \\
& & & & \\
\hline 1 & 1,380 & $-1,152$ & 0,423 & 0,041 \\
3 & 0,633 & $-0,683$ & 0,179 & 0,087 \\
5 & 0,772 & $-0,930$ & 0,311 & 0,096 \\
7 & 0,366 & $-0,395$ & 0,144 & 0,087 \\
9 & 0,690 & $-0,744$ & 0,277 & 0,154 \\
12 & 0,266 & $-0,302$ & 0,100 & 0,258 \\
14 & 0,344 & $-0,279$ & 0,107 & 0,096 \\
16 & 0,075 & $-0,088$ & 0,030 & 0,154 \\
\hline
\end{tabular}




\section{D.3 Catenária-3 - Velocidade de $1,13 \mathrm{~m} / \mathrm{s}$ e $V_{r 1}=$ 12,29}

Abaixo serão apresentados os gráficos com alguns detalhes da análise referentes ao arranjo Catenária-3 para a velocidade de $1,13 \mathrm{~m} / \mathrm{s}$ e $V_{r 1}=12,29$.
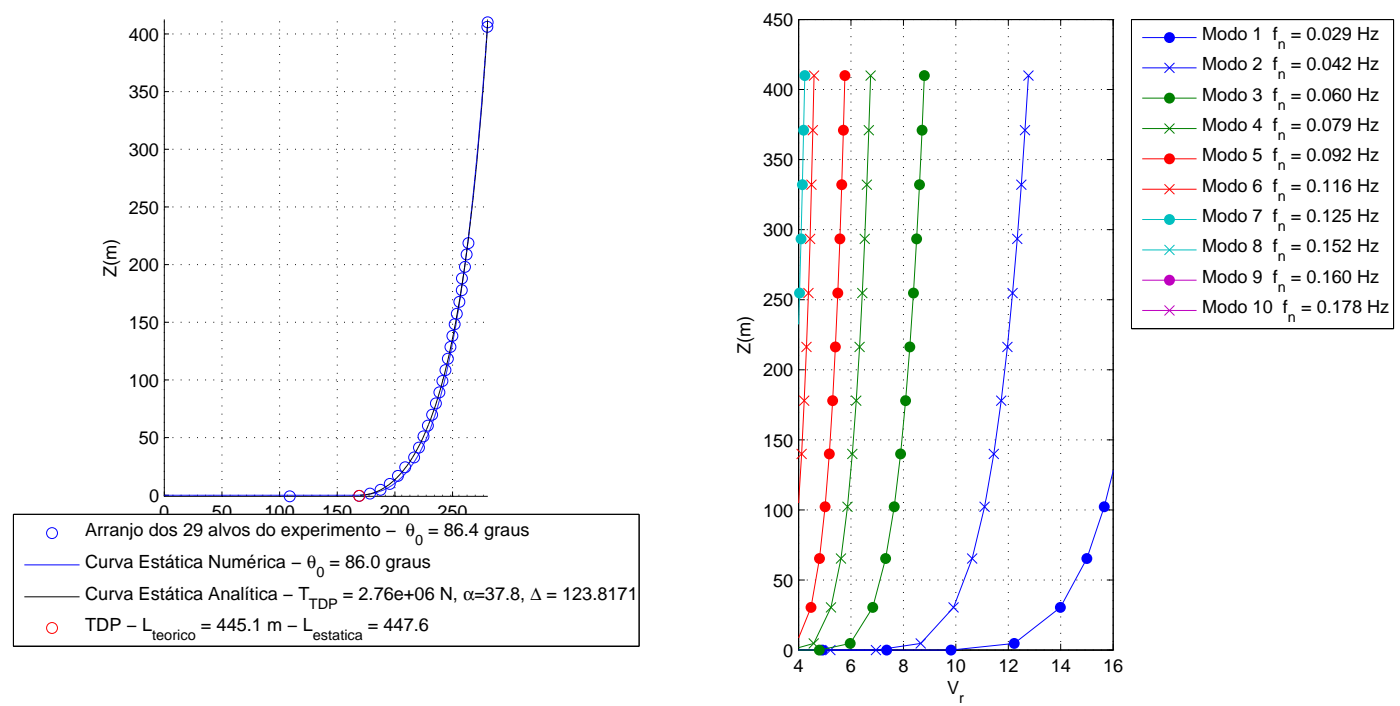

Figura D.11: Variação da velocidade no modelo durante o ensaio para Catenária-3 na $U_{\text {max }}=1,13 \mathrm{~m} / \mathrm{s}$ e $V_{r 1}=12,287$.

Como pode ser visto na Tabela D.9 e nas Figuras de D.12 a D.14, os maiores deslocamentos máximos apresentados na direção X, Y e Z foram de 1,871, 1,468 e 1,273 $\mathrm{m}$, respectivamente. Estes valores ocorreram para os alvos 4, 7 e 13. Nestes alvos, as suas frequências de resposta com maior energia foi de 0,0917 Hz. 

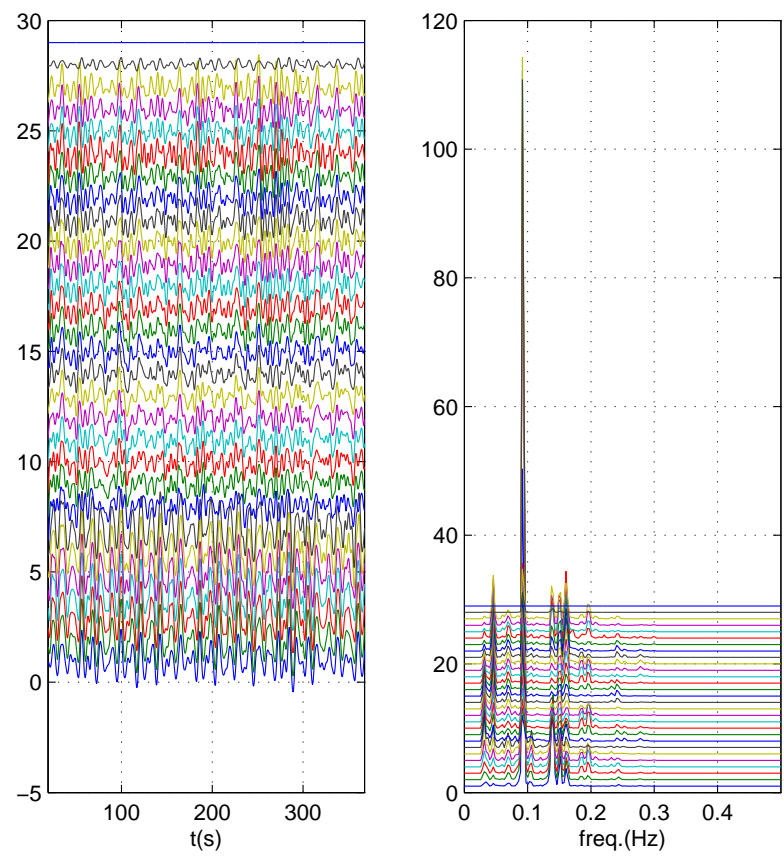

Figura D.12: Série temporal com frequências de resposta para X obtida experimentalmente por alvo para o arranjo de Catenária-3 na $U_{\max }=1,13 \mathrm{~m} / \mathrm{s}$ e $V_{r 1}=12,287$.
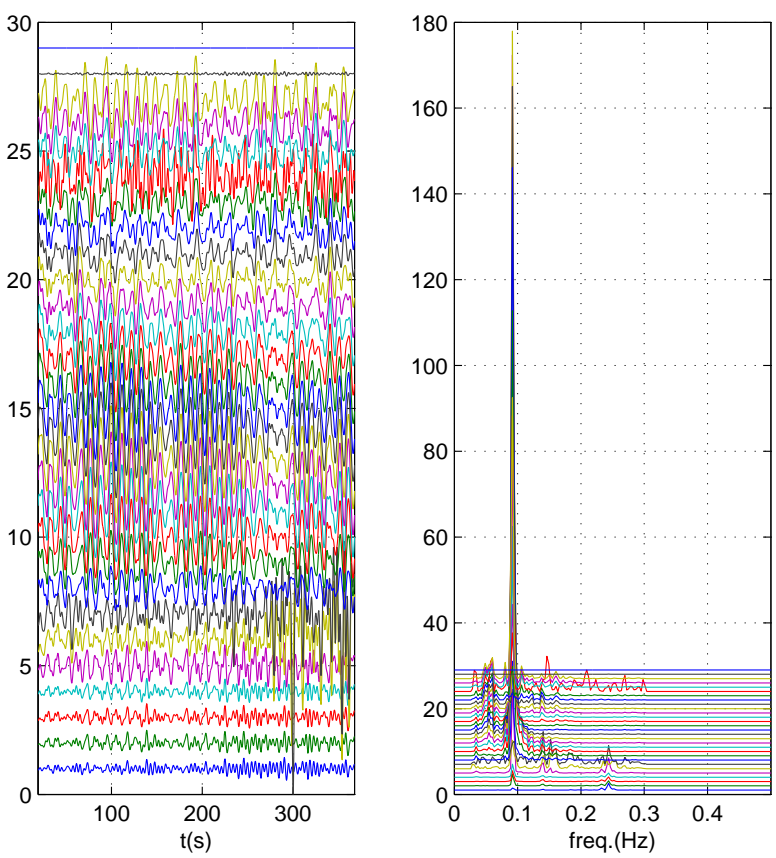

Figura D.13: Série temporal com frequências de resposta para Y obtida experimentalmente por alvo para o arranjo de Catenária-3 na $U_{\max }=1,13 \mathrm{~m} / \mathrm{s}$ e $V_{r 1}=12,287$. 

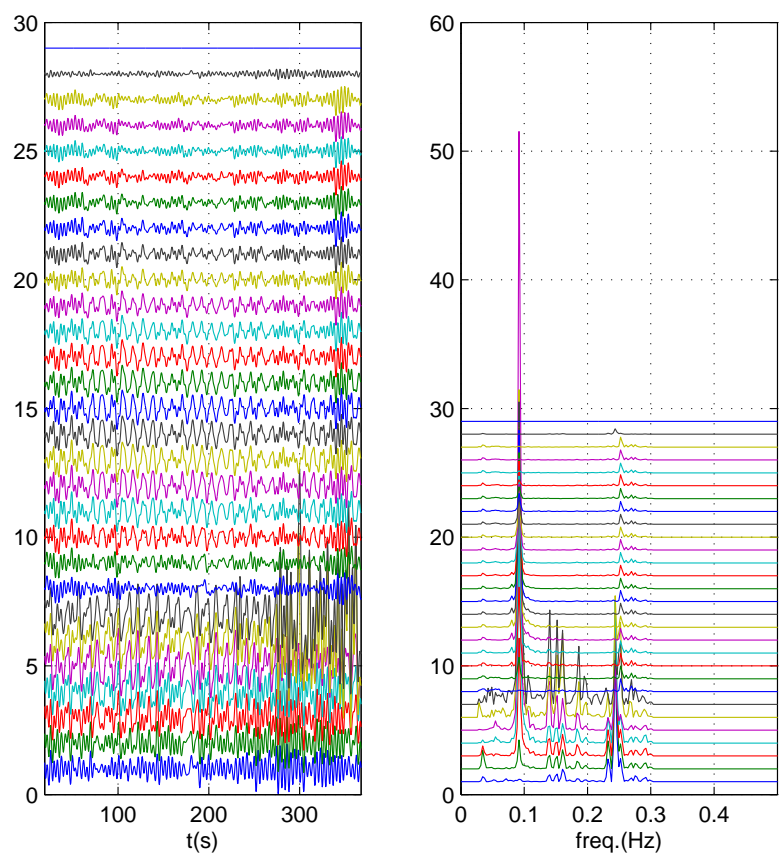

Figura D.14: Série temporal com frequências de resposta para Z obtida experimentalmente por alvo para o arranjo de Catenária-3 na $U_{\max }=1,13 \mathrm{~m} / \mathrm{s}$ e $V_{r 1}=12,287$. 
Tabela D.9: Propriedades da série temporal do ensaio Catenária-3 para a

$$
U_{\max }=1,13 \mathrm{~m} / \mathrm{s} \text {. }
$$

\begin{tabular}{|c|c|c|c|c|c|c|c|c|c|c|c|c|}
\hline \multirow[b]{2}{*}{ ID. Alvo } & \multirow[b]{2}{*}{$\mathrm{X}(\mathrm{m})$} & \multicolumn{2}{|c|}{ Máximo } & \multirow[b]{2}{*}{$\mathrm{X}(\mathrm{m})$} & \multirow{2}{*}{$\begin{array}{l}\text { Mínimo } \\
\mathrm{Y}(\mathrm{m})\end{array}$} & \multirow{2}{*}{$\mathrm{Z}(\mathrm{m})$} & \multicolumn{3}{|c|}{ Desvio padrão } & \multicolumn{3}{|c|}{ Freq. máxima em $\mathrm{Hz}$} \\
\hline & & $\mathrm{Y}(\mathrm{m})$ & $\mathrm{Z}(\mathrm{m})$ & & & & $\mathrm{X}(\mathrm{m})$ & $\mathrm{Y}(\mathrm{m})$ & $\mathrm{Z}(\mathrm{m})$ & $\mathrm{X}$ & $\mathrm{Y}$ & $\mathrm{Z}$ \\
\hline 1 & 1,352 & 0,140 & 0,708 & $-0,795$ & $-0,185$ & $-0,640$ & 0,503 & 0,073 & 0,305 & 0,092 & 0,244 & 0,244 \\
\hline 2 & 1,773 & 0,199 & 0,683 & $-1,107$ & $-0,164$ & $-0,757$ & 0,702 & 0,096 & 0,326 & 0,092 & 0,092 & 0,244 \\
\hline 3 & 1,822 & 0,230 & 0,699 & $-1,177$ & $-0,174$ & $-0,877$ & 0,754 & 0,099 & 0,362 & 0,092 & 0,092 & 0,244 \\
\hline 4 & 1,871 & 0,219 & 0,680 & $-1,212$ & $-0,192$ & $-0,891$ & 0,808 & 0,098 & 0,384 & 0,092 & 0,092 & 0,092 \\
\hline 5 & 1,715 & 0,484 & 0,837 & $-1,293$ & $-0,678$ & $-0,917$ & 0,789 & 0,275 & 0,425 & 0,092 & 0,092 & 0,092 \\
\hline 6 & 1,766 & 0,637 & 1,029 & $-1,246$ & $-0,895$ & $-0,806$ & 0,820 & 0,341 & 0,449 & 0,092 & 0,092 & 0,092 \\
\hline 7 & 1,655 & 0,819 & 1,273 & $-1,226$ & $-1,366$ & $-0,801$ & 0,801 & 0,486 & 0,477 & 0,092 & 0,140 & 0,092 \\
\hline 8 & 0,859 & 0,677 & 0,492 & $-1,543$ & $-0,743$ & $-0,558$ & 0,484 & 0,359 & 0,249 & 0,032 & 0,092 & 0,252 \\
\hline 9 & 0,893 & 0,931 & 0,584 & $-1,532$ & $-1,019$ & $-0,587$ & 0,486 & 0,505 & 0,260 & 0,032 & 0,092 & 0,092 \\
\hline 10 & 0,933 & 1,184 & 0,704 & $-1,423$ & $-1,279$ & $-0,640$ & 0,479 & 0,658 & 0,288 & 0,032 & 0,092 & 0,092 \\
\hline 11 & 1,033 & 1,334 & 0,766 & $-1,237$ & $-1,407$ & $-0,666$ & 0,467 & 0,740 & 0,306 & 0,032 & 0,092 & 0,092 \\
\hline 12 & 1,114 & 1,434 & 0,791 & $-1,018$ & $-1,470$ & $-0,668$ & 0,460 & 0,797 & 0,316 & 0,092 & 0,092 & 0,092 \\
\hline 13 & 1,152 & 1,468 & 0,777 & $-0,932$ & $-1,403$ & $-0,658$ & 0,465 & 0,797 & 0,310 & 0,092 & 0,092 & 0,092 \\
\hline 14 & 1,143 & 1,390 & 0,725 & $-0,872$ & $-1,240$ & $-0,625$ & 0,480 & 0,751 & 0,293 & 0,092 & 0,092 & 0,092 \\
\hline 15 & 1,092 & 1,288 & 0,674 & $-0,821$ & $-1,068$ & $-0,613$ & 0,501 & 0,686 & 0,278 & 0,092 & 0,092 & 0,092 \\
\hline 16 & 1,021 & 1,148 & 0,602 & $-0,884$ & $-0,953$ & $-0,564$ & 0,521 & 0,592 & 0,253 & 0,092 & 0,092 & 0,092 \\
\hline 17 & 0,962 & 1,086 & 0,542 & $-1,017$ & $-0,883$ & $-0,527$ & 0,536 & 0,504 & 0,233 & 0,092 & 0,092 & 0,092 \\
\hline 18 & 0,978 & 1,041 & 0,479 & $-1,121$ & $-0,785$ & $-0,512$ & 0,547 & 0,419 & 0,220 & 0,092 & 0,092 & 0,092 \\
\hline 19 & 1,019 & 0,944 & 0,426 & $-1,165$ & $-0,707$ & $-0,477$ & 0,550 & 0,367 & 0,205 & 0,092 & 0,092 & 0,092 \\
\hline 20 & 1,051 & 0,897 & 0,370 & $-1,221$ & $-0,661$ & $-0,448$ & 0,550 & 0,344 & 0,192 & 0,092 & 0,092 & 0,092 \\
\hline 21 & 1,071 & 0,810 & 0,366 & $-1,224$ & $-0,766$ & $-0,427$ & 0,544 & 0,360 & 0,185 & 0,092 & 0,060 & 0,092 \\
\hline 22 & 1,094 & 0,738 & 0,383 & $-1,169$ & $-0,820$ & $-0,433$ & 0,534 & 0,383 & 0,185 & 0,092 & 0,060 & 0,092 \\
\hline 23 & 1,099 & 0,743 & 0,392 & $-1,141$ & $-0,916$ & $-0,406$ & 0,519 & 0,425 & 0,181 & 0,092 & 0,092 & 0,092 \\
\hline 24 & 1,413 & 1,264 & 0,326 & $-1,416$ & $-1,280$ & $-0,428$ & 0,647 & 0,609 & 0,171 & 0,092 & 0,092 & 0,252 \\
\hline 25 & 1,103 & 0,987 & 0,406 & $-0,947$ & $-1,045$ & $-0,418$ & 0,493 & 0,501 & 0,184 & 0,092 & 0,092 & 0,252 \\
\hline 26 & 1,100 & 1,080 & 0,391 & $-0,822$ & $-1,108$ & $-0,390$ & 0,481 & 0,538 & 0,182 & 0,092 & 0,092 & 0,252 \\
\hline 27 & 1,098 & 1,131 & 0,385 & $-0,811$ & $-1,138$ & $-0,386$ & 0,470 & 0,555 & 0,179 & 0,092 & 0,092 & 0,252 \\
\hline 28 & 0,314 & 0,031 & 0,136 & $-0,185$ & $-0,030$ & $-0,136$ & 0,120 & 0,015 & 0,064 & 0,092 & 0,244 & 0,244 \\
\hline 29 & 0,000 & 0,000 & 0,000 & 0,000 & 0,000 & 0,000 & 0,000 & 0,000 & 0,000 & 0,000 & 0,000 & 0,000 \\
\hline
\end{tabular}

Considerando agora a decomposição modal, na Tabela D.10 através da interpolação do sinal do ensaio, correspondente a uma velocade reduzida do primeiro modo $V_{r 1}=12.29$, as maiores amplitudes máximas apresentadas na direção X, Y e Z foram de 1,572, 1,931 e 1,351 m, respectivamente. Estes valores ocorreram para os modos 1, 4 e 10. Nestes modos, as suas frequências de resposta com maior energia foram de 0,0917 e 0,244 Hz. 

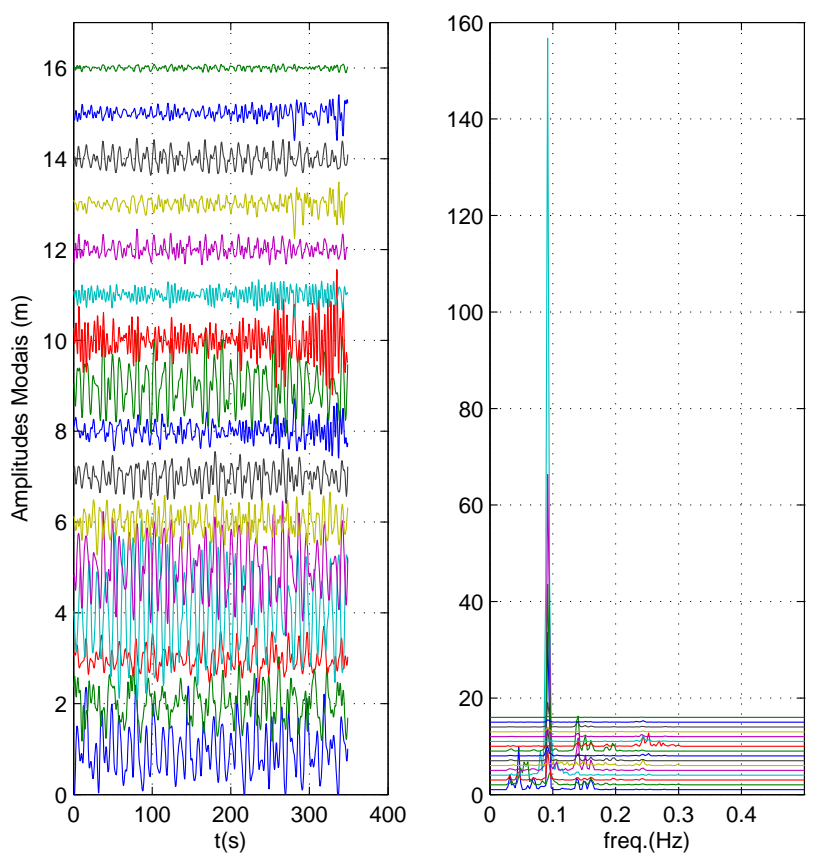

Figura D.15: Variação da amplitude modal acoplada ao longo do tempo através da interpolação do sinal do ensaio para Catenária-3 na $U_{\max }=1,13 \mathrm{~m} / \mathrm{s}$ e $V_{r 1}=12,287$.

Tabela D.10: Propriedades das amplitudes modais do ensaio Catenária-3 através da interpolação do sinal do ensaio para a $V_{\max }=1,13 \mathrm{~m} / \mathrm{s}$.

\begin{tabular}{lccccccccccccc}
\hline \multicolumn{1}{c}{ Máximo } & \multicolumn{1}{c}{ Mínimo } & & \multicolumn{3}{c}{ Desvio padrão } & \multicolumn{7}{c}{ Freq. máxima em Hz } \\
\multicolumn{1}{c}{ Modo } & $\mathrm{X}(\mathrm{m})$ & $\mathrm{Y}(\mathrm{m})$ & $\mathrm{Z}(\mathrm{m})$ & $\mathrm{X}(\mathrm{m})$ & $\mathrm{Y}(\mathrm{m})$ & $\mathrm{Z}(\mathrm{m})$ & $\mathrm{X}(\mathrm{m})$ & $\mathrm{Y}(\mathrm{m})$ & $\mathrm{Z}(\mathrm{m})$ & $\mathrm{X}$ & $\mathrm{Y}$ & $\mathrm{Z}$ \\
& & & & & & & & & & & & \\
\hline 1 & 1,572 & 0,000 & 0,000 & $-1,162$ & $-0,000$ & $-0,000$ & 0,540 & 0,000 & 0,000 & 0,092 & 0,060 & 0,092 \\
2 & 0,003 & 1,024 & 0,186 & $-0,002$ & $-0,806$ & $-0,140$ & 0,001 & 0,355 & 0,051 & 0,092 & 0,060 & 0,092 \\
3 & 0,712 & 0,000 & 0,000 & $-0,762$ & $-0,000$ & $-0,000$ & 0,247 & 0,000 & 0,000 & 0,092 & 0,060 & 0,092 \\
4 & 0,000 & 1,931 & 0,248 & $-0,000$ & $-1,766$ & $-0,300$ & 0,000 & 0,818 & 0,094 & 0,092 & 0,092 & 0,092 \\
5 & 1,481 & 0,000 & 0,000 & $-1,534$ & $-0,000$ & $-0,000$ & 0,606 & 0,000 & 0,000 & 0,092 & 0,092 & 0,092 \\
6 & 0,000 & 0,728 & 0,160 & $-0,000$ & $-0,663$ & $-0,166$ & 0,000 & 0,233 & 0,067 & 0,092 & 0,244 & 0,092 \\
7 & 0,608 & 0,000 & 0,000 & $-0,597$ & $-0,000$ & $-0,000$ & 0,234 & 0,000 & 0,000 & 0,092 & 0,244 & 0,092 \\
8 & 0,000 & 0,580 & 0,285 & $-0,000$ & $-0,530$ & $-0,242$ & 0,000 & 0,186 & 0,066 & 0,092 & 0,092 & 0,092 \\
9 & 1,293 & 0,000 & 0,000 & $-1,048$ & $-0,000$ & $-0,000$ & 0,494 & 0,000 & 0,000 & 0,092 & 0,092 & 0,244 \\
10 & 0,000 & 0,237 & 1,351 & $-0,000$ & $-0,184$ & $-1,112$ & 0,000 & 0,069 & 0,327 & 0,092 & 0,092 & 0,244 \\
11 & 0,000 & 0,290 & 0,289 & $-0,000$ & $-0,444$ & $-0,316$ & 0,000 & 0,104 & 0,099 & 0,092 & 0,138 & 0,244 \\
12 & 0,457 & 0,000 & 0,000 & $-0,340$ & $-0,000$ & $-0,000$ & 0,141 & 0,000 & 0,000 & 0,092 & 0,138 & 0,244 \\
13 & 0,000 & 0,411 & 0,124 & $-0,000$ & $-0,555$ & $-0,202$ & 0,000 & 0,123 & 0,047 & 0,092 & 0,092 & 0,244 \\
14 & 0,454 & 0,000 & 0,000 & $-0,392$ & $-0,000$ & $-0,000$ & 0,184 & 0,000 & 0,000 & 0,092 & 0,092 & 0,244 \\
15 & 0,000 & 0,263 & 0,146 & $-0,000$ & $-0,426$ & $-0,237$ & 0,000 & 0,091 & 0,042 & 0,092 & 0,092 & 0,244 \\
16 & 0,090 & 0,000 & 0,000 & $-0,111$ & $-0,000$ & $-0,000$ & 0,042 & 0,000 & 0,000 & 0,092 & 0,092 & 0,244 \\
\hline
\end{tabular}

A Tabela D.11 apresenta para o ensaio Catenária-3 apenas os movimentos referentes 
a deslocamento no plano da catenária através da interpolação do sinal do ensaio, a maior amplitude acoplada máxima foi de 2,048 m. Este valor ocorreu para o modo 4 . Neste modo, a sua frequência de resposta com maior energia foi de 0,092 Hz.

Tabela D.11: Propriedades das amplitudes modais acopladas no plano da catenária do ensaio Catenária-3 através da interpolação do sinal do ensaio para a $V_{\max }=1,13 \mathrm{~m} / \mathrm{s}$.

\section{Amplitude}

\section{Modo Máxima(m) Mínima(m) Desvio Padrão(m) Freq. máxima (Hz)}

\begin{tabular}{lllll}
\hline 2 & 1,033 & $-0,858$ & 0,372 & 0,060 \\
4 & 2,048 & $-1,914$ & 0,883 & 0,092 \\
6 & 0,677 & $-0,727$ & 0,257 & 0,103 \\
8 & 0,713 & $-0,593$ & 0,193 & 0,092 \\
10 & 1,558 & $-1,201$ & 0,339 & 0,252 \\
11 & 0,333 & $-0,490$ & 0,135 & 0,244 \\
13 & 0,483 & $-0,752$ & 0,140 & 0,092 \\
15 & 0,406 & $-0,598$ & 0,126 & 0,092 \\
\hline
\end{tabular}

A Tabela D.12 para o ensaio Catenária-3 com apenas as amplitudes correspondentes a movimentos fora do plano através da interpolação do sinal do ensaio, a maior amplitude acoplada máxima apresentada foi de 1,557 m. Este valor ocorreu para o modo 1 . Neste modo, a sua frequência de resposta com maior energia foi de 0,092 Hz.

Tabela D.12: Propriedades das amplitudes modais acopladas fora do plano da catenária do ensaio Catenária-3 através da interpolação do sinal do ensaio para a

$$
V_{\max }=1,13 \mathrm{~m} / \mathrm{s} \text {. }
$$

Amplitude

Modo Máxima(m) Mínima(m) Desvio Padrão(m) Freq. máxima (Hz)

\begin{tabular}{lllll}
\hline 1 & 1,557 & $-1,151$ & 0,535 & 0,092 \\
3 & 0,703 & $-0,752$ & 0,243 & 0,092 \\
5 & 1,460 & $-1,513$ & 0,598 & 0,092 \\
7 & 0,600 & $-0,589$ & 0,231 & 0,092 \\
9 & 1,277 & $-1,036$ & 0,488 & 0,092 \\
12 & 0,452 & $-0,336$ & 0,140 & 0,092 \\
14 & 0,449 & $-0,388$ & 0,182 & 0,092 \\
16 & 0,089 & $-0,110$ & 0,042 & 0,092 \\
\hline
\end{tabular}




\section{D.4 Catenária-3 - Velocidade de $1,43 \mathrm{~m} / \mathrm{s}$ e $V_{r 1}=$ 15,47}

Abaixo serão apresentados os gráficos com alguns detalhes da análise referentes ao arranjo Catenária-3 para a velocidade de $1,43 \mathrm{~m} / \mathrm{s}$ e $V_{r 1}=15,47$.
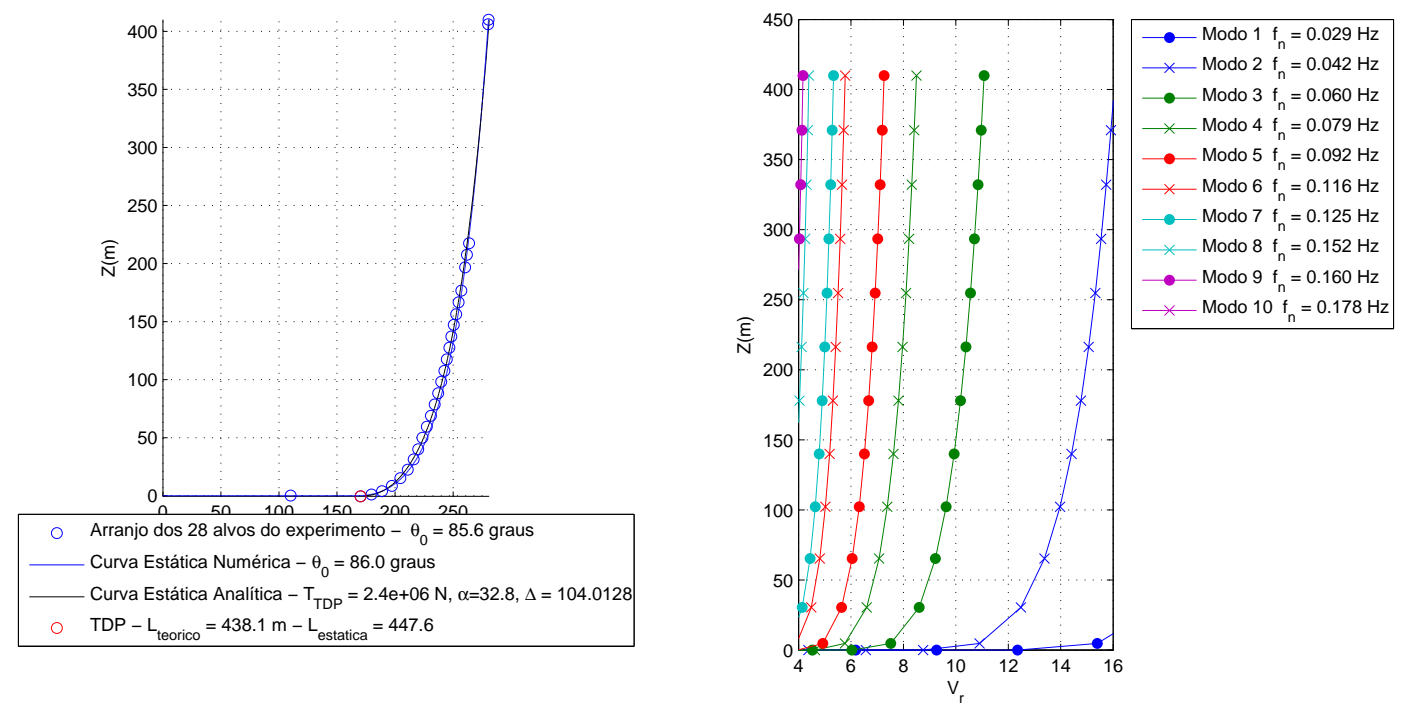

Figura D.16: Variação da velocidade no modelo durante o ensaio para Catenária-3 na $U_{\text {max }}=1,43 \mathrm{~m} / \mathrm{s}$ e $V_{r 1}=15,472$.

Como pode ser visto na Tabela D.13 e nas Figuras de D.17 a D.19, os maiores deslocamentos máximos apresentados na direção X, Y e Z foram de 0,982, 1,496 e 0,632 $\mathrm{m}$, respectivamente. Estes valores ocorreram para os alvos 4, 6 e 10. Nestes alvos, as suas frequências de resposta com maior energia foram de 0,0639, 0,122 e 0,25 Hz. 

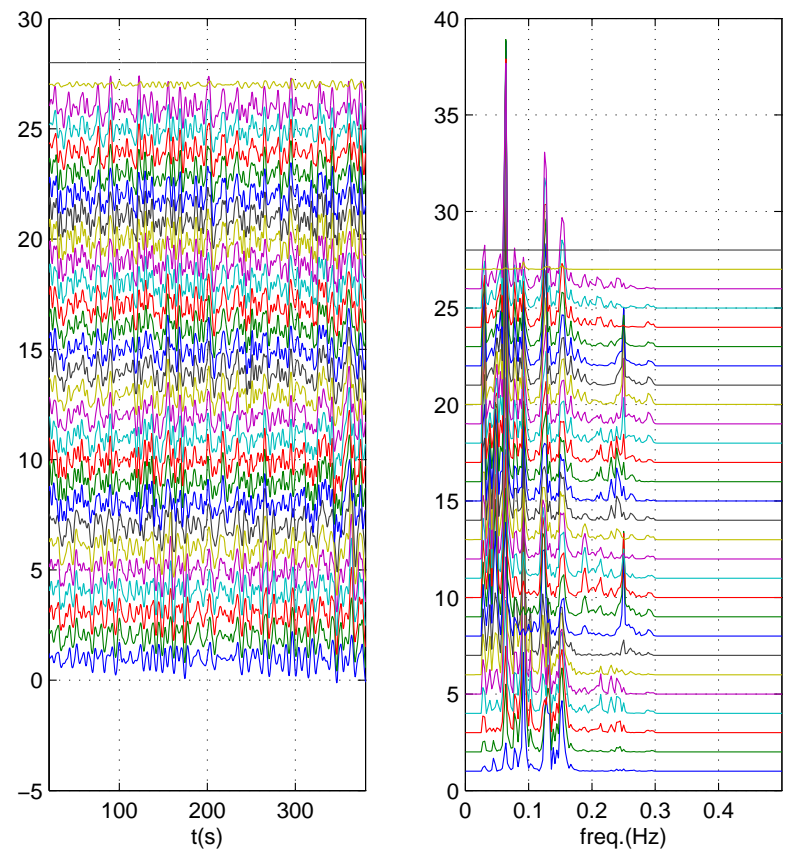

Figura D.17: Série temporal com frequências de resposta para X obtida experimentalmente por alvo para o arranjo de Catenária-3 na $U_{\max }=1,43 \mathrm{~m} / \mathrm{s}$ e $V_{r 1}=15,472$.
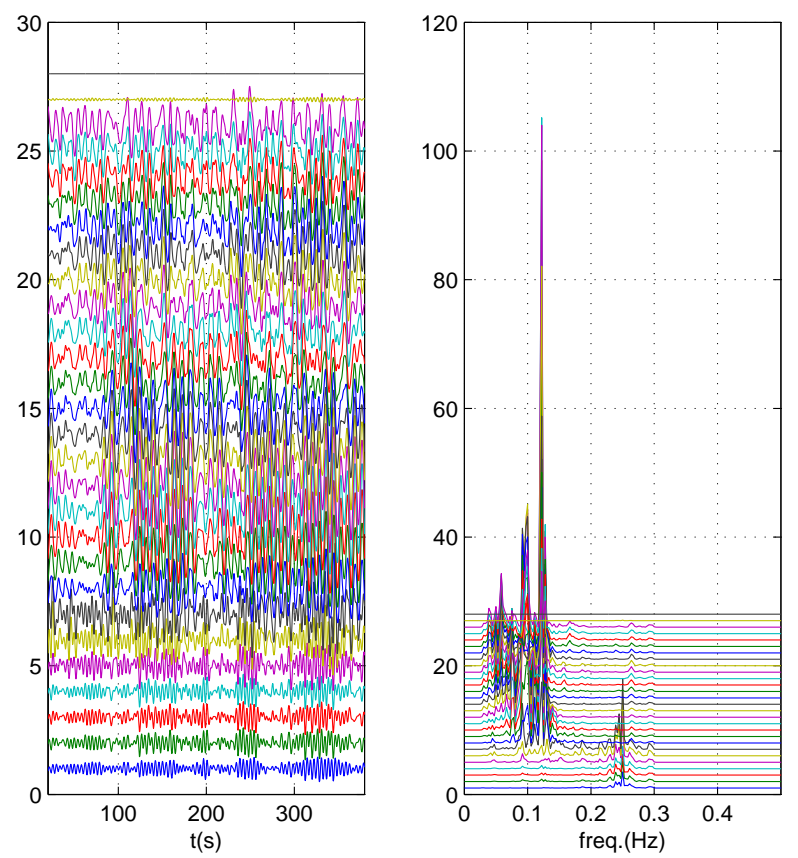

Figura D.18: Série temporal com frequências de resposta para Y obtida experimentalmente por alvo para o arranjo de Catenária-3 na $U_{\max }=1,43 \mathrm{~m} / \mathrm{s}$ e $V_{r 1}=15,472$. 

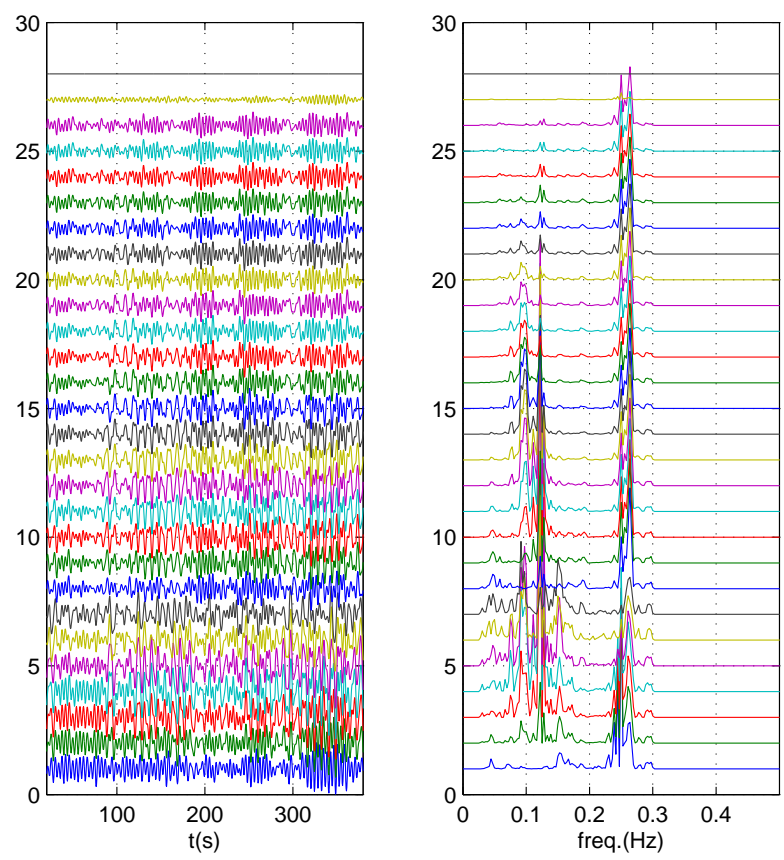

Figura D.19: Série temporal com frequências de resposta para Z obtida experimentalmente por alvo para o arranjo de Catenária-3 na $U_{\max }=1,43 \mathrm{~m} / \mathrm{s}$ e $V_{r 1}=15,472$. 
Tabela D.13: Propriedades da série temporal do ensaio Catenária-3 para a

$$
U_{\max }=1,43 \mathrm{~m} / \mathrm{s} \text {. }
$$

\begin{tabular}{|c|c|c|c|c|c|c|c|c|c|c|c|c|}
\hline \multirow[b]{2}{*}{ ID. Alvo } & \multirow[b]{2}{*}{$\mathrm{X}(\mathrm{m})$} & \multicolumn{2}{|c|}{ Máximo } & \multirow[b]{2}{*}{$\mathrm{X}(\mathrm{m})$} & \multirow{2}{*}{$\begin{array}{l}\text { Mínimo } \\
\mathrm{Y}(\mathrm{m})\end{array}$} & \multirow[b]{2}{*}{$\mathrm{Z}(\mathrm{m})$} & \multicolumn{3}{|c|}{ Desvio padrão } & \multicolumn{3}{|c|}{ Freq. máxima em $\mathrm{Hz}$} \\
\hline & & $\mathrm{Y}(\mathrm{m})$ & $\mathrm{Z}(\mathrm{m})$ & & & & $\mathrm{X}(\mathrm{m})$ & $\mathrm{Y}(\mathrm{m})$ & $\mathrm{Z}(\mathrm{m})$ & $\mathrm{X}$ & $\mathrm{Y}$ & Z \\
\hline 1 & 0,649 & 0,174 & 0,555 & $-0,434$ & $-0,214$ & $-0,565$ & 0,258 & 0,112 & 0,307 & 0,092 & 0,250 & 0,250 \\
\hline 2 & 0,820 & 0,196 & 0,540 & $-0,665$ & $-0,276$ & $-0,693$ & 0,349 & 0,118 & 0,309 & 0,092 & 0,250 & 0,250 \\
\hline 3 & 0,908 & 0,232 & 0,566 & $-0,735$ & $-0,273$ & $-0,764$ & 0,381 & 0,124 & 0,316 & 0,092 & 0,250 & 0,122 \\
\hline 4 & 0,965 & 0,260 & 0,632 & $-0,789$ & $-0,329$ & $-0,819$ & 0,408 & 0,126 & 0,338 & 0,092 & 0,250 & 0,122 \\
\hline 5 & 0,921 & 0,483 & 0,511 & $-0,738$ & $-0,510$ & $-0,664$ & 0,406 & 0,223 & 0,275 & 0,092 & 0,250 & 0,122 \\
\hline 6 & 0,853 & 1,496 & 0,556 & $-0,770$ & $-0,790$ & $-0,856$ & 0,427 & 0,438 & 0,300 & 0,092 & 0,250 & 0,122 \\
\hline 7 & 0,708 & 1,450 & 0,608 & $-0,926$ & $-1,017$ & $-0,755$ & 0,435 & 0,496 & 0,302 & 0,092 & 0,250 & 0,092 \\
\hline 8 & 0,946 & 0,496 & 0,501 & $-0,798$ & $-0,573$ & $-0,532$ & 0,454 & 0,272 & 0,208 & 0,064 & 0,122 & 0,264 \\
\hline 9 & 0,965 & 0,682 & 0,522 & $-0,861$ & $-0,713$ & $-0,576$ & 0,481 & 0,345 & 0,227 & 0,064 & 0,122 & 0,122 \\
\hline 10 & 0,982 & 0,868 & 0,500 & $-0,876$ & $-0,847$ & $-0,601$ & 0,479 & 0,402 & 0,239 & 0,064 & 0,122 & 0,122 \\
\hline 11 & 0,940 & 0,920 & 0,467 & $-0,792$ & $-0,873$ & $-0,590$ & 0,453 & 0,405 & 0,236 & 0,064 & 0,122 & 0,122 \\
\hline 12 & 0,829 & 0,968 & 0,457 & $-0,686$ & $-0,902$ & $-0,560$ & 0,428 & 0,396 & 0,229 & 0,064 & 0,122 & 0,122 \\
\hline 13 & 0,818 & 0,911 & 0,428 & $-0,791$ & $-0,846$ & $-0,520$ & 0,421 & 0,364 & 0,216 & 0,064 & 0,122 & 0,122 \\
\hline 14 & 0,915 & 0,822 & 0,397 & $-0,909$ & $-0,769$ & $-0,474$ & 0,428 & 0,335 & 0,200 & 0,064 & 0,122 & 0,122 \\
\hline 15 & 0,945 & 0,749 & 0,388 & $-0,964$ & $-0,701$ & $-0,444$ & 0,436 & 0,323 & 0,191 & 0,064 & 0,122 & 0,264 \\
\hline 16 & 0,910 & 0,641 & 0,372 & $-0,950$ & $-0,611$ & $-0,418$ & 0,439 & 0,309 & 0,179 & 0,064 & 0,092 & 0,264 \\
\hline 17 & 0,854 & 0,575 & 0,358 & $-0,925$ & $-0,550$ & $-0,401$ & 0,442 & 0,306 & 0,173 & 0,064 & 0,092 & 0,264 \\
\hline 18 & 0,876 & 0,534 & 0,346 & $-0,910$ & $-0,477$ & $-0,404$ & 0,451 & 0,297 & 0,174 & 0,064 & 0,092 & 0,264 \\
\hline 19 & 0,911 & 0,597 & 0,328 & $-0,919$ & $-0,509$ & $-0,398$ & 0,466 & 0,288 & 0,171 & 0,064 & 0,122 & 0,264 \\
\hline 20 & 0,901 & 0,645 & 0,305 & $-0,934$ & $-0,561$ & $-0,382$ & 0,478 & 0,280 & 0,164 & 0,064 & 0,122 & 0,264 \\
\hline 21 & 0,873 & 0,673 & 0,301 & $-0,908$ & $-0,627$ & $-0,373$ & 0,476 & 0,283 & 0,161 & 0,064 & 0,122 & 0,264 \\
\hline 22 & 0,859 & 0,694 & 0,315 & $-0,852$ & $-0,719$ & $-0,377$ & 0,461 & 0,306 & 0,164 & 0,064 & 0,122 & 0,264 \\
\hline 23 & 0,818 & 0,691 & 0,309 & $-0,776$ & $-0,853$ & $-0,376$ & 0,434 & 0,329 & 0,163 & 0,064 & 0,122 & 0,264 \\
\hline 24 & 0,783 & 0,676 & 0,322 & $-0,848$ & $-1,056$ & $-0,375$ & 0,398 & 0,411 & 0,165 & 0,064 & 0,122 & 0,264 \\
\hline 25 & 0,833 & 0,662 & 0,332 & $-0,918$ & $-1,156$ & $-0,367$ & 0,394 & 0,464 & 0,160 & 0,064 & 0,122 & 0,264 \\
\hline 26 & 0,919 & 0,732 & 0,340 & $-0,963$ & $-1,206$ & $-0,369$ & 0,400 & 0,506 & 0,162 & 0,064 & 0,100 & 0,264 \\
\hline 27 & 0,141 & 0,035 & 0,107 & $-0,105$ & $-0,046$ & $-0,113$ & 0,059 & 0,022 & 0,061 & 0,092 & 0,250 & 0,250 \\
\hline 28 & 0,000 & 0,000 & 0,000 & 0,000 & 0,000 & 0,000 & 0,000 & 0,000 & 0,000 & 0,000 & 0,000 & 0,000 \\
\hline
\end{tabular}

Considerando agora a decomposição modal, na Tabela D.14 através da interpolação do sinal do ensaio, correspondente a uma velocade reduzida do primeiro modo $V_{r 1}=15.47$, as maiores amplitudes máximas apresentadas na direção X, Y e Z foram de 1,760, 1,441 e $0,887 \mathrm{~m}$, respectivamente. Estes valores ocorreram para os modos 1, 4 e 10. Nestes modos, as suas frequências de resposta com maior energia foram de 0,0639, 0,1 e 0,264 $\mathrm{Hz}$. 

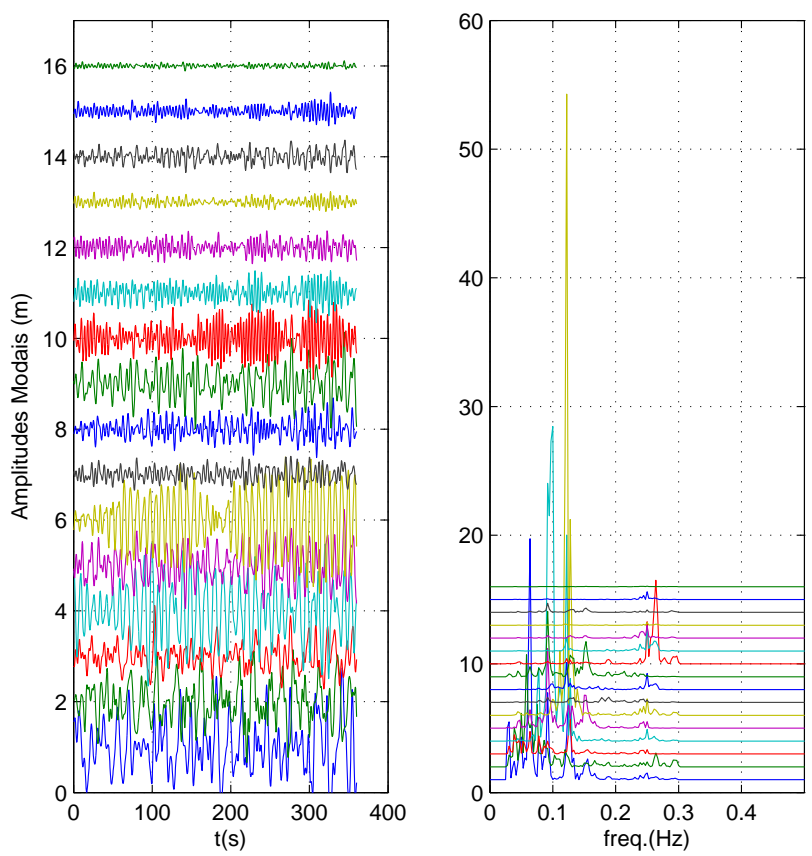

Figura D.20: Variação da amplitude modal acoplada ao longo do tempo através da interpolação do sinal do ensaio para Catenária-3 na $U_{\max }=1,43 \mathrm{~m} / \mathrm{s}$ e $V_{r 1}=15,472$.

Tabela D.14: Propriedades das amplitudes modais do ensaio Catenária-3 através da interpolação do sinal do ensaio para a $V_{\max }=1,43 \mathrm{~m} / \mathrm{s}$.

\begin{tabular}{lccccccccccccc}
\hline \multicolumn{1}{c}{ Máximo } & \multicolumn{1}{c}{ Mínimo } & & \multicolumn{3}{c}{ Desvio padrão } & \multicolumn{7}{c}{ Freq. máxima em Hz } \\
\multicolumn{1}{c}{ Modo } & $\mathrm{X}(\mathrm{m})$ & $\mathrm{Y}(\mathrm{m})$ & $\mathrm{Z}(\mathrm{m})$ & $\mathrm{X}(\mathrm{m})$ & $\mathrm{Y}(\mathrm{m})$ & $\mathrm{Z}(\mathrm{m})$ & $\mathrm{X}(\mathrm{m})$ & $\mathrm{Y}(\mathrm{m})$ & $\mathrm{Z}(\mathrm{m})$ & $\mathrm{X}$ & $\mathrm{Y}$ & $\mathrm{Z}$ \\
& & & & & & & & & & & & \\
\hline 1 & 1,760 & 0,000 & 0,000 & $-1,489$ & $-0,000$ & $-0,000$ & 0,583 & 0,000 & 0,000 & 0,064 & 0,058 & 0,122 \\
2 & 0,003 & 1,107 & 0,106 & $-0,003$ & $-1,293$ & $-0,075$ & 0,001 & 0,430 & 0,032 & 0,064 & 0,058 & 0,122 \\
3 & 1,135 & 0,000 & 0,000 & $-0,731$ & $-0,000$ & $-0,000$ & 0,290 & 0,000 & 0,000 & 0,128 & 0,058 & 0,122 \\
4 & 0,000 & 1,441 & 0,226 & $-0,000$ & $-1,587$ & $-0,192$ & 0,000 & 0,575 & 0,077 & 0,153 & 0,100 & 0,122 \\
5 & 1,246 & 0,000 & 0,000 & $-0,964$ & $-0,000$ & $-0,000$ & 0,375 & 0,000 & 0,000 & 0,092 & 0,100 & 0,122 \\
6 & 0,000 & 1,263 & 0,216 & $-0,000$ & $-1,503$ & $-0,190$ & 0,000 & 0,562 & 0,080 & 0,092 & 0,122 & 0,122 \\
7 & 0,408 & 0,000 & 0,000 & $-0,501$ & $-0,000$ & $-0,000$ & 0,156 & 0,000 & 0,000 & 0,189 & 0,122 & 0,122 \\
8 & 0,000 & 0,522 & 0,257 & $-0,000$ & $-0,467$ & $-0,249$ & 0,000 & 0,166 & 0,084 & 0,092 & 0,122 & 0,122 \\
9 & 1,154 & 0,000 & 0,000 & $-1,003$ & $-0,000$ & $-0,000$ & 0,337 & 0,000 & 0,000 & 0,092 & 0,122 & 0,122 \\
10 & 0,000 & 0,297 & 0,887 & $-0,000$ & $-0,207$ & $-0,887$ & 0,000 & 0,084 & 0,318 & 0,092 & 0,122 & 0,264 \\
11 & 0,000 & 0,350 & 0,279 & $-0,000$ & $-0,462$ & $-0,345$ & 0,000 & 0,140 & 0,108 & 0,250 & 0,122 & 0,264 \\
12 & 0,372 & 0,000 & 0,000 & $-0,361$ & $-0,000$ & $-0,000$ & 0,141 & 0,000 & 0,000 & 0,250 & 0,122 & 0,264 \\
13 & 0,000 & 0,129 & 0,192 & $-0,000$ & $-0,118$ & $-0,185$ & 0,000 & 0,043 & 0,056 & 0,092 & 0,119 & 0,250 \\
14 & 0,370 & 0,000 & 0,000 & $-0,358$ & $-0,000$ & $-0,000$ & 0,134 & 0,000 & 0,000 & 0,092 & 0,119 & 0,250 \\
15 & 0,000 & 0,250 & 0,175 & $-0,000$ & $-0,242$ & $-0,118$ & 0,000 & 0,071 & 0,040 & 0,250 & 0,250 & 0,250 \\
16 & 0,114 & 0,000 & 0,000 & $-0,114$ & $-0,000$ & $-0,000$ & 0,035 & 0,000 & 0,000 & 0,250 & 0,250 & 0,250 \\
\hline
\end{tabular}

A Tabela D.15 apresenta para o ensaio Catenária-3 apenas os movimentos referentes 
a deslocamento no plano da catenária através da interpolação do sinal do ensaio, a maior amplitude acoplada máxima foi de 1,499 m. Este valor ocorreu para o modo 4. Neste modo, a sua frequência de resposta com maior energia foi de 0,100 Hz.

Tabela D.15: Propriedades das amplitudes modais acopladas no plano da catenária do ensaio Catenária-3 através da interpolação do sinal do ensaio para a $V_{\max }=1,43 \mathrm{~m} / \mathrm{s}$.

\section{Amplitude}

\section{Modo Máxima(m) Mínima(m) Desvio Padrão(m) Freq. máxima (Hz)}

\begin{tabular}{lllll}
\hline 2 & 1,144 & $-1,336$ & 0,444 & 0,058 \\
4 & 1,499 & $-1,657$ & 0,624 & 0,100 \\
6 & 1,387 & $-1,609$ & 0,622 & 0,122 \\
8 & 0,690 & $-0,624$ & 0,199 & 0,122 \\
10 & 0,839 & $-0,903$ & 0,298 & 0,264 \\
11 & 0,492 & $-0,654$ & 0,183 & 0,250 \\
13 & 0,230 & $-0,205$ & 0,073 & 0,250 \\
15 & 0,423 & $-0,320$ & 0,100 & 0,250 \\
\hline
\end{tabular}

A Tabela D.16 para o ensaio Catenária-3 com apenas as amplitudes correspondentes a movimentos fora do plano através da interpolação do sinal do ensaio, a maior amplitude acoplada máxima apresentada foi de 1,743 m. Este valor ocorreu para o modo 1. Neste modo, a sua frequência de resposta com maior energia foi de 0,064 Hz.

Tabela D.16: Propriedades das amplitudes modais acopladas fora do plano da catenária do ensaio Catenária-3 através da interpolação do sinal do ensaio para a

$$
V_{\max }=1,43 \mathrm{~m} / \mathrm{s} \text {. }
$$

Amplitude

Modo Máxima(m) Mínima(m) Desvio Padrão(m) Freq. máxima (Hz)

\begin{tabular}{lllll}
\hline 1 & 1,743 & $-1,474$ & 0,577 & 0,064 \\
3 & 1,120 & $-0,721$ & 0,286 & 0,128 \\
5 & 1,228 & $-0,951$ & 0,370 & 0,092 \\
7 & 0,403 & $-0,494$ & 0,154 & 0,189 \\
9 & 1,140 & $-0,991$ & 0,333 & 0,092 \\
12 & 0,368 & $-0,357$ & 0,140 & 0,250 \\
14 & 0,366 & $-0,354$ & 0,133 & 0,092 \\
16 & 0,113 & $-0,113$ & 0,035 & 0,250 \\
\hline
\end{tabular}


Anexo E - Resultados de VIV nas linhas em Catenária-4 
Neste anexo é apresentado um conjunto mais completo de resultados do VIV na linha flexível para a Catenária-4, particularmente aqueles referentes às velocidades reduzidas mais importantes. Vale lembrar que todos os resultados estão apresentados na escala real (1:100) conforme definido em [Rateiro et al., 2012]. Neste sentido, as seções que se seguem dizem respeito a:

- Na seção E.1: Velocidade de $0,537 \mathrm{~m} / \mathrm{s}$ e $V_{r 1}=6,87$

- Na seção E.2: Velocidade de $0,818 \mathrm{~m} / \mathrm{s}$ e $V_{r 1}=10,47$

- Na seção E.3: Velocidade de $1,34 \mathrm{~m} / \mathrm{s}$ e $V_{r 1}=17,17$

- Na seção E.4: Velocidade de $1,42 \mathrm{~m} / \mathrm{s}$ e $V_{r 1}=18,22$

\section{E.1 Catenária-4 - Velocidade de $0,537 \mathrm{~m} / \mathrm{s}$ e $V_{r 1}=$ 6,87}

Abaixo serão apresentados os gráficos com alguns detalhes da análise referentes ao arranjo Catenária-4 para a velocidade de $0,537 \mathrm{~m} / \mathrm{s}$ e $V_{r 1}=6,87$.
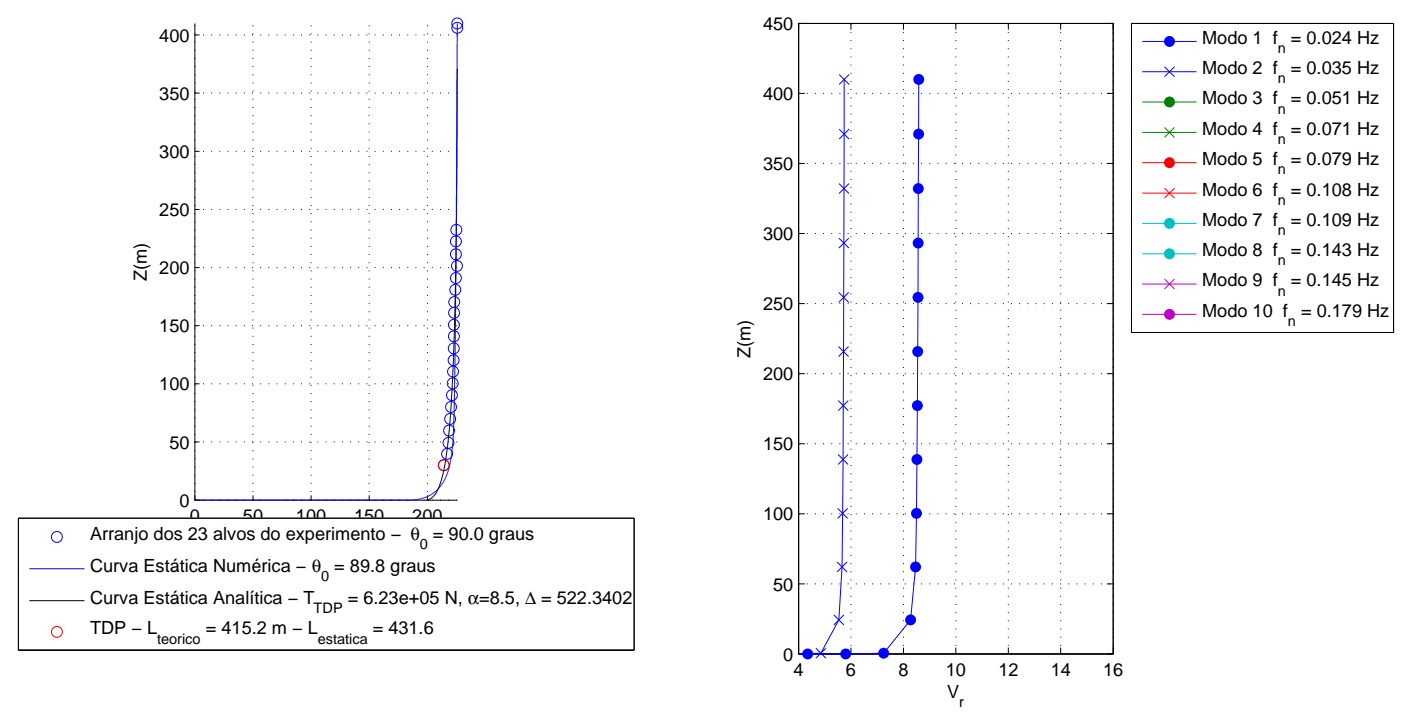

Figura E.1: Variação da velocidade no modelo durante o ensaio para Catenária-4 na

$$
U_{\text {max }}=0,537 \mathrm{~m} / \mathrm{s} \text { e } V_{r 1}=6,866 \text {. }
$$

Como pode ser visto na Tabela E.1 e nas Figuras de E.2 a E.4, os maiores deslocamentos máximos apresentados na direção X, Y e Z foram de 1,046, 1,407 e 0,392 
m, respectivamente. Estes valores ocorreram para o alvo 17, Neste alvo, a sua frequência de resposta com maior energia foi de 0,0470.0470.047 Hz.
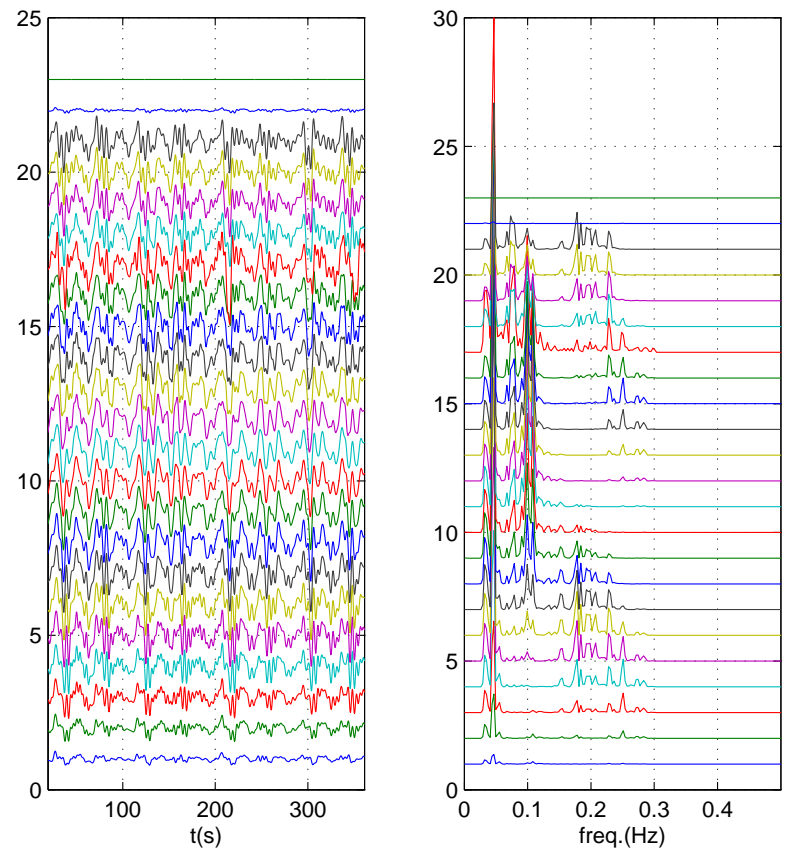

Figura E.2: Série temporal com frequências de resposta para X obtida experimentalmente por alvo para o arranjo de Catenária-4 na $U_{\max }=0,537 \mathrm{~m} / \mathrm{s}$ e $V_{r 1}=6,866$. 

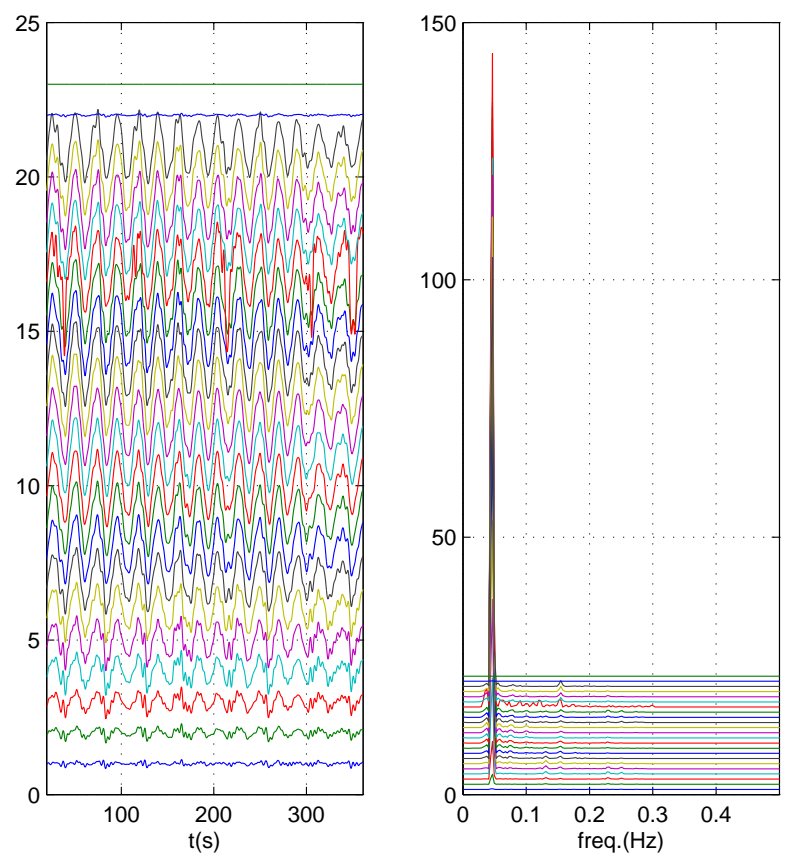

Figura E.3: Série temporal com frequências de resposta para Y obtida experimentalmente por alvo para o arranjo de Catenária-4 na $U_{\max }=0,537 \mathrm{~m} / \mathrm{s}$ e $V_{r 1}=6,866$.
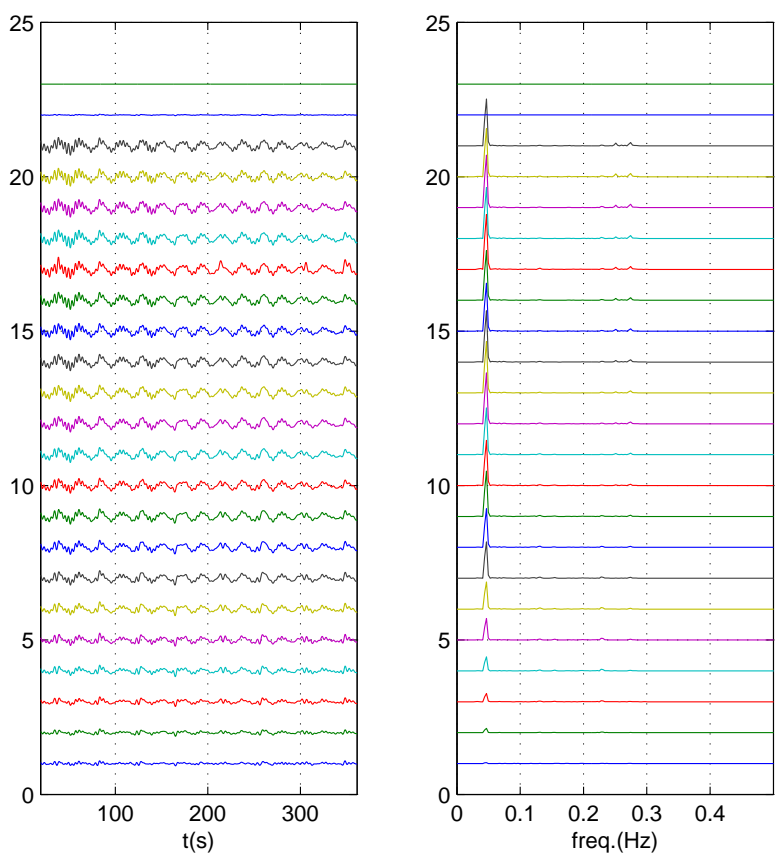

Figura E.4: Série temporal com frequências de resposta para Z obtida experimentalmente por alvo para o arranjo de Catenária-4 na $U_{\max }=0,537 \mathrm{~m} / \mathrm{s}$ e $V_{r 1}=6,866$. 
Tabela E.1: Propriedades da série temporal do ensaio Catenária-4 para a

$$
U_{\max }=0,537 \mathrm{~m} / \mathrm{s} \text {. }
$$

\begin{tabular}{|c|c|c|c|c|c|c|c|c|c|c|c|c|}
\hline \multirow[b]{2}{*}{ ID. Alvo } & \multirow[b]{2}{*}{$\mathrm{X}(\mathrm{m})$} & \multicolumn{2}{|c|}{ Máximo } & \multirow[b]{2}{*}{$\mathrm{X}(\mathrm{m})$} & \multirow{2}{*}{$\begin{array}{l}\text { Mínimo } \\
\mathrm{Y}(\mathrm{m})\end{array}$} & \multirow[b]{2}{*}{$\mathrm{Z}(\mathrm{m})$} & \multicolumn{3}{|c|}{ Desvio padrão } & \multicolumn{3}{|c|}{ Freq. máxima em $\mathrm{Hz}$} \\
\hline & & $\mathrm{Y}(\mathrm{m})$ & $\mathrm{Z}(\mathrm{m})$ & & & & $\mathrm{X}(\mathrm{m})$ & $\mathrm{Y}(\mathrm{m})$ & $\mathrm{Z}(\mathrm{m})$ & $\mathrm{X}$ & $\mathrm{Y}$ & Z \\
\hline 1 & 0,252 & 0,099 & 0,066 & $-0,201$ & $-0,136$ & $-0,063$ & 0,102 & 0,045 & 0,031 & 0,047 & 0,047 & 0,047 \\
\hline 2 & 0,450 & 0,219 & 0,086 & $-0,431$ & $-0,279$ & $-0,085$ & 0,198 & 0,112 & 0,038 & 0,047 & 0,047 & 0,047 \\
\hline 3 & 0,590 & 0,400 & 0,120 & $-0,686$ & $-0,510$ & $-0,115$ & 0,286 & 0,212 & 0,052 & 0,047 & 0,047 & 0,047 \\
\hline 4 & 0,696 & 0,613 & 0,147 & $-0,890$ & $-0,783$ & $-0,148$ & 0,368 & 0,325 & 0,065 & 0,047 & 0,047 & 0,047 \\
\hline 5 & 0,786 & 0,790 & 0,182 & $-1,023$ & $-0,973$ & $-0,180$ & 0,424 & 0,424 & 0,077 & 0,047 & 0,047 & 0,047 \\
\hline 6 & 0,872 & 0,865 & 0,187 & $-1,152$ & $-1,071$ & $-0,186$ & 0,460 & 0,502 & 0,084 & 0,047 & 0,047 & 0,047 \\
\hline 7 & 0,917 & 1,005 & 0,208 & $-1,252$ & $-1,159$ & $-0,222$ & 0,484 & 0,585 & 0,096 & 0,047 & 0,047 & 0,047 \\
\hline 8 & 0,945 & 1,054 & 0,210 & $-1,270$ & $-1,182$ & $-0,226$ & 0,492 & 0,645 & 0,099 & 0,047 & 0,047 & 0,047 \\
\hline 9 & 0,927 & 1,128 & 0,226 & $-1,237$ & $-1,205$ & $-0,246$ & 0,493 & 0,701 & 0,107 & 0,047 & 0,047 & 0,047 \\
\hline 10 & 0,882 & 1,120 & 0,223 & $-1,139$ & $-1,181$ & $-0,243$ & 0,484 & 0,726 & 0,106 & 0,047 & 0,047 & 0,047 \\
\hline 11 & 0,825 & 1,199 & 0,220 & $-1,050$ & $-1,226$ & $-0,249$ & 0,481 & 0,762 & 0,108 & 0,047 & 0,047 & 0,047 \\
\hline 12 & 0,803 & 1,228 & 0,236 & $-0,969$ & $-1,312$ & $-0,267$ & 0,475 & 0,786 & 0,113 & 0,047 & 0,047 & 0,047 \\
\hline 13 & 0,817 & 1,269 & 0,244 & $-0,894$ & $-1,405$ & $-0,274$ & 0,466 & 0,806 & 0,117 & 0,047 & 0,047 & 0,047 \\
\hline 14 & 0,809 & 1,312 & 0,247 & $-0,816$ & $-1,440$ & $-0,281$ & 0,450 & 0,813 & 0,119 & 0,047 & 0,047 & 0,047 \\
\hline 15 & 0,791 & 1,320 & 0,241 & $-0,873$ & $-1,400$ & $-0,278$ & 0,430 & 0,804 & 0,119 & 0,047 & 0,047 & 0,047 \\
\hline 16 & 0,748 & 1,323 & 0,259 & $-0,924$ & $-1,490$ & $-0,291$ & 0,406 & 0,808 & 0,125 & 0,047 & 0,047 & 0,047 \\
\hline 17 & 1,046 & 1,407 & 0,392 & $-1,447$ & $-2,786$ & $-0,297$ & 0,479 & 0,914 & 0,139 & 0,047 & 0,047 & 0,047 \\
\hline 18 & 0,660 & 1,239 & 0,274 & $-1,027$ & $-1,309$ & $-0,302$ & 0,369 & 0,751 & 0,130 & 0,047 & 0,047 & 0,047 \\
\hline 19 & 0,654 & 1,239 & 0,277 & $-1,070$ & $-1,352$ & $-0,305$ & 0,361 & 0,745 & 0,132 & 0,047 & 0,047 & 0,047 \\
\hline 20 & 0,651 & 1,147 & 0,273 & $-1,058$ & $-1,269$ & $-0,299$ & 0,354 & 0,709 & 0,130 & 0,047 & 0,047 & 0,047 \\
\hline 21 & 0,626 & 1,069 & 0,271 & $-1,016$ & $-1,162$ & $-0,299$ & 0,344 & 0,674 & 0,129 & 0,047 & 0,047 & 0,047 \\
\hline 22 & 0,090 & 0,044 & 0,017 & $-0,086$ & $-0,056$ & $-0,017$ & 0,040 & 0,022 & 0,008 & 0,047 & 0,047 & 0,047 \\
\hline 23 & 0,000 & $-0,000$ & 0,000 & 0,000 & $-0,000$ & 0,000 & 0,000 & 0,000 & 0,000 & 0,000 & 0,000 & 0,000 \\
\hline
\end{tabular}

Considerando agora a decomposição modal, na Tabela E.2 através da interpolação do sinal do ensaio, correspondente a uma velocade reduzida do primeiro modo $V_{r 1}=6.87$, as maiores amplitudes máximas apresentadas na direção X, Y e Z foram de 0,801, 1,248 e $0,271 \mathrm{~m}$, respectivamente. Estes valores ocorreram para os modos 1, 2 e 12 . Nestes modos, as suas frequências de resposta com maior energia foi de 0,0467 Hz. 

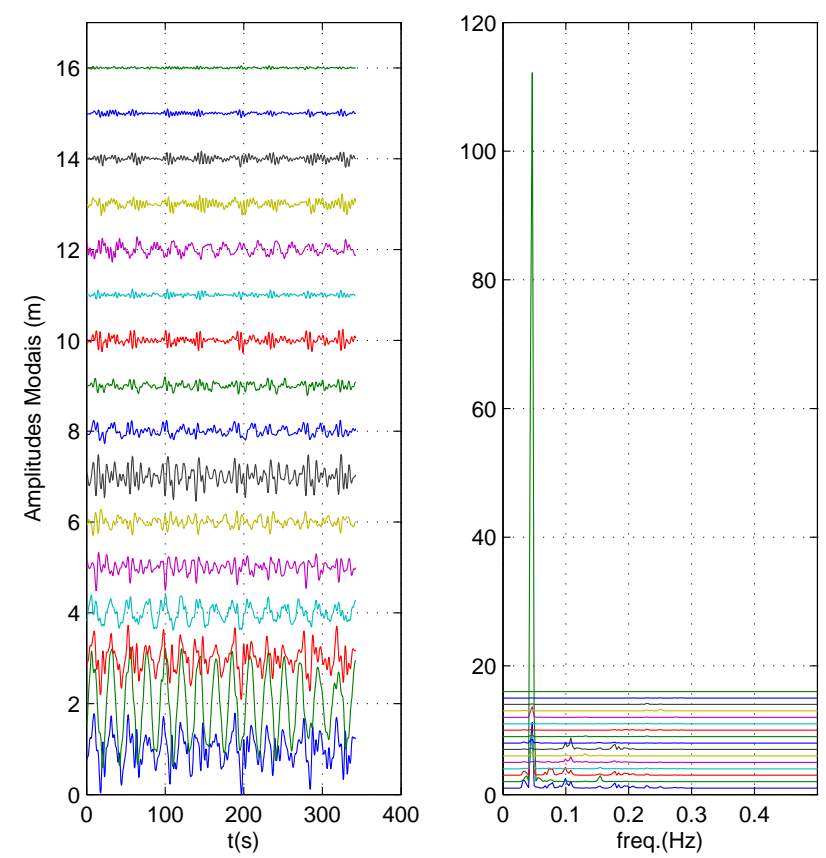

Figura E.5: Variação da amplitude modal acoplada ao longo do tempo através da interpolação do sinal do ensaio para Catenária-4 na $U_{\max }=0,537 \mathrm{~m} / \mathrm{s}$ e $V_{r 1}=6,866$.

Tabela E.2: Propriedades das amplitudes modais do ensaio Catenária-4 através da interpolação do sinal do ensaio para a $V_{\max }=0,537 \mathrm{~m} / \mathrm{s}$.

\begin{tabular}{lcccccccccccccc}
\hline \multicolumn{1}{c}{ Máximo } & \multicolumn{1}{c}{ Mínimo } & \multicolumn{3}{c}{ Desvio padrão } & \multicolumn{3}{c}{ Freq. máxima em Hz } \\
\multicolumn{1}{c}{ Modo } & $\mathrm{X}(\mathrm{m})$ & $\mathrm{Y}(\mathrm{m})$ & $\mathrm{Z}(\mathrm{m})$ & $\mathrm{X}(\mathrm{m})$ & $\mathrm{Y}(\mathrm{m})$ & $\mathrm{Z}(\mathrm{m})$ & $\mathrm{X}(\mathrm{m})$ & $\mathrm{Y}(\mathrm{m})$ & $\mathrm{Z}(\mathrm{m})$ & $\mathrm{X}$ & $\mathrm{Y}$ & $\mathrm{Z}$ \\
& & & & & & & & & & & & \\
\hline 1 & 0,801 & 0,000 & 0,000 & $-1,016$ & $-0,000$ & $-0,000$ & 0,341 & 0,000 & 0,000 & 0,047 & 0,047 & 0,047 \\
2 & 0,000 & 1,248 & 0,004 & $-0,000$ & $-1,413$ & $-0,004$ & 0,000 & 0,733 & 0,001 & 0,047 & 0,047 & 0,047 \\
3 & 0,739 & 0,000 & 0,000 & $-0,922$ & $-0,000$ & $-0,000$ & 0,287 & 0,000 & 0,000 & 0,047 & 0,047 & 0,047 \\
4 & 0,000 & 0,400 & 0,006 & $-0,000$ & $-0,390$ & $-0,006$ & 0,000 & 0,182 & 0,002 & 0,108 & 0,047 & 0,047 \\
5 & 0,337 & 0,000 & 0,000 & $-0,520$ & $-0,000$ & $-0,000$ & 0,136 & 0,000 & 0,000 & 0,108 & 0,047 & 0,047 \\
6 & 0,000 & 0,278 & 0,006 & $-0,000$ & $-0,298$ & $-0,007$ & 0,000 & 0,102 & 0,002 & 0,108 & 0,047 & 0,047 \\
7 & 0,495 & 0,000 & 0,000 & $-0,552$ & $-0,000$ & $-0,000$ & 0,190 & 0,000 & 0,000 & 0,108 & 0,047 & 0,047 \\
8 & 0,245 & 0,000 & 0,000 & $-0,278$ & $-0,000$ & $-0,000$ & 0,095 & 0,000 & 0,000 & 0,047 & 0,047 & 0,047 \\
9 & 0,001 & 0,202 & 0,007 & $-0,001$ & $-0,218$ & $-0,007$ & 0,000 & 0,069 & 0,003 & 0,047 & 0,047 & 0,047 \\
10 & 0,243 & 0,000 & 0,000 & $-0,271$ & $-0,000$ & $-0,000$ & 0,083 & 0,000 & 0,000 & 0,228 & 0,228 & 0,047 \\
11 & 0,000 & 0,127 & 0,010 & $-0,000$ & $-0,115$ & $-0,010$ & 0,000 & 0,034 & 0,004 & 0,228 & 0,228 & 0,047 \\
12 & 0,000 & 0,009 & 0,271 & $-0,000$ & $-0,008$ & $-0,274$ & 0,000 & 0,004 & 0,098 & 0,047 & 0,047 & 0,047 \\
13 & 0,225 & 0,000 & 0,000 & $-0,257$ & $-0,000$ & $-0,000$ & 0,076 & 0,000 & 0,000 & 0,251 & 0,231 & 0,047 \\
14 & 0,000 & 0,168 & 0,000 & $-0,000$ & $-0,191$ & $-0,001$ & 0,000 & 0,056 & 0,000 & 0,251 & 0,231 & 0,047 \\
15 & 0,098 & 0,000 & 0,000 & $-0,102$ & $-0,000$ & $-0,000$ & 0,030 & 0,000 & 0,000 & 0,228 & 0,228 & 0,047 \\
16 & 0,001 & 0,048 & 0,001 & $-0,001$ & $-0,039$ & $-0,001$ & 0,000 & 0,014 & 0,000 & 0,228 & 0,228 & 0,047 \\
\hline
\end{tabular}

A Tabela E.3 apresenta para o ensaio Catenária-4 apenas os movimentos referentes a 
deslocamento no plano da catenária através da interpolação do sinal do ensaio, a maior amplitude acoplada máxima foi de 1,244 m. Este valor ocorreu para o modo 2. Neste modo, a sua frequência de resposta com maior energia foi de 0,047 Hz.

Tabela E.3: Propriedades das amplitudes modais acopladas no plano da catenária do ensaio Catenária-4 através da interpolação do sinal do ensaio para a $V_{\max }=0,537 \mathrm{~m} / \mathrm{s}$.

Amplitude

Modo Máxima(m) Mínima(m) Desvio Padrão(m) Freq. máxima (Hz)

\begin{tabular}{lllll}
\hline 2 & 1,244 & $-1,408$ & 0,731 & 0,047 \\
4 & 0,394 & $-0,384$ & 0,180 & 0,047 \\
6 & 0,278 & $-0,295$ & 0,100 & 0,047 \\
9 & 0,197 & $-0,214$ & 0,067 & 0,047 \\
11 & 0,130 & $-0,110$ & 0,034 & 0,228 \\
12 & 0,279 & $-0,279$ & 0,101 & 0,047 \\
14 & 0,167 & $-0,190$ & 0,056 & 0,231 \\
16 & 0,048 & $-0,039$ & 0,014 & 0,228 \\
\hline
\end{tabular}

A Tabela E.4 para o ensaio Catenária-4 com apenas as amplitudes correspondentes a movimentos fora do plano através da interpolação do sinal do ensaio, a maior amplitude acoplada máxima apresentada foi de 0,792 m. Este valor ocorreu para o modo 1 . Neste modo, a sua frequência de resposta com maior energia foi de 0,047 Hz.

Tabela E.4: Propriedades das amplitudes modais acopladas fora do plano da catenária do ensaio Catenária-4 através da interpolação do sinal do ensaio para a

$$
V_{\text {max }}=0,537 \mathrm{~m} / \mathrm{s} \text {. }
$$

\begin{tabular}{lllll}
\hline \multicolumn{5}{c}{ Amplitude } \\
Modo & Máxima(m) & Mínima(m) & Desvio Padrão(m) & Freq. máxima $(\mathrm{Hz})$ \\
\hline 1 & 0,792 & $-1,004$ & 0,337 & 0,047 \\
3 & 0,726 & $-0,905$ & 0,282 & 0,047 \\
5 & 0,330 & $-0,508$ & 0,133 & 0,108 \\
7 & 0,485 & $-0,541$ & 0,186 & 0,108 \\
8 & 0,241 & $-0,274$ & 0,093 & 0,047 \\
10 & 0,239 & $-0,268$ & 0,082 & 0,228 \\
13 & 0,223 & $-0,254$ & 0,076 & 0,251 \\
15 & 0,097 & $-0,101$ & 0,030 & 0,228 \\
\hline
\end{tabular}




\section{E.2 Catenária-4 - Velocidade de $0,818 \mathrm{~m} / \mathrm{s}$ e $V_{r 1}=$ 10,47}

Abaixo serão apresentados os gráficos com alguns detalhes da análise referentes ao arranjo Catenária-4 para a velocidade de $0,818 \mathrm{~m} / \mathrm{s}$ e $V_{r 1}=10,47$.
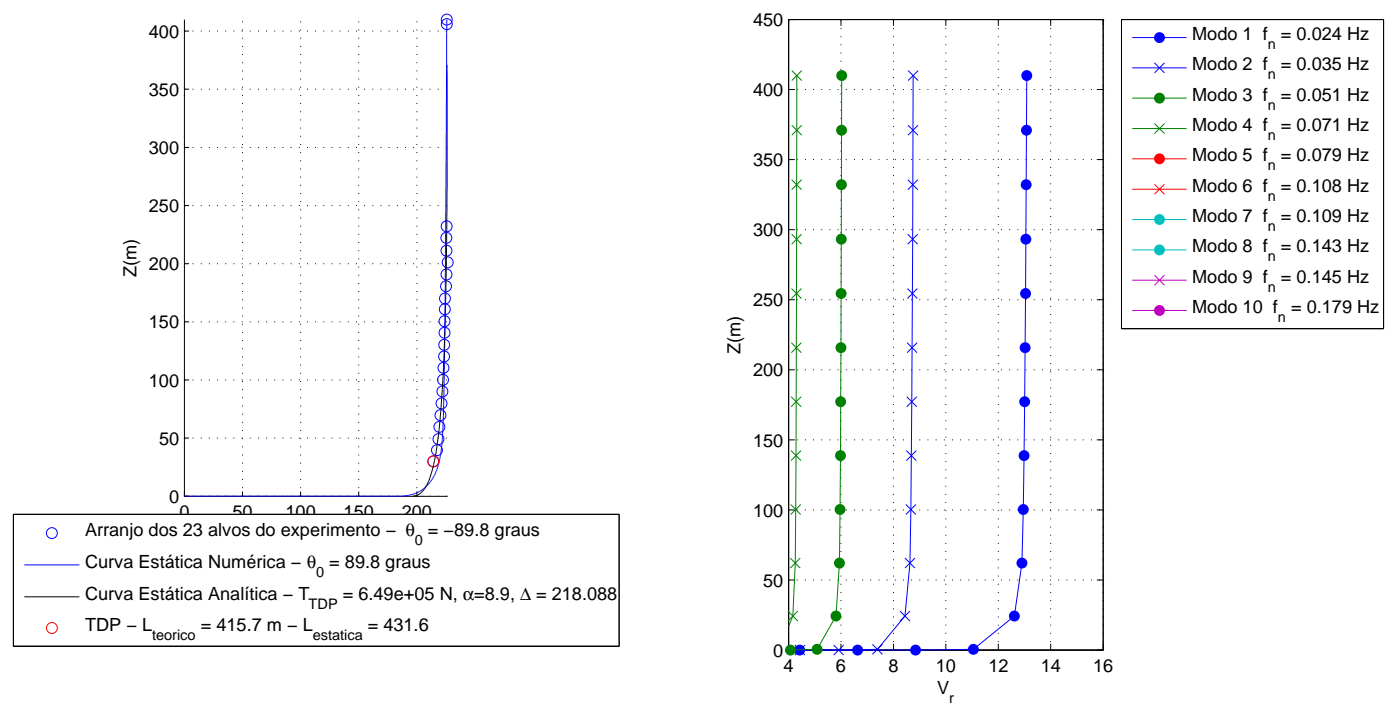

Figura E.6: Variação da velocidade no modelo durante o ensaio para Catenária-4 na $U_{\max }=0,818 \mathrm{~m} / \mathrm{s}$ e $V_{r 1}=10,468$.

Como pode ser visto na Tabela E.5 e nas Figuras de E.7 a E.9, os maiores deslocamentos máximos apresentados na direção X, Y e Z foram de 1,744, 1,182 e 0,363 m, respectivamente. Estes valores ocorreram para o alvo 17, Neste alvo, a sua frequência de resposta com maior energia foi de 0,0800.1080.080 Hz. 

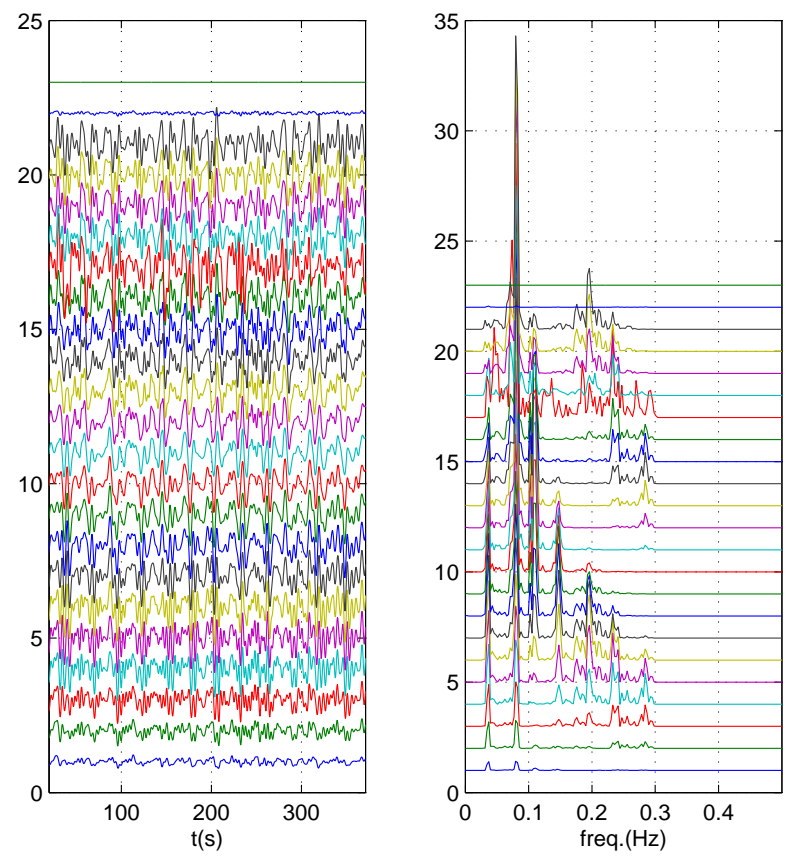

Figura E.7: Série temporal com frequências de resposta para X obtida experimentalmente por alvo para o arranjo de Catenária-4 na $U_{\max }=0,818 \mathrm{~m} / \mathrm{s}$ e $V_{r 1}=10,468$.
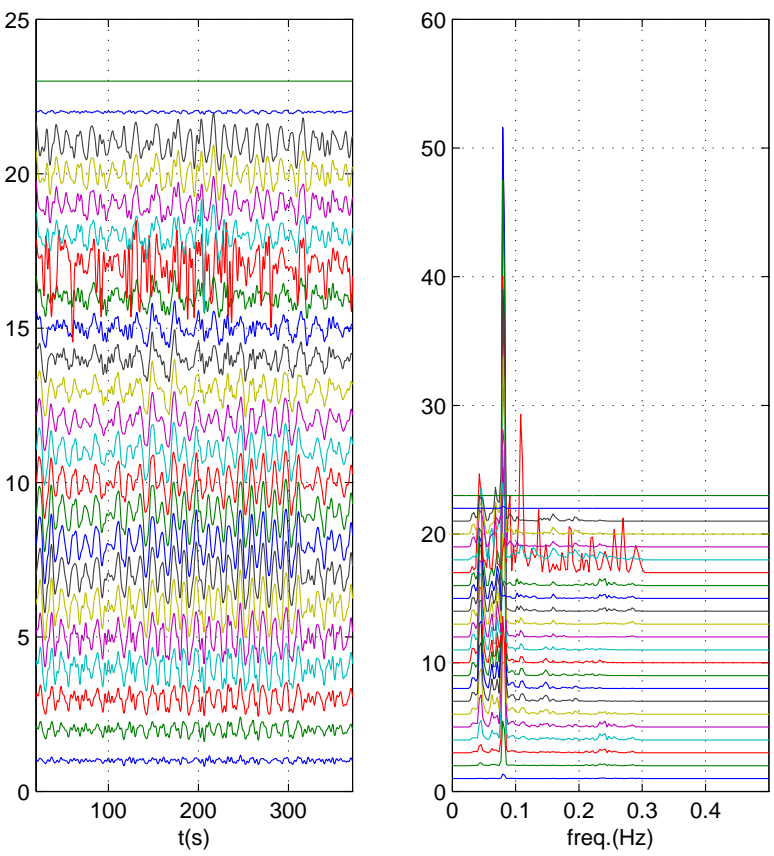

Figura E.8: Série temporal com frequências de resposta para Y obtida experimentalmente por alvo para o arranjo de Catenária-4 na $U_{\max }=0,818 \mathrm{~m} / \mathrm{s}$ e $V_{r 1}=10,468$. 

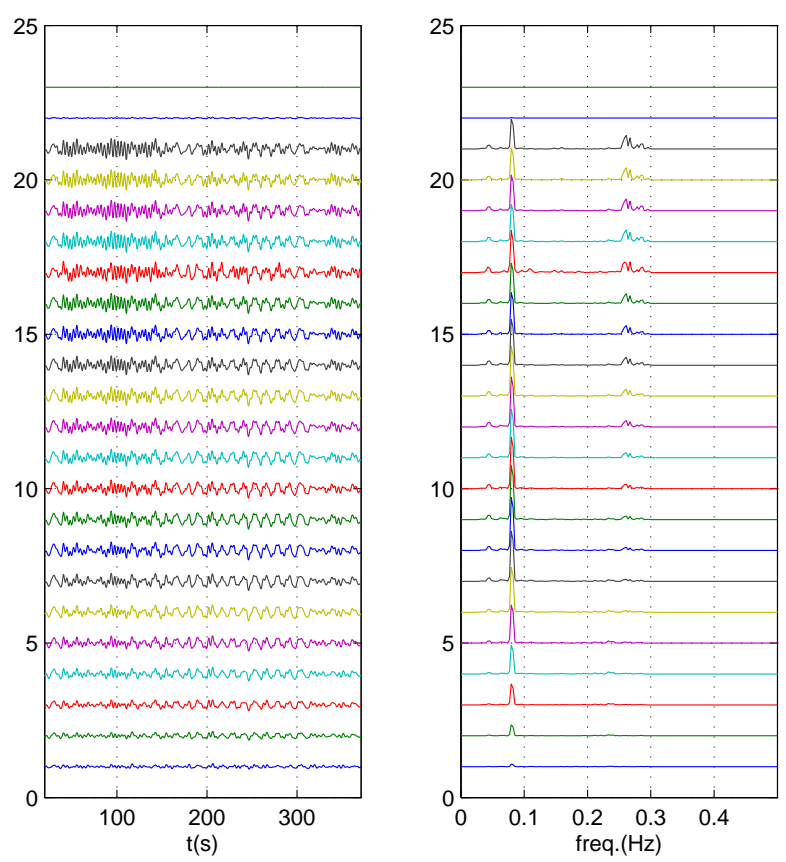

Figura E.9: Série temporal com frequências de resposta para Z obtida experimentalmente por alvo para o arranjo de Catenária-4 na $U_{\max }=0,818 \mathrm{~m} / \mathrm{s}$ e $V_{r 1}=10,468$. 
Tabela E.5: Propriedades da série temporal do ensaio Catenária-4 para a

$$
U_{\max }=0,818 \mathrm{~m} / \mathrm{s} \text {. }
$$

\begin{tabular}{|c|c|c|c|c|c|c|c|c|c|c|c|c|}
\hline \multirow[b]{2}{*}{ ID. Alvo } & \multirow[b]{2}{*}{$\mathrm{X}(\mathrm{m})$} & \multicolumn{2}{|l|}{ Máximo } & \multirow[b]{2}{*}{$\mathrm{X}(\mathrm{m})$} & \multirow{2}{*}{$\begin{array}{l}\text { Mínimo } \\
\mathrm{Y}(\mathrm{m})\end{array}$} & \multirow[b]{2}{*}{$\mathrm{Z}(\mathrm{m})$} & \multicolumn{3}{|c|}{ Desvio padrão } & \multicolumn{3}{|c|}{ Freq. máxima em $\mathrm{Hz}$} \\
\hline & & $\mathrm{Y}(\mathrm{m})$ & $\mathrm{Z}(\mathrm{m})$ & & & & $\mathrm{X}(\mathrm{m})$ & $\mathrm{Y}(\mathrm{m})$ & $\mathrm{Z}(\mathrm{m})$ & $\mathrm{X}$ & $\mathrm{Y}$ & Z \\
\hline 1 & 0,196 & 0,112 & 0,059 & $-0,133$ & $-0,099$ & $-0,058$ & 0,080 & 0,051 & 0,028 & 0,080 & 0,080 & 0,080 \\
\hline 2 & 0,335 & 0,266 & 0,096 & $-0,361$ & $-0,302$ & $-0,088$ & 0,165 & 0,145 & 0,049 & 0,080 & 0,080 & 0,080 \\
\hline 3 & 0,445 & 0,440 & 0,134 & $-0,546$ & $-0,501$ & $-0,121$ & 0,251 & 0,251 & 0,067 & 0,080 & 0,080 & 0,080 \\
\hline 4 & 0,642 & 0,663 & 0,177 & $-0,748$ & $-0,767$ & $-0,160$ & 0,335 & 0,373 & 0,086 & 0,080 & 0,080 & 0,080 \\
\hline 5 & 0,737 & 0,786 & 0,201 & $-0,917$ & $-0,962$ & $-0,172$ & 0,387 & 0,458 & 0,096 & 0,080 & 0,080 & 0,080 \\
\hline 6 & 0,749 & 0,915 & 0,214 & $-1,003$ & $-1,109$ & $-0,183$ & 0,404 & 0,517 & 0,102 & 0,080 & 0,080 & 0,080 \\
\hline 7 & 0,823 & 0,996 & 0,232 & $-1,023$ & $-1,209$ & $-0,187$ & 0,399 & 0,556 & 0,111 & 0,080 & 0,080 & 0,080 \\
\hline 8 & 0,799 & 0,981 & 0,246 & $-0,975$ & $-1,275$ & $-0,195$ & 0,383 & 0,575 & 0,118 & 0,080 & 0,080 & 0,080 \\
\hline 9 & 0,694 & 0,920 & 0,243 & $-0,898$ & $-1,237$ & $-0,183$ & 0,364 & 0,559 & 0,117 & 0,080 & 0,080 & 0,080 \\
\hline 10 & 0,581 & 0,837 & 0,256 & $-0,823$ & $-1,164$ & $-0,181$ & 0,350 & 0,518 & 0,118 & 0,080 & 0,080 & 0,080 \\
\hline 11 & 0,641 & 0,772 & 0,255 & $-0,781$ & $-1,081$ & $-0,191$ & 0,343 & 0,476 & 0,118 & 0,080 & 0,080 & 0,080 \\
\hline 12 & 0,688 & 0,717 & 0,275 & $-0,734$ & $-0,962$ & $-0,207$ & 0,341 & 0,423 & 0,125 & 0,080 & 0,080 & 0,080 \\
\hline 13 & 0,729 & 0,624 & 0,280 & $-0,718$ & $-0,844$ & $-0,215$ & 0,346 & 0,364 & 0,127 & 0,080 & 0,080 & 0,080 \\
\hline 14 & 0,765 & 0,508 & 0,284 & $-0,679$ & $-0,757$ & $-0,219$ & 0,355 & 0,305 & 0,127 & 0,080 & 0,043 & 0,080 \\
\hline 15 & 0,873 & 0,554 & 0,287 & $-0,663$ & $-0,625$ & $-0,220$ & 0,363 & 0,261 & 0,126 & 0,080 & 0,043 & 0,080 \\
\hline 16 & 0,907 & 0,676 & 0,298 & $-0,632$ & $-0,621$ & $-0,229$ & 0,359 & 0,250 & 0,131 & 0,080 & 0,043 & 0,080 \\
\hline 17 & 1,744 & 1,182 & 0,363 & $-1,646$ & $-1,626$ & $-0,281$ & 0,708 & 0,707 & 0,136 & 0,080 & 0,108 & 0,080 \\
\hline 18 & 1,007 & 0,753 & 0,310 & $-0,801$ & $-0,499$ & $-0,242$ & 0,384 & 0,265 & 0,135 & 0,080 & 0,080 & 0,080 \\
\hline 19 & 0,953 & 0,792 & 0,311 & $-0,900$ & $-0,586$ & $-0,251$ & 0,383 & 0,280 & 0,135 & 0,080 & 0,080 & 0,080 \\
\hline 20 & 0,919 & 0,760 & 0,314 & $-0,980$ & $-0,666$ & $-0,248$ & 0,401 & 0,304 & 0,135 & 0,080 & 0,080 & 0,080 \\
\hline 21 & 0,859 & 0,706 & 0,321 & $-1,014$ & $-0,714$ & $-0,250$ & 0,402 & 0,335 & 0,136 & 0,080 & 0,080 & 0,080 \\
\hline 22 & 0,067 & 0,053 & 0,019 & $-0,072$ & $-0,060$ & $-0,018$ & 0,033 & 0,029 & 0,010 & 0,080 & 0,080 & 0,080 \\
\hline 23 & 0,000 & $-0,000$ & 0,000 & 0,000 & $-0,000$ & 0,000 & 0,000 & 0,000 & 0,000 & 0,000 & 0,000 & 0,000 \\
\hline
\end{tabular}

Considerando agora a decomposição modal, na Tabela E.6 através da interpolação do sinal do ensaio, correspondente a uma velocade reduzida do primeiro modo $V_{r 1}=10.47$, as maiores amplitudes máximas apresentadas na direção X, Y e Z foram de 0,950, 0,771 e $0,323 \mathrm{~m}$, respectivamente. Estes valores ocorreram para os modos 2, 3 e 12 . Nestes modos, as suas frequências de resposta com maior energia foram de 0,0426 e 0,0795 Hz. 

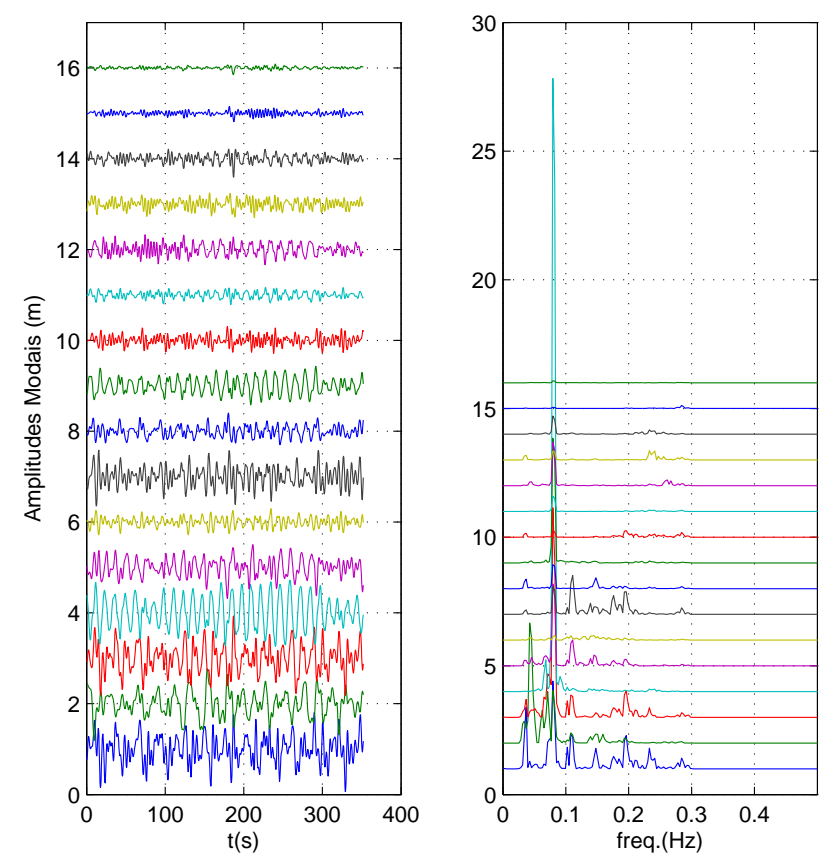

Figura E.10: Variação da amplitude modal acoplada ao longo do tempo através da interpolação do sinal do ensaio para Catenária-4 na $U_{\max }=0,818 \mathrm{~m} / \mathrm{s}$ e $V_{r 1}=10,468$.

Tabela E.6: Propriedades das amplitudes modais do ensaio Catenária-4 através da interpolação do sinal do ensaio para a $V_{\max }=0,818 \mathrm{~m} / \mathrm{s}$.

\begin{tabular}{lcccccccccccccc}
\hline \multicolumn{1}{c}{ Máximo } & \multicolumn{1}{c}{ Mínimo } & & \multicolumn{3}{c}{ Desvio padrão } & \multicolumn{7}{c}{ Freq. máxima em Hz } \\
\multicolumn{1}{c}{ Modo } & $\mathrm{X}(\mathrm{m})$ & $\mathrm{Y}(\mathrm{m})$ & $\mathrm{Z}(\mathrm{m})$ & $\mathrm{X}(\mathrm{m})$ & $\mathrm{Y}(\mathrm{m})$ & $\mathrm{Z}(\mathrm{m})$ & $\mathrm{X}(\mathrm{m})$ & $\mathrm{Y}(\mathrm{m})$ & $\mathrm{Z}(\mathrm{m})$ & $\mathrm{X}$ & $\mathrm{Y}$ & $\mathrm{Z}$ \\
& & & & & & & & & & & & \\
\hline 1 & 0,815 & 0,000 & 0,000 & $-0,943$ & $-0,000$ & $-0,000$ & 0,311 & 0,000 & 0,000 & 0,080 & 0,043 & 0,080 \\
2 & 0,000 & 0,771 & 0,005 & $-0,000$ & $-0,812$ & $-0,004$ & 0,000 & 0,267 & 0,002 & 0,080 & 0,043 & 0,080 \\
3 & 0,950 & 0,000 & 0,000 & $-0,831$ & $-0,000$ & $-0,000$ & 0,317 & 0,000 & 0,000 & 0,080 & 0,043 & 0,080 \\
4 & 0,000 & 0,719 & 0,007 & $-0,000$ & $-0,736$ & $-0,007$ & 0,000 & 0,360 & 0,003 & 0,080 & 0,080 & 0,080 \\
5 & 0,516 & 0,000 & 0,000 & $-0,702$ & $-0,000$ & $-0,000$ & 0,204 & 0,000 & 0,000 & 0,080 & 0,080 & 0,080 \\
6 & 0,000 & 0,300 & 0,008 & $-0,000$ & $-0,288$ & $-0,008$ & 0,000 & 0,103 & 0,003 & 0,111 & 0,082 & 0,080 \\
7 & 0,597 & 0,000 & 0,000 & $-0,662$ & $-0,000$ & $-0,000$ & 0,217 & 0,000 & 0,000 & 0,111 & 0,082 & 0,080 \\
8 & 0,406 & 0,000 & 0,000 & $-0,301$ & $-0,000$ & $-0,000$ & 0,124 & 0,000 & 0,000 & 0,080 & 0,080 & 0,080 \\
9 & 0,001 & 0,434 & 0,008 & $-0,002$ & $-0,424$ & $-0,009$ & 0,001 & 0,175 & 0,003 & 0,080 & 0,080 & 0,080 \\
10 & 0,311 & 0,000 & 0,000 & $-0,291$ & $-0,000$ & $-0,000$ & 0,105 & 0,000 & 0,000 & 0,196 & 0,080 & 0,080 \\
11 & 0,000 & 0,166 & 0,012 & $-0,000$ & $-0,210$ & $-0,012$ & 0,000 & 0,067 & 0,005 & 0,196 & 0,080 & 0,080 \\
12 & 0,000 & 0,008 & 0,323 & $-0,000$ & $-0,008$ & $-0,329$ & 0,000 & 0,003 & 0,120 & 0,196 & 0,080 & 0,080 \\
13 & 0,250 & 0,000 & 0,000 & $-0,300$ & $-0,000$ & $-0,000$ & 0,099 & 0,000 & 0,000 & 0,233 & 0,080 & 0,080 \\
14 & 0,000 & 0,213 & 0,000 & $-0,000$ & $-0,410$ & $-0,001$ & 0,000 & 0,086 & 0,000 & 0,233 & 0,080 & 0,287 \\
15 & 0,151 & 0,000 & 0,000 & $-0,188$ & $-0,000$ & $-0,000$ & 0,044 & 0,000 & 0,000 & 0,284 & 0,080 & 0,080 \\
16 & 0,002 & 0,087 & 0,001 & $-0,002$ & $-0,150$ & $-0,001$ & 0,000 & 0,027 & 0,000 & 0,284 & 0,080 & 0,080 \\
\hline
\end{tabular}

A Tabela E.7 apresenta para o ensaio Catenária-4 apenas os movimentos referentes a 
deslocamento no plano da catenária através da interpolação do sinal do ensaio, a maior amplitude acoplada máxima foi de 0,769 m. Este valor ocorreu para o modo 2. Neste modo, a sua frequência de resposta com maior energia foi de $0,043 \mathrm{~Hz}$.

Tabela E.7: Propriedades das amplitudes modais acopladas no plano da catenária do ensaio Catenária-4 através da interpolação do sinal do ensaio para a $V_{\max }=0,818 \mathrm{~m} / \mathrm{s}$.

Amplitude

Modo Máxima(m) Mínima(m) Desvio Padrão(m) Freq. máxima (Hz)

\begin{tabular}{lllll}
\hline 2 & 0,769 & $-0,810$ & 0,267 & 0,043 \\
4 & 0,718 & $-0,736$ & 0,359 & 0,080 \\
6 & 0,294 & $-0,281$ & 0,102 & 0,082 \\
9 & 0,427 & $-0,419$ & 0,171 & 0,080 \\
11 & 0,166 & $-0,211$ & 0,070 & 0,080 \\
12 & 0,326 & $-0,334$ & 0,122 & 0,080 \\
14 & 0,212 & $-0,407$ & 0,086 & 0,080 \\
16 & 0,086 & $-0,148$ & 0,026 & 0,080 \\
\hline
\end{tabular}

A Tabela E.8 para o ensaio Catenária-4 com apenas as amplitudes correspondentes a movimentos fora do plano através da interpolação do sinal do ensaio, a maior amplitude acoplada máxima apresentada foi de 0,933 m. Este valor ocorreu para o modo 3. Neste modo, a sua frequência de resposta com maior energia foi de 0,080 Hz.

Tabela E.8: Propriedades das amplitudes modais acopladas fora do plano da catenária do ensaio Catenária-4 através da interpolação do sinal do ensaio para a

$$
V_{\text {max }}=0,818 \mathrm{~m} / \mathrm{s} \text {. }
$$

\begin{tabular}{lllll}
\hline \multicolumn{5}{c}{ Amplitude } \\
Modo & Máxima(m) & Mínima(m) & Desvio Padrão(m) & Freq. máxima (Hz) \\
& & & & \\
\hline 1 & 0,805 & $-0,931$ & 0,307 & 0,080 \\
3 & 0,933 & $-0,816$ & 0,312 & 0,080 \\
5 & 0,505 & $-0,687$ & 0,200 & 0,080 \\
7 & 0,585 & $-0,649$ & 0,213 & 0,111 \\
8 & 0,399 & $-0,296$ & 0,122 & 0,080 \\
10 & 0,306 & $-0,287$ & 0,104 & 0,196 \\
13 & 0,247 & $-0,296$ & 0,098 & 0,233 \\
15 & 0,150 & $-0,185$ & 0,043 & 0,284 \\
\hline
\end{tabular}




\section{E.3 Catenária-4 - Velocidade de $1,34 \mathrm{~m} / \mathrm{s}$ e $V_{r 1}=$ 17,17}

Abaixo serão apresentados os gráficos com alguns detalhes da análise referentes ao arranjo Catenária-4 para a velocidade de $1,34 \mathrm{~m} / \mathrm{s}$ e $V_{r 1}=17,17$.
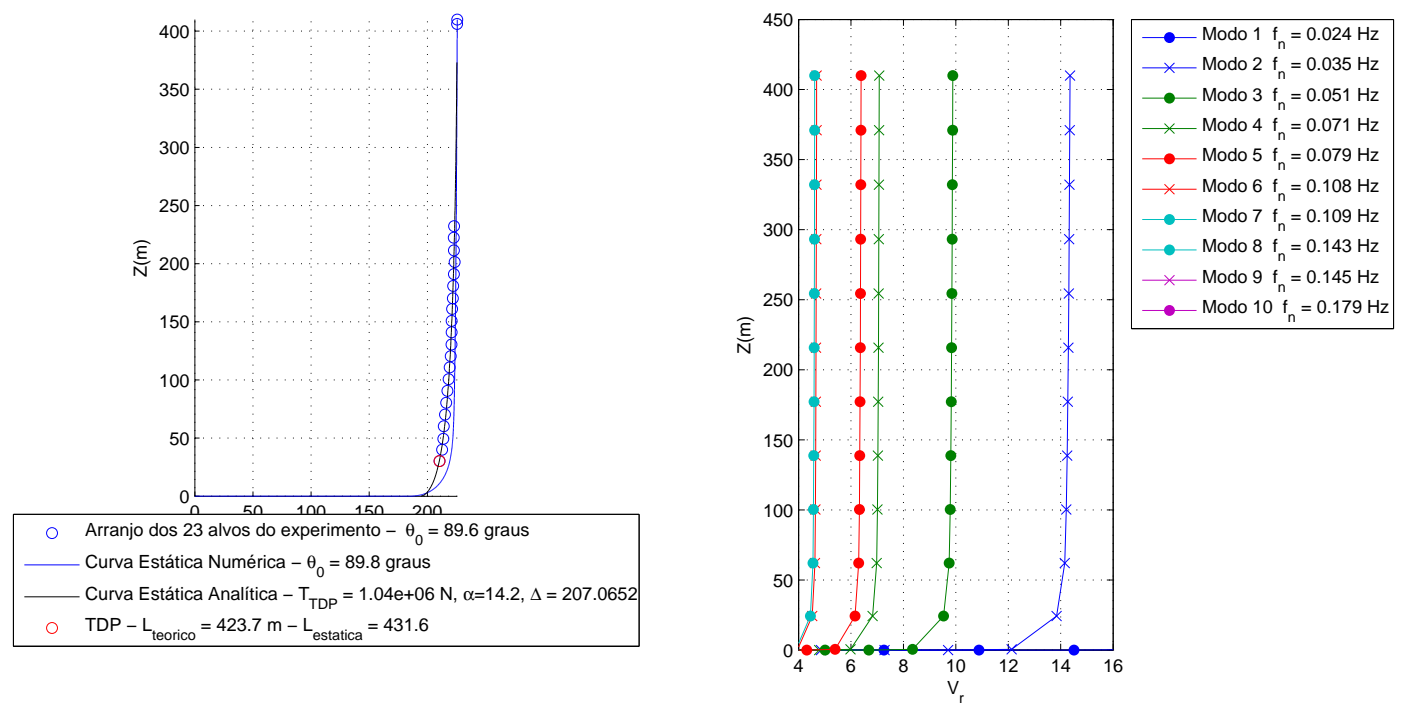

Figura E.11: Variação da velocidade no modelo durante o ensaio para Catenária-4 na $U_{\text {max }}=1,34 m / s$ e $V_{r 1}=17,169$.

Como pode ser visto na Tabela E.9 e nas Figuras de E.12 a E.14, os maiores deslocamentos máximos apresentados na direção X, Y e Z foram de 1,948, 2,255 e 0,532 $\mathrm{m}$, respectivamente. Estes valores ocorreram para os alvos 5 e 13. Nestes alvos, as suas frequências de resposta com maior energia foi de $0,117 \mathrm{~Hz}$. 

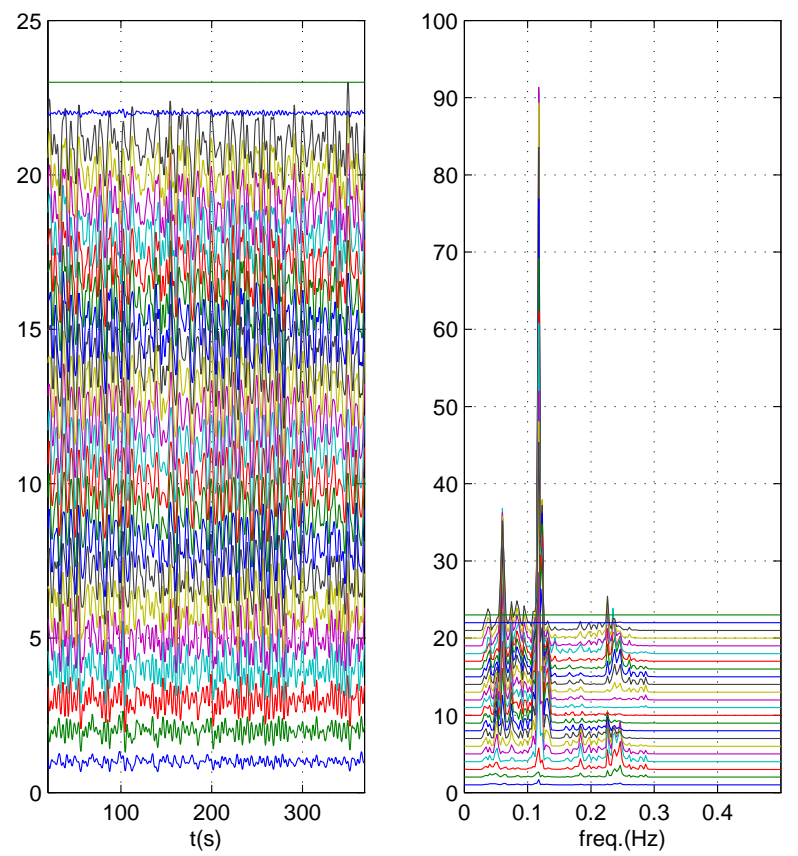

Figura E.12: Série temporal com frequências de resposta para X obtida experimentalmente por alvo para o arranjo de Catenária-4 na $U_{\max }=1,34 \mathrm{~m} / \mathrm{s}$ e $V_{r 1}=17,169$.
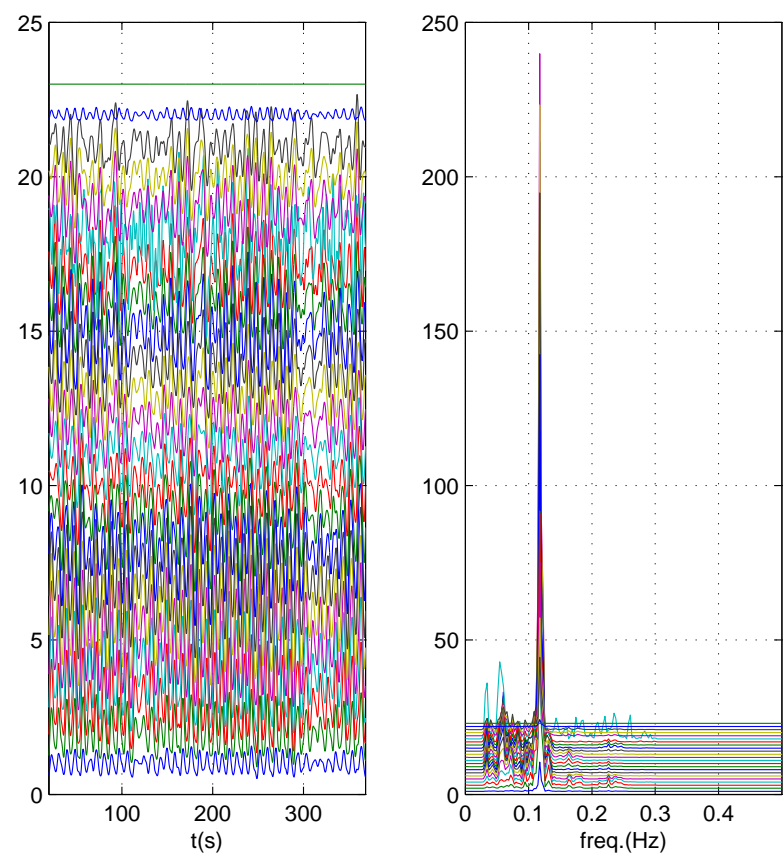

Figura E.13: Série temporal com frequências de resposta para Y obtida experimentalmente por alvo para o arranjo de Catenária-4 na $U_{\max }=1,34 \mathrm{~m} / \mathrm{s}$ e $V_{r 1}=17,169$. 

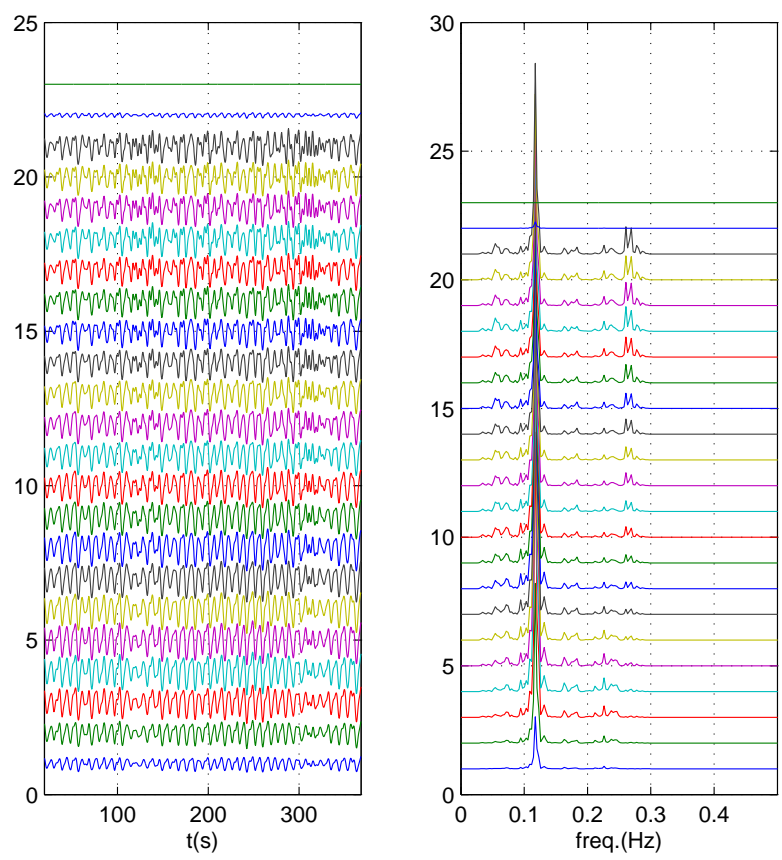

Figura E.14: Série temporal com frequências de resposta para Z obtida experimentalmente por alvo para o arranjo de Catenária-4 na $U_{\max }=1,34 \mathrm{~m} / \mathrm{s}$ e $V_{r 1}=17,169$. 
Tabela E.9: Propriedades da série temporal do ensaio Catenária-4 para a

$$
U_{\max }=1,34 \mathrm{~m} / \mathrm{s} \text {. }
$$

\begin{tabular}{|c|c|c|c|c|c|c|c|c|c|c|c|c|}
\hline \multirow[b]{2}{*}{ ID. Alvo } & \multirow[b]{2}{*}{$\mathrm{X}(\mathrm{m})$} & \multicolumn{2}{|l|}{ Máximo } & \multirow[b]{2}{*}{$\mathrm{X}(\mathrm{m})$} & \multirow{2}{*}{$\begin{array}{l}\text { Mínimo } \\
\mathrm{Y}(\mathrm{m})\end{array}$} & \multirow[b]{2}{*}{$\mathrm{Z}(\mathrm{m})$} & \multicolumn{3}{|c|}{ Desvio padrão } & \multicolumn{3}{|c|}{ Freq. máxima em $\mathrm{Hz}$} \\
\hline & & $\mathrm{Y}(\mathrm{m})$ & $\mathrm{Z}(\mathrm{m})$ & & & & $\mathrm{X}(\mathrm{m})$ & $\mathrm{Y}(\mathrm{m})$ & $\mathrm{Z}(\mathrm{m})$ & $\mathrm{X}$ & $\mathrm{Y}$ & Z \\
\hline 1 & 0,263 & 0,469 & 0,202 & $-0,318$ & $-0,390$ & $-0,262$ & 0,125 & 0,263 & 0,124 & 0,117 & 0,117 & 0,117 \\
\hline 2 & 0,410 & 1,157 & 0,333 & $-0,667$ & $-0,841$ & $-0,444$ & 0,233 & 0,623 & 0,215 & 0,246 & 0,117 & 0,117 \\
\hline 3 & 0,731 & 1,735 & 0,455 & $-0,931$ & $-1,347$ & $-0,593$ & 0,369 & 0,957 & 0,283 & 0,246 & 0,117 & 0,117 \\
\hline 4 & 1,128 & 2,137 & 0,510 & $-1,105$ & $-1,853$ & $-0,659$ & 0,526 & 1,186 & 0,311 & 0,117 & 0,117 & 0,117 \\
\hline 5 & 1,364 & 2,255 & 0,532 & $-1,122$ & $-2,262$ & $-0,676$ & 0,631 & 1,287 & 0,329 & 0,117 & 0,117 & 0,117 \\
\hline 6 & 1,451 & 2,198 & 0,493 & $-1,295$ & $-2,471$ & $-0,681$ & 0,708 & 1,266 & 0,319 & 0,117 & 0,117 & 0,117 \\
\hline 7 & 1,406 & 2,144 & 0,492 & $-1,458$ & $-2,611$ & $-0,679$ & 0,772 & 1,216 & 0,318 & 0,117 & 0,117 & 0,117 \\
\hline 8 & 1,300 & 2,021 & 0,500 & $-1,574$ & $-2,484$ & $-0,659$ & 0,835 & 1,088 & 0,312 & 0,117 & 0,117 & 0,117 \\
\hline 9 & 1,374 & 1,879 & 0,472 & $-1,689$ & $-2,247$ & $-0,640$ & 0,888 & 0,955 & 0,300 & 0,117 & 0,117 & 0,117 \\
\hline 10 & 1,612 & 1,686 & 0,474 & $-1,735$ & $-1,914$ & $-0,659$ & 0,919 & 0,835 & 0,295 & 0,117 & 0,117 & 0,117 \\
\hline 11 & 1,780 & 1,468 & 0,407 & $-1,802$ & $-1,712$ & $-0,646$ & 0,944 & 0,813 & 0,272 & 0,117 & 0,117 & 0,117 \\
\hline 12 & 1,878 & 1,419 & 0,400 & $-1,794$ & $-1,639$ & $-0,645$ & 0,960 & 0,847 & 0,268 & 0,117 & 0,117 & 0,117 \\
\hline 13 & 1,948 & 1,698 & 0,376 & $-1,728$ & $-1,656$ & $-0,643$ & 0,969 & 0,906 & 0,260 & 0,117 & 0,117 & 0,117 \\
\hline 14 & 1,922 & 1,895 & 0,344 & $-1,601$ & $-1,711$ & $-0,640$ & 0,963 & 0,979 & 0,248 & 0,117 & 0,117 & 0,117 \\
\hline 15 & 1,865 & 2,079 & 0,331 & $-1,574$ & $-1,879$ & $-0,620$ & 0,947 & 1,111 & 0,229 & 0,117 & 0,117 & 0,117 \\
\hline 16 & 1,708 & 1,876 & 0,342 & $-1,699$ & $-1,682$ & $-0,628$ & 0,921 & 0,961 & 0,241 & 0,117 & 0,117 & 0,117 \\
\hline 17 & 1,471 & 1,722 & 0,343 & $-1,783$ & $-1,756$ & $-0,617$ & 0,889 & 0,938 & 0,241 & 0,117 & 0,117 & 0,117 \\
\hline 18 & 1,653 & 2,003 & 0,379 & $-1,864$ & $-1,795$ & $-0,640$ & 0,868 & 0,884 & 0,245 & 0,117 & 0,117 & 0,117 \\
\hline 19 & 1,320 & 1,505 & 0,327 & $-1,825$ & $-1,791$ & $-0,602$ & 0,827 & 0,830 & 0,234 & 0,117 & 0,117 & 0,117 \\
\hline 20 & 1,388 & 1,249 & 0,321 & $-1,773$ & $-1,662$ & $-0,596$ & 0,791 & 0,707 & 0,233 & 0,117 & 0,117 & 0,117 \\
\hline 21 & 1,450 & 1,021 & 0,326 & $-1,665$ & $-1,576$ & $-0,594$ & 0,759 & 0,617 & 0,235 & 0,117 & 0,117 & 0,117 \\
\hline 22 & 0,082 & 0,231 & 0,067 & $-0,133$ & $-0,168$ & $-0,089$ & 0,047 & 0,125 & 0,043 & 0,246 & 0,117 & 0,117 \\
\hline 23 & 0,000 & $-0,000$ & 0,000 & 0,000 & $-0,000$ & 0,000 & 0,000 & 0,000 & 0,000 & 0,000 & 0,000 & 0,000 \\
\hline
\end{tabular}

Considerando agora a decomposição modal, na Tabela E.10 através da interpolação do sinal do ensaio, correspondente a uma velocade reduzida do primeiro modo $V_{r 1}=17.17$, as maiores amplitudes máximas apresentadas na direção X, Y e Z foram de 1,695, 1,819 e $0,619 \mathrm{~m}$, respectivamente. Estes valores ocorreram para os modos 3, 6 e 12 . Nestes modos, as suas frequências de resposta com maior energia foi de 0,117 Hz. 

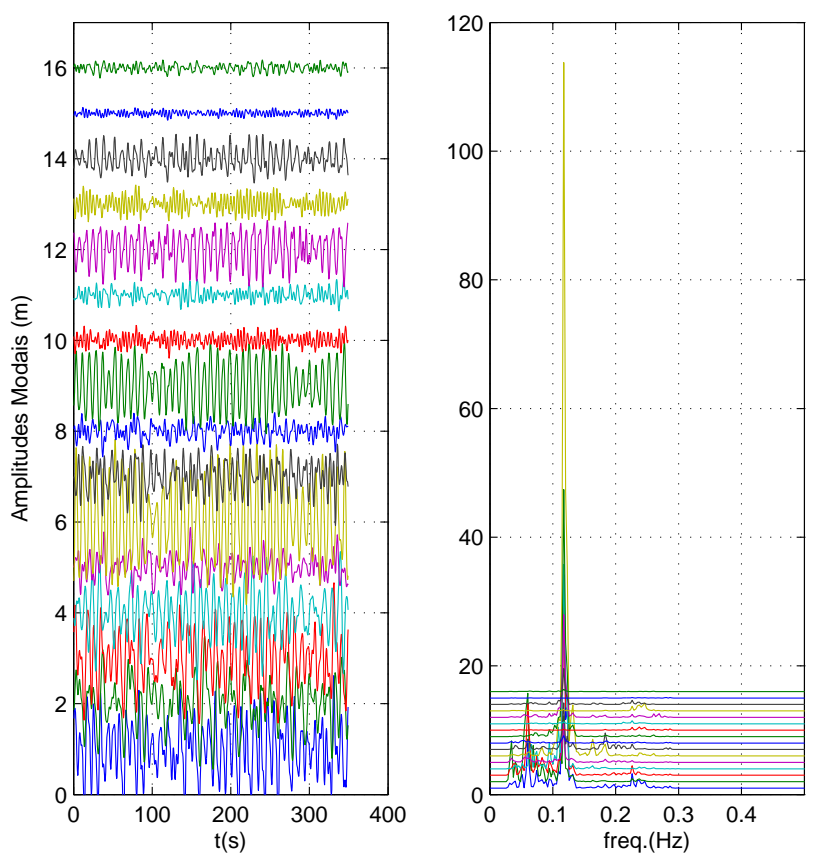

Figura E.15: Variação da amplitude modal acoplada ao longo do tempo através da interpolação do sinal do ensaio para Catenária-4 na $U_{\max }=1,34 \mathrm{~m} / \mathrm{s}$ e $V_{r 1}=17,169$.

Tabela E.10: Propriedades das amplitudes modais do ensaio Catenária-4 através da interpolação do sinal do ensaio para a $V_{\max }=1,34 \mathrm{~m} / \mathrm{s}$.

\begin{tabular}{lccccccccccccc}
\hline \multicolumn{1}{c}{ Máximo } & \multicolumn{1}{c}{ Mínimo } & & \multicolumn{3}{c}{ Desvio padrão } & \multicolumn{3}{c}{ Freq. máxima em Hz } \\
\multicolumn{1}{c}{ Modo } & $\mathrm{X}(\mathrm{m})$ & $\mathrm{Y}(\mathrm{m})$ & $\mathrm{Z}(\mathrm{m})$ & $\mathrm{X}(\mathrm{m})$ & $\mathrm{Y}(\mathrm{m})$ & $\mathrm{Z}(\mathrm{m})$ & $\mathrm{X}(\mathrm{m})$ & $\mathrm{Y}(\mathrm{m})$ & $\mathrm{Z}(\mathrm{m})$ & $\mathrm{X}$ & $\mathrm{Y}$ & $\mathrm{Z}$ \\
& & & & & & & & & & & & \\
\hline 1 & 1,637 & 0,000 & 0,000 & $-1,578$ & $-0,000$ & $-0,000$ & 0,604 & 0,000 & 0,000 & 0,117 & 0,060 & 0,117 \\
2 & 0,000 & 1,480 & 0,010 & $-0,000$ & $-1,447$ & $-0,008$ & 0,000 & 0,534 & 0,004 & 0,117 & 0,060 & 0,117 \\
3 & 1,695 & 0,000 & 0,000 & $-1,460$ & $-0,000$ & $-0,000$ & 0,598 & 0,000 & 0,000 & 0,117 & 0,060 & 0,117 \\
4 & 0,000 & 1,349 & 0,014 & $-0,000$ & $-1,474$ & $-0,018$ & 0,000 & 0,521 & 0,008 & 0,117 & 0,117 & 0,117 \\
5 & 0,903 & 0,000 & 0,000 & $-0,680$ & $-0,000$ & $-0,000$ & 0,262 & 0,000 & 0,000 & 0,117 & 0,117 & 0,117 \\
6 & 0,000 & 1,819 & 0,022 & $-0,000$ & $-1,814$ & $-0,017$ & 0,000 & 0,852 & 0,009 & 0,117 & 0,117 & 0,117 \\
7 & 0,729 & 0,002 & 0,000 & $-1,096$ & $-0,002$ & $-0,000$ & 0,349 & 0,001 & 0,000 & 0,117 & 0,117 & 0,117 \\
8 & 0,414 & 0,000 & 0,000 & $-0,571$ & $-0,000$ & $-0,000$ & 0,169 & 0,000 & 0,000 & 0,117 & 0,117 & 0,117 \\
9 & 0,003 & 0,991 & 0,017 & $-0,002$ & $-1,072$ & $-0,023$ & 0,001 & 0,509 & 0,009 & 0,117 & 0,117 & 0,117 \\
10 & 0,336 & 0,000 & 0,000 & $-0,399$ & $-0,000$ & $-0,000$ & 0,128 & 0,000 & 0,000 & 0,238 & 0,226 & 0,117 \\
11 & 0,000 & 0,341 & 0,033 & $-0,000$ & $-0,335$ & $-0,025$ & 0,000 & 0,117 & 0,014 & 0,238 & 0,226 & 0,117 \\
12 & 0,000 & 0,024 & 0,619 & $-0,000$ & $-0,032$ & $-0,802$ & 0,000 & 0,015 & 0,332 & 0,226 & 0,117 & 0,117 \\
13 & 0,424 & 0,000 & 0,000 & $-0,392$ & $-0,000$ & $-0,000$ & 0,164 & 0,000 & 0,000 & 0,246 & 0,117 & 0,117 \\
14 & 0,000 & 0,543 & 0,001 & $-0,000$ & $-0,541$ & $-0,001$ & 0,000 & 0,224 & 0,000 & 0,246 & 0,117 & 0,117 \\
15 & 0,130 & 0,000 & 0,000 & $-0,155$ & $-0,000$ & $-0,000$ & 0,052 & 0,000 & 0,000 & 0,286 & 0,117 & 0,117 \\
16 & 0,001 & 0,177 & 0,001 & $-0,002$ & $-0,226$ & $-0,001$ & 0,001 & 0,077 & 0,000 & 0,286 & 0,117 & 0,261 \\
\hline
\end{tabular}

A Tabela E.11 apresenta para o ensaio Catenária-4 apenas os movimentos referentes 
a deslocamento no plano da catenária através da interpolação do sinal do ensaio, a maior amplitude acoplada máxima foi de 1,824 m. Este valor ocorreu para o modo 6 . Neste modo, a sua frequência de resposta com maior energia foi de $0,117 \mathrm{~Hz}$.

Tabela E.11: Propriedades das amplitudes modais acopladas no plano da catenária do ensaio Catenária-4 através da interpolação do sinal do ensaio para a $V_{\max }=1,34 \mathrm{~m} / \mathrm{s}$.

Amplitude

Modo Máxima(m) Mínima(m) Desvio Padrão(m) Freq. máxima (Hz)

\begin{tabular}{lllll}
\hline 2 & 1,481 & $-1,445$ & 0,533 & 0,060 \\
4 & 1,347 & $-1,477$ & 0,522 & 0,117 \\
6 & 1,824 & $-1,813$ & 0,854 & 0,117 \\
9 & 0,967 & $-1,057$ & 0,498 & 0,117 \\
11 & 0,369 & $-0,351$ & 0,122 & 0,226 \\
12 & 0,638 & $-0,823$ & 0,344 & 0,117 \\
14 & 0,539 & $-0,537$ & 0,222 & 0,117 \\
16 & 0,176 & $-0,224$ & 0,077 & 0,117 \\
\hline
\end{tabular}

A Tabela E.12 para o ensaio Catenária-4 com apenas as amplitudes correspondentes a movimentos fora do plano através da interpolação do sinal do ensaio, a maior amplitude acoplada máxima apresentada foi de 1,664 m. Este valor ocorreu para o modo 3. Neste modo, a sua frequência de resposta com maior energia foi de 0,117 Hz.

Tabela E.12: Propriedades das amplitudes modais acopladas fora do plano da catenária do ensaio Catenária-4 através da interpolação do sinal do ensaio para a

$$
V_{\max }=1,34 \mathrm{~m} / \mathrm{s} \text {. }
$$

Amplitude

Modo Máxima(m) Mínima(m) Desvio Padrão(m) Freq. máxima (Hz)

\begin{tabular}{lllll}
\hline 1 & 1,617 & $-1,559$ & 0,597 & 0,117 \\
3 & 1,664 & $-1,433$ & 0,587 & 0,117 \\
5 & 0,884 & $-0,665$ & 0,256 & 0,117 \\
7 & 0,714 & $-1,074$ & 0,342 & 0,117 \\
8 & 0,408 & $-0,561$ & 0,166 & 0,117 \\
10 & 0,331 & $-0,393$ & 0,126 & 0,238 \\
13 & 0,419 & $-0,388$ & 0,162 & 0,246 \\
15 & 0,128 & $-0,154$ & 0,051 & 0,286 \\
\hline
\end{tabular}




\section{E.4 Catenária-4 - Velocidade de $1,42 \mathrm{~m} / \mathrm{s}$ e $V_{r 1}=$ 18,22}

Abaixo serão apresentados os gráficos com alguns detalhes da análise referentes ao arranjo Catenária-4 para a velocidade de $1,42 \mathrm{~m} / \mathrm{s}$ e $V_{r 1}=18,22$.
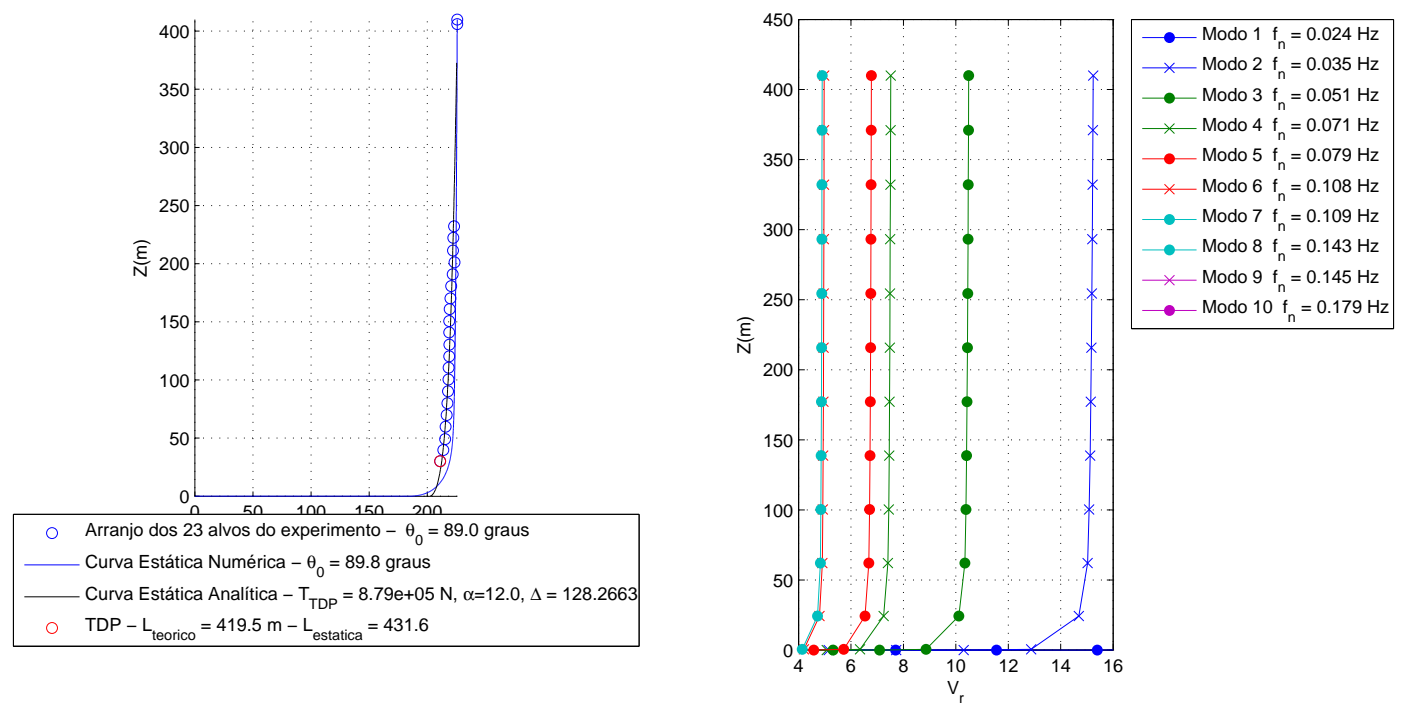

Figura E.16: Variação da velocidade no modelo durante o ensaio para Catenária-4 na $U_{\text {max }}=1,42 \mathrm{~m} / \mathrm{s}$ e $V_{r 1}=18,223$.

Como pode ser visto na Tabela E.13 e nas Figuras de E.17 a E.19, os maiores deslocamentos máximos apresentados na direção X, Y e Z foram de 1,482, 2,512 e 0,459 $\mathrm{m}$, respectivamente. Estes valores ocorreram para o alvo 5, Neste alvo, a sua frequência de resposta com maior energia foi de 0,1210.1240.121 Hz. 

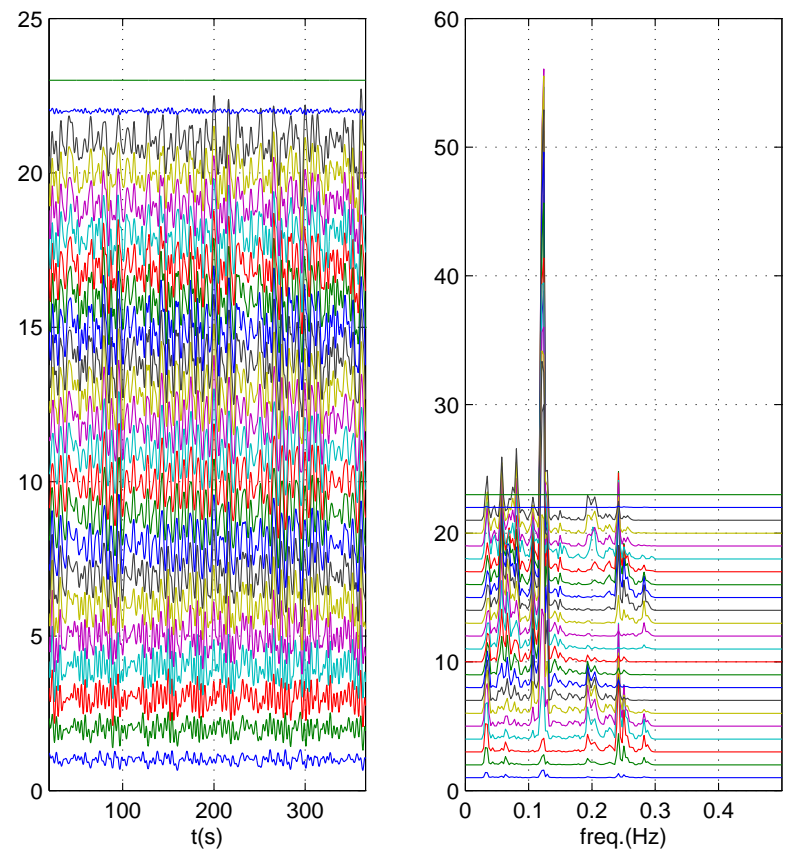

Figura E.17: Série temporal com frequências de resposta para X obtida experimentalmente por alvo para o arranjo de Catenária-4 na $U_{\max }=1,42 \mathrm{~m} / \mathrm{s}$ e $V_{r 1}=18,223$.
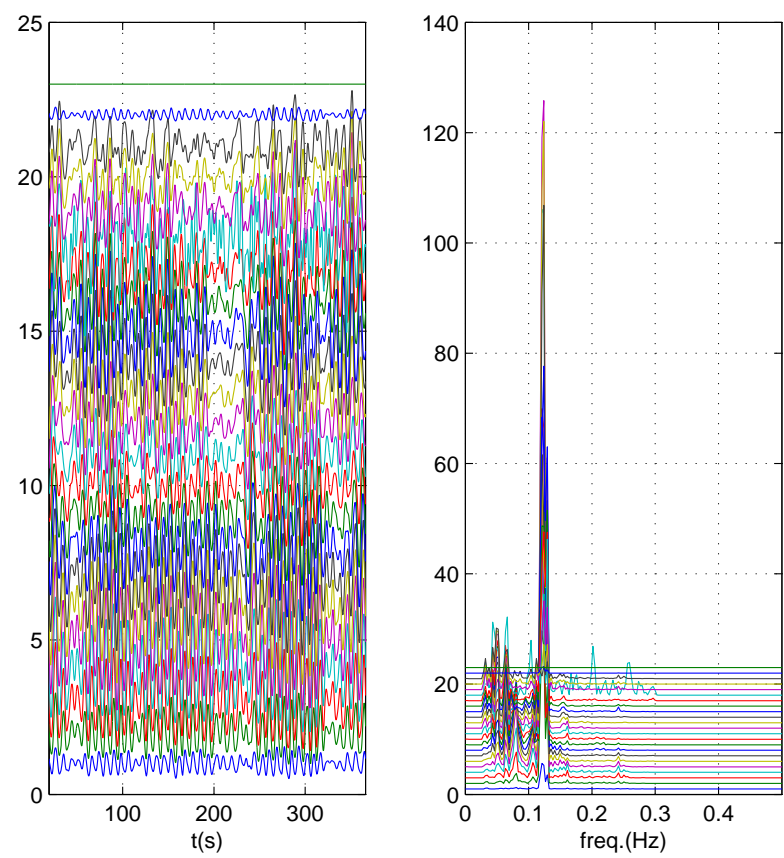

Figura E.18: Série temporal com frequências de resposta para Y obtida experimentalmente por alvo para o arranjo de Catenária-4 na $U_{\max }=1,42 \mathrm{~m} / \mathrm{s}$ e $V_{r 1}=18,223$. 

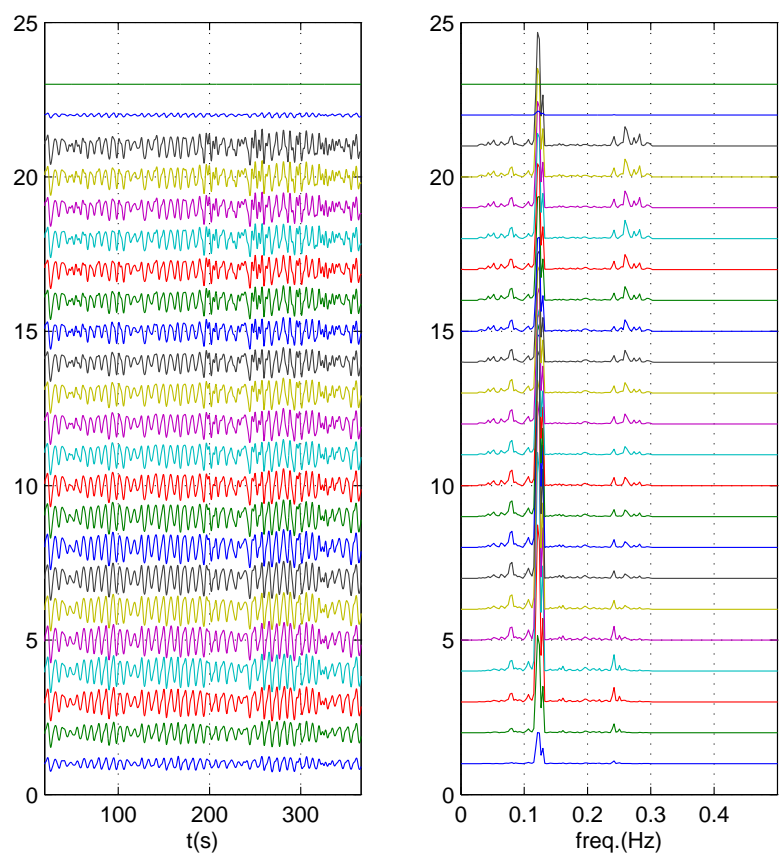

Figura E.19: Série temporal com frequências de resposta para Z obtida experimentalmente por alvo para o arranjo de Catenária-4 na $U_{\max }=1,42 \mathrm{~m} / \mathrm{s}$ e $V_{r 1}=18,223$. 
Tabela E.13: Propriedades da série temporal do ensaio Catenária-4 para a

$$
U_{\max }=1,42 \mathrm{~m} / \mathrm{s} \text {. }
$$

\begin{tabular}{|c|c|c|c|c|c|c|c|c|c|c|c|c|}
\hline \multirow[b]{2}{*}{ ID. Alvo } & \multirow[b]{2}{*}{$\mathrm{X}(\mathrm{m})$} & \multicolumn{3}{|l|}{ Máximo } & \multicolumn{2}{|l|}{ Mínimo } & \multicolumn{3}{|c|}{ Desvio padrão } & \multicolumn{3}{|c|}{ Freq. máxima em $\mathrm{Hz}$} \\
\hline & & $\mathrm{Y}(\mathrm{m})$ & $\mathrm{Z}(\mathrm{m})$ & $\mathrm{X}(\mathrm{m})$ & $\mathrm{Y}(\mathrm{m})$ & $\mathrm{Z}(\mathrm{m})$ & $\mathrm{X}(\mathrm{m})$ & $\mathrm{Y}(\mathrm{m})$ & $\mathrm{Z}(\mathrm{m})$ & $\mathrm{X}$ & $\mathrm{Y}$ & Z \\
\hline 1 & 0,241 & 0,511 & 0,200 & $-0,210$ & $-0,339$ & $-0,249$ & 0,105 & 0,211 & 0,098 & 0,124 & 0,121 & 0,121 \\
\hline 2 & 0,467 & 1,284 & 0,318 & $-0,444$ & $-0,739$ & $-0,470$ & 0,210 & 0,488 & 0,168 & 0,242 & 0,121 & 0,121 \\
\hline 3 & 0,904 & 1,926 & 0,418 & $-0,817$ & $-1,169$ & $-0,614$ & 0,324 & 0,758 & 0,223 & 0,242 & 0,121 & 0,121 \\
\hline 4 & 1,312 & 2,387 & 0,456 & $-1,108$ & $-1,502$ & $-0,699$ & 0,436 & 0,943 & 0,251 & 0,242 & 0,121 & 0,121 \\
\hline 5 & 1,482 & 2,512 & 0,459 & $-1,148$ & $-1,745$ & $-0,737$ & 0,490 & 1,009 & 0,263 & 0,121 & 0,124 & 0,121 \\
\hline 6 & 1,456 & 2,396 & 0,428 & $-1,006$ & $-1,808$ & $-0,704$ & 0,510 & 0,983 & 0,254 & 0,121 & 0,124 & 0,121 \\
\hline 7 & 1,293 & 2,248 & 0,436 & $-0,936$ & $-1,722$ & $-0,708$ & 0,519 & 0,944 & 0,259 & 0,124 & 0,124 & 0,121 \\
\hline 8 & 1,060 & 1,976 & 0,436 & $-1,042$ & $-1,541$ & $-0,716$ & 0,529 & 0,846 & 0,259 & 0,124 & 0,124 & 0,124 \\
\hline 9 & 0,894 & 1,712 & 0,416 & $-1,143$ & $-1,348$ & $-0,696$ & 0,537 & 0,750 & 0,249 & 0,124 & 0,124 & 0,124 \\
\hline 10 & 0,862 & 1,581 & 0,405 & $-1,148$ & $-1,160$ & $-0,685$ & 0,536 & 0,690 & 0,242 & 0,124 & 0,121 & 0,124 \\
\hline 11 & 0,901 & 1,575 & 0,366 & $-1,080$ & $-1,357$ & $-0,648$ & 0,540 & 0,695 & 0,227 & 0,124 & 0,121 & 0,124 \\
\hline 12 & 0,928 & 1,558 & 0,372 & $-1,071$ & $-1,632$ & $-0,659$ & 0,550 & 0,753 & 0,226 & 0,124 & 0,121 & 0,124 \\
\hline 13 & 0,930 & 1,576 & 0,358 & $-1,130$ & $-1,770$ & $-0,650$ & 0,567 & 0,810 & 0,221 & 0,124 & 0,121 & 0,124 \\
\hline 14 & 0,909 & 1,658 & 0,340 & $-1,200$ & $-1,806$ & $-0,624$ & 0,577 & 0,860 & 0,211 & 0,124 & 0,121 & 0,124 \\
\hline 15 & 0,952 & 1,885 & 0,305 & $-1,229$ & $-1,820$ & $-0,576$ & 0,575 & 0,932 & 0,199 & 0,124 & 0,121 & 0,124 \\
\hline 16 & 0,981 & 1,577 & 0,332 & $-1,208$ & $-1,669$ & $-0,616$ & 0,565 & 0,836 & 0,208 & 0,124 & 0,130 & 0,124 \\
\hline 17 & 0,929 & 1,771 & 0,301 & $-1,159$ & $-1,826$ & $-0,613$ & 0,534 & 0,846 & 0,207 & 0,124 & 0,124 & 0,121 \\
\hline 18 & 0,993 & 1,882 & 0,369 & $-1,112$ & $-3,155$ & $-0,611$ & 0,478 & 1,148 & 0,209 & 0,124 & 0,130 & 0,121 \\
\hline 19 & 0,851 & 1,661 & 0,331 & $-1,134$ & $-1,131$ & $-0,599$ & 0,506 & 0,684 & 0,205 & 0,124 & 0,124 & 0,121 \\
\hline 20 & 0,849 & 1,554 & 0,337 & $-1,075$ & $-1,021$ & $-0,594$ & 0,485 & 0,610 & 0,204 & 0,121 & 0,049 & 0,121 \\
\hline 21 & 0,849 & 1,449 & 0,355 & $-0,994$ & $-1,076$ & $-0,595$ & 0,464 & 0,570 & 0,207 & 0,121 & 0,049 & 0,121 \\
\hline 22 & 0,093 & 0,257 & 0,064 & $-0,089$ & $-0,148$ & $-0,094$ & 0,042 & 0,098 & 0,034 & 0,242 & 0,121 & 0,121 \\
\hline 23 & 0,000 & $-0,000$ & 0,000 & 0,000 & $-0,000$ & 0,000 & 0,000 & 0,000 & 0,000 & 0,000 & 0,000 & 0,000 \\
\hline
\end{tabular}

Considerando agora a decomposição modal, na Tabela E.14 através da interpolação do sinal do ensaio, correspondente a uma velocade reduzida do primeiro modo $V_{r 1}=18.22$, as maiores amplitudes máximas apresentadas na direção X, Y e Z foram de 1,594, 1,876 e $0,583 \mathrm{~m}$, respectivamente. Estes valores ocorreram para os modos 1, 6 e 12 . Nestes modos, as suas frequências de resposta com maior energia foram de 0,121 e 0,124 Hz. 

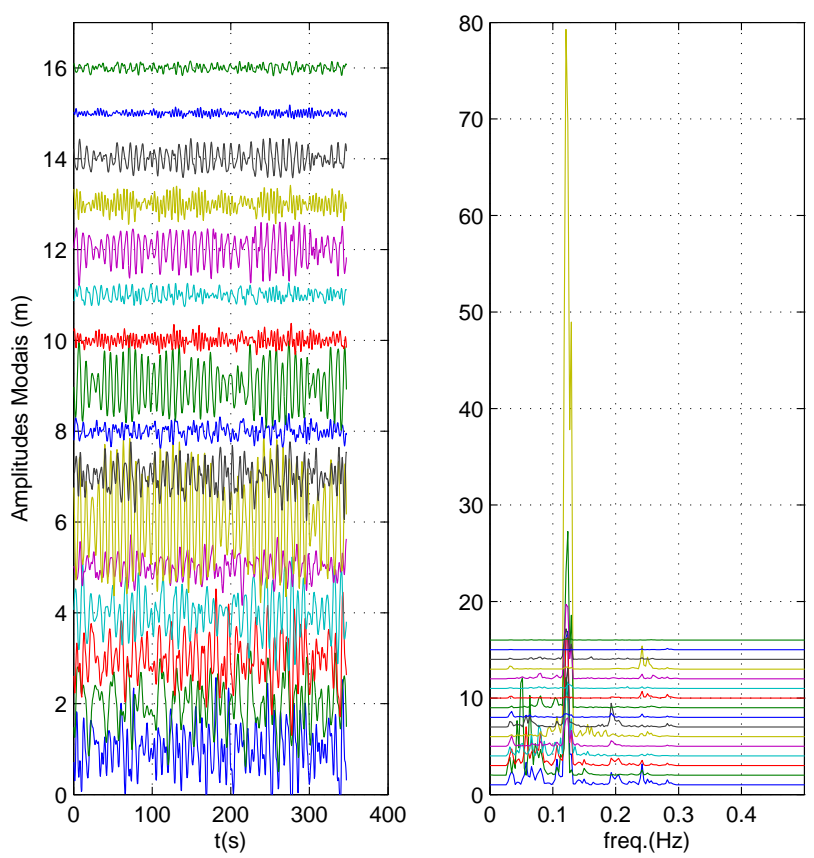

Figura E.20: Variação da amplitude modal acoplada ao longo do tempo através da interpolação do sinal do ensaio para Catenária-4 na $U_{\max }=1,42 \mathrm{~m} / \mathrm{s}$ e $V_{r 1}=18,223$.

Tabela E.14: Propriedades das amplitudes modais do ensaio Catenária-4 através da interpolação do sinal do ensaio para a $V_{\max }=1,42 \mathrm{~m} / \mathrm{s}$.

\begin{tabular}{lccccccccccccc}
\hline \multicolumn{1}{c}{ Máximo } & \multicolumn{1}{c}{ Mínimo } & & \multicolumn{3}{c}{ Desvio padrão } & \multicolumn{3}{c}{ Freq. máxima em Hz } \\
\multicolumn{1}{c}{ Modo } & $\mathrm{X}(\mathrm{m})$ & $\mathrm{Y}(\mathrm{m})$ & $\mathrm{Z}(\mathrm{m})$ & $\mathrm{X}(\mathrm{m})$ & $\mathrm{Y}(\mathrm{m})$ & $\mathrm{Z}(\mathrm{m})$ & $\mathrm{X}(\mathrm{m})$ & $\mathrm{Y}(\mathrm{m})$ & $\mathrm{Z}(\mathrm{m})$ & $\mathrm{X}$ & $\mathrm{Y}$ & $\mathrm{Z}$ \\
& & & & & & & & & & & & \\
\hline 1 & 1,594 & 0,000 & 0,000 & $-1,681$ & $-0,000$ & $-0,000$ & 0,516 & 0,000 & 0,000 & 0,124 & 0,052 & 0,121 \\
2 & 0,000 & 1,355 & 0,010 & $-0,000$ & $-1,501$ & $-0,008$ & 0,000 & 0,530 & 0,004 & 0,124 & 0,052 & 0,121 \\
3 & 1,556 & 0,000 & 0,000 & $-1,727$ & $-0,000$ & $-0,000$ & 0,500 & 0,000 & 0,000 & 0,124 & 0,052 & 0,121 \\
4 & 0,000 & 1,234 & 0,013 & $-0,000$ & $-1,269$ & $-0,017$ & 0,000 & 0,448 & 0,007 & 0,124 & 0,124 & 0,121 \\
5 & 0,735 & 0,000 & 0,000 & $-0,852$ & $-0,000$ & $-0,000$ & 0,241 & 0,000 & 0,000 & 0,124 & 0,124 & 0,121 \\
6 & 0,000 & 1,876 & 0,021 & $-0,000$ & $-1,773$ & $-0,017$ & 0,000 & 0,901 & 0,008 & 0,124 & 0,121 & 0,121 \\
7 & 0,782 & 0,002 & 0,000 & $-0,983$ & $-0,002$ & $-0,000$ & 0,321 & 0,001 & 0,000 & 0,124 & 0,121 & 0,121 \\
8 & 0,395 & 0,000 & 0,000 & $-0,380$ & $-0,000$ & $-0,000$ & 0,141 & 0,000 & 0,000 & 0,035 & 0,124 & 0,121 \\
9 & 0,002 & 1,131 & 0,017 & $-0,002$ & $-0,989$ & $-0,022$ & 0,001 & 0,475 & 0,008 & 0,035 & 0,124 & 0,121 \\
10 & 0,381 & 0,000 & 0,000 & $-0,317$ & $-0,000$ & $-0,000$ & 0,121 & 0,000 & 0,000 & 0,242 & 0,124 & 0,124 \\
11 & 0,000 & 0,265 & 0,031 & $-0,000$ & $-0,262$ & $-0,024$ & 0,000 & 0,115 & 0,012 & 0,242 & 0,124 & 0,121 \\
12 & 0,000 & 0,027 & 0,583 & $-0,000$ & $-0,030$ & $-0,766$ & 0,000 & 0,015 & 0,291 & 0,242 & 0,124 & 0,121 \\
13 & 0,419 & 0,000 & 0,000 & $-0,454$ & $-0,000$ & $-0,000$ & 0,167 & 0,000 & 0,000 & 0,242 & 0,121 & 0,121 \\
14 & 0,000 & 0,451 & 0,001 & $-0,000$ & $-0,424$ & $-0,002$ & 0,000 & 0,200 & 0,000 & 0,242 & 0,121 & 0,121 \\
15 & 0,183 & 0,000 & 0,000 & $-0,125$ & $-0,000$ & $-0,000$ & 0,051 & 0,000 & 0,000 & 0,282 & 0,130 & 0,121 \\
16 & 0,002 & 0,151 & 0,001 & $-0,001$ & $-0,176$ & $-0,001$ & 0,001 & 0,068 & 0,000 & 0,282 & 0,130 & 0,259 \\
\hline
\end{tabular}

A Tabela E.15 apresenta para o ensaio Catenária-4 apenas os movimentos referentes 
a deslocamento no plano da catenária através da interpolação do sinal do ensaio, a maior amplitude acoplada máxima foi de 1,875 m. Este valor ocorreu para o modo 6 . Neste modo, a sua frequência de resposta com maior energia foi de $0,121 \mathrm{~Hz}$.

Tabela E.15: Propriedades das amplitudes modais acopladas no plano da catenária do ensaio Catenária-4 através da interpolação do sinal do ensaio para a $V_{\max }=1,42 \mathrm{~m} / \mathrm{s}$.

Amplitude

Modo Máxima(m) Mínima(m) Desvio Padrão(m) Freq. máxima (Hz)

\begin{tabular}{lllll}
\hline 2 & 1,347 & $-1,496$ & 0,528 & 0,121 \\
4 & 1,230 & $-1,274$ & 0,448 & 0,124 \\
6 & 1,875 & $-1,773$ & 0,902 & 0,121 \\
9 & 1,107 & $-0,978$ & 0,465 & 0,124 \\
11 & 0,264 & $-0,259$ & 0,113 & 0,124 \\
12 & 0,603 & $-0,791$ & 0,303 & 0,121 \\
14 & 0,447 & $-0,422$ & 0,198 & 0,121 \\
16 & 0,150 & $-0,174$ & 0,068 & 0,130 \\
\hline
\end{tabular}

A Tabela E.16 para o ensaio Catenária-4 com apenas as amplitudes correspondentes a movimentos fora do plano através da interpolação do sinal do ensaio, a maior amplitude acoplada máxima apresentada foi de 1,575 m. Este valor ocorreu para o modo 1 . Neste modo, a sua frequência de resposta com maior energia foi de 0,124 Hz.

Tabela E.16: Propriedades das amplitudes modais acopladas fora do plano da catenária do ensaio Catenária-4 através da interpolação do sinal do ensaio para a

$$
V_{\max }=1,42 \mathrm{~m} / \mathrm{s} \text {. }
$$

\begin{tabular}{lllll}
\hline \multicolumn{5}{c}{ Amplitude } \\
Modo & Máxima(m) & Mínima(m) & Desvio Padrão(m) & Freq. máxima (Hz) \\
& & & & \\
\hline 1 & 1,575 & $-1,661$ & 0,510 & 0,124 \\
3 & 1,527 & $-1,696$ & 0,491 & 0,124 \\
5 & 0,719 & $-0,833$ & 0,236 & 0,124 \\
7 & 0,766 & $-0,963$ & 0,314 & 0,124 \\
8 & 0,388 & $-0,374$ & 0,139 & 0,035 \\
10 & 0,376 & $-0,313$ & 0,119 & 0,242 \\
13 & 0,414 & $-0,449$ & 0,165 & 0,242 \\
15 & 0,181 & $-0,124$ & 0,051 & 0,282 \\
\hline
\end{tabular}


Anexo F - Resultados de VIV nas linhas em Catenária-5 
Neste anexo é apresentado um conjunto mais completo de resultados do VIV na linha flexível para a Catenária-5, particularmente aqueles referentes às velocidades reduzidas mais importantes. Vale lembrar que todos os resultados estão apresentados na escala real (1:100) conforme definido em [Rateiro et al., 2012]. Neste sentido, as seções que se seguem dizem respeito a:

- Na seção F.1: Velocidade de $1,12 \mathrm{~m} / \mathrm{s}$ e $V_{r 1}=6,95$

- Na seção F.2: Velocidade de $1,3 \mathrm{~m} / \mathrm{s}$ e $V_{r 1}=8,10$

- Na seção F.3: Velocidade de $1,4 \mathrm{~m} / \mathrm{s}$ e $V_{r 1}=8,67$

- Na seção F.4: Velocidade de $1,67 \mathrm{~m} / \mathrm{s}$ e $V_{r 1}=10,39$

- Na seção F.5: Velocidade de 1,95 m/s e $V_{r 1}=12,12$

- Na seção F.6: Velocidade de $2,27 \mathrm{~m} / \mathrm{s}$ e $V_{r 1}=14,12$

\section{F.1 Catenária-5 - Velocidade de $1,12 \mathrm{~m} / \mathrm{s}$ e $V_{r 1}=$ 6,95}

Abaixo serão apresentados os gráficos com alguns detalhes da análise referentes ao arranjo Catenária-5 para a velocidade de $1,12 \mathrm{~m} / \mathrm{s}$ e $V_{r 1}=6,95$.
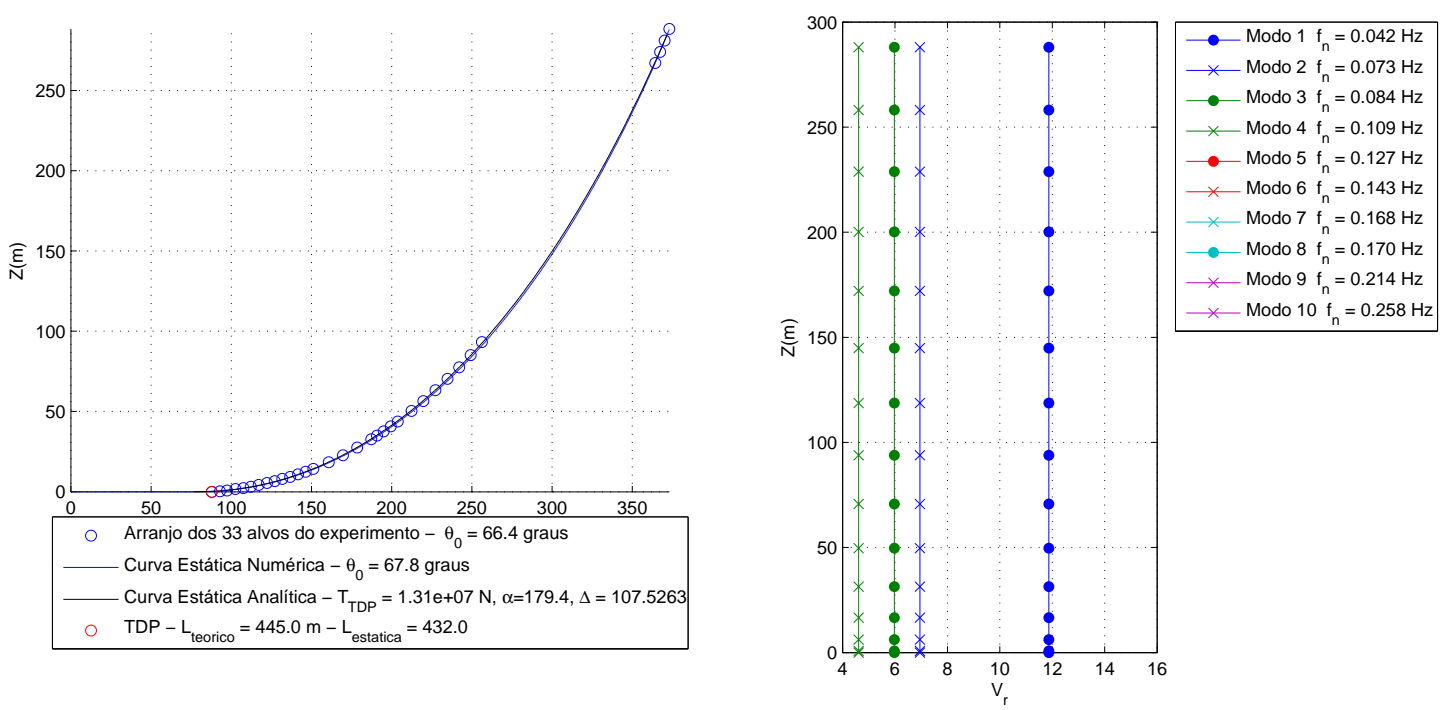

Figura F.1: Variação da velocidade no modelo durante o ensaio para Catenária-5 na

$$
U_{\max }=1,12 \mathrm{~m} / \mathrm{s} \text { e } V_{r 1}=6,951 \text {. }
$$


Como pode ser visto na Tabela F.1 e nas Figuras de F.2 a F.4, os maiores deslocamentos máximos apresentados na direção X, Y e Z foram de 0,508, 1,057 e 1,418 $\mathrm{m}$, respectivamente. Estes valores ocorreram para os alvos 14 e 29. Nestes alvos, as suas frequências de resposta com maior energia foram de 0,0748 e 0,149 Hz.
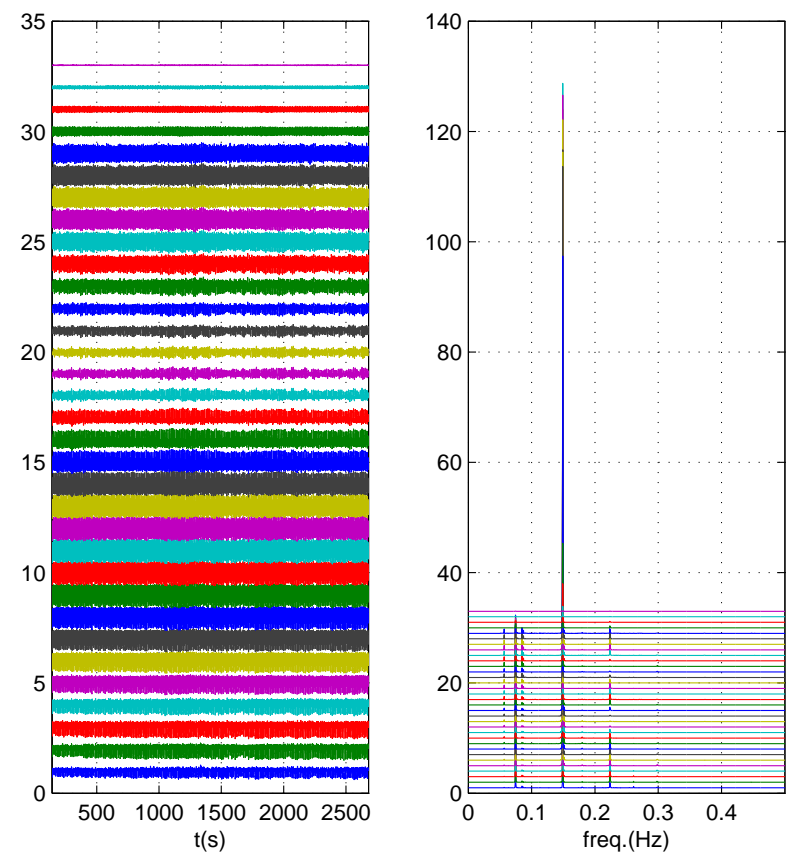

Figura F.2: Série temporal com frequências de resposta para X obtida experimentalmente por alvo para o arranjo de Catenária-5 na $U_{\max }=1,12 \mathrm{~m} / \mathrm{s}$ e $V_{r 1}=6,951$. 

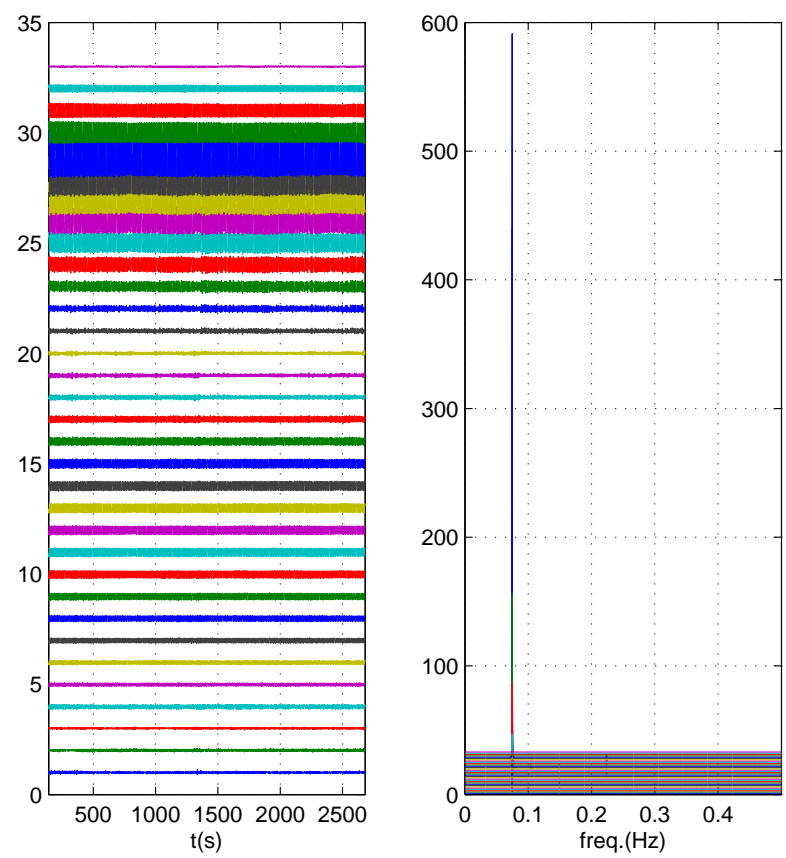

Figura F.3: Série temporal com frequências de resposta para Y obtida experimentalmente por alvo para o arranjo de Catenária-5 na $U_{\max }=1,12 \mathrm{~m} / \mathrm{s}$ e $V_{r 1}=6,951$.
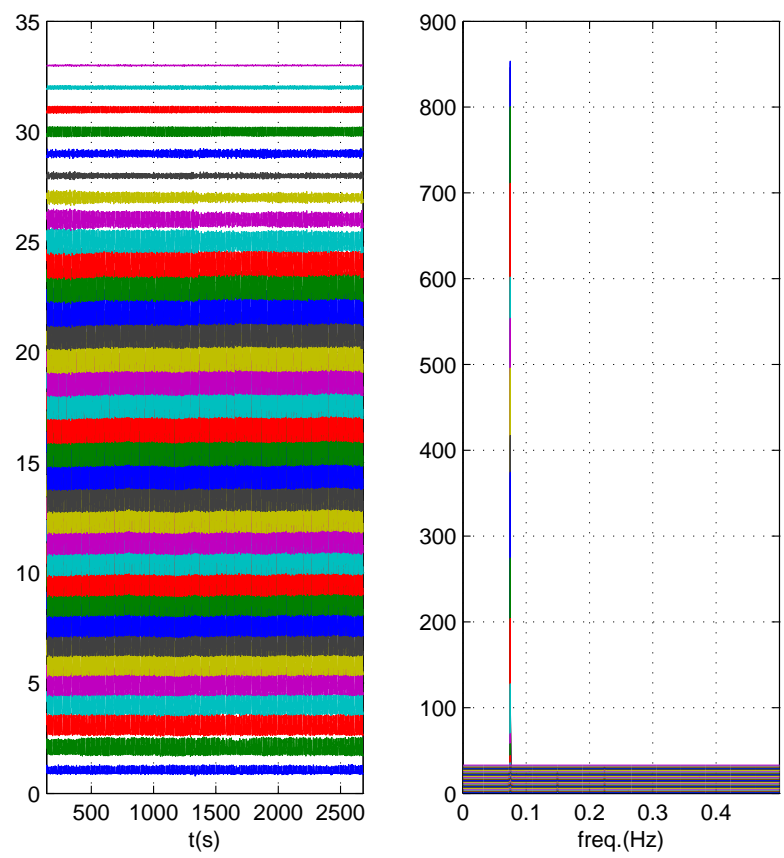

Figura F.4: Série temporal com frequências de resposta para Z obtida experimentalmente por alvo para o arranjo de Catenária-5 na $U_{\max }=1,12 \mathrm{~m} / \mathrm{s}$ e $V_{r 1}=6,951$. 
Tabela F.1: Propriedades da série temporal do ensaio Catenária-5 para a

$$
U_{\max }=1,12 \mathrm{~m} / \mathrm{s} \text {. }
$$

\begin{tabular}{|c|c|c|c|c|c|c|c|c|c|c|c|c|}
\hline \multirow[b]{2}{*}{ ID. Alvo } & \multirow[b]{2}{*}{$\mathrm{X}(\mathrm{m})$} & \multicolumn{2}{|c|}{ Máximo } & \multirow[b]{2}{*}{$\mathrm{X}(\mathrm{m})$} & \multirow{2}{*}{$\begin{array}{l}\text { Mínimo } \\
\mathrm{Y}(\mathrm{m})\end{array}$} & \multirow{2}{*}{$\mathrm{Z}(\mathrm{m})$} & \multicolumn{3}{|c|}{ Desvio padrão } & \multicolumn{3}{|c|}{ Freq. máxima em $\mathrm{Hz}$} \\
\hline & & $\mathrm{Y}(\mathrm{m})$ & $\mathrm{Z}(\mathrm{m})$ & & & & $\mathrm{X}(\mathrm{m})$ & $\mathrm{Y}(\mathrm{m})$ & $\mathrm{Z}(\mathrm{m})$ & $\mathrm{X}$ & $\mathrm{Y}$ & Z \\
\hline 1 & 0,142 & 0,072 & 0,277 & $-0,272$ & $-0,080$ & $-0,113$ & 0,110 & 0,038 & 0,115 & 0,149 & 0,075 & 0,074 \\
\hline 2 & 0,182 & 0,018 & 0,473 & $-0,342$ & $-0,019$ & $-0,235$ & 0,151 & 0,009 & 0,250 & 0,149 & 0,074 & 0,074 \\
\hline 3 & 0,247 & 0,017 & 0,623 & $-0,411$ & $-0,022$ & $-0,349$ & 0,192 & 0,010 & 0,341 & 0,149 & 0,074 & 0,074 \\
\hline 4 & 0,241 & 0,060 & 0,628 & $-0,385$ & $-0,125$ & $-0,446$ & 0,176 & 0,068 & 0,355 & 0,149 & 0,075 & 0,074 \\
\hline 5 & 0,302 & 0,059 & 0,810 & $-0,423$ & $-0,106$ & $-0,580$ & 0,221 & 0,059 & 0,479 & 0,149 & 0,075 & 0,074 \\
\hline 6 & 0,332 & 0,080 & 0,946 & $-0,455$ & $-0,125$ & $-0,688$ & 0,245 & 0,072 & 0,563 & 0,149 & 0,075 & 0,074 \\
\hline 7 & 0,366 & 0,101 & 1,057 & $-0,493$ & $-0,146$ & $-0,797$ & 0,269 & 0,087 & 0,640 & 0,149 & 0,075 & 0,074 \\
\hline 8 & 0,393 & 0,117 & 1,120 & $-0,492$ & $-0,173$ & $-0,917$ & 0,281 & 0,102 & 0,706 & 0,149 & 0,074 & 0,074 \\
\hline 9 & 0,442 & 0,136 & 1,249 & $-0,532$ & $-0,191$ & $-0,993$ & 0,304 & 0,114 & 0,771 & 0,149 & 0,075 & 0,074 \\
\hline 10 & 0,465 & 0,156 & 1,316 & $-0,541$ & $-0,210$ & $-1,082$ & 0,311 & 0,127 & 0,827 & 0,149 & 0,075 & 0,074 \\
\hline 11 & 0,481 & 0,176 & 1,373 & $-0,544$ & $-0,226$ & $-1,156$ & 0,316 & 0,144 & 0,873 & 0,149 & 0,075 & 0,074 \\
\hline 12 & 0,496 & 0,180 & 1,399 & $-0,541$ & $-0,232$ & $-1,198$ & 0,316 & 0,144 & 0,899 & 0,149 & 0,075 & 0,074 \\
\hline 13 & 0,498 & 0,196 & 1,416 & $-0,527$ & $-0,240$ & $-1,227$ & 0,311 & 0,151 & 0,921 & 0,149 & 0,075 & 0,074 \\
\hline 14 & 0,508 & 0,193 & 1,418 & $-0,524$ & $-0,237$ & $-1,259$ & 0,309 & 0,152 & 0,932 & 0,149 & 0,075 & 0,075 \\
\hline 15 & 0,460 & 0,192 & 1,379 & $-0,473$ & $-0,222$ & $-1,246$ & 0,269 & 0,144 & 0,925 & 0,149 & 0,075 & 0,075 \\
\hline 16 & 0,415 & 0,173 & 1,297 & $-0,411$ & $-0,174$ & $-1,192$ & 0,228 & 0,122 & 0,890 & 0,149 & 0,075 & 0,075 \\
\hline 17 & 0,338 & 0,138 & 1,180 & $-0,314$ & $-0,144$ & $-1,121$ & 0,171 & 0,093 & 0,833 & 0,149 & 0,075 & 0,075 \\
\hline 18 & 0,253 & 0,085 & 1,064 & $-0,208$ & $-0,124$ & $-1,015$ & 0,118 & 0,057 & 0,760 & 0,075 & 0,075 & 0,075 \\
\hline 19 & 0,214 & 0,076 & 1,016 & $-0,161$ & $-0,112$ & $-0,973$ & 0,099 & 0,049 & 0,729 & 0,074 & 0,075 & 0,075 \\
\hline 20 & 0,169 & 0,085 & 0,966 & $-0,125$ & $-0,096$ & $-0,913$ & 0,085 & 0,051 & 0,687 & 0,074 & 0,074 & 0,075 \\
\hline 21 & 0,145 & 0,143 & 0,901 & $-0,169$ & $-0,100$ & $-0,830$ & 0,089 & 0,073 & 0,625 & 0,074 & 0,074 & 0,075 \\
\hline 22 & 0,162 & 0,193 & 0,886 & $-0,200$ & $-0,128$ & $-0,792$ & 0,102 & 0,101 & 0,595 & 0,074 & 0,074 & 0,075 \\
\hline 23 & 0,286 & 0,301 & 0,793 & $-0,252$ & $-0,237$ & $-0,694$ & 0,156 & 0,169 & 0,508 & 0,149 & 0,074 & 0,075 \\
\hline 24 & 0,359 & 0,394 & 0,716 & $-0,301$ & $-0,348$ & $-0,620$ & 0,205 & 0,236 & 0,437 & 0,149 & 0,074 & 0,075 \\
\hline 25 & 0,428 & 0,496 & 0,608 & $-0,332$ & $-0,474$ & $-0,509$ & 0,243 & 0,320 & 0,344 & 0,149 & 0,074 & 0,075 \\
\hline 26 & 0,480 & 0,619 & 0,461 & $-0,362$ & $-0,600$ & $-0,383$ & 0,273 & 0,419 & 0,243 & 0,149 & 0,074 & 0,075 \\
\hline 27 & 0,500 & 0,743 & 0,329 & $-0,414$ & $-0,727$ & $-0,261$ & 0,284 & 0,515 & 0,157 & 0,149 & 0,074 & 0,075 \\
\hline 28 & 0,497 & 0,899 & 0,167 & $-0,440$ & $-0,877$ & $-0,143$ & 0,283 & 0,630 & 0,087 & 0,149 & 0,074 & 0,074 \\
\hline 29 & 0,451 & 1,057 & 0,206 & $-0,433$ & $-1,019$ & $-0,181$ & 0,262 & 0,738 & 0,112 & 0,149 & 0,075 & 0,074 \\
\hline 30 & 0,211 & 0,505 & 0,215 & $-0,229$ & $-0,457$ & $-0,234$ & 0,128 & 0,360 & 0,170 & 0,149 & 0,075 & 0,075 \\
\hline 31 & 0,144 & 0,338 & 0,148 & $-0,156$ & $-0,303$ & $-0,162$ & 0,087 & 0,241 & 0,117 & 0,149 & 0,075 & 0,075 \\
\hline 32 & 0,075 & 0,175 & 0,085 & $-0,082$ & $-0,156$ & $-0,084$ & 0,045 & 0,122 & 0,063 & 0,149 & 0,075 & 0,075 \\
\hline 33 & 0,014 & 0,036 & 0,024 & $-0,017$ & $-0,033$ & $-0,025$ & 0,009 & 0,025 & 0,018 & 0,149 & 0,075 & 0,075 \\
\hline
\end{tabular}

Considerando agora a decomposição modal, na Tabela F.2 através da interpolação do sinal do ensaio, correspondente a uma velocade reduzida do primeiro modo $V_{r 1}=6.95$, as maiores amplitudes máximas apresentadas na direção X, Y e Z foram de 0,448, 1,246 e 0,712 m, respectivamente. Estes valores ocorreram para os modos 2, 5 e 6, Nestes modos, as suas frequências de resposta com maior energia foram de 0,0748 e 0,149 Hz. 

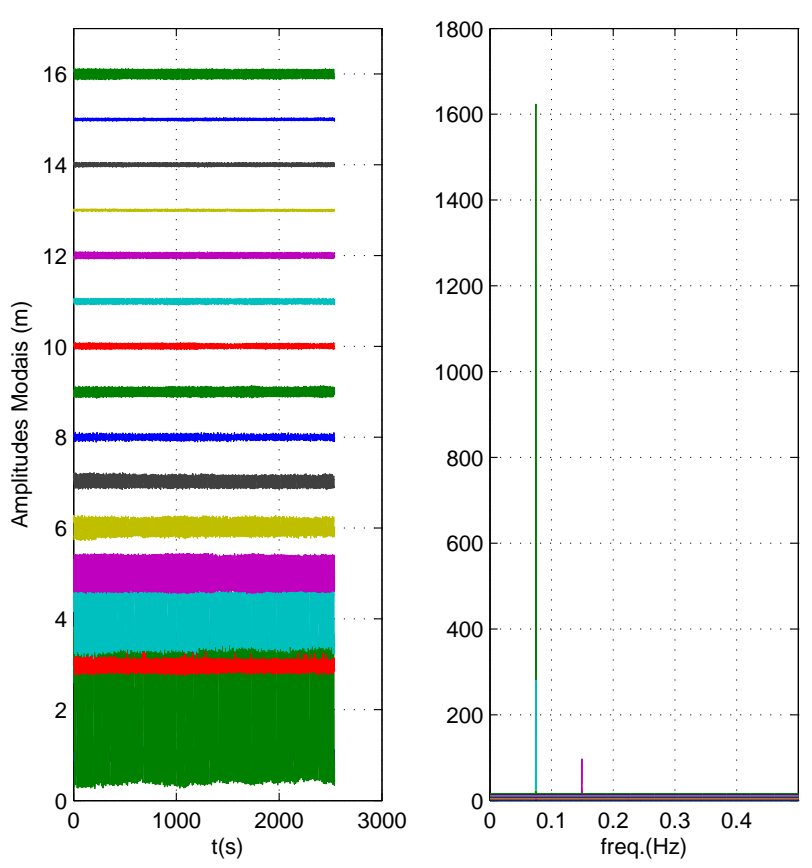

Figura F.5: Variação da amplitude modal acoplada ao longo do tempo através da interpolação do sinal do ensaio para Catenária-5 na $U_{\max }=1,12 \mathrm{~m} / \mathrm{s}$ e $V_{r 1}=6,951$.

Tabela F.2: Propriedades das amplitudes modais do ensaio Catenária-5 através da interpolação do sinal do ensaio para a $V_{\max }=1,12 \mathrm{~m} / \mathrm{s}$.

\begin{tabular}{lccccccccccccc}
\hline \multicolumn{1}{c}{ Máximo } & \multicolumn{1}{c}{ Mínimo } & & \multicolumn{3}{c}{ Desvio padrão } & \multicolumn{3}{c}{ Freq. máxima em Hz } \\
\multicolumn{1}{c}{ Modo } & $\mathrm{X}(\mathrm{m})$ & $\mathrm{Y}(\mathrm{m})$ & $\mathrm{Z}(\mathrm{m})$ & $\mathrm{X}(\mathrm{m})$ & $\mathrm{Y}(\mathrm{m})$ & $\mathrm{Z}(\mathrm{m})$ & $\mathrm{X}(\mathrm{m})$ & $\mathrm{Y}(\mathrm{m})$ & $\mathrm{Z}(\mathrm{m})$ & $\mathrm{X}$ & $\mathrm{Y}$ & $\mathrm{Z}$ \\
& & & & & & & & & & & & \\
\hline 1 & 0,233 & 0,000 & 0,000 & $-0,232$ & $-0,000$ & $-0,000$ & 0,079 & 0,000 & 0,000 & 0,074 & 0,075 & 0,075 \\
2 & 0,000 & 1,246 & 0,582 & $-0,000$ & $-1,220$ & $-0,528$ & 0,000 & 0,828 & 0,364 & 0,074 & 0,075 & 0,075 \\
3 & 0,282 & 0,000 & 0,000 & $-0,253$ & $-0,000$ & $-0,000$ & 0,096 & 0,000 & 0,000 & 0,149 & 0,075 & 0,075 \\
4 & 0,000 & 0,378 & 0,488 & $-0,000$ & $-0,423$ & $-0,463$ & 0,000 & 0,245 & 0,257 & 0,149 & 0,075 & 0,075 \\
5 & 0,448 & 0,000 & 0,000 & $-0,444$ & $-0,000$ & $-0,000$ & 0,279 & 0,000 & 0,000 & 0,149 & 0,075 & 0,074 \\
6 & 0,000 & 0,499 & 0,712 & $-0,000$ & $-0,472$ & $-0,599$ & 0,000 & 0,312 & 0,408 & 0,149 & 0,075 & 0,075 \\
7 & 0,000 & 0,090 & 0,158 & $-0,000$ & $-0,078$ & $-0,102$ & 0,000 & 0,045 & 0,065 & 0,074 & 0,074 & 0,074 \\
8 & 0,113 & 0,001 & 0,001 & $-0,105$ & $-0,001$ & $-0,002$ & 0,045 & 0,000 & 0,001 & 0,074 & 0,074 & 0,074 \\
9 & 0,000 & 0,104 & 0,089 & $-0,000$ & $-0,116$ & $-0,063$ & 0,000 & 0,065 & 0,032 & 0,224 & 0,074 & 0,224 \\
10 & 0,000 & 0,097 & 0,078 & $-0,000$ & $-0,098$ & $-0,078$ & 0,000 & 0,069 & 0,040 & 0,149 & 0,075 & 0,074 \\
11 & 0,064 & 0,000 & 0,000 & $-0,090$ & $-0,000$ & $-0,000$ & 0,036 & 0,000 & 0,000 & 0,149 & 0,075 & 0,074 \\
12 & 0,000 & 0,040 & 0,049 & $-0,000$ & $-0,039$ & $-0,043$ & 0,000 & 0,020 & 0,022 & 0,149 & 0,075 & 0,074 \\
13 & 0,025 & 0,000 & 0,000 & $-0,039$ & $-0,000$ & $-0,000$ & 0,013 & 0,000 & 0,000 & 0,149 & 0,075 & 0,074 \\
14 & 0,000 & 0,169 & 0,141 & $-0,000$ & $-0,159$ & $-0,141$ & 0,000 & 0,110 & 0,083 & 0,149 & 0,074 & 0,074 \\
15 & 0,033 & 0,000 & 0,000 & $-0,040$ & $-0,000$ & $-0,000$ & 0,016 & 0,000 & 0,000 & 0,149 & 0,074 & 0,074 \\
16 & 0,000 & 0,425 & 0,302 & $-0,000$ & $-0,413$ & $-0,329$ & 0,000 & 0,274 & 0,204 & 0,149 & 0,074 & 0,074 \\
\hline
\end{tabular}

A Tabela F.3 apresenta para o ensaio Catenária-5 apenas os movimentos referentes a 
deslocamento no plano da catenária através da interpolação do sinal do ensaio, a maior amplitude acoplada máxima foi de 1,815 m. Este valor ocorreu para o modo 2. Neste modo, a sua frequência de resposta com maior energia foi de $0,075 \mathrm{~Hz}$.

Tabela F.3: Propriedades das amplitudes modais acopladas no plano da catenária do ensaio Catenária-5 através da interpolação do sinal do ensaio para a $V_{\max }=1,12 \mathrm{~m} / \mathrm{s}$.

Amplitude

Modo Máxima(m) Mínima(m) Desvio Padrão(m) Freq. máxima (Hz)

\begin{tabular}{lllll}
\hline 2 & 1,815 & $-1,737$ & 1,184 & 0,075 \\
4 & 0,847 & $-0,874$ & 0,496 & 0,075 \\
6 & 0,281 & $-0,274$ & 0,138 & 0,074 \\
7 & 0,216 & $-0,153$ & 0,099 & 0,074 \\
9 & 0,137 & $-0,138$ & 0,062 & 0,074 \\
10 & 0,082 & $-0,070$ & 0,035 & 0,075 \\
12 & 0,083 & $-0,077$ & 0,040 & 0,074 \\
14 & 0,053 & $-0,053$ & 0,028 & 0,075 \\
16 & 0,118 & $-0,131$ & 0,071 & 0,075 \\
\hline
\end{tabular}

A Tabela F.4 para o ensaio Catenária-5 com apenas as amplitudes correspondentes a movimentos fora do plano através da interpolação do sinal do ensaio, a maior amplitude acoplada máxima apresentada foi de 0,443 m. Este valor ocorreu para o modo 5 . Neste modo, a sua frequência de resposta com maior energia foi de 0,149 Hz.

Tabela F.4: Propriedades das amplitudes modais acopladas fora do plano da catenária do ensaio Catenária-5 através da interpolação do sinal do ensaio para a $V_{\max }=1,12 \mathrm{~m} / \mathrm{s}$.

Amplitude

Modo Máxima(m) Mínima(m) Desvio Padrão(m) Freq. máxima (Hz)

\begin{tabular}{lllll}
\hline 1 & 0,230 & $-0,230$ & 0,078 & 0,074 \\
3 & 0,279 & $-0,250$ & 0,095 & 0,149 \\
5 & 0,443 & $-0,440$ & 0,276 & 0,149 \\
8 & 0,112 & $-0,104$ & 0,044 & 0,074 \\
11 & 0,063 & $-0,089$ & 0,035 & 0,149 \\
13 & 0,025 & $-0,038$ & 0,013 & 0,149 \\
15 & 0,032 & $-0,040$ & 0,016 & 0,149 \\
\hline
\end{tabular}




\section{F.2 Catenária-5 - Velocidade de $1,3 \mathrm{~m} / \mathrm{s}$ e $V_{r 1}=8,10$}

Abaixo serão apresentados os gráficos com alguns detalhes da análise referentes ao arranjo Catenária-5 para a velocidade de $1,3 \mathrm{~m} / \mathrm{s}$ e $V_{r 1}=8,10$.
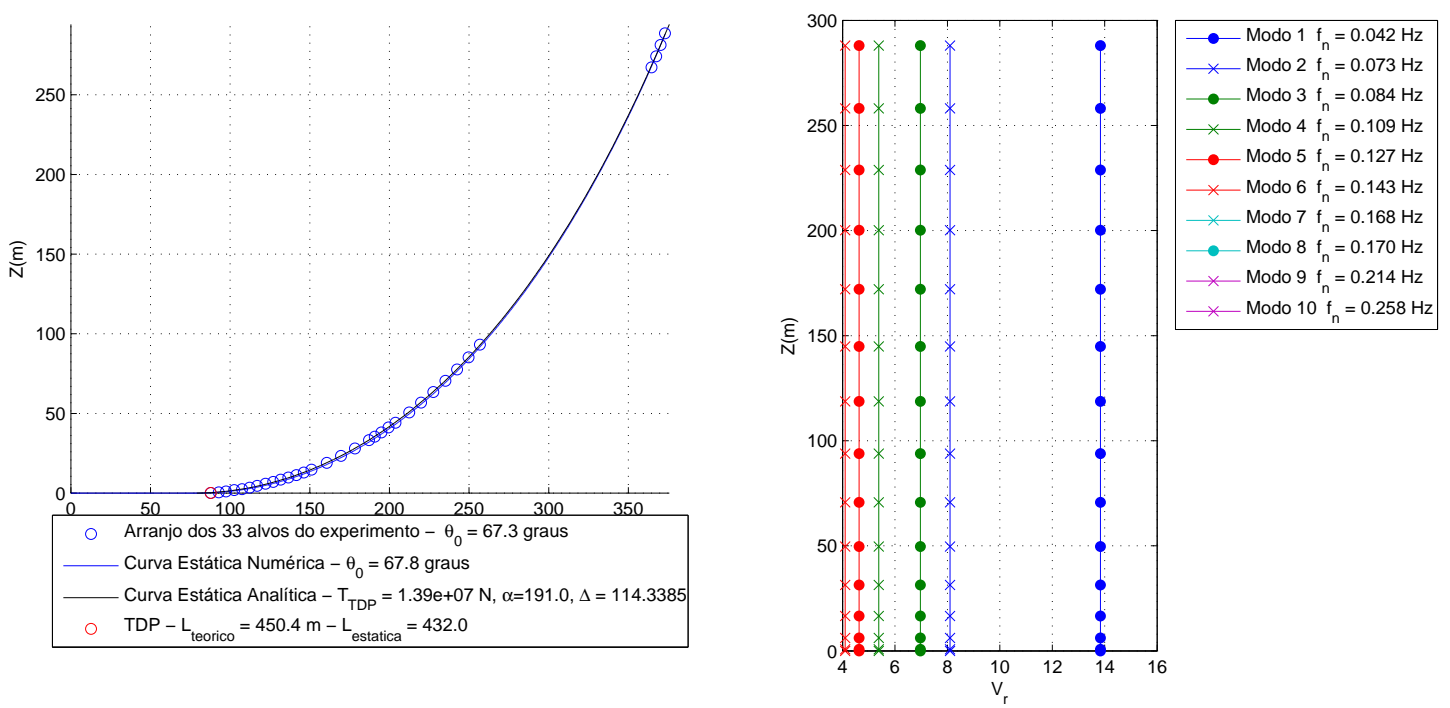

Figura F.6: Variação da velocidade no modelo durante o ensaio para Catenária-5 na $U_{\text {max }}=1,3 \mathrm{~m} / \mathrm{s}$ e $V_{r 1}=8,102$.

Como pode ser visto na Tabela F.5 e nas Figuras de F.7 a F.9, os maiores deslocamentos máximos apresentados na direção X, Y e Z foram de 0,297, 0,919 e 0,995 m, respectivamente. Estes valores ocorreram para os alvos 9, 15 e 29. Nestes alvos, as suas frequências de resposta com maior energia foram de 0,0862 e 0,189 Hz. 

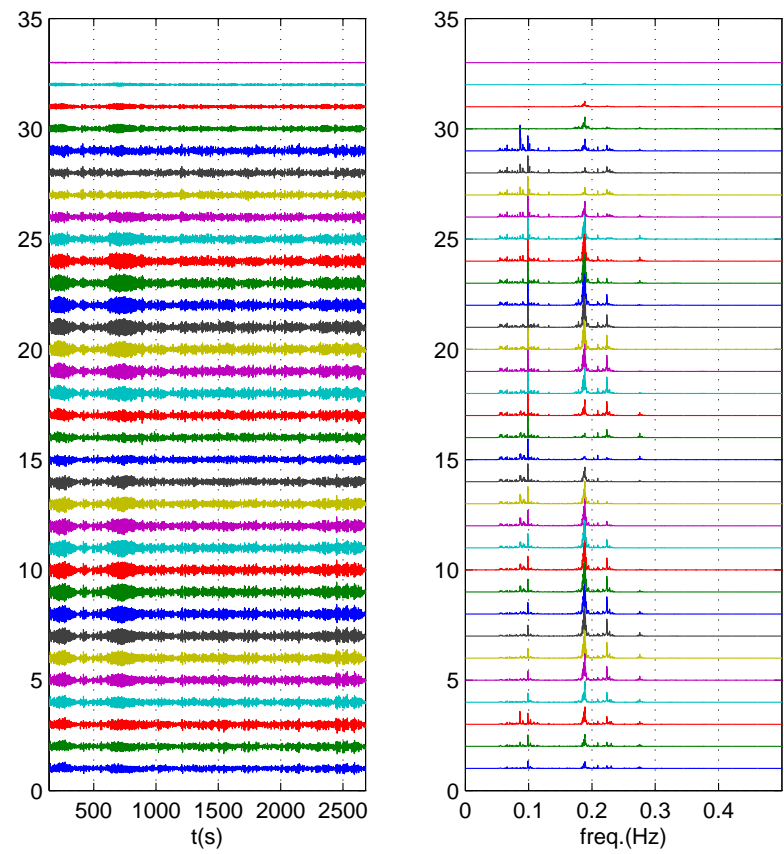

Figura F.7: Série temporal com frequências de resposta para X obtida experimentalmente por alvo para o arranjo de Catenária-5 na $U_{\max }=1,3 \mathrm{~m} / \mathrm{s}$ e $V_{r 1}=8,102$.
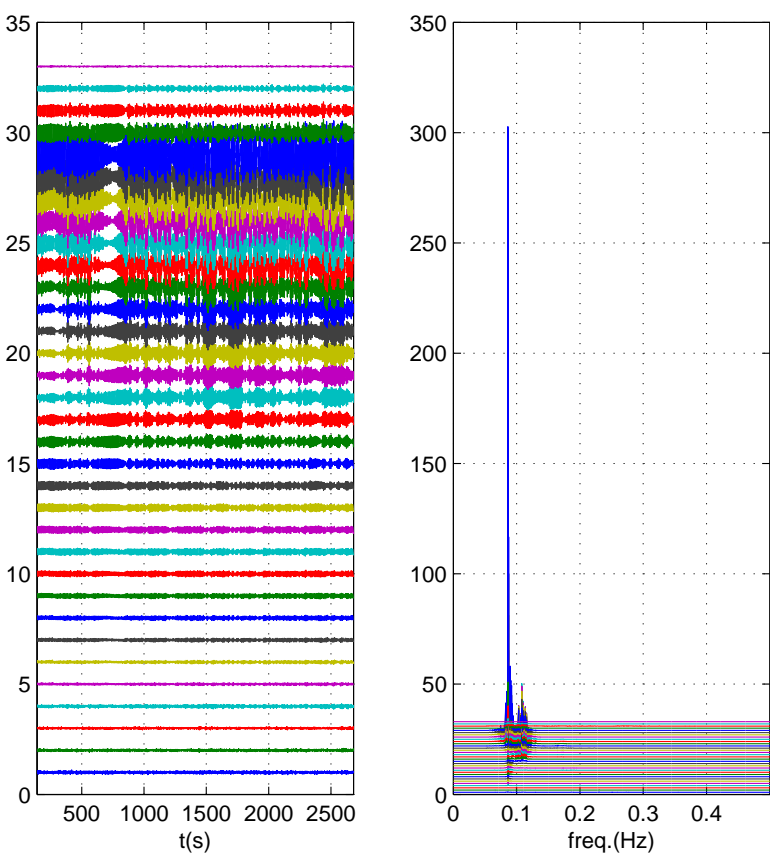

Figura F.8: Série temporal com frequências de resposta para Y obtida experimentalmente por alvo para o arranjo de Catenária-5 na $U_{\max }=1,3 \mathrm{~m} / \mathrm{s}$ e $V_{r 1}=8,102$. 

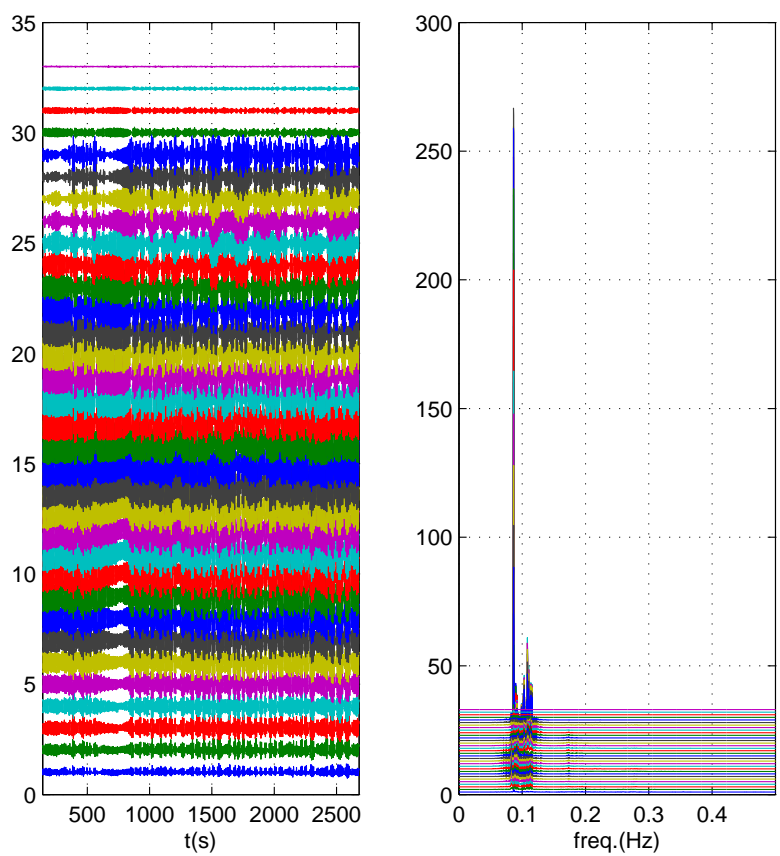

Figura F.9: Série temporal com frequências de resposta para Z obtida experimentalmente por alvo para o arranjo de Catenária-5 na $U_{\max }=1,3 \mathrm{~m} / \mathrm{s}$ e $V_{r 1}=8,102$. 
Tabela F.5: Propriedades da série temporal do ensaio Catenária-5 para a

$$
U_{\max }=1,3 \mathrm{~m} / \mathrm{s} \text {. }
$$

\begin{tabular}{|c|c|c|c|c|c|c|c|c|c|c|c|c|}
\hline \multirow[b]{2}{*}{ ID. Alvo } & \multirow[b]{2}{*}{$\mathrm{X}(\mathrm{m})$} & \multicolumn{2}{|c|}{ Máximo } & \multirow[b]{2}{*}{$\mathrm{X}(\mathrm{m})$} & \multirow{2}{*}{$\begin{array}{l}\text { Mínimo } \\
\mathrm{Y}(\mathrm{m})\end{array}$} & \multirow{2}{*}{$\mathrm{Z}(\mathrm{m})$} & \multicolumn{3}{|c|}{ Desvio padrão } & \multicolumn{3}{|c|}{ Freq. máxima em $\mathrm{Hz}$} \\
\hline & & $\mathrm{Y}(\mathrm{m})$ & $\mathrm{Z}(\mathrm{m})$ & & & & $\mathrm{X}(\mathrm{m})$ & $\mathrm{Y}(\mathrm{m})$ & $\mathrm{Z}(\mathrm{m})$ & $\mathrm{X}$ & $\mathrm{Y}$ & $\mathrm{Z}$ \\
\hline 1 & 0,231 & 0,071 & 0,158 & $-0,173$ & $-0,087$ & $-0,116$ & 0,094 & 0,037 & 0,084 & 0,099 & 0,086 & 0,087 \\
\hline 2 & 0,239 & 0,057 & 0,219 & $-0,182$ & $-0,064$ & $-0,159$ & 0,100 & 0,028 & 0,132 & 0,189 & 0,099 & 0,087 \\
\hline 3 & 0,168 & 0,024 & 0,234 & $-0,162$ & $-0,032$ & $-0,256$ & 0,093 & 0,014 & 0,184 & 0,189 & 0,099 & 0,086 \\
\hline 4 & 0,272 & 0,051 & 0,299 & $-0,197$ & $-0,058$ & $-0,289$ & 0,120 & 0,033 & 0,210 & 0,189 & 0,087 & 0,086 \\
\hline 5 & 0,261 & 0,054 & 0,403 & $-0,192$ & $-0,040$ & $-0,393$ & 0,123 & 0,032 & 0,290 & 0,189 & 0,086 & 0,086 \\
\hline 6 & 0,270 & 0,066 & 0,484 & $-0,197$ & $-0,052$ & $-0,478$ & 0,132 & 0,040 & 0,349 & 0,189 & 0,086 & 0,086 \\
\hline 7 & 0,279 & 0,082 & 0,568 & $-0,209$ & $-0,071$ & $-0,557$ & 0,140 & 0,051 & 0,407 & 0,189 & 0,086 & 0,086 \\
\hline 8 & 0,294 & 0,101 & 0,653 & $-0,228$ & $-0,094$ & $-0,646$ & 0,143 & 0,064 & 0,469 & 0,189 & 0,086 & 0,086 \\
\hline 9 & 0,297 & 0,114 & 0,717 & $-0,249$ & $-0,104$ & $-0,706$ & 0,147 & 0,074 & 0,510 & 0,189 & 0,086 & 0,086 \\
\hline 10 & 0,283 & 0,128 & 0,798 & $-0,250$ & $-0,124$ & $-0,794$ & 0,143 & 0,086 & 0,560 & 0,189 & 0,086 & 0,086 \\
\hline 11 & 0,267 & 0,153 & 0,849 & $-0,269$ & $-0,147$ & $-0,852$ & 0,139 & 0,100 & 0,606 & 0,189 & 0,086 & 0,086 \\
\hline 12 & 0,243 & 0,156 & 0,895 & $-0,260$ & $-0,162$ & $-0,897$ & 0,128 & 0,104 & 0,638 & 0,189 & 0,086 & 0,086 \\
\hline 13 & 0,222 & 0,166 & 0,938 & $-0,258$ & $-0,183$ & $-0,935$ & 0,120 & 0,112 & 0,662 & 0,189 & 0,086 & 0,086 \\
\hline 14 & 0,193 & 0,172 & 0,956 & $-0,240$ & $-0,194$ & $-0,965$ & 0,110 & 0,115 & 0,682 & 0,099 & 0,087 & 0,086 \\
\hline 15 & 0,115 & 0,175 & 0,995 & $-0,190$ & $-0,215$ & $-0,971$ & 0,089 & 0,117 & 0,688 & 0,099 & 0,087 & 0,086 \\
\hline 16 & 0,166 & 0,161 & 0,989 & $-0,138$ & $-0,204$ & $-0,950$ & 0,087 & 0,104 & 0,670 & 0,099 & 0,087 & 0,086 \\
\hline 17 & 0,209 & 0,141 & 0,942 & $-0,138$ & $-0,172$ & $-0,887$ & 0,097 & 0,084 & 0,631 & 0,099 & 0,108 & 0,087 \\
\hline 18 & 0,235 & 0,115 & 0,850 & $-0,190$ & $-0,109$ & $-0,794$ & 0,112 & 0,056 & 0,570 & 0,189 & 0,108 & 0,087 \\
\hline 19 & 0,238 & 0,103 & 0,806 & $-0,208$ & $-0,077$ & $-0,753$ & 0,117 & 0,051 & 0,539 & 0,189 & 0,108 & 0,087 \\
\hline 20 & 0,242 & 0,108 & 0,738 & $-0,228$ & $-0,109$ & $-0,695$ & 0,123 & 0,059 & 0,498 & 0,189 & 0,108 & 0,087 \\
\hline 21 & 0,243 & 0,116 & 0,646 & $-0,238$ & $-0,165$ & $-0,611$ & 0,127 & 0,085 & 0,433 & 0,189 & 0,108 & 0,087 \\
\hline 22 & 0,242 & 0,130 & 0,593 & $-0,251$ & $-0,223$ & $-0,596$ & 0,131 & 0,118 & 0,401 & 0,189 & 0,108 & 0,087 \\
\hline 23 & 0,213 & 0,236 & 0,471 & $-0,247$ & $-0,352$ & $-0,516$ & 0,126 & 0,194 & 0,311 & 0,189 & 0,086 & 0,087 \\
\hline 24 & 0,195 & 0,351 & 0,390 & $-0,203$ & $-0,457$ & $-0,445$ & 0,109 & 0,265 & 0,240 & 0,189 & 0,086 & 0,108 \\
\hline 25 & 0,169 & 0,473 & 0,288 & $-0,165$ & $-0,552$ & $-0,329$ & 0,089 & 0,341 & 0,161 & 0,189 & 0,086 & 0,108 \\
\hline 26 & 0,124 & 0,596 & 0,188 & $-0,145$ & $-0,644$ & $-0,198$ & 0,070 & 0,423 & 0,102 & 0,099 & 0,086 & 0,108 \\
\hline 27 & 0,089 & 0,698 & 0,157 & $-0,148$ & $-0,717$ & $-0,161$ & 0,067 & 0,494 & 0,102 & 0,099 & 0,086 & 0,108 \\
\hline 28 & 0,155 & 0,823 & 0,223 & $-0,163$ & $-0,807$ & $-0,232$ & 0,085 & 0,573 & 0,145 & 0,099 & 0,086 & 0,086 \\
\hline 29 & 0,217 & 0,919 & 0,280 & $-0,176$ & $-0,876$ & $-0,298$ & 0,114 & 0,635 & 0,194 & 0,087 & 0,086 & 0,086 \\
\hline 30 & 0,147 & 0,341 & 0,187 & $-0,135$ & $-0,380$ & $-0,163$ & 0,080 & 0,254 & 0,122 & 0,189 & 0,087 & 0,087 \\
\hline 31 & 0,101 & 0,226 & 0,128 & $-0,092$ & $-0,253$ & $-0,113$ & 0,055 & 0,169 & 0,084 & 0,189 & 0,087 & 0,087 \\
\hline 32 & 0,055 & 0,117 & 0,077 & $-0,049$ & $-0,124$ & $-0,055$ & 0,029 & 0,086 & 0,045 & 0,189 & 0,087 & 0,087 \\
\hline 33 & 0,011 & 0,025 & 0,020 & $-0,009$ & $-0,023$ & $-0,016$ & 0,006 & 0,017 & 0,012 & 0,189 & 0,087 & 0,087 \\
\hline
\end{tabular}

Considerando agora a decomposição modal, na Tabela F.6 através da interpolação do sinal do ensaio, correspondente a uma velocade reduzida do primeiro modo $V_{r 1}=8.10$, as maiores amplitudes máximas apresentadas na direção X, Y e Z foram de 0,422, 1,233 e 0,736 m, respectivamente. Estes valores ocorreram para os modos 2, 3 e 4, Nestes modos, as suas frequências de resposta com maior energia foram de 0,0862, 0,0866 e 0,108 Hz. 

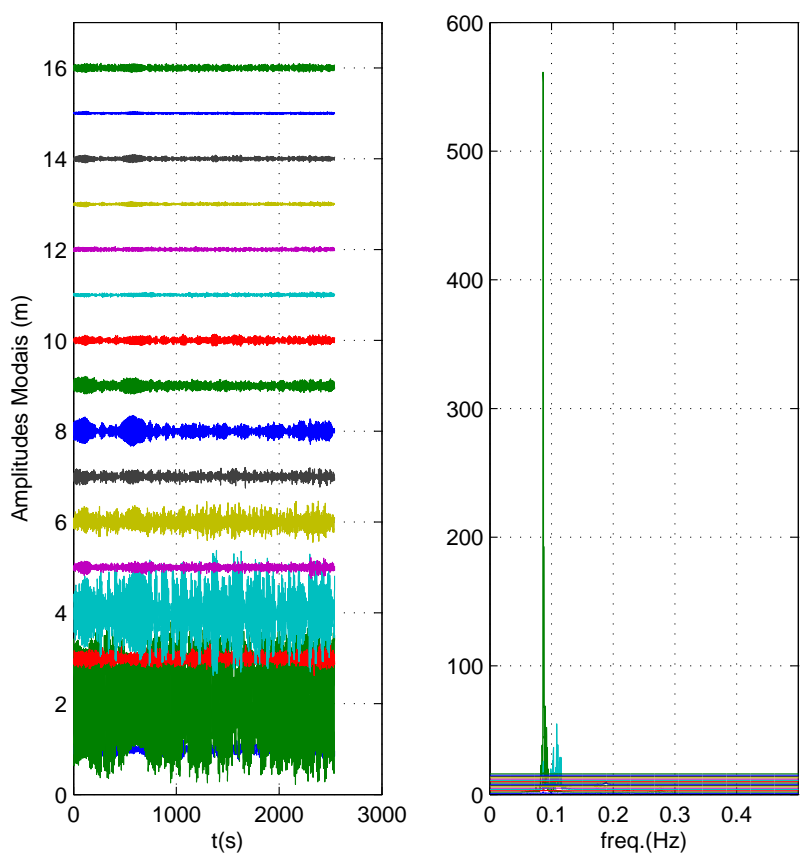

Figura F.10: Variação da amplitude modal acoplada ao longo do tempo através da interpolação do sinal do ensaio para Catenária-5 na $U_{\max }=1,3 \mathrm{~m} / \mathrm{s}$ e $V_{r 1}=8,102$.

Tabela F.6: Propriedades das amplitudes modais do ensaio Catenária-5 através da interpolação do sinal do ensaio para a $V_{\max }=1,3 \mathrm{~m} / \mathrm{s}$.

\begin{tabular}{lccccccccccccc}
\hline \multicolumn{1}{c}{ Máximo } & \multicolumn{1}{c}{ Mínimo } & \multicolumn{3}{c}{ Desvio padrão } & \multicolumn{2}{c}{ Freq. máxima em Hz } \\
\multicolumn{1}{c}{ Modo } & $\mathrm{X}(\mathrm{m})$ & $\mathrm{Y}(\mathrm{m})$ & $\mathrm{Z}(\mathrm{m})$ & $\mathrm{X}(\mathrm{m})$ & $\mathrm{Y}(\mathrm{m})$ & $\mathrm{Z}(\mathrm{m})$ & $\mathrm{X}(\mathrm{m})$ & $\mathrm{Y}(\mathrm{m})$ & $\mathrm{Z}(\mathrm{m})$ & $\mathrm{X}$ & $\mathrm{Y}$ & $\mathrm{Z}$ \\
& & & & & & & & & & & & \\
\hline 1 & 0,353 & 0,000 & 0,000 & $-0,297$ & $-0,000$ & $-0,000$ & 0,076 & 0,000 & 0,000 & 0,087 & 0,086 & 0,086 \\
2 & 0,000 & 1,233 & 0,688 & $-0,000$ & $-1,196$ & $-0,618$ & 0,000 & 0,657 & 0,305 & 0,099 & 0,086 & 0,086 \\
3 & 0,422 & 0,000 & 0,000 & $-0,382$ & $-0,000$ & $-0,000$ & 0,081 & 0,000 & 0,000 & 0,087 & 0,086 & 0,086 \\
4 & 0,000 & 0,653 & 0,736 & $-0,000$ & $-0,636$ & $-0,749$ & 0,000 & 0,258 & 0,283 & 0,189 & 0,108 & 0,108 \\
5 & 0,215 & 0,000 & 0,000 & $-0,247$ & $-0,000$ & $-0,000$ & 0,049 & 0,000 & 0,000 & 0,189 & 0,087 & 0,086 \\
6 & 0,000 & 0,554 & 0,566 & $-0,000$ & $-0,574$ & $-0,508$ & 0,000 & 0,238 & 0,270 & 0,189 & 0,087 & 0,087 \\
7 & 0,000 & 0,148 & 0,185 & $-0,000$ & $-0,147$ & $-0,192$ & 0,000 & 0,045 & 0,053 & 0,189 & 0,103 & 0,108 \\
8 & 0,351 & 0,002 & 0,002 & $-0,334$ & $-0,002$ & $-0,002$ & 0,105 & 0,000 & 0,001 & 0,189 & 0,103 & 0,108 \\
9 & 0,000 & 0,143 & 0,085 & $-0,000$ & $-0,133$ & $-0,082$ & 0,000 & 0,051 & 0,024 & 0,224 & 0,087 & 0,086 \\
10 & 0,000 & 0,102 & 0,158 & $-0,000$ & $-0,104$ & $-0,135$ & 0,000 & 0,054 & 0,055 & 0,276 & 0,087 & 0,086 \\
11 & 0,071 & 0,000 & 0,000 & $-0,064$ & $-0,000$ & $-0,000$ & 0,018 & 0,000 & 0,000 & 0,087 & 0,087 & 0,086 \\
12 & 0,001 & 0,075 & 0,087 & $-0,001$ & $-0,075$ & $-0,072$ & 0,000 & 0,024 & 0,030 & 0,189 & 0,108 & 0,086 \\
13 & 0,063 & 0,000 & 0,000 & $-0,059$ & $-0,000$ & $-0,000$ & 0,016 & 0,000 & 0,000 & 0,189 & 0,108 & 0,086 \\
14 & 0,000 & 0,205 & 0,218 & $-0,000$ & $-0,211$ & $-0,219$ & 0,000 & 0,095 & 0,087 & 0,224 & 0,086 & 0,086 \\
15 & 0,044 & 0,000 & 0,000 & $-0,032$ & $-0,000$ & $-0,000$ & 0,010 & 0,000 & 0,000 & 0,224 & 0,086 & 0,086 \\
16 & 0,000 & 0,597 & 0,558 & $-0,000$ & $-0,594$ & $-0,601$ & 0,000 & 0,257 & 0,228 & 0,189 & 0,086 & 0,086 \\
\hline
\end{tabular}

A Tabela F.7 apresenta para o ensaio Catenária-5 apenas os movimentos referentes a 
deslocamento no plano da catenária através da interpolação do sinal do ensaio, a maior amplitude acoplada máxima foi de 1,901 m. Este valor ocorreu para o modo 2. Neste modo, a sua frequência de resposta com maior energia foi de 0,086 Hz.

Tabela F.7: Propriedades das amplitudes modais acopladas no plano da catenária do ensaio Catenária-5 através da interpolação do sinal do ensaio para a $V_{\max }=1,3 \mathrm{~m} / \mathrm{s}$.

\section{Amplitude}

\section{Modo Máxima(m) Mínima(m) Desvio Padrão(m) Freq. máxima (Hz)}

\begin{tabular}{lllll}
\hline 2 & 1,901 & $-1,776$ & 0,953 & 0,086 \\
4 & 1,374 & $-1,373$ & 0,534 & 0,108 \\
6 & 0,458 & $-0,442$ & 0,142 & 0,086 \\
7 & 0,202 & $-0,250$ & 0,063 & 0,107 \\
9 & 0,210 & $-0,181$ & 0,064 & 0,086 \\
10 & 0,134 & $-0,126$ & 0,047 & 0,108 \\
12 & 0,061 & $-0,056$ & 0,022 & 0,086 \\
14 & 0,087 & $-0,095$ & 0,028 & 0,087 \\
16 & 0,098 & $-0,099$ & 0,043 & 0,087 \\
\hline
\end{tabular}

A Tabela F.8 para o ensaio Catenária-5 com apenas as amplitudes correspondentes a movimentos fora do plano através da interpolação do sinal do ensaio, a maior amplitude acoplada máxima apresentada foi de 0,418 m. Este valor ocorreu para o modo 3. Neste modo, a sua frequência de resposta com maior energia foi de 0,087 Hz.

Tabela F.8: Propriedades das amplitudes modais acopladas fora do plano da catenária do ensaio Catenária-5 através da interpolação do sinal do ensaio para a $V_{\max }=1,3 \mathrm{~m} / \mathrm{s}$.

Amplitude

Modo Máxima(m) Mínima(m) Desvio Padrão(m) Freq. máxima (Hz)

\begin{tabular}{lllll}
\hline 1 & 0,350 & $-0,295$ & 0,075 & 0,087 \\
3 & 0,418 & $-0,378$ & 0,080 & 0,087 \\
5 & 0,213 & $-0,245$ & 0,048 & 0,189 \\
8 & 0,347 & $-0,330$ & 0,104 & 0,189 \\
11 & 0,071 & $-0,063$ & 0,018 & 0,087 \\
13 & 0,062 & $-0,058$ & 0,016 & 0,189 \\
15 & 0,043 & $-0,032$ & 0,010 & 0,224 \\
\hline
\end{tabular}




\section{F.3 Catenária-5 - Velocidade de $1,4 \mathrm{~m} / \mathrm{s}$ e $V_{r 1}=8,67$}

Abaixo serão apresentados os gráficos com alguns detalhes da análise referentes ao arranjo Catenária-5 para a velocidade de $1,4 \mathrm{~m} / \mathrm{s}$ e $V_{r 1}=8,67$.
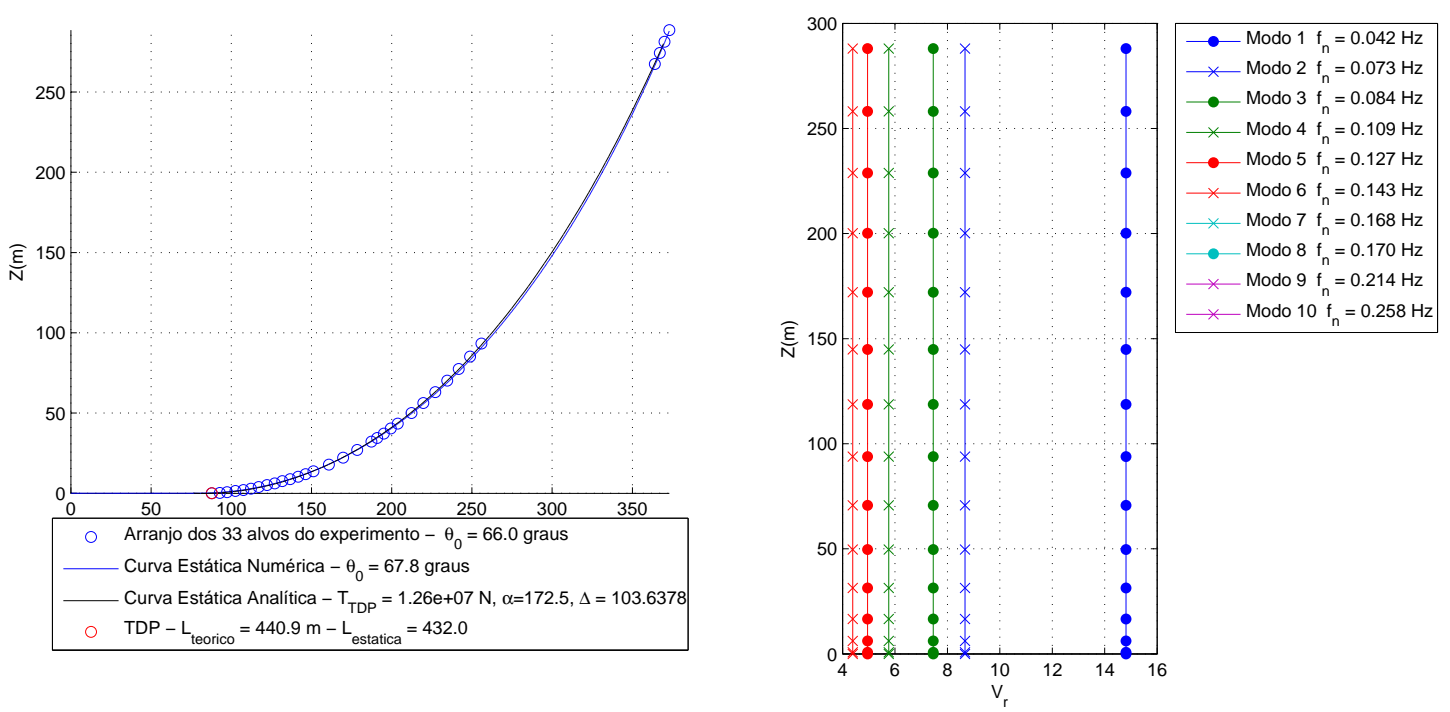

Figura F.11: Variação da velocidade no modelo durante o ensaio para Catenária-5 na $U_{\max }=1,4 \mathrm{~m} / \mathrm{s}$ e $V_{r 1}=8,673$.

Como pode ser visto na Tabela F.9 e nas Figuras de F.12 a F.14, os maiores deslocamentos máximos apresentados na direção X, Y e Z foram de 0,319, 1,097 e 1,113 $\mathrm{m}$, respectivamente. Estes valores ocorreram para os alvos 18 e 27. Nestes alvos, as suas frequências de resposta com maior energia foram de 0,114 e 0,229 Hz. 

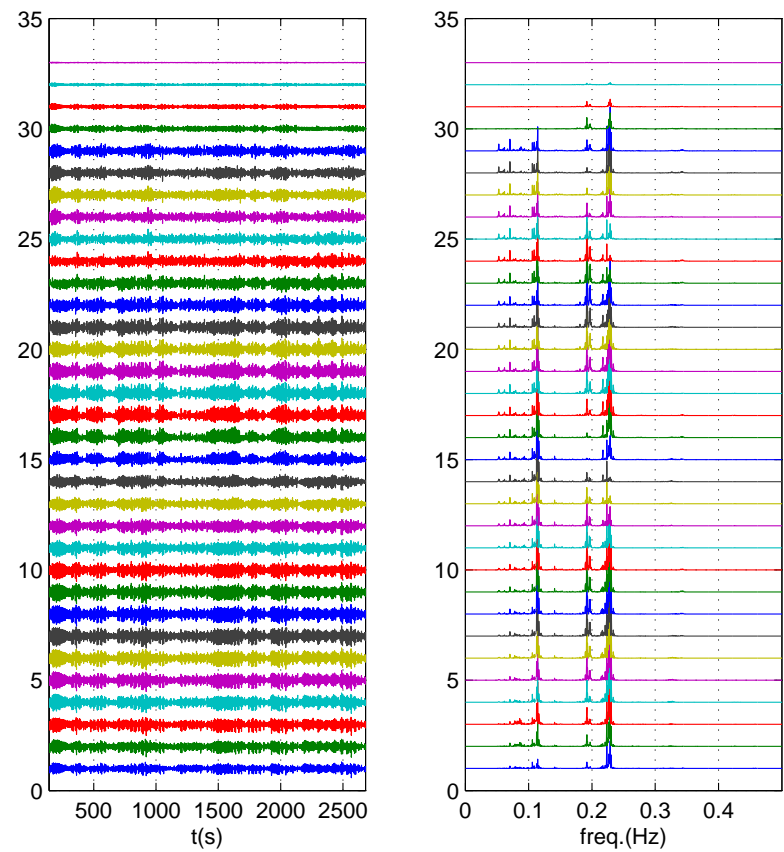

Figura F.12: Série temporal com frequências de resposta para $\mathrm{X}$ obtida experimentalmente por alvo para o arranjo de Catenária-5 na $U_{\max }=1,4 \mathrm{~m} / \mathrm{s}$ e $V_{r 1}=8,673$.
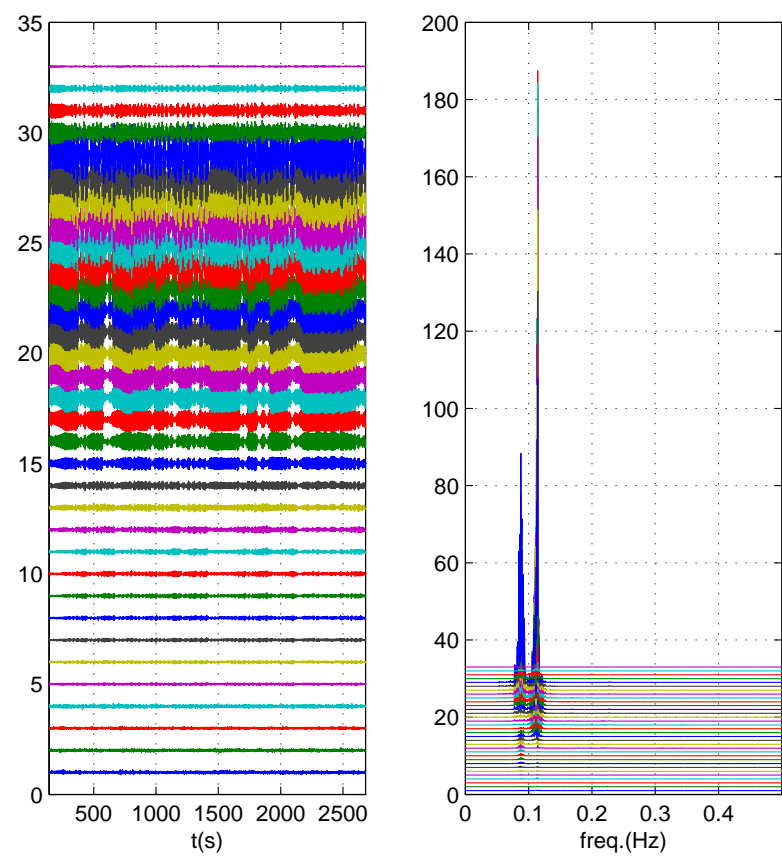

Figura F.13: Série temporal com frequências de resposta para Y obtida experimentalmente por alvo para o arranjo de Catenária-5 na $U_{\max }=1,4 \mathrm{~m} / \mathrm{s}$ e $V_{r 1}=8,673$. 

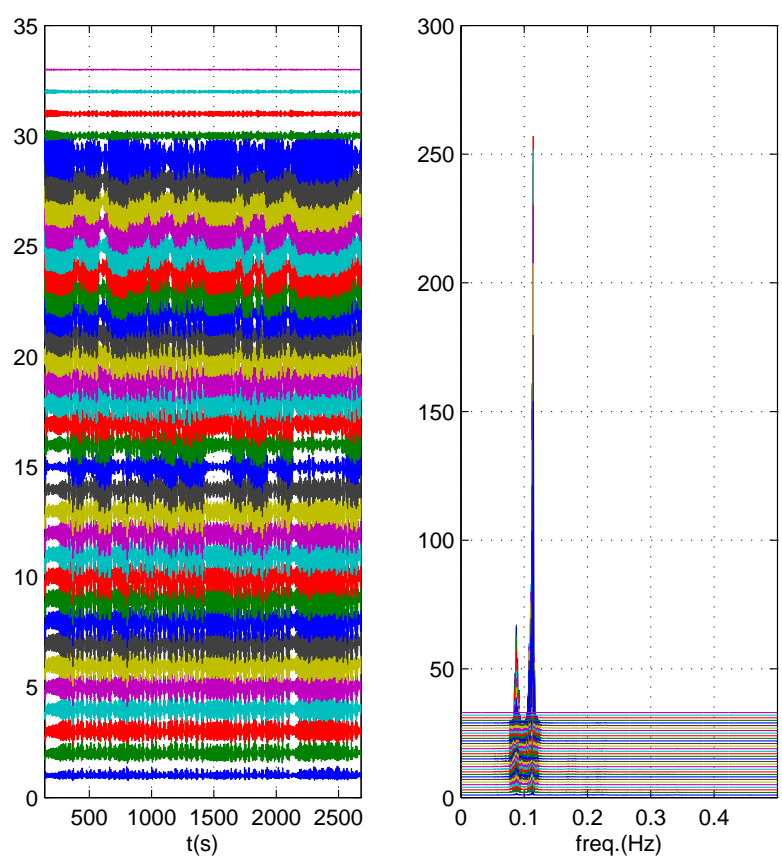

Figura F.14: Série temporal com frequências de resposta para Z obtida experimentalmente por alvo para o arranjo de Catenária-5 na $U_{\max }=1,4 \mathrm{~m} / \mathrm{s}$ e $V_{r 1}=8,673$. 
Tabela F.9: Propriedades da série temporal do ensaio Catenária-5 para a

$$
U_{\max }=1,4 \mathrm{~m} / \mathrm{s} \text {. }
$$

\begin{tabular}{|c|c|c|c|c|c|c|c|c|c|c|c|c|}
\hline \multirow[b]{2}{*}{ ID. Alvo } & \multirow[b]{2}{*}{$\mathrm{X}(\mathrm{m})$} & \multicolumn{3}{|c|}{ Máximo } & \multicolumn{2}{|l|}{ Mínimo } & \multicolumn{3}{|c|}{ Desvio padrão } & \multicolumn{3}{|c|}{ Freq. máxima em $\mathrm{Hz}$} \\
\hline & & $\mathrm{Y}(\mathrm{m})$ & $\mathrm{Z}(\mathrm{m})$ & $\mathrm{X}(\mathrm{m})$ & $\mathrm{Y}(\mathrm{m})$ & $\mathrm{Z}(\mathrm{m})$ & $\mathrm{X}(\mathrm{m})$ & $\mathrm{Y}(\mathrm{m})$ & $\mathrm{Z}(\mathrm{m})$ & $\mathrm{X}$ & $\mathrm{Y}$ & $\mathrm{Z}$ \\
\hline 1 & 0,147 & 0,047 & 0,175 & $-0,200$ & $-0,050$ & $-0,126$ & 0,091 & 0,025 & 0,084 & 0,224 & 0,114 & 0,114 \\
\hline 2 & 0,136 & 0,055 & 0,359 & $-0,270$ & $-0,046$ & $-0,259$ & 0,113 & 0,027 & 0,182 & 0,229 & 0,224 & 0,114 \\
\hline 3 & 0,224 & 0,037 & 0,409 & $-0,257$ & $-0,050$ & $-0,398$ & 0,129 & 0,021 & 0,234 & 0,229 & 0,114 & 0,114 \\
\hline 4 & 0,217 & 0,060 & 0,389 & $-0,222$ & $-0,065$ & $-0,438$ & 0,122 & 0,037 & 0,238 & 0,229 & 0,114 & 0,114 \\
\hline 5 & 0,209 & 0,047 & 0,502 & $-0,234$ & $-0,044$ & $-0,544$ & 0,128 & 0,025 & 0,315 & 0,229 & 0,114 & 0,114 \\
\hline 6 & 0,231 & 0,056 & 0,559 & $-0,231$ & $-0,046$ & $-0,633$ & 0,134 & 0,029 & 0,360 & 0,229 & 0,114 & 0,114 \\
\hline 7 & 0,246 & 0,070 & 0,606 & $-0,237$ & $-0,050$ & $-0,706$ & 0,139 & 0,034 & 0,397 & 0,229 & 0,088 & 0,114 \\
\hline 8 & 0,241 & 0,080 & 0,639 & $-0,233$ & $-0,053$ & $-0,786$ & 0,136 & 0,038 & 0,430 & 0,229 & 0,088 & 0,114 \\
\hline 9 & 0,230 & 0,089 & 0,648 & $-0,225$ & $-0,055$ & $-0,809$ & 0,132 & 0,039 & 0,438 & 0,229 & 0,088 & 0,114 \\
\hline 10 & 0,199 & 0,097 & 0,660 & $-0,209$ & $-0,065$ & $-0,838$ & 0,121 & 0,042 & 0,446 & 0,114 & 0,088 & 0,114 \\
\hline 11 & 0,204 & 0,085 & 0,639 & $-0,201$ & $-0,061$ & $-0,850$ & 0,110 & 0,038 & 0,441 & 0,114 & 0,088 & 0,114 \\
\hline 12 & 0,177 & 0,079 & 0,620 & $-0,191$ & $-0,065$ & $-0,838$ & 0,098 & 0,040 & 0,427 & 0,114 & 0,088 & 0,088 \\
\hline 13 & 0,152 & 0,088 & 0,588 & $-0,186$ & $-0,073$ & $-0,799$ & 0,088 & 0,043 & 0,410 & 0,114 & 0,114 & 0,088 \\
\hline 14 & 0,148 & 0,113 & 0,557 & $-0,186$ & $-0,087$ & $-0,758$ & 0,083 & 0,051 & 0,387 & 0,114 & 0,114 & 0,088 \\
\hline 15 & 0,189 & 0,181 & 0,448 & $-0,182$ & $-0,128$ & $-0,581$ & 0,089 & 0,089 & 0,321 & 0,114 & 0,114 & 0,088 \\
\hline 16 & 0,260 & 0,264 & 0,415 & $-0,210$ & $-0,182$ & $-0,454$ & 0,111 & 0,146 & 0,280 & 0,114 & 0,114 & 0,088 \\
\hline 17 & 0,293 & 0,348 & 0,436 & $-0,235$ & $-0,294$ & $-0,584$ & 0,126 & 0,211 & 0,279 & 0,229 & 0,114 & 0,114 \\
\hline 18 & 0,319 & 0,439 & 0,486 & $-0,251$ & $-0,452$ & $-0,723$ & 0,138 & 0,291 & 0,327 & 0,229 & 0,114 & 0,114 \\
\hline 19 & 0,301 & 0,476 & 0,523 & $-0,241$ & $-0,518$ & $-0,788$ & 0,132 & 0,326 & 0,361 & 0,229 & 0,114 & 0,114 \\
\hline 20 & 0,281 & 0,521 & 0,572 & $-0,227$ & $-0,604$ & $-0,840$ & 0,127 & 0,372 & 0,400 & 0,229 & 0,114 & 0,114 \\
\hline 21 & 0,267 & 0,583 & 0,626 & $-0,210$ & $-0,696$ & $-0,900$ & 0,120 & 0,421 & 0,441 & 0,114 & 0,114 & 0,114 \\
\hline 22 & 0,241 & 0,659 & 0,717 & $-0,196$ & $-0,808$ & $-0,996$ & 0,108 & 0,477 & 0,518 & 0,192 & 0,114 & 0,114 \\
\hline 23 & 0,161 & 0,814 & 0,874 & $-0,138$ & $-0,962$ & $-1,077$ & 0,091 & 0,572 & 0,618 & 0,114 & 0,114 & 0,114 \\
\hline 24 & 0,198 & 0,930 & 0,975 & $-0,105$ & $-1,094$ & $-1,113$ & 0,087 & 0,644 & 0,689 & 0,114 & 0,114 & 0,114 \\
\hline 25 & 0,216 & 1,029 & 1,055 & $-0,173$ & $-1,185$ & $-1,107$ & 0,099 & 0,694 & 0,736 & 0,114 & 0,114 & 0,114 \\
\hline 26 & 0,220 & 1,081 & 1,087 & $-0,223$ & $-1,218$ & $-1,047$ & 0,114 & 0,714 & 0,745 & 0,114 & 0,114 & 0,114 \\
\hline 27 & 0,232 & 1,097 & 1,113 & $-0,246$ & $-1,223$ & $-1,052$ & 0,126 & 0,709 & 0,736 & 0,229 & 0,114 & 0,114 \\
\hline 28 & 0,223 & 1,069 & 1,065 & $-0,241$ & $-1,171$ & $-1,010$ & 0,123 & 0,678 & 0,691 & 0,229 & 0,114 & 0,114 \\
\hline 29 & 0,210 & 1,001 & 0,976 & $-0,201$ & $-1,067$ & $-0,933$ & 0,110 & 0,619 & 0,627 & 0,229 & 0,114 & 0,114 \\
\hline 30 & 0,125 & 0,424 & 0,231 & $-0,141$ & $-0,508$ & $-0,188$ & 0,069 & 0,263 & 0,116 & 0,229 & 0,114 & 0,114 \\
\hline 31 & 0,086 & 0,284 & 0,159 & $-0,097$ & $-0,343$ & $-0,130$ & 0,048 & 0,178 & 0,081 & 0,229 & 0,114 & 0,114 \\
\hline 32 & 0,047 & 0,146 & 0,087 & $-0,053$ & $-0,178$ & $-0,075$ & 0,026 & 0,092 & 0,043 & 0,229 & 0,114 & 0,114 \\
\hline 33 & 0,009 & 0,030 & 0,023 & $-0,013$ & $-0,037$ & $-0,024$ & 0,006 & 0,019 & 0,012 & 0,229 & 0,114 & 0,114 \\
\hline
\end{tabular}

Considerando agora a decomposição modal, na Tabela F.10 através da interpolação do sinal do ensaio, correspondente a uma velocade reduzida do primeiro modo $V_{r 1}=8.67$, as maiores amplitudes máximas apresentadas na direção X, Y e Z foram de 0,391, 1,139 e 0,998 m, respectivamente. Estes valores ocorreram para os modos 1, 2 e 4, Nestes modos, as suas frequências de resposta com maior energia foram de 0,0878 e 0,114 Hz. 

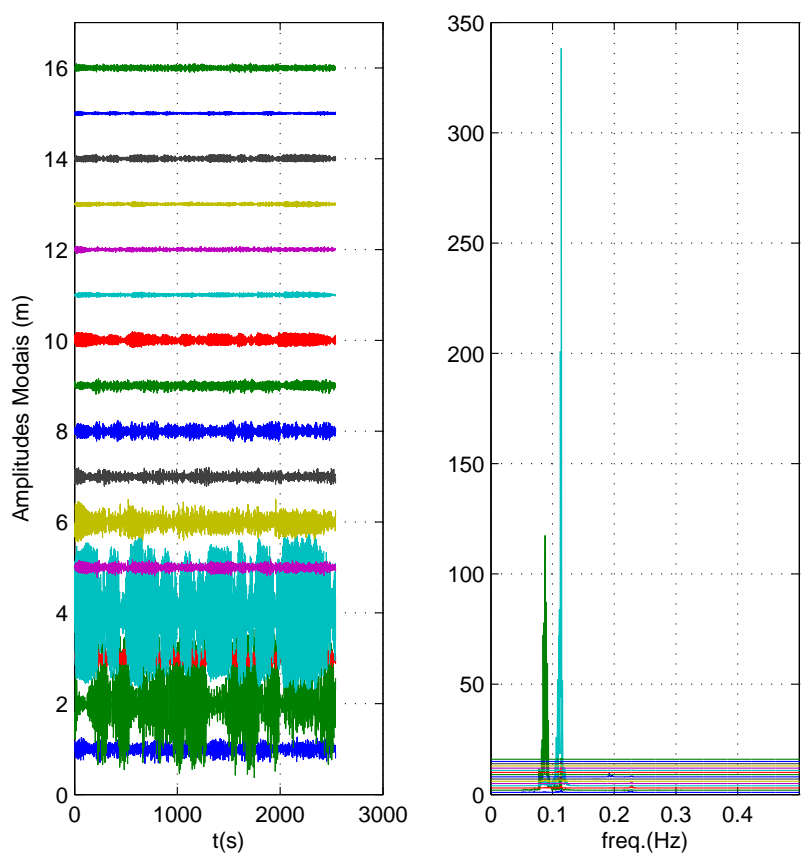

Figura F.15: Variação da amplitude modal acoplada ao longo do tempo através da interpolação do sinal do ensaio para Catenária-5 na $U_{\max }=1,4 \mathrm{~m} / \mathrm{s}$ e $V_{r 1}=8,673$.

Tabela F.10: Propriedades das amplitudes modais do ensaio Catenária-5 através da interpolação do sinal do ensaio para a $V_{\max }=1,4 \mathrm{~m} / \mathrm{s}$.

\begin{tabular}{lccccccccccccc}
\hline \multicolumn{1}{c}{ Máximo } & \multicolumn{1}{c}{ Mínimo } & \multicolumn{3}{c}{ Desvio padrão } & \multicolumn{3}{c}{ Freq. máxima em Hz } \\
\multicolumn{1}{c}{ Modo } & $\mathrm{X}(\mathrm{m})$ & $\mathrm{Y}(\mathrm{m})$ & $\mathrm{Z}(\mathrm{m})$ & $\mathrm{X}(\mathrm{m})$ & $\mathrm{Y}(\mathrm{m})$ & $\mathrm{Z}(\mathrm{m})$ & $\mathrm{X}(\mathrm{m})$ & $\mathrm{Y}(\mathrm{m})$ & $\mathrm{Z}(\mathrm{m})$ & $\mathrm{X}$ & $\mathrm{Y}$ & $\mathrm{Z}$ \\
& & & & & & & & & & & & \\
\hline 1 & 0,391 & 0,000 & 0,000 & $-0,316$ & $-0,000$ & $-0,000$ & 0,094 & 0,000 & 0,000 & 0,114 & 0,088 & 0,088 \\
2 & 0,000 & 1,139 & 0,588 & $-0,000$ & $-1,080$ & $-0,552$ & 0,000 & 0,405 & 0,217 & 0,114 & 0,088 & 0,088 \\
3 & 0,304 & 0,000 & 0,000 & $-0,238$ & $-0,000$ & $-0,000$ & 0,082 & 0,000 & 0,000 & 0,229 & 0,088 & 0,088 \\
4 & 0,000 & 0,807 & 0,998 & $-0,000$ & $-0,789$ & $-0,978$ & 0,000 & 0,398 & 0,486 & 0,114 & 0,114 & 0,114 \\
5 & 0,182 & 0,000 & 0,000 & $-0,225$ & $-0,000$ & $-0,000$ & 0,055 & 0,000 & 0,000 & 0,229 & 0,114 & 0,114 \\
6 & 0,000 & 0,507 & 0,551 & $-0,000$ & $-0,530$ & $-0,535$ & 0,000 & 0,224 & 0,188 & 0,229 & 0,114 & 0,088 \\
7 & 0,000 & 0,185 & 0,217 & $-0,000$ & $-0,189$ & $-0,183$ & 0,000 & 0,058 & 0,075 & 0,192 & 0,114 & 0,114 \\
8 & 0,238 & 0,002 & 0,002 & $-0,239$ & $-0,002$ & $-0,002$ & 0,081 & 0,001 & 0,001 & 0,192 & 0,114 & 0,114 \\
9 & 0,000 & 0,111 & 0,117 & $-0,000$ & $-0,136$ & $-0,099$ & 0,000 & 0,046 & 0,027 & 0,229 & 0,114 & 0,114 \\
10 & 0,000 & 0,101 & 0,178 & $-0,000$ & $-0,098$ & $-0,147$ & 0,000 & 0,035 & 0,064 & 0,229 & 0,088 & 0,114 \\
11 & 0,080 & 0,000 & 0,000 & $-0,068$ & $-0,000$ & $-0,000$ & 0,021 & 0,000 & 0,000 & 0,229 & 0,088 & 0,114 \\
12 & 0,001 & 0,090 & 0,114 & $-0,001$ & $-0,093$ & $-0,099$ & 0,000 & 0,042 & 0,044 & 0,229 & 0,114 & 0,114 \\
13 & 0,065 & 0,000 & 0,000 & $-0,072$ & $-0,000$ & $-0,000$ & 0,019 & 0,000 & 0,000 & 0,229 & 0,114 & 0,114 \\
14 & 0,000 & 0,188 & 0,220 & $-0,000$ & $-0,200$ & $-0,225$ & 0,000 & 0,073 & 0,097 & 0,229 & 0,088 & 0,114 \\
15 & 0,044 & 0,000 & 0,000 & $-0,049$ & $-0,000$ & $-0,000$ & 0,014 & 0,000 & 0,000 & 0,229 & 0,088 & 0,114 \\
16 & 0,000 & 0,568 & 0,588 & $-0,000$ & $-0,594$ & $-0,607$ & 0,000 & 0,236 & 0,244 & 0,192 & 0,114 & 0,114 \\
\hline
\end{tabular}

A Tabela F.11 apresenta para o ensaio Catenária-5 apenas os movimentos referentes 
a deslocamento no plano da catenária através da interpolação do sinal do ensaio, a maior amplitude acoplada máxima foi de 1,755 m. Este valor ocorreu para o modo 4 . Neste modo, a sua frequência de resposta com maior energia foi de $0,114 \mathrm{~Hz}$.

Tabela F.11: Propriedades das amplitudes modais acopladas no plano da catenária do ensaio Catenária-5 através da interpolação do sinal do ensaio para a $V_{\max }=1,4 \mathrm{~m} / \mathrm{s}$.

\section{Amplitude}

\section{Modo Máxima(m) Mínima(m) Desvio Padrão(m) Freq. máxima (Hz)}

\begin{tabular}{lllll}
\hline 2 & 1,703 & $-1,623$ & 0,607 & 0,088 \\
4 & 1,755 & $-1,750$ & 0,875 & 0,114 \\
6 & 0,502 & $-0,433$ & 0,164 & 0,114 \\
7 & 0,203 & $-0,210$ & 0,063 & 0,114 \\
9 & 0,152 & $-0,186$ & 0,057 & 0,114 \\
10 & 0,191 & $-0,161$ & 0,073 & 0,114 \\
12 & 0,068 & $-0,085$ & 0,021 & 0,114 \\
14 & 0,099 & $-0,086$ & 0,041 & 0,114 \\
16 & 0,104 & $-0,103$ & 0,039 & 0,114 \\
\hline
\end{tabular}

A Tabela F.12 para o ensaio Catenária-5 com apenas as amplitudes correspondentes a movimentos fora do plano através da interpolação do sinal do ensaio, a maior amplitude acoplada máxima apresentada foi de $0,388 \mathrm{~m}$. Este valor ocorreu para o modo 1 . Neste modo, a sua frequência de resposta com maior energia foi de 0,114 Hz.

Tabela F.12: Propriedades das amplitudes modais acopladas fora do plano da catenária do ensaio Catenária-5 através da interpolação do sinal do ensaio para a $V_{\max }=1,4 \mathrm{~m} / \mathrm{s}$.

Amplitude

Modo Máxima(m) Mínima(m) Desvio Padrão(m) Freq. máxima (Hz)

\begin{tabular}{lllll}
\hline 1 & 0,388 & $-0,313$ & 0,093 & 0,114 \\
3 & 0,301 & $-0,235$ & 0,081 & 0,229 \\
5 & 0,180 & $-0,223$ & 0,055 & 0,229 \\
8 & 0,236 & $-0,236$ & 0,080 & 0,192 \\
11 & 0,079 & $-0,067$ & 0,021 & 0,229 \\
13 & 0,064 & $-0,071$ & 0,019 & 0,229 \\
15 & 0,044 & $-0,049$ & 0,014 & 0,229 \\
\hline
\end{tabular}




\section{F.4 Catenária-5 - Velocidade de $1,67 \mathrm{~m} / \mathrm{s}$ e $V_{r 1}=$ 10,39}

Abaixo serão apresentados os gráficos com alguns detalhes da análise referentes ao arranjo Catenária-5 para a velocidade de $1,67 \mathrm{~m} / \mathrm{s}$ e $V_{r 1}=10,39$.
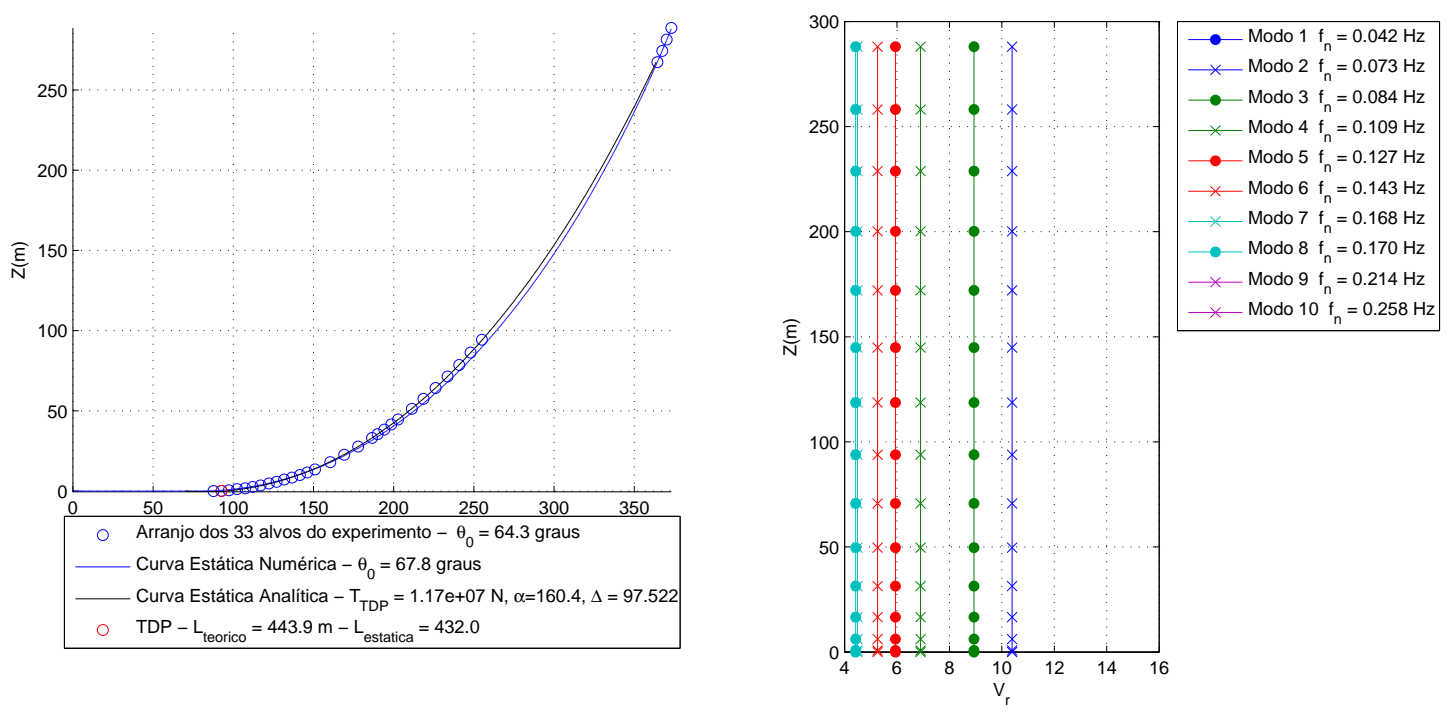

Figura F.16: Variação da velocidade no modelo durante o ensaio para Catenária-5 na $U_{\text {max }}=1,67 \mathrm{~m} / \mathrm{s}$ e $V_{r 1}=10,391$.

Como pode ser visto na Tabela F.13 e nas Figuras de F.17 a F.19, os maiores deslocamentos máximos apresentados na direção X, Y e Z foram de 0,630, 1,278 e 1,603 $\mathrm{m}$, respectivamente. Estes valores ocorreram para os alvos 16, 23 e 25. Nestes alvos, as suas frequências de resposta com maior energia foi de $0,121 \mathrm{~Hz}$. 

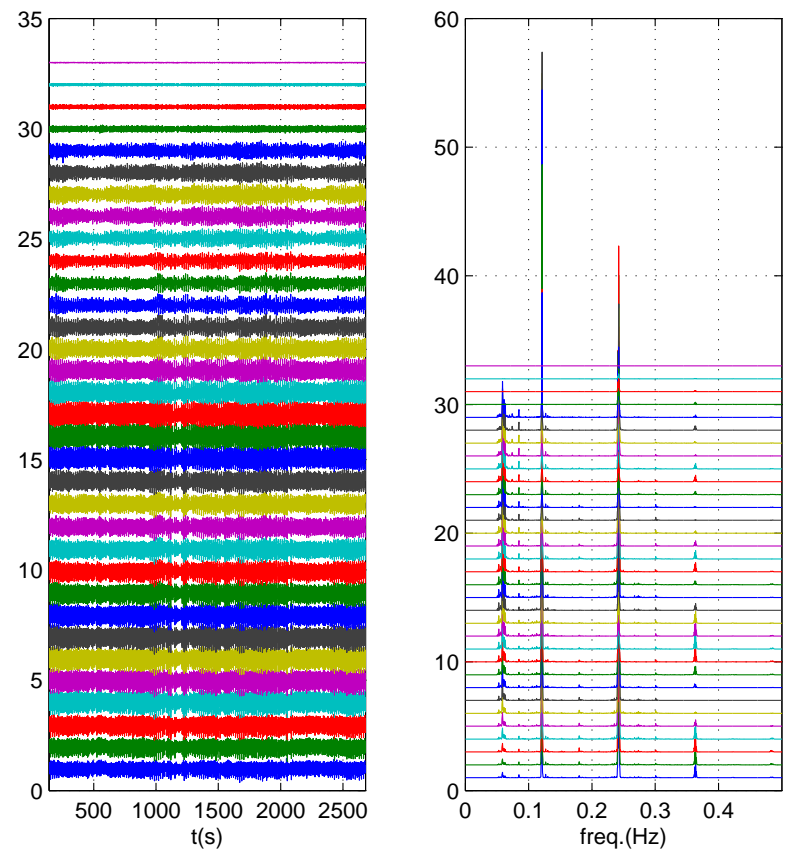

Figura F.17: Série temporal com frequências de resposta para $\mathrm{X}$ obtida experimentalmente por alvo para o arranjo de Catenária-5 na $U_{\max }=1,67 \mathrm{~m} / \mathrm{s}$ e $V_{r 1}=10,391$.
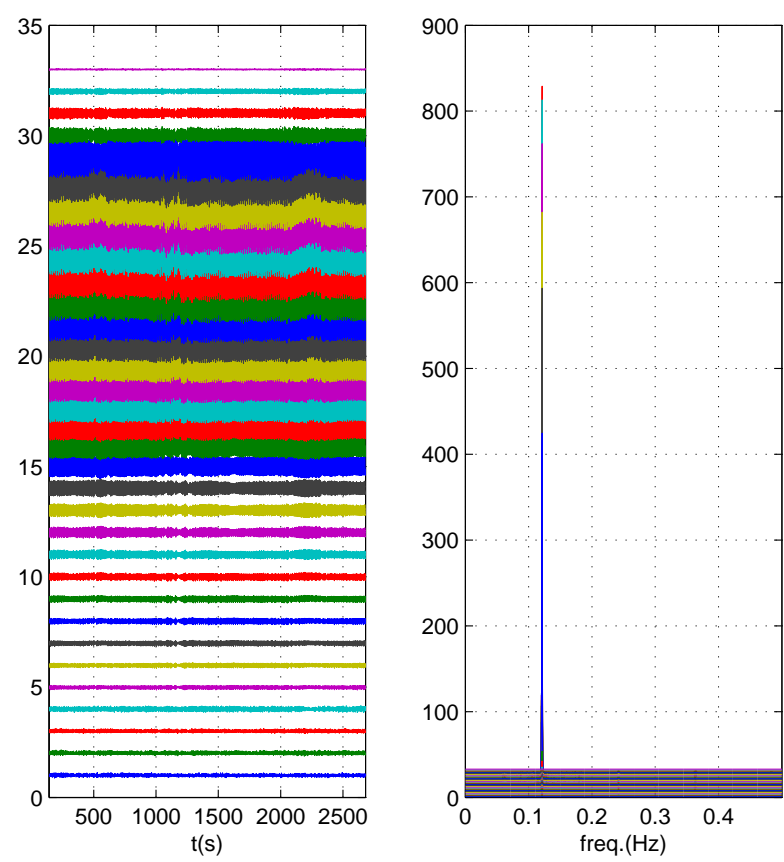

Figura F.18: Série temporal com frequências de resposta para Y obtida experimentalmente por alvo para o arranjo de Catenária-5 na $U_{\max }=1,67 \mathrm{~m} / \mathrm{s}$ e $V_{r 1}=10,391$. 

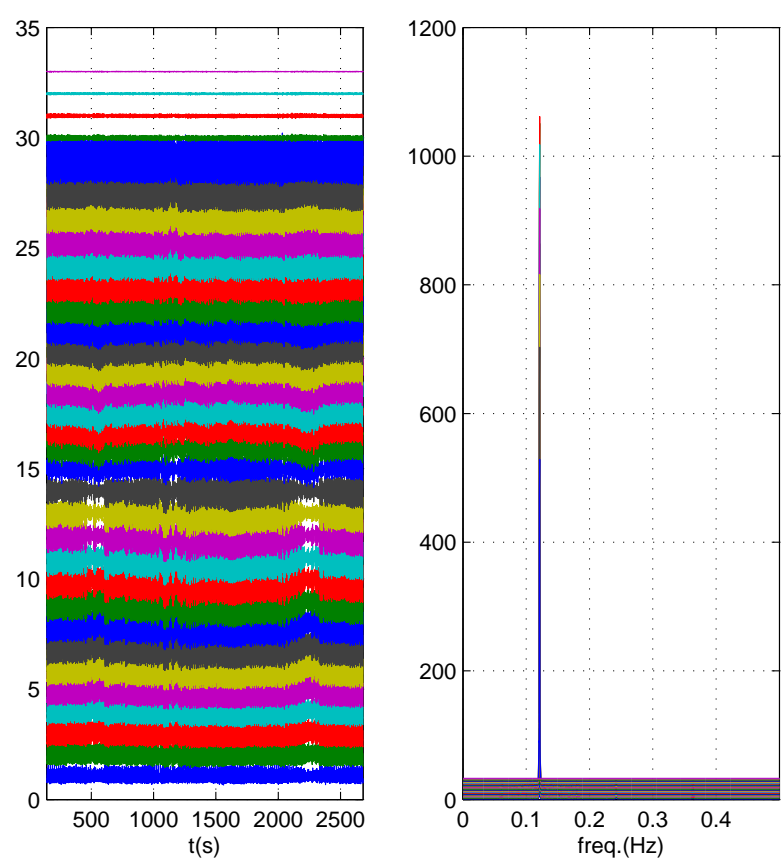

Figura F.19: Série temporal com frequências de resposta para Z obtida experimentalmente por alvo para o arranjo de Catenária-5 na $U_{\max }=1,67 \mathrm{~m} / \mathrm{s}$ e $V_{r 1}=10,391$. 
Tabela F.13: Propriedades da série temporal do ensaio Catenária-5 para a

$$
U_{\max }=1,67 \mathrm{~m} / \mathrm{s} \text {. }
$$

\begin{tabular}{|c|c|c|c|c|c|c|c|c|c|c|c|c|}
\hline \multirow[b]{2}{*}{ ID. Alvo } & \multirow[b]{2}{*}{$\mathrm{X}(\mathrm{m})$} & \multicolumn{2}{|c|}{ Máximo } & \multirow[b]{2}{*}{$\mathrm{X}(\mathrm{m})$} & \multirow{2}{*}{$\begin{array}{l}\text { Mínimo } \\
\mathrm{Y}(\mathrm{m})\end{array}$} & \multirow[b]{2}{*}{$\mathrm{Z}(\mathrm{m})$} & \multicolumn{3}{|c|}{ Desvio padrão } & \multicolumn{3}{|c|}{ Freq. máxima em $\mathrm{Hz}$} \\
\hline & & $\mathrm{Y}(\mathrm{m})$ & $\mathrm{Z}(\mathrm{m})$ & & & & $\mathrm{X}(\mathrm{m})$ & $\mathrm{Y}(\mathrm{m})$ & $\mathrm{Z}(\mathrm{m})$ & $\mathrm{X}$ & $\mathrm{Y}$ & Z \\
\hline 1 & 0,338 & 0,085 & 0,537 & $-0,482$ & $-0,055$ & $-0,250$ & 0,186 & 0,038 & 0,232 & 0,121 & 0,121 & 0,121 \\
\hline 2 & 0,332 & 0,092 & 0,742 & $-0,474$ & $-0,065$ & $-0,417$ & 0,198 & 0,045 & 0,353 & 0,121 & 0,121 & 0,121 \\
\hline 3 & 0,342 & 0,080 & 0,837 & $-0,584$ & $-0,069$ & $-0,606$ & 0,236 & 0,045 & 0,441 & 0,121 & 0,121 & 0,121 \\
\hline 4 & 0,458 & 0,124 & 0,804 & $-0,563$ & $-0,105$ & $-0,616$ & 0,258 & 0,064 & 0,424 & 0,242 & 0,121 & 0,121 \\
\hline 5 & 0,430 & 0,076 & 0,930 & $-0,586$ & $-0,113$ & $-0,759$ & 0,265 & 0,054 & 0,531 & 0,242 & 0,121 & 0,121 \\
\hline 6 & 0,428 & 0,089 & 0,951 & $-0,612$ & $-0,126$ & $-0,847$ & 0,276 & 0,060 & 0,579 & 0,242 & 0,121 & 0,121 \\
\hline 7 & 0,415 & 0,102 & 0,941 & $-0,619$ & $-0,137$ & $-0,893$ & 0,276 & 0,067 & 0,601 & 0,121 & 0,121 & 0,121 \\
\hline 8 & 0,399 & 0,117 & 0,917 & $-0,608$ & $-0,140$ & $-0,899$ & 0,267 & 0,073 & 0,594 & 0,121 & 0,121 & 0,121 \\
\hline 9 & 0,358 & 0,120 & 0,892 & $-0,582$ & $-0,153$ & $-0,921$ & 0,251 & 0,084 & 0,593 & 0,121 & 0,121 & 0,121 \\
\hline 10 & 0,326 & 0,132 & 0,871 & $-0,556$ & $-0,149$ & $-0,916$ & 0,238 & 0,094 & 0,570 & 0,121 & 0,121 & 0,121 \\
\hline 11 & 0,323 & 0,174 & 0,818 & $-0,514$ & $-0,153$ & $-0,887$ & 0,222 & 0,110 & 0,521 & 0,121 & 0,121 & 0,121 \\
\hline 12 & 0,321 & 0,214 & 0,761 & $-0,448$ & $-0,195$ & $-0,815$ & 0,213 & 0,129 & 0,465 & 0,121 & 0,121 & 0,121 \\
\hline 13 & 0,352 & 0,272 & 0,697 & $-0,406$ & $-0,242$ & $-0,732$ & 0,216 & 0,157 & 0,410 & 0,121 & 0,121 & 0,121 \\
\hline 14 & 0,414 & 0,329 & 0,621 & $-0,384$ & $-0,296$ & $-0,616$ & 0,228 & 0,193 & 0,351 & 0,121 & 0,121 & 0,121 \\
\hline 15 & 0,556 & 0,471 & 0,494 & $-0,385$ & $-0,440$ & $-0,494$ & 0,261 & 0,297 & 0,303 & 0,121 & 0,121 & 0,121 \\
\hline 16 & 0,630 & 0,616 & 0,593 & $-0,407$ & $-0,603$ & $-0,704$ & 0,285 & 0,415 & 0,416 & 0,121 & 0,121 & 0,121 \\
\hline 17 & 0,612 & 0,753 & 0,779 & $-0,410$ & $-0,796$ & $-0,893$ & 0,276 & 0,534 & 0,590 & 0,242 & 0,121 & 0,121 \\
\hline 18 & 0,530 & 0,889 & 1,037 & $-0,399$ & $-0,993$ & $-1,020$ & 0,244 & 0,646 & 0,740 & 0,242 & 0,121 & 0,121 \\
\hline 19 & 0,483 & 0,944 & 1,154 & $-0,391$ & $-1,066$ & $-1,094$ & 0,225 & 0,688 & 0,799 & 0,242 & 0,121 & 0,121 \\
\hline 20 & 0,420 & 1,008 & 1,260 & $-0,379$ & $-1,156$ & $-1,165$ & 0,202 & 0,737 & 0,863 & 0,242 & 0,121 & 0,121 \\
\hline 21 & 0,365 & 1,068 & 1,410 & $-0,361$ & $-1,242$ & $-1,243$ & 0,184 & 0,780 & 0,927 & 0,121 & 0,121 & 0,121 \\
\hline 22 & 0,315 & 1,124 & 1,504 & $-0,306$ & $-1,304$ & $-1,307$ & 0,147 & 0,824 & 0,981 & 0,121 & 0,121 & 0,121 \\
\hline 23 & 0,219 & 1,207 & 1,603 & $-0,268$ & $-1,365$ & $-1,397$ & 0,142 & 0,864 & 1,017 & 0,121 & 0,121 & 0,121 \\
\hline 24 & 0,234 & 1,256 & 1,584 & $-0,230$ & $-1,350$ & $-1,440$ & 0,141 & 0,870 & 1,015 & 0,121 & 0,121 & 0,121 \\
\hline 25 & 0,335 & 1,278 & 1,476 & $-0,245$ & $-1,270$ & $-1,458$ & 0,166 & 0,854 & 0,987 & 0,121 & 0,121 & 0,121 \\
\hline 26 & 0,387 & 1,259 & 1,343 & $-0,299$ & $-1,163$ & $-1,419$ & 0,192 & 0,820 & 0,930 & 0,121 & 0,121 & 0,121 \\
\hline 27 & 0,401 & 1,193 & 1,215 & $-0,336$ & $-1,056$ & $-1,333$ & 0,204 & 0,770 & 0,872 & 0,121 & 0,121 & 0,121 \\
\hline 28 & 0,361 & 1,121 & 1,117 & $-0,360$ & $-0,965$ & $-1,250$ & 0,196 & 0,714 & 0,808 & 0,242 & 0,121 & 0,121 \\
\hline 29 & 0,334 & 0,892 & 1,009 & $-0,328$ & $-0,849$ & $-1,055$ & 0,187 & 0,598 & 0,698 & 0,121 & 0,121 & 0,121 \\
\hline 30 & 0,109 & 0,374 & 0,125 & $-0,166$ & $-0,323$ & $-0,137$ & 0,074 & 0,199 & 0,081 & 0,242 & 0,121 & 0,121 \\
\hline 31 & 0,076 & 0,261 & 0,088 & $-0,116$ & $-0,224$ & $-0,100$ & 0,051 & 0,137 & 0,057 & 0,242 & 0,121 & 0,121 \\
\hline 32 & 0,044 & 0,141 & 0,047 & $-0,064$ & $-0,120$ & $-0,049$ & 0,028 & 0,074 & 0,029 & 0,242 & 0,121 & 0,121 \\
\hline 33 & 0,011 & 0,028 & 0,011 & $-0,013$ & $-0,026$ & $-0,017$ & 0,006 & 0,016 & 0,008 & 0,242 & 0,121 & 0,121 \\
\hline
\end{tabular}

Considerando agora a decomposição modal, na Tabela F.14 através da interpolação do sinal do ensaio, correspondente a uma velocade reduzida do primeiro modo $V_{r 1}=10.39$, as maiores amplitudes máximas apresentadas na direção X, Y e Z foram de 0,646, 0,876 e 1,090 m, respectivamente. Estes valores ocorreram para os modos 3 e 4, Nestes modos, as suas frequências de resposta com maior energia foi de $0,121 \mathrm{~Hz}$. 

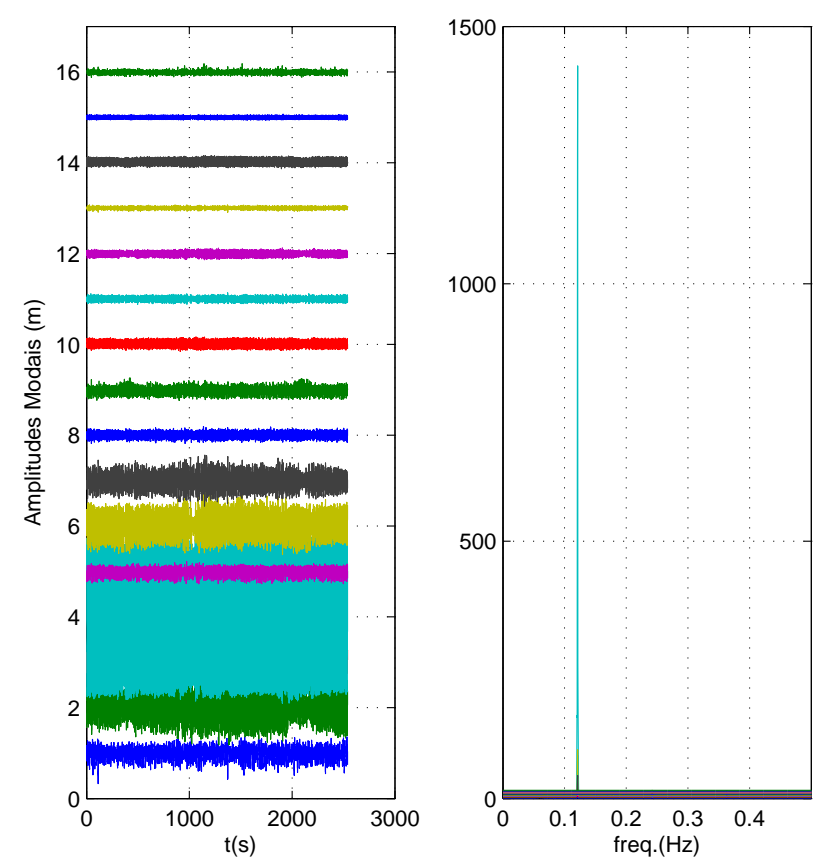

Figura F.20: Variação da amplitude modal acoplada ao longo do tempo através da interpolação do sinal do ensaio para Catenária-5 na $U_{\max }=1,67 \mathrm{~m} / \mathrm{s}$ e $V_{r 1}=10,391$.

Tabela F.14: Propriedades das amplitudes modais do ensaio Catenária-5 através da interpolação do sinal do ensaio para a $V_{\max }=1,67 \mathrm{~m} / \mathrm{s}$.

\begin{tabular}{lcccccccccccccc}
\hline \multicolumn{1}{c}{ Máximo } & \multicolumn{1}{c}{ Mínimo } & \multicolumn{3}{c}{ Desvio padrão } & \multicolumn{3}{c}{ Freq. máxima em Hz } \\
\multicolumn{1}{c}{ Modo } & $\mathrm{X}(\mathrm{m})$ & $\mathrm{Y}(\mathrm{m})$ & $\mathrm{Z}(\mathrm{m})$ & $\mathrm{X}(\mathrm{m})$ & $\mathrm{Y}(\mathrm{m})$ & $\mathrm{Z}(\mathrm{m})$ & $\mathrm{X}(\mathrm{m})$ & $\mathrm{Y}(\mathrm{m})$ & $\mathrm{Z}(\mathrm{m})$ & $\mathrm{X}$ & $\mathrm{Y}$ & $\mathrm{Z}$ \\
& & & & & & & & & & & & \\
\hline 1 & 0,364 & 0,000 & 0,000 & $-0,678$ & $-0,000$ & $-0,000$ & 0,142 & 0,000 & 0,000 & 0,121 & 0,121 & 0,121 \\
2 & 0,000 & 0,432 & 0,327 & $-0,000$ & $-0,496$ & $-0,363$ & 0,000 & 0,169 & 0,155 & 0,121 & 0,121 & 0,121 \\
3 & 0,646 & 0,000 & 0,000 & $-0,433$ & $-0,000$ & $-0,000$ & 0,162 & 0,000 & 0,000 & 0,121 & 0,121 & 0,121 \\
4 & 0,000 & 0,876 & 1,090 & $-0,000$ & $-0,944$ & $-1,100$ & 0,000 & 0,512 & 0,688 & 0,121 & 0,121 & 0,121 \\
5 & 0,214 & 0,000 & 0,000 & $-0,277$ & $-0,000$ & $-0,000$ & 0,089 & 0,000 & 0,000 & 0,121 & 0,121 & 0,121 \\
6 & 0,000 & 0,508 & 0,590 & $-0,000$ & $-0,411$ & $-0,655$ & 0,000 & 0,206 & 0,274 & 0,121 & 0,121 & 0,121 \\
7 & 0,000 & 0,218 & 0,481 & $-0,000$ & $-0,193$ & $-0,409$ & 0,000 & 0,075 & 0,169 & 0,242 & 0,121 & 0,121 \\
8 & 0,192 & 0,002 & 0,004 & $-0,188$ & $-0,002$ & $-0,005$ & 0,069 & 0,001 & 0,002 & 0,242 & 0,121 & 0,121 \\
9 & 0,000 & 0,151 & 0,142 & $-0,000$ & $-0,145$ & $-0,125$ & 0,000 & 0,046 & 0,043 & 0,242 & 0,242 & 0,121 \\
10 & 0,000 & 0,097 & 0,148 & $-0,000$ & $-0,060$ & $-0,122$ & 0,000 & 0,023 & 0,059 & 0,242 & 0,243 & 0,121 \\
11 & 0,134 & 0,000 & 0,000 & $-0,119$ & $-0,000$ & $-0,000$ & 0,047 & 0,000 & 0,000 & 0,242 & 0,243 & 0,121 \\
12 & 0,001 & 0,104 & 0,141 & $-0,001$ & $-0,089$ & $-0,122$ & 0,000 & 0,046 & 0,063 & 0,242 & 0,121 & 0,121 \\
13 & 0,069 & 0,000 & 0,000 & $-0,092$ & $-0,000$ & $-0,000$ & 0,024 & 0,000 & 0,000 & 0,242 & 0,121 & 0,121 \\
14 & 0,000 & 0,167 & 0,236 & $-0,000$ & $-0,166$ & $-0,207$ & 0,000 & 0,079 & 0,123 & 0,364 & 0,121 & 0,121 \\
15 & 0,067 & 0,000 & 0,000 & $-0,062$ & $-0,000$ & $-0,000$ & 0,027 & 0,000 & 0,000 & 0,364 & 0,121 & 0,121 \\
16 & 0,000 & 0,449 & 0,497 & $-0,000$ & $-0,467$ & $-0,537$ & 0,000 & 0,274 & 0,289 & 0,364 & 0,121 & 0,121 \\
\hline
\end{tabular}

A Tabela F.15 apresenta para o ensaio Catenária-5 apenas os movimentos referentes 
a deslocamento no plano da catenária através da interpolação do sinal do ensaio, a maior amplitude acoplada máxima foi de 1,904 m. Este valor ocorreu para o modo 4. Neste modo, a sua frequência de resposta com maior energia foi de $0,121 \mathrm{~Hz}$.

Tabela F.15: Propriedades das amplitudes modais acopladas no plano da catenária do ensaio Catenária-5 através da interpolação do sinal do ensaio para a $V_{\max }=1,67 \mathrm{~m} / \mathrm{s}$.

\section{Amplitude}

\section{Modo Máxima(m) Mínima(m) Desvio Padrão(m) Freq. máxima (Hz)}

\begin{tabular}{lllll}
\hline 2 & 0,662 & $-0,816$ & 0,314 & 0,121 \\
4 & 1,904 & $-1,902$ & 1,183 & 0,121 \\
6 & 0,864 & $-0,627$ & 0,305 & 0,121 \\
7 & 0,559 & $-0,559$ & 0,195 & 0,121 \\
9 & 0,259 & $-0,231$ & 0,080 & 0,121 \\
10 & 0,162 & $-0,155$ & 0,066 & 0,121 \\
12 & 0,122 & $-0,135$ & 0,046 & 0,242 \\
14 & 0,157 & $-0,132$ & 0,055 & 0,121 \\
16 & 0,181 & $-0,123$ & 0,035 & 0,121 \\
\hline
\end{tabular}

A Tabela F.16 para o ensaio Catenária-5 com apenas as amplitudes correspondentes a movimentos fora do plano através da interpolação do sinal do ensaio, a maior amplitude acoplada máxima apresentada foi de 0,639 m. Este valor ocorreu para o modo 3. Neste modo, a sua frequência de resposta com maior energia foi de 0,121 Hz.

Tabela F.16: Propriedades das amplitudes modais acopladas fora do plano da catenária do ensaio Catenária-5 através da interpolação do sinal do ensaio para a

$$
V_{\max }=1,67 \mathrm{~m} / \mathrm{s} \text {. }
$$

Amplitude

Modo Máxima(m) Mínima(m) Desvio Padrão(m) Freq. máxima (Hz)

\begin{tabular}{lllll}
\hline 1 & 0,361 & $-0,672$ & 0,141 & 0,121 \\
3 & 0,639 & $-0,428$ & 0,161 & 0,121 \\
5 & 0,212 & $-0,274$ & 0,088 & 0,121 \\
8 & 0,190 & $-0,186$ & 0,068 & 0,242 \\
11 & 0,133 & $-0,118$ & 0,046 & 0,242 \\
13 & 0,068 & $-0,091$ & 0,024 & 0,242 \\
15 & 0,066 & $-0,061$ & 0,027 & 0,364 \\
\hline
\end{tabular}




\section{F.5 Catenária-5 - Velocidade de $1,95 \mathrm{~m} / \mathrm{s}$ e $V_{r 1}=$ 12,12}

Abaixo serão apresentados os gráficos com alguns detalhes da análise referentes ao arranjo Catenária-5 para a velocidade de $1,95 \mathrm{~m} / \mathrm{s}$ e $V_{r 1}=12,12$.
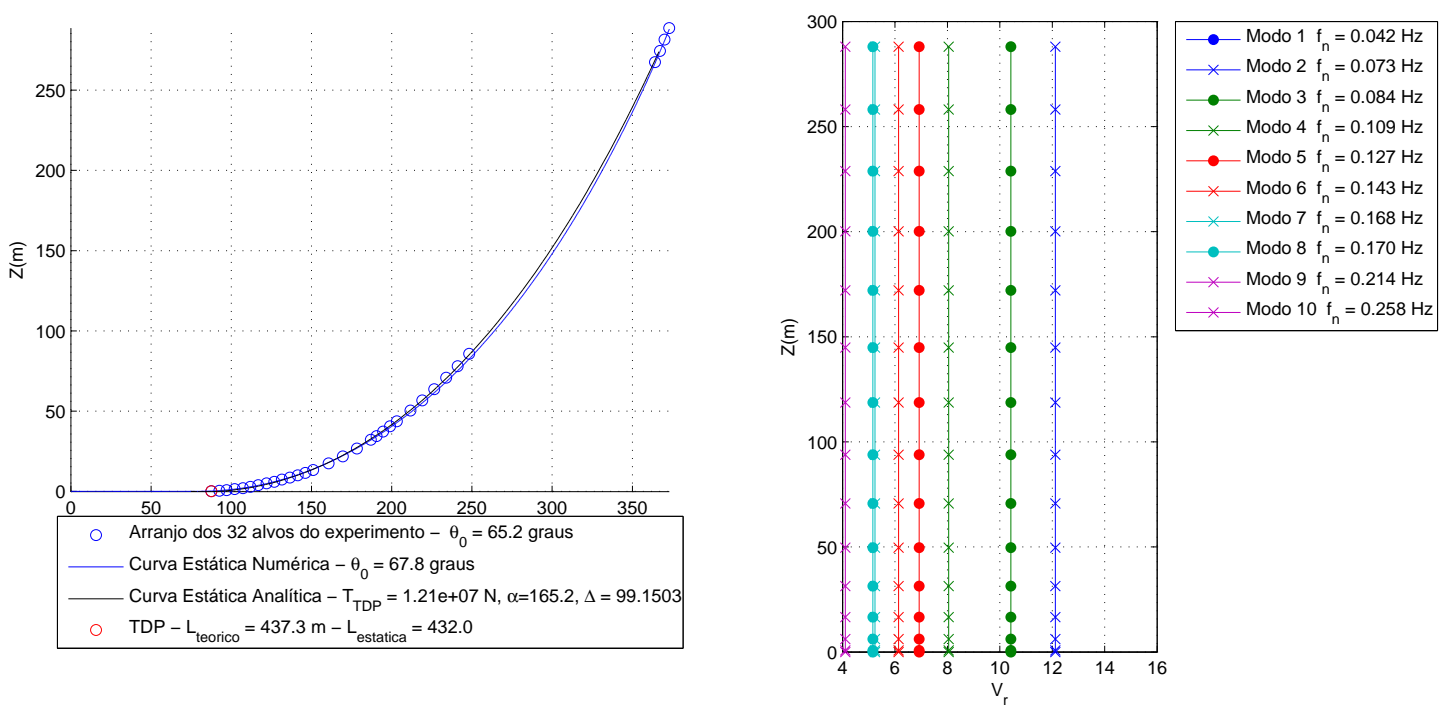

Figura F.21: Variação da velocidade no modelo durante o ensaio para Catenária-5 na $U_{\text {max }}=1,95 \mathrm{~m} / \mathrm{s}$ e $V_{r 1}=12,116$.

Como pode ser visto na Tabela F.17 e nas Figuras de F.22 a F.24, os maiores deslocamentos máximos apresentados na direção X, Y e Z foram de 0,632, 1,038 e 1,538 $\mathrm{m}$, respectivamente. Estes valores ocorreram para os alvos 12, 20 e 23. Nestes alvos, as suas frequências de resposta com maior energia foi de $0,161 \mathrm{~Hz}$. 

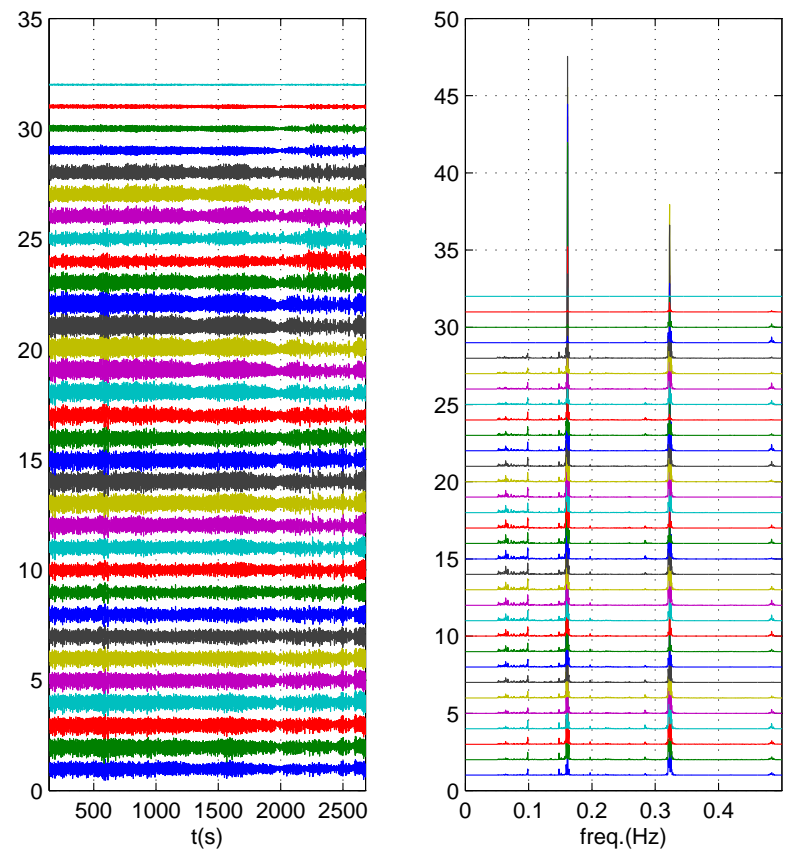

Figura F.22: Série temporal com frequências de resposta para X obtida experimentalmente por alvo para o arranjo de Catenária-5 na $U_{\max }=1,95 \mathrm{~m} / \mathrm{s} \mathrm{e}$ $V_{r 1}=12,116$.
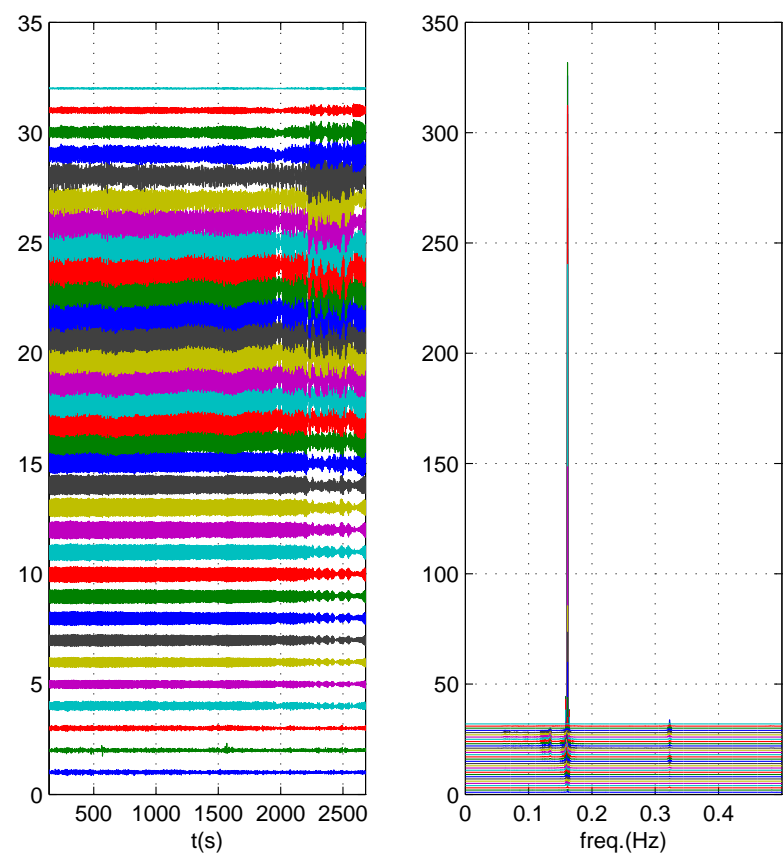

Figura F.23: Série temporal com frequências de resposta para Y obtida experimentalmente por alvo para o arranjo de Catenária-5 na $U_{\max }=1,95 \mathrm{~m} / \mathrm{s} \mathrm{e}$ $V_{r 1}=12,116$. 

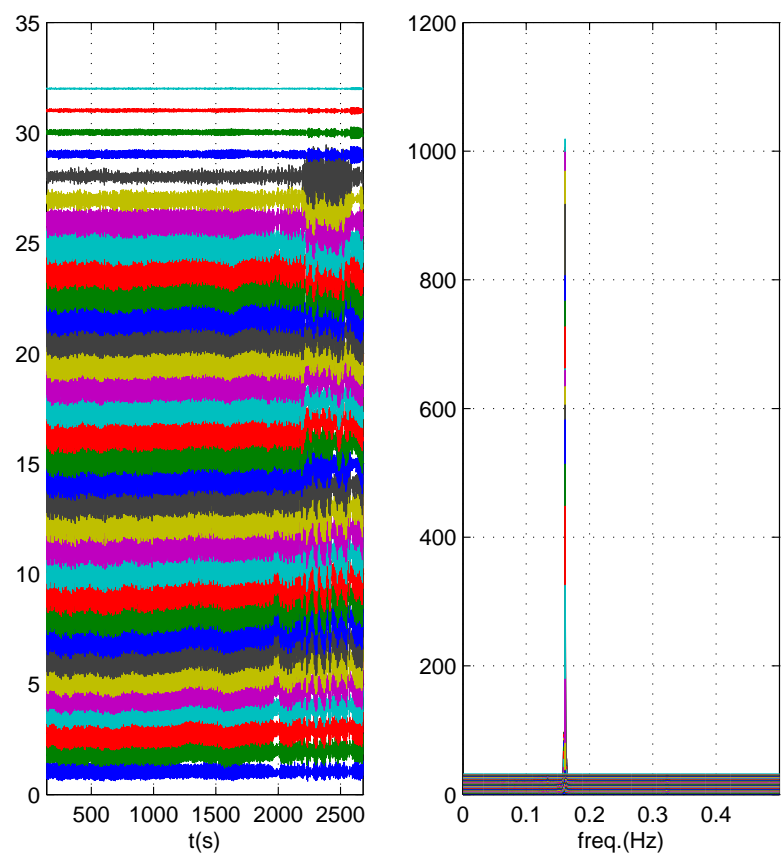

Figura F.24: Série temporal com frequências de resposta para Z obtida experimentalmente por alvo para o arranjo de Catenária-5 na $U_{\max }=1,95 \mathrm{~m} / \mathrm{s}$ e $V_{r 1}=12,116$. 
Tabela F.17: Propriedades da série temporal do ensaio Catenária-5 para a

$$
U_{\max }=1,95 \mathrm{~m} / \mathrm{s} \text {. }
$$

\begin{tabular}{|c|c|c|c|c|c|c|c|c|c|c|c|c|}
\hline \multirow[b]{2}{*}{ ID. Alvo } & \multirow[b]{2}{*}{$\mathrm{X}(\mathrm{m})$} & \multicolumn{2}{|l|}{ Máximo } & \multirow[b]{2}{*}{$\mathrm{X}(\mathrm{m})$} & \multirow{2}{*}{$\begin{array}{l}\text { Mínimo } \\
\mathrm{Y}(\mathrm{m})\end{array}$} & \multirow[b]{2}{*}{$\mathrm{Z}(\mathrm{m})$} & \multicolumn{3}{|c|}{ Desvio padrão } & \multicolumn{3}{|c|}{ Freq. máxima em $\mathrm{Hz}$} \\
\hline & & $\mathrm{Y}(\mathrm{m})$ & $\mathrm{Z}(\mathrm{m})$ & & & & $\mathrm{X}(\mathrm{m})$ & $\mathrm{Y}(\mathrm{m})$ & $\mathrm{Z}(\mathrm{m})$ & $\mathrm{X}$ & $\mathrm{Y}$ & Z \\
\hline 1 & 0,261 & 0,102 & 0,525 & $-0,373$ & $-0,076$ & $-0,311$ & 0,160 & 0,041 & 0,260 & 0,323 & 0,161 & 0,161 \\
\hline 2 & 0,332 & 0,048 & 0,771 & $-0,451$ & $-0,065$ & $-0,559$ & 0,201 & 0,030 & 0,430 & 0,161 & 0,161 & 0,161 \\
\hline 3 & 0,243 & 0,083 & 0,780 & $-0,424$ & $-0,115$ & $-0,891$ & 0,192 & 0,044 & 0,556 & 0,161 & 0,161 & 0,161 \\
\hline 4 & 0,287 & 0,215 & 0,846 & $-0,417$ & $-0,159$ & $-0,940$ & 0,192 & 0,108 & 0,609 & 0,323 & 0,161 & 0,161 \\
\hline 5 & 0,305 & 0,160 & 1,000 & $-0,387$ & $-0,174$ & $-1,219$ & 0,183 & 0,119 & 0,757 & 0,323 & 0,161 & 0,161 \\
\hline 6 & 0,325 & 0,192 & 1,110 & $-0,364$ & $-0,208$ & $-1,426$ & 0,178 & 0,140 & 0,875 & 0,323 & 0,161 & 0,161 \\
\hline 7 & 0,325 & 0,217 & 1,227 & $-0,343$ & $-0,248$ & $-1,599$ & 0,166 & 0,164 & 0,970 & 0,161 & 0,161 & 0,161 \\
\hline 8 & 0,315 & 0,260 & 1,313 & $-0,322$ & $-0,303$ & $-1,667$ & 0,158 & 0,195 & 1,035 & 0,161 & 0,161 & 0,161 \\
\hline 9 & 0,287 & 0,259 & 1,436 & $-0,288$ & $-0,325$ & $-1,750$ & 0,144 & 0,204 & 1,094 & 0,161 & 0,161 & 0,161 \\
\hline 10 & 0,274 & 0,272 & 1,506 & $-0,280$ & $-0,359$ & $-1,753$ & 0,151 & 0,220 & 1,123 & 0,161 & 0,161 & 0,161 \\
\hline 11 & 0,285 & 0,283 & 1,537 & $-0,254$ & $-0,381$ & $-1,689$ & 0,162 & 0,229 & 1,121 & 0,161 & 0,161 & 0,161 \\
\hline 12 & 0,351 & 0,319 & 1,538 & $-0,236$ & $-0,390$ & $-1,596$ & 0,181 & 0,235 & 1,098 & 0,161 & 0,161 & 0,161 \\
\hline 13 & 0,386 & 0,347 & 1,529 & $-0,265$ & $-0,399$ & $-1,509$ & 0,195 & 0,239 & 1,071 & 0,161 & 0,161 & 0,161 \\
\hline 14 & 0,414 & 0,402 & 1,512 & $-0,300$ & $-0,412$ & $-1,419$ & 0,206 & 0,249 & 1,028 & 0,161 & 0,161 & 0,161 \\
\hline 15 & 0,366 & 0,519 & 1,428 & $-0,378$ & $-0,421$ & $-1,383$ & 0,200 & 0,294 & 0,934 & 0,161 & 0,161 & 0,161 \\
\hline 16 & 0,350 & 0,613 & 1,317 & $-0,430$ & $-0,504$ & $-1,392$ & 0,191 & 0,362 & 0,876 & 0,161 & 0,161 & 0,161 \\
\hline 17 & 0,461 & 0,686 & 1,209 & $-0,437$ & $-0,700$ & $-1,330$ & 0,201 & 0,437 & 0,829 & 0,161 & 0,161 & 0,161 \\
\hline 18 & 0,566 & 0,754 & 1,223 & $-0,429$ & $-0,851$ & $-1,196$ & 0,228 & 0,505 & 0,782 & 0,161 & 0,161 & 0,161 \\
\hline 19 & 0,608 & 0,792 & 1,287 & $-0,439$ & $-0,901$ & $-1,156$ & 0,241 & 0,532 & 0,784 & 0,161 & 0,161 & 0,161 \\
\hline 20 & 0,632 & 0,844 & 1,327 & $-0,440$ & $-0,942$ & $-1,111$ & 0,249 & 0,562 & 0,775 & 0,161 & 0,161 & 0,161 \\
\hline 21 & 0,612 & 0,908 & 1,345 & $-0,460$ & $-0,975$ & $-1,078$ & 0,248 & 0,589 & 0,766 & 0,161 & 0,161 & 0,161 \\
\hline 22 & 0,584 & 0,975 & 1,336 & $-0,429$ & $-0,993$ & $-1,076$ & 0,236 & 0,612 & 0,758 & 0,161 & 0,161 & 0,161 \\
\hline 23 & 0,449 & 1,038 & 1,254 & $-0,350$ & $-0,967$ & $-1,086$ & 0,189 & 0,620 & 0,716 & 0,161 & 0,161 & 0,161 \\
\hline 24 & 0,234 & 1,021 & 1,136 & $-0,257$ & $-0,924$ & $-1,069$ & 0,128 & 0,599 & 0,660 & 0,161 & 0,161 & 0,161 \\
\hline 25 & 0,293 & 0,902 & 0,905 & $-0,197$ & $-0,846$ & $-0,957$ & 0,123 & 0,522 & 0,547 & 0,161 & 0,161 & 0,161 \\
\hline 26 & 0,416 & 0,675 & 0,637 & $-0,278$ & $-0,744$ & $-0,755$ & 0,152 & 0,415 & 0,388 & 0,323 & 0,161 & 0,161 \\
\hline 27 & 0,420 & 0,412 & 0,398 & $-0,348$ & $-0,631$ & $-0,538$ & 0,177 & 0,323 & 0,241 & 0,323 & 0,161 & 0,161 \\
\hline 28 & 0,376 & 0,450 & 0,241 & $-0,327$ & $-0,478$ & $-0,292$ & 0,179 & 0,276 & 0,137 & 0,323 & 0,161 & 0,161 \\
\hline 29 & 0,202 & 0,358 & 0,182 & $-0,136$ & $-0,305$ & $-0,123$ & 0,097 & 0,178 & 0,078 & 0,323 & 0,161 & 0,161 \\
\hline 30 & 0,145 & 0,253 & 0,127 & $-0,099$ & $-0,207$ & $-0,089$ & 0,069 & 0,124 & 0,055 & 0,323 & 0,161 & 0,161 \\
\hline 31 & 0,083 & 0,138 & 0,072 & $-0,051$ & $-0,098$ & $-0,051$ & 0,039 & 0,066 & 0,031 & 0,323 & 0,161 & 0,161 \\
\hline 32 & 0,021 & 0,029 & 0,025 & $-0,014$ & $-0,019$ & $-0,019$ & 0,010 & 0,014 & 0,011 & 0,323 & 0,161 & 0,161 \\
\hline
\end{tabular}

Considerando agora a decomposição modal, na Tabela F.18 através da interpolação do sinal do ensaio, correspondente a uma velocade reduzida do primeiro modo $V_{r 1}=12.12$, as maiores amplitudes máximas apresentadas na direção X, Y e Z foram de 0,565, 0,972 e 1,105 m, respectivamente. Estes valores ocorreram para os modos 3 e 4, Nestes modos, as suas frequências de resposta com maior energia foi de $0,161 \mathrm{~Hz}$. 

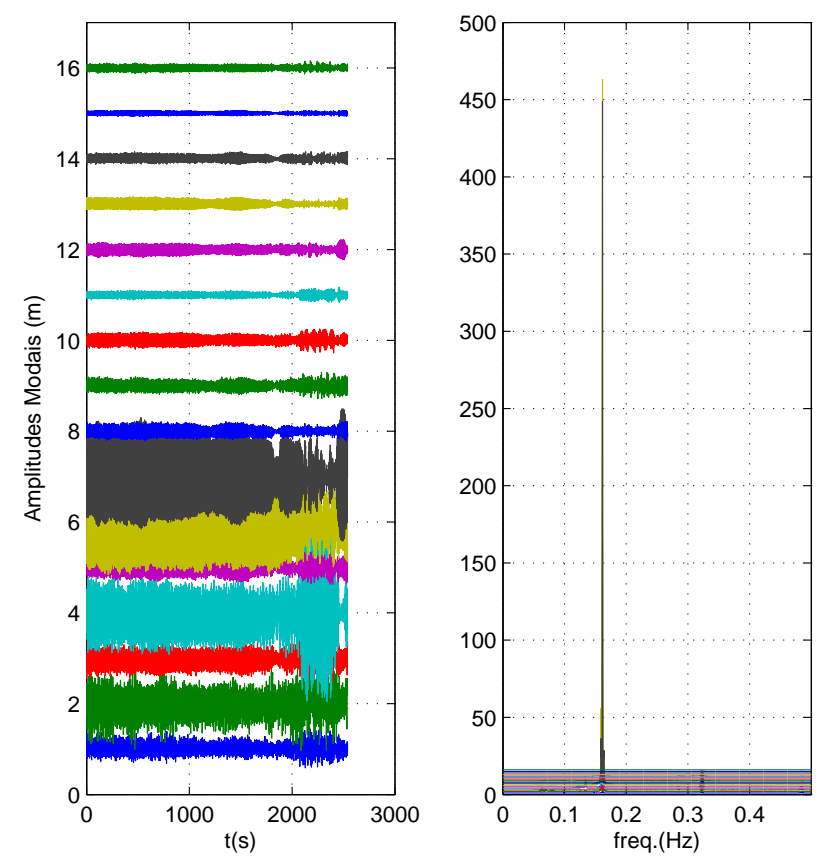

Figura F.25: Variação da amplitude modal acoplada ao longo do tempo através da interpolação do sinal do ensaio para Catenária-5 na $U_{\max }=1,95 \mathrm{~m} / \mathrm{s}$ e $V_{r 1}=12,116$.

Tabela F.18: Propriedades das amplitudes modais do ensaio Catenária-5 através da interpolação do sinal do ensaio para a $V_{\max }=1,95 \mathrm{~m} / \mathrm{s}$.

\begin{tabular}{|c|c|c|c|c|c|c|c|c|c|c|c|c|}
\hline \multirow[b]{2}{*}{ Modo } & \multirow[b]{2}{*}{$\mathrm{X}(\mathrm{m})$} & \multicolumn{2}{|c|}{ Máximo } & \multirow[b]{2}{*}{$\mathrm{X}(\mathrm{m})$} & \multirow{2}{*}{$\begin{array}{l}\text { Mínimo } \\
\mathrm{Y}(\mathrm{m})\end{array}$} & \multirow[b]{2}{*}{$\mathrm{Z}(\mathrm{m})$} & \multicolumn{3}{|c|}{ Desvio padrão } & \multicolumn{3}{|c|}{ Freq. máxima em $\mathrm{Hz}$} \\
\hline & & $\mathrm{Y}(\mathrm{m})$ & $\mathrm{Z}(\mathrm{m})$ & & & & $\mathrm{X}(\mathrm{m})$ & $\mathrm{Y}(\mathrm{m})$ & $\mathrm{Z}(\mathrm{m})$ & $\mathrm{X}$ & $\mathrm{Y}$ & Z \\
\hline 1 & 0,475 & 0,000 & 0,000 & $-0,414$ & $-0,000$ & $-0,000$ & 0,119 & 0,000 & 0,000 & 0,161 & 0,161 & 0,161 \\
\hline 2 & 0,000 & 0,664 & 0,471 & $-0,000$ & $-0,614$ & $-0,458$ & 0,000 & 0,177 & 0,176 & 0,161 & 0,161 & 0,161 \\
\hline 3 & 0,565 & 0,000 & 0,000 & $-0,496$ & $-0,000$ & $-0,000$ & 0,156 & 0,000 & 0,000 & 0,161 & 0,161 & 0,161 \\
\hline 4 & 0,000 & 0,972 & 1,105 & $-0,000$ & $-0,917$ & $-1,146$ & 0,000 & 0,243 & 0,376 & 0,323 & 0,161 & 0,161 \\
\hline 5 & 0,338 & 0,000 & 0,000 & $-0,373$ & $-0,000$ & $-0,000$ & 0,113 & 0,000 & 0,000 & 0,323 & 0,161 & 0,161 \\
\hline 6 & 0,000 & 0,619 & 1,013 & $-0,000$ & $-0,675$ & $-1,082$ & 0,000 & 0,167 & 0,572 & 0,323 & 0,161 & 0,161 \\
\hline 7 & 0,000 & 0,807 & 0,749 & $-0,000$ & $-0,743$ & $-0,775$ & 0,000 & 0,281 & 0,390 & 0,161 & 0,161 & 0,161 \\
\hline 8 & 0,222 & 0,008 & 0,008 & $-0,224$ & $-0,008$ & $-0,008$ & 0,082 & 0,003 & 0,004 & 0,161 & 0,161 & 0,161 \\
\hline 9 & 0,000 & 0,291 & 0,189 & $-0,000$ & $-0,337$ & $-0,256$ & 0,000 & 0,122 & 0,100 & 0,161 & 0,161 & 0,161 \\
\hline 10 & 0,000 & 0,096 & 0,199 & $-0,000$ & $-0,085$ & $-0,210$ & 0,000 & 0,027 & 0,062 & 0,323 & 0,161 & 0,161 \\
\hline 11 & 0,173 & 0,000 & 0,000 & $-0,161$ & $-0,000$ & $-0,000$ & 0,049 & 0,000 & 0,000 & 0,323 & 0,161 & 0,161 \\
\hline 12 & 0,002 & 0,114 & 0,145 & $-0,002$ & $-0,140$ & $-0,133$ & 0,001 & 0,036 & 0,044 & 0,323 & 0,161 & 0,161 \\
\hline 13 & 0,168 & 0,000 & 0,000 & $-0,145$ & $-0,000$ & $-0,000$ & 0,066 & 0,000 & 0,000 & 0,323 & 0,161 & 0,161 \\
\hline 14 & 0,000 & 0,174 & 0,224 & $-0,000$ & $-0,158$ & $-0,178$ & 0,000 & 0,059 & 0,045 & 0,323 & 0,161 & 0,323 \\
\hline 15 & 0,067 & 0,000 & 0,000 & $-0,071$ & $-0,000$ & $-0,000$ & 0,027 & 0,000 & 0,000 & 0,323 & 0,161 & 0,323 \\
\hline 16 & 0,000 & 0,462 & 0,471 & $-0,000$ & $-0,440$ & $-0,522$ & 0,000 & 0,100 & 0,108 & 0,323 & 0,161 & 0,161 \\
\hline
\end{tabular}

A Tabela F.19 apresenta para o ensaio Catenária-5 apenas os movimentos referentes 
a deslocamento no plano da catenária através da interpolação do sinal do ensaio, a maior amplitude acoplada máxima foi de 2,013 m. Este valor ocorreu para o modo 4 . Neste modo, a sua frequência de resposta com maior energia foi de $0,161 \mathrm{~Hz}$.

Tabela F.19: Propriedades das amplitudes modais acopladas no plano da catenária do ensaio Catenária-5 através da interpolação do sinal do ensaio para a $V_{\max }=1,95 \mathrm{~m} / \mathrm{s}$.

Amplitude

Modo Máxima(m) Mínima(m) Desvio Padrão(m) Freq. máxima (Hz)

\begin{tabular}{lllll}
\hline 2 & 1,004 & $-1,037$ & 0,321 & 0,161 \\
4 & 2,013 & $-1,950$ & 0,555 & 0,161 \\
6 & 1,233 & $-1,159$ & 0,642 & 0,161 \\
7 & 1,489 & $-1,416$ & 0,634 & 0,161 \\
9 & 0,294 & $-0,282$ & 0,084 & 0,323 \\
10 & 0,257 & $-0,273$ & 0,081 & 0,161 \\
12 & 0,214 & $-0,224$ & 0,067 & 0,161 \\
14 & 0,158 & $-0,137$ & 0,057 & 0,161 \\
16 & 0,154 & $-0,131$ & 0,049 & 0,161 \\
\hline
\end{tabular}

A Tabela F.20 para o ensaio Catenária-5 com apenas as amplitudes correspondentes a movimentos fora do plano através da interpolação do sinal do ensaio, a maior amplitude acoplada máxima apresentada foi de 0,559 m. Este valor ocorreu para o modo 3. Neste modo, a sua frequência de resposta com maior energia foi de 0,161 Hz.

Tabela F.20: Propriedades das amplitudes modais acopladas fora do plano da catenária do ensaio Catenária-5 através da interpolação do sinal do ensaio para a

$$
V_{\max }=1,95 \mathrm{~m} / \mathrm{s} \text {. }
$$

Amplitude

Modo Máxima(m) Mínima(m) Desvio Padrão(m) Freq. máxima (Hz)

\begin{tabular}{lllll}
\hline 1 & 0,470 & $-0,410$ & 0,118 & 0,161 \\
3 & 0,559 & $-0,491$ & 0,155 & 0,161 \\
5 & 0,335 & $-0,369$ & 0,112 & 0,323 \\
8 & 0,220 & $-0,222$ & 0,081 & 0,161 \\
11 & 0,171 & $-0,160$ & 0,048 & 0,323 \\
13 & 0,167 & $-0,143$ & 0,065 & 0,323 \\
15 & 0,066 & $-0,070$ & 0,027 & 0,323 \\
\hline
\end{tabular}




\section{F.6 Catenária-5 - Velocidade de $2,27 \mathrm{~m} / \mathrm{s}$ e $V_{r 1}=$ 14,12}

Abaixo serão apresentados os gráficos com alguns detalhes da análise referentes ao arranjo Catenária-5 para a velocidade de $2,27 \mathrm{~m} / \mathrm{s}$ e $V_{r 1}=14,12$.
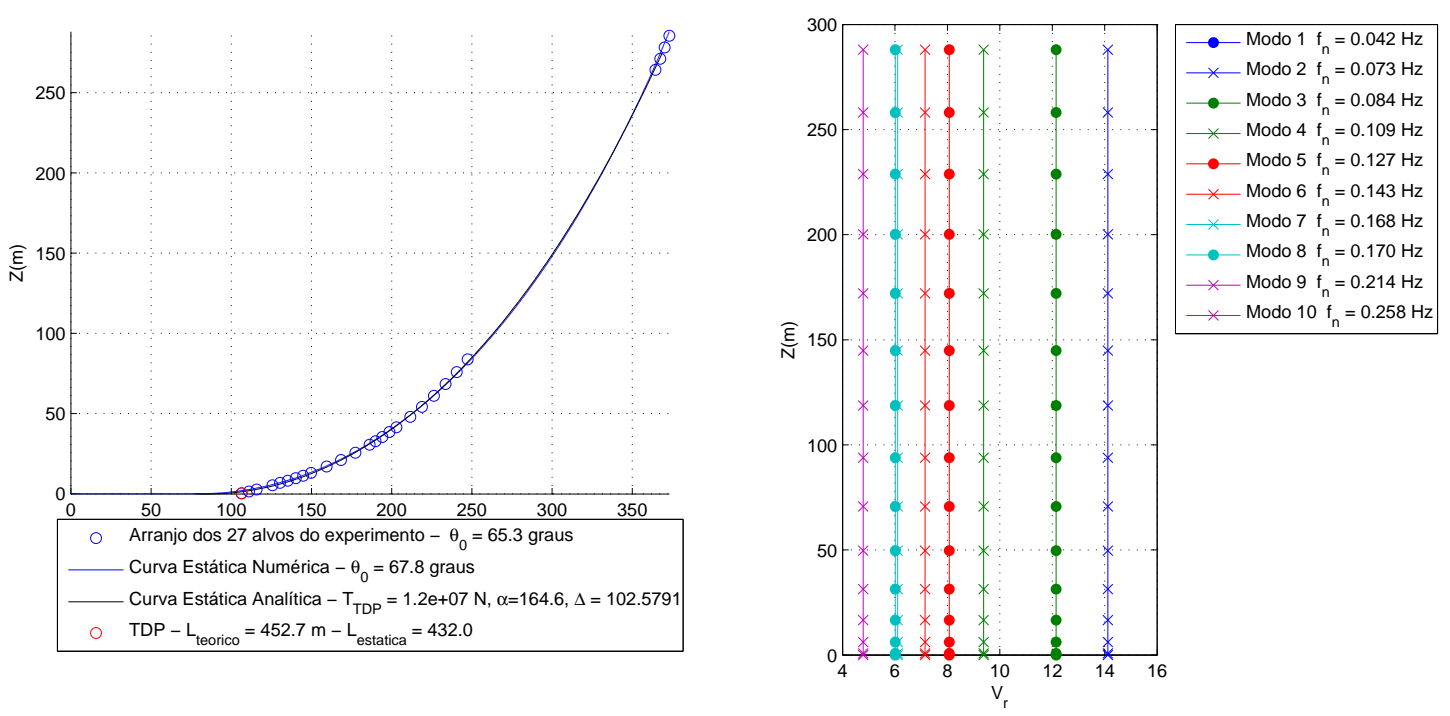

Figura F.26: Variação da velocidade no modelo durante o ensaio para Catenária-5 na

$$
U_{\text {max }}=2,27 \mathrm{~m} / \mathrm{s} \text { e } V_{r 1}=14,121 \text {. }
$$

Como pode ser visto na Tabela F.21 e nas Figuras de F.27 a F.29, os maiores deslocamentos máximos apresentados na direção X, Y e Z foram de 0,485, 1,096 e 1,823 $\mathrm{m}$, respectivamente. Estes valores ocorreram para os alvos 5, 17 e 20. Nestes alvos, as suas frequências de resposta com maior energia foram de 0,17 e 0,172 Hz. 

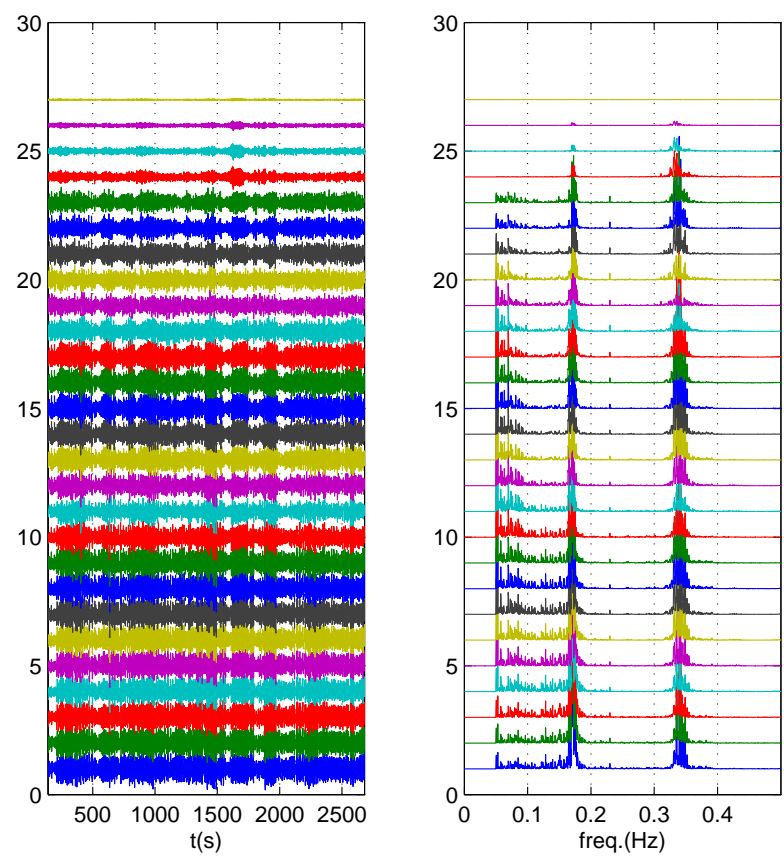

Figura F.27: Série temporal com frequências de resposta para $\mathrm{X}$ obtida experimentalmente por alvo para o arranjo de Catenária-5 na $U_{\max }=2,27 \mathrm{~m} / \mathrm{s}$ e $V_{r 1}=14,121$.
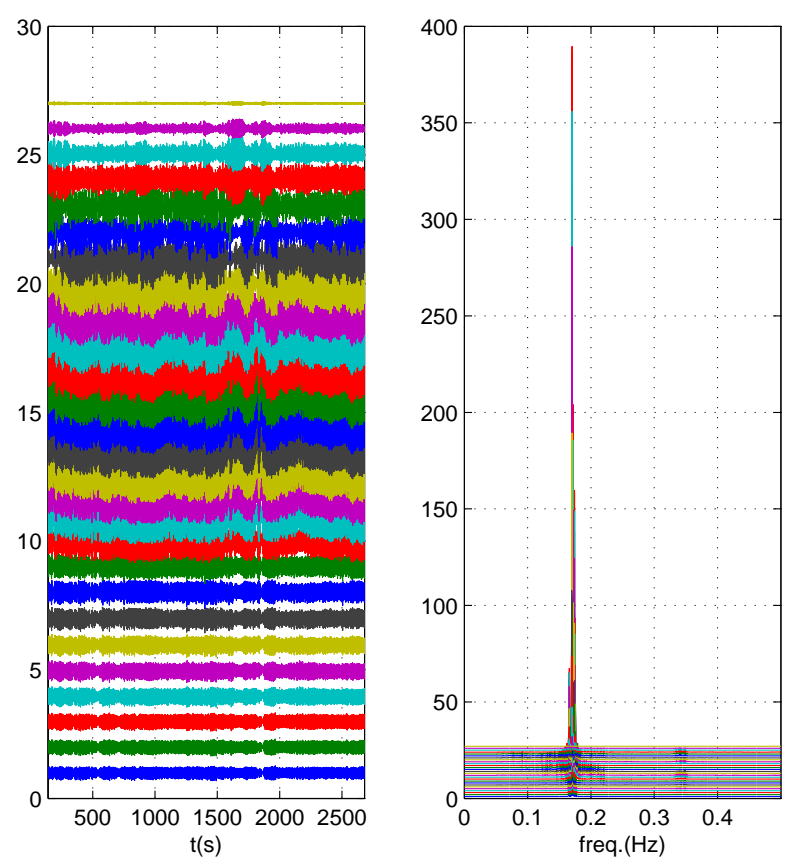

Figura F.28: Série temporal com frequências de resposta para Y obtida experimentalmente por alvo para o arranjo de Catenária-5 na $U_{\max }=2,27 \mathrm{~m} / \mathrm{s}$ e $V_{r 1}=14,121$. 

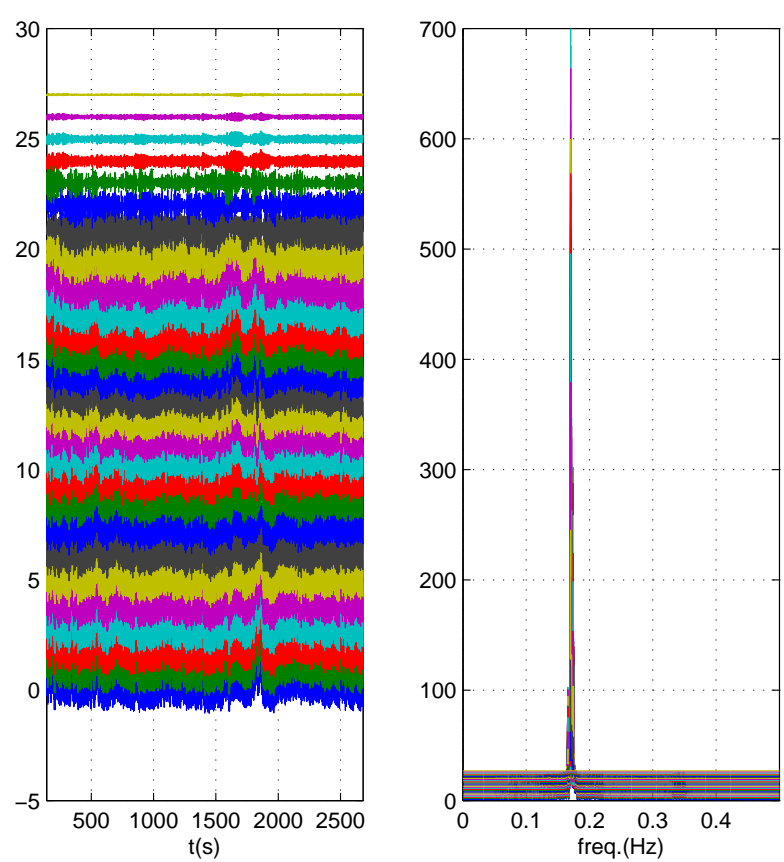

Figura F.29: Série temporal com frequências de resposta para Z obtida experimentalmente por alvo para o arranjo de Catenária-5 na $U_{\max }=2,27 \mathrm{~m} / \mathrm{s}$ e $V_{r 1}=14,121$. 
Tabela F.21: Propriedades da série temporal do ensaio Catenária-5 para a

$$
U_{\max }=2,27 \mathrm{~m} / \mathrm{s} \text {. }
$$

\begin{tabular}{|c|c|c|c|c|c|c|c|c|c|c|c|c|}
\hline \multirow[b]{2}{*}{ ID. Alvo } & \multirow[b]{2}{*}{$\mathrm{X}(\mathrm{m})$} & \multicolumn{2}{|c|}{ Máximo } & \multirow[b]{2}{*}{$\mathrm{X}(\mathrm{m})$} & \multirow{2}{*}{$\begin{array}{l}\text { Mínimo } \\
\mathrm{Y}(\mathrm{m})\end{array}$} & \multirow{2}{*}{$\mathrm{Z}(\mathrm{m})$} & \multicolumn{3}{|c|}{ Desvio padrão } & \multicolumn{3}{|c|}{ Freq. máxima em $\mathrm{Hz}$} \\
\hline & & $\mathrm{Y}(\mathrm{m})$ & $\mathrm{Z}(\mathrm{m})$ & & & & $\mathrm{X}(\mathrm{m})$ & $\mathrm{Y}(\mathrm{m})$ & $\mathrm{Z}(\mathrm{m})$ & $\mathrm{X}$ & $\mathrm{Y}$ & $\mathrm{Z}$ \\
\hline 1 & 0,296 & 0,218 & 1,545 & $-0,364$ & $-0,248$ & $-1,648$ & 0,163 & 0,147 & 0,995 & 0,170 & 0,170 & 0,170 \\
\hline 2 & 0,273 & 0,251 & 1,650 & $-0,361$ & $-0,275$ & $-1,877$ & 0,155 & 0,168 & 1,103 & 0,170 & 0,170 & 0,170 \\
\hline 3 & 0,242 & 0,280 & 1,718 & $-0,353$ & $-0,305$ & $-2,040$ & 0,145 & 0,186 & 1,181 & 0,170 & 0,170 & 0,170 \\
\hline 4 & 0,163 & 0,305 & 1,814 & $-0,306$ & $-0,344$ & $-2,141$ & 0,119 & 0,209 & 1,236 & 0,170 & 0,170 & 0,170 \\
\hline 5 & 0,191 & 0,307 & 1,823 & $-0,293$ & $-0,363$ & $-2,086$ & 0,123 & 0,217 & 1,220 & 0,170 & 0,170 & 0,170 \\
\hline 6 & 0,223 & 0,311 & 1,802 & $-0,279$ & $-0,373$ & $-1,977$ & 0,129 & 0,218 & 1,174 & 0,170 & 0,170 & 0,170 \\
\hline 7 & 0,239 & 0,337 & 1,710 & $-0,280$ & $-0,376$ & $-1,790$ & 0,135 & 0,220 & 1,091 & 0,170 & 0,170 & 0,170 \\
\hline 8 & 0,251 & 0,389 & 1,610 & $-0,274$ & $-0,376$ & $-1,644$ & 0,141 & 0,230 & 1,019 & 0,170 & 0,170 & 0,170 \\
\hline 9 & 0,259 & 0,451 & 1,471 & $-0,269$ & $-0,383$ & $-1,501$ & 0,150 & 0,250 & 0,933 & 0,170 & 0,170 & 0,170 \\
\hline 10 & 0,176 & 0,575 & 1,146 & $-0,223$ & $-0,501$ & $-1,360$ & 0,134 & 0,337 & 0,770 & 0,170 & 0,170 & 0,170 \\
\hline 11 & 0,250 & 0,674 & 1,074 & $-0,207$ & $-0,716$ & $-1,332$ & 0,127 & 0,450 & 0,726 & 0,170 & 0,170 & 0,170 \\
\hline 12 & 0,306 & 0,768 & 1,162 & $-0,238$ & $-0,913$ & $-1,254$ & 0,147 & 0,559 & 0,743 & 0,170 & 0,170 & 0,170 \\
\hline 13 & 0,334 & 0,904 & 1,279 & $-0,287$ & $-1,031$ & $-1,229$ & 0,168 & 0,642 & 0,813 & 0,339 & 0,170 & 0,170 \\
\hline 14 & 0,342 & 0,969 & 1,291 & $-0,309$ & $-1,050$ & $-1,232$ & 0,173 & 0,664 & 0,831 & 0,339 & 0,170 & 0,170 \\
\hline 15 & 0,339 & 1,032 & 1,273 & $-0,333$ & $-1,062$ & $-1,236$ & 0,178 & 0,683 & 0,843 & 0,170 & 0,170 & 0,170 \\
\hline 16 & 0,332 & 1,086 & 1,287 & $-0,318$ & $-1,042$ & $-1,217$ & 0,175 & 0,689 & 0,841 & 0,170 & 0,170 & 0,170 \\
\hline 17 & 0,342 & 1,096 & 1,279 & $-0,330$ & $-0,997$ & $-1,246$ & 0,176 & 0,677 & 0,824 & 0,170 & 0,170 & 0,170 \\
\hline 18 & 0,378 & 1,022 & 1,200 & $-0,335$ & $-0,872$ & $-1,189$ & 0,179 & 0,609 & 0,739 & 0,172 & 0,170 & 0,170 \\
\hline 19 & 0,420 & 0,805 & 1,060 & $-0,311$ & $-0,713$ & $-0,972$ & 0,178 & 0,485 & 0,589 & 0,172 & 0,170 & 0,170 \\
\hline 20 & 0,485 & 0,617 & 0,824 & $-0,305$ & $-0,516$ & $-0,652$ & 0,197 & 0,308 & 0,398 & 0,172 & 0,170 & 0,170 \\
\hline 21 & 0,474 & 0,332 & 0,573 & $-0,253$ & $-0,335$ & $-0,373$ & 0,191 & 0,186 & 0,220 & 0,172 & 0,170 & 0,170 \\
\hline 22 & 0,397 & 0,537 & 0,430 & $-0,212$ & $-0,624$ & $-0,557$ & 0,158 & 0,317 & 0,275 & 0,339 & 0,170 & 0,170 \\
\hline 23 & 0,326 & 0,754 & 0,761 & $-0,253$ & $-0,990$ & $-0,783$ & 0,158 & 0,535 & 0,468 & 0,339 & 0,170 & 0,169 \\
\hline 24 & 0,168 & 0,772 & 0,300 & $-0,168$ & $-0,534$ & $-0,343$ & 0,085 & 0,382 & 0,174 & 0,332 & 0,170 & 0,170 \\
\hline 25 & 0,124 & 0,525 & 0,207 & $-0,120$ & $-0,348$ & $-0,241$ & 0,062 & 0,259 & 0,121 & 0,332 & 0,170 & 0,170 \\
\hline 26 & 0,074 & 0,274 & 0,110 & $-0,068$ & $-0,188$ & $-0,130$ & 0,036 & 0,136 & 0,067 & 0,332 & 0,170 & 0,170 \\
\hline 27 & 0,019 & 0,055 & 0,038 & $-0,015$ & $-0,040$ & $-0,043$ & 0,010 & 0,028 & 0,020 & 0,170 & 0,170 & 0,170 \\
\hline
\end{tabular}

Considerando agora a decomposição modal, na Tabela F.22 através da interpolação do sinal do ensaio, correspondente a uma velocade reduzida do primeiro modo $V_{r 1}=14.12$, as maiores amplitudes máximas apresentadas na direção X, Y e Z foram de 0,654, 0,905 e 1,025 m, respectivamente. Estes valores ocorreram para os modos 3 e 7, Nestes modos, as suas frequências de resposta com maior energia foi de $0,17 \mathrm{~Hz}$. 

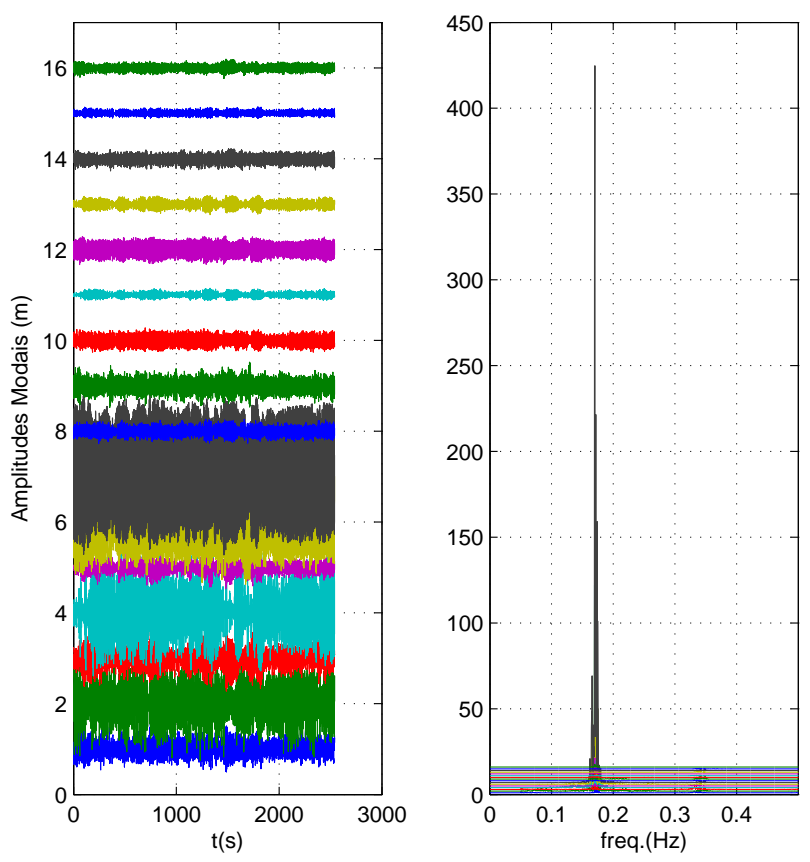

Figura F.30: Variação da amplitude modal acoplada ao longo do tempo através da interpolação do sinal do ensaio para Catenária-5 na $U_{\max }=2,27 \mathrm{~m} / \mathrm{s}$ e $V_{r 1}=14,121$.

Tabela F.22: Propriedades das amplitudes modais do ensaio Catenária-5 através da interpolação do sinal do ensaio para a $V_{\max }=2,27 \mathrm{~m} / \mathrm{s}$.

\begin{tabular}{lcccccccccccccc}
\hline \multicolumn{1}{c}{ Máximo } & \multicolumn{1}{c}{ Mínimo } & & \multicolumn{3}{c}{ Desvio padrão } & \multicolumn{3}{c}{ Freq. máxima em Hz } \\
\multicolumn{1}{c}{ Modo } & $\mathrm{X}(\mathrm{m})$ & $\mathrm{Y}(\mathrm{m})$ & $\mathrm{Z}(\mathrm{m})$ & $\mathrm{X}(\mathrm{m})$ & $\mathrm{Y}(\mathrm{m})$ & $\mathrm{Z}(\mathrm{m})$ & $\mathrm{X}(\mathrm{m})$ & $\mathrm{Y}(\mathrm{m})$ & $\mathrm{Z}(\mathrm{m})$ & $\mathrm{X}$ & $\mathrm{Y}$ & $\mathrm{Z}$ \\
& & & & & & & & & & & & \\
\hline 1 & 0,578 & 0,000 & 0,000 & $-0,504$ & $-0,000$ & $-0,000$ & 0,167 & 0,000 & 0,000 & 0,170 & 0,174 & 0,170 \\
2 & 0,000 & 0,772 & 0,556 & $-0,000$ & $-0,794$ & $-0,481$ & 0,000 & 0,267 & 0,210 & 0,170 & 0,174 & 0,170 \\
3 & 0,654 & 0,000 & 0,000 & $-0,728$ & $-0,000$ & $-0,000$ & 0,184 & 0,000 & 0,000 & 0,170 & 0,174 & 0,170 \\
4 & 0,000 & 0,672 & 0,858 & $-0,000$ & $-0,633$ & $-0,903$ & 0,000 & 0,249 & 0,399 & 0,170 & 0,174 & 0,170 \\
5 & 0,367 & 0,000 & 0,000 & $-0,482$ & $-0,000$ & $-0,000$ & 0,110 & 0,000 & 0,000 & 0,170 & 0,174 & 0,170 \\
6 & 0,000 & 0,680 & 1,016 & $-0,000$ & $-0,685$ & $-0,990$ & 0,000 & 0,199 & 0,506 & 0,170 & 0,170 & 0,170 \\
7 & 0,000 & 0,905 & 1,025 & $-0,000$ & $-0,765$ & $-1,113$ & 0,000 & 0,446 & 0,549 & 0,336 & 0,170 & 0,170 \\
8 & 0,265 & 0,008 & 0,011 & $-0,274$ & $-0,009$ & $-0,010$ & 0,088 & 0,005 & 0,006 & 0,336 & 0,170 & 0,170 \\
9 & 0,000 & 0,350 & 0,406 & $-0,000$ & $-0,423$ & $-0,471$ & 0,000 & 0,155 & 0,157 & 0,339 & 0,170 & 0,170 \\
10 & 0,000 & 0,138 & 0,202 & $-0,000$ & $-0,118$ & $-0,226$ & 0,000 & 0,037 & 0,079 & 0,339 & 0,170 & 0,170 \\
11 & 0,148 & 0,000 & 0,000 & $-0,124$ & $-0,000$ & $-0,000$ & 0,045 & 0,000 & 0,000 & 0,339 & 0,170 & 0,170 \\
12 & 0,002 & 0,133 & 0,227 & $-0,003$ & $-0,150$ & $-0,243$ & 0,001 & 0,045 & 0,103 & 0,339 & 0,170 & 0,170 \\
13 & 0,198 & 0,000 & 0,000 & $-0,238$ & $-0,000$ & $-0,000$ & 0,070 & 0,000 & 0,000 & 0,339 & 0,170 & 0,170 \\
14 & 0,000 & 0,238 & 0,326 & $-0,000$ & $-0,202$ & $-0,297$ & 0,000 & 0,084 & 0,106 & 0,339 & 0,170 & 0,170 \\
15 & 0,145 & 0,000 & 0,001 & $-0,114$ & $-0,000$ & $-0,001$ & 0,044 & 0,000 & 0,000 & 0,339 & 0,170 & 0,170 \\
16 & 0,000 & 0,414 & 0,439 & $-0,000$ & $-0,523$ & $-0,414$ & 0,000 & 0,128 & 0,119 & 0,170 & 0,170 & 0,170 \\
\hline
\end{tabular}

A Tabela F.23 apresenta para o ensaio Catenária-5 apenas os movimentos referentes 
a deslocamento no plano da catenária através da interpolação do sinal do ensaio, a maior amplitude acoplada máxima foi de 1,858 m. Este valor ocorreu para o modo 7, Neste modo, a sua frequência de resposta com maior energia foi de $0,170 \mathrm{~Hz}$.

Tabela F.23: Propriedades das amplitudes modais acopladas no plano da catenária do ensaio Catenária-5 através da interpolação do sinal do ensaio para a $V_{\max }=2,27 \mathrm{~m} / \mathrm{s}$.

\section{Amplitude}

\section{Modo Máxima(m) Mínima(m) Desvio Padrão(m) Freq. máxima (Hz)}

\begin{tabular}{lllll}
\hline 2 & 1,227 & $-1,243$ & 0,437 & 0,174 \\
4 & 1,475 & $-1,392$ & 0,577 & 0,170 \\
6 & 1,356 & $-1,369$ & 0,623 & 0,170 \\
7 & 1,858 & $-1,720$ & 0,964 & 0,170 \\
9 & 0,519 & $-0,474$ & 0,143 & 0,342 \\
10 & 0,273 & $-0,257$ & 0,101 & 0,170 \\
12 & 0,296 & $-0,333$ & 0,138 & 0,170 \\
14 & 0,222 & $-0,267$ & 0,084 & 0,349 \\
16 & 0,192 & $-0,232$ & 0,069 & 0,170 \\
\hline
\end{tabular}

A Tabela F.24 para o ensaio Catenária-5 com apenas as amplitudes correspondentes a movimentos fora do plano através da interpolação do sinal do ensaio, a maior amplitude acoplada máxima apresentada foi de 0,647 m. Este valor ocorreu para o modo 3. Neste modo, a sua frequência de resposta com maior energia foi de $0,170 \mathrm{~Hz}$.

Tabela F.24: Propriedades das amplitudes modais acopladas fora do plano da catenária do ensaio Catenária-5 através da interpolação do sinal do ensaio para a

$$
V_{\max }=2,27 \mathrm{~m} / \mathrm{s} \text {. }
$$

\section{Amplitude}

Modo Máxima(m) Mínima(m) Desvio Padrão(m) Freq. máxima (Hz)

\begin{tabular}{lllll}
\hline 1 & 0,572 & $-0,499$ & 0,166 & 0,170 \\
3 & 0,647 & $-0,720$ & 0,182 & 0,170 \\
5 & 0,363 & $-0,477$ & 0,109 & 0,170 \\
8 & 0,262 & $-0,271$ & 0,087 & 0,336 \\
11 & 0,146 & $-0,122$ & 0,045 & 0,339 \\
13 & 0,196 & $-0,235$ & 0,069 & 0,339 \\
15 & 0,143 & $-0,113$ & 0,044 & 0,339 \\
\hline
\end{tabular}

